\author{
UNIVERSIDADE DE SÃO PAULO \\ FACULDADE DE MEDICINA DE RIBEIRÃO PRETO \\ DEPARTAMENTO DE NEUROCIÊNCIAS E CIÊNCIAS DO COMPORTAMENTO
}

\title{
MAYARA THAIS CORRER
}

Tradução e adaptação cultural dos instrumentos: Hammersmith Neonatal Neurological Assessment (HNNE) e Hammersmith Infant Neurological Assessment (HINE); e validação do instrumento HNNE para lactentes brasileiros com risco de Paralisia Cerebral 


\section{UNIVERSIDADE DE SÃO PAULO \\ FACULDADE DE MEDICINA DE RIBEIRÃO PRETO \\ DEPARTAMENTO DE NEUROCIÊNCIAS E CIÊNCIAS DO COMPORTAMENTO}

Linha de Pesquisa: Avaliação funcional do Desempenho de crianças e adolescentes:

Neuropediatria e comportamento lúdico

Versão Corrigida

Tradução e adaptação cultural dos instrumentos: Hammersmith Neonatal Neurological Assessment (HNNE) e Hammersmith Infant Neurological Assessment (HINE); e validação do instrumento HNNE para lactentes brasileiros com risco de Paralisia Cerebral

Tese apresentada ao Departamento de Neurociências e Ciências do Comportamento da Faculdade de Medicina de Ribeirão Preto da Universidade de São Paulo para obtenção do título de Doutora em Neurologia e Neurociências

Orientado(a): Mayara Thais Correr Orientador(a): Profa. Dra. Luzia Iara Pfeifer 
Autorizo a reprodução e divulgação total ou parcial deste trabalho, por qualquer meio convencional ou eletrônico, para fins de estudo e pesquisa, desde que citada a fonte.

Correr, Mayara Thais.

Tradução e adaptação cultural dos instrumentos: Hammersmith Neonatal Neurological Assessment (HNNE) e Hammersmith Infant Neurological Assessment (HINE); e validação do instrumento HNNE para lactentes brasileiros com risco de Paralisia Cerebral, 2020.

224 f.: il.; $30 \mathrm{~cm}$

Tese de doutorado, apresentada à Faculdade de Medicina de Ribeirão Preto/USP. Área de concentração: Neurologia.

Orientador: Pfeifer, Luzia Iara

1. Paralisia Cerebral.

2. Diagnóstico Precoce.

3. Neurologia. 
Nome: CORRER, Mayara Thais

Título: Tradução e adaptação cultural dos instrumentos: Hammersmith Neonatal Neurological Assessment (HNNE) e Hammersmith Infant Neurological Assessment (HINE); e validação do instrumento HNNE para lactentes brasileiros com risco de Paralisia Cerebral

Tese apresentada à Faculdade de Medicina de Ribeirão Preto da Universidade de São Paulo para obtenção do título de Doutora em Ciências - Subárea: Neurociências

Aprovado em:

\section{Banca Examinadora}

Prof Dr:

Instituição:

Assinatura:

Prof Dr:

Instituição:

Assinatura:

Prof Dr:

Instituição:

Assinatura:

Prof Dr:

Instituição:

Assinatura:

O presente trabalho foi realizado com apoio da Coordenação de Aperfeiçoamento de Pessoal de Nível Superior - Brasil (CAPES) - Código de Financiamento 001 


\section{DEDICATÓRIA}

A todos pais, mães e cuidadores que, gentilmente, colaboraram com esta pesquisa e em especial aos seus bebês. Dedico ainda aos profissionais da saúde que tanto amam a neurologia. 


\section{AGRADECIMENTOS}

A melhor parte de escrever a tese, é quando temos a oportunidade de agradecer, e de retribuir com sentimentos e palavras aquilo que, de alguma forma, recebemos. Mas agradecer nem sempre é uma tarefa fácil, quando nossas palavras não são capazes de expressar o tamanho da nossa gratidão. Isso porque o agradecimento, que é o momento em que não queremos mais receber e sim nos doar diante das dádivas alcançadas, diante dos favores, da graça, dos detalhes, do reconhecimento e carinho recebidos, ainda continuamos a ganhar. Digo isso, porque a gratidão traz com ela inúmeros benefícios que transcendem as alterações fisiológicas e neurológicas, permitindo a nossa elevação e expansão espiritual.

Dito isso, eu quero agradecer a Deus em primeiro lugar, porque compreendo e entendo parte dos motivos que me fizeram chegar até aqui, sem dúvida foi Ele quem me abriu essa porta, quem facilitou o processo, e quem me proporcionou a quantidade de aprendizado que tive durante toda essa jornada. Não foi fácil, não foi nada fácil. Mas sei que Ele esteve do meu lado em cada momento difícil e prazeroso que vivi.

Em segundo lugar, gostaria de agradecer a minha orientadora, não apenas por ela ter exercido o papel de orientação com excelência e maestria, mas pelo ser humano incrível que ela é. Sabe aquelas pessoas que nos inspiram? Que nos faz olhar para nossa vida, não no quesito de TER mas sim como SER? Pois é, ela tem minha gratidão e minha admiração. Muitas e muitas vezes eu observei a forma com que ela encarava uma situação e desejei ser evoluída como ela e busquei aprender com ela. Confesso que por muito tempo eu quis desistir deste título, mas foi por ela e pela gratidão por Deus ter me aberto essa porta, que eu me mantive aqui.

Depois quero agradecer a minha família e ao meu marido por ter compreendido a minha ausência e por apoiar cada decisão que tive. Ao meu irmão Rafa que me ajudou tanto nas traduções da vida, sendo ele fluente e eu com extrema dificuldade com língua estrangeira.

Quero agradecer meus amigos mais próximos por compreenderem minha ausência e meu isolamento durante este período. Aos meus colegas da casa 13 que dividiram muitos momentos durante os 3 primeiros anos que estive em Ribeirão. Às minhas colegas de quarto Mariana, Victoria, Barbara e Viviane: que bom que a vida me permitiu conhecer vocês, obrigada por terem feito parte da minha vida.

Minha gratidão à Fernanda que foi meu braço direito durante boa parte da coleta, à Renata que foi outro presentinho que Deus me permitiu conhecer. À profa. Dra. Ana Claudia que me recebeu de braços abertos durante a realização do PAE. Aos bebês que participaram do estudo e aos seus familiares: meu MUITO OBRIGADA. 
"Não há transição que não implique um ponto de partida, um processo e um ponto de chegada. Todo amanhã se cria num ontem, através de um hoje. De modo que o nosso futuro se baseia no passado e se corporifica no presente.

Temos de saber o que fomos e o que somos, para sabermos o que seremos." 


\section{RESUMO}

CORRER, M.T.C. Tradução e adaptação cultural dos instrumentos: Hammersmith Neonatal Neurological Assessment (HNNE) e Hammersmith Infant Neurological Assessment (HINE); e validação do instrumento HNNE para lactentes brasileiros com risco de Paralisia Cerebral. 2020. 224 f. Tese - Faculdade de Medicina de Ribeirão Preto, Universidade de São Paulo, Ribeirão Preto, 2020.

Introdução: A Paralisia Cerebral (PC) engloba um grupo de desordens permanentes do desenvolvimento do movimento e postura, causando alterações motoras e cognitivas que influenciam negativamente as habilidades funcionais do indivíduo. $\mathrm{O}$ diagnóstico da PC é definido através da observação clínica e por exames de imagem e é frequentemente fechado tardiamente, em torno dos 12 aos 24 meses de idade, gerando um prejuízo no desenvolvimento motor destes indivíduos, uma vez que não são encaminhados para tratamento precoce. Instrumentos fidedignos para avaliar precocemente os fatores de risco para PC são de extrema importância para que essas crianças sejam encaminhadas para a estimulação precoce beneficiando o seu desenvolvimento. A maioria dos instrumentos de avaliação neurológica são elaborados em países desenvolvidos, como os instrumentos Hammersmith Neonatal Neurological Assessment - HNNE e o Hammersmith Infant Neurological Examination - HINE. Ambos apresentam alta sensibilidade preditiva para detectar a PC antes dos 5 meses de idade corrigida, porém necessitam ser adaptados e validados para a cultura brasileira, afim de constituir uma linguagem comum entre profissionais e pesquisadores. Objetivo: 1 - Realizar a tradução e adaptação cultural dos instrumentos Hammersmith Neonatal Neurological Assessment (HNNE) - versões expandida e resumida, e do Hammersmith Infant Neurological Assessment - HINE para a língua portuguesa; 2- validar e avaliar as propriedades psicométricas do HNNE; 3 - Verificar a sensibilidade do HINE para predizer alterações neurológicas de lactentes com risco para PC aos 3, 6, 9, 12 meses e aos 2 anos e verificar associação entre os escores do HINE com a AIMS (Alberta Infant Motor Scale) nos lactentes sem comprometimento neurológico e a classificação motora nos lactentes com diagnóstico de PC através do Gross Motor Function Classification System for Cerebral Palsy - GMFCS.O HNNE e o HINE têm como objetivo examinar os lactentes com idades entre 0 e 24 meses, a fim de diagnosticar riscos para a PC. Eles são compostos por três seções que avaliam a função do nervo craniano, postura, quantidade e qualidade do movimento, tônus, reflexos, desenvolvimento da função motora, e o comportamento. O GMFCS é um sistema de classificação para crianças e adolescentes de 0 a 18 anos com PC. São cinco níveis de classificação de acordo com as limitações funcionais e a idade do sujeito. Método: Esta tese foi dividida em 3 estudos. Estudo 1: realizar a adaptação cultural do HNNE e do HINE, para isto foi realizado a tradução inicial dos instrumentos por 2 tradutores e elaborada uma síntese das traduções que posteriormente foi analisada por um comitê de especialistas para resolver discrepâncias linguísticas, gramaticais e semânticas, criando-se uma versão consenso. Este documento passou por um processo de retrotradução para a língua original do instrumento, com 2 retrotradutores independentes. As versões retrotraduzidas foram sintetizadas e analisadas, determinando a versão consenso da retrotradução. As versões consensuais foram avaliadas e aprovadas pelos autores dos instrumentos consolidando as versões finais. Estudo 2: realizar a validação da escala HNNE para o Brasil. Para a confiabilidade teste-reteste, inter e intra-examinador, 30 recém-nascidos foram recrutados. Para a reprodutibilidade do tipo teste-reteste, foi dado um pequeno intervalo entre as avaliações, sendo que o participante foi reavaliado no mesmo dia. Para confiabilidade intra-avaliador, as avaliações foram filmadas e pontuadas em um intervalo de 14 dias. Para confiabilidade inter-avaliador, participaram dois profissionais da área da saúde de diferentes formações. Foi utilizado o Coeficiente de Kappa Ponderado e Correlação Intraclasse para 
identificar se as correlações apresentaram comportamentos semelhantes. Para testar a fidedignidade do instrumento, foi utilizado o Alfa de Cronbach na análise de consistência interna. As análises de reprodutibilidade apresentaram confiabilidades quase perfeitas em mais de $80 \%$ dos itens, porém os dados de consistência interna não foram satisfatórios. Estudo 3: Para o estudo preditivo, foi avaliado o desenvolvimento neuromotor de 143 lactentes com risco para PC por meio do HNNE e HINE. As avaliações ocorreram no período neonatal e foram reaplicadas a cada 3 meses no primeiro ano de vida (3, 6, 9 e 12 meses de idade) e, aos 24 meses foi feito um contato com a mãe do participante, via telefone, para correlacionar as manifestações clínicas estabelecidas até essa idade com os escores obtidos pela avaliação neurológica. Foi utilizado a curva ROC para análise preditiva. Resultados: Estudo 1-Seguiu-se todos os passos de tradução e adaptação cultural proposta pela literatura científica e o processo foi aprovado pelos autores do instrumento. Estudo 2 - Durante a validação do instrumento, foi encontrada uma alta concordância na confiabilidade intra e inter avaliadores e no teste-reteste em todos os domínios. Estudo 3 - Apenas 16 lactentes tiveram alterações neurológicas comprovadas por exame de imagem, sendo que 11 foram encontrados após 2 anos de idade. Destes 11, apenas 2 apresentaram manifestação clínica compatível com PC. Conclusão: Os instrumentos HINE e HNNE foram adaptados para os lactentes brasileiros e o HNNE foi validado para o Brasil. Ambos demonstraram serem sensíveis para a predição de PC. O HINE apresentou maior sensibilidade aos 6,9 e 12 meses.

Palavras - chave: Paralisia Cerebral, Diagnóstico Precoce, Neurologia. 


\begin{abstract}
Title: Translation and cultural adaptation of the Hammersmith Neonatal Neurological Assessment (HNNE) and the Hammersmith Infant Neurological Assessment; and validation of the HNNE instrument for Brazilian infants at risk for Cerebral Palsy.

Introduction: Cerebral Palsy (CP) involves a group of permanent disorders of the development of movement and posture, causing motor and cognitive changes that negatively influence the individual's functional abilities. The diagnosis of $\mathrm{CP}$ is defined by clinical observation of changes in movement and posture and by image exams and is often given late, around 12 to 24 months of age, causing impairment in the motor development of these individuals, since they do not are referred for early treatment. Reliable instruments for early assessment of risk factors for $\mathrm{CP}$ are extremely important for these children to be referred for early stimulation, benefiting their development. Most neurological assessment instruments are developed in developed countries, such as Hammersmith Neonatal Neurological Assessment HNNE and Hammersmith Infant Neurological Examination - HINE. Both have high predictive sensitivity for detecting $\mathrm{CP}$ before 5 months of corrected age, but they need to be adapted and validated for Brazilian culture, in order to constitute a common language between professionals and researchers. Objective: 1 - Provide the translation and cultural adaptation of the Hammersmith Neonatal Neurological Assessment (HNNE) instruments - expanded and summarized versions, and the Hammersmith Infant Neurological Assessment - HINE into Portuguese; 2- validity and evaluate the psychometric properties of the HNNE; 3 - Check the sensitivity of HINE to predict neurological changes in infants at risk for $\mathrm{CP}$ at 3, 6, 9, 12 months and 2 years and verify the association between HINE scores with the AIMS (Alberta Infant Motor Scale) in infants without neurological impairment and motor classification in infants diagnosed with CP using the Gross Motor Function Classification System for Cerebral Palsy GMFCSThe HNNE and HINE aim to examine infants aged 0 to 24 months in order to diagnose risks for $\mathrm{CP}$. They are composed of three sections that assess cranial nerve function, posture, quantity and quality of movement, tone, reflexes, motor function development, and behavior. GMFCS is a classification system for children and adolescents aged 0 to 18 years with $\mathrm{CP}$. There are five levels of classification according to the subject's functional limitations and age. Method: This thesis was divided into 3 studies. Study 1: carry out the cultural adaptation of HNNE and HINE, for that was initialized, the translation of the instruments by 2 translators and a synthesis of the translations was elaborated, which was later analyzed by a committee of experts to resolve linguistic, grammatical and semantic discrepancies, creating a consensus version. This document went through a process of back-translation to the original language of the instrument, with 2 independent back-translators. The back-translated versions were synthesized and analyzed, determining the consensus version of the back-translation. The consensual versions were evaluated and approved by the authors of the instruments, consolidating the final versions. Study 2: perform the HNNE scale validation for Brazil. For test-retest, inter- and intra-examiner reliability, 30 newborns were recruited. For reproducibility of the test-retest type, a short interval was given between the evaluations, and the participant was reassessed on the same day. For intra-rater reliability, assessments were filmed and scored over an interval of 14 days. For inter-rater reliability, two health professionals from different backgrounds participated. The Kappa Coefficient and Interclass Correlation were used to identify whether the correlations showed similar behaviors. To test the reliability of the instrument, Cronbach's Alpha was used in the analysis of internal consistency. The reproducibility analyzes showed almost perfect reliability in more than 80\% of the items, however the data of internal consistency were not satisfactory. Study 3: For the predictive study, the neuromotor development of 143 infants at risk for $\mathrm{CP}$ was evaluated
\end{abstract}


through HNNE and HINE. The assessments took place in the neonatal period and were reapplied at each 3 months in the first year of life (3, 6, 9 and 12 months of age) and, at 24 months, contact was made with the participant's mother, via telephone, to correlate the clinical manifestations established up to that age with the scores obtained by the neurological evaluation. The ROC curve was used for predictive analysis. Results: Study 1 - All the translation and cultural adaptation steps proposed by the scientific literature were followed and the process was approved by the authors of the instrument. Study 2 - During instrument validation, a high agreement was found in intra- and inter-rater reliability and in test-retest in all domains. Study 3 - Only 16 infants had neurological changes confirmed by image examination, 11 of which were found after 2 years of age. Of these 11, only 2 had a clinical manifestation compatible with CP. Conclusion: The HINE and HNNE instruments were adapted for Brazilian infants and the HNNE was validated for Brazil. Both proved to be sensitive to the prediction of CP. HINE was more sensitive at 6,9 and 12 months.

Keyword: Cerebral Palsy, Early diagnosis, Neurology. 


\section{LISTA DE QUADROS}

Quadro 1: Representação dos níveis do Mini - MACS ............................................................26

Quadro 2: Itens da seção CARACTERIZAÇÃO do instrumento HNNE resumido .................50

Quadro 3: Itens da seção POSTURA e TÔNUS do instrumento HNNE resumido ...................50

Quadro 4: Itens da seção MOVIMENTOS do instrumento HNNE resumido .........................53

Quadro 5: Itens da seção REFLEXOS do instrumento HNNE resumido .................................54

Quadro 6: Itens da seção ORIENTAÇÃO E COMPORTAMENTO do instrumento HNNE

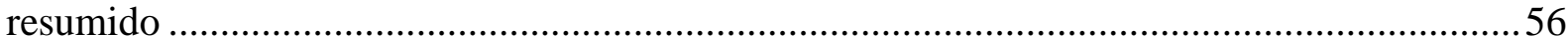

Quadro 7: Itens da seção CARACTERIZAÇÃO do instrumento HNNE expandido ...............58

Quadro 8: Itens da seção POSTURA e TÔNUS do instrumento HNNE expandido .................58

Quadro 9: Itens da seção PADRÕES DE TÔNUS do instrumento HNNE expandido .............62

Quadro 10: Itens da seção REFLEXOS do instrumento HNNE expandido...............................64

Quadro 11: Itens da seção MOVIMENTOS do instrumento HNNE expandido........................66

Quadro 12: Itens da seção SINAIS/PADRÕES ANORMAIS do instrumento HNNE

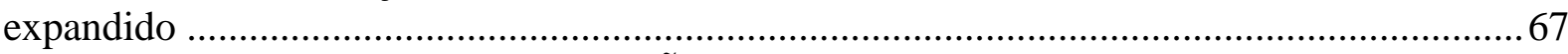

Quadro 13: Itens da seção ORIENTAÇÃO E COMPORTAMENTO do instrumento HNNE

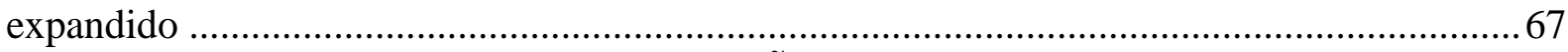

Quadro 14: Itens da seção CARACTERIZAÇÃO do instrumento HINE-infant ......................70

Quadro 15: Itens da seção FUNÇÃO DOS NERVOS CRANIANOS do instrumento HINE-

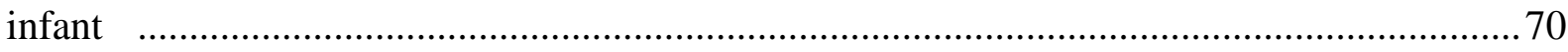

Quadro 16: Itens da seção MOVIMENTOS do instrumento HINE-infant ............................. 73

Quadro 17: Itens da seção TÔNUS do instrumento HINE-infant ...........................................74

Quadro 18: Itens da seção REFLEXOS E REAÇÕES do instrumento HINE-infant ..............75

Quadro 19: Itens da seção 2, MARCOS MOTORES do instrumento HINE infant...................76

Quadro 20: Itens da seção 3, COMPORTAMENTO do instrumento HINE infant ..................78

Quadro 21: Itens que obtiveram menos de $80 \%$ de concordância e sofreram algum tipo de

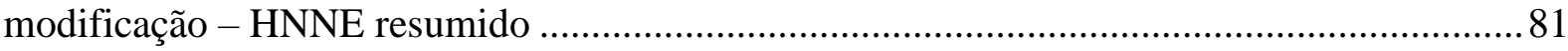

Quadro 22: Itens que obtiveram mais de $80 \%$ de concordância e sofreram algum tipo de modificação - HNNE resumido ....................................................................................... 82

Quadro 23: Itens que obtiveram menos de $80 \%$ de concordância e não sofreram nenhum tipo

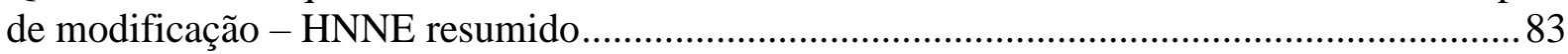

Quadro 24: Itens que obtiveram menos de $80 \%$ de concordância e sofreram algum tipo de

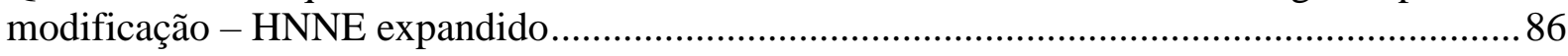

Quadro 25: Itens que obtiveram mais de $80 \%$ de concordância e sofreram algum tipo de

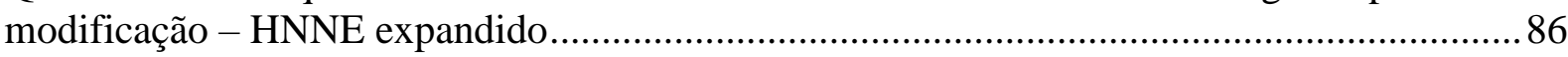

Quadro 26: Itens que obtiveram menos de $80 \%$ de concordância e não sofreram nenhum tipo

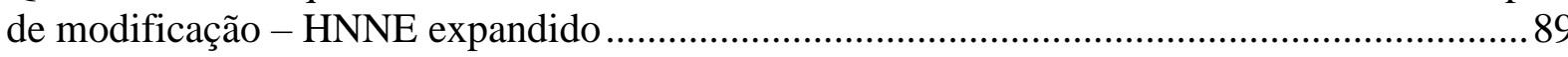

Quadro 27: Itens que obtiveram menos de $80 \%$ de concordância e sofreram algum tipo de

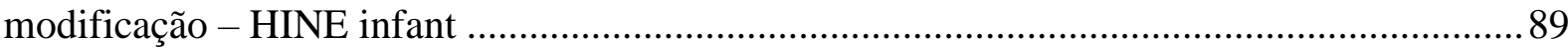

Quadro 28: Itens que obtiveram mais de $80 \%$ de concordância e sofreram algum tipo de modificação - HINE infant

Quadro 29: Itens que obtiveram menos de $80 \%$ de concordância e não sofreram nenhum tipo

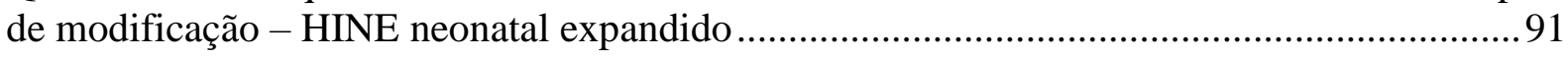

Quadro 30: Versões finais do processo de adaptação cultural do HNNE resumido .................93

Quadro 31: Versões finais do processo de adaptação cultural do HNNE expandido............... 97

Quadro 32: Versões finais do processo de adaptação cultural do HINE INFANT ................. 104 


\section{LISTA DE TABELAS}

Tabela 1: Correlação entre os fatores de risco para PC e o desempenho obtido pelo HNNE 125

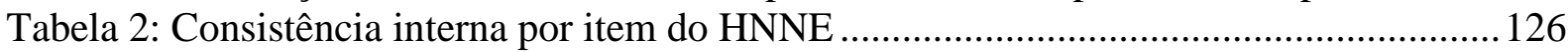

Tabela 3: Consistência interna por domínio do HNNE ....................................................... 127

Tabela 4: Confiabilidade inter avaliadores através da correlação Intraclasse ........................127

Tabela 5: Valores de Kappa ponderado por item para a confiabilidade inter avaliadores ..... 128

Tabela 6: Confiabilidade intra avaliadores por domínio, pela correlação Intraclasse ............129

Tabela 7: Valores de Kappa ponderado por item para a confiabilidade intra avaliadores ..... 130

Tabela 8: Confiabilidade teste-reteste, pela correlação Intraclasse ....................................... 131

Tabela 9: Valores de Kappa ponderado por item para a confiabilidade teste-reteste............. 131

Tabela 10: Correlação entre escore total e escore por domínio entre AIMS e HNNE...........132

Tabela 11: Dados descritivos dos participantes do estudo .................................................. 146

Tabela 12: Dados descritivos sobre a frequência de participantes e peso por IG. .................. 147

Tabela 13: Dados descritivos sobre as condições dos participantes ao nascer........................147

Tabela 14: Dados descritivos sobre a caracterização da família .......................................... 148

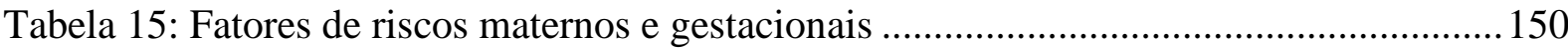

Tabela 16: Condições clínicas diagnosticadas intra-útero ou logo após o nascimento ...........151

Tabela 17: Frequência dos participantes no decorrer do acompanhamento preditivo ............152

Tabela 18: Média do escore total das avaliações neurológicas, obtido pelos grupos ao nascer e

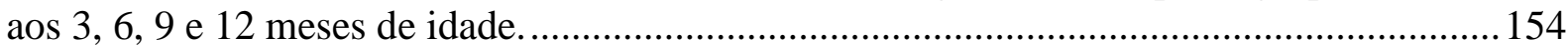

Tabela 19: Frequência de lactentes pela classificação de escore por normalidade. ................ 155

Tabela 20: Média do escore total obtido pelas avaliações motoras aos 3, 6, 9 e 12 meses de

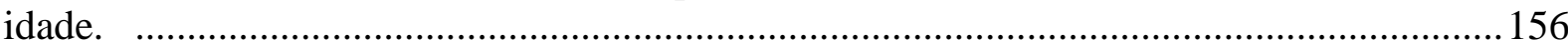

Tabela 21: Correlações entre as avaliações neurológicas e motoras. ..................................... 157

Tabela 22: Descrição dos casos com alteração neurológica comprovada por exames de

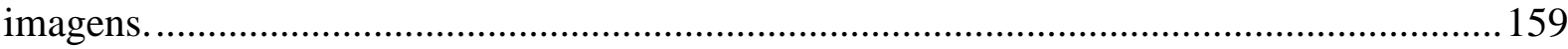

Tabela 23: Diagnósticos ou condições relatadas nos prontuários dos participantes. .............. 160

Tabela 24: Diagnósticos relatados pelas mães dos participantes .......................................... 161 


\section{LISTA DE FIGURAS}

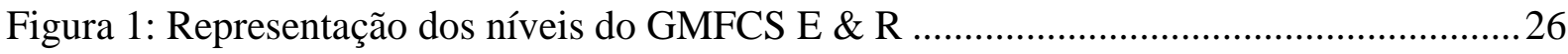

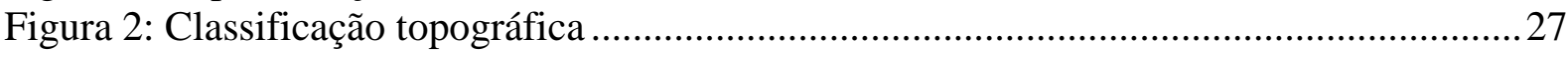

Figura 3: Exemplo de itens de avaliação do HNNE .............................................................. 34

Figura 4: Estágios e procedimentos da adaptação cultural das escalas HNNE (expandido;

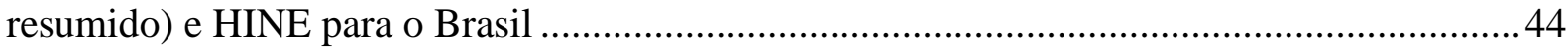

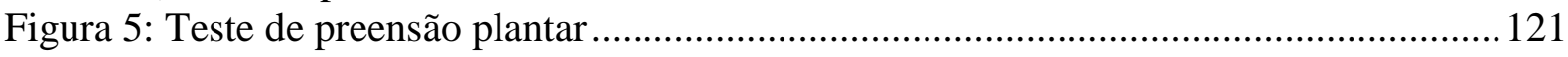

Figura 6: Teste de tônus flexor de cabeça - 121

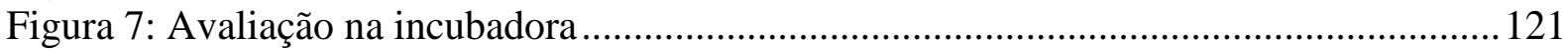

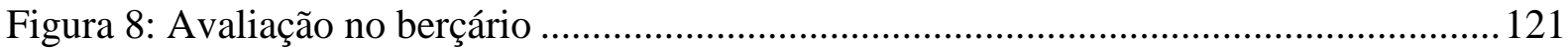

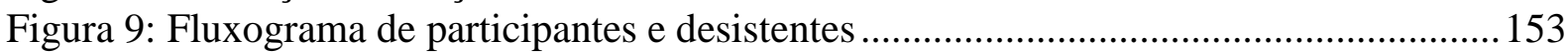

Figura 10: Representação dos casos com alguma alteração neurológica ............................... 161

Figura 11: Teste de sensibilidade dos instrumentos HNNE e HINE com o diagnóstico

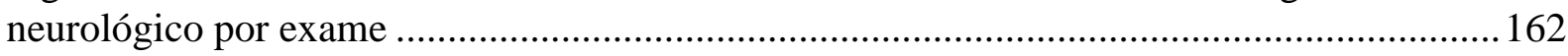

Figura 12: Teste de sensibilidade dos instrumentos HNNE e HINE com o diagnóstico neurológico, pela sua manifestação clínica 


\section{LISTA DE SIGLAS}

ADNM - Atraso no desenvolvimento neuropsicomotor

AVD - Atividades de vida diária

AVDI - Atividades de vida diária instrumentais

GMFCS E \& R- Sistema de Classificação da Função Motora Grossa Expandida e Revisada

GMs - Prechtl Qualitative Assessment of General Movements

HINE - Hammersmith Infant Neurological Assessment

HNNE - Hammersmith Neonatal Neurological Assessment

IG - Idade gestacional

IC - Iniciação científica

LEPTOI - Laboratório de Ensino e Pesquisa de Terapia Ocupacional na Infância e Adolescência

PC - Paralisia Cerebral

PN - Peso ao nascer

RCIU - Restrição de crescimento intrauterino

RM - Ressonância Magnética

SN - Sistema Nervoso

SNC - Sistema Nervoso Central

TC - Tomografia Computadorizada

UCIN - Unidade de Cuidados Intermediários

UTI - Unidade de terapia intensiva 


\section{SUMÁRIO}

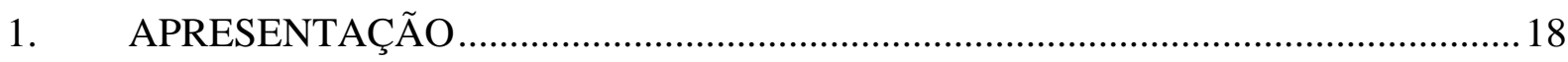

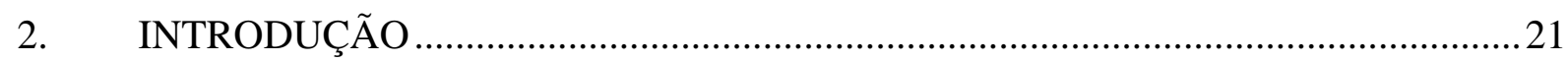

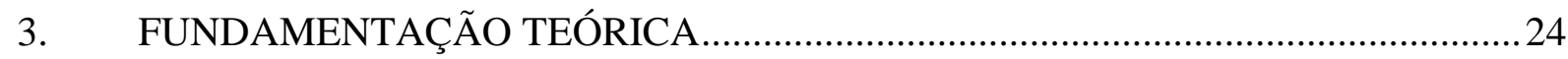

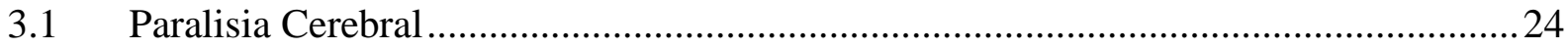

3.2 Diagnóstico da PC e a importância do diagnóstico precoce …………………………......29

3.3 Instrumentos de avaliação para diagnóstico precoce da PC ............................................30

3.4 Hammersmith neurological Assessment - "Neonatal" e "Infant"..................................31

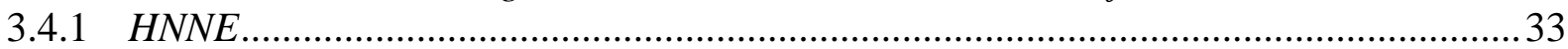

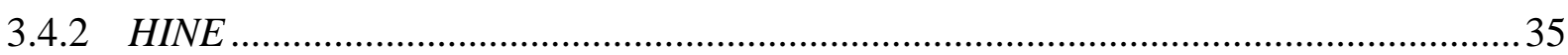

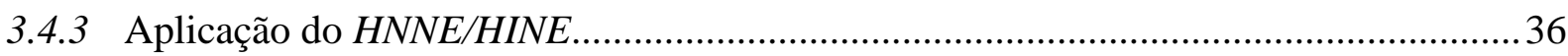

3.5 Tradução, adaptação cultural e validação de instrumentos.............................................39

3.6 Propriedades Psicométricas .................................................................................... 40

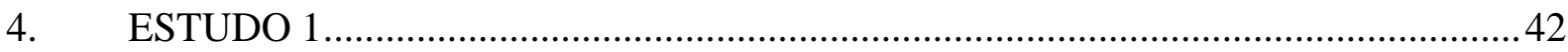

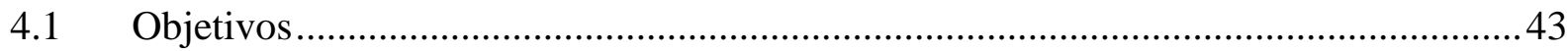

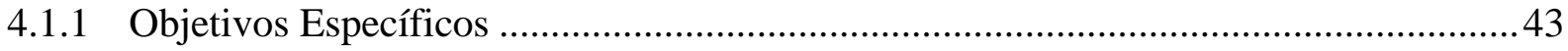

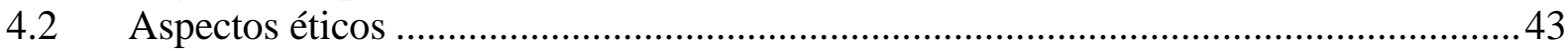

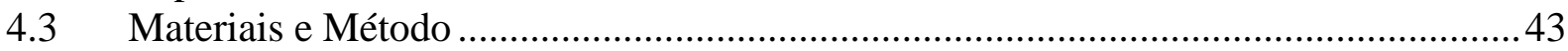

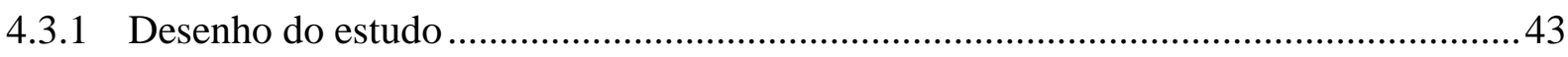

4.3.2 Procedimentos para adaptação cultural........................................................................ 43

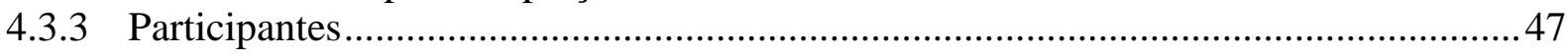

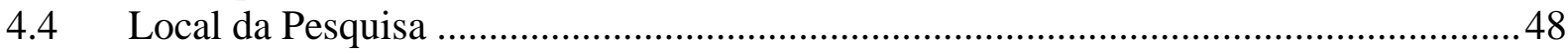

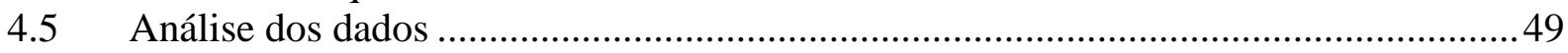

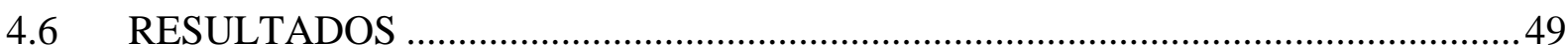

4.6.1 Resultados: Estágios 1 e 2 ……………………………………………………....49

4.6.1.1 Resultados estágios 1 e 2: HNNE resumido e HNNE expandido .................................50

4.6.1.2 Resultados estágios 1 e 2: HINE infant ………………………………………....... 70

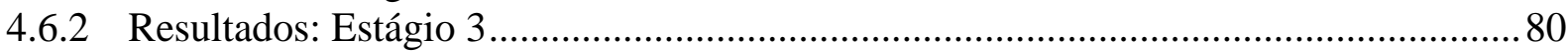

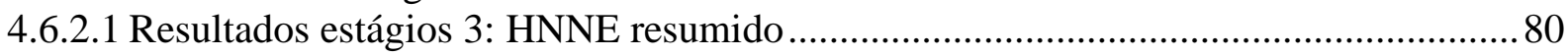

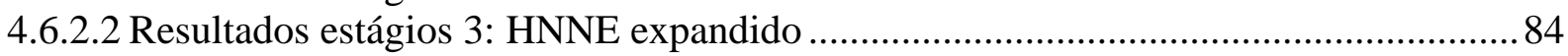

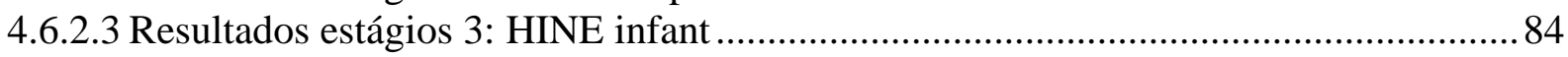

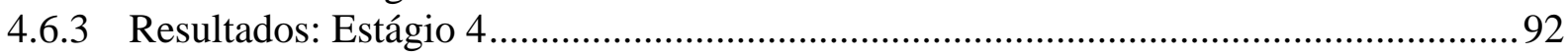

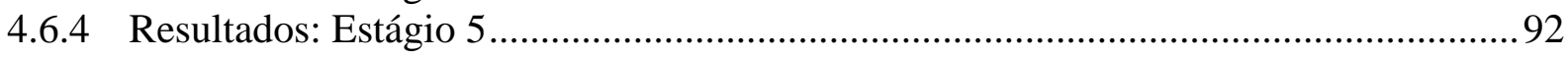

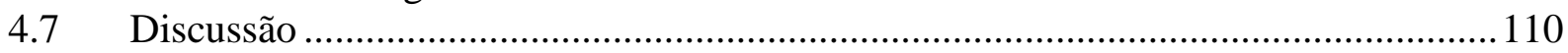

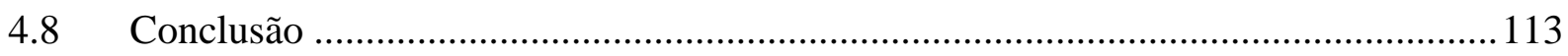

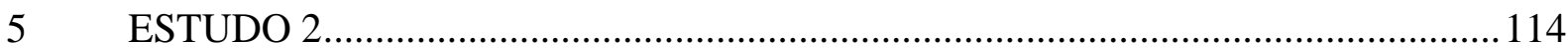

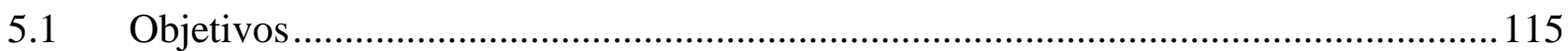

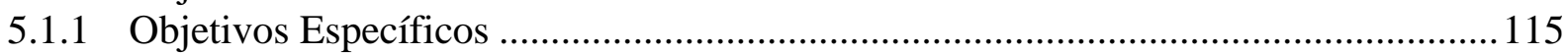

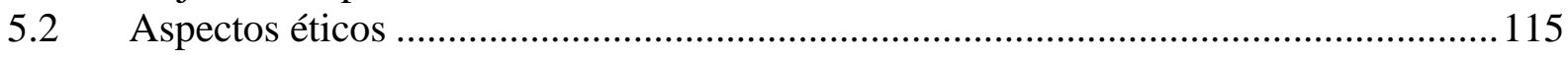

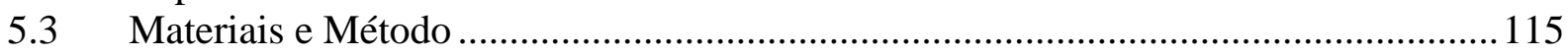

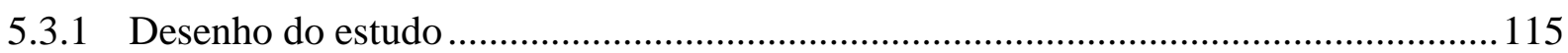

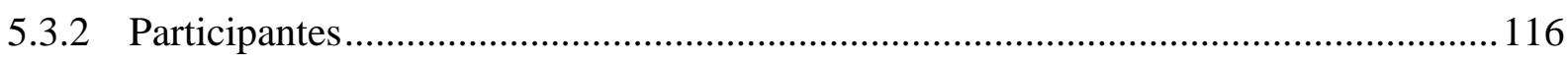

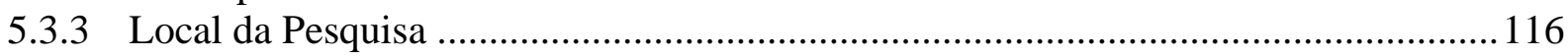

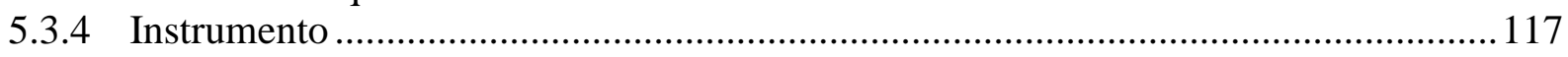




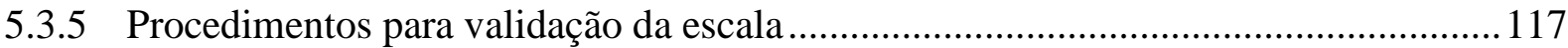

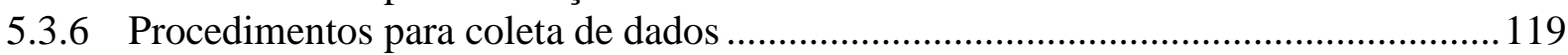

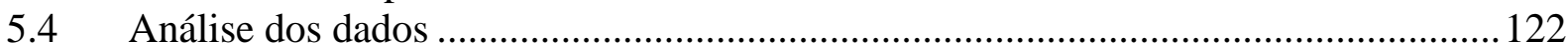

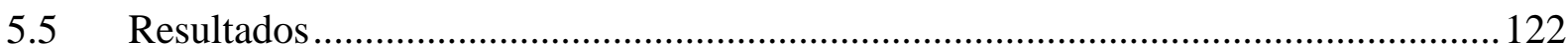

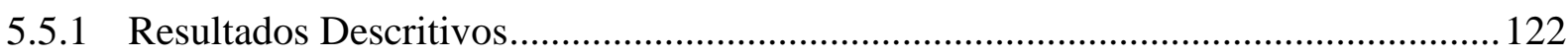

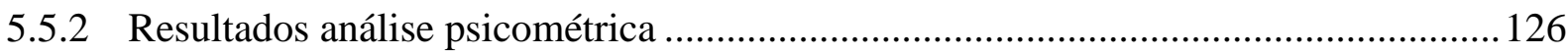

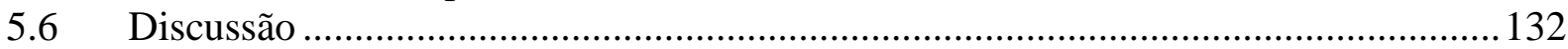

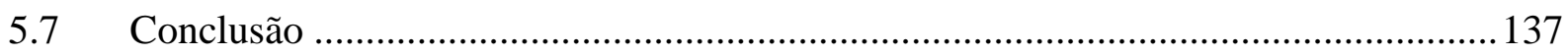

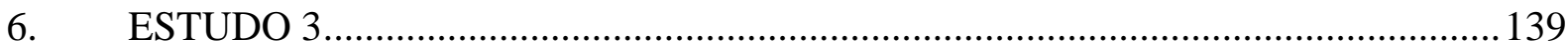

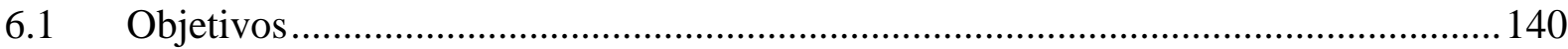

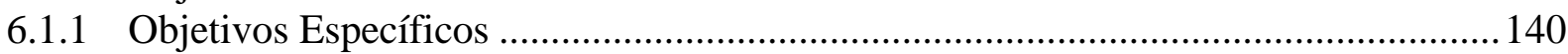

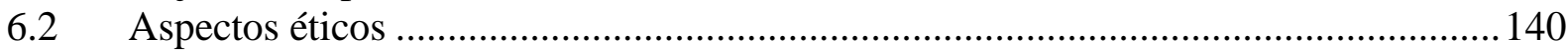

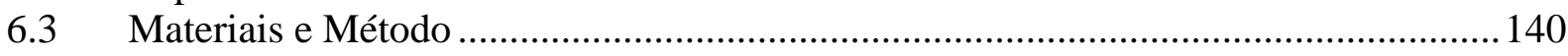

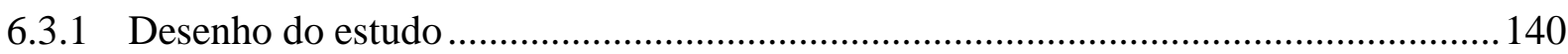

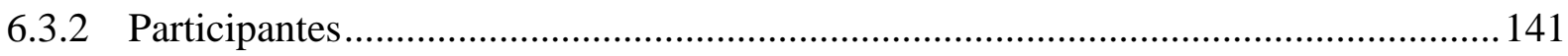

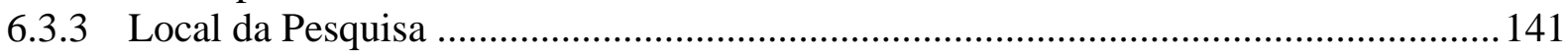

6.3.4 Procedimentos para continuidade de validação do instrumento .................................. 142

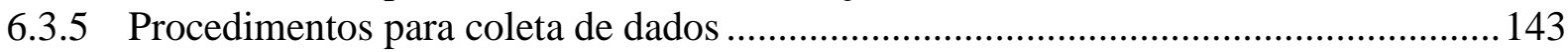

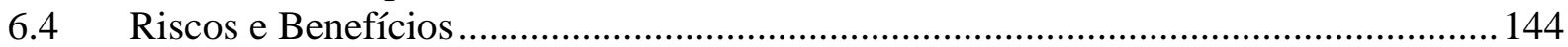

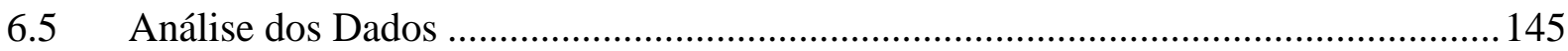

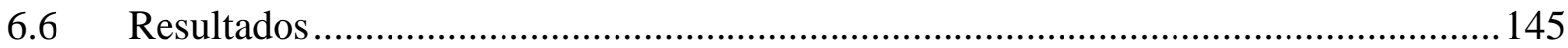

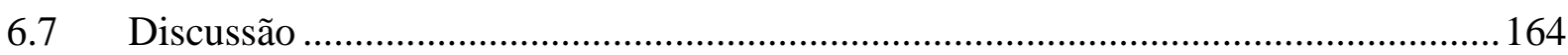

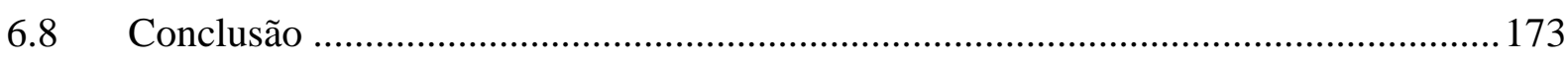

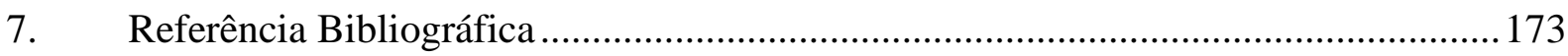

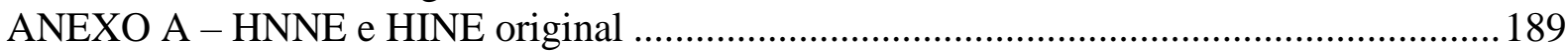

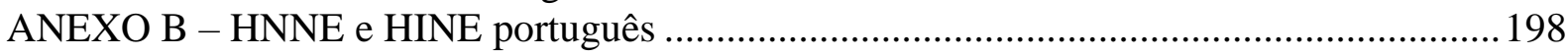

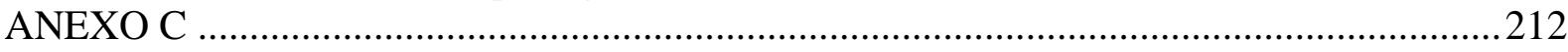

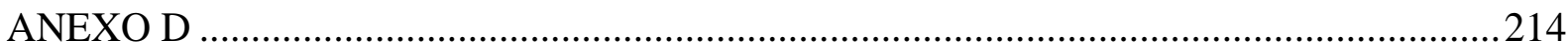

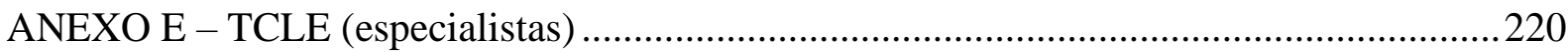

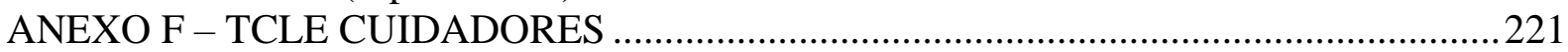




\section{APRESENTAÇÃO}

Este trabalho faz parte dos estudos do LEPTOI - Laboratório de Ensino e Pesquisa de Terapia Ocupacional na Infância e Adolescência ${ }^{1}$, dentro da linha de pesquisa Desempenho ocupacional de crianças e adolescentes em diferentes contextos.

O LEPTOI reúne ações e projetos de pesquisa, ensino e extensão que se propõem a integrar aspectos clínicos e sociais, a partir de duas linhas centrais de pesquisa: Formação profissional (perfil dos estudantes de Terapia Ocupacional, acompanhamento de ingressantes através do processo de tutoria institucional, desenvolvimento de estratégias de ensino em terapia ocupacional: tecnologia e arte) e Desempenho ocupacional de crianças e adolescentes em diferentes contextos (desenvolvimento em condições adversas - violência doméstica, pobreza e institucionalização; doenças crônicas, hospitalização, deficiências; comportamento lúdico e de lazer de crianças e adolescente, cuidadores), linha na qual se insere o presente estudo.

As investigações a partir desta linha estão centradas no desenvolvimento infantojuvenil, com ênfase para o desempenho ocupacional nas ocupações mais importantes para o seguimento etário em questão: atividades de vida diária (AVD), atividades de vida diária instrumentais (AVDI), o brincar, a educação (escola) e a participação social. Pretende-se, desta forma, aprofundar a compreensão acerca da influência dos eventos de vida sobre o desenvolvimento de crianças e adolescentes, na perspectiva da Terapia Ocupacional e áreas afins, ou seja, atentando para as habilidades de desempenho mais importantes na garantia da participação em contextos de vida, para cada etapa deste período do curso de vida (infância e adolescência).

Sobre a apresentação da minha história, eu vim de uma família humilde, da qual não havia nenhuma pessoa com formação em ensino superior, mas com a sorte de ser filha de um casal muito trabalhador que suou a camisa para nunca deixar faltar nada para seus 4 filhos e para ensinar a dignidade, o caráter, o respeito e as batalhas da vida, nos ensinou a lutar pelos nossos sonhos e ideais.

Meu irmão mais velho sempre foi um exemplo por ser muito estudioso e sonhava com uma formação em uma universidade pública; enquanto eu pensava em trabalhar e ser bemsucedida no trabalho. Cito meu irmão mais velho porque temos somente 1 ano de diferença, então caminhamos juntos pelo que queríamos e acreditávamos. Então, enquanto ele pesquisava sobre cursinhos e estudava horas e horas, eu buscava um emprego. Comecei a trabalhar com 15 anos como menor-aprendiz em uma farmácia grande, porém sempre fui requisitada a ter um 
cargo bom; ele por sua vez seguiu seu rumo e aos 17 anos ingressou na USP de São Carlos. Porém, depois de 5 anos de empresa, vivendo uma rotina de trabalho, notei que não tinha grandes perspectivas além de ser chefe de setor e me frustrei ao perceber que poderia mais do que aquilo, então decidi prestar um vestibular em uma universidade particular, pois não queria deixar minha família, pois sabia que existia uma vulnerabilidade no âmbito familiar e não queria me distanciar. A fisioterapia não era uma paixão, eu não tinha referências sobre a área, mas ao ler sobre a profissão me encantei e quis me arriscar. Comecei o curso noturno, trabalhando e estudando, até que chegou um momento que não estava conseguindo conciliar as duas coisas. Eis que a primeira porta da fisioterapia se abriu para mim e fui escolhida para fazer iniciação científica (IC). A bolsa era bem menor que meu salário, mas fiz uma escolha assertiva e consegui me dedicar melhor ao curso. E me apaixonei pela pesquisa, recebi um prêmio no meu primeiro ano de IC, renovei minha bolsa e fui premiada pelo segundo ano consecutivo, depois participei de um projeto de pesquisa extensão e ensino e consegui ser selecionada no incrível projeto RONDON e continuei contribuindo com a pesquisa. Me apaixonei pela neurologia infantil e sabia que este seria parte do meu caminho.

Quando me formei, não tinha dúvidas sobre o caminho a seguir. Então fiz uma pósgraduação lato sensu em intervenção precoce na Universidade Federal de São Carlos (trabalhava concomitantemente) e me decidi, faltando menos de 1 mês para o processo seletivo, prestar o mestrado em neurologia da FMRP-USP. Menos de 1 mês para estudar para a prova de nivelamento de neurologia, montar um projeto, e eu ainda trabalhava e fazia a pós-graduação. Achei que não iria passar. Mas Deus me abriu essa porta, porque neste tempo entre mestrado e doutorado, o crescimento seria muito mais pessoal e espiritual do que profissional. Não foi fácil, porque eu sempre fiz muitas coisas ao mesmo tempo, e quando parei para fazer uma única coisa, eu perdi meu chão pois não sabia lidar com isso.

Perdi minha avó da qual eu era muito apegada, saí de perto da minha família da qual eu sabia que precisava de mim, perdi meu noivo que estava comigo há 8 anos, e comecei a conviver numa casa com 21 pessoas desconhecidas e de várias etnias. Foi tão enriquecedor, tão maravilhoso, mas ao mesmo tempo eu não sabia gerenciar e lidar com o tempo que eu tinha. Não sabia lidar com a oportunidade de apenas estudar, sem precisar fazer um bilhão de coisas, e passei a compreender as injustiças e diferenças sociais, bem como, a falta de oportunidade que muitas pessoas têm e acabei adoecendo. Vivi um aprisionamento dentro de mim e pude me conhecer e me reconhecer, adoeci novamente. Me frustrei por não ter conseguido realizar o mestrado como eu gostaria (pois consegui recrutar um número reduzido de participantes e me cobrei muito sobre talvez não ter feito a escolha certa). No meu mestrado eu já havia descoberto 
que aqueles eram os meus melhores e piores dias. Melhores porque eu estava vivendo um sonho e piores porque eu não sabia conviver com o silêncio. Quando a gente para pra refletir sobre a vida e sobre as nossas escolhas e caminhada, o processo é doloroso, mas muito gratificante e lindo também. Escolhi continuar e aprender mais sobre tudo o que a vida estava me proporcionando e emendei com o doutorado. Ganhei um prêmio pela apresentação do meu trabalho de mestrado em um Simpósio Internacional, mas não conseguimos publicar o nosso artigo nas revistas que gostaríamos, e óbvio que me senti muito mal por isso.

Ganhei um novo namorado e enfrentei a maior de todas as batalhas até hoje, vivi um isolamento social antes de qualquer Covid-19, perdi um filho; chorei muito, quis desistir do doutorado, mas não o fiz por consideração à minha orientadora, e porque não queria ser ingrata à oportunidade que Deus me deu ao me permitir aprender tanto com estes momentos; e é claro, em respeito aos familiares que participaram da coleta, e ao meu compromisso com a pesquisa. Me permiti, aprendi, amadureci e compreendi meu papel, minha missão, as minhas motivações e o porquê eu ainda permanecia aqui. Ao acabar a coleta, retornei para minha cidade natal, casei, e abri meu espaço de trabalho, na minha casa mesmo, e hoje me sinto feliz e completa. Tenho mil e um afazeres aqui, mas consegui escrever a tese e concluir esta missão.

Apesar de concluído, este período estará para sempre eternizado em meu coração, num misto de caos e sonho, de dor e muito, mas MUITO aprendizado. Não me arrependo nem por um segundo por ter me desafiado de tal maneira e sim, ainda prestarei um concurso para professora em neurologia infantil; percebi o quanto eu amo dividir conhecimento, somar aprendizado e me desafiar.

Desejo do fundo do meu coração, que esta pesquisa gere frutos e contribua com o encaminhamento precoce de bebês nas unidades de serviço de saúde, para que eles tenham melhores oportunidades de desenvolvimento e de qualidade de vida. 


\section{INTRODUÇÃO}

A taxa de Paralisia Cerebral (PC) em sobreviventes neonatais varia significativamente com o nível de risco ao nascer. A incidência é que cerca de $30-40 \%$ de todos os indivíduos com PC são prematuros (e quanto mais prematuro maior a probabilidade de PC); $15-20 \%$ sofrem de encefalopatia neonatal; e 40 - 50\% são nascidos a termo sendo que não necessitaram de cuidados especiais no período neonatal e não parecem ter fatores de risco identificáveis no nascimento (BADAWI et al., 2005; WU et al., 2006; MCINTYRE et al., 2011).

A taxa global de PC para bebês nascidos a termo tem se mantido consistentemente entre 1,4-1,7/1.000 nascidos vivos nos últimos 30 anos (WATSON et al., 2006; HIMMELMANN; HAGBERG; UVEBRANT, 2010). Dos bebês nascidos a termo, destaca-se a encefalopatia neonatal como a principal causa de PC, apresentando uma taxa entre 100 e 125/1.000 sobreviventes neonatais, sendo que quanto mais grave a encefalopatia neonatal, maior risco de PC; já os partos múltiplos com nascimento a termo aumentam em quatro vezes o risco de PC quando comparados com partos de uma só criança nascida a termo; sendo que o risco aumenta novamente quando ocorre a morte de um gêmeo (PHAROAH, 2006).

Se pensarmos na incidência 1/1.000 sobreviventes neonatais diríamos que o grupo de bebês nascidos a termo que receberam cuidados de rotina no nascimento, apesar de apresentar menor risco para PC, representam $45 \%$ de todas as crianças com PC e, numericamente, compõem o maior grupo de PC (MCINTYRE et al. 2011).

O National Collaborative Perinatal Project relatou que a maioria das crianças com PC não deriva de grupos de alto risco (baixos índices de Apgar, ou a presença de sinais neonatais), sendo que cerca de $43 \%$ dos casos foram examinados e classificados como "neurologicamente normais" no período neonatal e, desta forma, uma grande proporção de casos de PC apresenta causas desconhecidas (NELSON; ELLENBERG, 1986; ELLENBERG; NELSON, 1988).

Na Austrália, um grupo de pesquisadores comparou 295 crianças com PC nascidas a termo, com 442 crianças típicas também nascidas a termo - nenhuma das quais necessitaram de cuidados especiais. Os pesquisadores identificaram seis preditores independentes de PC no período neonatal: fontanela anormal; tônus anormal; defeitos congênitos; assistência ventilatória restrita à sala de trabalho; consciência anormal apresentando irritabilidade e letargia e temperatura anormal baixa ou flutuante. Segundo os pesquisadores, neste grupo de baixo risco que tinha PC, 60\% apresentaram um acometimento moderado a grave (MCINTYRE et al., 2011). 
Tanto os lactentes que compõem os grupos de baixo ou alto risco, precisam de um diagnóstico que oportunizem um atendimento de cuidados e reabilitação o mais precocemente possível. Pesquisadores apontam o diagnóstico da PC como sendo tardio em pacientes que apresentam alto risco para PC e ainda mais tardio em bebês nascidos a termo, sem quaisquer sinais visíveis durante o período neonatal. De acordo com Watson e colaboradores (2006), a idade média para diagnóstico de PC é de 19 meses. Entretanto, pacientes com sequelas graves podem receber o diagnóstico com 1 semana de vida até 3 anos de idade, enquanto pacientes que apresentam sequelas leve a moderada, o diagnóstico varia de 1 semana para 5 anos de idade.

O diagnóstico precoce permite o acesso oportuno a intervenção precoce em um período onde são possíveis os maiores ganhos em função da neuroplasticidade. Por outro lado, o diagnóstico tardio pode ser prejudicial para o desenvolvimento de uma criança porque pode privá-la de intervenção precoce por meses ou mesmo anos (BOSANQUET, et al., 2013; MCINTYRE et al., 2011).

Alguns autores apontam como período crítico para intervenção precoce os primeiros 4 meses de vida. Portanto, é de extrema importância que os lactentes sejam encaminhados para intervenção nessa etapa ou o mais rápido possível, quando qualquer anormalidade no desenvolvimento seja detectada (FORMIGA; PEDRAZZANI. TUDELLA, 2010). É entendido como um período crítico ou sensível, o período de tempo durante o qual um indivíduo é mais susceptível à determinada influência externa (LOPES; MAIA, 2000).

Além disso, Baird; McConachie e Scrutton (2000) descobriram através de um estudo populacional realizado na Grã-Bretanha, que a insatisfação dos pais com diagnóstico tardio da PC está associada a taxas mais elevadas de depressão parental. Apesar da dificuldade que os familiares têm para lidar com a situação, o diagnóstico é o primeiro passo para a família encontrar a melhor forma para ajudar o seu filho (NOVAK, 2014).

A avaliação neurológica é uma das ferramentas clínicas utilizadas para monitorar o desenvolvimento de bebês que correm o risco de desenvolver deficiências no desenvolvimento neurológico (NOVAK et al., 2017; ROMEO et al., 2016); sendo que a maior parte dos estudos estão vinculados à avaliação do desenvolvimento global e aquisição de habilidades motoras, cognitivas, de linguagem e socioemocional (BODEAU-LIVINIC et al., 2013). As ferramentas que predizem uma PC são escassas e a maioria das que avaliam a condição neurológica são elaboradas em países de língua inglesa (BORSA; DAMÁSIO; BANDEIRA, 2012).

De acordo com Novak et al. (2017), dentre as ferramentas com melhor validade preditiva para detectar a PC antes da idade corrigida de 5 meses são: ressonância magnética (RM) neonatal cuja sensibilidade é de 86 - 89\%; Prechtl Qualitative Assessment of General 
Movements - GMs (Avaliação Qualitativa de Movimentos Gerais da Prechtl) com 98\% de sensibilidade e o Hammersmith Infant Neurological Examination - HINE com $90 \%$ de sensibilidade (ROMEO et al., 2016; BOSANQUET et al., 2013).

No Brasil, são raras as ferramentas de avaliação validadas e voltadas para a predição de alterações neurológicas. Pelo fato do HINE ter sido identificado como um dos melhores e mais simples exames neurológicos para o diagnóstico precoce de comprometimento neurológico em bebês de baixo e alto risco, e por ser uma ferramenta facilmente aplicada, inclusive por profissionais inexperientes (NOVAK et al., 2017; ROMEO et al., 2016/2013/2007), decidiu-se realizar a tradução e a adaptação cultural para a língua portuguesa e avaliar a validade cultural do Hammersmith Infant Neurological Assessment (HINE) para utilizar junto às crianças brasileiras com Paralisia Cerebral.

A adaptação cultural de um instrumento, é imprescindível quando sua utilização será realizada em um país do qual a ferramenta não foi desenvolvida, pois os costumes e comportamentos populares são distintos em diferentes etnias e culturas, afetando os resultados encontrados. 


\section{FUNDAMENTAÇÃO TEÓRICA}

\subsection{Paralisia Cerebral}

A Paralisia Cerebral (PC) foi descrita inicialmente em 1843, através da observação do cirurgião ortopédico William John Little (1810-1894), de que várias crianças apresentavam espasticidade. Ele relacionou a espasticidade com um histórico adverso ao nascimento como: apresentação pélvica, prematuridade, dificuldade no trabalho de parto, demora em chorar e respirar ao nascer, convulsões e coma nas primeiras horas de vida. $\mathrm{Na}$ época, a doença ficou conhecida como Doença de Little e, só em 1889 passou a ser chamada de Paralisia Cerebral (OSLER, 1889; ROTTA, 2002; MORRIS, 2007; BRASIL, 2013).

Após cerca de um século da primeira descrição da PC, o também ortopedista Winthrop M. Phelps (1894-1971), fundou o Children's Rehabilitation Institute (1937). O instituto tinha como objetivo treinar médicos e terapeutas, além de tratar de crianças com PC. Os principais objetivos de tratamento eram locomoção, autocuidado, fala e aspectos gerais. Phelps ressaltou a importância de uma abordagem holística e individual, ao invés de se concentrar em aspectos específicos das deficiências mecânicas e/ou neurológicas (MORRIS, 2007).

Phelps também foi um dos fundadores e primeiro presidente da Academia Americana de Paralisia Cerebral, criada em 1947. Ele propôs uma classificação da PC baseada na funcionalidade incluindo habilidades físicas e mentais. Classificou ainda, as alterações de movimento sob o termo de discinesia e utilizou espasticidade, atetose, sincinesia, ataxia e tremores como subcategorias (MORRIS, 2007; PAKULA, et.al., 2009).

Em 2004, foi realizado um Workshop Internacional sobre Definição e Classificação da Paralisia Cerebral em Bethesda, Maryland (EUA) cuja definição se mantém nos dias atuais:

\footnotetext{
"Paralisia Cerebral descreve um grupo de distúrbios permanentes do desenvolvimento do movimento e postura, causando limitação da atividade, que é atribuída a distúrbios não progressivos que ocorrem no cérebro fetal ou infantil. Os distúrbios motores da PC são frequentemente acompanhados por distúrbios de sensação, percepção, cognição, comunicação e comportamento, por epilepsia e secundários à problemas musculoesqueléticos" (BAX et al., 2005; ROSENBAUM et al., 2007; PAKULA et al., 2009).
}

Paralisia Cerebral, portanto, é um termo genérico que descreve um grupo de desordens motoras, acompanhado por muitas deficiências associadas. Atualmente, é a desordem mais comum na infância e é a causa mais prevalente de comprometimento da função motora, com uma frequência de cerca de 1/500 nascimentos (NOVAK, 2014). Em países desenvolvidos e 
com alta renda, a prevalência é de 2,1/1000 (OSKOUI et al., 2013), por outro lado, em países subdesenvolvidos ou em desenvolvimento, cujas famílias possuem rendas baixas ou médias, há uma tendência de maior prevalência e maior gravidade sobre o acometimento físico, que pode estar relacionado à maior exposição de doenças infecciosas, e diferenças no acompanhamento pré e peri natal (KHANDAKER et al., 2015).

Apesar das taxas de incidência e prevalência global ainda não serem precisamente conhecidas, estimou-se em 2015, a existência de cerca de 17 milhões de pessoas com PC no mundo (PALISANO et al., 1997; MCINTYRE et al., 2011; NOVAK, 2014).

Atualmente a PC tem sido classificada de acordo com a função - através do Sistema de Classificação da Função Motora Grossa - Expandido e Revisado - GMFCS \& R, além do MACS - Manual Ability Classification System; e MINI-MACS), pela distribuição topográfica (hemiplegia, diplegia ou quadriplegia) e pelas características provenientes da lesão (espasticidade, hipotonia, discinesia ou ataxia) (NOVAK, 2014).

O GMFCS \& R avalia a função motora grossa e possui cinco níveis de acordo com as limitações funcionais de crianças e adolescentes de zero a dezoito anos, em relação a capacidade de sentar e deambular (controle de tronco). Os níveis variam de acordo com a assistência que a criança necessita, sendo o nível I maior independência e o nível V totalmente dependente. As classificações são divididas ainda por faixa etária, sendo inferior a 2 anos, de 2 a 4 anos, de 4 a 6 anos, de 6 a 12 anos e de 12 a 18 anos (PALISANO et al., 2008). Antes dos 24 meses de idade, entretanto, é possível que haja mudanças nos níveis de classificação em cerca de $40 \%$ dos casos. Após 2 anos de idade, o sistema de classificação é estável (GORTER et al., 2008). $\mathrm{Na}$ figura 1, podemos observar a distinção entre os níveis do GMFCS E \& R sem as especificidades por faixa etária.

Para classificar a função motora fina das crianças com PC, foi publicado em 2006 um sistema de classificação da habilidade manual - MACS, que consiste em um sistema de classificação da função manual de crianças e adolescentes de 4 a 18 anos e tem enfoque no desempenho bimanual, ou seja, não classifica a criança a partir das dificuldades impostas pelo seu membro afetado ou pelo tipo de preensão manual, mas sim pelo que ela é capaz de fazer (ELIASSON et al., 2006; BRASIL, 2013). Em 2016, foi publicado o Mini-MACS, o mesmo sistema de avaliação, porém engloba crianças com PC com idades entre 1 e 4 anos (Quadro 1) (ELIASSON et al., 2016). 
Figura 1: Representação dos níveis do GMFCS E \& R

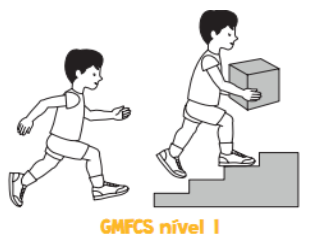

-Marcha independente sem limitações;

- Pula, corre;

- Velocidade, coordenação e equilíbrio prejudicados

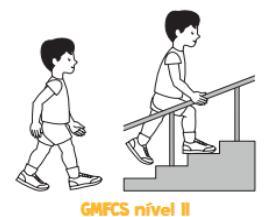

- Marcha independente com limitações

- Anda de gatas em casa

- Dificuldade para correr

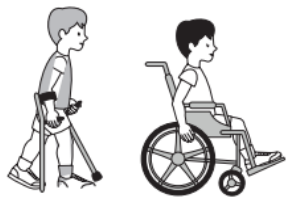

- Marcha com auxílio de muletas e andadores;

- Sobe escadas segurando em corrimão;

-Utiliza os MMSS para tocar a cadeira de rodas.

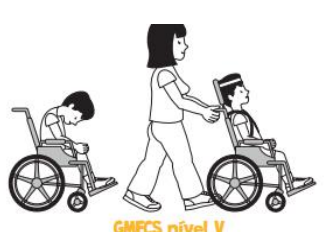

- Senta-se em cadeira de rodas adaptadas e pode adquirir autonomia se esta for motorizada; - Anda com andador em curtas distâncias:

- Faz transferências com auxílio.

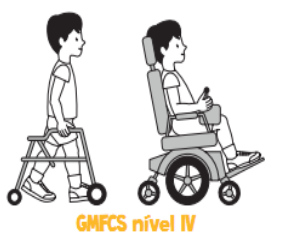

-Necessita de adaptações para sentar-se;

- É totalmente dependente em AVD'S e locomoção;

- Pode tocar cadeira de rodas motorizada com adaptações.

Imagens adaptadas de: Professor Graham, H. K. Royal Children's Hospital, Melbourne, Austrália.

Quadro 1: Representação dos níveis do Mini - MACS

\begin{tabular}{l|l}
\hline \hline Nível & Aptidões \\
\hline 1 & $\begin{array}{l}\text { Manuseia objetos facilmente e com sucesso, mas pode apresentar uma } \\
\text { leve limitação nas ações de desempenho que exigem precisão e } \\
\text { coordenação entre as mãos. } \\
\text { Manuseia objetos, mas com uma qualidade e / ou velocidade reduzidas e } \\
\text { pode escolher formas alternativas de execução. Precisa de assistência } \\
\text { para manusear os objetos mais frequentemente quando comparadas às } \\
\text { crianças. }\end{array}$ \\
\hline 3 & $\begin{array}{l}\text { Manipula objetos com dificuldade; a execução é lenta e os resultados } \\
\text { com êxito são obtidos em períodos mais curtos. Pode necessitar de ajuda } \\
\text { para pegar ou apoiar objetos } \\
\text { Requer esforço e suporte contínuo através assistência e/ou adaptações } \\
\text { para manipular objetos e atingir êxitos parciais. }\end{array}$ \\
\hline 5 & $\begin{array}{l}\text { Não manipula objetos. Tem habilidade limitada para executar tarefas } \\
\text { simples de manipulação. }\end{array}$ \\
\hline
\end{tabular}

Fonte: Adaptado de ELIASSON et al., 2016 
Dados Canadenses e Australianos apontam que 23\% dos indivíduos com PC são quadriplégicos, $38 \%$ diplégicos e 39\% hemiplégicos. A espasticidade está presente em 85 - $91 \%$ dos sujeitos, a discinesia (incluindo distonia e atetose) em 4 - $7 \%$, a hipotonia em $2 \%$ e ataxia em 4 - 6\%. A discinesia, ataxia e hipotonia geralmente afetam os 4 membros, enquanto a espasticidade é categorizada topograficamente como: unilateral (38\%) - conhecida como hemiplegia ou hemiparesia; bilateral (37\%) incluindo a diplegia/paresia; quadriplegia/paresia (24\%) (SHEVELL; DAGENAIS; HALL, 2009; ACPR GROUP, 2013/2016; NOVAK, 2014).

Em relação a deambulação, $60 \%$ dos indivíduos com PC realizam de forma independente, $10 \%$ deambulam com auxílio e 30\% utilizam cadeira de rodas. Se analisarmos pela distribuição topográfica, conforme demonstrado na figura 2 , apenas $1 \%$ dos hemiplégicos são incapazes de deambular, $2 \%$ dos diplégicos são cadeirantes e $77 \%$ dos quadriplégicos dependem da cadeira de rodas para se locomoverem (SHEVELL; DAGENAIS; HALL, 2009; ACPR GROUP, 2013/2016; NOVAK, 2014).

Figura 2: Classificação topográfica

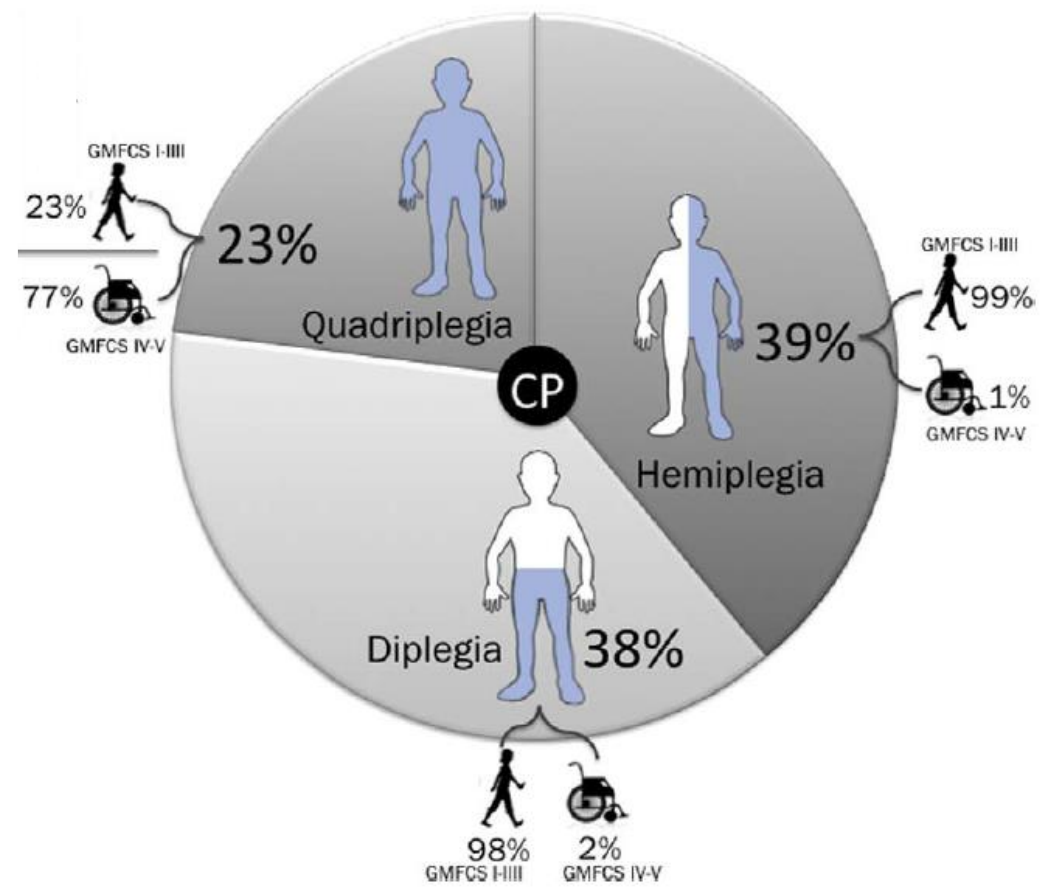

Fonte: Novak, 2014

Sabe-se que as causas da PC são múltiplas e provenientes de lesões no SNC que podem ocorrer em períodos pré-natal (por fatores maternos, infecções congênitas, fatores metabólicos maternos, transtorno tóxicos por uso de medicamentos), perinatal (infecções, hipoxemia cerebral, hemorragias, anóxia) e pós-natal (icterícia grave, meningoencefalites bacterianas, 
encefalopatias desmielinizantes, traumatismos cranioencefálicos e convulsões neonatais) (GOMES et al., 2001; PATO, et al., 2002).

Lesões no sistema nervoso central (SNC) gera um déficit na integração sensorial dos principais sistemas, interferindo diretamente no desenvolvimento do controle postural contra a gravidade e no desenvolvimento motor normal (BROGREN; FORSSBERG; HADDERSALGRA,1998). Para aquisição das habilidades motoras e do controle postural, é necessário a combinação de informações sensoriais dos sistemas visuais, auditivos, proprioceptivos e vestibulares integradas e coordenadas com o sistema musculoesquelético (ROSENBAUM et al., 2007; BRASIL, 2013).

Como resultado da lesão, crianças com PC podem apresentar dificuldades em desenvolver estratégias adequadas de locomoção e dificuldade para realizar atividades funcionais (de higiene e autocuidado) que necessitam de preensão e manipulação de objetos (WOOLLACOTT; SHUMWAY-COOK, 2005; MCCONNELL; JOHNSTON; KERR, 2011). As atividades sociais e de lazer também são prejudicadas gerando um impacto negativo na saúde e no bem-estar da criança e da família (MORALES et al., 2008).

Dependendo do tamanho e do local da lesão, algumas crianças apresentam ainda, outras deficiências associadas com a PC, tais como deficiência visual (11\%), auditiva (4\%), cognitiva (49\%), síndromes e epilepsias (35\%). A probabilidade da gravidade de deficiências associadas aumenta com a gravidade do comprometimento motor (HIMMELMANN et al., 2006; ODDING; ROEBROECK; STAM, 2006). As deficiências associadas impactam ainda mais sobre a função e a qualidade de vida do indivíduo (NOVAK et al., 2012; HIMMELMANN; UVEBRANT, 2011).

Outras comorbidades fortemente associadas com a PC são dor crônica (70 - 75\%) (JAHNSEN et al., 2004.; ARNAUD et al, 2008); deslocamento do quadril (27-35\%) e luxação do quadril (8\%) (HAGGLUND et al., 2005; SOO et al., 2006); distúrbios de comportamento (26\%) (PARKES et al., 2008); incontinência urinária e fecal (24\%) (ROIJEN et al., 2001); deformidades da coluna vertebral, distúrbios do sono (23\%) (NEWMAN; O’REGAN; HENSEY, 2006); sialorreia (22\%) (PARKES et al., 2010); e dificuldade para se alimentar (8\% alimentação por sonda) (SHEVELL; DAGENAIS; HALL, 2009; SIGURDARDOTTIR; VIK, 2011). 


\subsection{Diagnóstico da PC e a importância do diagnóstico precoce}

O diagnóstico da Paralisia Cerebral é definido através da observação clínica das alterações do movimento e postura e por exames de imagem, como tomografia computadorizada (TC) e ressonância magnética (RM). Entretanto, o diagnóstico é dado tardiamente em torno dos 12 aos 24 meses de idade (KRAGELOH-MANN; HORBER, 2007; MCINTYRE et al., 2011, GRANILD-JENSEN et al., 2015; HUBERMANN et al., 2016).

Antes dessa idade, a maioria dos lactentes com PC são diagnosticados como tendo atraso no desenvolvimento neuropsicomotor (ADNM). ADNM é um termo genérico que descreve dois ou mais atrasos no desenvolvimento da fala e da linguagem, social, emocional, cognitivo e motor (MCINTYRE et al., 2011).

Com o diagnóstico tardio, os pacientes estão sujeitos à um grande prejuízo no seu desenvolvimento motor, uma vez que são encaminhados para estimulação ou reabilitação apenas quando não alcançam os principais marcos motores esperados no desenvolvimento típico (tais como rolar, sentar, andar). Essa abordagem tardia é bastante prejudicial ao desenvolvimento uma vez que as crianças com baixo risco para PC não recebem nenhuma intervenção durante o período crítico de desenvolvimento neural (BOSANQUET et al., 2013; MCINTYRE et al., 2011).

Vários pesquisadores já apontam que a intervenção é mais eficiente quando iniciada em idade precoce, principalmente pela grande atividade cerebral e pelo constante amadurecimento do sistema nervoso central (GRANTHAM-MCGREGOR et al., 2007).

No Brasil, o Ministério da Saúde (BRASIL, 2013) lançou um Manual de Diretrizes ao Atendimento da Pessoa com PC, que recomenda a priorização e implementação da intervenção precoce, levando em conta a alta plasticidade cerebral uso-dependente, que possibilita alterações estruturais e funcionais no sistema nervoso e no sistema musculoesquelético.

Alguns pesquisadores destacam a importância em identificar deficiências e fornecer a intervenção o mais cedo possível, a fim de evitar disfunções e minimizar os resultados adversos do desenvolvimento neurológico, uma vez que bebês prematuros que são encaminhados para programas de intervenção precoce demonstram melhores resultados no desenvolvimento (KAARESEN et al., 2008; SPITTLE et al., 2015).

É considerado de extrema importância discriminar precocemente as diferentes desordens motoras (ADNM, dispraxia, síndromes, condições progressivas e metabólicas e PC) para que a criança receba, o mais breve possível, o tratamento adequado. Uma vez que tenha sido observado distúrbios de movimentos tais como espasticidade e/ou distonia, a intervenção 
deve ser iniciada imediatamente, principalmente se a criança apresentar risco para PC (MCINTYRE et al., 2011).

Embora os fatores causais que levam a PC não sejam completamente apontados em $80 \%$ dos casos, os fatores de risco são identificáveis desde a pré-concepção, até o período pós-natal (NELSON, 2008).

De acordo com McIntyre e colaboradores (2011) os riscos para PC são:

- Antes de concepção: história ginecológica anterior de natimortos, vários abortos, morte neonatal, parto prematuro, história familiar de PC e outras predisposições genéticas; além do diagnóstico materno de incapacidade intelectual, epilepsia e baixo nível socioeconômico.

- No início da gestação: Infecção, anomalias congênitas, gemelaridade, gênero masculino, e outras predisposições genéticas.

- Durante a gestação: Doença maternal (distúrbios da tireoide, pressão alta não controlada), complicações na gravidez (pré-eclâmpsia, hemorragia no segundo e terceiro trimestres, infecção e inflamação, restrição de crescimento intrauterino - RCIU, anormalidades placentárias e outros precursores de parto prematuro).

- Em torno da época do nascimento e no período neonatal: hipóxia durante o parto, acidente vascular cerebral, convulsões, hipoglicemia, icterícia e infecção aguda.

- Pós-natal: Infecções, lesões acidentais e não acidentais, acidente vascular cerebral.

\subsection{Instrumentos de avaliação para diagnóstico precoce da $\mathrm{PC}$}

Sabe-se que os primeiros meses de vida consistem em um período de maior adaptabilidade e plasticidade do SN, então, avaliar o neonato em seus aspectos neurológicos, é de suma importância para a detecção precoce de disfunções do desenvolvimento e encaminhamento à intervenção multidisciplinar (VIEIRA; RIBEIRO; FORMIGA, 2009).

Ainda que o recém-nascido não tenha apresentado intercorrências significativas nos períodos pré, peri e pós-natal imediato, é necessária uma avaliação minuciosa, para determinar se o nível de desenvolvimento está adequado, e se corresponde com a idade do mesmo (PEDROSO; ROTTA, 2003).

Apesar dos exames de imagens serem tão importantes quanto o exame clínico, estudos apontam que a associação entre ambas as formas de avaliação é mais eficaz para o diagnóstico neurológico, bem como, seu provável prognóstico (DUBOWITZ et al., 1984; MERCURI et al., 1999). 
Atualmente existem algumas ferramentas para identificação da Paralisia Cerebral, com precisão, em idade precoce, em populações de alto risco. São eles: Qualitative Assessment of General Movements (EINSPIELER et al., 2004); Developmental Assessment of Young Children (MAITRE; SLAUGHTER; ASCHNER, 2013) e Hammersmith Infant Neurological Assessment (PIZZARDI et al., 2008). Alguns autores apontam essas ferramentas como promissoras para a população de menor risco (MCINTYRE et al., 2011; NOVAK, 2014).

Dos instrumentos citados, o Hammersmith infant neurological assessment (HINE) é o único que não precisa adquirir kits ou licenças para aplicação, se tornando disponível e sem custo para todos os profissionais de saúde. De acordo Maruish (2018), as ferramentas utilizadas no cuidado primário pediátrico, precisam ser fáceis e rápidas de aplicar, o que também é o caso do HINE.

Entretanto, ele não está adaptado culturalmente e nem validado para a população brasileira. Considerando que a PC é a desordem mais comum de causa de deficiência na infância e que o seu encaminhamento precoce para a estimulação ou reabilitação pode trazer benefícios para o desenvolvimento de crianças com PC, é especialmente importante a tradução e adaptação cultural para que esse instrumento se torne uma ferramenta padronizada para a população brasileira.

Vários estudos populacionais que utilizaram o HINE para diagnosticar riscos para PC, evidenciaram que o instrumento é útil e preditivo já em idade precoce (HAATAJA et al., 2001/2003; FRISONE et al., 2002; RICCI et al., 2006; PIZZARDI et al., 2008; ROMEO et al., $2008 \mathrm{a} / \mathrm{b})$.

\subsection{Hammersmith neurological Assessment - "Neonatal" e "Infant"}

Os métodos de avaliação neurológica neonatal, avaliam basicamente os mesmos aspectos: como o tônus do tronco e membros, os reflexos e a movimentação ativa, que são preditivos de alterações neuromotoras e alguns abordam itens comportamentais (DUBOWITZ; DUBOWITZ, 1981; MERCURI et al., 2003).

Na década de 50, o foco da avaliação neurológica, centrava-se no tônus e nos reflexos primitivos do recém-nascido (DUBOWITZ; DUBOWITZ; MERCURI, 1999). A investigação dos reflexos primitivos é importante para avaliar a integridade do SN, já que alguns reflexos desaparecem nos primeiros meses de vida do lactente, retornando como atividade motora voluntária no segundo semestre de vida. A permanência dos reflexos pode indicar uma alteração patológica do SN (OLHWEILER; SILVA; ROTTA, 2005). 
Na década de 1960, foi desenvolvido por Prechtl um método que incluía postura, motilidade, movimentos patológicos, tônus muscular, reflexos neonatais e uma escala de 5 pontos para o estado infantil (PRECHTL; DIJKSTRA, 1960).

No início dos anos 1970, Brazelton sugere a avaliação da interação do neonato com seu cuidador considerando os aspectos comportamentais, a resposta auditiva, visual, tátil, dolorosa, irritabilidade e consolabilidade, trazendo um grande avanço para a clínica (DUBOWITZ; DUBOWITZ; MERCURI, 1999; FUNAYAMA, 1996).

Ainda na década de 1970, foi desenvolvida por Parmelee e Michaelis uma avaliação neurológica quantitativa baseada no exame de Prechtl, com uma pontuação total classificando as respostas para cada item (PARMELEE; MICHAELIS, 1971)

Em 1991, Prechtl propôs a observação da mobilidade e do estado comportamental da criança (EINSPIELER et al., 2004). E em 1997, Prechtl e seus colaboradores propuseram uma nova avaliação baseada na observação de movimentos espontâneos com descrição do desenvolvimento de padrões normais e anormais de movimentos gerais em bebês a termo e prematuros (PRECHTL et al., 1997)

Em 1981, Dubowitz e Dubowitz, desenvolveram um método de avaliação neurológica (Hammersmith infant neurological assessment - HINE) que foi atualizada, revisada e padronizada por Mercuri e Dubowitz em 1999 (ANEXO A), considerando todos os aspectos abordados anteriormente. O objetivo da avaliação é examinar os neonatos e lactentes para diagnosticar riscos para a PC. A avaliação pode ser utilizada como um componente da avaliação clínica de rotina e pode ser aplicada nos primeiros dias de vida, tanto de recém-nascidos à termo, como recém-nascidos prematuros em uma incubadora (DUBOWITZ; RICCI; MERCURI, 2005).

Esta avaliação também tem sido amplamente utilizada em estudos científicos; é de fácil aplicabilidade, pois apresenta instruções para realização de cada item. Pode ser aplicado por qualquer profissional da saúde com conhecimento na área de neurologia, sem necessidade de treinamento (DUBOWITZ et al., 1981; PALMER et al., 1982; MCGREAD et al., 2000; HIEU et al., 2006).

Além disso, uma versão deste instrumento foi validado em recém-nascidos de baixo risco, prematuros e a termo, o que permitiu estabelecer a variabilidade do tônus, movimentos e comportamento em diferentes idades gestacionais e forneceu algumas diretrizes gerais sobre quais são os achados mais comuns em cada idade gestacional (MERCURI et al., 2005).

Há três versões desta avaliação, sendo a versão expandida do HNNE (Hammersmith Neonatal Neurological Examination) e a versão resumida do mesmo instrumento, com foco na 
avaliação de neonatos; e a versão do HINE (Hammersmith Infant Neurological Examination) que avalia lactentes a partir dos 30 dias de vida até 24 meses.

\subsubsection{HNNE}

Neste estudo, chamamos de HNNE, o instrumento que avalia recém-nascidos. O HNNE está disponível em duas versões, a versão expandida e a versão resumida.

A versão expandida é composta por 34 tópicos subdivididos em 6 categorias:

1) postura e tônus (10 tópicos);

2) padrões de tônus (5 tópicos);

3) reflexos (6 tópicos);

4) movimentos (3 tópicos);

5) sinais anormais (3 tópicos); e

6) orientação e comportamento (7 tópicos).

A aplicação do HNNE dura em média cerca de 15 minutos, e pode ser aplicado até mesmo no recém-nascido com condição instável. O desempenho do RN é avaliado sem a necessidade de seguir a sequência proposta na ficha de avaliação, escolhendo uma sequência mais adequada em relação ao posicionamento do bebê ou seu estado de alerta (DUBOWITZ; MERCURI; DUBOWITZ, 1998; DUBOWITZ; DUBOWITZ; MERCURI, 1999).

Cada item pode pontuar 0,0 - anormal; 0,5 - intermediário; ou 1,0 - normal. As pontuações são calculadas pela soma de todos os itens, sendo a faixa de normalidade total de 30,5 a 34 (NASCIMENTO et al., 2011). Se o score global estiver na zona limítrofe não significa necessariamente que o RN avaliado apresente anormalidades neurológicas, mas identifica que esta deve manter seguimento neurológico regular (DUBOWITZ; DUBOWITZ; MERCURI, 1999).

Em 2005, foi elaborada uma versão curta e simplificada da HNNE (Figura 3), que funciona como uma triagem, devido ao grande volume de RN que necessitam de avaliação em relação a quantidade de médicos disponíveis para realizá-las (MERCURI et al., 2005). Essa versão é composta por 25 itens, sendo: postura e tônus (10 itens); movimentos (4 itens); reflexos (5 itens); orientação e comportamento (6 itens). Este instrumento foi estruturado de forma que a primeira e última coluna fossem sempre anormais para lactentes a termo.

Desta forma, lactentes a termo que pontuam dois ou mais itens destas colunas, ou um ou mais dos sinais anormais que são listados no final do instrumento, devem ser avaliados pela 
versão completa. Ambos os instrumentos podem ser aplicados em RN pré-termo (ROMEO et al., 2008; DUBOWITZ; RICCI; MERCURI, 2005).

Figura 3: Exemplo de itens de avaliação do HNNE

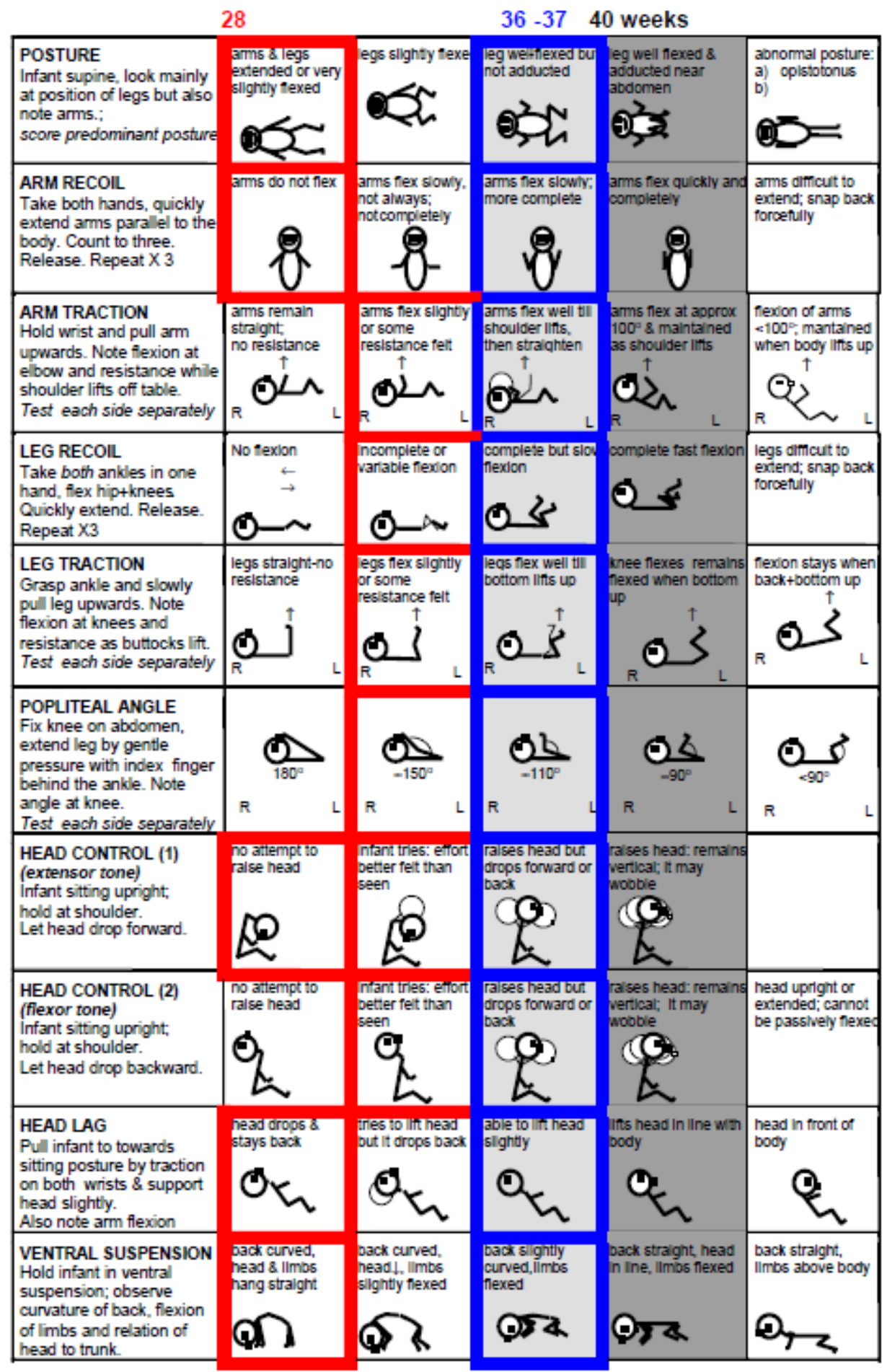

Fonte: Mercuri et al., 2005 
O HNNE possui figuras e descrições em cada item e para pontuar basta marcar a descrição ou a figura que melhor se adapta ao estado do lactente. A avaliação deve ser realizada quando o lactente estiver alimentado e calmo (DUBOWITZ; RICCI; MERCURI, 2005).

Este instrumento fornece um "escore de otimização" o qual foi validado com uma amostra de 224 bebês a termo saudáveis (DUBOWITZ et al., 1998) e ainda em uma amostra de 380 RN prematuros (RICCI et al., 2008).

\subsubsection{HINE}

A versão expandida é composta por 37 tópicos de avaliação subdivididos em 6 categorias que englobam 3 seções:

- A primeira seção é composta por: Categoria 1 - Função dos nervos cranianos (11 tópicos); categoria 2 - Movimentos (2 tópicos); Categoria 3 - Tônus (8 tópicos); Categoria 4 - Reflexos e reações (5 tópicos).

- A segunda seção avalia o desenvolvimento da função motora através dos marcos motores (8 tópicos) - Categoria 5

- A terceira seção avalia o comportamento (3 tópicos) - Categoria 6

A segunda e a terceira seções não fazem parte da pontuação global, mas fornecem informações sobre o progresso do desenvolvimento, portanto, 26 itens são pontuados. Cada item pode receber uma pontuação de 0 a 3, podendo alcançar um escore global de 78 pontos (HAATAJA et al., 1999; PIZZARDI et al., 2008).

Os autores do instrumento apresentam um escore normativo por faixa etária, considerando escore ótimo (sem risco de alterações neurológicas), lactentes que com 3 meses apresenta escore $\geq 67$; com 6 meses escore $\geq 70$ escore; e com 9 e 12 meses escore $\geq 73$. Para prematuro, é recomendado o uso da idade corrigida para considerar estes mesmos escores (DUBOWITZ; MERCURI; DUBOWITZ, 1998).

Esta avaliação tem duração de 5 a 15 minutos e não é necessário nenhum treinamento formal, afinal o exame pode ser facilmente realizado até mesmo por pessoas que não possuem experiência com o instrumento. A pontuação é baseada na otimização da distribuição de frequência dos escores na população típica, sendo definido como ideais, os escores encontrados em pelo menos $90 \%$ de uma coorte de baixo risco, com lactentes em diferentes idades que apresentam desenvolvimento típico (HAATAJA et al., 1999/2003; DUBOWITZ; RICCI; MERCURI, 2005). 
Estudiosos relataram uma confiabilidade interobservador acima de $96 \%$ mesmo por profissionais de uma equipe inexperiente (DUBOWITZ; DUBOWITZ; MERCURI,1999; MCGREADY et al., 2000).

Assim como no instrumento anterior, cada item do HINE possui figuras e descrições para facilitar a observação e pontuação do item mais adequado. A avaliação deve ser realizada quando o lactente estiver alimentado e calmo (DUBOWITZ; RICCI; MERCURI, 2005).

\subsubsection{Aplicação do HNNE/HINE}

O exame se inicia por um período observacional cuja postura da cabeça, tronco, extremidades, movimentos espontâneos, padrões respiratórios e presença de contraturas articulares podem ser facilmente avaliados. O bebê também deve ser inspecionado para evidenciar qualquer trauma ou malformações. Todas as observações devem ser listadas como "outros sinais", no final da avaliação. A circunferência da cabeça e o tamanho da fontanela também devem ser avaliados (DUBOWITZ; RICCI; MERCURI, 2005).

Neste capítulo serão descritas as categorias avaliadas pelos instrumentos.

\section{Postura e Padrões de Tônus}

Quando examinados em idade a termo, bebês prematuros são mais hiperexcitáveis que bebês a termo e tendem a ter menos tônus flexor nos membros e menos tônus extensor no pescoço na postura sentada (MERCURI et al., 2003).

A hipotonia neonatal é o sinal neurológico anormal mais comum e pode estar associada ao envolvimento do sistema nervoso central e periférico (MERCURI et al. 2005). Para Vasta et al. (2005), a diminuição do tônus pode estar associada ainda à fraqueza e/ou contraturas. A fraqueza muscular em RN, é geralmente avaliada pela presença ou ausência de movimentos antigravitacionais, sendo que movimentos antigravitacionais ausentes ou severamente reduzidos são um marcador confiável de distúrbios neuromusculares.

Já a hipertonia extensora de membros inferiores e flexora de membros superiores, ou um tônus extensor predominante nos músculos do pescoço e tronco são sempre sugestivos de envolvimento grave do SNC e são frequentemente associados a padrões específicos de lesões. Essa condição pode ser evidenciada por lactentes a termo que apresentem lesões difusas no córtex, substância branca ou nos gânglios da base; ou em lactentes prematuros que apresentam leucomalácia periventricular (MERCURI et al. 2005). 
Em relação ao controle e às mudanças de tônus automáticas, são fundamentais para garantir as reações posturais de equilíbrio, proteção e retificação. A automatização e os movimentos ativos atuam em conjunto para fornecer o mecanismo de controle postural adequado para que o movimento voluntário ocorra (SHUMWAY-COOK; WOOLLACOTT, 2001).

De acordo com Cunha et al. (2009), em casos de PC, o mecanismo de controle postural é deficiente, gerando alterações nas reações posturais que são a base estável para a realização dos movimentos contra a gravidade.

\section{$\underline{\text { Reflexos }}$}

Os reflexos são movimentos simples que ocorrem diante de uma resposta à um determinado estímulo sensorial. É controlado pela medula e, algumas vezes, conta com a modulação mesencefálica, sendo que esta resposta deverá ser suprimida ou substituída por reações automáticas, controladas pelo mesencéfalo. Este fenômeno ocorre perante o amadurecimento do SNC, que estabelece novas sinapses, à medida que o comportamento motor progride. Desta forma, alguns reflexos se transformam em reações e, posteriormente, em movimentos mais elaborados, como padrões rítmicos, preensão e marcha (PAPALIA et al., 2000; SHUMWAY-COOK, WOOLLACOTT, 2001; LENT, 2010).

Os principais reflexos observados em RN típicos são: reflexo de sucção, de Moro, de preensão tônica palmar e plantar, de liberação de vias aéreas, de Galant, de sustentação do membro inferior, de colocação do membro e de marcha automática. Também podem ser observados: Reflexo Tônico Cervical Assimétrico (RTCA), Reflexo Tônico Cervical Simétrico (RTCS) e Reação Cervical de Retificação (SHEPHERD, 1996).

Quando há alguma lesão no SNC, os mecanismos de reações posturais são insuficientes. Reflexos anormais ou aumentados sugerem lesão do SNC (DIAMENT et al., 2010). Para Flehmig (2005) indivíduos com PC podem apresentar a permanência dos reflexos primitivos.

A má sucção por exemplo, pode estar presente em distúrbios neuromusculares e doenças generalizadas graves, mas se presente e associada a outros sinais anormais do SNC, é fortemente sugestivo um acometimento de gânglios da base ou do tronco cerebral (MERCURI et al., 2005; DIAMENT et al., 2010). A falta de descarga de peso nas mãos e a alteração do tônus, faz com que o reflexo de preensão tônica palmar permaneça, dificultando ainda mais a exploração manual e todas as atividades perceptivo-motoras que dependem desta. $\mathrm{O}$ mesmo 
ocorre com o reflexo de preensão plantar, cuja permanência dificulta o alinhamento do pé no chão, impedindo a postura de ortostase e inviabiliza a ocorrência da marcha (FLEHMIG, 2005).

A permanência do RTCA impede o alinhamento dos membros superiores, dificulta as atividades em linha média, e causa assimetrias em tronco e membros inferiores (FONSECA, LIMA; 2008), já o RTCS é bastante comum em pacientes com diparesia (SHEPHERD, 1996).

O reflexo de marcha automática pode ser um indicador precoce de lesão neurológica, caso persista após o segundo ou terceiro mês de vida (BRANDÃO, 1985; LEVITT, 1982); da mesma forma, sua ausência nas primeiras horas de vida é considerada sinal precoce de encefalopatia grave (FIGUEIREDO, 1984).

Em relação ao reflexo de Moro, considera-se que a sua persistência após o sexto mês de vida pode indicar suspeita de lesão neurológica (CAPUTE et al., 1982; LEVITT, 1982; MOLNAR, 1979). Enquanto a ausência deste reflexo nos primeiros meses de vida é considerada um sinal precoce de lesão do sistema nervoso central (FIGUEIREDO, 1984; CAPUTE et al., 1978).

\section{Movimentos}

Em RN a termo, os movimentos espontâneos tendem a ser fluentes havendo alternância entre a postura flexora padrão e alguns movimentos mais alongados, podendo apresentar esporadicamente tremores. Em contrapartida, bebês muito prematuros apresentam movimentos bruscos que vão diminuindo com o aumento da idade gestacional (MERCURI et al. 2005).

\section{$\underline{\text { Sinais anormais }}$}

A seção de sinais anormais inclui uma lista de sinais que precisam ser verificados, como por exemplo, posições anormais das mãos e dos pés (na ausência de contraturas), clônus tremores e "startles" (desordem neurológica caracterizada por respostas de sobressalto acentuado por estímulos acústicos, táteis e hipertonia) que são sugestivos de um envolvimento do SNC subjacente (DUBOWITZ; RICCI; MERCURI, 2005).

\section{Orientacão e Comportamento}

A seção comportamental inclui a avaliação da orientação visual e auditiva, movimentos oculares, estado de alerta, que, quando anormais, são sinais importantes de suspeita de lesão do 
SNC. Irritabilidade e consolabilidade fornecem um reflexo claro se a criança é indiferente, apático, difícil para despertar ou se é mais ágil, hiper-irritado e difícil de consolar. Ambos podem refletir um estado neurológico anormal. O choro também é avaliado, se o choro for fraco ou alto e agudo também refletem um estado neurológico anormal (DUBOWITZ; RICCI; MERCURI, 2005).

Em relação a avaliação do sistema visual, lactentes a termo são capazes de fixar e seguir um objeto com contraste. Já os prematuros extremos possuem pouca capacidade de fixar e seguir um objeto, sendo que esta capacidade aumenta com o aumento da idade gestacional (MERCURI et al. 2005).

Quanto ao sistema auditivo, a audição reduzida ou ausente pode indicar alteração no SNC (MERCURI et al. 2005).

\subsection{Tradução, adaptação cultural e validação de instrumentos}

A maioria dos instrumentos de avaliação foram elaborados em países desenvolvidos e têm sido utilizados erroneamente, por falta de equivalência cultural, em realidades socioculturais distintas de sua origem. Esse fator interfere na designação dos resultados em realidades etnoculturais diferentes (BORSA; DAMÁSIO; BANDEIRA, 2012).

É bem documentado nos estudos científicos que as diferentes manifestações clínicas, evoluções e prognósticos são interdependentes da cultura onde os sujeitos estão inseridos. Portanto, é importante padronizar um instrumento para constituir uma linguagem comum entre profissionais e pesquisadores; e elaborar um panorama mundial entre as variações etnoculturais e os fatores socioculturais em detrimento das regiões distintas (BORSA; DAMÁSIO; BANDEIRA, 2012). Pois o uso de instrumentos padronizados aumenta o grau de concordância entre investigadores e possibilita comparação de resultados (MENEZES; NASCIMENTO, 2000).

Os instrumentos HNNE (expandido e resumido) e HINE foram desenvolvidos no idioma inglês; para a utilização em outros idiomas, é necessário realizar um rigoroso processo de adaptação cultural, para que suas características semânticas e psicométricas sejam mantidas.

A validação semântica é composta por 5 etapas: traduções independentes iniciais (a partir do idioma original), conciliação das traduções (versão síntese), traduções reversas independentes para o inglês (retrotradução), revisão, finalização e formatação da escala traduzida (BEATON et al., 2000; EREMENCO; CELLA; ARNOLD, 2005). 
Durante o processo de tradução e adaptação cultural, é importante se atentar para a adequação dos fatores linguísticos e socioculturais, pois a linguagem verbal ou escrita pode ter significados diferentes em culturas distintas (GUILLEMIN; BOMBARDIER; BEATON, 2002; COSTER; MANCINI, 2015).

Outros procedimentos complementares para a adaptação cultural, são constituídos pela tradução por pessoas bilíngues; retrotradução por pessoas não familiarizadas com a versão original do instrumento; análise de todas as versões traduzidas e retrotraduzidas por um comitê de especialistas; além de um estudo piloto junto à população-alvo, passíveis de modificações se necessário (WESTERMEYER; JANCA, 1997; GUILLEMIN; BOMBARDIER; BEATON, 2002; COSTER; MANCINI, 2015; EPSTEIN; SANTO; GUILLEMIN, 2015).

A validação psicométrica é composta pela avaliação das medidas de confiabilidade e da validade do instrumento. A confiabilidade é obtida pela consistência interna (medida pelo coeficiente alfa de Cronbach) e pela reprodutibilidade (medida pela aplicação de teste e reteste) (CRONBACH, 1951; CHRONBACH; MEEHL, 1955). Mais detalhes sobre a validação psicométrica são abordados no capítulo a seguir.

\subsection{Propriedades Psicométricas}

A validação de um instrumento se dá pela confiabilidade em se medir precisamente, com consistência e estabilidade o que se propõe, e com alto grau de concordância entre múltiplas medidas de um mesmo objeto. Conforme mencionado anteriormente, a confiabilidade é obtida pela consistência interna e pela reprodutibilidade (CRONBACH, 1951; CHRONBACH; MEEHL, 1955; PASQUALI, 2001; WATKINS, 2008; ALEXANDRE; COLUCI, 2011; PORTNEY; WATKINS, 2008).

É chamado de reprodutibilidade, quando se aplica o mesmo instrumento mais de uma vez no mesmo indivíduo (teste-reteste). Podemos ainda avaliar a reprodutibilidade através da confiabilidade intra-avaliador (quando o mesmo avaliador avalia o mesmo sujeito em momentos distintos); e através da confiabilidade inter-avaliador (quando diferentes avaliadores investigam o mesmo aspecto ou sujeito em uma mesma ocasião, buscando a concordância de aplicação e ou de interpretação dos resultados) (PASQUALI, 2010; PORTNEY; WATKINS, 2008; FITZNER, 2007).

Os objetivos do teste-reteste em avaliar os mesmos sujeitos em momentos distintos, são para garantir a estabilidade da medida e de calcular a correlação entre as distribuições de escores obtidos (WALTZ; STRICKLAND; LENZ, 2005; OHL et al., 2012). O período de diferença 
entre as medições do teste e do reteste devem ser longas o suficiente para evitar recordações das respostas na primeira aplicação e curta o suficiente para garantir que mudanças clínicas não tenham ocorrido (TERWEE et al., 2007), sendo ideal um intervalo entre 10 a 14 dias (KESZEI; NOVAKA; STREINER, 2010).

Em relação à consistência interna, é uma medida que verifica se os itens e subitens de um instrumento tem o mesmo conceito e se relacionam. Por isso, é um importante dado para questionários que pretendem medir um único conceito utilizando diversas variáveis (TERWEE et al., 2007). O teste mais aplicado na estatística para avaliar este fator é o alfa de Cronbach. Seus valores variam de zero a um com correlações positivas entre os itens, sendo considerado aceitáveis os valores entre 0,70 e 0,80 ; bons os valores acima de 0,80 ; e excelente 0,90 . Valores acima de 0,90 não são recomendados, pois podem indicar redundância dos itens (WALTZ; STRICKLAND; LENZ, 2005).

Porém, erros de critério, de informação e de situação podem afetar negativamente a confiabilidade de uma medida. É considerado como erros de critério, os erros relacionados com o avaliador/entrevistador; os erros de informação ocorrem quando o respondente não compreende o item avaliado ou por fornecer informações incorretas; e erros de situação se referem à instabilidade dos fenômenos que estão sendo investigados (MENEZES; NASCIMENTO, 2000; PORTNEY; WATKINS, 2008).

Diante do exposto acima, essa tese foi dividida em três estudos:

1. Adaptação cultural e validação semântica das escalas HNNE (expandida e resumida) e HINE para uso no Brasil;

2. Validação da versão brasileira da escala HNNE.

3. Acompanhamento preditivo de lactentes de médio e alto risco para PC utilizando a escala HINE. 


\section{Estudo 1}

Tradução e adaptação cultural dos instrumentos Hammersmith Neonatal Neurological Assessment (HNNE) - versão expandida e resumida; e Hammersmith Infant Neurological Assessment (HINE) para o Brasil 


\subsection{OBJETIVOS}

Realizar a tradução e a adaptação cultural dos instrumentos HNNE (Hammersmith Neonatal Neurological Assessment - versões expandida e resumida); e HINE (Hammersmith Infant Neurological Assessment) para o idioma português do Brasil, para utilizar junto às crianças brasileiras com Paralisia Cerebral.

\subsubsection{Objetivos Específicos}

Traduzir e adaptar culturalmente para o português falado no Brasil os aspectos semânticos, gramaticais, idiomáticos e conceituais de ambos os instrumentos.

\subsection{Aspectos éticos}

Este estudo respeitando as exigências da Resolução 466/12 da Comissão Nacional de Ética em Pesquisa do Conselho Nacional de Saúde do Ministério da Saúde (BRASIL, 2012) foi aprovado pelo comitê de ética do Hospital das Clínicas da Faculdade de Medicina de Ribeirão Preto da Universidade de São Paulo (HC - FMRP/USP), sob o parecer ${ }^{\circ} 1.809 .858$. O estudo 1 foi desenvolvido entre 2016 e 2017.

\subsection{MATERIAIS E MÉTODO}

\subsubsection{Desenho do estudo}

Estudo transversal e metodológico de tradução e adaptação cultural das escalas $H N N E$ - Hammersmith Neonatal Neurological Assesment, em suas duas versões: expandido e resumido; e HINE - Hammersmith Infant Neurological Assesment, para diagnosticar riscos de Paralisia Cerebral em lactentes brasileiros.

\subsubsection{Procedimentos para adaptação cultural}

Foi realizado contato via e-mail com os autores do instrumento, solicitando a autorização para a realização do processo de tradução e adaptação cultural do HNNE (versões expandida e resumida) e do HINE. O Dr. Eugenio Mercuri, neuropediatra, colaborador do 
instrumento e pesquisador na Università Cattolica del Sacro Cuore - Campus situado em Roma na Itália, nos concedeu a permissão para iniciar o processo. A permissão encontra-se no anexo B.

O processo de tradução e adaptação cultural foi baseado conforme as recomendações de Wild et al. (2005), Beaton et al. (2007), Pasquali (1998/2001/ 2003) e Ferrer et al. (1996) e foi dividido em seis estágios para cada um dos instrumentos conforme a figura 4, sendo o sexto estágio descrito no Estudo 2.

Figura 4: Estágios e procedimentos da adaptação cultural das escalas HNNE (expandido; resumido) e HINE para o Brasil.

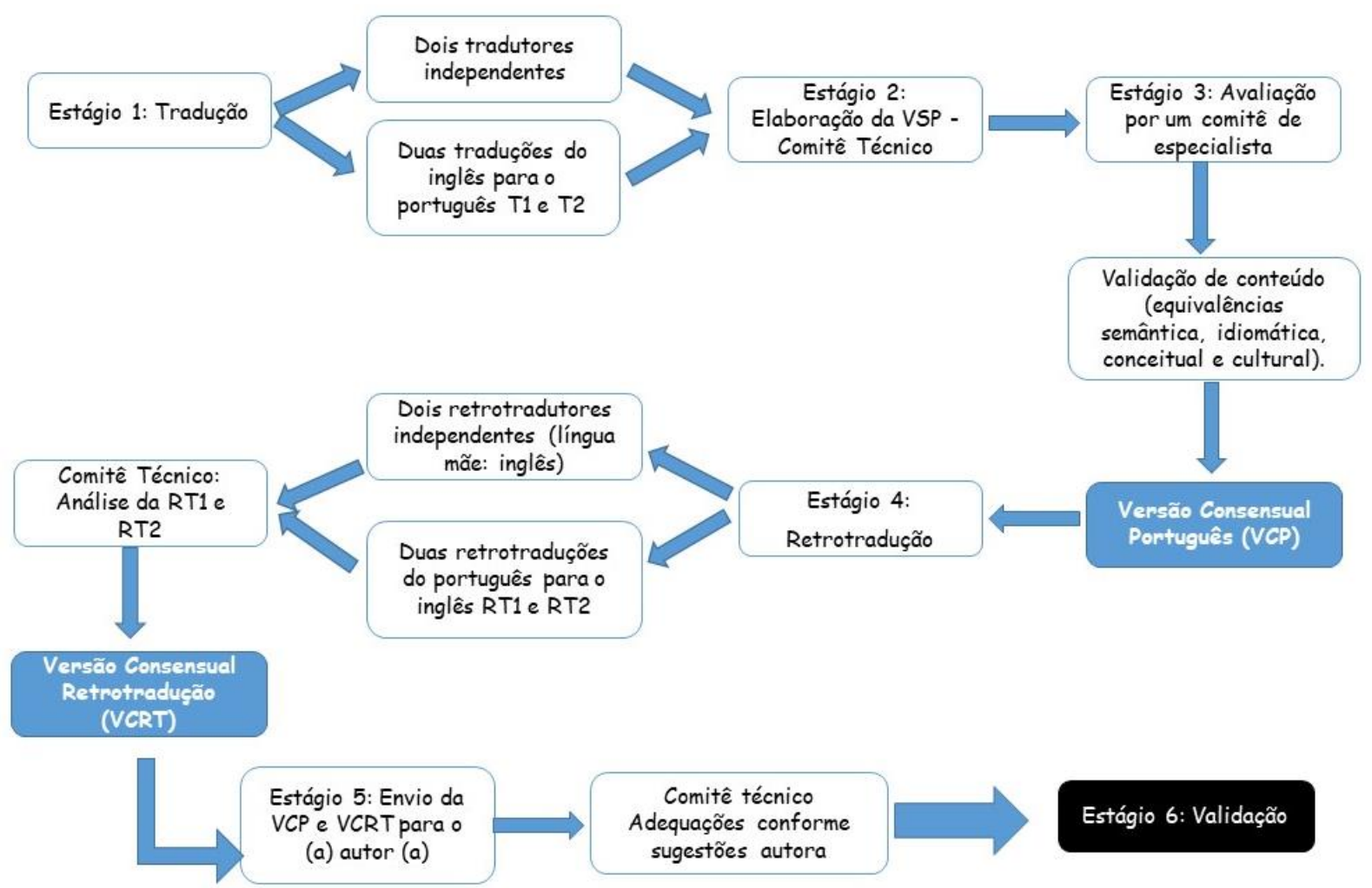

Legenda: T1 - Tradutor 1; T2 - Tradutor 2; VSP - Versão Síntese Protuguês, VCP - Versão consensual português; RT1 - Retrotradução 1; RT2 - Retrotradução 2; VCRT - Versão consensual retrotradução.

Fonte: Do autor

- Estágio 1 - tradução inicial: Foi realizada uma tradução simples da língua inglesa para a portuguesa de forma independente por dois tradutores brasileiros (T1 e T2). O T1 possui conhecimento na área de neuropediatria, ciência dos conceitos examinados pelo instrumento e domínio de ambos idiomas e elaborou a Versão Tradução 1 (VT1). O T2 possui amplo domínio de ambas línguas, porém não possui conhecimento prévio do instrumento e nem 
experiência na área de neuropediatria e elaborou a Versão Tradução 2 (VT2). Os dados dessas traduções foram plotados em documento do Microsoft Word®.

- Estágio 2 - Síntese das traduções: Foi formado um comitê técnico por um pesquisador mestre em neurologia e com experiência na área de neuropediatria e um pesquisador doutor na área de neuropediatria com mais de 20 anos de atuação e com domínio em ambas as línguas para comparar as versões VT1 e VT2 e elaborar a Versão Síntese Português (VSP). Para isso, seguiu as recomendações feitas por Koller et al. (2012) que fornecem nove opções para realizar a tradução síntese: 1) Escolher e encaminhar a tradução "A" como está, isto é, sem modificações; 2) Escolher e encaminhar a tradução "B" como está; 3) Utilizar A com pequenas modificações; 4) Utilizar B com pequenas modificações; 5) Mesclar A e B como são, com A adaptado para B; 6) Mesclar A e B como elas são, com B adaptado para A; 7) Mesclar A e B com modificações/adições, com A adaptado para B; 8) Mesclar A e B com modificações/adições, com B adaptado para A; 9) Preparar uma tradução completamente nova (KOLLER et al., 2012). Foi escolhido mesclar A e B com modificações/adições, com B adaptado para A. Nesta etapa, os resultados foram sintetizados para produzir uma versão consensual fidedigna ao instrumento original e plotados em documento do Microsoft Word® para seguir para o próximo estágio.

- Estágio 3 - Comitê de Especialistas: As versões, original (inglês) e VSP, foram avaliados por um Comitê de Especialistas composto por 10 profissionais com experiência em neuropediatria. Devido à impossibilidade de reunir os especialistas, a equipe técnica optou por realizar a avaliação por meio de formulário plotado em documento do Microsoft Word®, disponibilizado via e-mail. O formulário continha uma página introdutória com informações sobre a finalidade do estudo, caracterização do especialista participante com dados como: nome, profissão, tempo de atuação profissional na área, titulação, especialidade(s) e as principais atividades desenvolvidas em sua área de especialidade, além de uma ficha com respostas em formato dicotômicas simples com as opções: de acordo e não está de acordo, e quando não estivesse de acordo poderia sugerir o que considerasse mais adequado. O Comitê de Especialista se atentou para a validação de conteúdo considerando as questões semânticas, idiomática, conceitual e experiencial.

De acordo com Beaton et al. (2007) a equivalência semântica se refere à clareza dos itens, ou seja, se o significado das palavras se corresponde ou se há diferentes significados para uma mesma palavra ou sentença, e se existem dificuldades gramaticais na tradução. 
A equivalência idiomática refere-se às expressões coloquiais, ou seja, linguagem informal de um determinado idioma, como gírias, que geralmente são utilizadas popularmente em situações informais. Neste caso, o comitê técnico ou de especialistas deve formular uma expressão equivalente em sua versão traduzida (BEATON et al., 2007).

A equivalência conceitual se relaciona com o conteúdo explorado pelo instrumento original, ou seja, garante a validade dos conceitos e ideias fidedignas. Ocasionalmente, as palavras ou sentenças podem se equivaler em significado semânticos, mas não se equivalem conceitualmente (BEATON et al., 2007).

Equivalência cultural ou experiencial aborda situações coerentes ao contexto cultural onde o instrumento será utilizado. Mesmo que a palavra seja traduzível, algumas vivências podem não ser experimentadas na cultura de destino do instrumento em processo de adaptação. Nesses casos o processo de equivalência cultural deve garantir a identificação e substituição do item original por um item culturalmente equivalente (BEATON et al., 2007).

Esta etapa foi importante para a equivalência cultural, pois assegura a validade de conteúdo do instrumento. A validade de face também foi realizada nesta etapa, já que o comitê foi formado por profissionais da área, apontando clareza nos itens que compõe o instrumento.

Após o feedback dos especialistas, os dados foram plotados em tabela do Microsoft Excel® e foi avaliada a porcentagem de concordância entre as respostas (HIRATUKA; MATSUKURA; PFEIFER, 2010; PASQUALI, 2003, BEATON et al., 2000). Foi considerado aceitável uma taxa de concordância acima de $80 \%$. Quando a taxa foi abaixo de $80 \%$ o item foi reavaliado pelo comitê técnico e reestruturado. Esse processo assegurou a validade de conteúdo da versão criada pelo comitê técnico e garantiu a elaboração da versão consensual português (VCP) e sua fidedignidade aos instrumentos originais. Essa versão foi encaminhada para o processo de retrotradução.

- Estágio 4 - Retrotradução: A versão produzida na etapa anterior (VCP) foi retrotraduzida para o inglês por 2 retrotradutores independentes que possuem o inglês como língua materna e proficiência em português, ambos sem conhecimento da versão original do instrumento e sem experiência em neuropediatria. Cada retrotradutor elaborou uma versão retrotraduzida individualmente (Versão Retrotradução 1 - RT1 e Versão Retrotradução 2 RT2) cujos dados foram plotados no Microsof Word®. O mesmo comitê técnico formado na fase de tradução se reuniu para produzir a síntese das retrotraduções 1 e 2 e então analisar as equivalências semânticas, idiomáticas, culturais e conceituais. Após esse processo de análise, a 
Versão Consensual Retrotradução (VCRT) foi elaborada. Esta etapa foi importante para validar se a tradução reflete o mesmo conteúdo dos itens do instrumento original.

- Estágio 5 - Submissão à autora: As versões VCP e VCRT foram enviadas à autora do instrumento Dra. Lilly Dubowitz e sua equipe, que aprovaram as versões consolidando a versão final dos instrumentos Hammersmith Neonatal Neurological Assessment; e Hammersmith Infant Neurological Assessment em todas as suas versões para a população brasileira. É importante ressaltar que os autores não fizeram sugestões e nem apontaram mudanças nos documentos enviados.

Outra ressalva é em relação à validade de face do instrumento traduzido e adaptado culturalmente para verificar a compreensibilidade dos itens do instrumento. $\mathrm{O}$ comitê de especialistas foi formado justamente por profissionais da área que compreenderam de forma técnica todos os itens, demonstrando compreensão e clareza em cada sentença.

Já o estudo-piloto refere-se a uma aplicação prévia dos instrumentos em uma amostra que reflita as características da população-alvo a qual se destinará o instrumento adaptado (GUDMUNDSSON, 2009; HAMBLETON, 2005; ITC, 2010). Esta fase não precisou ser realizada uma vez que o instrumento é aplicado apenas por profissionais da área de forma técnica e direta, ou seja, não precisam entrevistar os pacientes ou familiares. Além disso, a amostra dos participantes foi restrita, passando direto para a fase de validação do instrumento.

\subsubsection{Participantes}

No estágio 1 - Tradução do instrumento para o português do Brasil, participaram os seguintes sujeitos: Tradutor 1 (T1), profissional da saúde, fisioterapeuta, com experiência clínica em reabilitação e mestre em neurociências; Tradutor 2 (T2), físico biomolecular, com fluência em inglês e português.

$\underline{\text { O estágio } 2}$ - Síntese das traduções, contou com 2 participantes: Profissional da saúde, terapeuta ocupacional, pesquisador e doutor em neuropediatria; profissional da saúde, fisioterapeuta, pesquisador e mestre em neurociências.

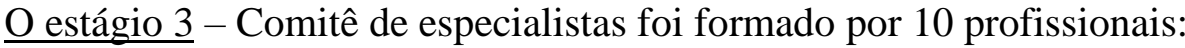

- Médica (neuropediatra e fisiatra), mestre em neurologia, atua com avaliação do neurodesenvolvimento e de tratamento da espasticidade; 
- Médica (neuropediatra), professora associada, atua com orientação em ambulatório de neurologia infantil e orientação de pós-graduação em Mestrado Profissional - área de neurodesenvolvimento;

- Fisioterapeuta, mestre em neurociências, atuação prática com crianças com alterações neurológicas e supervisão de estágio na graduação em fisioterapia;

- Terapeuta Ocupacional, docente e mestre em ciências terapêuticas (saúde mental). Atua como docente e supervisora de estágio na área de reabilitação infantil;

- Fisioterapeuta, mestre em neurociências, especialista em fisioterapia neurofuncional da infância, atua com reabilitação infantil;

- Terapeuta Ocupacional, doutora em Neurociências, atuação na área de neurologia infantil, com ênfase em paralisia cerebral;

- Terapeuta Ocupacional, mestre em neurociências, atua com atendimento individual, adaptações e inclusão escolar;

- Médica (neuropediatra), mestranda em neurodesenvolvimento, atua em consultório e como médica colaboradora no Ambulatório de Distúrbios de Comportamento e Aprendizagem da HCFMRP-USP e em uma escola de Educação Básica Municipal;

- Fisioterapeuta, docente, mestre em Fisioterapia, atua como supervisora de estágio do curso de Fisioterapia - área neuropediatria;

- Fisioterapeuta, especialista em neuropediatria, atua com atendimentos de crianças com atrasos no desenvolvimento e comprometimentos neurológicos.

$\underline{\text { O estágio } 4}$ - Retrotradução, contou com quatro participantes, sendo dois deles os mesmos participantes do estágio 2, e outros dois descritos a seguir: Retrotradutor 1 (RT1), professor de inglês no Brasil pela escola Education USA, nativo nos EUA; Retrotradutor 2 (RT2), professor de inglês no Brasil, pela empresa Carmela Carvalho - Tradutora e Intérprete, nativa dos EUA.

\subsection{Local da Pesquisa}

O processo de tradução e adaptação cultural dos instrumentos em questão foi realizado no Laboratório de Ensino e Pesquisa em Terapia Ocupacional, Infância e Adolescência (LEPTOI), na Universidade de São Paulo, Campus Ribeirão Preto, São Paulo. 


\subsection{Análise dos dados}

O estágio 1 não necessita de análise, pois se trata da coleta das traduções independentes. Já no estágio 2, foi feita uma análise a partir das recomendações de Koller et al. (2012) em optar por uma das traduções, mesclar as traduções independentes T1 e T2, ou adicionar modificações sempre que o comitê técnico julgasse necessário.

Para análise dos dados do estágio 3, foram feitas análises semântica e de conteúdo através das respostas obtidas pelo comitê de especialistas que responderam uma ficha que continha a descrição do item em sua língua original, a descrição do item da versão síntese, as opções de acordo e não está de acordo e um campo para sugestão de modificação do item para melhor compreensão (HIRATUKA; MATSUKURA; PFEIFER, 2010, PASQUALI, 2003, BEATON et al., 2000). Foi verificado o número de concordância e discordância entre as respostas e considerado aceitável uma taxa de concordância acima de $80 \%$.

No estágio 4, foi feita análise de acordo com as recomendações de Koller et al. (2012), da mesma forma que o estágio 2, porém relação as retrotraduções. $\mathrm{O}$ estágio 5 também não necessita de análises.

\subsection{RESULTADOS}

\subsubsection{Resultados: Estágios 1 e 2}

O primeiro processo para tradução e adaptação dos instrumentos, se deu pelas traduções iniciais (estágio 1), que foram realizadas de forma independente por dois tradutores nativos do Brasil que possuem proficiência em inglês, os quais elaboraram duas versões independentes dos instrumentos originais. Os dados dessas traduções foram plotados em documento do Microsoft Word®, comparados e analisados por um comitê técnico para elaborar a versão síntese (VS) de cada instrumento - estágio 2. A técnica escolhida para a elaboração da versão síntese foi de mesclagem entre as duas traduções com modificações e/ou adições e/ou exclusões (KOLLER et al., 2012).

A seguir estão os quadros 2 - 20 que apresentam estes dados para cada instrumento, sendo eles divididos pelos domínios avaliados. 
4.6.1.1 Resultados estágios 1 e 2: HNNE resumido e HNNE expandido

Quadro 2: Itens da seção CARACTERIZAÇÃO do instrumento HNNE resumido

\begin{tabular}{|c|c|c|c|}
\hline \multicolumn{4}{|c|}{ HNNE resumido } \\
\hline Item Original & T1 & T2 & VSP \\
\hline $\begin{array}{l}\text { Hammersmith Short Neonatal } \\
\text { Neurological Examination }\end{array}$ & $\begin{array}{l}\text { Exame Neurológico Neonatal Curto de } \\
\text { Hammersmith }\end{array}$ & $\begin{array}{l}\text { Exame Neonatal Neurológico Curto de } \\
\text { Hammersmith }\end{array}$ & Hammersmith - Exame Neonatal Neurológico \\
\hline Name & Nome & Nome & Nome \\
\hline Code & Código & Código & Código \\
\hline No OF EXAM: & $\mathrm{N}^{\circ}$ do exame & Número do exame & Número do exame \\
\hline D.O.B & $\mathrm{DN}$ & Data de Nascimento & Data de Nascimento \\
\hline D.O.E & Data & Data do exame & Data do exame \\
\hline Age & Idade & Idade & Idade \\
\hline G.A & IG & Tempo de gestação & Idade Gestacional \\
\hline Sex & Sexo & Sexo & Sexo \\
\hline BW & (não sei) & (deixou em branco) & (Não informado) \\
\hline
\end{tabular}

Quadro 3: Itens da seção POSTURA e TÔNUS do instrumento HNNE resumido

\begin{tabular}{|c|c|c|c|}
\hline \multicolumn{4}{|c|}{ HNNE resumido } \\
\hline Item Original & T1 & $\mathbf{T 2}$ & VSP \\
\hline $\begin{array}{l}\text { POSTURE - Baby lying on back. } \\
\text { Look mainly at position of the legs, } \\
\text { but also note arms. You may change } \\
\text { drawing }\end{array}$ & $\begin{array}{l}\text { POSTURA - Bebê deitado em supino. Observe } \\
\text { principalmente a posição das pernas, mas } \\
\text { também observe os braços. Você pode alterar o } \\
\text { desenho }\end{array}$ & $\begin{array}{l}\text { POSTURA - Bebê deitado de costas. Olhe } \\
\text { principalmente para a posição das pernas, mas } \\
\text { também observe os braços. Você pode mudar } \\
\text { o desenho }\end{array}$ & $\begin{array}{l}\text { POSTURA - Bebê deitado em supino. } \\
\text { Observe principalmente a posição das pernas, } \\
\text { mas também observe os braços. Você pode } \\
\text { alterar o desenho }\end{array}$ \\
\hline Arms \& legs extended & Braços e pernas estendidas & Braços e pernas estendidos & Braços e pernas estendidas \\
\hline Legs slightly flexed & Pernas ligeiramente flexionadas & Pernas ligeiramente flexionadas & Pernas ligeiramente flexionadas \\
\hline Legs well flexed but not adducted & Pernas bem flexionadas, mas não aduzidas & Pernas bem flexionadas, mas não aduzidas & Pernas bem flexionadas, mas não aduzidas \\
\hline Arms very flexed, legs very extended & $\begin{array}{l}\text { Braços muito flexionados, pernas muito } \\
\text { estendidas }\end{array}$ & $\begin{array}{l}\text { Braços muito flexionados, pernas muito } \\
\text { estendidas }\end{array}$ & $\begin{array}{l}\text { Braços muito flexionados, pernas muito } \\
\text { estendidas }\end{array}$ \\
\hline $\begin{array}{l}\text { ARM RECOIL - Quickly extend } \\
\text { (straighten) both arms; put next to } \\
\text { body. Count to two. Let go. Repeat } 3 \\
\text { times }\end{array}$ & $\begin{array}{l}\text { RECOLHIMENTO DO BRAÇO/Padrão flexor } \\
\text { de braço - Estenda rapidamente (alinhando) } \\
\text { ambos os braços próximos ao corpo. Conte até } \\
\text { dois. Solte. Repita } 3 \text { vezes. }\end{array}$ & $\begin{array}{l}\text { RECUO DO BRAÇO - Estender rapidamente } \\
\text { (endireitando) ambos os braços; colocar ao } \\
\text { lado do corpo. Conte até dois. Solte. Repita } 3 \\
\text { vezes }\end{array}$ & $\begin{array}{l}\text { PADRÃO FLEXOR DE BRAÇO - Estenda } \\
\text { rapidamente (alinhando) ambos os braços } \\
\text { próximos ao corpo. Conte até dois. Solte. } \\
\text { Repita } 3 \text { vezes. }\end{array}$ \\
\hline Arm does not flex & Braços não flexionam & Braços não flexionam & Braços não flexionam \\
\hline
\end{tabular}


Quadro 3 (continuação): Itens da seção POSTURA e TÔNUS do instrumento HNNE resumido

\begin{tabular}{|c|c|}
\hline $\begin{array}{l}\text { Arm flexes slowly, not always; not } \\
\text { completely }\end{array}$ & $\begin{array}{l}\text { Braços flexionam devagar, não sempre, não } \\
\text { completamente }\end{array}$ \\
\hline Arm flexes slowly; more completely & $\begin{array}{l}\text { Braços flexionam devagar, porém, } \\
\text { completamente. }\end{array}$ \\
\hline Arm flexes and remains flexed & Braços flexionam e permanecem flexionados \\
\hline $\begin{array}{l}\text { Arm difficult to extend; snap back } \\
\text { forcefully }\end{array}$ & $\begin{array}{l}\text { Braços difíceis de estender; flexiona de volta } \\
\text { vigorosamente }\end{array}$ \\
\hline $\begin{array}{l}\text { ARM TRACTION - Hold wrist and } \\
\text { pull upwards. Note flexion at arm, } \\
\text { and resistance while shoulder lifts off } \\
\text { table. }\end{array}$ & $\begin{array}{l}\text { TRAÇÃO DO BRAÇO - Segure no punho e } \\
\text { puxe para cima. Observe a flexão e a resistência } \\
\text { do braço, enquanto o ombro é levantado da } \\
\text { mesa. }\end{array}$ \\
\hline Arm remains straight - no resistance & Braços permanecem eretos - sem resistência. \\
\hline $\begin{array}{l}\text { Arm flexes slightly or some } \\
\text { resistance felt }\end{array}$ & $\begin{array}{l}\text { Braços flexionam ligeiramente ou sente/percebe } \\
\text { alguma resistência }\end{array}$ \\
\hline $\begin{array}{l}\text { Arm flexes well till shoulder lifts, } \\
\text { then straightens }\end{array}$ & $\begin{array}{l}\text { Braços flexionam bem até elevar o ombro, então } \\
\text { endireita }\end{array}$ \\
\hline $\begin{array}{l}\text { Arm flexes and remains flexed as } \\
\text { shoulder lifts }\end{array}$ & $\begin{array}{l}\text { Braços flexionados e permanecem fletidos na } \\
\text { elevação de ombros }\end{array}$ \\
\hline $\begin{array}{l}\text { Arm remains flexed when body lifts } \\
\text { up }\end{array}$ & $\begin{array}{l}\text { O braço permanece flexionado quando o corpo é } \\
\text { levantado }\end{array}$ \\
\hline $\begin{array}{l}\text { LEG RECOIL - Take both ankles, } \\
\text { bend hips + knees. Quickly extend } \\
\text { when infant not pushing. Let go. } \\
\text { Repeat x } 3\end{array}$ & $\begin{array}{l}\text { RETRAÇÃO DA PERNA - Pegue ambos os } \\
\text { tornozelos, flexione quadril + joelhos. Estenda } \\
\text { rapidamente quando o lactente não empurrar. } \\
\text { Solte. Repita } 3 \text { vezes. }\end{array}$ \\
\hline No flexion & Não flexiona \\
\hline Incomplete flexion, not every time & Flexão incompleta, não o tempo todo \\
\hline Complete slow flexion & Flexão lenta e completa \\
\hline Complete fast flexion & Flexão rápida e completa \\
\hline $\begin{array}{l}\text { Legs difficult to extend; snap back } \\
\text { forcefully }\end{array}$ & $\begin{array}{l}\text { Perna difícil para estender; flexiona de volta } \\
\text { rapidamente e com força }\end{array}$ \\
\hline $\begin{array}{l}\text { LEG TRACTION - Hold ankle, pull } \\
\text { leg upwards. Look at flexion \& } \\
\text { resistance as bottom pulled up. }\end{array}$ & $\begin{array}{l}\text { TRAÇÃO DA PERNA - Segure o tornozelo e } \\
\text { puxe a perna para cima. Observe a flexão e a } \\
\text { resistência enquanto os glúteos são puxados } \\
\text { para cima. }\end{array}$ \\
\hline Leg straight & Perna ereta - sem resistência \\
\hline
\end{tabular}

Braços flexionam lentamente, mas nem

empre; não completamente

Braços flexionam lentamente; mais

completamente

Braços flexionam e permanecem flexionados Braços difíceis de estender; retraem (recuam, snap back= pular de volta) vigorosamente TRAÇÃO DO BRAÇO - Segure o punho e puxe-o para cima. Observe a flexão do braço e resistência enquanto o ombro é levantado da mesa.

Braços permanecem retos - nenhuma resistência

Braços flexionam ligeiramente ou alguma resistência observada

Braços flexionam bem até que os ombros se levantam, então endireitam-se

Braços flexionam e mantêm-se flexionados quando os ombros se erguem

O braço permanece flexionado enquanto o

corpo é levantado

RETRAÇÃO DA PERNA - Segure ambos os tornozelos, dobre os quadris + joelhos.

Estenda rapidamente quando a criança não estiver empurrando. Solte. Repita 3x. Sem flexão

Flexão incompleta, não o tempo todo Flexão completa e lenta

Flexão completa e rápida

Pernas difíceis de estender; retraem vigorosamente

TRAÇ̃̃O DA PERNA - Segure o tornozelo, puxe a perna para cima. Observe a flexão e a resistência conforme as nádegas são puxadas para cima.

Perna reta - sem resistência
Braços flexionam lentamente, mas nem sempre; não completamente Braços flexionam devagar, porém, completamente.

Braços flexionam e permanecem flexionados Braços difíceis de estender; flexionam de volta vigorosamente

TRAÇÃO DO BRAÇO - Segure no punho e puxe o braço para cima. Observe a flexão e a resistência do cotovelo, enquanto o ombro é levantado da mesa.

Braços permanecem retos - nenhuma resistência

Braços flexionam ligeiramente ou alguma resistência é observada

Braços flexionam bem até elevar o ombro, então endireitam-se

Braços flexionados e permanecem fletidos na elevação de ombros

O braço permanece flexionado quando o corpo é levantado

RETRAÇÃO DA PERNA- Segure ambos os tornozelos, dobre os quadris + joelhos.

Estenda rapidamente quando a criança não estiver empurrando. Solte. Repita 3x. Não flexiona

Flexão incompleta, não o tempo todo

Flexão lenta e completa

Flexão rápida e completa

Pernas difíceis de estenderem; flexionam de volta rapidamente e com forca

TRAÇÃO DA PERNA- Segure o tornozelo e puxe a perna para cima. Observe a flexão e a resistência enquanto os glúteos são puxados para cima.

Perna reta - sem resistência 
Quadro 3 (continuação): Itens da seção POSTURA e TÔNUS do instrumento HNNE resumido

Leg flexes slightly or some resistance felt

Leg flexes well till bottom lifts up

Knee flexes - remains flexed when bottom up

Flexion stays when back + bottom up

\section{POPLITEAL ANGLE - Fix knee on} abdomen (belly), try to extend knee with first finger. Note distance (angle) between upper and lower

limb.

HEAD CONTROL (1) - Baby sitting upright. Encircle chest with both hands holding shoulders. Let head drop forward.

No attempt to raise head

Infant tries: effort better felt than seen

Raises head but drops forward or back

Raises head: remains vertical;

wobbles

HEAD CONTROL (2) - Baby sitting upright. Encircle chest with both

hands holding shoulders. Let head drop backward.

No attempt to raise head

Infant tries: effort better felt than seen

Raises head but drops forward or back

Raises head: remains vertical;

wobbles
Pernas flexionam levemente ou sente alguma resistência

Pernas flexionam bem/suficiente até elevar os glúteos/quadril.

Joelhos flexionam -permanecem flexionados quando glúteos/quadril são levantados

Flexão permanece quando coluna + quadril são elevados.

ÂNGULO POPLÍTEO - Fixe o joelho no abdômen (barriga), tente estender o joelho com o primeiro dedo. Observe a distância (ângulo) entre os membros superiores e inferiores.

\section{CONTROLE DE CABEÇA (1) - Bebê sentado} verticalmente. Circundar peito com ambas as mãos segurando os ombros. Deixe a cabeça cair para frente.

Nenhuma tentativa de levantar a cabeça

Tentativas imaturas/lactente se esforça: esforço é mais sentido do que visto

Levanta a cabeça, mas cai para a frente ou para trás

Levanta a cabeça: permanece na vertical;

apresenta oscilacões

CONTROLE DE CABEÇA (2) - Bebê sentado verticalmente. Circundar peito com ambas as

mãos segurando os ombros. Deixe a cabeça cair para trás.

Nenhuma tentativa de levantar a cabeca

Lactente se esforça: esforço é mais sentido do que visto

Levanta a cabeça, mas cai para a frente ou para trás

Levanta a cabeça: permanece na vertical;

apresenta oscilações
Pernas flexionam ligeiramente ou alguma resistência observada

Pernas flexionam bem até que quadril se levanta

Joelhos se flexionam -mantêm-se flexionados quando o quadril se ergue

Flexão se mantem quando o quadril e as costas se erguem

ÂNGULO POPLÍTEO - Mantenha os joelhos no abdômen (barriga), tente estender o joelho com o primeiro dedo. Note a distância (ângulo) entre os membros superiores e inferiores.

CONTROLE DA CABEÇA (1) - Bebê sentado. Abrace o peito com ambas mãos, segurando os ombros. Deixe a cabeça cair para frente

Sem tentativa de levantar a cabeça

Criança tenta levantar; esforço é mais sentido do que observado (ou visto)

Levanta a cabeça, mas a deixa cair para frente ou para trás

Levanta a cabeça: permanece vertical; oscilações

CONTROLE DA CABEÇA (2) - Bebê

sentado. Abrace o peito com ambas mãos,

segurando os ombros. Deixe a cabeça cair para trás.

Sem tentativa de levantar a cabeça

Criança tenta levantar; esforço é mais sentido do que observado (ou visto)

Levanta a cabeça, mas a deixa cair para frente ou para trás

Levanta a cabeça: permanece vertical;

oscilações
Pernas flexionam levemente ou alguma resistência é sentida

Pernas flexionam bem até elevar os quadris

Joelhos flexionam e permanecem flexionados quando os quadris são levantados

Flexão se mantem quando o quadril e as costas são levantadas

ÂNGULO POPLÍTEO - Coloque o joelho no abdome, estenda a perna realizando uma leve pressão por trás do tornozelo com o dedo indicador. Observe o ângulo do joelho.

\section{CONTROLE DA CABEÇA (1) - Bebê} sentado. Abrace o peito do bebê com ambas as mãos, segurando os ombros. Deixe a cabeça cair para frente

Nenhuma tentativa de levantar a cabeca

Bebê tenta levantar; esforço é mais sentido do que observado

Levanta a cabeça, mas a deixa cair para frente ou para trás

Levanta a cabeça: permanece na vertical; apresenta oscilacões

\section{CONTROLE DA CABEÇA (2) - Bebê}

sentado. Abrace o peito com ambas mãos,

segurando os ombros. Deixe a cabeça cai para trás.

Nenhuma tentativa de levantar a cabeca

Bebê tenta levantar; esforço é mais sentido do que observado

Levanta a cabeça, mas a deixa cair para frente ou para trás

Levanta a cabeça: permanece na vertical;

apresenta oscilações 
Quadro 3 (continuação): Itens da seção POSTURA e TÔNUS do instrumento HNNE resumido

Head upright or extended, cannot be passively flexed (pushed forward)

HEAD LAG - Pull baby to sit by the wrists \& support head slightly.

Head drops \& stays back

Tries to lift head but it drops back

Able to lift head slightly

Lifts head in line with body

Head in front of body

VENTRAL SUSPENSION - Hold

baby horizontal under the belly. Look at posture of back, arms, legs and head. If it looks different, DRAW.

Back curved, head \& limbs hang

straight

Back curved, head $\downarrow$, limb slightly

flexed

Back slightly curved, limbs flexed

Back straight, head in line with body, limbs flexed

Back straight, head above body

Cabeça ereta ou estendida, não pode ser

flexionada passivamente (empurrada para a frente)

ATRASO DA CABEÇA - Puxe o bebê pelos punhos para sentar e apoie levemente a cabeça.

Cabeça cai e permanece para trás

Tenta elevar a cabeça, mas cai de volta. Capaz de elevar a cabeça ligeiramente

Eleva a cabeça alinhada com o corpo

Cabeça à frente do corpo

SUSPENSÃO VENTRAL - Segure o bebê pelo

abdômen em suspensão ventral. Observe a

postura da coluna, braços, pernas e cabeça. Se

ele parecer diferente, DESENHE.

Coluna curvada, cabeça e membros suspensos e eretos

Coluna curvada, cabeça membros levemente

flexionados

Coluna ligeiramente curvada, membros

flexionados

Coluna ereta, cabeça alinhada com o tronco,

membros flexionados

Coluna ereta, cabeça acima do corpo
Cabeça ereta ou estendida; não pode ser

flexionada passivamente (empurrada para a frente)

ATRASO DA CABEÇA - Puxe o bebê

através dos pulsos para sentar. Apoie a cabeça ligeiramente.

Cabeca cai e permanece para trás

Tenta levantar a cabeça, mas esta cai para trás Capaz de levantar a cabeça ligeiramente

Levanta a cabeça alinhada com o corpo

Cabeça à frente do corpo

SUSPENSÃO VENTRAL - Sustente o bebê

de forma horizontal, pegando por baixo da

barriga. Observe a postura das costas, braços,

pernas e cabeça. Se parece diferente

DESENHE.

Costas curvadas. Cabeça e membros

suspensos e retos

Costas curvadas. Cabeça para baixo e

membros ligeiramente flexionados

Costas ligeiramente curvadas. Membros

flexionados

Costas retas, cabeça alinhada com o corpo

membros flexionados

Costas retas, cabeça acima do corpo
Cabeça ereta ou estendida, não pode ser

flexionada passivamente (empurrada para a frente)

ATRASO DA CABEÇA - Puxe o bebê pelos

punhos para sentar e apoie levemente a cabeça.

Cabeça cai e permanece para trás

Tenta levantar a cabeça, mas esta cai para trás Capaz de levantar a cabeça levemente

Levanta a cabeça alinhada com o corpo

Cabeça à frente do corpo

SUSPENSÃO VENTRAL - Segure o bebê

pelo abdome em suspensão ventral. Observe a postura das costas, braços, pernas e cabeça. Se ele parecer diferente, DESENHE

Costas curvadas. Cabeça e membros

suspensos e retos

Coluna curvada, cabeça, membros levemente flexionados

Costas levemente curvadas. Membros

flexionados

Costas retas, cabeça alinhada com o tronco

membros flexionados

Costas retas, cabeça acima do corpo

Quadro 4: Itens da seção MOVIMENTOS do instrumento HNNE resumido

\begin{tabular}{|c|c|c|c|}
\hline \multicolumn{4}{|c|}{ HNNE resumido } \\
\hline Item Original & T1 & $\mathbf{T 2}$ & VSP \\
\hline MOVEMENTS & MOVIMENTOS & MOVIMENTOS & MOVIMENTOS \\
\hline $\begin{array}{l}\text { SPONTANEOUS MOVEMENT - } \\
\text { Watch baby while (s) he is lying on } \\
\text { back. }\end{array}$ & $\begin{array}{l}\text { MOVIMENTOS ESPONTÂNEOS - } \\
\text { Observe o bebê enquanto ele (a) está deitado em } \\
\text { supino. }\end{array}$ & $\begin{array}{l}\text { MOVIMENTOS ESPONTÂNEOS - } \\
\text { Observe o bebê enquanto ele (a) está deitado } \\
\text { de costas. }\end{array}$ & $\begin{array}{l}\text { MOVIMENTOS ESPONTÂNEOS -Observe } \\
\text { o bebê enquanto ele (a) está deitado em } \\
\text { supino. }\end{array}$ \\
\hline No movement & Sem movimento & Sem movimento & Sem movimento \\
\hline Few stretches, no other movement & $\begin{array}{l}\text { Poucos alongamentos, nenhum outro } \\
\text { movimento }\end{array}$ & Algumas alongadas, nenhum outro movimento & $\begin{array}{l}\text { Poucos alongamentos, nenhum outro } \\
\text { movimento }\end{array}$ \\
\hline
\end{tabular}


Quadro 4 (continuação): Itens da seção MOVIMENTOS do instrumento HNNE resumido

Jerky movement, stretches, but also some smooth movement

Smooth movements of arms + legs

Fits, cramped or other abnormal

movements: DESCRIBE!!

ABNORMAL HAND OR TOE

POSTURES

Hands open

Hands fisted or thumbs adduct

intermittently but open

Hands fist or thumb adducts, or finger

$\&$ thumb oppose

Big toe up (extended) or all toes flex

\section{TREMOR}

No tremor

Tremor only when crying or after

Moro reflex

Some tremor when awake

Frequent tremors

Continuous tremors

STARTLE - Similar movements to

Moro reflex but not doing Moro test

No startle

Startle to sudden noise or bang on

table

2 or 3 spontaneous startles

3 - 5 spontaneous startles

Movimentos espasmódicos, alongamentos, porém apresenta algum movimento suave Movimentos suaves de braços e pernas Convulsões, espasmos ou outros movimentos anormais: DESCREVA!! POSTURA ANORMAL DAS MÃOS OU DEDOS

Mãos abertas

Mãos cerradas ou polegares em adução

intermitente, porém aberto

Mãos cerradas ou polegar aduzido ou dedo

(indicador) e polegar em oposição.

Dedão (polegar) para cima (estendido) ou todos os dedos flexionados

Sem tremor

Tremor somente quando chora ou após reflexo de Moro

Alguns tremores quando acordado

Tremores frequentes

Tremores contínuos

SOBRESSALTO/SUSTO - Movimentos

semelhantes aos do Reflexo de Moro, porém

não executado no teste de Moro

Não assusta

Sobressalto à barulhos repentinos ou ao bater na mesa

2 ou 3 sobressaltos espontâneos

3 - 5 sobressaltos espontâneos

Mais que 6 sobressaltos espontâneos
Espasmos, alongamentos, mas também alguns movimentos mais suaves.

Movimentos suaves de braços e pernas

Convulsões, câimbras e outros movimentos

anormais. DESCREVA!

POSTURAS ANORMAIS DAS MÃOS OU

DEDOS

Mãos abertas

Mãos fechadas/cerradas ou dedões aduzidos

de forma intermitente, porém abertos

Mãos fechadas/cerradas ou dedões aduzidos

ou dedos e dedão fazendo pinça

Dedão para cima estendido ou todos os dedos flexionados

TREMOR

Sem tremor

Tremor somente quando chorando ou após

reflexo de Moro

Alguns tremores quando acordado

Tremores frequentes

Tremores contínuos

SOBRESSALTO/SUSTO - Movimentos

similares ao reflexo Moro mas sem fazer o teste Moro

Sem susto

Susto com barulhos repentinos ou batida na mesa

2 ou 3 sustos espontâneos

$3-5$ sustos espontâneos

Mais que 6 sustos espontâneos
Espasmos, alongamentos, mas também alguns movimentos mais suaves.

Movimentos suaves de braços e pernas

Convulsões, espasmos ou outros movimentos anormais: DESCREVA!!

POSTURA ANORMAL DAS MÃOS OU

DEDOS

Mãos abertas

Mãos fechadas ou polegares aduzidos de

forma intermitente, porém abertos

Mãos fechadas ou polegar aduzido, ou dedo (indicador) e polegar em oposição.

Polegar para cima (estendido) ou todos os dedos flexionados

Sem tremor

Tremor somente quando chora ou após reflexo de Moro

Alguns tremores quando acordado

Tremores frequentes

Tremores contínuos

SOBRESSALTO/SUSTO - Movimentos

semelhantes aos do Reflexo de Moro, porém não executado no teste de Moro Sem susto/sobressalto

Susto/sobressaltos com barulhos repentinos ou ao bater na mesa

2 ou 3 sustos/sobressaltos espontâneos

3 - 5 sustos/sobressaltos espontâneos

Mais que 6 sustos/sobressaltos espontâneos

Quadro 5: Itens da seção REFLEXOS do instrumento HNNE resumido

\begin{tabular}{|c|c|c|c|}
\hline \multicolumn{4}{|c|}{ HNNE resumido } \\
\hline Item Original & $\begin{array}{l}\text { T1 } \\
\end{array}$ & T2 & VSP \\
\hline REFLEXES = test both sides & REFLEXOS = teste ambos os lados & REFLEXOS = teste ambos os lados & REFLEXOS = teste ambos os lados \\
\hline
\end{tabular}


Quadro 5 (continuação): Itens da seção REFLEXOS do instrumento HNNE resumido

SUCK \& GAG - Watch on breast; if
no suck is seen, put little finger into mouth with pulp of finger upwards.

\section{No gag/ no suck}

Weak suck only: A) irregular B)

regular. No stripping

Infant sucks well on the breast

Strong suck: A) irregular B) regular

Good stripping

No suck but strong clenching

PALMAR GRASP - Stroke inside of hand. DO NOT TOUCH BACK OF

HAND!!

\section{No reaction}

Short, weak flexion of fingers

Strong flexion of fingers

Strong finger flexion, shoulder

Strong finger flexion, whole body

PLANTAR GRASP - Press on sole

below toes.

No response

Toes flex (bend) slightly

Toes curve around finger

MORO REFLEX - Put baby in

position shown in drawing 1 below.

Bring head forward and suddenly let it fall back slightly

No response

Full abduction of the arms, extension at the elbow, no adduction

Full abduction, little or delayed

adduction

\section{REFLEXO DE SUCÇÃO E RETIRADA -}

Observe no peito, se não for vista a sucção, coloque o dedo mínimo dentro da boca com a ponta do dedo para cima

\section{Não amordaça / não suga}

Somente sucção fraca: a) irregular b) regular. Sem retirada

Lactente suga bem no peito

Sucção forte: (a) irregular (b) regular

Boa retirada

Não suga mas aperta (cerrar - fechar a boca)

forte

PREENSÃO PALMAR - Pressione a palma da mão. NÃO TOQUE O DORSO DA MÃO!!

\section{Sem reação}

Flexão dos dedos curta e fraca

Forte flexão dos dedos

Forte flexão dos dedos, ombro

Forte flexão dos dedos, corpo inteiro

PREENSÃO PLANTAR - Pressione a sola

abaixo dos dedos.

Sem resposta

Dedos flexionam (dobram) ligeiramente

Os dedos curvam sobre o dedo

REFLEXO DE MORO - Coloque o bebê na

posição ilustrada no desenho 1 abaixo. Traga a

cabeça para a frente e de repente deixe-a cair

ligeiramente

Não responde

Abdução completa dos braços, extensão dos cotovelos; nenhuma adução

Abdução completa, adução breve ou atrasada
SUCÇÃO E ENGASGO - Observe no peito, se não se vê nenhuma sucção, coloque o dedo mínimo na boca com a polpa do dedo virada para cima.

\section{Sem engasgo / sem sucção}

Somente sucção fraca: a) irregula

b) regular. Não faz retirada

Criança suga bem no peito

Sucção forte: (a) irregular (b) regular

Boa retirada

Sem sucção porém pegada/aperto firme/forte

\section{GARRA PALMAR}

Bata na palma da mão. NÃO TOQUE O

DORSO DA MÃO!!

Sem reação

Flexão dos dedos fraca e curta

Forte flexão dos dedos

Forte flexão dos dedos, ombros para cima

Forte flexão dos dedos, corpo inteiro para cima

GARRA PLANTAR - Pressione na sola

abaixo dos dedos do pé.

Sem resposta

Dedos flexionam (dobram) ligeiramente

Dedos curvam em torno do dedo

REFLEXO MORO - Coloque o bebê na

posição do desenho 1 abaixo. Traga a cabeça para frente e de forma repentina deixe-a cair um pouco para trás.

\section{Sem resposta}

Abdução completa dos braços, extensão dos cotovelos; nenhuma adução

Abdução completa, adução breve ou atrasada

\section{REFLEXO DE SUCÇÃO E}

VOMITO/ÂNSIA - Observe no peito, se não for percebida a sucção, coloque o dedo mínimo dentro da boca com a ponta do dedo para cima Sem vômito-ânsia/sem sucção

Somente sucção fraca: a) irregular b) regular. Não remove a boca do estímulo

Lactente suga bem no peito

Sucção forte: (a) irregular (b) regular

Remove a boca do estímulo adequadamente

Não suga, porém apresenta forte "pega"

PREENSÃO PALMAR - Pressione a palma da mão. NÃO TOQUE O DORSO DA

MÃO!!

Sem reação

Flexão dos dedos fraca e curta

Forte flexão dos dedos

Forte flexão dos dedos, ombro

Forte flexão dos dedos, corpo inteiro

PREENSÃO PLANTAR - Pressione a sola

abaixo dos dedos dos pés.

Sem resposta

Dedos flexionam (dobram) ligeiramente

Dedos curvam em torno do dedo

REFLEXO DE MORO - Coloque o bebê na posição ilustrada no desenho 1 abaixo. Traga a cabeça para a frente e de forma repentina

deixe-a cair levemente para trás

Não responde

Abdução completa dos braços, extensão dos cotovelos; nenhuma adução

Abdução completa, adução breve ou atrasada 
Quadro 5 (continuação): Itens da seção REFLEXOS do instrumento HNNE resumido

\begin{tabular}{|l|l|}
\hline $\begin{array}{l}\text { Arms do not fully abduct but good } \\
\text { adduction }\end{array}$ & $\begin{array}{l}\text { Braços não abduz totalmente, mas apresenta boa } \\
\text { adução }\end{array}$ \\
\hline $\begin{array}{l}\text { Adduction only } \\
\text { Extension at the elbow only }\end{array}$ & $\begin{array}{l}\text { Somente adução } \\
\text { Somente extensão do cotovelo }\end{array}$ \\
\hline $\begin{array}{l}\text { PLACING - Hold infant upright. } \\
\text { Stroke front of the baby's lower leg } \\
\text { on edge of table. }\end{array}$ & $\begin{array}{l}\text { COLOCAÇÃO DAS PERNAS - Segure o } \\
\text { lactente na posição vertical. Bata anteriormente } \\
\text { o membro inferior do bebê na borda da mesa. }\end{array}$ \\
\hline Nothing happens & Nada acontece \\
\hline Baby flexes ankle & Bebê flexiona o tornozelo \\
\hline $\begin{array}{l}\text { Baby flexes hip, knee, and ankle \& } \\
\text { steps on table }\end{array}$ & $\begin{array}{l}\text { Bebê flexiona quadril, joelho e tornozelo e dá } \\
\text { "passos" na mesa }\end{array}$ \\
\hline
\end{tabular}

Braços não abduz totalmente, porém boa adução

Somente adução

Somente extensão do cotovelo

COLOCAÇÃO - Segure a criança em pé. Bata o dorso do pé contra a borda de uma superfície plana.

Nada acontece

Bebê flexiona o tornozelo

Bebê flexiona quadril, joelho e tornozelo e pisa na mesa
Braços não abduzem totalmente, porém boa adução

Somente adução, Somente extensão do cotovelo

COLOCAÇÃO DAS PERNAS - Segure o lactente na posição vertical. Bata o dorso do pé do bebê na borda da mesa.

Nada acontece

Bebê flexiona o tornozelo

Bebê flexiona quadril, joelho e tornozelo e pisa na mesa

\section{Quadro 6: Itens da seção ORIENTAÇÃO E COMPORTAMENTO do instrumento HNNE resumido}

\begin{tabular}{|c|c|c|c|}
\hline \multicolumn{4}{|c|}{ HNNE resumido } \\
\hline Item Original & T1 & $\mathbf{T 2}$ & VSP \\
\hline ORIENTATION AND BEHAVIOR & ORIENTAÇÃO E COMPORTAMENTO & ORIENTAÇÃO E COMPORTAMENTO & ORIENTAÇÃO E COMPORTAMENTO \\
\hline EYE & OLHO & $\mathrm{OLHO}$ & OLHO \\
\hline Does not open eyes & Não abre os olhos & Não abre os olhos & Não abre os olhos \\
\hline $\begin{array}{l}\text { Normal eye movement, eyes move } \\
\text { together }\end{array}$ & $\begin{array}{l}\text { Movimento normal do olho, os olhos se movem } \\
\text { juntos }\end{array}$ & $\begin{array}{l}\text { Movimento normal do olho, os olhos se } \\
\text { movem juntos }\end{array}$ & $\begin{array}{l}\text { Movimento normal do olho, os olhos se } \\
\text { movem juntos }\end{array}$ \\
\hline $\begin{array}{l}\text { Abnormal eye movements: } \\
\text { DESCRIBE!! }\end{array}$ & Movimentos anormais dos olhos. DESCREVA!! & $\begin{array}{l}\text { Movimentos anormais dos olhos. } \\
\text { DESCREVA!! }\end{array}$ & $\begin{array}{l}\text { Movimentos anormais dos olhos. } \\
\text { DESCREVA!! }\end{array}$ \\
\hline $\begin{array}{l}\text { AUDITORY ORIENTATION - Must } \\
\text { not be asleep. Wrap infant. Hold } \\
\text { rattle } 10 \text { to } 15 \mathrm{~cm} \text { from ear. }\end{array}$ & $\begin{array}{l}\text { ORIENTAÇÃO AUDITIVA - Não deverá estar } \\
\text { dormindo. Enrole o lactente. Segure um } \\
\text { chocalho } 10 \text { a } 15 \mathrm{~cm} \text { de distância da orelha. }\end{array}$ & $\begin{array}{l}\text { ORIENTAÇÃO AUDITIVA - Criança não } \\
\text { deverá estar dormindo. Enrole a criança. } \\
\text { Mantenha o chocalho entre } 10 \text { a } 15 \mathrm{~cm} \text { da } \\
\text { orelha. }\end{array}$ & $\begin{array}{l}\text { ORIENTAÇÃO AUDITIVA - Não deverá } \\
\text { estar dormindo. Enrole o lactente. Segure um } \\
\text { chocalho } 10(0 \%) \text { a } 15 \mathrm{~cm} \text { de distância da } \\
\text { orelha. }\end{array}$ \\
\hline No reaction & Sem reação & Sem reação & Sem reação \\
\hline Brightens (wakes up) & Animada (acordar) & Criança alerta (acordar) & Anima-se (acorda) \\
\hline $\begin{array}{l}\text { Turns eyes and sometimes turns head } \\
\text { a bit also }\end{array}$ & $\begin{array}{l}\text { Vira olhos e às vezes também vira um pouco a } \\
\text { cabeça }\end{array}$ & $\begin{array}{l}\text { Vira os olhos e as vezes também vira um } \\
\text { pouco a cabeça }\end{array}$ & $\begin{array}{l}\text { Vira olhos e às vezes também vira um pouco a } \\
\text { cabeça }\end{array}$ \\
\hline $\begin{array}{l}\text { Turns eyes and head fully to side of } \\
\text { noise }\end{array}$ & $\begin{array}{l}\text { Vira totalmente os olhos e a cabeça para o lado } \\
\text { do ruído }\end{array}$ & $\begin{array}{l}\text { Vira os olhos e a cabeça totalmente para o } \\
\text { lado do barulho }\end{array}$ & $\begin{array}{l}\text { Vira os olhos e a cabeça totalmente para o } \\
\text { lado do barulho }\end{array}$ \\
\hline $\begin{array}{l}\text { Turns head and eyes strongly to } \\
\text { noise; does not tire }\end{array}$ & $\begin{array}{l}\text { Vira fortemente a cabeça e os olhos para o } \\
\text { barulho/ruído; não se cansa }\end{array}$ & $\begin{array}{l}\text { Vira a cabeça e os olhos com força para o } \\
\text { barulho; não se cansa }\end{array}$ & $\begin{array}{l}\text { Vira fortemente a cabeça e os olhos para o } \\
\text { barulho/ruído; não se cansa }\end{array}$ \\
\hline
\end{tabular}


Quadro 6 (continuação): Itens da seção ORIENTAÇÃO E COMPORTAMENTO do instrumento HNNE resumido VISUAL ALERTNESS - Wrap infant, wake up with rattle if needed or rock baby a bit. Look if baby can see and follow red ball (B) or a target (T)

Does not follow or focus on red ball or target

Stills, focuses, follows very briefly to side and up but loses it quickly

Follows with eyes to the side and up, may turn head

Follows with eyes to the side and up, turns head always

Follows in a circle

ALERTNESS - Tested as response to red ball $(\mathrm{R})$ or target $(\mathrm{T})$. How long infant interested.

Will not respond to red ball

When awake, looks only briefly

When awake, looks at red ball but

loses it

Keeps interest in red ball

Does not tire

PEAK OF EXCITEMENT - Circle

' $\mathrm{H}$ ' if high-pitch cry

Quiet all the time

Awakes briefly, does not cry

Awakes briefly, cries sometimes

Cries always when handled

Cries always

CONSOLABILITY - How easy is it

to make baby quiet?

Never awake or crying

\section{ALERTA VISUAL - Enrole o lactente, acorde-o}

com o chocalho se necessário, ou sacuda um pouco o bebê. Observe se o bebê pode ver e seguir uma bola vermelha (B) ou um objeto $(\mathrm{O})$

Não segue ou foca a bola vermelha nem o objeto

Fica parado, foca, segue muito rapidamente para

o lado e para cima, mas os perde rapidamente

Segue com os olhos para o lado e para cima, pode virar/acompanhar com a cabeça

Segue com os olhos para o lado e para cima, vira/acompanha com a cabeça sempre Segue em círculo

ALERTA - Testado as respostas para a bola vermelha ou o objeto. Quanto tempo o lactente demonstrou interesse

Não responderá à bola vermelha (aos estímulos) Quando acordado, apenas olha rapidamente Quando acordado, olha para a bola vermelha, porém a perde

Mantém interesse na bola vermelha

Não se cansa

AUGE DA EMOÇÃO/EXCITAÇÃO - Circule

$\mathrm{H}$ se chorar alto/ se o choro for estridente

Quieto o tempo todo

Acorda rapidamente, não chora.

Acorda rapidamente, chora às vezes.

Chora sempre que manuseado

Chora sempre

CONSOLABILIDADE - Quão fácil fazer o

bebê ficar quieto?

Nunca acordado ou chorando
VISÃO ALERTA - Embrulhe a criança, acorde-a com o chocalho se necessário ou sacuda-a brevemente. Observe se o bebê pode ver e seguir uma bola vermelha ou um objeto

Não segue ou foca a bola vermelha ou o objeto

Observa, foca, segue brevemente para o lado e para cima, mas o perde rapidamente

Segue com os olhos para o lado e para cima pode mover a cabeça

Segue com os olhos para o lado e para cima, sempre movendo a cabeça

Segue em um círculo

ALERTA - Testado as respostas para a bola

vermelha ou o objeto. Quanto tempo a criança

se manteve interessada

Não irá responder à bola vermelha

Quando acordado, olha apenas brevemente

Quando acordado, olha para a bola vermelha, porém a perde

Mantém interesse na bola vermelha

Não se cansa

PICO DE EXCITAÇÃO - Circule H se choro agudo

Quieto o tempo todo

Desperta brevemente, não chora

Desperta brevemente, às vezes chora

Sempre chora quando manuseado/manipulado Chora sempre

CONSOLABILIDADE - Quanto fácil é fazer

o bebê se acalmar?

Nunca acordado ou chorando
ORIENTAÇÃO VISUAL - Enrole o lactente, acorde-o com o chocalho se necessário, ou sacuda-o um pouco. Observe se o bebê pode ver e seguir uma bola vermelha (B) ou um objeto $(\mathrm{O})$

Não segue ou foca a bola vermelha ou o objeto

Fica quieto, foca, segue muito rapidamente para o lado e para cima, mas os perde rapidamente

Segue com os olhos para o lado e para cima pode virar a cabeça

Segue com os olhos para o lado e para cima, sempre virando a cabeça

Segue em um círculo

ESTADO DE ALERTA - Testado como

resposta à bola vermelha $(\mathrm{R})$ ou alvo $(\mathrm{T})$.

Quanto tempo o lactente se manteve

interessado

Não responderá à bola vermelha

Quando acordado, olha apenas brevemente

Quando acordado, olha para a bola vermelha, porém a perde

Mantém interesse na bola vermelha

Não se cansa

AUGE DA EXCITAÇÃO - Circule H se o

choro for estridente

Quieto o tempo todo

Acorda brevemente, não chora

Acorda brevemente, às vezes chora

Sempre chora quando manuseado

Chora sempre

CONSOLABILIDADE - O quanto é fácil

acalmar o bebê?

Nunca acordado ou chorando 
Quadro 6 (continuação): Itens da seção ORIENTAÇÃO E COMPORTAMENTO do instrumento HNNE resumido Awake but never cries; consoling not $\quad$ Acordado, mas nunca chora; não precisa de needed

Becomes quiet when talked to consolo

\begin{tabular}{|l|l|}
\hline Needs picking up to console & Precisa ser carregado para ser consolado \\
\hline Cannot be consoled & Não pode ser consolado \\
\hline COMMENT & COMENTÁRIOS \\
\hline EXAMINER & EXAMINADOR \\
\hline
\end{tabular}

EXAMINER
Acordado nunca chora; consolo não

necessário

Fica calmo/quieto quando se conversa com ele/ela

Precisa ser carregado para ser consolado (para parar de chorar, para ser acalmado)

Não pode ser consolado/acalmado

COMENTÁRIOS

EXAMINADOR
Acordado, mas nunca chora; não precisa de consolo

Fica calmo/quieto quando se conversa com ele

Precisa ser carregado para ser consolado

Não pode ser consolado

COMENTÁRIOS

EXAMINADOR

Quadro 7: Itens da seção CARACTERIZAÇÃO do instrumento HNNE expandido

\begin{tabular}{|c|c|c|c|}
\hline \multicolumn{4}{|c|}{ HNNE expandido } \\
\hline Item Original & T1 & T2 & VSP \\
\hline $\begin{array}{l}\text { Hammersmith Neonatal } \\
\text { Neurological Examination }\end{array}$ & $\begin{array}{l}\text { Exame Neurológico Neonatal de } \\
\text { Hammersmith }\end{array}$ & $\begin{array}{l}\text { Exame Neonatal Neurológico de } \\
\text { Hammersmith }\end{array}$ & Hammersmith - Exame Neonatal Neurológico \\
\hline Code & Código & Código & Código \\
\hline D.O.E & Data & Data do exame & Data do exame \\
\hline Name & Nome & Nome & Nome \\
\hline Sex & Sexo & Sexo & Sexo \\
\hline Race & Raça & Raça & Raça \\
\hline D.O.B & Data de Nacimento & Data de Nascimento & Data de Nascimento \\
\hline Age & Idade & Idade & Idade \\
\hline G.A & Idade gestacional & Tempo de gestação & Tempo de gestação \\
\hline $\mathbf{B W}$ & (não sei) & (deixou em branco) & Não informado \\
\hline
\end{tabular}

Quadro 8: Itens da seção POSTURA e TÔNUS do instrumento HNNE expandido

\begin{tabular}{|c|c|c|c|}
\hline \multicolumn{4}{|c|}{ HNNE expandido } \\
\hline Item Original & T1 & $\mathbf{T 2}$ & VSP \\
\hline POSTURE AND TONE & POSTURA E TÔNUS & POSTURA E TÔNUS & POSTURA E TÔNUS \\
\hline $\begin{array}{l}\text { POSTURE - Infant supine. Look } \\
\text { mainly at position of legs but also } \\
\text { note arms. Score predominant } \\
\text { posture. }\end{array}$ & $\begin{array}{l}\text { POSTURA - Lactente em supino. Observe } \\
\text { principalmente a posição das pernas, mas } \\
\text { também observe os braços. Pontue a postura } \\
\text { predominante }\end{array}$ & $\begin{array}{l}\text { Postura - Supino Infantil. Olhe principalmente } \\
\text { para a posição das pernas, mas também } \\
\text { observe os braços. Anote a postura } \\
\text { predominante }\end{array}$ & $\begin{array}{l}\text { POSTURA - Lactente em supino. Observe } \\
\text { principalmente a posição das pernas, mas } \\
\text { também observe os braços. Pontue a postura } \\
\text { predominante }\end{array}$ \\
\hline
\end{tabular}


Quadro 8 (continuação): Itens da seção POSTURA e TÔNUS do instrumento HNNE expandido

\begin{tabular}{|c|c|c|c|}
\hline $\begin{array}{l}\text { Arms \& legs extended or very } \\
\text { slightly flexed }\end{array}$ & $\begin{array}{l}\text { Braços e pernas estendidas ou muito } \\
\text { ligeiramente flexionadas }\end{array}$ & $\begin{array}{l}\text { Braços e pernas estendidos ou muito pouco } \\
\text { flexionados }\end{array}$ & $\begin{array}{l}\text { Braços e pernas estendidas ou muito pouco } \\
\text { flexionadas }\end{array}$ \\
\hline Legs slightly flexed & Pernas ligeiramente flexionadas & Pernas ligeiramente flexionadas & Pernas ligeiramente flexionadas \\
\hline Legs well flexed but not adducted & Pernas bem flexionadas, mas não aduzidas & Pernas bem flexionadas, mas não aduzidas & Pernas bem flexionadas, mas não aduzidas \\
\hline $\begin{array}{l}\text { Legs well flexed \& adducted near } \\
\text { abdomen }\end{array}$ & $\begin{array}{l}\text { Pernas bem flexionadas e aduzidas próximas } \\
\text { ao abdômen }\end{array}$ & $\begin{array}{l}\text { Pernas bem flexionadas e aduzidas perto do } \\
\text { abdômen (próximas ao abdômen) }\end{array}$ & $\begin{array}{l}\text { Pernas bem flexionadas e aduzidas próximas } \\
\text { ao abdômen }\end{array}$ \\
\hline $\begin{array}{l}\text { Abnormal posture: a) opisthotonos } \\
\text { b) marked leg extension, strong arm } \\
\text { flexion }\end{array}$ & $\begin{array}{l}\text { Postura anormal: a) opistótono } \\
\text { b) Extensão acentuada da perna e forte flexão } \\
\text { dos braços }\end{array}$ & $\begin{array}{l}\text { Postura anormal: a) opistótono } \\
\text { b) extensão acentuada da perna. Forte flexão } \\
\text { do braço }\end{array}$ & $\begin{array}{l}\text { Postura anormal: a) opistótono } \\
\text { b) Extensão acentuada da perna e forte flexão } \\
\text { dos braços }\end{array}$ \\
\hline $\begin{array}{l}\text { ARM RECOIL - Take both hands; } \\
\text { quickly extend arms parallel to the } \\
\text { body, Count to three. Release. } \\
\text { Repeat } 3 \text { times }\end{array}$ & $\begin{array}{l}\text { RECOLHIMENTO DO BRAÇO/PADRÃO } \\
\text { FLEXOR DE BRAÇO - Pegue ambas as } \\
\text { mãos, estenda rapidamente os braços paralelo } \\
\text { ao corpo, conte até três. Relaxe. Repita } 3 \\
\text { vezes. }\end{array}$ & $\begin{array}{l}\text { RECUO DO BRAÇO - Pegue ambas as mãos, } \\
\text { rapidamente estique os braços paralelamente } \\
\text { ao corpo. Conte até três. Repita três vezes }\end{array}$ & $\begin{array}{l}\text { PADRÃ A FLEXOR DE BRAÇO - Pegue } \\
\text { ambas as mãos, estenda rapidamente os braços } \\
\text { paralelo ao corpo, conte até três. Relaxe. } \\
\text { Repita } 3 \text { vezes. }\end{array}$ \\
\hline Arms do not flex & Braços não flexionam & Braços não flexionam & Braços não flexionam \\
\hline $\begin{array}{l}\text { Arms flex slowly, not always; not } \\
\text { completely }\end{array}$ & $\begin{array}{l}\text { Braços flexionam devagar, não sempre, não } \\
\text { completamente }\end{array}$ & $\begin{array}{l}\text { Braços flexionam lentamente, mas nem } \\
\text { sempre; não completamente }\end{array}$ & $\begin{array}{l}\text { Braços flexionam lentamente, mas nem } \\
\text { sempre; não completamente }\end{array}$ \\
\hline Arms flex slowly; more completely & $\begin{array}{l}\text { Braços flexionam devagar, e/mas/porém } \\
\text { completamente. }\end{array}$ & $\begin{array}{l}\text { Braços flexionam lentamente; mais } \\
\text { completamente }\end{array}$ & $\begin{array}{l}\text { Braços flexionam lentamente, porém } \\
\text { completamente. }\end{array}$ \\
\hline Arms flex quickly and completely & $\begin{array}{l}\text { Braços flexionam rapidamente } \mathrm{e} \\
\text { completamente }\end{array}$ & Braços flexionam rápida e completamente & Braços flexionam rápido e completamente \\
\hline $\begin{array}{l}\text { Arms difficult to extend; snap back } \\
\text { forcefully }\end{array}$ & $\begin{array}{l}\text { Braços difíceis de estender; flexionam de } \\
\text { volta vigorosamente }\end{array}$ & $\begin{array}{l}\text { Braços difíceis de estender; retraem } \\
\text { vigorosamente }\end{array}$ & $\begin{array}{l}\text { Braços difíceis de estender; flexionam de } \\
\text { volta vigorosamente }\end{array}$ \\
\hline $\begin{array}{l}\text { ARM TRACTION - Hold wrist and } \\
\text { pull arm upwards. Note flexion at } \\
\text { elbow and resistance while shoulder } \\
\text { lifts off table. Test each side } \\
\text { separately. }\end{array}$ & $\begin{array}{l}\text { TRAÇÃO DO BRAÇO - Segure no punho e } \\
\text { puxe o braço para cima. Observe a flexão e a } \\
\text { resistência do cotovelo, enquanto o ombro é } \\
\text { levantado da mesa. Teste cada lado } \\
\text { separadamente. }\end{array}$ & $\begin{array}{l}\text { TRAÇÃO DO BRAÇO - Segure o punho e } \\
\text { puxe o braço para cima. Observe a flexão no } \\
\text { cotovelo e resistência enquanto o ombro é } \\
\text { levantado da mesa. Teste cada lado } \\
\text { separadamente }\end{array}$ & $\begin{array}{l}\text { TRAÇÃO DO BRAÇO - Segure no punho e } \\
\text { puxe o braço para cima. Observe a flexão e a } \\
\text { resistência do cotovelo, enquanto o ombro é } \\
\text { levantado da mesa. Teste cada lado } \\
\text { separadamente. }\end{array}$ \\
\hline $\begin{array}{l}\text { Arms remain straight; no resistance } \\
\text { felt }\end{array}$ & $\begin{array}{l}\text { Braços permanecem eretos. Não sente } \\
\text { resistência. }\end{array}$ & $\begin{array}{l}\text { Braços permanecem retos; nenhuma } \\
\text { resistência observada }\end{array}$ & $\begin{array}{l}\text { Braços permanecem retos; nenhuma } \\
\text { resistência observada }\end{array}$ \\
\hline $\begin{array}{l}\text { Arms flex slightly or some resistance } \\
\text { felt }\end{array}$ & $\begin{array}{l}\text { Braços flexionam ligeiramente ou } \\
\text { sente/percebe alguma resistência }\end{array}$ & $\begin{array}{l}\text { Braços flexionam ligeiramente ou alguma } \\
\text { resistência observada }\end{array}$ & $\begin{array}{l}\text { Braços flexionam ligeiramente ou alguma } \\
\text { resistência é observada }\end{array}$ \\
\hline $\begin{array}{l}\text { Arms flex well till shoulder lifts, then } \\
\text { straighten }\end{array}$ & $\begin{array}{l}\text { Braços flexionam bem até elevar o ombro, } \\
\text { então endireitam-se }\end{array}$ & $\begin{array}{l}\text { Braços flexionam bem até que os ombros se } \\
\text { levantam, então endireitam-se }\end{array}$ & $\begin{array}{l}\text { Braços flexionam bem até elevar o ombro, } \\
\text { então endireitam-se }\end{array}$ \\
\hline $\begin{array}{l}\text { Arms flex at approx. } 100^{\circ} \& \\
\text { maintained as shoulder lifts }\end{array}$ & $\begin{array}{l}\text { Braços flexionam até aproximadamente } 100^{\circ} \mathrm{e} \\
\text { se mantém na elevação de ombros }\end{array}$ & $\begin{array}{l}\text { Braços flexionam em aprox. } 100^{\circ} \text { e mantêm- } \\
\text { se quando os ombros se erguem }\end{array}$ & $\begin{array}{l}\text { Braços flexionam até aproximadamente } 100^{\circ} \mathrm{e} \\
\text { mantêm-se quando os ombros são elevados }\end{array}$ \\
\hline
\end{tabular}


Quadro 8 (continuação): Itens da seção POSTURA e TÔNUS do instrumento HNNE expandido

\begin{tabular}{|l|l|}
\hline Flexion of arms $\left\langle\mathbf{1 0 0}^{\circ}\right.$. Maintained & Flexão de braços $<100^{\circ}$; mantido quando o
\end{tabular}

when body lifts up

LEG RECOIL - Take both ankles in one hand, flex hips + knees. Quickly

extend. Release. Repeat 3 times

\section{No flexion}

Incomplete or variable flexion

Complete but slow flexion

Complete fast flexion

Legs difficult to extend; snap back forcefully

LEG TRACTION - Grasp ankle and slowly pull leg upwards. Note flexion at knees and resistance as buttocks

lift. Teste each side separately.

Legs straight - no resistance felt Legs flex slightly or some resistance felt corpo é levantado

RECOLHIMENTO DA PERNA - Pegue ambos tornozelos em uma mão, flexione quadris + joelhos. Estenda rapidamente. Relaxe. Repita 3 vezes. Não flexiona

Flexão incompleta ou variável Flexão completa, mas lenta.

Flexão rápida e completa

Perna difícil para estender; flexiona de volta rapidamente e com forca

TRAÇ̃̃O DA PERNA - Segure o tornozelo e puxe lentamente a perna para cima. Observe a flexão e a resistência do joelho enquanto eleva os glúteos/quadris. Teste cada lado separadamente.

Pernas eretas - não sente resistência

Pernas flexionam levemente ou sente alguma resistência

Legs flex well till bottom lifts up

Pernas flexionam bem até elevar os glúteos/quadris

Knee flexes remains flexed when bottom up

Joelhos flexionam e permanecem flexionados quando os glúteos/quadris são levantados

Flexion stays when back + bottom up

POPLITEAL ANGLE - Fix knee on

abdomen, extend leg by gentle pressure with index finger behind

the ankle. Note angle at knee. Test each side separately.

HEAD CONTROL (1) (extensor

tone) - Infant sitting upright.

Encircle chest with both hands

holding shoulders. Let head drop

forward.

No attempt to raise head

são elevados.

ÂNGULO POPLÍTEO - Fixar joelho no abdômen, estenda a perna realizando uma leve pressão por trás do tornozelo com o dedo indicador. Observe o ângulo do joelho. Teste cada lado separadamente.

CONTROLE DE CABEÇA (1) (tônus

extensor) - Lactente sentado verticalmente.

Circundar peito com ambas as mãos

segurando os ombros. Deixe a cabeça cair para frente.

Nenhuma tentativa de levantar a cabeça
Flexão dos braços menor que $100^{\circ}$; mantida

enquanto o corpo é levantado

RECUO DA PERNA - Segure ambo

tornozelos em uma mão, flexione o quadril e

os joelhos. Estenda rapidamente. Solte. Repita três vezes.

Sem flexão

Flexão incompleta ou variável

Flexão completa, porém, lenta

Flexão completa e rápida

Pernas difíceis de estender; retraem

vigorosamente

TRAÇÃO DA PERNA - Segure o tornozelo e

puxe a perna para cima lentamente. Note a

flexão do joelho e a resistência durante o

levantar das nádegas. Teste cada lado separadamente.

Pernas retas - sem resistência observad

Pernas flexionam ligeiramente ou alguma resistência observada

Pernas flexionam bem até que quadril se levanta

Joelhos se flexionam mantêm-se flexionados quando o quadril se ergue

Flexão se mantem quando o quadril e as costas se erguem
ÂNGULO POPLÍTEO - Coloque o joelho no abdômen, estique a perna aplicando uma ligeira pressão no tornozelo com o indicador. Observe o ângulo no joelho. Teste cada lado separadamente.

\section{CONTROLEDA CABEÇA (1)}

(tônus do extensor) - Criança sentada

Abrace o peito com ambas mãos, segurando

os ombros. Deixe a cabeça cair para frente.

Sem tentativa de levantar a cabeça
Flexão de braços $\left\langle 100^{\circ}\right.$; mantido quando o corpo é levantado

RECOLHIMENTO DA PERNA - Segure ambos tornozelos em uma mão, flexione o quadril e os joelhos. Estenda rapidamente. Solte. Repita três vezes.

Flexão incompleta ou variáve

Flexão completa, porém, lenta

Flexão completa e rápida

Pernas difíceis de estender; retraem de volta vigorosamente

TRAÇÃO DA PERNA - Segure o tornozelo puxe lentamente a perna para cima. Observe a flexão e a resistência do joelho enquanto eleva os quadris. Teste cada lado separadamente.

Pernas retas - sem resistência observad Pernas flexionam levemente ou alguma resistência é observada

Pernas flexionam bem até elevar os quadris

Joelhos flexionam e permanecem flexionados quando os quadris são levantado

Flexão se mantem quando o quadril e as costas são levantadas

ÂNGULO POPLÍTEO - Coloque o joelho no abdômen, estenda a perna realizando uma leve pressão por trás do tornozelo com o dedo indicador. Observe o ângulo do joelho. Teste cada lado separadamente.

CONTROLE DE CABECA (1) (tônus

extensor). - Lactente sentado.

Abrace o peito com ambas mãos, segurando

os ombros. Deixe a cabeça cair para frente.

Nenhuma tentativa de levantar a cabeça 
Quadro 8 (continuação): Itens da seção POSTURA e TÔNUS do instrumento HNNE expandido

\begin{tabular}{|c|c|c|c|}
\hline $\begin{array}{l}\text { Infant tries: effort better felt than } \\
\text { seen }\end{array}$ & $\begin{array}{l}\text { Tentativas imaturas/lactente se esforça: } \\
\text { esforço é mais sentido do que visto }\end{array}$ & $\begin{array}{l}\text { Criança tenta levantar; esforço é mais sentido } \\
\text { do que observado (ou visto) }\end{array}$ & $\begin{array}{l}\text { Lactente tenta levantar; esforço é mais sentido } \\
\text { do que observado (ou visto) }\end{array}$ \\
\hline $\begin{array}{l}\text { Raises head but drops forward or } \\
\text { back }\end{array}$ & $\begin{array}{l}\text { Levanta a cabeça, mas cai para a frente ou } \\
\text { para trás }\end{array}$ & $\begin{array}{l}\text { Levanta a cabeça, mas a deixa cair para frente } \\
\text { ou para trás }\end{array}$ & $\begin{array}{l}\text { Levanta a cabeça, mas cai para a frente ou } \\
\text { para trás }\end{array}$ \\
\hline $\begin{array}{l}\text { Raises head: remains vertical; it may } \\
\text { wobble }\end{array}$ & $\begin{array}{l}\text { Levanta a cabeça: permanece na vertical; } \\
\text { podendo oscilar }\end{array}$ & $\begin{array}{l}\text { Levanta a cabeça: permanece vertical; a } \\
\text { cabeça pode oscilar }\end{array}$ & $\begin{array}{l}\text { Levanta a cabeça: permanece na vertical; } \\
\text { podendo oscilar }\end{array}$ \\
\hline $\begin{array}{l}\text { HEAD CONTROL (2) (flexor tone) } \\
\text { Infant sitting upright. Encircle chest } \\
\text { with both hands holding shoulders. } \\
\text { Let head drop backward. }\end{array}$ & $\begin{array}{l}\text { CONTROLE DE CABEÇA (2) (tônus flexor) } \\
\text { - Lactente sentado verticalmente. Circundar } \\
\text { peito com ambas as mãos segurando os } \\
\text { ombros. Deixe a cabeça cair para trás. }\end{array}$ & $\begin{array}{l}\text { CONTROLE DA CABEÇA (2) } \\
\text { (tônus do flexor) - Criança sentada. Abrace o } \\
\text { peito com ambas mãos, segurando os ombros. } \\
\text { Deixe a cabeça cair para trás. }\end{array}$ & $\begin{array}{l}\text { CONTROLE DE CABEÇA (2) (tônus flexor) } \\
\text { - Lactente sentado. Abrace o peito com ambas } \\
\text { mãos, segurando os ombros. Deixe a cabeça } \\
\text { cair para trás. }\end{array}$ \\
\hline No attempt to raise head & Nenhuma tentativa de levantar a cabeça & Sem tentativa de levantar a cabeça & Nenhuma tentativa de levantar a cabeça \\
\hline $\begin{array}{l}\text { Infant tries: effort better felt than } \\
\text { seen }\end{array}$ & $\begin{array}{l}\text { Lactente se esforça: esforço é mais sentido do } \\
\text { que visto }\end{array}$ & $\begin{array}{l}\text { Criança tenta levantar; esforço é mais sentido } \\
\text { do que observado (ou visto) }\end{array}$ & $\begin{array}{l}\text { Lactente tenta levantar; esforço é mais sentido } \\
\text { do que observado (ou visto) }\end{array}$ \\
\hline $\begin{array}{l}\text { Raises head but drops forward or } \\
\text { back }\end{array}$ & $\begin{array}{l}\text { Levanta a cabeça, mas cai para a frente ou } \\
\text { para trás }\end{array}$ & $\begin{array}{l}\text { Levanta a cabeça, mas a deixa cair para frente } \\
\text { ou para trás }\end{array}$ & $\begin{array}{l}\text { Levanta a cabeça, mas cai para a frente ou } \\
\text { para trás }\end{array}$ \\
\hline $\begin{array}{l}\text { Raises head: remains vertical; it may } \\
\text { wobble }\end{array}$ & $\begin{array}{l}\text { Levanta a cabeça: permanece na vertical; } \\
\text { podendo oscilar }\end{array}$ & $\begin{array}{l}\text { Levanta a cabeça: permanece vertical; a } \\
\text { cabeça pode oscilar }\end{array}$ & $\begin{array}{l}\text { Levanta a cabeça: permanece na vertical; } \\
\text { podendo oscilar }\end{array}$ \\
\hline $\begin{array}{l}\text { Head upright or extended, cannot be } \\
\text { passively flexed }\end{array}$ & $\begin{array}{l}\text { Cabeça ereta ou estendida, não pode ser } \\
\text { flexionada passivamente }\end{array}$ & $\begin{array}{l}\text { tendida; não pode ser } \\
\text { mente }\end{array}$ & $\begin{array}{l}\text { Cabeça ereta ou estendida; não pode ser } \\
\text { flexionada passivamente }\end{array}$ \\
\hline $\begin{array}{l}\text { HEAD LAG - Pull infant towards } \\
\text { sitting posture by traction on both } \\
\text { wrists \& support head slightly. Also } \\
\text { note arm flexion }\end{array}$ & $\begin{array}{l}\text { ATRASO DA CABEÇA - Puxe o lactente } \\
\text { para a postura sentada com tração em ambos } \\
\text { os punhos e apoiando levemente a cabeça. } \\
\text { Observe também a flexão do braço }\end{array}$ & $\begin{array}{l}\text { ATRASO (RETARDO) DA CABEÇA - Puxe } \\
\text { a criança em direção a postura de sentar } \\
\text { através dos pulsos. Apoie a cabeça } \\
\text { ligeiramente. Também observar a flexão dos } \\
\text { braços. }\end{array}$ & $\begin{array}{l}\text { ATRASO DA CABEÇA - Puxe o lactente } \\
\text { para a postura sentada com tração em ambos } \\
\text { os punhos e apoiando levemente a cabeça. } \\
\text { Observe também a flexão do braço }\end{array}$ \\
\hline Head drops \&stays back & & Cabeça cai e permanece para trás & Cabeça cai e permanece para trás \\
\hline Tries to lift head but it drops back & Tenta elevar a cabeça, mas cai de volta. & Tenta levantar a cabeça, mas esta cai para trás & Tenta levantar a cabeça, mas esta cai para trás \\
\hline Able to lift head slightly & Capaz de elevar a cabeça ligeiramente & Capaz de levantar a cabeça ligeiramente & Capaz de levantar a cabeça ligeiramente \\
\hline Lifts head in line with body & $\begin{array}{l}\text { Eleva a cabeça alinhada com o/a } \\
\text { corpo/tronco/coluna }\end{array}$ & Levanta a cabeça alinhada com o corpo & Levanta a cabeça alinhada com o tronco \\
\hline Head in front of body & te do corpo & & \\
\hline $\begin{array}{l}\text { VENTRAL SUSPENSION } \\
\text { Hold infant in ventral suspension. } \\
\text { Observe back, flexion of limbs, and } \\
\text { relation of head to trunk. If it looks } \\
\text { different, DRAW. }\end{array}$ & $\begin{array}{l}\text { SUSPENSÃO VENTRAL } \\
\text { Segure o lactente em suspensão ventral. } \\
\text { Observe a coluna, flexão dos membros e } \\
\text { relação da cabeça com o tronco. Se ele parecer } \\
\text { diferente, DESENHE }\end{array}$ & $\begin{array}{l}\text { SUSPENSÃO VENTRAL } \\
\text { Segure a criança em suspensão ventral. } \\
\text { Observe as costas, flexão dos membros e a } \\
\text { relação da cabeça com o tronco. Se diferente, } \\
\text { DESENHE. }\end{array}$ & $\begin{array}{l}\text { SUSPENSÃO VENTRAL } \\
\text { Segure o lactente em suspensão ventral. } \\
\text { Observe a coluna, flexão dos membros e } \\
\text { relação da cabeça com o tronco. Se ele parecer } \\
\text { diferente, DESENHE }\end{array}$ \\
\hline $\begin{array}{l}\text { Back curved, head \&limbs hang } \\
\text { straight }\end{array}$ & $\begin{array}{l}\text { Coluna curvada, cabeça e membros suspensos } \\
\text { e eretos }\end{array}$ & $\begin{array}{l}\text { Costas curvadas. Cabeça e membros } \\
\text { suspensos e retos }\end{array}$ & $\begin{array}{l}\text { Costas curvadas. Cabeça e membros } \\
\text { suspensos e retos }\end{array}$ \\
\hline
\end{tabular}


Quadro 8 (continuação): Itens da seção POSTURA e TÔNUS do instrumento HNNE expandido

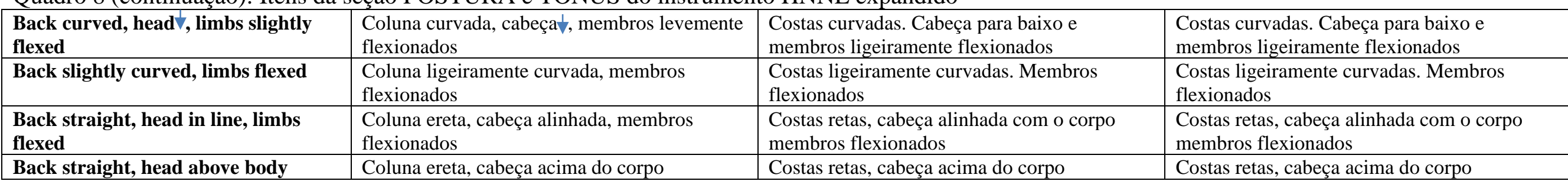

Back straight, head above body Coluna ereta, cabeça acima do corpo

Costas retas, cabeça acima do corpo

Costas retas, cabeça acima do corpo

Quadro 9: Itens da seção PADRÕES DE TÔNUS do instrumento HNNE expandido

\begin{tabular}{|c|c|c|c|}
\hline \multicolumn{4}{|c|}{ HNNE expandido } \\
\hline Item Original & T1 & T2 & VSP \\
\hline TONE PATTERNS & PADRÃO DE TÔNUS & PADRÕES DE TÔNUS & PADRÕES DE TÔNUS \\
\hline $\begin{array}{l}\text { FLEXOR TONE (1) (on traction: } \\
\text { arm versus leg) - Compare scores of } \\
\text { arm traction with leg traction }\end{array}$ & $\begin{array}{l}\text { TÔNUS FLEXOR (1) (Tração: braço x } \\
\text { perna)-Compare o desempenho/pontuação da } \\
\text { tração do braço com a tração de perna }\end{array}$ & $\begin{array}{l}\text { TÔNUS FLEXOR (1) (tração: braço vs. } \\
\text { perna) - Compare os resultados de tração do } \\
\text { braço com os de tração de perna }\end{array}$ & $\begin{array}{l}\text { TÔNUS FLEXOR (1) (tração: braço vs. } \\
\text { perna) - Compare os resultados de tração do } \\
\text { braço com os de tração de perna }\end{array}$ \\
\hline $\begin{array}{l}\text { Score for arm flexion less than leg } \\
\text { flexion }\end{array}$ & $\begin{array}{l}\text { Desempenho/pontuação da flexão dos braços é } \\
\text { menor que a flexão das pernas }\end{array}$ & $\begin{array}{l}\text { Pontuação para flexão de braços menor que } \\
\text { flexão de pernas }\end{array}$ & $\begin{array}{l}\text { Pontuação para flexão dos braços é menor que } \\
\text { a flexão de pernas }\end{array}$ \\
\hline $\begin{array}{l}\text { Score for arm flexion equal to leg } \\
\text { flexion }\end{array}$ & $\begin{array}{l}\text { Desempenho/pontuação da flexão dos braços é } \\
\text { igual a flexão das pernas }\end{array}$ & $\begin{array}{l}\text { Pontuação para flexão de braços igual a flexão } \\
\text { de pernas }\end{array}$ & $\begin{array}{l}\text { pontuação da flexão dos braços é igual à da } \\
\text { flexão das pernas }\end{array}$ \\
\hline $\begin{array}{l}\text { Score for arm flexion more than leg } \\
\text { flexion but difference } 1 \text { column or } \\
\text { less }\end{array}$ & $\begin{array}{l}\text { Desempenho/pontuação da flexão dos braços é } \\
\text { maior que a flexão das pernas, mas a diferença } \\
\text { da coluna é } 1 \text { ou menor }\end{array}$ & $\begin{array}{l}\text { Pontuação para flexão de braços maior que } \\
\text { flexão de pernas, porém com diferença de uma } \\
\text { coluna ou menos }\end{array}$ & $\begin{array}{l}\text { Pontuação da flexão de braços é maior que a } \\
\text { de flexão de pernas, porém com diferença de } \\
\text { uma coluna ou menos }\end{array}$ \\
\hline $\begin{array}{l}\text { Score for arm flexion more than leg } \\
\text { flexion but difference more than } 1 \\
\text { column }\end{array}$ & $\begin{array}{l}\text { Desempenho/pontuação da flexão dos braços é } \\
\text { maior que a flexão das pernas, mas a diferença } \\
\text { da coluna é maior que } 1 .\end{array}$ & $\begin{array}{l}\text { Pontuação para flexão de braços maior que } \\
\text { flexão de pernas, porém com diferença de uma } \\
\text { coluna ou mais }\end{array}$ & $\begin{array}{l}\text { Pontuação da flexão de braços é maior que a } \\
\text { de flexão de pernas, porém com diferença de } \\
\text { uma coluna ou mais }\end{array}$ \\
\hline $\begin{array}{l}\text { FLEXOR TONE (2) (arm versus leg) } \\
\text { - Posture in supine. }\end{array}$ & $\begin{array}{l}\text { TÔNUS FLEXOR (2) (braço x perna) - } \\
\text { Postura em supino. }\end{array}$ & $\begin{array}{l}\text { TÔNUS FLEXOR (2) (braço vs. perna) - } \\
\text { Postura em supino. }\end{array}$ & $\begin{array}{l}\text { TÔNUS FLEXOR (2) (braço vs. perna) - } \\
\text { Postura em supino. }\end{array}$ \\
\hline Arms and legs flexed & Braços e pernas flexionados & Braços e pernas flexionados & Braços e pernas flexionados \\
\hline $\begin{array}{l}\text { Strong arm flexion with strong leg } \\
\text { extension intermittent }\end{array}$ & $\begin{array}{l}\text { Forte flexão do braço com forte extensão } \\
\text { intermitente da perna }\end{array}$ & $\begin{array}{l}\text { Forte flexão do braço com forte extensão } \\
\text { intermitente da perna }\end{array}$ & $\begin{array}{l}\text { Forte flexão do braço com forte extensão } \\
\text { intermitente da perna }\end{array}$ \\
\hline $\begin{array}{l}\text { Strong arm flexion with strong leg } \\
\text { extension continuous }\end{array}$ & $\begin{array}{l}\text { Forte flexão do braço com forte extensão } \\
\text { contínua da perna }\end{array}$ & $\begin{array}{l}\text { Forte flexão do braço com forte extensão } \\
\text { contínua da perna }\end{array}$ & $\begin{array}{l}\text { Forte flexão do braço com forte extensão } \\
\text { contínua da perna }\end{array}$ \\
\hline $\begin{array}{l}\text { LEG EXTENSOR TONE - Compare } \\
\text { scores of leg traction and popliteal } \\
\text { angle. }\end{array}$ & $\begin{array}{l}\text { TÔNUS EXTENSOR DA PERNA - Compare } \\
\text { a pontuação da tração da perna e do ângulo } \\
\text { poplíteo }\end{array}$ & $\begin{array}{l}\text { TÔNUS EXTENSOR DA PERNA - Compare } \\
\text { a pontuação da tração da perna e o ângulo } \\
\text { poplíteo }\end{array}$ & $\begin{array}{l}\text { TÔNUS EXTENSOR DA PERNA - Compare } \\
\text { a pontuação da tração da perna e do ângulo } \\
\text { poplíteo }\end{array}$ \\
\hline
\end{tabular}


Quadro 9 (continuação): Itens da seção PADRÕES DE TÔNUS do instrumento HNNE expandido

Score for leg traction more than

score for popliteal angle

Score for leg traction equal to score

for popliteal angle

Score for leg traction less than score

for popliteal angle, by 1 column only

Score for leg traction less than score

for popliteal angle, by more than 1

\section{column}

NECK EXTENSOR TONE

(SITTING) - Compare scores of head

control 1 and 2.

Score for head extension less than

head flexion

Score for head extension equal to

head flexion

Score for head extension more than

head flexion, but difference 1 column

or less

Score for head extension more than

head flexion, but difference more

than 1 column

INCREASED EXTENSOR TONE

(HORIZONTAL) - Compare scores

of head lag and ventral suspension.

Score for ventral suspension less

than head lag

Score for ventral suspension equal to

head lag

Score for ventral suspension more

than head lag but difference 1

column or less

Score for ventral suspension more

than head lag but difference more

than 1 column
Pontuação da tração da perna é maior que a

pontuação do ângulo poplíteo

Pontuação da tração da perna é igual a

pontuação do ângulo poplíteo

Pontuação da tração da perna é menor que a

pontuação do ângulo poplíteo, mas somente 1

coluna

Pontuação da tração da perna é menor que a

pontuação do ângulo poplíteo, mas a coluna é maior que 1

TÔNUS EXTENSOR DO PESCOÇO

(sentado) - Compare a pontuação do controle de cabeça 1 e 2.

Pontuação da extensão de cabeça é menor que a flexão de cabeça

Pontuação da extensão de cabeça é igual a flexão de cabeça

Pontuação da extensão de cabeça é maior que

a flexão de cabeça, mas com diferença de uma coluna ou menos

Pontuação da extensão de cabeça é maior que

a flexão de cabeça, porém a diferença da coluna é maior que 1.

AUMENTO DE TONUS EXTENSOR

(horizontal) - Compare a pontuação do atraso da cabeça e a suspensão ventral.

Pontuação da suspensão ventral é menor que o atraso da cabeça

Pontuação da suspensão ventral é igual ao atraso da cabeça

Pontuação da suspensão ventral é maior que o atraso da cabeça, mas a diferença da coluna é 1 ou menos

Pontuação da suspensão ventral é maior que o atraso da cabeça, mas a diferença da coluna é maior que 1
Pontuação para tração de perna maior que

pontuação de ângulo poplíteo

Pontuação para tração de perna igual a pontuação de ângulo poplíteo

Pontuação para tração de perna igual a

pontuação de ângulo poplíteo, com diferença

de somente uma coluna

Pontuação para tração de perna menor que ângulo poplíteo, porém com diferença maior que uma coluna

TÔNUS EXTENSOR DO PESCOÇO

(sentar) - Compare os pontos do controle de cabeça 1 e 2.

Pontuação para extensão de cabeça menor que flexão de cabeça

Pontuação para extensão de cabeça igual a flexão de cabeça

Pontuação para extensão de cabeça maior que flexão de cabeça, porém com diferença de uma coluna ou menos

Pontuação para extensão de cabeça maior que flexão de cabeça, porém com diferença maior que uma coluna

TÔNUS EXTENSOR AUMENTADO

(horizontal) - Compare os pontos do atraso (retardo) da cabeça com a suspensão vertical.

Pontuação para suspensão vertical menor que atraso (retardo) de cabeça

Pontuação para suspensão vertical igual a atraso (retardo) de cabeça

Pontuação para suspensão vertical maior que atraso (retardo) de cabeça, porém com

diferença de uma coluna ou menos

Pontuação para suspensão vertical maior que

atraso (retardo) de cabeça, porém com

diferença maior que uma coluna
Pontuação da tração da perna é maior que a pontuação do ângulo poplíteo

Pontuação da tração da perna é igual a pontuação do ângulo poplíteo

Pontuação da tração da perna é menor que a pontuação do ângulo poplíteo, com diferença de somente uma coluna

Pontuação da tração da perna é menor que a pontuação do ângulo poplíteo, porém com diferença maior que uma coluna

TÔNUS EXTENSOR DO PESCOÇO

(sentado) - Compare a pontuação do controle de cabeça 1 e 2 .

Pontuação da extensão de cabeça é menor que a da flexão de cabeça

Pontuação da extensão de cabeça é igual flexão de cabeça

Pontuação da extensão de cabeça é maior que a da flexão de cabeça, porém com diferença maior que uma coluna

Pontuação da extensão de cabeça é maior que a da flexão de cabeça, porém com diferença maior que uma coluna

AUMENTO DE TÔNUS EXTENSOR

(horizontal) - Compare a pontuação do atraso da cabeça e a suspensão ventral.

Pontuação da suspensão ventral é menor que a do atraso da cabeça

Pontuação da suspensão ventral é igual a do atraso da cabeça

Pontuação da suspensão ventral é maior que a do atraso da cabeça, porém com diferença de uma coluna ou menos

Pontuação da suspensão ventral é maior que a

do atraso da cabeça, porém com diferença maior que uma coluna 
Quadro 10: Itens da seção REFLEXOS do instrumento HNNE expandido

\begin{tabular}{|c|c|c|c|}
\hline \multicolumn{4}{|c|}{ HNNE expandido } \\
\hline Item Original & T1 & T2 & VSP \\
\hline REFLEXES & REFLEXOS & REFLEXOS & REFLEXOS \\
\hline $\begin{array}{l}\text { TENDON REFLEX - Test biceps, } \\
\text { knee, and ankle jerks }\end{array}$ & $\begin{array}{l}\text { REFLEXO DO TENDÃO - Teste os reflexos } \\
\text { do bíceps, joelho e tornozelo }\end{array}$ & $\begin{array}{l}\text { REFLEXO DO TENDÃO - Teste os reflexos } \\
\text { do bíceps, joelho e tornozelo }\end{array}$ & $\begin{array}{l}\text { REFLEXO TENDÍNEO - Teste os reflexos do } \\
\text { bíceps, joelho e tornozelo }\end{array}$ \\
\hline Absent & Ausente & Ausente & Ausente \\
\hline Felt, not seen & Sente na palpação, mas não vê & Sentido, não visto & Sente na palpação, mas não vê \\
\hline Seen & Presente & Visto/observado & Presente \\
\hline "exaggerated" (very brisk) & "Exagerado" (muito vigoroso/rápido) & "exagerado" (muito vivo/ativo) & "Exagerado" (muito ativo) \\
\hline Clonus & Clônus & Clônico & Clônus \\
\hline $\begin{array}{l}\text { SUCK/GAG - Little finger into } \\
\text { mouth with pulp of finger upwards. }\end{array}$ & $\begin{array}{l}\text { REFLEXO DE SUCÇÃO E DE } \\
\text { MORDAÇA/RETIRADA - Colocar dedo } \\
\text { mínimo dentro da boca com a ponta do dedo } \\
\text { para cima }\end{array}$ & $\begin{array}{l}\text { SUCÇÃO/ENGASGO - Dedo mínimo na } \\
\text { boca com a polpa voltada para cima (céu da } \\
\text { boca?) }\end{array}$ & $\begin{array}{l}\text { REFLEXO DE SUCÇÃO/VÔMITO/ÂNSIA - } \\
\text { Colocar dedo mínimo dentro da boca com a } \\
\text { polpa do dedo para cima }\end{array}$ \\
\hline No gag/ no suck & Não amordaça / não suga & Sem engasgo / sem sucção & Sem vômito-ânsia / sem sucção \\
\hline $\begin{array}{l}\text { Weak irregular suck only. No } \\
\text { stripping }\end{array}$ & Somente sucção fraca e irregular. Não retira & Somente sucção fraca e irregular & $\begin{array}{l}\text { Somente sucção fraca e irregular. Não remove } \\
\text { a boca do estímulo }\end{array}$ \\
\hline Weak regular suck. Some stripping & $\begin{array}{l}\text { Sucção regular e fraca. Alguma retirada (tenta } \\
\text { retirar) }\end{array}$ & Sucção regular e fraca & $\begin{array}{l}\text { Sucção fraca e regular. Remove a boca do } \\
\text { estímulo algumas vezes }\end{array}$ \\
\hline $\begin{array}{l}\text { Strong suck: A) irregular } \\
\text { B) regular. Good stripping }\end{array}$ & $\begin{array}{l}\text { Sucção forte: (a) irregular (b) regular } \\
\text { Boa retirada }\end{array}$ & Sucção forte: (a) irregular (b) regular & $\begin{array}{l}\text { Sucção forte: (a) irregular (b) regular } \\
\text { Remove adequadamente a boca do estímulo }\end{array}$ \\
\hline No suck but strong clenching & $\begin{array}{l}\text { Não suga mas aperta (cerrar - fechar a boca) } \\
\text { forte }\end{array}$ & Sem sucção porém pegada/aperto firme/forte & Sem sucção, porém a pegada é forte \\
\hline $\begin{array}{l}\text { PALMAR GRASP - Put index finger } \\
\text { into the hand and gently press } \\
\text { palmar surface. Do not touch dorsal } \\
\text { surface. Test each side separately. }\end{array}$ & $\begin{array}{l}\text { PREENSÃO PALMAR - Coloque o dedo } \\
\text { indicador na palma da mão e pressione } \\
\text { gentilmente a superfície palmar. Não toque a } \\
\text { superfície dorsal. Teste cada lado } \\
\text { separadamente }\end{array}$ & $\begin{array}{l}\text { GARRA PALMAR - Coloque o indicador na } \\
\text { mão e pressione gentilmente a palma } \\
\text { (superfície palmar). Não toque o dorso da mão } \\
\text { (superfície dorsal). Teste cada lado } \\
\text { separadamente }\end{array}$ & $\begin{array}{l}\text { PREENSÃO PALMAR - Coloque o dedo } \\
\text { indicador na palma da mão e pressione } \\
\text { gentilmente a superfície palmar. Não toque a } \\
\text { superfície dorsal. Teste cada lado } \\
\text { separadamente }\end{array}$ \\
\hline No response & Sem resposta & Sem resposta & Sem resposta \\
\hline Short, weak flexion of fingers & Flexão dos dedos curta e fraca & Flexão dos dedos fraca e curta & Flexão dos dedos curta e fraca \\
\hline Strong flexion of fingers & Forte flexão dos dedos & Forte flexão dos dedos & Forte flexão dos dedos \\
\hline Strong finger flexion, shoulder & Forte flexão dos dedos, ombro & Forte flexão dos dedos, ombros para cima & Forte flexão dos dedos, ombros \\
\hline $\begin{array}{l}\text { Very strong grasp; infant can be } \\
\text { lifted off couch }\end{array}$ & $\begin{array}{l}\text { Preensão muito forte; lactente pode ser } \\
\text { "levantado da cama" }\end{array}$ & $\begin{array}{l}\text { Garra muito forte; } \\
\text { Criança pode ser levantada }\end{array}$ & $\begin{array}{l}\text { Preensão muito forte; lactente pode ser } \\
\text { levantado da cama/superfície }\end{array}$ \\
\hline
\end{tabular}


Quadro 10 (continuação): Itens da seção REFLEXOS do instrumento HNNE expandido

PLANTAR GRASP - Press thumb

on the sole below the toes. Test each side separately.

No response

Partial plantar flexion of toes

Toes curve around the examiner's

finger

PLACING - Lift infant in an upright position and stroke the dorsum of the foot against a protruding edge of a

flat surface. Test each side separately

\section{No response}

Dorsiflexion of ankle only

Full placing response with flexion of

hip and knee \& placing sole on

surface

MORO REFLEX - One hand

supports infant's head in midline, the

other the back. Raise infant to $45^{\circ}$

and when infant is relaxed let head

fall through $10^{\circ}$. Note if jerky.

Repeat 3 times.

No response, or opening of hands only

Full abduction at shoulder and

extension of the arms; no adduction

Full abduction, but only delayed or

partial adduction

Partial abduction at shoulder, and

extension of arms followed by

smooth adduction

(a) Minimal abduction or adduction

(b) No abduction or adduction, only

forward extension of arms (c)

Marked adduction only
PREENSÃO PLANTAR - Pressione o polegar

na sola abaixo dos dedos. Teste cada lado separadamente

Sem resposta

Flexão plantar parcial dos dedos

Os dedos curvam sobre o dedo do examinador

COLOCAÇÃO DAS PERNAS - Levante o

lactente na posição vertical e bata o dorso do

pé projetando-o contra a borda de uma

superfície plana. Teste cada lado separadamente

Sem resposta

Somente dorsiflexão do tornozelo

Resposta completa do reflexo de colocação da perna, flexão do quadril e joelho; coloca sola na superfície

REFLEXO DE MORO - Uma mão suporta a cabeça do lactente em linha média e a outra a coluna. Levante o lactente a $45^{\circ}$ e quando o lactente estiver relaxado deixe a cabeça cair $10^{\circ}$. Observe se há espasmos. Repita 3 vezes

Não responde, ou apenas abre as mãos

Abdução completa dos ombros e extensão dos braços; sem adução (não realiza adução)

Abdução completa, porém, lenta ou adução parcial

Abdução parcial dos ombros e extensão dos braços seguida por uma suave adução

(a) Mínima abdução ou adução (b) Nenhuma abdução ou adução; somente extensão dos

braços para frente (c) Somente adução acentuada
GARRA PLANTAR - Pressione o polegar na

sola abaixo dos dedos. Teste cada lado separadamente

Sem resposta

Flexão plantar parcial dos dedos

Dedos curvam em torno do dedo do

examinador

COLOCAÇÃO - Erga a criança em pé e bata o dorso do pé contra a borda de uma superfície plana. Teste cada lado separadamente

Sem resposta

Dorsiflexão somente do tornozelo

Resposta completa com flexão do quadril e joelho; coloca sola na superfície

REFLEXO MORO - Uma mão suporta a cabeça na linha média enquanto outra suporta as costas. Erga a criança até $45^{\circ}$ e quando ela relaxar deixe a cabeça cair $10^{\circ}$. Note se espástico. Repita 3 vezes

Sem resposta, ou somente abertura das mãos

Abdução completa dos ombros e extensão dos braços; sem adução

Abdução completa, porém, adução atrasada ou parcial

Abdução parcial dos ombros e extensão dos

braços seguida de adução suave

(a) Abdução ou adução mínimas (b) Sem abdução ou adução; apenas extensão dos

braços para frente (c) Somente adução acentuada
PREENSÃO PLANTAR - Pressione o polegar na sola abaixo dos dedos. Teste cada lado separadamente Sem resposta

Flexão plantar parcial dos dedos

Os dedos curvam sobre o dedo do examinador

COLOCAÇÃO DAS PERNAS - Levante o lactente na posição vertical e bata o dorso do pé projetando-o contra a borda de uma superfície plana. Teste cada lado separadamente

Sem resposta

Somente dorsiflexão do tornozelo

Resposta completa do reflexo de colocação da perna, flexão do quadril e joelho; coloca sola na superfície

REFLEXO DE MORO - Uma mão suporta a cabeça do lactente em linha média e a outra as costas. Levante o lactente a $45^{\circ}$ e quando o lactente estiver relaxado deixe a cabeça cair $10^{\circ}$. Observe se há espasmos. Repita 3 vezes

Sem resposta, ou somente abertura das mãos

Abdução completa dos ombros e extensão dos braços; sem adução

Abdução completa, porém, adução atrasada ou parcial

Abdução parcial dos ombros e extensão dos braços seguida por uma suave adução

(a) Mínima abdução ou adução (b) Nenhuma abdução ou adução; somente extensão dos braços para frente (c) Somente adução acentuada 
Quadro 11: Itens da seção MOVIMENTOS do instrumento HNNE expandido

\begin{tabular}{|c|c|c|c|}
\hline \multicolumn{4}{|c|}{ HNNE expandido } \\
\hline Item Original & T1 & T2 & VSP \\
\hline MOVEMENTS & MOVIMENTOS & MOVIMENTOS & MOVIMENTOS \\
\hline $\begin{array}{l}\text { SPONTANEOUS MOVEMENT } \\
\text { (quantity) - Watch infant lying } \\
\text { supine. }\end{array}$ & $\begin{array}{l}\text { MOVIMENTOS ESPONTÂNEOS } \\
\text { (quantidade) - Observe o lactente deitado em } \\
\text { supino }\end{array}$ & $\begin{array}{l}\text { MOVIMENTO ESPONTÂNEO (quantidade) } \\
\text { - Observe a criança deitada em supino }\end{array}$ & $\begin{array}{l}\text { MOVIMENTOS ESPONTÂNEOS } \\
\text { (quantidade) - Observe o lactente deitado em } \\
\text { supino }\end{array}$ \\
\hline No movement & Sem movimento & Sem movimento & Sem movimento \\
\hline $\begin{array}{l}\text { Sporadic and short isolated } \\
\text { movements }\end{array}$ & Movimentos isolados esporádicos e curtos & Movimentos isolados curtos e esporádicos & Movimentos isolados esporádicos e curtos \\
\hline Frequent isolated movements & Movimentos isolados frequentes & Movimentos isolados frequentes & Movimentos isolados frequentes \\
\hline Frequent generalized movements & Movimentos frequentes generalizados & Movimentos frequentes gerais & Movimentos frequentes generalizados \\
\hline Continuous exaggerated movements & Movimentos contínuos exagerados & Movimentos contínuos exagerados & Movimentos contínuos exagerados \\
\hline $\begin{array}{l}\text { SPONTANEOUS MOVEMENT } \\
\text { (quality) - Watch infant lying supine. }\end{array}$ & $\begin{array}{l}\text { MOVIMENTOS ESPONTÂNEOS } \\
\text { (qualidade) - Observe lactente deitado em } \\
\text { supino }\end{array}$ & $\begin{array}{l}\text { MOVIMENTO ESPONTÂNEO (qualidade) - } \\
\text { Observe a criança deitada em supino }\end{array}$ & $\begin{array}{l}\text { MOVIMENTOS ESPONTÂNEOS } \\
\text { (qualidade) - Observe o lactente deitado em } \\
\text { supino }\end{array}$ \\
\hline Only stretches & Apenas alonga-se & Apenas alongamento & Alonga-se apenas \\
\hline $\begin{array}{l}\text { Stretches and random abrupt } \\
\text { movements; some smooth } \\
\text { movements }\end{array}$ & $\begin{array}{l}\text { Alongamentos e movimentos aleatórios } \\
\text { abruptos; algum movimento suave }\end{array}$ & $\begin{array}{l}\text { Alongamentos e movimentos aleatórios } \\
\text { abruptos; alguns movimentos suaves }\end{array}$ & $\begin{array}{l}\text { Alongamentos e movimentos aleatórios } \\
\text { abruptos; alguns movimentos suaves }\end{array}$ \\
\hline Fluent movements but monotonous & Movimentos fluentes, porém, monótonos & Movimentos fluentes, porém, monótonos & Movimentos fluentes, porém, monótonos \\
\hline $\begin{array}{l}\text { Fluent alternating movements of } \\
\text { arms + legs; good variability }\end{array}$ & $\begin{array}{l}\text { Movimentos fluentes e alternados de braços e } \\
\text { pernas; boa variabilidade }\end{array}$ & $\begin{array}{l}\text { Movimentos fluentes alternados de braços e } \\
\text { pernas; boa variabilidade }\end{array}$ & $\begin{array}{l}\text { Movimentos fluentes alternados de braços e } \\
\text { pernas; boa variabilidade }\end{array}$ \\
\hline $\begin{array}{l}\text { (a) cramped, synchronized; (b) } \\
\text { mouthing (c) jerky or other } \\
\text { abnormal movements }\end{array}$ & $\begin{array}{l}\text { (a) Espasmódico/em bloco, sincronizado; (b) } \\
\text { Movimento de mastigação/ movimentos da } \\
\text { boca (c) Espasmos ou outros movimentos } \\
\text { anormais }\end{array}$ & $\begin{array}{l}\text { (a) Espasmódico, sincronizado; (b) } \\
\text { Movimento de mastigação, (c) Abrupto } \\
\text { (irregular) ou outros movimentos anormais }\end{array}$ & $\begin{array}{l}\text { (a) Espasmódico, sincronizado; (b) } \\
\text { Movimento de mastigação (c) Espasmos ou } \\
\text { outros movimentos anormais }\end{array}$ \\
\hline $\begin{array}{l}\text { HEAD RAISING PRONE - Infant in } \\
\text { prone, head in midline }\end{array}$ & $\begin{array}{l}\text { LEVANTANDO A CABEÇA EM PRONO - } \\
\text { Lactente em prono, cabeça na linha média }\end{array}$ & $\begin{array}{l}\text { CABEÇA LEVANTANDO EM PRONAÇÃO } \\
\text { - Criança em pronação, cabeça na linha média }\end{array}$ & $\begin{array}{l}\text { LEVANTANDO A CABEÇA EM PRONO - } \\
\text { Lactente em prono, cabeça na linha média }\end{array}$ \\
\hline No response & Sem resposta & Sem resposta & Sem resposta \\
\hline $\begin{array}{l}\text { Infant rolls head over, chin not } \\
\text { raised }\end{array}$ & $\begin{array}{l}\text { Lactente rola a cabeça para o lado, queixo não } \\
\text { levantado }\end{array}$ & Criança rola a cabeça, queixo não levantado & $\begin{array}{l}\text { Lactente rola a cabeça para o lado, queixo não } \\
\text { levantado }\end{array}$ \\
\hline Infant raises chin, rolls head over & $\begin{array}{l}\text { Lactente levanta o queixo, rola a cabeça para o } \\
\text { lado }\end{array}$ & Criança levanta o queixo, rola a cabeça & $\begin{array}{l}\text { Lactente levanta o queixo, rola a cabeça para o } \\
\text { lado }\end{array}$ \\
\hline Infant brings head and chin up & $\begin{array}{l}\text { Lactente levanta a cabeça e o queixo para } \\
\text { cima }\end{array}$ & Criança levanta a cabeça e o queixo & $\begin{array}{l}\text { Lactente levanta a cabeça e o queixo para } \\
\text { cima }\end{array}$ \\
\hline $\begin{array}{l}\text { Infant brings head up and keeps it } \\
\text { up }\end{array}$ & Lactente leva a cabeça para cima e a mantém & Criança levanta a cabeça e mantém-na erguida & Lactente leva a cabeça para cima e a mantém \\
\hline
\end{tabular}


Quadro 12: Itens da seção SINAIS/PADRÕES ANORMAIS do instrumento HNNE expandido

\begin{tabular}{|c|c|c|c|}
\hline \multicolumn{4}{|c|}{ HNNE expandido } \\
\hline Item Original & T1 & 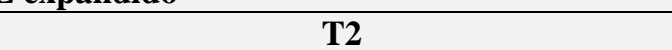 & VSP \\
\hline ABNORMAL SIGNS/PATTERNS & SINAIS/PADRÕES ANORMAIS & SINAIS/PADRÕES ANORMAIS & SINAIS/PADRÕES ANORMAIS \\
\hline $\begin{array}{l}\text { ABNORMAL HAND OR TOES } \\
\text { POSTURES }\end{array}$ & $\begin{array}{l}\text { POSTURA ANORMAL DAS MÃOS OU } \\
\text { DEDOS }\end{array}$ & $\begin{array}{l}\text { POSTURAS ANORMAIS DAS MÃOS OU } \\
\text { DEDOS }\end{array}$ & $\begin{array}{l}\text { POSTURA ANORMAL DAS MÃOS OU } \\
\text { DEDOS }\end{array}$ \\
\hline $\begin{array}{l}\text { Hands open, toes straight most of the } \\
\text { time }\end{array}$ & $\begin{array}{l}\text { Mãos abertas, dedos esticados na maior parte } \\
\text { do tempo }\end{array}$ & $\begin{array}{l}\text { Mãos abertas, dedos esticados na maior parte } \\
\text { do tempo }\end{array}$ & $\begin{array}{l}\text { Mãos abertas, dedos esticados na maior parte } \\
\text { do tempo }\end{array}$ \\
\hline $\begin{array}{l}\text { Intermittent fisting or thumb } \\
\text { adduction }\end{array}$ & Punho intermitente ou adução do polegar & Punho intermitente ou adução do polegar & Punho intermitente ou adução do polegar \\
\hline $\begin{array}{l}\text { Continuous fisting or thumb } \\
\text { adduction; index finger flexion, } \\
\text { thumb opposition }\end{array}$ & $\begin{array}{l}\text { Punho contínuo ou adução do polegar; flexão } \\
\text { do dedo indicador e oposição do polegar }\end{array}$ & $\begin{array}{l}\text { Punho contínuo ou adução do polegar; flexão } \\
\text { do dedo indicador, oposição do polegar }\end{array}$ & $\begin{array}{l}\text { Punho contínuo ou adução do polegar; flexão } \\
\text { do dedo indicador, oposição do polegar }\end{array}$ \\
\hline $\begin{array}{l}\text { Continuous big toe extension or } \\
\text { flexion of all toes }\end{array}$ & $\begin{array}{l}\text { Grande extensão contínua de dedos ou flexão } \\
\text { de todos os dedos }\end{array}$ & $\begin{array}{l}\text { Extensão contínua do dedão ou flexão de } \\
\text { todos os dedos }\end{array}$ & $\begin{array}{l}\text { Extensão contínua do hálux ou flexão de todos } \\
\text { os dedos }\end{array}$ \\
\hline TREMOR & TREMOR & TREMOR & TREMOR \\
\hline $\begin{array}{l}\text { No tremor, or tremor only when } \\
\text { crying or only after Moro reflex }\end{array}$ & $\begin{array}{l}\text { Sem tremor ou tremor somente quando chora } \\
\text { ou somente após reflexo de Moro }\end{array}$ & $\begin{array}{l}\text { Sem tremor, tremor somente quando chorando } \\
\text { ou somente após reflexo de Moro }\end{array}$ & $\begin{array}{l}\text { Sem tremor ou tremor somente quando chora } \\
\text { ou somente após reflexo de Moro }\end{array}$ \\
\hline Tremor occasionally when awake & Tremor ocasional quando acordado & Tremor ocasional quando acordado & Tremor ocasional quando acordado \\
\hline Frequent tremors when awake & Tremores frequentes quando acordado & Tremores frequentes quando acordado & Tremores frequentes quando acordado \\
\hline Continuous tremors & Tremores contínuos & Tremores contínuos & Tremores contínuos \\
\hline STARTLE & SOBRESSALTO/SUSTO & SOBRESSALTO/SUSTO & SOBRESSALTO/SUSTO \\
\hline No startle even to sudden noise & Não assusta mesmo com barulho repentino & Sem susto, mesmo com barulho repentino & Não se assusta, mesmo com barulho repentino \\
\hline $\begin{array}{l}\text { No spontaneous startle but reacts to } \\
\text { sudden noise }\end{array}$ & $\begin{array}{l}\text { Não assusta espontaneamente, porém reage a } \\
\text { barulhos repentinos }\end{array}$ & $\begin{array}{l}\text { Sem susto espontâneo, porém reage a barulho } \\
\text { repentino }\end{array}$ & $\begin{array}{l}\text { Não se assusta espontaneamente, porém reage } \\
\text { a barulho repentino }\end{array}$ \\
\hline 2-3 spontaneous startles & 2-3 sobressaltos espontâneos & 2-3 sustos espontâneos & 2-3 sobressaltos espontâneos \\
\hline More than 3 spontaneous startles & Mais que 3 sobressaltos espontâneos & Mais que 3 sustos espontâneos & Mais que 3 sobressaltos espontâneos \\
\hline Continuous startles & Sobressaltos contínuos & Sustos contínuos & Sobressaltos contínuos \\
\hline
\end{tabular}

Quadro 13: Itens da seção ORIENTAÇÃO E COMPORTAMENTO do instrumento HNNE expandido

\begin{tabular}{|c|c|c|c|}
\hline \multicolumn{4}{|c|}{ HNNE expandido } \\
\hline Item Original & T1 & $\mathbf{T 2}$ & VSP \\
\hline ORIENTATION AND BEHAVIOR & ORIENTAÇÃO E COMPORTAMENTO & ORIENTAÇÃO E COMPORTAMENTO & ORIENTAÇÃO E COMPORTAMENTO \\
\hline EYE APPEARANCES & APARÊNCIA DOS OLHOS & APARÊNCIA DO OLHO & APARÊNCIA DOS OLHOS \\
\hline Does not open eyes & Não abre os olhos & Não abre os olhos & Não abre os olhos \\
\hline Full conjugated eye movements & $\begin{array}{l}\text { Movimentos oculares completamente } \\
\text { conjugados }\end{array}$ & $\begin{array}{l}\text { Movimentos dos olhos conjugados } \\
\text { completamente }\end{array}$ & $\begin{array}{l}\text { Movimentos oculares completamente } \\
\text { conjugados }\end{array}$ \\
\hline
\end{tabular}


Quadro 13 (continuação): Itens da seção ORIENTAÇÃO E COMPORTAMENTO do instrumento HNNE expandido

Transient: (a) nystagmus (b) strabismus (c) roving eye movements (d) sunset sign

Persistent: (a) nystagmus (b)

strabismus (c) roving eye movements (d) abnormal pupils

\section{AUDITORY ORIENTATION -}

Infant awake. Wrap infant. Hold rattle 10 to $15 \mathrm{~cm}$ from ear.

\section{No reaction}

Auditory startle; brightens and stills; no true orientation

Shifting of eyes, head might turn towards source

Prolonged head turn to stimulus;

search with eyes, smooth

Turns head (jerkily, abruptly) \&

eyes towards noise every time

\section{VISUAL ORIENTATION - Wrap} infant, Wake up with rattle if needed or rock gently. Note if baby can see and follow red ball $(B)$ or target $(T)$

Does not follow or focus on stimuli Stills, focuses, follows briefly to the side but loses stimuli

Follows horizontally and vertically;

no head turn

Follows horizontally and vertically,

turns head

Follows in a circle

ALERTNESS - Tested as response to

visual stimuli (B or T).

Will not respond to stimuli

When awake, looks only briefly
Transitório: (a) nistagmo (b) estrabismo (c)

movimentos de olhos errantes/perdidos

(d) sinal de olhos caindo

Persistente: (a) nistagmo (b) estrabismo (c)

movimentos de olhos errantes/perdidos (d) pupilas anormais

ORIENTAÇ̃̃O AUDITIVA - Lactente

acordado. Enrole o lactente. Segure um chocalho 10 a $15 \mathrm{~cm}$ de distância da orelha. Sem reação

Sobressalto auditivo; se anima e acalma-se; sem orientação verdadeira

Deslocamento dos olhos, a cabeça pode se virar em direção à fonte

Cabeça prolongamente virada para o estímulo; procura com olhos; tranquilamente

Vira a cabeça (abruptamente com espasmo) e olhos em direção ao barulho o tempo todo

ORIENTAÇÃO VISUAL - Enrole o lactente, acorde-o com o chocalho se necessário, ou sacuda-o gentilmente. Observe se o bebê pode ver e seguir uma bola vermelha (B) ou um objeto $(\mathrm{O})$

Não segue ou foca nos estímulos

Fica parado, foca, segue rapidamente para o

lado, mas perde estímulo

Segue horizontalmente e verticalmente; sem

virar a cabeça

Segue horizontalmente e verticalmente; vira a cabeça

Segue em círculo

ALERTA - Teste as respostas do estímulo visual (B ou O)

Não responderá aos estímulos

Quando acordado, apenas olha rapidamente transiente: (a) nistagmo (b) estrabismo (c)

movimentos de olhos vagueantes (d) sinal de

pôr-do-sol (olhos caídos)

Persistente: (a) nistagmo (b) estrabismo (c)

movimentos de olhos pairantes (d) pupilas anormais

ORIENTAÇÃO AUDITIVA - Criança

desperta. Enrole a criança. Mantenha o chocalho entre 10 a $15 \mathrm{~cm}$ da orelha.

Sem reação

Susto auditivo; fica alerta e acalma-se (em seguida); sem orientação real

Desvio dos olhos, a cabeça pode se mover em direção à fonte sonora

Virada de cabeça prolongada em direção ao estímulo; busca com olhos; suave

Move a cabeça/vira a cabeça (agitada e

abruptamente) e olhos em direção ao nariz toda vez

ORIENTAÇÃO VISUAL - Embrulhe a

criança, acorde-a com o chocalho se

necessário ou sacuda-a gentilmente. Observe

se o bebê pode ver e seguir uma bola vermelha ou um objeto

Não segue ou foca nos estímulos

Acalma-se, foca, segue brevemente para o

lado, porém perde estímulo

Segue horizontalmente e verticalmente; sem

virada de cabeça

Segue horizontalmente e verticalmente; vira a cabeça

Segue em um círculo

ALERTA - Testado como resposta ao

estímulo visual (bola ou objeto)

Não irá responder aos estímulos

Quando acordado, olha apenas brevemente
Transitório: (a) nistagmo (b) estrabismo (c) movimentos de olhos vagueantes (d) sinal de pôr-do-sol (olhos caídos)

Persistente: (a) nistagmo (b) estrabismo (c) movimentos de olhos vagueantes (d) pupilas anormais

ORIENTAÇÃO AUDITIVA - Lactente acordado. Enrole o lactente. Segure um chocalho entre 10 a $15 \mathrm{~cm}$ da orelha.

Sem reação

Sobressalto auditivo; fica alerta e acalma-se em seguida; sem orientação real

Desvio dos olhos, a cabeça pode se virar em direção à fonte sonora

Vira a cabeça lentamente em direção ao estímulo; busca com olhos; suavemente

Vira a cabeça (abruptamente, com espasmo) e olhos em direção ao barulho o tempo todo

ORIENTAÇÃO VISUAL - Enrole o lactente, acorde-o com o chocalho se necessário, ou sacuda-o gentilmente. Observe se o bebê pode ver e seguir uma bola vermelha (B) ou um objeto $(\mathrm{O})$

Não segue ou foca nos estímulos

Acalma-se, foca, segue rapidamente para o lado, porém perde estímulo

Segue horizontalmente e verticalmente; sem virar a cabeça

Segue horizontalmente e verticalmente; vira a cabeça

Segue em círculo

ALERTA - Teste as respostas do estímulo visual (B ou O)

Não irá responder aos estímulos

Quando acordado, apenas olha rapidamente 
Quadro 13 (continuação): Itens da seção ORIENTAÇÃO E COMPORTAMENTO do instrumento HNNE expandido

\begin{tabular}{|c|c|c|c|}
\hline $\begin{array}{l}\text { When awake, looks at stimuli but } \\
\text { loses them }\end{array}$ & $\begin{array}{l}\text { Quando acordado, olha para o estímulo, } \\
\text { porém o perde }\end{array}$ & $\begin{array}{l}\text { Quando acordado, olha para os estímulos, } \\
\text { porém os perde/perde o interesse }\end{array}$ & $\begin{array}{l}\text { Quando acordado, olha para o estímulo, } \\
\text { porém o perde }\end{array}$ \\
\hline Keeps interest in stimuli & Mantém interesse no estímulo & Mantém interesse nos estímulos & Mantém interesse no estímulo \\
\hline Does not tire (hyper-reactive) & Não se cansa (hiper-reatividade) & Não se cansa (hiper-reativo) & Não se cansa (hiper-reatividade) \\
\hline $\begin{array}{l}\text { IRRITABILITY - In response to } \\
\text { stimuli }\end{array}$ & IRRITABILIDADE - Em resposta ao estímulo & $\begin{array}{l}\text { IRRITABILIDADE - Em resposta aos } \\
\text { estímulos }\end{array}$ & IRRITABILIDADE - Em resposta ao estímulo \\
\hline $\begin{array}{l}\text { Quiet all the time, not irritable to } \\
\text { any stimuli }\end{array}$ & $\begin{array}{l}\text { Quieto o tempo todo, não se irrita com } \\
\text { estímulo algum }\end{array}$ & $\begin{array}{l}\text { Quieto o tempo todo, não irritável a nenhum } \\
\text { dos estímulos }\end{array}$ & $\begin{array}{l}\text { Quieto o tempo todo, não se irrita com } \\
\text { estímulo algum }\end{array}$ \\
\hline $\begin{array}{l}\text { Awakes, cries sometimes when } \\
\text { handled }\end{array}$ & $\begin{array}{l}\text { Acordado, chora algumas vezes quando } \\
\text { manuseado }\end{array}$ & $\begin{array}{l}\text { Desperta, chora algumas vezes quando } \\
\text { manuseado/manipulado }\end{array}$ & $\begin{array}{l}\text { Desperta, chora algumas vezes quando } \\
\text { manuseado }\end{array}$ \\
\hline Cries often when handled & Chora frequentemente quando manuseado & $\begin{array}{l}\text { Chora frequentemente quando } \\
\text { manuseado/manipulado }\end{array}$ & Chora frequentemente quando manuseado \\
\hline Cries always when handled & Chora sempre que manuseado & Sempre chora quando manuseado/manipulado & Sempre chora quando manuseado \\
\hline Cries even when not handled & Chora mesmo quando não manipulado & $\begin{array}{l}\text { Chora mesmo quando não } \\
\text { manipulado/manuseado }\end{array}$ & Chora mesmo quando não manuseado \\
\hline $\begin{array}{l}\text { CONSOLABILITY - Ease to quiet } \\
\text { infant. }\end{array}$ & $\begin{array}{l}\text { CONSOLABILIDADE - Facilidade para } \\
\text { acalmar o lactente }\end{array}$ & $\begin{array}{l}\text { CONSOLABILIDADE - Facilidade para } \\
\text { acalmar a criança }\end{array}$ & $\begin{array}{l}\text { CONSOLABILIDADE - } \\
\text { Facilidade para acalmar o lactente }\end{array}$ \\
\hline Not crying; consoling not needed & Não chora; não precisa de consolo & Sem chorar; consolo não necessário & Não chora; não precisa de consolo \\
\hline Cries briefly; consoling not needed & Chora brevemente; não precisa de consolo & Chora brevemente; consolo não necessário & Chora brevemente; não precisa de consolo \\
\hline Cries; becomes quiet when talked to & $\begin{array}{l}\text { Chora; mas fica quieto quando conversa com } \\
\text { ele }\end{array}$ & $\begin{array}{l}\text { Chora; fica calmo/quieto quando se conversa } \\
\text { com ele/ela }\end{array}$ & $\begin{array}{l}\text { Chora; mas fica quieto quando se conversa } \\
\text { com ele }\end{array}$ \\
\hline Cries; need picking up to be consoled & $\begin{array}{l}\text { Chora; precisa ser carregado para ser } \\
\text { consolado }\end{array}$ & $\begin{array}{l}\text { Chora; precisa ser carregado para ser } \\
\text { consolado }\end{array}$ & $\begin{array}{l}\text { Chora; precisa ser carregado para ser } \\
\text { consolado }\end{array}$ \\
\hline Cries; cannot be consoled & Chora; não pode ser consolado & Chora; não pode ser consolado/acalmado & Chora; não pode ser consolado \\
\hline CRY & CHORO & CHORO & CHORO \\
\hline No cry at all & Nunca chora & Nenhum choro & Nenhum choro \\
\hline Whimpering cry only & Apenas choraminga & Somente choramingando & Apenas choraminga \\
\hline Cries to stimuli but normal pitch & $\begin{array}{l}\text { Chora para estímulo, porém com intensidade } \\
\text { normal }\end{array}$ & $\begin{array}{l}\text { Chora para os estímulos, porém em tom } \\
\text { normal }\end{array}$ & $\begin{array}{l}\text { Chora para estímulo, porém com intensidade } \\
\text { normal }\end{array}$ \\
\hline High-pitched cry; often continuous & $\begin{array}{l}\text { Chora intensivamente; continuamente e } \\
\text { frequentemente }\end{array}$ & Choro agudo; normalmente contínuo & Choro agudo; normalmente contínuo \\
\hline SUMMARY OF EXAMINATION & RESUMO DA EXAMINAÇÃO & RESUMO DO EXAME & RESUMO DO EXAME \\
\hline HEAD AND TRUNK TONE & TÔNUS DA CABEÇA E COLUNA & TÔNUS DA CABEÇA E TRONCO & TÔNUS DA CABEÇA E TRONCO \\
\hline MOTILITY & MOTILIDADE & MOTILIDADE & MOBILIDADE \\
\hline ORIENTATION AND ALETNESS & ORIENTAÇÃO E ALERTA & ORIENTAÇÃO E ALERTA & ORIENTAÇÃO E ALERTA \\
\hline CONSOLABILITY & CONSOLABILIDADE & CONSOLABILIDADE & CONSOLABILIDADE \\
\hline LIMB TONE & TÔNUS DOS MEMBROS & TÔNUS DOS MEMBROS & TÔNUS DOS MEMBROS \\
\hline
\end{tabular}


Quadro 13 (continuação): Itens da seção ORIENTAÇÃO E COMPORTAMENTO do instrumento HNNE expandido

\begin{tabular}{|l|l|l|}
\hline REFLEXES & REFLEXOS & REFLEXOS \\
\hline IRRITABILITY & IRRITABILIDADE & IRRITABILIDADE \\
\hline LIST DEVIANT SIGNS & LISTA DE SINAIS DIVERGENTES & LISTA DE SINAIS DIVERGENTES \\
\hline
\end{tabular}
REFLEXOS

IRRITABILIDADE

LISTA DE SINAIS DIVERGENTES

\subsubsection{Resultados estágios 1 e 2: HINE infant}

Quadro 14: Itens da seção CARACTERIZAÇÃO do instrumento HINE-infant

\begin{tabular}{|c|c|c|c|}
\hline \multicolumn{4}{|c|}{ HINE (infant) } \\
\hline Item Original & T1 & T2 & VSP \\
\hline $\begin{array}{l}\text { Hammersmith Infant Neurological } \\
\text { Examination }\end{array}$ & $\begin{array}{l}\text { Hammersmith - Exame Neurológico do } \\
\text { lactente }\end{array}$ & Exame Infantil Neurológico de Hammersmith & Hammersmith: exame infantil neurológico \\
\hline Name & Nome & Nome & Nome \\
\hline Date of birth & Data de aniversário & Data de aniversário & Data de aniversário \\
\hline Gestational age & Idade gestacional & Idade gestacional & Idade gestacional \\
\hline Date of examination & Data da avaliação & Data do exame & Data do exame \\
\hline SUMMARY OF EXAMINATION & RESUMO DO EXAME & RESUMO DO EXAME & RESUMO DO EXAME \\
\hline No of asymmetries in section $1:$ & Número de assimetrias da sessão 1 & Número de assimetrias da sessão 1 & Número de assimetrias da sessão 1 \\
\hline Neurological items score: & Pontuação dos itens neurológicos & Pontuação nos itens neurológicos & Pontuação dos itens neurológicos \\
\hline Behavioural score: & Pontuação comportamental & Pontuação comportamental & Pontuação comportamental \\
\hline COMMENTS: & COMENTÁRIOS & COMENTÁRIOS & COMENTÁRIOS \\
\hline Cranial nerves functions & Funções dos nervos cranianos & Funções dos nervos cranianos & Funções dos nervos cranianos \\
\hline Posture & Postura & Postura & Postura \\
\hline Movements & Movimentos & Movimentos & Movimentos \\
\hline Tone & Tônus & Tônus & Tônus \\
\hline Reflexes and reactions & Reflexos e reações & Reflexos e reações & Reflexos e reações \\
\hline Behaviour & Comportamento & Comportamento & Comportamento \\
\hline $\begin{array}{l}\text { SECTION 1: NEUROLOGICAL } \\
\text { ITEMS }\end{array}$ & SEÇÃO 1: ITENS NEUROLÓGICOS & SEÇÃO 1: ITENS NEUROLÓGICOS & SEÇÃO 1: ITENS NEUROLÓGICOS \\
\hline
\end{tabular}

Quadro 15: Itens da seção FUNÇÃO DOS NERVOS CRANIANOS do instrumento HINE-infant

\begin{tabular}{|c|c|c|c|}
\hline \multicolumn{4}{|c|}{ HINE (infant) } \\
\hline Item Original & T1 & $\mathbf{T 2}$ & VSP \\
\hline Assessment of cranial nerve function & Avaliação da função dos nervos craniais & Avaliação da função dos nervos craniais & Avaliação da função dos nervos craniais \\
\hline Column 1 (score 2) & Coluna 1 (pontue 2) & Coluna 1 (pontue 2) & Coluna 1 (pontue 2) \\
\hline
\end{tabular}


Quadro 15(continuação): Itens da seção FUNÇÃO DOS NERVOS CRANIANOS do instrumento HINE-infant

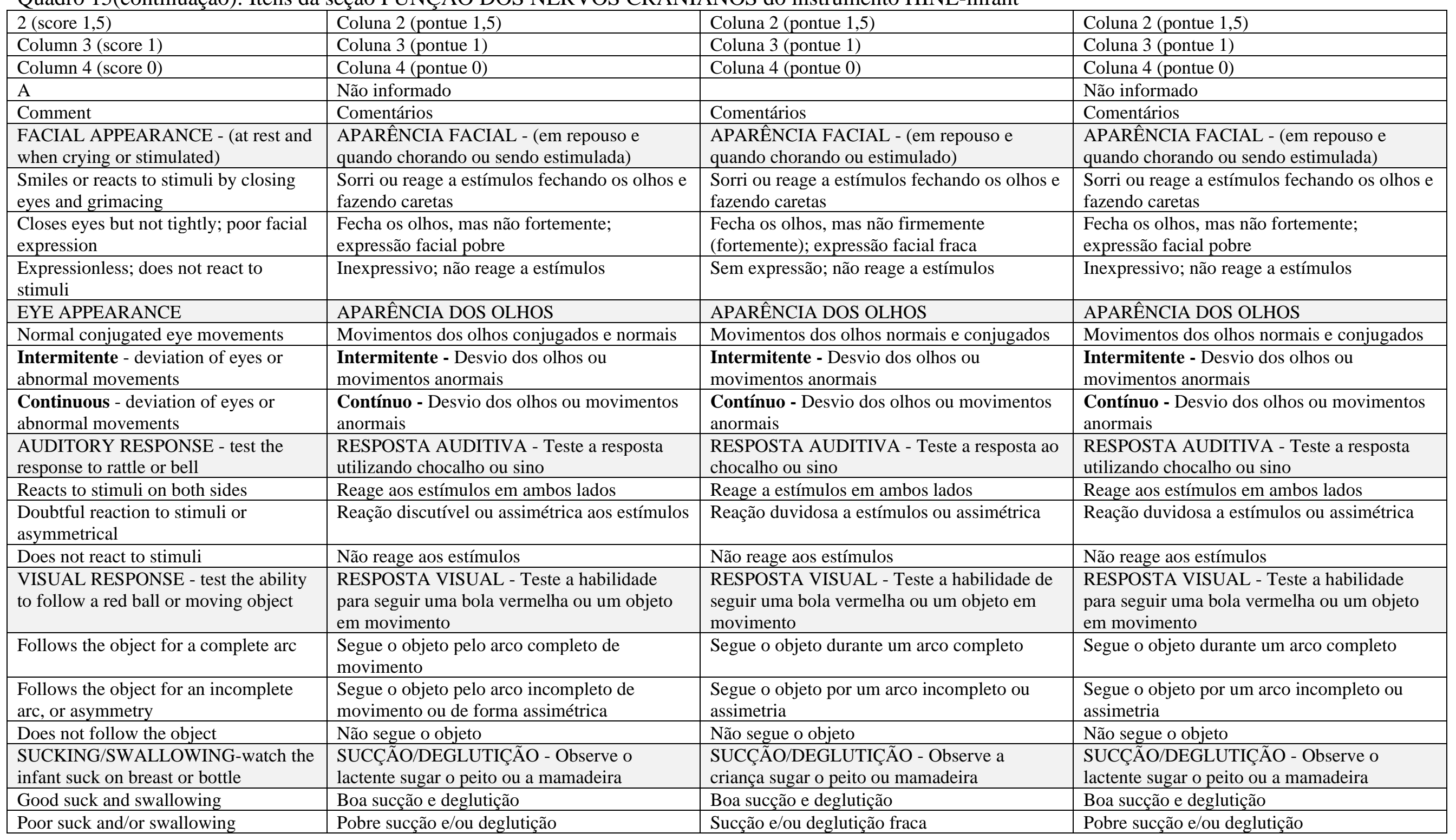


Quadro 15 (continuação): Itens da seção FUNÇÃO DOS NERVOS CRANIANOS do instrumento HINE-infant

\begin{tabular}{|c|c|c|c|}
\hline No suck reflex, no swallowing & Sem reflexo de sucção e deglutição & Sem reflexo de sucção, sem deglutição & Sem reflexo de sucção, sem deglutição \\
\hline HEAD - in sitting & CABEÇA - Lactente sentado & CABEÇA - (sentado) & CABEÇA - (sentado) \\
\hline Straight, in midline & Alinhada na linha média & Reta; na linha média & Alinhada na linha média \\
\hline Slightly to side or backward or forward & $\begin{array}{l}\text { Ligeiramente para o lado ou para trás ou para } \\
\text { a frente }\end{array}$ & $\begin{array}{l}\text { Levemente para o lado, para trás ou para } \\
\text { frente }\end{array}$ & $\begin{array}{l}\text { Levemente para o lado ou para trás ou para a } \\
\text { frente }\end{array}$ \\
\hline $\begin{array}{l}\text { Markedly to side or backward or } \\
\text { forward }\end{array}$ & $\begin{array}{l}\text { Acentuadamente para o lado ou para trás ou } \\
\text { para a frente }\end{array}$ & $\begin{array}{l}\text { Notavelmente para o lado, para trás ou para } \\
\text { frente }\end{array}$ & $\begin{array}{l}\text { Acentuadamente para o lado ou para trás ou } \\
\text { para a frente }\end{array}$ \\
\hline TRUNK - in sitting & TRONCO - (sentado) & TRONCO - (sentado) & TRONCO - (sentado) \\
\hline Straight & Alinhado & Reto & Alinhado \\
\hline Slightly curved or bent to side & Ligeiramente curvado ou inclinado para o lado & Levemente curvado ou dobrado para o lado & Levemente curvado ou inclinado para o lado \\
\hline $\begin{array}{l}\text { Very rounded/ rocking back/ bent } \\
\text { sideways }\end{array}$ & $\begin{array}{l}\text { Muito curvado / balançando para trás/ } \\
\text { inclinado lateralmente }\end{array}$ & $\begin{array}{l}\text { Muito curvado/ balançando para trás/ dobrado } \\
\text { para o lado }\end{array}$ & $\begin{array}{l}\text { Muito curvado / balançando para trás/ } \\
\text { inclinado lateralmente }\end{array}$ \\
\hline ARMS - at rest & BRAÇOS - em repouso & BRAÇOS - (em repouso) & BRAÇOS - em repouso \\
\hline $\begin{array}{l}\text { In neutral position: central, straight or } \\
\text { slightly bent }\end{array}$ & $\begin{array}{l}\text { Em posição neutra: centralizados, alinhados } \\
\text { ou levemente flexionados }\end{array}$ & $\begin{array}{l}\text { Em posição neutra: central, retos ou levemente } \\
\text { dobrados }\end{array}$ & $\begin{array}{l}\text { Em posição neutra: centralizados, alinhados } \\
\text { ou levemente flexionados }\end{array}$ \\
\hline $\begin{array}{l}\text { Slight } \\
\text { internal rotation or external rotation }\end{array}$ & $\begin{array}{l}\text { Leve } \\
\text { Rotação interna ou externa }\end{array}$ & $\begin{array}{l}\text { Leve } \\
\text { Rotação interna ou externa }\end{array}$ & $\begin{array}{l}\text { Leve } \\
\text { Rotação interna ou externa }\end{array}$ \\
\hline $\begin{array}{l}\text { Marked - internal rotation or external } \\
\text { rotation or dystonic posture, } \\
\text { hemiplegic posture }\end{array}$ & $\begin{array}{l}\text { Acentuada - Rotação interna ou externa ou } \\
\text { postura distônica e hemiplégica }\end{array}$ & $\begin{array}{l}\text { Acentuada - Rotação interna ou externa ou } \\
\text { postura distônica, postura hemiplégica }\end{array}$ & $\begin{array}{l}\text { Acentuada - Rotação interna ou externa ou } \\
\text { postura distônica, postura hemiplégica }\end{array}$ \\
\hline HANDS & MÃOS & MÃOS & MÃOS \\
\hline Hands open & Mãos abertas & Mãos abertas & Mãos abertas \\
\hline $\begin{array}{l}\text { Intermittent } \\
\text { adducted thumb or fisting }\end{array}$ & $\begin{array}{l}\text { Intermitente } \\
\text { Polegar ou punhos em adução }\end{array}$ & $\begin{array}{l}\text { Intermitente } \\
\text { Polegar em adução ou punhos fechados }\end{array}$ & $\begin{array}{l}\text { Intermitente } \\
\text { Polegar em adução ou punhos fechados }\end{array}$ \\
\hline $\begin{array}{l}\text { Persistent } \\
\text { adducted thumb or fisting }\end{array}$ & $\begin{array}{l}\text { Persistente } \\
\text { Polegar ou punhos em adução }\end{array}$ & $\begin{array}{l}\text { Persistente } \\
\text { Polegar em adução ou punhos fechados }\end{array}$ & $\begin{array}{l}\text { Persistente } \\
\text { Polegar em adução ou punhos fechados }\end{array}$ \\
\hline $\begin{array}{l}\text { LEGS - in sitting/ in supine and in } \\
\text { standing }\end{array}$ & PERNAS - Sentado/ Em supino/ Em pé & PERNAS - (sentado)/ (em supino e em pé) & PERNAS - (sentado)/ (em supino e em pé) \\
\hline $\begin{array}{l}\text { Able to sit with straight back, and legs } \\
\text { straight or slightly bent (long sitting) } \\
\text { legs in neutral position: straight or } \\
\text { slightly bent }\end{array}$ & $\begin{array}{l}\text { Capaz de sentar com a coluna alinhada e as } \\
\text { pernas estendidas ou ligeiramente flexionadas } \\
\text { (sentado com as pernas estendidas) } \\
\text { Pernas em posição neutra: alinhadas ou } \\
\text { ligeiramente flexionadas }\end{array}$ & $\begin{array}{l}\text { Capaz de sentar com costas retas e pernas } \\
\text { retas ou levemente curvadas (sentar longo) } \\
\text { Pernas em posição neutra: retas ou levemente } \\
\text { dobradas }\end{array}$ & $\begin{array}{l}\text { Capaz de sentar com a coluna alinhada e as } \\
\text { pernas estendidas ou ligeiramente flexionadas } \\
\text { (sentado com as pernas estendidas) } \\
\text { Pernas em posição neutra: alinhadas ou } \\
\text { ligeiramente flexionadas }\end{array}$ \\
\hline $\begin{array}{l}\text { Slight } \\
\text { internal rotation or external rotation }\end{array}$ & $\begin{array}{l}\text { Leve } \\
\text { Rotação interna ou externa }\end{array}$ & $\begin{array}{l}\text { Leve } \\
\text { Rotação interna ou externa }\end{array}$ & $\begin{array}{l}\text { Leve } \\
\text { Rotação interna ou externa }\end{array}$ \\
\hline
\end{tabular}


Quadro 15 (continuação): Itens da seção FUNÇÃO DOS NERVOS CRANIANOS do instrumento HINE-infant Sit with straight back but knees bent at $15-20 \%$ internal rotation or external rotation at hips

Unable to sit straight unless knees markedly bent (no long sitting)

\section{marked}

internal rotation or external rotation or

fixed extension or flexion or

contractures at hips and knees

FEET - in supine and in standing Central; in neutral position/

toes straight midway between flexion and extension

Slight - internal rotation or external rotation

intermittent - tendency to stand on tiptoes; or toes up or curling under

Marked - internal rotation or external

rotation at the ankle

persistent - tendency to stand on

tiptoes or toes up or curling under

Senta com a coluna alinhada, porém os

joelhos flexionam em 15-20\% Rotação interna ou externa do quadril

Incapaz de sentar com a coluna alinhada, a

não ser que os joelhos estejam

acentuadamente flexionados (não senta com as

pernas estendidas)

Acentuada

Rotação interna ou externa ou extensão ou

flexão fixada ou contraturas de quadril e

joelhos

PÉS - Em supino e em pé

Centralizados; em posição neutra/

Dedos alinhados entre flexão e extensão

Leve - Rotação interna ou externa

Intermitente - Tendência para ficar em pé nas

pontas dos dedos; ou dedos para cima ou

curvados para baixo

Acentuada - Rotação interna ou externa do

tornozelo

Persistente - Tendência de ficar em pé nas

pontas dos dedos; ou dedos para cima ou

curvados para baixo
Senta com as costas retas, porém joelhos

dobram em $15-20^{\circ}$ / Rotação interna ou externa

no quadril

Não é capaz de sentar reto a menos com os

joelhos acentuadamente dobrados (sentar

curto)

\section{Acentuada}

Rotação interna ou externa ou extensão ou

flexão fixa ou contraturas no quadril e joelhos

PÉS - Em supino ou em pé

Central; em posição neutra/

Dedos dos pés retos entre flexão e extensão

\section{Leve - Rotação interna ou externa}

Intermitente - Tendência de ficar em pé nas pontas dos dedos; ou dedos para cima ou

curvados para baixo

Acentuada - Rotação interna ou externa

Persistente - Tendência de ficar em pé nas

pontas dos dedos; ou dedos para cima ou

curvados para baixo
Senta com a coluna alinhada, porém os joelhos flexionam em 15-20\% Rotação interna ou externa do quadril

Incapaz de sentar com a coluna alinhada, a não ser que os joelhos estejam

acentuadamente flexionados (não senta com as pernas estendidas)

Acentuada

Rotação interna ou externa ou extensão ou flexão fixa ou contraturas no quadril e joelhos

\section{PÉS - Em supino ou em pé}

Centralizados; em posição neutra/

Dedos dos pés alinhados entre flexão e extensão

Leve - Rotação interna ou externa

Intermitente - Tendência de ficar em pé nas pontas dos dedos; ou dedos para cima ou

curvados para baixo

Acentuada - Rotação interna ou externa do tornozelo

Persistente - Tendência de ficar em pé nas pontas dos dedos; ou dedos para cima ou curvados para baixo

Quadro 16: Itens da seção MOVIMENTOS do instrumento HINE-infant

\begin{tabular}{|c|c|c|c|}
\hline \multicolumn{4}{|c|}{ HINE (infant) } \\
\hline Item Original & T1 & T2 & VSP \\
\hline MOVEMENTS & MOVIMENTOS & MOVIMENTOS & MOVIMENTOS \\
\hline $\begin{array}{l}\text { Quantity - watch infant lying in the } \\
\text { supine }\end{array}$ & $\begin{array}{l}\text { Quantidade - Observe a criança deitada em } \\
\text { supino }\end{array}$ & $\begin{array}{l}\text { Quantidade - Observe a criança deitada em } \\
\text { supino }\end{array}$ & $\begin{array}{l}\text { Quantidade - Observe a criança deitada em } \\
\text { supino }\end{array}$ \\
\hline Normal & Normal & Normal & Normal \\
\hline Excessive or sluggish & Excessiva ou lenta & Excessivo ou lento & Excessivo ou lento \\
\hline Minimal or none & Mínimo ou nenhum & Mínimo ou nenhum & Mínimo ou nenhum \\
\hline Quality & Qualidade & Qualidade & Qualidade \\
\hline
\end{tabular}


Quadro 16 (continuação): Itens da seção MOVIMENTOS do instrumento HINE-infant

\begin{tabular}{|c|c|c|c|}
\hline Free, alternating, smooth & Livres, alternados, suaves & Livres, alternados, suaves & Livres, alternados, suaves \\
\hline Jerky, slight tremor & Bruscos, tremores leves & Bruscos, tremores leves & Bruscos, tremores leves \\
\hline $\begin{array}{l}\text { - Cramped \& synchronous } \\
\text { - Extensor spasms } \\
\text { - Athetoid } \\
\text { - Ataxic } \\
\text { - } \text { Mery tremulous } \\
\text { - Dystonic spasm }\end{array}$ & $\begin{array}{l}\text { - Espasmos sincronizados } \\
\text { - Espasmos extensores } \\
\text { - Atetóide } \\
\text { - Atáxico } \\
\text { - Muito tremor } \\
\text { - Espasmos mioclônicos } \\
\text { - Distônico }\end{array}$ & $\begin{array}{l}\text { - } \text { espásmico e sincronizados } \\
\text { - espasmos extensores } \\
\text { - } \text { atetóide } \\
\text { - } \text { atáxico } \\
\text { - } \text { muito trêmulo } \\
\text { - espasmo mioclônico } \\
\text { - distônico }\end{array}$ & $\begin{array}{l}\text { - Espasmos sincronizados } \\
\text { - Espasmos extensores } \\
\text { - Atetóide } \\
\text { - Atáxico } \\
\text { - Muito tremor } \\
\text { - Espasmos mioclônicos } \\
\text { - Distônico }\end{array}$ \\
\hline
\end{tabular}

Quadro 17: Itens da seção TÔNUS do instrumento HINE-infant

\begin{tabular}{|c|c|c|c|}
\hline \multicolumn{4}{|c|}{ HINE (infant) } \\
\hline Item Original & T1 & $\mathbf{T 2}$ & VSP \\
\hline TONE & TÔNUS & TÔNUS & TÔNUS \\
\hline $\begin{array}{l}\text { SCARF SIGN - Take the infant's hand } \\
\text { and pull the arm across the chest until } \\
\text { there is resistance. Note the position of } \\
\text { the elbow. }\end{array}$ & $\begin{array}{l}\text { SINAL DE CACHECOL - Pegue a mão do } \\
\text { lactente e puxe o braço sobre o peito até que } \\
\text { haja resistência. Observe a posição do } \\
\text { cotovelo. }\end{array}$ & $\begin{array}{l}\text { SINAL DE CACHECOL - Tome a mão da } \\
\text { criança e puxe através do peito até que haja } \\
\text { resistência. Note a posição do cotovelo }\end{array}$ & $\begin{array}{l}\text { SINAL DE CACHECOL - Pegue a mão do } \\
\text { lactente e puxe o braço sobre o peito até que } \\
\text { haja resistência. Observe a posição do } \\
\text { cotovelo. }\end{array}$ \\
\hline Range & Amplitude & Alcance & Amplitude \\
\hline PASSIVE SHOULDER ELEVATION & ELEVAÇÃO PASSIVA DO OMBRO & ELEVAÇÃO PASSIVA DO OMBRO & ELEVAÇÃO PASSIVA DO OMBRO \\
\hline Resistance, but overcome & Resistência, porém, é superada & Resistência, porém, vencida & Resistência, porém, vencida \\
\hline No resistance & Sem resistência & Sem resistência & Sem resistência \\
\hline Resistance, not overcome & Resistência não superada & Resistência, não vencida/superada & Resistência, não vencida \\
\hline $\begin{array}{l}\text { PRONATION/SUPINATION - Steady } \\
\text { upper arm while pronating and } \\
\text { supinating forearm. Note resistance. }\end{array}$ & $\begin{array}{l}\text { PRONAÇÃO/SUPINAÇÃO - Estabilize a } \\
\text { região superior do braço, enquanto realiza a } \\
\text { pronação e supinação do antebraço. Observe a } \\
\text { resistência. }\end{array}$ & $\begin{array}{l}\text { PRONAÇÃO/SUPINAÇÃO - Estabilize o } \\
\text { braço enquanto prona e supina o antebraço. } \\
\text { Observe a resistência }\end{array}$ & $\begin{array}{l}\text { PRONAÇÃO/SUPINAÇÃO - Estabilize a } \\
\text { região superior do braço, enquanto realiza a } \\
\text { pronação e supinação do antebraço. Observe a } \\
\text { resistência. }\end{array}$ \\
\hline $\begin{array}{l}\text { Full pronation and supination, no } \\
\text { resistance }\end{array}$ & $\begin{array}{l}\text { Pronação e supinação completas, sem } \\
\text { resistência }\end{array}$ & $\begin{array}{l}\text { Pronação e supinação completas, sem } \\
\text { resistência }\end{array}$ & $\begin{array}{l}\text { Pronação e supinação completas, sem } \\
\text { resistência }\end{array}$ \\
\hline $\begin{array}{l}\text { Full pronation and supination but } \\
\text { resistance to be overcome }\end{array}$ & $\begin{array}{l}\text { Pronação e supinação completas, porém a } \\
\text { resistência pode ser superada }\end{array}$ & $\begin{array}{l}\text { Pronação e supinação completas, porém com } \\
\text { resistência a ser vencida }\end{array}$ & $\begin{array}{l}\text { Pronação e supinação completas, porém a } \\
\text { resistência pode ser vencida }\end{array}$ \\
\hline $\begin{array}{l}\text { Full pronation and supination not } \\
\text { possible, marked resistance }\end{array}$ & $\begin{array}{l}\text { Não é possível realizar a pronação e supinação } \\
\text { completa, pois a resistência é acentuada }\end{array}$ & $\begin{array}{l}\text { Não é possível pronação e supinação } \\
\text { completas, resistência acentuada }\end{array}$ & $\begin{array}{l}\text { Não é possível pronação e supinação } \\
\text { completas, resistência acentuada }\end{array}$ \\
\hline
\end{tabular}


Quadro 17 (continuação): Itens da seção TÔNUS do instrumento HINE-infant

ADDUCTORS - With the infant's legs The angle formed by the legs is noted. Range

POPLITEAL ANGLE - Legs are

flexed at the hip simultaneously on to the side of the abdomen, then extended at the knee until there is resistance.

Note angle between lower and upper leg.

ANKLE DORSIFLEXION - With knee extended, dorsiflex ankle. Note the angle between foot and leg.

\section{PULLED TO SIT - Pull infant to sit by} wrists

VENTRAL SUSPENSION - Hold

infant in ventral suspension; note

position of back, limbs, and head.

ADUTORES - Com as pernas do lactente

estendida, abduza na medida do possível.

Observe o ângulo formado pelas pernas Amplitude

ÂNGULO POPLÍTEO - Flexione

simultaneamente as pernas ao lado do

abdômen (abdução de quadril), então estenda

os joelhos até que haja resistência. Observe o

ângulo entre a coxa e a parte inferior da perna

DORSIFLEXÃO DO TORNOZELO - Com o joelho estendido, realize a dorsiflexão do

tornozelo. Observe o ângulo entre o pé e a perna

PUXADO PARA SENTAR - Segurando nos

punhos, puxe o lactente para sentar

SUSPENSÃO VENTRAL - Sustente o

lactente em suspensão ventral; observe a

posição da coluna, membros e cabeça.
ADUTORES - Com as pernas da criança estendidas, abra-as o máximo possível.

Observe o ângulo formado pelas pernas range $=$ intervalo

ANGULO POPLÍTEO - Pernas são

flexionadas no quadril simultaneamente ao lado do abdômen, então estendidas no joelho até que haja resistência. Observar o ângulo entre a coxa e a parte de baixo da perna

DORSIFLEX̃̃O DO TORNOZELO - Com 0 joelho estendido, dorsiflexe o tornozelo. Note o ângulo entre o pé e a perna

\section{PUXADO PARA SENTAR - Puxe a criança}

para sentar através dos pulsos

SUSPENSÃO VENTRAL - Segure a criança em suspensão ventral; observe a posição das

costas, membros e cabeça.
ADUTORES - Com as pernas do lactente estendida, abduza na medida do possível. Observe o ângulo formado pelas pernas Amplitude

ÂNGULO POPLÍTEO - Flexione

simultaneamente as pernas ao lado do abdômen (abdução de quadril), então estenda os joelhos até que haja resistência. Observe o ângulo entre a coxa e a parte inferior da perna

DORSIFLEX̃̃O DO TORNOZELO - Com o joelho estendido, realize a dorsiflexão do tornozelo. Observe o ângulo entre o pé e a perna

PUXADO PARA SENTAR - Segurando nos punhos, puxe o lactente para sentar SUSPENSÃO VENTRAL - Sustente o lactente em suspensão ventral; observe a posição da coluna, membros e cabeça.

Quadro 18: Itens da seção REFLEXOS E REAÇÕES do instrumento HINE-infant

\begin{tabular}{|c|c|c|c|}
\hline \multicolumn{4}{|c|}{ HINE (infant) } \\
\hline Item Original & T1 & $\mathbf{T 2}$ & VSP \\
\hline REFLEXES AND REACTIONS & REFLEXOS E REAÇÕES & REFLEXOS E REAÇÕES & REFLEXOS E REAÇÕES \\
\hline TENDON REFLEXES & REFLEXOS TENDÍNEOS & REFLEXOS DE TENDÕES & REFLEXOS TENDÍNEOS \\
\hline $\begin{array}{l}\text { Easily elicitable } \\
\text { biceps, knee, ankle }\end{array}$ & $\begin{array}{l}\text { Facilmente elicitável } \\
\text { Bíceps, joelho, tornozelo }\end{array}$ & $\begin{array}{l}\text { Facilmente elicitável } \\
\text { Bíceps, joelho, tornozelo }\end{array}$ & $\begin{array}{l}\text { Facilmente elicitável } \\
\text { Bíceps, joelho, tornozelo }\end{array}$ \\
\hline $\begin{array}{l}\text { Mildly brisk } \\
\text { biceps, knee, ankle }\end{array}$ & $\begin{array}{l}\text { Moderadamente rápido } \\
\text { bíceps, joelho, tornozelo }\end{array}$ & $\begin{array}{l}\text { Suavemente ativo } \\
\text { bíceps, joelho, tornozelo }\end{array}$ & $\begin{array}{l}\text { Moderadamente rápido } \\
\text { bíceps, joelho, tornozelo }\end{array}$ \\
\hline $\begin{array}{l}\text { Brisk } \\
\text { biceps, knee, ankle }\end{array}$ & $\begin{array}{l}\text { Rápido/Vigoroso } \\
\text { Bíceps, joelho, tornozelo }\end{array}$ & $\begin{array}{l}\text { Ativo } \\
\text { Bíceps, joelho, tornozelo }\end{array}$ & $\begin{array}{l}\text { Rápido } \\
\text { Bíceps, joelho, tornozelo }\end{array}$ \\
\hline $\begin{array}{l}\text { Clonus or absent } \\
\text { biceps, knee, ankle }\end{array}$ & $\begin{array}{l}\text { Clônus ou ausente } \\
\text { Bíceps, joelho, tornozelo }\end{array}$ & $\begin{array}{l}\text { Espasmo clônico ou ausente } \\
\text { Bíceps, joelho, tornozelo }\end{array}$ & $\begin{array}{l}\text { Clônus ou ausente } \\
\text { Bíceps, joelho, tornozelo }\end{array}$ \\
\hline
\end{tabular}


Quadro 18 (continuação): Itens da seção REFLEXOS E REAÇÕES do instrumento HINE-infant

\begin{tabular}{|c|c|c|c|}
\hline $\begin{array}{l}\text { ARM PROTECTION - Pull the infant } \\
\text { by one arm from the supine position } \\
\text { and note the reaction of the opposite } \\
\text { side }\end{array}$ & $\begin{array}{l}\text { PROTEÇÃO DO BRAÇO/REAÇÃO DE } \\
\text { PROTEÇÃO - Lactente em posição supina, } \\
\text { puxe-o por um braço e observe a reação do } \\
\text { lado oposto }\end{array}$ & $\begin{array}{l}\text { PROTEÇÃO DO BRAÇO - Puxe a criança } \\
\text { por um braço a partir da posição supina e } \\
\text { observe a reação do lado oposto }\end{array}$ & $\begin{array}{l}\text { REAÇÃO DE PROTEÇÃO - Lactente em } \\
\text { posição supina, puxe-o por um braço e } \\
\text { observe a reação do lado oposto }\end{array}$ \\
\hline Arm \& hand extend & Braço e mão estendido & Braço e mão estendidos & Braço e mão estendidos \\
\hline Arm semi-flexed & Braço semi-flexionado & Braço semi-flexionado & Braço semi-flexionado \\
\hline Arm fully flexed & Braço completamente flexionado & Braço completamente flexionado & Braço completamente flexionado \\
\hline $\begin{array}{l}\text { VERTICAL SUSPENSION - Hold } \\
\text { infant under axilla. Make sure legs do } \\
\text { not touch any surface. }\end{array}$ & $\begin{array}{l}\text { SUSPENSÃ̃O VERTICAL - Segure o lactente } \\
\text { por baixo das axilas. Certifique-se que as } \\
\text { pernas não toquem em qualquer superfície. }\end{array}$ & $\begin{array}{l}\text { SUSPENSÃ̃ VERTICAL - Segure a criança } \\
\text { pelas axilas. Tenha certeza que as pernas não } \\
\text { tocam nenhuma superfície. }\end{array}$ & $\begin{array}{l}\text { SUSPENSÃ̃ VERTICAL - Segure o lactente } \\
\text { por baixo das axilas. Certifique-se que as } \\
\text { pernas não toquem em qualquer superfície. }\end{array}$ \\
\hline Kicks symmetrically & Chuta simetricamente & Chuta simetricamente & Chuta simetricamente \\
\hline Kicks one leg more, or poor kicking & $\begin{array}{l}\text { Chuta mais com uma das pernas, ou chute } \\
\text { fraco }\end{array}$ & Chuta mais com uma perna ou chute fraco & $\begin{array}{l}\text { Chuta mais com uma das pernas, ou chute } \\
\text { fraco }\end{array}$ \\
\hline $\begin{array}{l}\text { No kicking even if stimulated, or } \\
\text { scissoring }\end{array}$ & $\begin{array}{l}\text { Sem chutes mesmo se estimulado, ou posição } \\
\text { de tesoura }\end{array}$ & $\begin{array}{l}\text { Sem chutes mesmo se estimulado, ou posição } \\
\text { de tesoura }\end{array}$ & $\begin{array}{l}\text { Sem chutes mesmo se estimulado, ou posição } \\
\text { de tesoura }\end{array}$ \\
\hline $\begin{array}{l}\text { LATERAL TILTING (describe side } \\
\text { up) - Infant held vertically, tilt quickly } \\
\text { to horizontal. Note spine, limbs, and } \\
\text { head }\end{array}$ & $\begin{array}{l}\text { INCLINAÇÃO LATERAL (descreva o lado } \\
\text { voltado para cima) - Lactente mantido na } \\
\text { posição vertical, incline rapidamente para a } \\
\text { horizontal. Observe a coluna, membros e } \\
\text { cabeça. }\end{array}$ & $\begin{array}{l}\text { INCLINAÇÃO LATERAL (descreva o lado } \\
\text { para cima) - Criança mantida na vertical, } \\
\text { incline rapidamente para a horizontal. Observe } \\
\text { a espinha, membros e cabeça. }\end{array}$ & $\begin{array}{l}\text { INCLINAÇÃO LATERAL (descreva o lado } \\
\text { voltado para cima) - Lactente mantido na } \\
\text { posição vertical, incline rapidamente para a } \\
\text { horizontal. Observe a coluna, membros e } \\
\text { cabeça. }\end{array}$ \\
\hline $\begin{array}{l}\text { FORWARD PARACHUTE - Infant } \\
\text { held vertically and suddenly tilted } \\
\text { forward. Note reaction of the arms. }\end{array}$ & $\begin{array}{l}\text { PARAQUEDAS PARA FRENTE - Lactente } \\
\text { mantido na posição vertical e subitamente } \\
\text { inclinado para frente. Observe a reação dos } \\
\text { braços. }\end{array}$ & $\begin{array}{l}\text { PARAQUEDAS PARA FRENTE - Criança } \\
\text { mantida verticalmente e subitamente inclinada } \\
\text { para frente. Observe a reação dos braços. }\end{array}$ & $\begin{array}{l}\text { PARAQUEDAS PARA FRENTE - Lactente } \\
\text { mantido na posição vertical e subitamente } \\
\text { inclinado para frente. Observe a reação dos } \\
\text { braços. }\end{array}$ \\
\hline (after 6 months) & (após 6 meses) & (após 6 meses) & (após 6 meses) \\
\hline
\end{tabular}

Quadro 19: Itens da seção 2, MARCOS MOTORES do instrumento HINE infant

\begin{tabular}{|c|c|c|c|}
\hline \multicolumn{4}{|c|}{ HINE infant } \\
\hline Item Original & T1 & T2 & VSP \\
\hline $\begin{array}{l}\text { SECTION 2: MOTOR } \\
\text { MILESTONES }\end{array}$ & SECÇÃO 2: MARCOS MOTORES & SECÇÃO 2: MARCAS MOTORAS & SECÇÃO 2: MARCOS MOTORES \\
\hline HEAD CONTROL & CONTROLE DA CABEÇA & CONTROLE DA CABEÇA & CONTROLE DA CABEÇA \\
\hline $\begin{array}{l}\text { Unable to maintain head upright } \\
\text { (normal }<3 \mathrm{mo} \text { ) }\end{array}$ & $\begin{array}{l}\text { Incapaz de manter a cabeça erguida (normal < } \\
3 \text { meses) }\end{array}$ & $\begin{array}{l}\text { Incapaz de manter a cabeça erguida (normal < } \\
3 \text { meses de idade) }\end{array}$ & $\begin{array}{l}\text { Incapaz de manter a cabeça erguida (normal < } \\
3 \text { meses) }\end{array}$ \\
\hline Wobbles (normal at $4 \mathrm{mo}$ ) & Oscila (normal aos 4 meses) & Oscila (normal aos 4 meses) & Oscila (normal aos 4 meses) \\
\hline
\end{tabular}


Quadro 19 (continuação): Itens da seção 2, MARCOS MOTORES do instrumento HINE infant

\begin{tabular}{|c|c|c|c|}
\hline $\begin{array}{l}\text { All the time maintained upright } \\
\text { (normal at } 5 \mathrm{mo} \text { ) }\end{array}$ & $\begin{array}{l}\text { Todo tempo mantem erguida (normal aos } 5 \\
\text { meses) }\end{array}$ & $\begin{array}{l}\text { Todo tempo mantem erguida (normal aos } 5 \\
\text { meses) }\end{array}$ & $\begin{array}{l}\text { Todo tempo mantem erguida (normal aos } 5 \\
\text { meses) }\end{array}$ \\
\hline SITTING & SENTAR & SENTAR & SENTAR \\
\hline Cannot sit & Não consegue sentar & Não consegue sentar & Não consegue sentar \\
\hline $\begin{array}{l}\text { Sits with support at hips (normal at } 4 \\
\text { mo) }\end{array}$ & $\begin{array}{l}\text { Senta com suporte no quadril } \\
\text { (normal aos } 4 \text { meses) }\end{array}$ & $\begin{array}{l}\text { Senta com suporte no quadril } \\
\text { (normal aos } 4 \text { meses) }\end{array}$ & $\begin{array}{l}\text { Senta com suporte no quadril } \\
\text { (normal aos } 4 \text { meses) }\end{array}$ \\
\hline Props (normal at $6 \mathrm{mo}$ ) & $\begin{array}{l}\text { Senta com apoio } \\
\text { (normal aos } 6 \text { meses) }\end{array}$ & $\begin{array}{l}\text { Sustem / mantem } \\
\text { (normal aos } 6 \text { meses) }\end{array}$ & $\begin{array}{l}\text { Senta com apoio } \\
\text { (normal aos } 6 \text { meses) }\end{array}$ \\
\hline Stable sit (normal at 7-8 mo) & $\begin{array}{l}\text { Sentar com estabilidade } \\
\text { (normal aos 7-8 meses) }\end{array}$ & $\begin{array}{l}\text { sentar estável } \\
\text { (normal aos 7-8 meses) }\end{array}$ & $\begin{array}{l}\text { Sentar com estabilidade } \\
\text { (normal aos 7-8 meses) }\end{array}$ \\
\hline Pivot (rotates) (normal at $9 \mathrm{mo}$ ) & $\begin{array}{l}\text { Pivot (rotaciona) } \\
\text { (normal aos } 9 \text { meses) }\end{array}$ & $\begin{array}{l}\text { (rotaciona) } \\
\text { (normal aos } 9 \text { meses) }\end{array}$ & $\begin{array}{l}\text { Pivot (rotaciona) } \\
\text { (normal aos } 9 \text { meses) }\end{array}$ \\
\hline Observed / reported (age) & & Observado / Reportado (idade): & Observado / Reportado (idade): \\
\hline VOLUNTARY GRASP & GARRA VOLUNTÁRIA & PEGADA VOLUNTÁRIA & GARRA VOLUNTÁRIA \\
\hline No grasp & Sem preensão & Sem pegada & Sem preensão \\
\hline Uses whole hand & Utiliza a mão inteira & Usa a mão inteira & Utiliza a mão inteira \\
\hline $\begin{array}{l}\text { Index finger and thumb but immature } \\
\text { grasp }\end{array}$ & $\begin{array}{l}\text { Com dedo indicador e polegar, porém, garra } \\
\text { imatura }\end{array}$ & $\begin{array}{l}\text { Usa o dedo indicador e polegar porém a } \\
\text { pegada é imatura }\end{array}$ & $\begin{array}{l}\text { Com dedo indicador e polegar, porém, garra } \\
\text { imatura }\end{array}$ \\
\hline Pincer grasp & Preensão em pinça & Pegada de pinça & Preensão em pinça \\
\hline ABILITY TO KICK (in supine) & HABILIDADE DE CHUTAR (em supino) & HABILIDADE DE CHUTAR (em supino) & HABILIDADE DE CHUTAR (em supino) \\
\hline No kicking & Sem chute & Sem chute & Sem chute \\
\hline Kicks horizontally legs do not lift & $\begin{array}{l}\text { Chuta horizontalmente, mas as pernas não } \\
\text { levantam }\end{array}$ & Chuta horizontalmente, pernas não levantam & Chuta horizontalmente, pernas não levantam \\
\hline Upward (vertically) (normal at $3 \mathrm{mo}$ ) & $\begin{array}{l}\text { Para cima (verticalmente) } \\
\text { (normal aos } 3 \text { meses) }\end{array}$ & $\begin{array}{l}\text { Para cima (verticalmente) } \\
\text { (normal aos } 3 \text { meses) }\end{array}$ & $\begin{array}{l}\text { Para cima (verticalmente) } \\
\text { (normal aos } 3 \text { meses) }\end{array}$ \\
\hline Touches leg (normal at 4-5 mo) & $\begin{array}{l}\text { Toca a perna } \\
\text { (normal aos } 4-5 \text { meses) }\end{array}$ & $\begin{array}{l}\text { Toca a perna } \\
\text { (normal aos 4-5 meses) }\end{array}$ & $\begin{array}{l}\text { Toca a perna } \\
\text { (normal aos } 4-5 \text { meses) }\end{array}$ \\
\hline Touches toes (normal at 5-6 mo) & $\begin{array}{l}\text { Toca os dedos dos pés } \\
\text { (normal aos 5-6 meses) }\end{array}$ & $\begin{array}{l}\text { Toca dos dedos dos pés } \\
\text { (normal aos 5-6 meses) }\end{array}$ & $\begin{array}{l}\text { Toca dos dedos dos pés } \\
\text { (normal aos 5-6 meses) }\end{array}$ \\
\hline ROLLING & ROLAR & ROLAR & ROLAR \\
\hline No rolling & Sem rolar & Sem rolar & Sem rolar \\
\hline Rolling to side (normal at $4 \mathrm{mo}$ ) & $\begin{array}{l}\text { Rola para o lado } \\
\text { (normal aos } 4 \text { meses) }\end{array}$ & $\begin{array}{l}\text { Rola para o lado } \\
\text { (normal aos } 4 \text { meses) }\end{array}$ & $\begin{array}{l}\text { Rola para o lado } \\
\text { (normal aos } 4 \text { meses) }\end{array}$ \\
\hline Prone to supine (normal at mo) & $\begin{array}{l}\text { Rola de prono para supino } \\
\text { (normal aos meses) }\end{array}$ & $\begin{array}{l}\text { Prono para supino } \\
\text { (normal aos ? meses) }\end{array}$ & $\begin{array}{l}\text { Prono para supino } \\
\text { (normal aos? meses) }\end{array}$ \\
\hline Supine to prone (normal at mo) & $\begin{array}{l}\text { Rola de supino para prono } \\
\text { (normal aos meses) }\end{array}$ & $\begin{array}{l}\text { Supino para prono } \\
\text { (normal aos ? meses) }\end{array}$ & $\begin{array}{l}\text { Supino para prono } \\
\text { (normal aos ? meses) }\end{array}$ \\
\hline
\end{tabular}


Quadro 19 (continuação): Itens da seção 2, MARCOS MOTORES do instrumento HINE infant

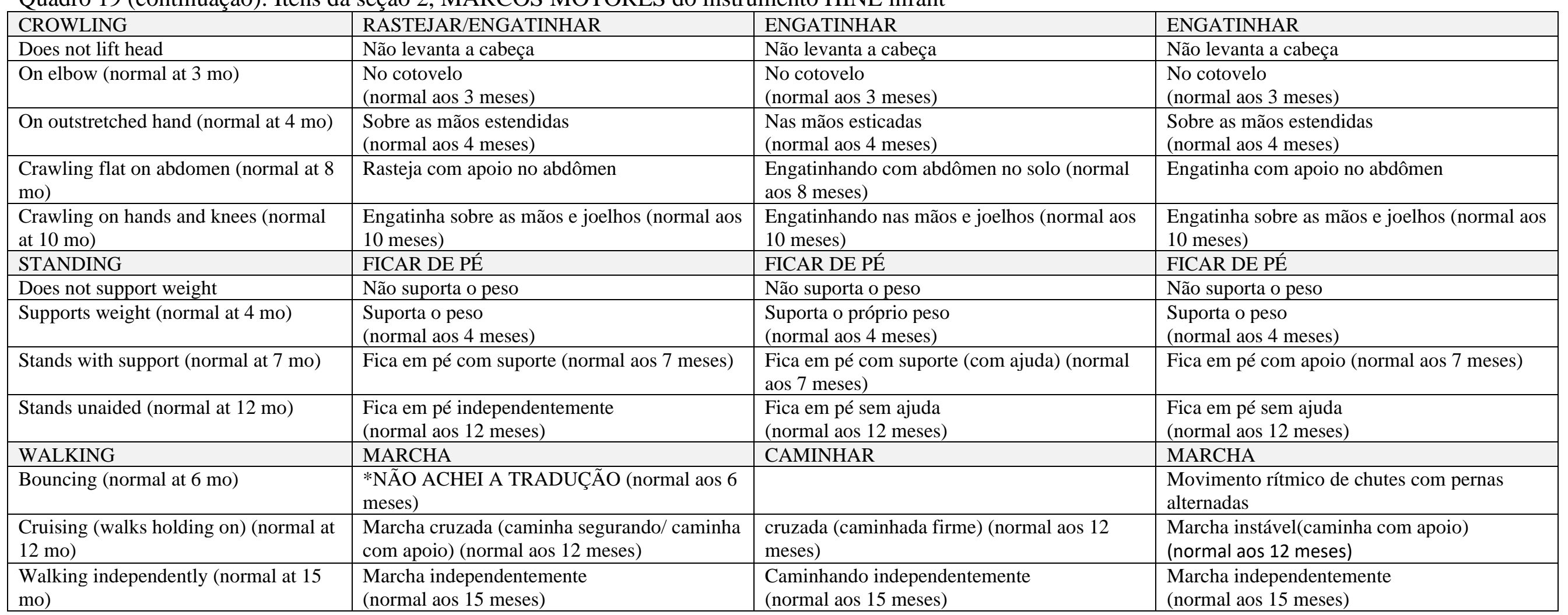

Quadro 20: Itens da seção 3, COMPORTAMENTO do instrumento HINE infant

\begin{tabular}{|c|c|c|c|}
\hline \multicolumn{4}{|c|}{ HINE infant } \\
\hline Item Original & $\begin{array}{c}\mathrm{T} 1 \\
\end{array}$ & T2 & VSP \\
\hline SECTION 3: BEHAVIOUR & SECÇÃO 3: COMPORTAMENTO & SECÇÃO 3: COMPORTAMENTO & SECÇÃO 3: COMPORTAMENTO \\
\hline STATE OF CONSCIOUSNESS & ESTADO DE CONSCIÊNCIA & ESTADO DE CONSCIÊNCIA & ESTADO DE CONSCIÊNCIA \\
\hline Unrousable & Desacordado & Não desperta & Não desperta \\
\hline Drowsy & Sonolento & Sonolento & Sonolento \\
\hline Sleep but wakes easily & Sonolento, porém acorda facilmente & Sonolento, porém desperta facilmente & Sonolento, porém desperta facilmente \\
\hline Awake but no interest & Acordado, porém, não apresenta interesse & Desperto, porém, sem interesse & Desperto, porém, sem interesse \\
\hline Loses interest & Perde interesse & Perde interesse & Perde interesse \\
\hline
\end{tabular}


Quadro 20 (continuação): Itens da seção 3, COMPORTAMENTO do instrumento HINE infant

\begin{tabular}{|l|l|l|l|}
\hline Maintains interest & Mantém interesse & Mantem interesse & Mantem interesse \\
\hline EMOTIONAL STATE & ESTADO EMOCIONAL & ESTADO EMOCIONAL & ESTADO EMOCIONAL \\
\hline Irritable, not consolable & Irritável, não consolável & Irritável, sem consolo (não consolável) & Irritável, sem consolo (não consolável) \\
\hline Irritable, mother can console & Irritável, mãe pode consolar & Irritável, mãe pode consolar & Irritável, mãe pode consolar \\
\hline Irritable when approached & Irritável quando aproximam-se & Irritável quando abordado & Irritável quando manipulado \\
\hline Neither happy or unhappy & Nem feliz, nem triste & Neutro, nem triste ou feliz & Nem feliz, nem triste \\
\hline Happy smiling & Feliz, sorrindo & Feliz, sorrindo & Feliz, sorrindo \\
\hline SOCIAL ORIENTATION & ORIENTAÇÃO SOCIAL & ORIENTAÇÃO SOCIAL & ORIENTAÇÃO SOCIAL \\
\hline Avoiding, withdrawn & Esquiva-se, retraíso & Evitando, recolhido & Esquiva-se, retraído \\
\hline Hesitant & Hesitante & Hesitante & Hesitante \\
\hline Accepts approach & Aceita aproximação & Aceita aproximação & Aceita aproximação \\
\hline Friendly & Amigável & Amigável & Amigável \\
\hline SCORE FOR BEHAVIOUR & PONTUAÇÃO PARA COMPORTAMENTO & PONTUAÇÃO PARA COMPORTAMENTO & PONTUAÇÃO PARA COMPORTAMENTO \\
\hline
\end{tabular}




\subsubsection{Resultados: Estágio 3}

O estágio 3 compreende a análise pelo comitê de especialistas, é o estágio de adaptação cultural, nele os itens que obtiveram alguma discordância, foram analisados de acordo com a validade semântica - foi verificado se as palavras tinham o mesmo significado em ambos os idiomas, se existiam significados múltiplos ou problemas gramaticais; pela validade conceitual - verificado se as palavras ou expressões mantiveram o significado conceitual entre ambas as culturas; pela validade idiomática - verificado se houve necessidade de formular expressão equivalente para facilitar entendimento mas que mantivesse o conteúdo; e por último pela validade experiencial - verificado se houve necessidade de substituição de uma atividade do país de origem por outra comum na nova cultura. Nesta etapa, se cumpriu a validade de face ao verificar a clareza dos itens.

A seguir, estão apresentados os resultados das análises realizadas no processo de adaptação cultural em cada um dos instrumentos.

\subsubsection{Resultados estágios 3: HNNE resumido}

Neste instrumento são avaliados 25 aspectos, porém cada aspecto avaliado pode apresentar 5 respostas diferentes à escolha do avaliador, e há espaços para se notar comentários e observações, além de um espaço para caracterizar o avaliado. No total, foram 157 itens traduzidos e adaptados para a cultura brasileira.

$\mathrm{Na}$ avaliação de equivalências do HNNE resumido, 9 especialistas participaram deste processo e houve concordância acima de $80 \%$ entre a versão original e a versão síntese em 141 itens. Treze itens obtiveram $77,7 \%$ de concordância, 1 item obteve $66,6 \%$, e 2 itens abaixo de $50 \%$.

No quadro 21 estão apresentados os itens que obtiveram menos de $80 \%$ de concordância e sofreram algum tipo de modificação; no quadro 22, os itens que obtiveram mais de $80 \%$ de concordância mas mesmo assim foi optado fazer alguma modificação para melhor entendimento; e no quadro 23 os itens que obtiveram menos de $80 \%$ de concordância sendo optado manter a tradução da versão síntese sem modificações.

Em relação a validade semântica foram alterados 3 itens, pela validade idiomática foram alterados 8 itens e pela validade conceitual 28 itens alterados. 
Quadro 21: Itens que obtiveram menos de $80 \%$ de concordância e sofreram algum tipo de modificação - HNNE resumido

\begin{tabular}{|c|c|c|c|c|}
\hline Item VSP & Validade & $\begin{array}{c}N^{\circ} \text { de acordo } \\
(\mathbf{n}=9)\end{array}$ & $\%$ & VCP \\
\hline Hammersmith - Exame Neonatal Neurológico & Idiomática & 1 & 11,1 & Exame Neurológico Neonatal Resumido - Hammersmith \\
\hline (Não informado) & $\begin{array}{c}\text { Experiência } \\
\text { dos juízes }\end{array}$ & 7 & 77,7 & Peso ao nascimento: \\
\hline $\begin{array}{l}\text { PADRÃO FLEXOR DE BRAÇO - Estenda rapidamente } \\
\text { (alinhando) ambos os braços próximos ao corpo. Conte até dois. } \\
\text { Solte. Repita } 3 \text { vezes. }\end{array}$ & Conceitual & 4 & 44,4 & $\begin{array}{l}\text { TESTE DE RECOLHIMENTO DOS BRAÇOS - Estenda } \\
\text { rapidamente (alinhando) ambos os braços próximos ao corpo. Conte } \\
\text { até dois. Solte. Repita } 3 \text { vezes. }\end{array}$ \\
\hline $\begin{array}{l}\text { TRAÇÃO DO BRAÇO - Segure no punho e puxe o braço para } \\
\text { cima. Observe a flexão e a resistência do cotovelo, enquanto o } \\
\text { ombro é levantado da mesa. }\end{array}$ & Conceitual & 7 & 77,7 & $\begin{array}{l}\text { TRAÇÃO DO BRAÇO - Segure nos punhos e puxe os braços para } \\
\text { cima. Observe a flexão e a resistência dos braços, enquanto os ombros } \\
\text { são levantados da mesa. }\end{array}$ \\
\hline $\begin{array}{l}\text { RETRAÇÃO DA PERNA- Segure ambos os tornozelos, dobre os } \\
\text { quadris +joelhos. Estenda rapidamente quando a criança não } \\
\text { estiver empurrando. Solte. Repita 3x. }\end{array}$ & Conceitual & 7 & 77,7 & $\begin{array}{l}\text { RECOLHIMENTO DA PERNA - Segure ambos os tornozelos, } \\
\text { flexione o quadril + joelhos. Estenda rapidamente quando a criança } \\
\text { estiver relaxada. Solte. Repita 3x. }\end{array}$ \\
\hline Coluna curvada, cabeça, membros levemente flexionados & Conceitual & 7 & 77,7 & Tronco flexionado, cabeça e membros levemente flexionados \\
\hline Costas retas, cabeça acima do corpo & Conceitual & 7 & 77,7 & Tronco alinhado, cabeça acima do corpo \\
\hline $\begin{array}{l}\text { Sucção forte: (a) irregular (b) regular Remove a boca do estímulo } \\
\text { adequadamente }\end{array}$ & Conceitual & 7 & 77,7 & $\begin{array}{l}\text { Sucção forte: (a) irregular; (b) regular. Retira adequadamente a boca } \\
\text { do estímulo }\end{array}$ \\
\hline $\begin{array}{l}\text { AGILIDADE VISUAL - Enrole o lactente, acorde-o com o } \\
\text { chocalho se necessário, ou sacuda-o um pouco. Observe se o bebê } \\
\text { pode ver e seguir uma bola vermelha }(\mathrm{B}) \text { ou um objeto }(\mathrm{O})\end{array}$ & Conceitual & 7 & 77,7 & $\begin{array}{l}\text { ALERTA VISUAL - Enrole o lactente, acorde-o com o chocalho se } \\
\text { necessário, ou gentilmente sacuda-o um pouco. Observe se o bebê } \\
\text { pode ver e seguir uma bola vermelha }(\mathrm{B}) \text { ou um objeto }(\mathrm{O})\end{array}$ \\
\hline Segue em um círculo & Idiomática & 7 & 77,7 & Segue o objeto em círculo \\
\hline $\begin{array}{l}\text { ESTADO DE ALERTA - Testado como resposta à bola vermelha } \\
\text { (R) ou alvo (T). Quanto tempo o lactente se manteve interessado }\end{array}$ & Semântico & 7 & 77,7 & $\begin{array}{l}\text { ESTADO DE ALERTA - Testado como resposta à bola vermelha }(\boldsymbol{B}) \\
\text { ou objeto }(\boldsymbol{O}) \text {. Quanto tempo o lactente se manteve interessado }\end{array}$ \\
\hline AUGE DA EXCITAÇÃO - Circule H se o choro for estridente & Semântico & 6 & 66,6 & AUGE DA EXCITAÇÃO - Circule $\boldsymbol{E}$ se o choro for estridente \\
\hline
\end{tabular}

Legenda: VSP - versão síntese em português; VCP - versão consensual em português) 
Quadro 22: Itens que obtiveram mais de $80 \%$ de concordância e sofreram algum tipo de modificação - HNNE resumido

\begin{tabular}{|c|c|c|c|c|}
\hline Item VSP & Validade & $\begin{array}{l}N^{\circ} \text { de } \\
\text { acordo } \\
(n=9)\end{array}$ & $\%$ & VCP \\
\hline Data do exame & Conceitual & 9 & 100 & Data da Avaliação \\
\hline Pernas ligeiramente flexionadas & Conceitual & 8 & 88,8 & Pernas levemente flexionadas \\
\hline Braços muito flexionados, pernas muito estendidas & Idiomática & 8 & 88,8 & Forte flexão dos braços e extensão acentuada da perna \\
\hline Braços flexionam devagar, porém, completamente. & Conceitual & 8 & 88,8 & Braços flexionam lentamente, porém completamente \\
\hline $\begin{array}{l}\text { Braços flexionam ligeiramente ou alguma resistência é } \\
\text { observada }\end{array}$ & Conceitual & 8 & 88,8 & Braços flexionam levemente ou alguma resistência é observada \\
\hline Braços flexionam bem até elevar o ombro, então endireitam-se & Conceitual & 8 & 88,8 & $\begin{array}{l}\text { Braços bem fletidos até elevação do ombro, seguido por retificação } \\
\text { do braço }\end{array}$ \\
\hline $\begin{array}{l}\text { Pernas difíceis de estenderem; flexionam de volta rapidamente } \\
\text { e com força }\end{array}$ & Conceitual & 8 & 88,8 & $\begin{array}{l}\text { Pernas difíceis de serem estendidas, flexionam de volta rapidamente e } \\
\text { com força }\end{array}$ \\
\hline $\begin{array}{l}\text { TRAÇÃO DA PERNA- Segure o tornozelo e puxe a perna para } \\
\text { cima. Observe a flexão e a resistência enquanto os glúteos são } \\
\text { puxados para cima. }\end{array}$ & Conceitual & 8 & 88,8 & $\begin{array}{l}\text { TRAÇÃO DA PERNA - Segure o tornozelo e puxe a perna para cima. } \\
\text { Observe a flexão e a resistência enquanto eleva o quadril. }\end{array}$ \\
\hline Pernas flexionam levemente ou alguma resistência é sentida & Conceitual & 8 & 88,8 & Pernas flexionam levemente ou alguma resistência é observada \\
\hline Bebê tenta levantar; esforço é mais sentido do que observado & Idiomática & 8 & 88,8 & Lactente tenta levantar; esforço é mais sentido do que observado \\
\hline Bebê tenta levantar; esforço é mais sentido do que observado & Idiomática & 8 & 88,8 & Lactente tenta levantar; esforço é mais sentido do que observado \\
\hline $\begin{array}{l}\text { ATRASO DA CABEÇA - Puxe o bebê pelos punhos para } \\
\text { sentar e apoie levemente a cabeça. }\end{array}$ & Idiomática & 8 & 88,8 & $\begin{array}{l}\text { PUXAR PARA SENTAR - Puxe o bebê pelos punhos para sentar e } \\
\text { apoie levemente a cabeça. }\end{array}$ \\
\hline Levanta a cabeça alinhada com o corpo & Conceitual & 8 & 88,8 & Levanta a cabeça alinhada com $\boldsymbol{o}$ tronco \\
\hline Costas curvadas. Cabeça e membros suspensos e retos & Idiomática & 8 & 88,8 & Tronco flexionado. Cabeça e membros suspensos e alinhados \\
\hline Costas levemente curvadas. Membros flexionados & Conceitual & 8 & 88,8 & Tronco levemente flexionado. Membros flexionados \\
\hline $\begin{array}{l}\text { Costas retas, cabeça alinhada com o tronco membros } \\
\text { flexionados }\end{array}$ & Conceitual & 8 & 88,8 & Tronco reto, cabeça alinhada com o tronco, membros flexionados \\
\hline POSTURA ANORMAL DAS MÃOS OU DEDOS & Idiomática & 8 & 88,8 & POSTURA ANORMAL DAS MÃOS OU DEDOS DOS PÉS \\
\hline Polegar para cima (estendido) ou todos os dedos flexionados & Semântica & 8 & 88,8 & Hálux para cima (estendido) ou todos os dedos flexionados \\
\hline $\begin{array}{l}\text { Susto/sobressaltos com barulhos repentinos ou ao bater na } \\
\text { mesa }\end{array}$ & Conceital & 8 & 88,8 & Susto/sobressaltos com barulhos súbitos ou ao bater na mesa \\
\hline $\begin{array}{l}\text { REFLEXO DE SUCÇÃO E VÔMITO/ÂNSIA - Observe no } \\
\text { peito, se não for percebida a sucção, coloque o dedo mínimo } \\
\text { dentro da boca com a ponta do dedo para cima }\end{array}$ & Conceitual & 8 & 88,8 & $\begin{array}{l}\text { REFLEXO DE SUCĈ̃̃ - Observe no peito, se não for percebida a } \\
\text { sucção, coloque o dedo mínimo dentro da boca com a polpa do dedo } \\
\text { para cima }\end{array}$ \\
\hline Sem vômito-ânsia/sem sucção & Conceitual & 8 & 88,8 & Sucção ausente \\
\hline
\end{tabular}


Quadro 22 (continuação): Itens que obtiveram mais de 80\% de concordância e sofreram algum tipo de modificação - HNNE resumido

\begin{tabular}{|l|l|l|l|l|}
\hline $\begin{array}{l}\text { PREENSÃO PLANTAR - Pressione a sola abaixo dos dedos } \\
\text { dos pés. }\end{array}$ & Conceitual & 8 & 88,8 & $\begin{array}{l}\text { PREENSÃO PLANTAR - Pressione na superfície plantar abaixo dos } \\
\text { dedos dos pés. }\end{array}$ \\
\hline Não responde & Conceitual & 8 & 88,8 & Sem resposta \\
\hline Vira olhos e às vezes também vira um pouco a cabeça & Conceitual & 8 & 88,8 & Movimenta os olhos e às vezes também vira um pouco a cabeça \\
\hline Vira os olhos e a cabeça totalmente para o lado do barulho & Conceitual & 8 & 88,8 & Movimenta os olhos e a cabeça totalmente para o lado do barulho \\
\hline $\begin{array}{l}\text { Fica quieto, foca, segue muito rapidamente para o lado e para } \\
\text { cima, mas os perde rapidamente }\end{array}$ & Conceitual & 8 & 88,8 & $\begin{array}{l}\text { Fica quieto, foca, segue muito brevemente para o lado e para cima, } \\
\text { mas os perde rapidamente }\end{array}$ \\
\hline Não responderá à bola vermelha & Conceitual & 8 & 88,8 & Não responde à bola vermelha \\
\hline
\end{tabular}

Não responderá à bola vermelha

Quadro 23: Itens que obtiveram menos de $80 \%$ de concordância e não sofreram nenhum tipo de modificação - HNNE resumido

\begin{tabular}{|c|c|c|c|}
\hline Item VSP & $\begin{array}{l}\mathbf{N}^{\circ} \text { de } \\
\text { acordo } \\
(\mathbf{n}=9)\end{array}$ & $\%$ & VCP \\
\hline Não flexiona & 7 & 77,7 & Não flexiona \\
\hline $\begin{array}{l}\text { ÂNGULO POPLÍTEO - Coloque o joelho no abdome, estenda a perna } \\
\text { realizando uma leve pressão por trás do tornozelo com o dedo indicador. } \\
\text { Observe o ângulo do joelho. }\end{array}$ & 7 & 77,7 & $\begin{array}{l}\text { ÂNGULO POPLÍTEO - Coloque o joelho no abdome, estenda a perna } \\
\text { realizando uma leve pressão por trás do tornozelo com o dedo indicador. } \\
\text { Observe o ângulo do joelho. }\end{array}$ \\
\hline Convulsões, espasmos ou outros movimentos anormais: DESCREVA!! & 7 & 77,7 & Convulsões, espasmos ou outros movimentos anormais: DESCREVA!! \\
\hline $\begin{array}{l}\text { ESTADO DE ALERTA - Testado como resposta à bola vermelha (R) ou alvo } \\
\text { (T). Quanto tempo o lactente se manteve interessado }\end{array}$ & 7 & 77,7 & $\begin{array}{l}\text { ESTADO DE ALERTA - Testado como resposta à bola vermelha }(\mathrm{B}) \text { ou } \\
\text { objeto }(\mathrm{O}) \text {. Quanto tempo o lactente se manteve interessado }\end{array}$ \\
\hline EXAMINADOR & 9 & 100 & EXAMINADOR: \\
\hline
\end{tabular}

Legenda: VSP - versão síntese em português; VCP - versão consensual em português) 


\subsubsection{Resultados estágios 3: HNNE expandido}

Neste instrumento são avaliados 34 aspectos, os quais podem apresentar 5 respostas diferentes. Há ainda, espaços para se notar comentários e observações, além de um espaço para caracterizar o avaliado e um resumo do instrumento. No total, foram 214 itens traduzidos e adaptados para a cultura brasileira.

Dez especialistas participaram da avaliação de equivalências deste instrumento, e houve concordância acima de $80 \%$ entre a versão original e versão síntese em 201 itens. Oito itens obtiveram $70 \%$ de concordância, 4 itens obtiveram $60 \%$, e apenas 1 item obteve concordância abaixo de $50 \%$, que foi o título do instrumento. Apenas 1 pessoa, concordou com o título (equivalente a $10 \%$ de concordância), portanto o título foi alterado.

No quadro 24 estão apresentados os itens que obtiveram menos de $80 \%$ de concordância e sofreram algum tipo de modificação; no quadro 25 , os itens que obtiveram mais de $80 \%$ de concordância mas mesmo assim foi optado fazer alguma modificação para melhor entendimento; e no quadro 26 os itens que obtiveram menos de $80 \%$ de concordância sendo optado manter a tradução. Em relação a validade semântica foram alterados 2 itens, pela validade idiomática foram 4 itens e pela validade conceitual 51 itens alterados.

\subsubsection{Resultados estágios 3: HINE infant}

Neste instrumento são avaliados ou observados 37 aspectos que podem apresentar 5 respostas diferentes, divididos em 3 seções. Há ainda, espaços para se notar comentários e observações, além de um espaço para caracterizar o avaliado e um resumo do instrumento. No total, foram 200 itens traduzidos e adaptados para a cultura brasileira.

Dez especialistas participaram da avaliação de equivalências deste instrumento. Em relação a concordância entre a versão original e versão síntese, 186 itens obtiveram acima de $80 \%, 6$ itens - 70\% de concordância, 3 itens - 60\%, 4 itens $-50 \%$, e apenas 1 item obteve concordância de $10 \%$. Esse item corresponde ao título do instrumento que foi alterado. Em relação a validade semântica foram alterados 2 itens, pela validade idiomática foram 13 itens e pela validade conceitual 20 itens alterados.

No quadro 27 estão apresentados os itens que obtiveram menos de $80 \%$ de concordância e sofreram algum tipo de modificação; no quadro 28, os itens que obtiveram mais de $80 \%$ de concordância mas mesmo assim foi optado fazer alguma modificação para melhor 
entendimento; e no quadro 29 os itens que obtiveram menos de $80 \%$ de concordância sendo optado manter a tradução. 
Quadro 24: Itens que obtiveram menos de $80 \%$ de concordância e sofreram algum tipo de modificação - HNNE expandido

\begin{tabular}{|c|c|c|c|c|}
\hline Item VSP & Validade & $\begin{array}{l}N^{*} \text { de acordo } \\
(n=10)\end{array}$ & $\%$ & VCP \\
\hline Hammersmith - Exame Neonatal Neurológico & Conceitual & 1 & 10 & Exame Neurológico Neonatal-Hammersmith \\
\hline Não informado & $\begin{array}{l}\text { Experiência } \\
\text { dos juízes }\end{array}$ & 7 & 70 & Peso ao nascimento \\
\hline $\begin{array}{l}\text { PADRÃO FLEXOR DE BRAÇO - Pegue ambas as mãos, } \\
\text { estenda rapidamente os braços paralelo ao corpo, conte até } \\
\text { três. Relaxe. Repita } 3 \text { vezes. }\end{array}$ & Conceitual & 7 & 70 & $\begin{array}{l}\text { TESTE DE RECOLHIMENTO DOS BRAÇOS - Pegue ambas as } \\
\text { mãos, estenda rapidamente os braços paralelos ao corpo, conte até } \\
\text { três. Relaxe. Repita } 3 \text { vezes. }\end{array}$ \\
\hline $\begin{array}{l}\text { TÔNUS FLEXOR (1) (tração: braço vs. perna) - Compare os } \\
\text { resultados de tração do braço com os de tração de perna }\end{array}$ & Conceitual & 6 & 60 & $\begin{array}{l}\text { TÔNUS FLEXOR (1) (tração: braço vs. perna) - Compare } a \\
\text { pontuação da tração dos braços com a tração das pernas }\end{array}$ \\
\hline $\begin{array}{l}\text { Pontuação para flexão dos braços é menor que a de flexão de } \\
\text { pernas }\end{array}$ & Conceitual & 7 & 70 & Pontuação para flexão dos braços é menor que a flexão das pernas \\
\hline $\begin{array}{l}\text { Pontuação da flexão de braços é maior que a de flexão de } \\
\text { pernas, porém com diferença de uma coluna ou menos }\end{array}$ & Conceitual & 7 & 70 & $\begin{array}{l}\text { Pontuação da flexão dos braços é maior que a flexão das pernas, } \\
\text { porém com diferença de } 1 \text { coluna ou menos }\end{array}$ \\
\hline $\begin{array}{l}\text { Pontuação da flexão de braços é maior que a de flexão de } \\
\text { pernas, porém com diferença de uma coluna ou mais }\end{array}$ & Conceitual & 7 & 70 & $\begin{array}{l}\text { Pontuação da flexão dos braços é maior que a flexão das pernas, } \\
\text { porém com diferença de } 1 \text { coluna ou mais }\end{array}$ \\
\hline Sente na palpação, mas não vê & Conceitual & 6 & 60 & Sente na palpação, mas não é observado \\
\hline $\begin{array}{l}\text { Somente sucção fraca e irregular. Não remove a boca do } \\
\text { estímulo }\end{array}$ & Idiomática & 6 & 60 & Somente sucção fraca e irregular. Não retira a boca do estímulo \\
\hline $\begin{array}{l}\text { Sucção fraca e regular. Remove a boca do estímulo algumas } \\
\text { vezes }\end{array}$ & Idiomática & 7 & 70 & Sucção fraca e regular. Retira a boca do estímulo algumas vezes \\
\hline $\begin{array}{l}\text { Sucção forte: (a) irregular (b) regular. Remove } \\
\text { adequadamente a boca do estímulo }\end{array}$ & Idiomática & 6 & 60 & $\begin{array}{l}\text { Sucção forte: (a) irregular (b) regular. Retira adequadamente a } \\
\text { boca do estímulo }\end{array}$ \\
\hline Lista de sinais divergentes & Conceitual & 7 & 70 & Lista de alterações \\
\hline
\end{tabular}

Quadro 25: Itens que obtiveram mais de $80 \%$ de concordância e sofreram algum tipo de modificação - HNNE expandido

\begin{tabular}{|c|c|c|c|c|}
\hline Item VSP & Validade & $\begin{array}{c}\mathbf{N}^{\mathbf{o}} \text { de } \\
\text { acordo } \\
(\mathrm{n}=\mathbf{1 0})\end{array}$ & $\%$ & VCP \\
\hline Código & Conceitual & $10(100 \%)$ & $0(0 \%)$ & Registro do paciente \\
\hline Data do exame & Conceitual & $9(90 \%)$ & $1(10 \%)$ & Data da avaliação \\
\hline Braços flexionam devagar, porém completamente. & Conceitual & $9(90 \%)$ & $1(10 \%)$ & Braços flexionam lentamente, porém completamente. \\
\hline Braços flexionam bem até elevar o ombro, então endireitam-se & Conceitual & $9(90 \%)$ & $1(10 \%)$ & $\begin{array}{l}\text { Braços bem fletidos até elevação do ombro, seguido por retificação } \\
\text { do braço }\end{array}$ \\
\hline
\end{tabular}


Quadro 25(continuação): Itens que obtiveram mais de $80 \%$ de concordância e sofreram algum tipo de modificação - HNNE expandido

\begin{tabular}{|c|c|c|c|c|}
\hline $\begin{array}{l}\text { RECOLHIMENTO DA PERNA - Segure ambos os tornozelos em } \\
\text { uma mão, flexione o quadril e os joelhos. Estenda rapidamente. } \\
\text { Solte. Repita três vezes. }\end{array}$ & Idiomática & $8(80 \%)$ & $2(20 \%)$ & $\begin{array}{l}\text { RECOLHIMENTO DA PERNA - Segure ambos os tornozelos com } \\
\text { uma mão, flexione o quadril e os joelhos. Estenda rapidamente. Solte. } \\
\text { Repita três vezes. }\end{array}$ \\
\hline Pernas flexionam bem até elevar os quadris. & Conceitual & $9(90 \%)$ & $1(10 \%)$ & Pernas flexionam bem até elevar o quadril. \\
\hline Flexão se mantém quando o quadril e as costas são levantados & Conceitual & $10(100 \%)$ & $0(0 \%)$ & Flexão se mantém quando o quadril e o tronco são levantados \\
\hline $\begin{array}{l}\text { CONTROLE DE CABEÇA (1) (tônus extensor). Lactente sentado. } \\
\text { Abrace o peito com ambas as mãos, segurando os ombros. Deixe a } \\
\text { cabeça cair para frente. }\end{array}$ & Conceitual & $9(90 \%)$ & $1(10 \%)$ & $\begin{array}{l}\text { CONTROLE DA CABEÇA (1) (tônus extensor). Lactente sentado. } \\
\text { Abrace o peito com ambas as mãos, segurando os ombros. Deixe a } \\
\text { cabeça cair para frente. }\end{array}$ \\
\hline $\begin{array}{l}\text { CONTROLE DE CABEÇA (2) (tônus flexor). Lactente sentado. } \\
\text { Abrace o peito com ambas as mãos, segurando os ombros. Deixe a } \\
\text { cabeça cair para trás. }\end{array}$ & Conceitual & $9(90 \%)$ & $1(10 \%)$ & $\begin{array}{l}\text { CONTROLE DA CABEÇA (2) (tônus flexor). Lactente sentado. } \\
\text { Abrace o peito com ambas as mãos, segurando os ombros. Deixe a } \\
\text { cabeça cair para trás. }\end{array}$ \\
\hline $\begin{array}{l}\text { ATRASO DA CABEÇA - Puxe o lactente para a postura sentada } \\
\text { com tração em ambos os punhos e apoiando levemente a cabeça. } \\
\text { Observe também a flexão do braço }\end{array}$ & Conceitual & $9(90 \%)$ & $1(10 \%)$ & $\begin{array}{l}\text { PUXAR PARA SENTAR - Puxe o lactente para a postura sentada } \\
\text { com tração em ambos os punhos e apoiando levemente a cabeça. } \\
\text { Observe também a flexão do braço }\end{array}$ \\
\hline Eleva a cabeça alinhada c & & & & o tronco \\
\hline suspensos e retos & & & $1(10 \%)$ & Tronco fl \\
\hline $\begin{array}{l}\text { Costas curvadas. Cabeça para baixo e membros levemente } \\
\text { flexionados }\end{array}$ & Conceitual & $8(80 \%)$ & $2(20 \%)$ & $\begin{array}{l}\text { Tronco flexionado. Cabeça para baixo e membros leve } \\
\text { flexionados }\end{array}$ \\
\hline Costas levemente curvadas. Membros flexionados & Conceitual & $9(90 \%)$ & $1(10 \%)$ & emente flexionado. Membros flexionados \\
\hline Costas retas, cabeça a & & & $20 \%)$ & Tronco \\
\hline Costas $\mathrm{r}$ & & & $0 \%)$ & Tronc \\
\hline Pontuação para flexão de braços é igual a & Conceitual & 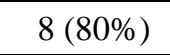 & $2(20 \%)$ & Pontuação para flexão dos braços é igual a fle \\
\hline $\begin{array}{l}\text { Pontuação da extensão de cabeça é maior que a da flexão de cabeça, } \\
\text { porém com diferença maior que } 1 \text { uma coluna }\end{array}$ & Semântica & $8(80 \%)$ & $2(20 \%)$ & $\begin{array}{l}\text { Pontuação da extensão } \mathrm{d} a \text { cabeça é maior q } \\
\text { porém com diferença } d e 1 \text { uma coluna ou } n\end{array}$ \\
\hline $\begin{array}{l}\text { AUMENTO DE TÔNUS EXTENSOR (horizontal) - Compare a } \\
\text { pontuação do atraso da cabeça e a suspensão ventral. }\end{array}$ & Conceitual & $9(90 \%)$ & $1(10 \%)$ & $\begin{array}{l}\text { AUMENTO DE TỐNUS EXTENSOR (horizontal) - Compare a } \\
\text { pontuação do controle da cabeça no puxar para sentar e } \boldsymbol{n} \text { a } \\
\text { suspensão ventral. }\end{array}$ \\
\hline Pontuação da suspensão ventral é menor que a do atraso da cabeça & Conceitual & $9(90 \%)$ & $1(10 \%)$ & $\begin{array}{l}\text { Pontuação do controle de cabeça na suspensão ventral é menor que a } \\
\text { no puxar para sentar }\end{array}$ \\
\hline Pontuação da suspensão ventral é igual a do atraso da cabeça & Conceitual & $9(90 \%)$ & $1(10 \%)$ & $\begin{array}{l}\text { Pontuação do controle da cabeça na suspensão ventral é igual a } \\
\text { pontuação do puxar para sentar }\end{array}$ \\
\hline $\begin{array}{l}\text { Pontuação da suspensão ventral é maior que a do atraso da cabeça, } \\
\text { porém com diferença de uma coluna ou menos }\end{array}$ & Conceitual & $9(90 \%)$ & $1(10 \%)$ & $\begin{array}{l}\text { Pontuação do controle da cabeça na suspensão ventral é maior que a } \\
\text { do puxar para sentar, porém com diferença de } 1 \text { coluna ou menos }\end{array}$ \\
\hline $\begin{array}{l}\text { Pontuação da suspensão ventral é maior que a do atraso da cabeça, } \\
\text { porém com diferença maior que uma coluna }\end{array}$ & Conceitual & $9(90 \%)$ & $1(10 \%)$ & $\begin{array}{l}\text { Pontuação do controle da cabeça na suspensão ventral é maior que a } \\
\text { do puxar para sentar, porém com diferença maior que } 1 \text { coluna }\end{array}$ \\
\hline
\end{tabular}


Quadro 25 (continuação): Itens que obtiveram mais de 80\% de concordância e sofreram algum tipo de modificação - HNNE expandido

REFLEXO TENDÍNEO - Teste os reflexos do bíceps, joelho e

tornozelo

Sem vômito-ânsia / sem sucção

Sem sucção, porém a pegada é forte

PREENSÃO PLANTAR - Pressione o polegar na sola abaixo dos dedos. Teste cada lado separadamente

Resposta completa do reflexo de colocação da perna, flexão do quadril e joelho; coloca sola na superfície

REFLEXO DE MORO - Uma mão suporta a cabeça do lactente em

linha média e a outra as costas. Levante o lactente a $45^{\circ}$ e quando o

lactente estiver relaxado deixe a cabeça cair $10^{\circ}$. Observe se há

espasmos. Repita 3 vezes

LEVANTANDO A CABEÇA EM PRONO - Lactente em prono,

cabeça na linha média

Lactente rola a cabeça para o lado, queixo não levantado

POSTURA ANORMAL DAS MÃOS OU DEDOS

Punho intermitente ou adução do polegar

Punho contínuo ou adução do polegar; flexão do dedo indicador, oposição do polegar

Não se assusta mesmo com barulho repentino

Conceitual

Conceitual

Não se assusta espontaneamente, porém reage a barulhos repentinos

2-3 sobressaltos espontâneos

Mais que 3 sobressaltos espontâneos

Sobressaltos contínuos

Transitório: - nistagmo - estrabismo - movimentos de olhos

vagueantes - sinal de pôr-do-sol (olhos caídos)

Persistente - nistagmo - estrabismo - movimentos de olhos

vagueantes - pupilas anormais

Segue em círculo

Não irá responder aos estímulos

Quando acordado, apenas olha rapidamente

Chora para estímulo, porém com intensidade normal

LISTA DE SINAIS DIVERGENTES

Conceitual

Conceitual

Semântica

Conceitual

Conceitual

Conceitual

Conceitual

Conceitual

Conceitual

Conceitual

Conceitual

Conceitual

Conceitual

Conceitual

Conceitual

\begin{tabular}{|c|c|}
\hline $9(90 \%)$ & $1(10 \%)$ \\
\hline $8(80 \%)$ & $2(20 \%)$ \\
\hline $8(80 \%)$ & $2(20 \%)$ \\
\hline $8(80 \%)$ & $2(20 \%)$ \\
\hline $8(80 \%)$ & $2(20 \%)$ \\
\hline
\end{tabular}

REFLEXO TENDÍNEO - Teste os reflexos bicipital, patelar $e$ aquiliano

Resposta de sucção/vômito/ânsia ausente

Sem sucção, porém com forte "pega"

PREENSÃO PLANTAR - Pressione o polegar na superfície plantar, abaixo dos dedos. Teste cada lado separadamente

Resposta completa do reflexo de colocação da perna, com flexão do quadril e joelho; coloca sola do pé na superfície

REFLEXO DE MORO - Uma mão suporta a cabeça do lactente em

linha média e a outra $o$ tronco. Levante o lactente a $45^{\circ}$ e quando o

lactente estiver relaxado deixe a cabeça cair $10^{\circ}$. Observe se há

espasmos. Repita 3 vezes

ELEVAÇ̃̃ O DA CABEÇA EM PRONO - Lactente em prono, cabeça na linha média

$9(90 \%) \quad 1(10 \%)$

Lactente rola a cal

$9(90 \%) \quad 1(10 \%)$

$9(90 \%) \quad 1(10 \%)$

\begin{tabular}{l|l}
$9(90 \%)$ & $1(10 \%)$ \\
\hline $8(80 \%)$ & $2(20 \%)$
\end{tabular}

$8(80 \%)$

$2(20 \%)$

$9(90 \%)$

$9(90 \%) \quad 1(10 \%)$

$8(80 \%)$

$8(80 \%)$

$8(80 \%)$

$2(20 \%)$

$2(20 \%)$

$2(20 \%)$

Mão fechada intermitente ou polegar aduzido

Mão fechada continuamente ou polegar aduzido; flexão do dedo indicador, oposição do polegar

Não se assusta mesmo com barulho súbito

Não se assusta espontaneamente, mas reage a barulhos súbitos

2-3 sobressaltos/sustos espontâneos

Mais que 3 sobressaltos/sustos espontâneos

Sobressaltos/sustos contínuos

Transitório: - nistagmo - estrabismo - movimentos oculares lentos -

sinal de pôr-do-sol (olhos caídos)

Persistente - nistagmo - estrabismo - movimentos oculares lentos pupilas anormais

$9(90 \%)$

$1(10 \%)$

$9(90 \%)$

$9(90 \%)$

$9(90 \%)$

$8(80 \%)$

$1(10 \%)$

$1(10 \%)$

$1(10 \%)$

Segue o objeto em círculo

Não responde aos estímulos

Quando acordado, apenas olha brevemente

Chora com estímulos porém em intensidade normal

LISTA DE ALTERACÕES 
Quadro 26: Itens que obtiveram menos de $80 \%$ de concordância e não sofreram nenhum tipo de modificação - HNNE expandido

\begin{tabular}{|c|c|c|c|}
\hline Item VSP & $\begin{array}{c}\mathrm{N}^{0} \text { de } \\
\text { acordo } \\
(\mathrm{n}=10)\end{array}$ & $\%$ & VCP \\
\hline Movimentos oculares completamente conjugados & 7 & 70 & Movimentos oculares completamente conjugados \\
\hline
\end{tabular}

Quadro 27: Itens que obtiveram menos de $80 \%$ de concordância e sofreram algum tipo de modificação - HINE infant

\begin{tabular}{|c|c|c|c|c|}
\hline Item VSP & Validade & $\begin{array}{c}N^{\circ} \text { de acordo } \\
(n=10)\end{array}$ & $\%$ & VCP \\
\hline Hammersmith: exame infantil neurológico & Conceitual & 1 & 10 & Exame neurológico Infantil-Hammersmith \\
\hline Data de aniversário & Conceitual & 5 & 50 & Data de Nascimento \\
\hline Coluna 1 (pontue 2) & Idiomática & 7 & 70 & Coluna 1 (2 pontos) \\
\hline Coluna 2 (pontue 1,5 ) & Idiomática & 7 & 70 & Coluna 2 (1,5 pontos) \\
\hline Coluna 3 (pontue 1) & Idiomática & 7 & 70 & Coluna 3 (1 pontos) \\
\hline Coluna 4 (pontue 0$)$ & Idiomática & 7 & 70 & Coluna 4 (0 pontos) \\
\hline Movimentos dos olhos normais e conjugados & Idiomática & 5 & 50 & Movimentos conjugado dos olhos estão normais \\
\hline Facilmente elicitável -Bíceps, joelho, tornozelo & Semântica & 7 & 70 & Facilmente desencadeado -Bíceps, joelho, tornozelo \\
\hline Todo tempo mantém erguida (normal aos 5 meses) & Idiomática & 6 & 40 & Mantém erguida o tempo todo (normal aos 5 meses) \\
\hline Pivot (rotaciona) (normal aos 9 meses) & Conceitual & 5 & 50 & Pivoteia (rotaciona) (normal aos 9 meses) \\
\hline Garra Voluntária & Conceitual & 5 & 50 & Preensão Voluntária \\
\hline Com dedo indicador e polegar, porém, garra imatura & Conceitual & 6 & 40 & Com dedo indicador e polegar, porém, preensão imatura \\
\hline
\end{tabular}

Quadro 28: Itens que obtiveram mais de $80 \%$ de concordância e sofreram algum tipo de modificação - HINE infant

\begin{tabular}{|c|c|c|c|c|}
\hline Item VSP & Validade & $\begin{array}{l}N^{\circ} \text { de acordo } \\
(\mathbf{n}=10)\end{array}$ & $\%$ & VCP \\
\hline Data do exame & Conceitual & 9 & 90 & Data da avaliação \\
\hline Resumo do exame & Conceitual & 9 & 90 & Resumo da avaliação \\
\hline Não informado & $\begin{array}{l}\text { Experiência } \\
\text { dos juízes }\end{array}$ & 9 & 90 & Assimetria \\
\hline Reação duvidosa a estímulos ou assimétrica & Idiomática & 8 & 80 & Reação duvidosa ou assimétrica a estímulos \\
\hline Levemente para o lado ou para trás ou para a frente & Conceitual & 9 & 90 & Levemente inclinada para o lado ou para trás ou para a frente \\
\hline Acentuadamente para o lado ou para trás ou para a frente & Conceitual & 9 & 90 & $\begin{array}{l}\text { Acentuadamente inclinada para o lado ou para trás ou para a } \\
\text { frente }\end{array}$ \\
\hline Levemente curvado ou inclinado para o lado & Conceitual & 9 & 90 & Levemente flexionado ou inclinado para o lado \\
\hline
\end{tabular}


Quadro 28 (continuação): Itens que obtiveram mais de 80\% de concordância e sofreram algum tipo de modificação - HINE infant Muito curvado / balançando para trás/ inclinado lateralmente Intermitente - Polegar em adução ou punhos fechados Persistente - Polegar em adução ou punhos fechados

Senta com a coluna alinhada, porém os joelhos flexionam em $15-20^{\circ}$. Rotação interna ou externa do quadril

Incapaz de sentar com a coluna alinhada, a não ser que os joelhos estejam acentuadamente flexionados (não senta com as pernas estendidas). Acentuada Rotação interna ou externa ou extensão ou flexão fixa ou contraturas no quadril e joelhos Intermitente - Tendência de ficar em pé nas pontas dos dedos; ou dedos para cima ou curvados para baixo

Acentuada - Rotação interna ou externa do tornozelo.

Persistente - Tendência de ficar em pé nas pontas dos dedos; ou dedos para cima ou curvados para baixo

Resistência, porém, vencida

Resistência, não vencida

Pronação e supinação completas, porém a resistência pode ser vencida

PARAQUEDAS PARA FRENTE - Lactente mantido na

posição vertical e subitamente inclinado para frente. Observe a reação dos braços.

Senta com suporte no quadril (normal aos 4 meses)

Sentar com estabilidade (normal aos 7-8 meses)

Sem rolar

Sobre as mãos estendidas (normal aos 4 meses)

Engatinha sobre as mãos e joelhos (normal aos 10 meses)

\begin{tabular}{|l|l|l|}
\hline Conceitual & 8 & 80 \\
\hline Conceitual & 8 & 80 \\
\hline Conceitual & 8 & 80 \\
\hline Idiomática & 8 & 80 \\
\hline Conceitual & 8 & 80 \\
\hline Conceitual & 9 & \\
\hline Idiomática & 8 & 90 \\
\hline Idiomática & 8 & 80 \\
\hline Idiomática & 9 & 80 \\
\hline Conceitual & 8 & 90 \\
\hline Conceitual & 9 & 80 \\
\hline Conceitual & 8 & 90 \\
\hline Conceitual & 8 & 80 \\
\hline Idiomática & 9 & 90 \\
\hline Idiomática & 9 & 90 \\
\hline Semântica & 8 & 80 \\
\hline
\end{tabular}
Muito flexionado / oscilando para trás/ inclinado lateralmente Intermitente - Polegar em adução ou mãos fechadas Persistente - Polegar em adução ou mãos fechadas Senta com a coluna alinhada, mas com os joelhos flexionados em $15-20^{\circ}$. Rotação interna ou externa do quadril

Incapaz de sentar com a coluna alinhada, a não ser que os joelhos estejam acentuadamente flexionados (não senta com as pernas estendidas). Acentuada Rotação interna ou externa ou flexão/extensãa fixas ou contraturas no quadril e joelhos Intermitente - Tendência de ficar em pé nas pontas dos dedos; ou dedos para cima ou dedos em garra

Acentuada - Rotação interna ou externa do tornozelo. Persistente -

Tendência de ficar em pé nas pontas dos dedos; ou dedos para cima ou dedos em garra

Resistência, porém, realiza

Resistência, não realiza

Pronação e supinação completas, porém a resistência pode ser vencida (movimento pode ser realizado)

REACÃO DE PARAOUEDAS- Lactente mantido na posição

vertical e subitamente inclinado para frente. Observe a reação dos braços.

Senta com apoio no quadril (normal aos 4 meses)

Marcha independentemente (normal aos 15 meses)

Semântica

80

sem apoio (normal aos 7-8 meses)

Não rola

Em extensão de braços, sobre as mãos (normal aos 4 meses)

Engatinha com 4 apoios ou com apoio sobre mãos e joelhos

(normal aos 10 meses)

Marcha independente (normal aos 15 meses) 
Quadro 29: Itens que obtiveram menos de $80 \%$ de concordância e não sofreram nenhum tipo de modificação - HINE neonatal expandido

\begin{tabular}{|c|c|c|c|}
\hline Item VSP & $\begin{array}{l}\mathbf{N}^{\circ} \text { de } \\
\text { acordo } \\
(\mathbf{n}=\mathbf{1 0})\end{array}$ & $\%$ & VCP \\
\hline $\begin{array}{l}\text { Espasmos sincronizados; Espasmos extensores; Atetóide; Atáxico; Muito } \\
\text { tremor; Espasmos mioclônicos; Distônico }\end{array}$ & 6 & 60 & $\begin{array}{l}\text { Espasmos sincronizados; Espasmos extensores; Atetóide; Atáxico; Muito } \\
\text { tremor; Espasmos mioclônicos; Distônico }\end{array}$ \\
\hline $\begin{array}{l}\text { ÂNGULO POPLÍTEO - Flexione simultaneamente as pernas ao lado do } \\
\text { abdome (abdução de quadril), então estenda os joelhos até que haja resistência. } \\
\text { Observe o ângulo entre a coxa e a parte inferior da perna }\end{array}$ & 7 & 70 & $\begin{array}{l}\text { ÂNGULO POPLÍTEO - Flexione simultaneamente as pernas ao lado do } \\
\text { abdome (abdução de quadril), então estenda os joelhos até que haja resistência } \\
\text { Observe o ângulo entre a coxa e a parte inferior da perna }\end{array}$ \\
\hline
\end{tabular}




\subsubsection{Resultados: Estágio 4}

O processo de retrotradução foi realizado nos 3 instrumentos (HNNE resumido, HNNE expandido e HINE) e optou-se utilizar a VCP.

A VCP foi encaminhada para dois tradutores distintos que possuíam domínio na língua portuguesa, mas que tinham o inglês como língua nativa. Eles realizaram a retrotradução dos instrumentos para o inglês, criando assim duas versões independentes que foram nomeadas de Retrotradução 1 (RT1) e Retrotradução 2 (RT2). A RT1 e RT2 foram plotadas em tabelas do Microsoft Excel® e analisadas pelo mesmo comitê técnico formado no processo de tradução, que comparou as duas versões e elaborou a versão consensual das retrotraduções (VCRT).

Os quadros 30, 31 e 32 apresentam os dados dos instrumentos originais, as VCP e as VCRT que foram encaminhadas para os autores dos instrumentos e que após a aprovação dos autores se tornaram as versões finais.

\subsubsection{Resultados: Estágio 5}

Todos os instrumentos tiveram suas versões consensuais, em português e retrotraduzidas (VCP e VCRT), enviadas juntamente com os modelos originais para que os autores pudessem avaliar a equivalência das versões e sugerir algumas modificações. Entretanto, nenhuma alteração foi solicitada ou sugestão acrescida para nenhum dos instrumentos, estando totalmente de acordo com as versões apresentadas. Desta forma, consolidou-se as versões finais de cada instrumento, apresentadas nos quadros 30, 31 e 32 - HNNE resumido, HNNE expandido, HINE infant; respectivamente. 
Estudo 1: Tradução e a d a ptação cu 1tura 1|93

Quadro 30: Versões finais do processo de adaptação cultural do HNNE resumido

\begin{tabular}{|c|c|c|}
\hline INGLÊS ORIGINAL & PORTUGUÊS - FINAL & RETROTRADUÇÃO - FINAL \\
\hline $\begin{array}{l}\text { Hammersmith Short Neonatal } \\
\text { Neurological Examination }\end{array}$ & $\begin{array}{l}\text { Exame Neurológico Neonatal Resumido - } \\
\text { Hammersmith }\end{array}$ & $\begin{array}{l}\text { Hammersmith Short Neonatal } \\
\text { Neurological Examination }\end{array}$ \\
\hline Name & Nome: & Name: \\
\hline Code & Registro do paciente: & Patient registration: \\
\hline No OF EXAM: & Número da avaliação: & Evaluation number: \\
\hline D.O.B & Data de Nascimento: & Date of birth: \\
\hline D.O.E & Data da Avaliação: & Evaluation date: \\
\hline Age & Idade: & Age: \\
\hline G.A & IG: & Gestational age: \\
\hline Sex & Sexo: & Sex: \\
\hline BW & Peso ao nascimento: & Birth weight: \\
\hline $\begin{array}{l}\text { Posture - Baby lying on back. } \\
\text { Look mainly at position of the } \\
\text { legs, but also note arms. You may } \\
\text { change drawing }\end{array}$ & $\begin{array}{l}\text { Postura - Bebê deitado em supino. Observe } \\
\text { principalmente a posição das pernas, mas } \\
\text { também observe os braços. Você pode alterar o } \\
\text { desenho }\end{array}$ & $\begin{array}{l}\text { Posture - Baby lying supine. Observe } \\
\text { especially the position of legs, but also } \\
\text { observe arms. You can change drawing }\end{array}$ \\
\hline Arms \& legs extended & Braços e pernas estendidas & Arms and legs extended \\
\hline Legs slightly flexed & Pernas levemente flexionadas & Legs slightly flexed \\
\hline Legs well flexed but not adducted & Pernas bem flexionadas, mas não aduzidas & Legs well flexed, but not adducted \\
\hline $\begin{array}{l}\text { Legs well flexed \& adducted near } \\
\text { belly }\end{array}$ & $\begin{array}{l}\text { Pernas bem flexionadas e aduzidas próximas ao } \\
\text { abdome }\end{array}$ & $\begin{array}{l}\text { Legs well flexed and adducted near the } \\
\text { abdomen }\end{array}$ \\
\hline $\begin{array}{l}\text { Arms very flexed, legs very } \\
\text { extended }\end{array}$ & $\begin{array}{l}\text { Forte flexão dos braços e Extensão acentuada da } \\
\text { perna }\end{array}$ & $\begin{array}{l}\text { Strong flexing of arms and accented leg } \\
\text { extension }\end{array}$ \\
\hline $\begin{array}{l}\text { Arm recoil - Quickly extend } \\
\text { (straighten) both arms; put next to } \\
\text { body. Count to two. Let go. Repeat } \\
3 \text { times }\end{array}$ & $\begin{array}{l}\text { Teste de recolhimento dos braços - Estenda } \\
\text { rapidamente (alinhando) ambos os braços } \\
\text { próximos ao corpo. Conte até dois. Solte. Repita } \\
3 \text { vezes. }\end{array}$ & $\begin{array}{l}\text { Arm recovery arm recoil test - } \\
\text { Quickly extend (aligning) both arms } \\
\text { close to the body. Count to two. } \\
\text { Release. Repeat } 3 \text { times. }\end{array}$ \\
\hline Arm does not flex & Braços não flexionam & Arms do not flex \\
\hline $\begin{array}{l}\text { Arm flexes slowly, not always; not } \\
\text { completely }\end{array}$ & $\begin{array}{l}\text { Braços flexionam lentamente, mas nem sempre; } \\
\text { não completamente }\end{array}$ & $\begin{array}{l}\text { Arms flex slowly, but not always; not } \\
\text { completely }\end{array}$ \\
\hline $\begin{array}{l}\text { Arm flexes slowly; more } \\
\text { completely }\end{array}$ & $\begin{array}{l}\text { Braços flexionam lentamente, porém } \\
\text { completamente }\end{array}$ & Arms flex slowly, but completely. \\
\hline Arm flexes and remains flexed & Braços flexionam e permanecem flexionados & Arms flex and remain flexed \\
\hline $\begin{array}{l}\text { Arm difficult to extend; snap back } \\
\text { forcefully }\end{array}$ & $\begin{array}{l}\text { Braços difíceis de estender; flexionam de volta } \\
\text { vigorosamente }\end{array}$ & $\begin{array}{l}\text { Arms difficult to extend. Return to } \\
\text { flexed position vigorously }\end{array}$ \\
\hline $\begin{array}{l}\text { Arm traction- Hold wrist and pull } \\
\text { upwards. Note flexion at arm, and } \\
\text { resistance while shoulder lifts off } \\
\text { table. }\end{array}$ & $\begin{array}{l}\text { Tração do braço - Segure nos punhos e puxe os } \\
\text { braços para cima. Observe a flexão e a } \\
\text { resistência dos braços, enquanto os ombros são } \\
\text { levantados da mesa. }\end{array}$ & $\begin{array}{l}\text { Arm traction - Hold wrists and pull } \\
\text { arms up. Observe flexion and resistance } \\
\text { of arms while the shoulders are raised } \\
\text { off the table. }\end{array}$ \\
\hline $\begin{array}{l}\text { Arm remains straight - no } \\
\text { resistance }\end{array}$ & Braços permanecem retos - nenhuma resistência & $\begin{array}{l}\text { Arms remain straight - no resistance } \\
\text { observed }\end{array}$ \\
\hline $\begin{array}{l}\text { Arm flexes slightly or some } \\
\text { resistance felt }\end{array}$ & $\begin{array}{l}\text { Braços flexionam levemente ou alguma } \\
\text { resistência é observada }\end{array}$ & $\begin{array}{l}\text { Arms flex slightly or some resistance } \\
\text { observed }\end{array}$ \\
\hline $\begin{array}{l}\text { Arm flexes well till shoulder lifts, } \\
\text { then straightens }\end{array}$ & $\begin{array}{l}\text { Braços bem fletidos até elevação do ombro, } \\
\text { seguido por retificação do braço }\end{array}$ & $\begin{array}{l}\text { Arms well-flexed until shoulder } \\
\text { elevation followed by rectification of } \\
\text { the arm }\end{array}$ \\
\hline $\begin{array}{l}\text { Arm flexes and remains flexed as } \\
\text { shoulder lifts }\end{array}$ & $\begin{array}{l}\text { Braços flexionados e permanecem fletidos na } \\
\text { elevação de ombros }\end{array}$ & $\begin{array}{l}\text { Arms flexed and remain flexed at } \\
\text { shoulder elevation }\end{array}$ \\
\hline $\begin{array}{l}\text { Arm remains flexed when body } \\
\text { lifts up }\end{array}$ & $\begin{array}{l}\text { O braço permanece flexionado quando o corpo é } \\
\text { levantado }\end{array}$ & $\begin{array}{l}\text { Arm remains flexed when the body is } \\
\text { lifted }\end{array}$ \\
\hline $\begin{array}{l}\text { Leg recoil- Take both ankles, bend } \\
\text { hips + knees. Quickly extend when } \\
\text { infant not pushing. Let go. Repeat } \\
\text { x } 3\end{array}$ & $\begin{array}{l}\text { Recolhimento da perna - Segure ambos os } \\
\text { tornozelos, flexione o quadril +joelhos. Estenda } \\
\text { rapidamente quando a criança estiver relaxada. } \\
\text { Solte. Repita 3x. } \\
\end{array}$ & $\begin{array}{l}\text { Leg recoil - Hold both ankles with one } \\
\text { hand, flex the hips }+ \text { knees. Quickly } \\
\text { extend when the child is relaxed. } \\
\text { Release. Repeat } 3 x\end{array}$ \\
\hline No flexion & Não flexiona & Does not flex \\
\hline Incomplete flexion, not every time & Flexão incompleta, não o tempo todo & Incomplete flexion, not all the time \\
\hline Complete slow flexion & Flexão lenta e completa & Slow and complete flexion \\
\hline Complete fast flexion & Flexão rápida e completa & Fast and complete flexion \\
\hline $\begin{array}{l}\text { Legs difficult to extend; snap back } \\
\text { forcefully }\end{array}$ & $\begin{array}{l}\text { Pernas difíceis de serem estendidas flexionam de } \\
\text { volta rapidamente e com força }\end{array}$ & $\begin{array}{l}\text { Legs difficult to extend, return quickly } \\
\text { and forcefully }\end{array}$ \\
\hline
\end{tabular}


Quadro 30 (continuação): Versões finais do processo de adaptação cultural do HNNE resumido

\begin{tabular}{|c|c|c|}
\hline $\begin{array}{l}\text { Leg traction - Hold ankle, pull leg } \\
\text { upwards. Look at flexion \& } \\
\text { resistance as bottom pulled up. }\end{array}$ & $\begin{array}{l}\text { Tração da perna - Segure o tornozelo e puxe a } \\
\text { perna para cima. Observe a flexão e a resistência } \\
\text { enquanto eleva o quadril. }\end{array}$ & $\begin{array}{l}\text { Leg traction - Hold the ankle and pull } \\
\text { the leg upward. Observe flexion and } \\
\text { resistance while raising hips. }\end{array}$ \\
\hline Leg straight - no resistance & Perna reta - sem resistência & Straight leg - no resistance \\
\hline $\begin{array}{l}\text { Leg flexes slightly or some } \\
\text { resistance felt }\end{array}$ & $\begin{array}{l}\text { Pernas flexionam levemente ou alguma } \\
\text { resistência é observada }\end{array}$ & $\begin{array}{l}\text { Legs slightly flexed or some resistance } \\
\text { observed }\end{array}$ \\
\hline Leg flexes well till bottom lifts up & Pernas flexionam bem até elevar os quadris & Legs flex well until hips are raised \\
\hline $\begin{array}{l}\text { Knee flexes - remains flexed when } \\
\text { bottom up }\end{array}$ & $\begin{array}{l}\text { Joelhos flexionam e permanecem flexionados } \\
\text { quando os quadris são levantados }\end{array}$ & $\begin{array}{l}\text { Knees flex and remain flexed when hips } \\
\text { are lifted }\end{array}$ \\
\hline $\begin{array}{l}\text { Flexion stays when back + bottom } \\
\text { up }\end{array}$ & $\begin{array}{l}\text { Flexão se mantem quando o quadril e as costas } \\
\text { são levantados }\end{array}$ & $\begin{array}{l}\text { Flexion is maintained when the hip and } \\
\text { back are lifted }\end{array}$ \\
\hline $\begin{array}{l}\text { Popliteal angle - Fix knee on } \\
\text { abdomen (belly), try to extend } \\
\text { knee with first finger. Note } \\
\text { distance (angle) between upper } \\
\text { and lower limb. }\end{array}$ & $\begin{array}{l}\text { Ângulo poplíteo - Coloque o joelho no abdome, } \\
\text { estenda a perna realizando uma leve pressão por } \\
\text { trás do tornozelo com o dedo indicador. Observe } \\
\text { o ângulo do joelho. }\end{array}$ & $\begin{array}{l}\text { Popliteal angle - Place knee to } \\
\text { abdomen, extend leg by pressing lightly } \\
\text { behind ankle with index finger. Observe } \\
\text { the angle at the knee. }\end{array}$ \\
\hline $\begin{array}{l}\text { Head control (1) - Baby sitting } \\
\text { upright. Encircle chest with both } \\
\text { hands holding shoulders. Let head } \\
\text { drop forward. }\end{array}$ & $\begin{array}{l}\text { Controle da cabeça (1) - Bebê sentado. Abrace } \\
\text { o peito do bebê com ambas as mãos, segurando } \\
\text { os ombros. Deixe a cabeça cair para frente }\end{array}$ & $\begin{array}{l}\text { Head control (1) - Babysitting. } \\
\text { Embrace the baby's chest with both } \\
\text { hands, holding shoulders. Let head fall } \\
\text { forward. }\end{array}$ \\
\hline No attempt to raise head & Nenhuma tentativa de levantar a cabeça & No attempt to raise head \\
\hline $\begin{array}{l}\text { Infant tries: effort better felt than } \\
\text { seen }\end{array}$ & $\begin{array}{l}\text { Lactente tenta levantar; esforço é mais sentido do } \\
\text { que observado }\end{array}$ & $\begin{array}{l}\text { Infant tries to get up; effort is more felt } \\
\text { than observed }\end{array}$ \\
\hline $\begin{array}{l}\text { Raises head but drops forward or } \\
\text { back }\end{array}$ & cabeça, mas a deixa cair para frente ou & $\begin{array}{l}\text { Raises head, but lets it fall forward or } \\
\text { backward }\end{array}$ \\
\hline $\begin{array}{l}\text { Raises head: remains vertical; } \\
\text { wobbles }\end{array}$ & $\begin{array}{l}\text { cabeça: permanece na vertical; } \\
\text { oscilações }\end{array}$ & $\begin{array}{l}\text { Raises head: stays upright; shows } \\
\text { oscillations }\end{array}$ \\
\hline $\begin{array}{l}\text { Head control (2) - Baby sitting } \\
\text { upright. Encircle chest with both } \\
\text { hands holding shoulders. Let head } \\
\text { drop backward. }\end{array}$ & $\begin{array}{l}\text { Controle da cabeça (2) - Bebê sentado. Abrace } \\
\text { o peito com ambas mãos, segurando os ombros. } \\
\text { Deixe a cabeça cair para trás. }\end{array}$ & $\begin{array}{l}\text { Head control (2) - Baby sitting. } \\
\text { Embrace chest with both hands, holding } \\
\text { shoulders. Let head fall back. }\end{array}$ \\
\hline ipt to raise head & beça & No \\
\hline $\begin{array}{l}\text { Infant tries: effort better felt than } \\
\text { seen }\end{array}$ & levantar; esforço é mais sentido do & $\begin{array}{l}\text { Infant tries to raise head; effort is more } \\
\text { felt than observed }\end{array}$ \\
\hline $\begin{array}{l}\text { Raises head but drops forward or } \\
\text { back }\end{array}$ & cabeça, mas a deixa cair para frente ou & $\begin{array}{l}\text { Raises head, but lets it fall forward or } \\
\text { backward }\end{array}$ \\
\hline $\begin{array}{l}\text { Raises head: remains vertical; } \\
\text { wobbles }\end{array}$ & $\begin{array}{l}\text { cabeça: permanece na vertical; } \\
\text { oscilações }\end{array}$ & $\begin{array}{l}\text { ead: remains vertical; shows } \\
\text { ons }\end{array}$ \\
\hline $\begin{array}{l}\text { Head upright or extended, cannot } \\
\text { be passively flexed (pushed } \\
\text { forward) }\end{array}$ & $\begin{array}{l}\text { Cabeça ereta ou estendida, não pode ser } \\
\text { flexionada passivamente (empurrada para a } \\
\text { frente) }\end{array}$ & $\begin{array}{l}\text { Head upright or straight, cannot be } \\
\text { flexed passively (pushed forward) }\end{array}$ \\
\hline $\begin{array}{l}\text { Head lag - Pull baby to sit by the } \\
\text { wrists \& support head slightly. }\end{array}$ & $\begin{array}{l}\text { para sentar - Puxe o bebê pelos punhos } \\
\text { ntar e apoie levemente a cabeça. }\end{array}$ & $\begin{array}{l}\text { Pull to sit - Pull the baby by the wrists } \\
\text { to sit and lightly support the head. }\end{array}$ \\
\hline Head drops \& stays back & Cabeça cai e permanece para trás & Head falls and stays back \\
\hline Tries to lift head but it drops back & Tenta levantar a cabeça, mas esta cai para trás & Tries to lift head, but it falls backwards \\
\hline Able to lift head slightly & Capaz de levantar levemente a cabeça & Able to \\
\hline Lifts head in line with body & evanta a cadeça anminauda & . 1 l 1.0 \\
\hline Head in front of body & Cabeça à frente do corpo & Head in front of body \\
\hline $\begin{array}{l}\text { Ventral suspension - Hold baby } \\
\text { horizontal under the belly. Look at } \\
\text { posture of back, arms, legs and } \\
\text { head. If it looks different, DRAW. }\end{array}$ & $\begin{array}{l}\text { Suspensão ventral - Segure o bebê pelo abdome } \\
\text { em suspensão ventral. Observe a postura das } \\
\text { costas, braços, pernas e cabeça. Se ele parecer } \\
\text { diferente, DESENHE }\end{array}$ & $\begin{array}{l}\text { Ventral suspension - Hold baby by } \\
\text { abdomen in ventral suspension. } \\
\text { Observe the posture of the back, arms, } \\
\text { legs and head. If it looks different, } \\
\text { DRAW }\end{array}$ \\
\hline $\begin{array}{l}\text { Back curved, head \& limbs hang } \\
\text { straight }\end{array}$ & $\begin{array}{l}\text { Tronco flexionado. Cabeça e membros suspensos } \\
\text { e alinhados }\end{array}$ & $\begin{array}{l}\text { Trunk flexed. Head and limbs } \\
\text { suspended and aligned }\end{array}$ \\
\hline $\begin{array}{l}\text { Back curved, head, limb slightly } \\
\text { flexed }\end{array}$ & $\begin{array}{l}\text { Tronco flexionado, cabeça e membros levemente } \\
\text { flexionados }\end{array}$ & $\begin{array}{l}\text { Trunk flexed, head and limbs slightly } \\
\text { flexed }\end{array}$ \\
\hline Back slightly curved, limbs flexed & $\begin{array}{l}\text { Tronco levemente flexionado. Membros } \\
\text { flexionados }\end{array}$ & Trunk slightly flexed. Limbs flexed \\
\hline
\end{tabular}


Quadro 30 (continuação): Versões finais do processo de adaptação cultural do HNNE resumido

\begin{tabular}{|c|c|c|}
\hline $\begin{array}{l}\text { Back straight, head in line with } \\
\text { body, limbs flexed }\end{array}$ & $\begin{array}{l}\text { Tronco reto, cabeça alinhada com o tronco, } \\
\text { membros flexionados }\end{array}$ & $\begin{array}{l}\text { Trunk straight, head aligned with trunk, } \\
\text { limbs flexed }\end{array}$ \\
\hline Back straight, head above body & Tronco alinhado, cabeça acima do corpo & Trunk aligned, head above the body \\
\hline MOVEMENTS & MOVIMENTOS & MOVEMENTS \\
\hline $\begin{array}{l}\text { Spontaneous movement - Watch } \\
\text { baby while (s) he is lying on back. }\end{array}$ & $\begin{array}{l}\text { Movimentos espontâneos - Observe o lactente } \\
\text { enquanto ele (a) está deitado em supino }\end{array}$ & $\begin{array}{l}\text { Spontaneous movements - Observe } \\
\text { the infant while he/she is lying in } \\
\text { supine }\end{array}$ \\
\hline No movement & Sem movimento & No movement \\
\hline Few stretches, no other movement & Poucos alongamentos, nenhum outro movimento & Few stretches, no other movement \\
\hline $\begin{array}{l}\text { Jerky movement, stretches, but } \\
\text { also some smooth movement }\end{array}$ & $\begin{array}{l}\text { Espasmos, alongamentos, mas também alguns } \\
\text { movimentos mais suaves. }\end{array}$ & $\begin{array}{l}\text { Spasms, stretching, but also some slight } \\
\text { movements. }\end{array}$ \\
\hline Smooth movements of arms + legs & Movimentos suaves de braços e pernas & Slight arm and leg movement \\
\hline $\begin{array}{l}\text { Fits, cramped or other abnormal } \\
\text { movements: DESCRIBE!! }\end{array}$ & $\begin{array}{l}\text { Convulsões, espasmos ou outros movimentos } \\
\text { anormais: DESCREVA!! }\end{array}$ & $\begin{array}{l}\text { Convulsions, spasms or other abnormal } \\
\text { movements: DESCRIBE!! }\end{array}$ \\
\hline Abnormal hand or toe postures & Postura anormal das mãos ou dedos dos pés & Abnormal hand or toe posture \\
\hline Hands open & Mãos abertas & Hands open \\
\hline $\begin{array}{l}\text { Hands fisted or thumbs adduct } \\
\text { intermittently but open }\end{array}$ & $\begin{array}{l}\text { Mãos fechadas ou polegares aduzidos de forma } \\
\text { intermitente, porém abertos }\end{array}$ & $\begin{array}{l}\text { Closed hands or thumbs adduct } \\
\text { intermittently but open }\end{array}$ \\
\hline $\begin{array}{l}\text { Hands fist or thumb adducts, or } \\
\text { finger \& thumb oppose }\end{array}$ & $\begin{array}{l}\text { Mãos fechadas ou polegar aduzido, ou dedo } \\
\text { (indicador) e polegar em oposição. }\end{array}$ & $\begin{array}{l}\text { Hands closed or thumb adducts, or } \\
\text { finger (forefinger) and thumb in } \\
\text { opposition. }\end{array}$ \\
\hline $\begin{array}{l}\text { Big toe up (extended) or all toes } \\
\text { flex }\end{array}$ & $\begin{array}{l}\text { Hálux para cima (estendido) ou todos os dedos } \\
\text { flexionados }\end{array}$ & Hallux up (extended) or all toes flex \\
\hline Tremor & Tremor & Tremor \\
\hline No tremor & Sem tremor & No tremor \\
\hline $\begin{array}{l}\text { Tremor only when crying or after } \\
\text { Moro reflex }\end{array}$ & $\begin{array}{l}\text { Tremor somente quando chora ou após reflexo de } \\
\text { Moro }\end{array}$ & $\begin{array}{l}\text { Tremor only when crying or after Moro } \\
\text { reflex }\end{array}$ \\
\hline Some tremor when awake & Alguns tremores quando acordado & Some tremors when awake \\
\hline Frequent tremors & Tremores frequentes & Frequent tremors \\
\hline Continuous tremors & Tremores contínuos & Continuous tremors \\
\hline $\begin{array}{l}\text { Startle - Similar movements to } \\
\text { Moro reflex but not doing Moro } \\
\text { test }\end{array}$ & $\begin{array}{l}\text { Sobressalto/Susto - Movimentos semelhantes } \\
\text { aos do Reflexo de Moro, porém não executado } \\
\text { no teste de Moro }\end{array}$ & $\begin{array}{l}\text { Startle/Shock - Movements similar to } \\
\text { those of Moro's Reflex, but not } \\
\text { executed in the Moro's test }\end{array}$ \\
\hline No startle & Sem susto/sobressalto & No shock/ startling \\
\hline $\begin{array}{l}\text { Startle to sudden noise or bang on } \\
\text { table }\end{array}$ & $\begin{array}{l}\text { Susto/sobressaltos com barulhos súbitos ou ao } \\
\text { bater na mesa }\end{array}$ & $\begin{array}{l}\text { Shock/startling with sudden noises or } \\
\text { hitting the table }\end{array}$ \\
\hline 2 or 3 spontaneous startles & 2 ou 3 sustos/sobressaltos espontâneos & 2 or 3 spontaneous shock/startling \\
\hline 3 - 5 spontaneous startles & 3 - 5 sustos/sobressaltos espontâneos & 3 - 5 spontaneous shock/startling \\
\hline More than 6 spontaneous startles & Mais que 6 sustos/sobressaltos espontâneos & $\begin{array}{l}\text { More than } 6 \text { spontaneous } \\
\text { shock/startling }\end{array}$ \\
\hline REFLEXES = test both sides & REFLEXOS = teste ambos os lados & REFLEXES = test both sides \\
\hline $\begin{array}{l}\text { Suck \& Gag - Watch on breast; if } \\
\text { no suck is seen, put little finger } \\
\text { into mouth with pulp of finger } \\
\text { upwards. }\end{array}$ & $\begin{array}{l}\text { Reflexo de Sucção - Observe no peito, se não for } \\
\text { percebida a sucção, coloque o dedo mínimo } \\
\text { dentro da boca com a polpa do dedo para cima }\end{array}$ & $\begin{array}{l}\text { Sucking Reflex - Observe on chest, if } \\
\text { suction is not noticeable, place the little } \\
\text { finger inside the mouth with the finger } \\
\text { pulp upwards }\end{array}$ \\
\hline No gag/ no suck & Sucção ausente & No suck \\
\hline $\begin{array}{l}\text { Weak suck only: A) irregular B) } \\
\text { regular No stripping }\end{array}$ & $\begin{array}{l}\text { Somente sucção fraca: a) irregular; b) regular. } \\
\text { Não remove a boca do estímulo }\end{array}$ & $\begin{array}{l}\text { Only weak suction: a) irregular; b) } \\
\text { regular. Does not withdraw the mouth } \\
\text { from the stimulus }\end{array}$ \\
\hline Infant sucks well on the breast & Lactente suga bem no peito & Infant sucks well on the breast \\
\hline $\begin{array}{l}\text { Strong suck: A) irregular B) } \\
\text { regular Good stripping }\end{array}$ & $\begin{array}{l}\text { Sucção forte: (a) irregular; (b) regular. Retira } \\
\text { adequadamente a boca do estímulo }\end{array}$ & $\begin{array}{l}\text { Strong suck: (a) irregular; (b) regular. } \\
\text { Properly withdraws the mouth from the } \\
\text { stimulus }\end{array}$ \\
\hline No suck but strong clenching & Não suga, porém, apresenta forte "pega" & $\begin{array}{l}\text { Does not suck, but presents strong "jaw } \\
\text { blockig" }\end{array}$ \\
\hline $\begin{array}{l}\text { Palmar Grasp - Stroke inside of } \\
\text { hand. Do not touch back of hand!! }\end{array}$ & $\begin{array}{l}\text { Preensão palmar - Pressione a palma da mão. } \\
\text { Não toque o dorso da mão!! }\end{array}$ & $\begin{array}{l}\text { Palmar Grasp - Press the palm of the } \\
\text { hand. Do not touch the back of the } \\
\text { hand!! }\end{array}$ \\
\hline No reaction & Sem reação & No reaction \\
\hline
\end{tabular}


Quadro 30 (continuação): Versões finais do processo de adaptação cultural do HNNE resumido

\begin{tabular}{|c|c|c|}
\hline Short, weak flexion of fingers & Flexão dos dedos fraca e curta & Flexion of the fingers weak and short \\
\hline Strong flexion of fingers & Forte flexão dos dedos & Strong flexion of fingers \\
\hline Strong finger flexion, shoulder & Forte flexão dos dedos, ombro $\uparrow$ & Strong flexion of fingers shoulder $\uparrow$ \\
\hline Strong finger flexion, whole body & Forte flexão dos dedos, corpo inteiro $\uparrow$ & Strong flexion fingers, whole body \\
\hline $\begin{array}{l}\text { Plantar Grasp - Press on sole } \\
\text { below toes. }\end{array}$ & $\begin{array}{l}\text { Preensão plantar - Pressione na superfície } \\
\text { plantar abaixo dos dedos dos pés. }\end{array}$ & $\begin{array}{l}\text { Plantar Grasp - Press on the plantar } \\
\text { surface below the toes. }\end{array}$ \\
\hline No response & Sem resposta & No response \\
\hline Toes flex (bend) slightly & Dedos flexionam (dobram) ligeiramente & Toe flex (fold) slightly \\
\hline Toes curve around finger & $\begin{array}{l}\text { Dedos flexionam em torno do dedo do } \\
\text { examinador }\end{array}$ & Toes flex around the examiner's finger \\
\hline $\begin{array}{l}\text { Moro Reflex - Put baby in } \\
\text { position shown in drawing } 1 \\
\text { below. Bring head forward and } \\
\text { suddenly let it fall back slightly }\end{array}$ & $\begin{array}{l}\text { Reflexo de Moro - Coloque o bebê na posição } \\
\text { ilustrada no desenho } 1 \text { abaixo. Traga a cabeça } \\
\text { para a frente e de forma repentina deixe-a cair } \\
\text { levemente para trás }\end{array}$ & $\begin{array}{l}\text { Moro Reflex - Place baby in the } \\
\text { position shown in drawing } 1 \text { below. } \\
\text { Bring head forward and suddenly let it } \\
\text { fall slightly backward }\end{array}$ \\
\hline No response & Sem resposta & No response \\
\hline $\begin{array}{l}\text { Full abduction of the arms, } \\
\text { extension at the elbow, no } \\
\text { adduction }\end{array}$ & $\begin{array}{l}\text { Abdução completa dos braços, extensão dos } \\
\text { cotovelos; nenhuma adução }\end{array}$ & $\begin{array}{l}\text { Complete abduction of arms, extension } \\
\text { of elbows; no adduction }\end{array}$ \\
\hline $\begin{array}{l}\text { Full abduction, little or delayed } \\
\text { adduction }\end{array}$ & Abdução completa, adução breve ou atrasada & $\begin{array}{l}\text { Complete abduction, brief or delayed } \\
\text { adduction }\end{array}$ \\
\hline $\begin{array}{l}\text { Arms do not fully abduct but good } \\
\text { adduction }\end{array}$ & $\begin{array}{l}\text { Braços não abduzem totalmente, porém boa } \\
\text { adução }\end{array}$ & $\begin{array}{l}\text { Arms do not fully abduct, but good } \\
\text { adduction }\end{array}$ \\
\hline $\begin{array}{l}\text { Adduction only; Extension at the } \\
\text { elbow only }\end{array}$ & $\begin{array}{l}\bullet \text { Somente adução; • Somente extensão do } \\
\text { cotovelo }\end{array}$ & $\begin{array}{l}\bullet \text { Adduction only; } \bullet \text { Elbow extension } \\
\text { only }\end{array}$ \\
\hline $\begin{array}{l}\text { Placing - Hold infant upright. } \\
\text { Stroke front of the baby's lower } \\
\text { leg on edge of table. }\end{array}$ & $\begin{array}{l}\text { Colocação das Pernas - Segure o lactente na } \\
\text { posição vertical. Toque o dorso do pé do bebê na } \\
\text { borda da mesa. }\end{array}$ & $\begin{array}{l}\text { Leg Placing - Hold the infant upright. } \\
\text { Touch the back of the baby's foot on the } \\
\text { edge of the table. }\end{array}$ \\
\hline Nothing happens & Nada acontece & Nothing happens \\
\hline Baby flexes ankle & Bebê flexiona o tornozelo & Baby flexes ankle \\
\hline $\begin{array}{l}\text { Baby flexes hip, knee, and ankle \& } \\
\text { steps on table }\end{array}$ & $\begin{array}{l}\text { Bebê flexiona quadril, joelho e tornozelo e pisa } \\
\text { na mesa }\end{array}$ & $\begin{array}{l}\text { Baby flexes hip, knee and ankle and } \\
\text { steps on the table }\end{array}$ \\
\hline $\begin{array}{l}\text { ORIENTATION AND } \\
\text { BEHAVIOR }\end{array}$ & ORIENTAÇÃO E COMPORTAMENTO & ORIENTATION AND BEHAVIOR \\
\hline Eye & Olho & Eye \\
\hline Does not open eyes & Não abre os olhos & Does not open eyes \\
\hline $\begin{array}{l}\text { Normal eye movement, eyes move } \\
\text { together }\end{array}$ & $\begin{array}{l}\text { Movimento normal do olho, os olhos se movem } \\
\text { juntos }\end{array}$ & $\begin{array}{l}\text { Normal eye movement, eyes move } \\
\text { together }\end{array}$ \\
\hline $\begin{array}{l}\text { Abnormal eye movements: } \\
\text { DESCRIBE!! }\end{array}$ & Movimentos anormais dos olhos. DESCREVA!! & $\begin{array}{l}\text { Abnormal movement of eyes. } \\
\text { DESCRIBE!! }\end{array}$ \\
\hline $\begin{array}{l}\text { Auditory Orientation - Must not } \\
\text { be asleep. Wrap infant. Hold rattle } \\
10(0 \%) \text { to } 15 \mathrm{~cm} \text { from ear. }\end{array}$ & $\begin{array}{l}\text { Orientação Auditiva - Não deverá estar } \\
\text { dormindo. Enrole o lactente. Segure um chocalho } \\
10 \text { a } 15 \mathrm{~cm} \text { de distância da orelha. }\end{array}$ & $\begin{array}{l}\text { Auditory Orientation - Must not be } \\
\text { sleeping. Wrap the infant. Hold a rattle } \\
10(0 \%) \text { to } 15 \mathrm{~cm} \text { from the ear. }\end{array}$ \\
\hline No reaction & Sem reação & No reaction \\
\hline Brightens (wakes up) & Anima-se (acorda) & Cheers up (wakes up) \\
\hline $\begin{array}{l}\text { Turns eyes and sometimes turns } \\
\text { head a bit also }\end{array}$ & $\begin{array}{l}\text { Movimenta os olhos e às vezes também vira um } \\
\text { pouco a cabeça }\end{array}$ & $\begin{array}{l}\text { Move eyes and sometimes turns head a } \\
\text { little too }\end{array}$ \\
\hline $\begin{array}{l}\text { Turns eyes and head fully to side } \\
\text { of noise }\end{array}$ & $\begin{array}{l}\text { Movimenta os olhos e a cabeça totalmente para o } \\
\text { lado do barulho }\end{array}$ & $\begin{array}{l}\text { Turn eyes and head completely toward } \\
\text { the noise side }\end{array}$ \\
\hline $\begin{array}{l}\text { Turns head and eyes strongly to } \\
\text { noise; does not tire }\end{array}$ & $\begin{array}{l}\text { Vira fortemente a cabeça e os olhos para o } \\
\text { barulho/ruído; não se cansa }\end{array}$ & $\begin{array}{l}\text { Turn eyes and head strongly toward the } \\
\text { noise/rattling; does not tire }\end{array}$ \\
\hline $\begin{array}{l}\text { Visual Alertness - Wrap infant, } \\
\text { wake up with rattle if needed or } \\
\text { rock baby a bit. Look if baby can } \\
\text { see and follow red ball (B) or a } \\
\text { target }(\mathrm{T})\end{array}$ & $\begin{array}{l}\text { Alerta Visual - Enrole o lactente, acorde-o com } \\
\text { o chocalho se necessário, ou gentilmente sacuda- } \\
\text { o um pouco. Observe se o bebê pode ver e seguir } \\
\text { uma bola vermelha (B) ou um objeto }(\mathrm{O})\end{array}$ & $\begin{array}{l}\text { Visual Alert - Wrap the infant, wake } \\
\text { with rattle if necessary, or gently shake } \\
\text { a little. Observe if baby can see and } \\
\text { follow a red ball (B) or an object }(\mathrm{O})\end{array}$ \\
\hline $\begin{array}{l}\text { Does not follow or focus on red } \\
\text { ball or target }\end{array}$ & Não segue ou foca a bola vermelha ou o objeto & $\begin{array}{l}\text { Does not follow or focus on the red ball } \\
\text { or object }\end{array}$ \\
\hline $\begin{array}{l}\text { Stills, focuses, follows very briefly } \\
\text { to side and up but loses it quickly }\end{array}$ & $\begin{array}{l}\text { Fica quieto, foca, segue muito brevemente para o } \\
\text { lado e para cima, mas os perde rapidamente }\end{array}$ & $\begin{array}{l}\text { Stay still, focuses, follows very briefly } \\
\text { to side and up, but quickly loses it }\end{array}$ \\
\hline
\end{tabular}


Quadro 30 (continuação): Versões finais do processo de adaptação cultural do HNNE resumido

\begin{tabular}{|c|c|c|}
\hline $\begin{array}{l}\text { Follows with eyes to the side and } \\
\text { up, may turn head }\end{array}$ & $\begin{array}{l}\text { Segue com os olhos para o lado e para cima, } \\
\text { pode virar a cabeça }\end{array}$ & $\begin{array}{l}\begin{array}{l}\text { Follows with eyes to side and up, can } \\
\text { turn head }\end{array} \\
\end{array}$ \\
\hline $\begin{array}{l}\text { Follows with eyes to the side and } \\
\text { up, turns head always }\end{array}$ & $\begin{array}{l}\text { Segue com os olhos para o lado e para cima, } \\
\text { sempre virando a cabeça }\end{array}$ & $\begin{array}{l}\text { Follows with eyes to side and up always } \\
\text { turning head }\end{array}$ \\
\hline Follows in a circle & Segue o objeto em círculo & Follows object in a circle \\
\hline $\begin{array}{l}\text { Alertness - Tested as response to } \\
\text { red ball }(\mathrm{R}) \text { or target }(\mathrm{T}) \text {. How } \\
\text { long infant interested. }\end{array}$ & $\begin{array}{l}\text { Estado de Alerta - Testado como resposta à bola } \\
\text { vermelha }(\mathrm{B}) \text { ou objeto }(\mathrm{O}) \text {. Quanto tempo o } \\
\text { lactente se manteve interessado }\end{array}$ & $\begin{array}{l}\text { Alertness State - Tested in response to } \\
\text { red ball }(\mathrm{R}) \text { or object }(\mathrm{O}) \text {. How long the } \\
\text { infant remained interested }\end{array}$ \\
\hline Will not respond to red ball & Não responde à bola vermelha & Does not respond to red ball \\
\hline When awake, looks only briefly & Quando acordado, olha apenas brevemente & When awake, looks only briefly \\
\hline $\begin{array}{l}\text { When awake, looks at red ball but } \\
\text { loses it }\end{array}$ & $\begin{array}{l}\text { Quando acordado, olha para a bola vermelha, } \\
\text { porém a perde }\end{array}$ & $\begin{array}{l}\text { When awake, looks at red ball, but loses } \\
\text { it }\end{array}$ \\
\hline Keeps interest in red ball & Mantém interesse na bola vermelha & Maintains interest in red ball \\
\hline Does not tire & Não se cansa & Does not get tired \\
\hline $\begin{array}{l}\text { Peak of Excitement - Circle ' } H \text { ' if } \\
\text { high-pitch cry }\end{array}$ & $\begin{array}{l}\text { Auge da Excitação - Circule E se o choro for } \\
\text { estridente }\end{array}$ & $\begin{array}{l}\text { Peak of Excitement - Circle S if the } \\
\text { cry is strident }\end{array}$ \\
\hline Quiet all the time & Quieto o tempo todo & Quiet all the time \\
\hline Awakes briefly, does not cry & Acorda brevemente, não chora & Wakes briefly, but does not cry \\
\hline Awakes briefly, cries sometimes & Acorda brevemente, às vezes chora & Wakes briefly, sometimes cries \\
\hline Cries always when handled & Sempre chora quando manuseado & Always cries when handled \\
\hline Cries always & Chora sempre & Always cries \\
\hline $\begin{array}{l}\text { Consolability - How easy is it to } \\
\text { make baby quiet? }\end{array}$ & $\begin{array}{l}\text { Consolabilidade - O quanto é fácil acalmar o } \\
\text { bebê? }\end{array}$ & $\begin{array}{l}\text { Consolability - How easy is it to calm } \\
\text { down the baby? }\end{array}$ \\
\hline Never awake or crying & Nunca acordado ou chorando & Never awake or crying \\
\hline $\begin{array}{l}\text { Awake but never cries; consoling } \\
\text { not needed }\end{array}$ & $\begin{array}{l}\text { Acordado, mas nunca chora; não precisa de } \\
\text { consolo }\end{array}$ & $\begin{array}{l}\text { Awake, but never cries; does not need } \\
\text { consolation }\end{array}$ \\
\hline Becomes quiet when talked to & Fica calmo/quieto quando se conversa com ele & Stays calm/quiet when talking to baby \\
\hline Needs picking up to console & Precisa ser carregado para ser consolado & Needs to be carried to be comforted \\
\hline Cannot be consoled & Não pode ser consolado & Cannot be consoled \\
\hline COMMENT & COMENTÁRIOS: & COMMENTS: \\
\hline EXAMINER & EXAMINADOR: & EXAMINER: \\
\hline
\end{tabular}

Quadro 31: Versões finais do processo de adaptação cultural do HNNE expandido

\begin{tabular}{|l|l|l|}
\hline \multicolumn{1}{|c|}{ INGLESS ORIGINAL } & \multicolumn{1}{|c|}{ PORTUGUÊS - FINAL } & \multicolumn{1}{c|}{ RETROTRADUÇÃO - FINAL } \\
\hline $\begin{array}{l}\text { Hammersmith Neonatal Neurological } \\
\text { Examination }\end{array}$ & $\begin{array}{l}\text { Exame Neurológico Neonatal - } \\
\text { Hammersmith }\end{array}$ & $\begin{array}{l}\text { Hammersmith Neonatal Neurological } \\
\text { Examination }\end{array}$ \\
\hline Code & Registro do paciente & Patient registration \\
\hline D.O.E & Data da avaliação & Date of assessment \\
\hline Name & Nome & Name \\
\hline Sex & Sexo & Sex \\
\hline Race & Raça & Race \\
\hline D.O.B & Data de Nascimento & Date of birth \\
\hline Age & Idade & Age \\
\hline G.A & Idade gestacional & Gestational age \\
\hline BW & Peso ao nascimento & Birth weigh \\
\hline POSTURE AND TONE & POSTURA E TÔNUS & POSTURE AND TONE \\
\hline $\begin{array}{l}\text { Posture - Infant supine. Look mainly } \\
\text { at position of legs but also note arms. } \\
\text { Score predominant posture. }\end{array}$ & $\begin{array}{l}\text { Postura - Lactente em supino. Observe } \\
\text { principalmente a posição das pernas, mas } \\
\text { também observe os braços. Pontue a postura } \\
\text { predominante }\end{array}$ & $\begin{array}{l}\text { Posture - Infant supine. Observe } \\
\text { especially the position of the legs, but } \\
\text { also observe the arms. Score the } \\
\text { predominant posture }\end{array}$ \\
\hline $\begin{array}{l}\text { Arms \& legs extended or very slightly } \\
\text { flexed }\end{array}$ & $\begin{array}{l}\text { Braços e pernas estendidos ou muito pouco } \\
\text { flexionados }\end{array}$ & $\begin{array}{l}\text { Arms and legs extended or slightly } \\
\text { flexed }\end{array}$ \\
\hline Legs slightly flexed & Pernas levemente flexionadas & Legs slightly flexed \\
\hline Legs well flexed but not adducted & Pernas bem flexionadas, mas não aduzidas & Legs well flexed, but not adducted \\
\hline $\begin{array}{l}\text { Legs well flexed \& adducted near } \\
\text { abdomen }\end{array}$ & $\begin{array}{l}\text { Pernas bem flexionadas e aduzidas próximas } \\
\text { ao abdome }\end{array}$ & $\begin{array}{l}\text { Legs well flexed and adducted near the } \\
\text { abdomen }\end{array}$ \\
\hline
\end{tabular}


Quadro 31 (continuação): Versões finais do processo de adaptação cultural do HNNE expandido

Abnormal posture: a) opisthotonos; b) marked leg extension, strong arm flexion

Arm Recoil - Take both hands; quickly extend arms parallel to the body, Count to three. Release. Repeat 3 times

Arms do not flex

Arms flex slowly, not always; not completely

Arms flex slowly; more completely

Arms flex quickly and completely

Arms difficult to extend; snap back forcefully

Arm Traction - Hold wrist and pull arm upwards. Note flexion at elbow and resistance while shoulder lifts off table. Test each side separately.

Arms remain straight; no resistance

felt

Arms flex slightly or some resistance felt

Arms flex well till shoulder lifts, then straighten

Arms flex at approx. $100^{\circ} \&$ maintained as shoulder lifts

Flexion of arms $<100^{\circ}$. Maintained when body lifts up

Leg Recoil - Take both ankles in one hand, flex hips + knees. Quickly extend. Release. Repeat 3 times

No flexion

Postura anormal: a) opistótono; b) Extensão acentuada da perna e forte flexão dos braços

Teste de Recolhimento dos Braços - Pegue ambas as mãos, estenda rapidamente os braços paralelos ao corpo, conte até três. Relaxe. Repita 3 vezes. Braços não flexionam

Braços flexionam lentamente, mas nem sempre; não completamente

Braços flexionam lentamente, porém completamente

Braços flexionam rápido e completamente

Braços difíceis de estender; flexionam de volta vigorosamente

Tração do Braço - Segure no punho e puxe o braço para cima. Observe a flexão e a resistência do cotovelo, enquanto o ombro é separadamente.

Braços permanecem retos; nenhuma resistência observada.

Braços flexionam levemente ou alguma resistência é observada.

Braços bem fletidos até elevação do ombro, seguido por retificação do braço.

Braços flexionam até aproximadamente $100^{\circ}$ e mantêm-se quando os ombros são elevados

Flexão de braços $<100^{\circ}$; mantido quando o corpo é levantado

Recolhimento da Perna - Segure ambos os tornozelos com uma mão, flexione o quadril e os joelhos. Estenda rapidamente. Solte.

Repita três vezes.

Sem flexão

Incomplete or variable flexion

Complete but slow flexion

Complete fast flexion

Flexão incompleta ou variável

Flexão completa, porém, lenta

Flexão completa e rápida

Pernas difíceis de estender; retraem de volta vigorosamente

forcefully

Leg Traction - Grasp ankle and slowly pull leg upwards. Note flexion at knees and resistance as buttocks lift. Teste each side separately.

Legs straight - no resistance felt Legs flex slightly or some resistance felt

Legs flex well till bottom lifts up Knee flexes remains flexed when bottom up

Flexion stays when back + bottom up

Popliteal Angle - Fix knee on abdomen, extend leg by gentle pressure with index finger behind the ankle. Note angle at knee. Test each side separately.

Tração da Perna - Segure o tornozelo e puxe lentamente a perna para cima. Observe a flexão e a resistência do joelho enquanto eleva os quadris. Teste cada lado separadamente.

Pernas retas - sem resistência observada

Pernas flexionam levemente ou alguma resistência é observada

Pernas flexionam bem até elevar o quadril. Joelhos flexionam e permanecem flexionados quando os quadris são levantados.

Flexão se mantém quando o quadril e o tronco são levantados.

Ângulo Poplíteo - Coloque o joelho no abdome, estenda a perna realizando uma leve pressão por trás do tornozelo com o dedo indicador. Observe o ângulo do joelho. Teste cada lado separadamente. levantado da mesa. Teste cada lado

Abnormal posture: a) opisthotonic; b)

extensive leg extension and strong arm flexion

Arm Recoil Test - Take both hands,

quickly extend arms parallel to the body, count to three. Relax. Repeat 3 times.

Arms do not flex

Arms flex slowly but not always; not completely

Arms flex slowly but completely.

Arms flex quickly and completely

Arms difficult to extend; return to

flexed position vigorously

Arm Traction - Hold wrists and pull arms up. Observe elbow flexion and resistance while shoulder is raised from the table. Test each side separately.

Arms remain straight; no resistance observed

Arms flex slightly or some resistance is observed

Arms well flexed until shoulder

elevation, followed by rectification of arm

Arms flex up to approximately $100^{\circ}$ and flexion is maintained as shoulders are raised

Arms flex $<100^{\circ}$; maintained when the body is lifted

Leg Recoil - Hold both ankles with one hand, flex the hips and knees. Extend quickly. Release. Repeat three times.

No flexion

Incomplete or variable flexion

Complete but slow flexion

Complete and fast flexion
Legs difficult to extend; retract back vigorously

Leg Traction - Hold ankle and slowly pull leg up. Observe knee flexion and resistance while lifting hips. Test each side separately.

Straight legs - no observed resistance

Legs slightly flexed or some resistance observed

Legs flex well until the hip is raised Knees flex and remain flexed when hips are lifted

Flexion maintained when the hip and trunk are raised

Popliteal Angle - Place knee to abdomen, extend leg by pressing lightly behind ankle with index finger. Note angle of knee. Test each side separately. 
Quadro 31 (continuação): Versões finais do processo de adaptação cultural do HNNE expandido

\begin{tabular}{|c|c|c|}
\hline $\begin{array}{l}\text { Head Control (1) (extensor tone) - } \\
\text { Infant sitting upright. Encircle chest } \\
\text { with both hands holding shoulders. } \\
\text { Let head drop forward. }\end{array}$ & $\begin{array}{l}\text { Controle da Cabeça (1) (tônus extensor) - } \\
\text { Lactente sentado. Abrace o peito com ambas } \\
\text { as mãos, segurando os ombros. Deixe a } \\
\text { cabeça cair para frente. }\end{array}$ & $\begin{array}{l}\text { Head Control (1) (extensor tone) - } \\
\text { Infant sitting. Embrace chest with both } \\
\text { hands, holding the shoulders. Let head } \\
\text { fall forward. }\end{array}$ \\
\hline No attempt to raise head & Nenhuma tentativa de levantar a cabeça & No attempt to raise head \\
\hline Infant tries: effort better felt than seen & $\begin{array}{l}\text { Lactente tenta levantar; esforço é mais } \\
\text { sentido do que observado }\end{array}$ & $\begin{array}{l}\text { Infant tries to get up; effort is more felt } \\
\text { than observed }\end{array}$ \\
\hline Raises head but drops forward or back & $\begin{array}{l}\text { Levanta a cabeça, mas cai para a frente ou } \\
\text { para trás }\end{array}$ & $\begin{array}{l}\text { Raises head but falls forward or } \\
\text { backward }\end{array}$ \\
\hline $\begin{array}{l}\text { Raises head: remains vertical; it may } \\
\text { wobble }\end{array}$ & $\begin{array}{l}\text { Levanta a cabeça: permanece na vertical; } \\
\text { podendo oscilar }\end{array}$ & Raises head: stays upright; can oscillate \\
\hline $\begin{array}{l}\text { Head Control (2) (flexor tone) - } \\
\text { Infant sitting upright. Encircle chest } \\
\text { with both hands holding shoulders. } \\
\text { Let head drop backward. }\end{array}$ & $\begin{array}{l}\text { Controle da Cabeça (2) - (tônus flexor). } \\
\text { Lactente sentado. Abrace o peito com ambas } \\
\text { as mãos, segurando os ombros. Deixe a } \\
\text { cabeça cair para trás. }\end{array}$ & $\begin{array}{l}\text { Head Control (2) (flexor tone). - Infant } \\
\text { sitting. Embrace chest with both hands, } \\
\text { holding the shoulders. Let head fall } \\
\text { back. }\end{array}$ \\
\hline No attempt to raise head & Nenhuma tentativa de levantar a cabeça & No attempt to raise the head \\
\hline Infant tries: effort better felt than seen & $\begin{array}{l}\text { Lactente tenta levantar; esforço é mais } \\
\text { sentido do que observado }\end{array}$ & $\begin{array}{l}\text { Infant tries to get up; effort is more felt } \\
\text { than observed }\end{array}$ \\
\hline Raises head but drops forward or back & $\begin{array}{l}\text { Levanta a cabeça, mas cai para a frente ou } \\
\text { para trás }\end{array}$ & $\begin{array}{l}\text { Raises head, but falls forward or } \\
\text { backward }\end{array}$ \\
\hline $\begin{array}{l}\text { Raises head: remains vertical; it may } \\
\text { wobble }\end{array}$ & $\begin{array}{l}\text { a cabeça: permanece na vertical; } \\
\text { oscilar }\end{array}$ & Raises head: stays upright; can oscillate \\
\hline $\begin{array}{l}\text { upright or extended, cannot be } \\
\text { ely flexed }\end{array}$ & $\begin{array}{l}\text { u estendida, não pode ser } \\
\text { ivamente }\end{array}$ & $\begin{array}{l}\text { Head upright or straight, cannot be } \\
\text { passively flexed }\end{array}$ \\
\hline $\begin{array}{l}\text { Head Lag - Pull infant towards sitting } \\
\text { posture by traction on both wrists \& } \\
\text { support head slightly. Also note arm } \\
\text { flexion }\end{array}$ & $\begin{array}{l}\text { Puxar para Sentar - Puxe o lactente para a } \\
\text { postura sentada com tração em ambos os } \\
\text { punhos e apoiando levemente a cabeça. } \\
\text { Observe também a flexão do braço. }\end{array}$ & $\begin{array}{l}\text { Pull to Sit - Pull infant to seated } \\
\text { position with traction on both wrists and } \\
\text { lightly supporting head. Observe also } \\
\text { arm flexion. }\end{array}$ \\
\hline Head drops \&stays back & Cabe & ind stays back \\
\hline Tries to lift head but it dro & Tenta levantar a cabeça, mas esta cai para trás & Tries to lift head, but it falls backwards \\
\hline Able & & \\
\hline & & \\
\hline Head in front of body & & Head in front of body \\
\hline $\begin{array}{l}\text { Ventral Suspension - Hold infant in } \\
\text { ventral suspension. Observe back, } \\
\text { flexion of limbs, and relation of head } \\
\text { to trunk. If it looks different, DRAW. }\end{array}$ & $\begin{array}{l}\text { Suspensão Ventral - Segure o lactente em } \\
\text { suspensão ventral. Observe a coluna, flexão } \\
\text { dos membros e relação da cabeça com o } \\
\text { tronco. Se ele parecer diferente, DESENHE }\end{array}$ & $\begin{array}{l}\text { Ventral Suspension - Hold infant in } \\
\text { ventral suspension. Observe spine, } \\
\text { flexion of limbs and relation of head to } \\
\text { trunk. If it looks different, DRAW }\end{array}$ \\
\hline $\begin{array}{l}\text { Back curved, head \&limbs hang } \\
\text { straight }\end{array}$ & $\begin{array}{l}\text { Tronco flexionado. Cabeça e membros } \\
\text { suspensos e alinhados }\end{array}$ & $\begin{array}{l}\text { Trunk flexed. Head and limbs } \\
\text { suspended and aligned }\end{array}$ \\
\hline $\begin{array}{l}\text { Back curved, head }(\downarrow) \text {, limbs slightly } \\
\text { flexed }\end{array}$ & $\begin{array}{l}\text { flexionado. Cabeça para baixo (seta) } \\
\text { bros levemente flexionados }\end{array}$ & $\begin{array}{l}\text { Trunk flexed. Head down (arrow) and } \\
\text { limbs slightly flexed }\end{array}$ \\
\hline Back slightly curved, limbs flexed & flexionado. Membros & Trunk slightly flexed. Limbs flexed \\
\hline $\begin{array}{l}\text { Back straight, head in line, limbs } \\
\text { flexed }\end{array}$ & hado, cabeça alinhada com o & $\begin{array}{l}\text { ead aligned with the } \\
\text { ed }\end{array}$ \\
\hline Back straight, head above body & Tronco alinhado, cabeça acima do corpo & Trunk aligned, head above the body \\
\hline & PADRÕES DE TÔNUS & \\
\hline $\begin{array}{l}\text { Flexor Tone (1) (on traction: arm } \\
\text { versus leg) - Compare scores of arm } \\
\text { traction with leg traction }\end{array}$ & $\begin{array}{l}\text { Tônus Flexor (1) (tração: braço vs. perna) - } \\
\text { Compare pontuação da tração dos braços com } \\
\text { a tração das pernas }\end{array}$ & $\begin{array}{l}\text { Flexor Tone (1) (traction: arm vs. leg) - } \\
\text { Compare arm traction scores with leg } \\
\text { traction }\end{array}$ \\
\hline $\begin{array}{l}\text { Score for arm flexion less than leg } \\
\text { flexion }\end{array}$ & $\begin{array}{l}\text { Pontuação para flexão dos braços é menor } \\
\text { que a flexão das pernas }\end{array}$ & $\begin{array}{l}\text { Score for arm flexion less than leg } \\
\text { flexion }\end{array}$ \\
\hline $\begin{array}{l}\text { Score for arm flexion equal to leg } \\
\text { flexion }\end{array}$ & $\begin{array}{l}\text { Pontuação para flexão dos braços é igual a } \\
\text { flexão das pernas }\end{array}$ & $\begin{array}{l}\text { Score for arm flexion less than leg } \\
\text { flexion }\end{array}$ \\
\hline $\begin{array}{l}\text { Score for arm flexion more than leg } \\
\text { flexion but difference } 1 \text { column or less }\end{array}$ & $\begin{array}{l}\text { Pontuação da flexão dos braços é maior que a } \\
\text { flexão das pernas, porém com diferença de } 1 \\
\text { coluna ou menos }\end{array}$ & $\begin{array}{l}\text { Score for arm flexion more than leg } \\
\text { flexion but with difference of } 1 \text { column } \\
\text { or less }\end{array}$ \\
\hline
\end{tabular}


Quadro 31 (continuação): Versões finais do processo de adaptação cultural do HNNE expandido

\begin{tabular}{|l|}
\hline $\begin{array}{l}\text { Score for arm flexion more than leg } \\
\text { flexion but difference more than } 1 \\
\text { column }\end{array}$ \\
\hline $\begin{array}{l}\text { Flexor Tone (2) (arm versus leg) - } \\
\text { Posture in supine. }\end{array}$ \\
\hline Arms and legs flexed \\
\hline $\begin{array}{l}\text { Strong arm flexion with strong leg } \\
\text { extension intermittent }\end{array}$ \\
\hline $\begin{array}{l}\text { Strong arm flexion with strong leg } \\
\text { extension continuous }\end{array}$ \\
\hline
\end{tabular}

Leg Extensor Tone - Compare scores of leg traction and popliteal angle.

Score for leg traction more than score for popliteal angle

Score for leg traction equal to score for popliteal angle

Score for leg traction less than score for popliteal angle, by 1 column only

Score for leg traction less than score for popliteal angle, by more than 1 column

\section{Neck Extensor Tone (sitting) -}

Compare scores of head control 1 and 2.

Score for head extension less than

head flexion

Score for head extension equal to head flexion

Score for head extension more than head flexion, but difference 1 column or less

Score for head extension more than head flexion, but difference more than 1 column

\section{Increased Extensor Tone}

(horizontal) Compare scores of head

lag and ventral suspension.

Score for ventral suspension less than head lag

Score for ventral suspension equal to head lag

Score for ventral suspension more than head lag but difference 1 column or less

Score for ventral suspension more than head lag but difference more than 1 column

\section{REFLEXES}

Tendon Reflex - Test biceps, knee, and ankle jerks

Absent

Felt, not seen

Seen

"exaggerated" (very brisk)
Pontuação da flexão dos braços é maior que a Score for arm flexion more than leg flexão das pernas, porém com diferença de 1 flexion but with difference of 1 column coluna ou mais

Tônus Flexor (2) (braço vs. perna) -Postura em supino.

Braços e pernas flexionados or more

Forte flexão do braço com forte extensão intermitente da perna

Forte flexão do braço com forte extensão contínua da perna

Tônus Extensor Da Perna - Compare a

pontuação da tração da perna e do ângulo poplíteo

Pontuação da tração da perna é maior que a pontuação do ângulo poplíteo

Pontuação da tração da perna é igual a pontuação do ângulo poplíteo

Flexor Tone (2) (arm vs. leg) -Supine posture.

Arms and legs flexed

Strong arm flexion with strong intermittent extension of the leg Strong arm flexion with strong and continuous leg extension

Leg Extensor Tone - Compare scores of leg traction and popliteal angle

Score for leg greater than score for popliteal angle

Pontuação da tração da perna é menor que a $\quad$ Score for leg traction smaller than score pontuação do ângulo poplíteo, com diferença for popliteal angle, with difference of de somente 1 coluna

Pontuação da tração da perna é menor que a pontuação do ângulo poplíteo, porém com diferença maior que 1 coluna

Tônus Extensor do Pescoço (sentado) -

Compare a pontuação do controle de cabeça 1 e 2 .

Pontuação da extensão de cabeça é menor que a da flexão de cabeça

only 1 column

Score for leg traction smaller than score for popliteal angle, but with difference of more than 1 column

Neck Extensor Tone (sitting) -

Compare the score for head control 1 and 2.

Score for head extension smaller than that of head flexion

Pontuação da extensão de cabeça é igual à da flexão de cabeça

Pontuação da extensão da cabeça é maior que a flexão da cabeça, porém com diferença de 1 uma coluna ou menos

Pontuação da extensão de cabeça é maior que a flexão de cabeça, porém com diferença maior que 1 coluna

Aumento de Tônus Extensor (horizontal) Compare a pontuação do controle da cabeça no puxar para sentar e na suspensão ventral.

Pontuação do controle de cabeça na suspensão ventral é menor que a no puxar para sentar

Pontuação do controle da cabeça na suspensão ventral é igual a pontuação do puxar para sentar

Pontuação do controle da cabeça na suspensão ventral é maior que a do puxar para sentar, porém com diferença de 1 coluna ou menos

Pontuação do controle da cabeça na suspensão ventral é maior que a do puxar para sentar, porém com diferença maior que 1 coluna

\section{REFLEXOS}

Score for head extension equal to that of head flexion

Score for head extension greater than that of head flexion but with difference of 1 column or less

Score for head extension greater than that of head flexion but with difference of more than 1 column

Increase of Extensor Tone (horizontal) - Compare the score of head control on pulling to sit and in ventral suspension.

Score of head control in ventral suspension smaller than that on pulling to sit

Score of head control in ventral suspension equal to that on pulling to sit

Score of head control in ventral

suspension is greater than that on pulling to sit, but with difference of 1 column or less

Score of head control in ventral suspension is greater than that on pulling to sit, but with difference of more than 1 column

REFLEXES

Reflexo Tendíneo - Testar os reflexos bicipital, patelar e aquiliano

Tendon Reflex - Test biceps, patellar and Achilles reflexes Ausente Absent Sente na palpação, mas não é observado Feel palpation, but not noticeable Presente "Exagerado" (muito ativo) Present "Exaggerated" (very active) 
Quadro 31 (continuação): Versões finais do processo de adaptação cultural do HNNE expandido

\begin{tabular}{|l|}
\hline Clonus \\
$\begin{array}{l}\text { Suck/Gag - Little finger into mouth } \\
\text { with pulp of finger upwards. }\end{array}$ \\
\hline No gag/no suck \\
\hline $\begin{array}{l}\text { Weak irregular suck only. No } \\
\text { stripping }\end{array}$ \\
\hline
\end{tabular}

Weak regular suck. Some stripping

Strong suck: A) irregular; B) regular. Good stripping

No suck but strong clenching

Palmar Grasp - Put index finger into the hand and gently press palmar surface. Do not touch dorsal surface. Test each side separately.

No response

Short, weak flexion of fingers

Strong flexion of fingers

Strong finger flexion, shoulder

Very strong grasp; infant can be lifted off couch

Plantar Grasp - Press thumb on the sole below the toes. Test each side separately.

No response

Partial plantar flexion of toes

Toes curve around the examiner's finger

Placing - Lift infant in an upright position and stroke the dorsum of the foot against a protruding edge of a flat surface. Test each side separately

\section{No response}

Dorsiflexion of ankle only

Full placing response with flexion of hip and knee \& placing sole on surface

Moro Reflex - One hand supports infant's head in midline, the other the infant is relaxed let head fall through $10^{\circ}$. Note if jerky. Repeat 3 times. back. Raise infant to $45^{\circ}$ and when

\section{Clônus}

Reflexo de Sucção - Colocar dedo mínimo

dentro da boca com a polpa do dedo para cima

Resposta de sucção ausente

Somente sucção fraca e irregular. Não retira a boca do estímulo

Sucção fraca e regular. Retira a boca do estímulo algumas vezes

Sucção forte: (a) irregular; (b) regular. Retira adequadamente a boca do estímulo

Sem sucção, porém com forte "trava mandibular"

Preensão Palmar - Coloque o dedo indicador na palma da mão e pressione gentilmente a superfície palmar. Não toque a superfície dorsal. Teste cada lado separadamente

Sem resposta

Flexão dos dedos curta e fraca

Forte flexão dos dedos

Forte flexão dos dedos, ombro elevado

Preensão muito forte; lactente pode ser levantado da cama/superfície

Preensão Plantar - Pressione o polegar na superfície plantar, abaixo dos dedos. Teste cada lado separadamente

Sem resposta

Flexão plantar parcial dos dedos

Os dedos curvam sobre o dedo do examinador

Colocação das Pernas - Levante o lactente na posição vertical e bata o dorso do pé projetando-o contra a borda de uma superfície plana. Teste cada lado separadamente

Sem resposta

Somente dorsiflexão do tornozelo

Resposta completa do reflexo de colocação da perna, com flexão do quadril e joelho; coloca sola do pé na superfície

Reflexo de Moro - Uma mão suporta a cabeça do lactente em linha média e a outra o tronco. Levante o lactente a $45^{\circ}$ e quando o lactente estiver relaxado deixe a cabeça cair $10^{\circ}$. Observe se há espasmos. Repita 3 vezes

\begin{tabular}{ll|l} 
No response, or opening of hands only & Sem resposta, ou somente abertura das mãos
\end{tabular}

Full abduction at shoulder and extension of the arms; no adduction

Full abduction, but only delayed or partial adduction

Partial abduction at shoulder, and extension of arms followed by smooth adduction

Minimal abduction or adduction. No abduction or adduction, only forward extension of arms. Marked adduction only

Abdução completa dos ombros e extensão dos braços; sem adução

Abdução completa, porém, adução atrasada ou parcial

Abdução parcial dos ombros e extensão dos braços seguida por uma suave adução

Mínima abdução ou adução. Nenhuma abdução ou adução; somente extensão dos braços para frente. Somente adução acentuada

\section{Clonus}

Suck Reflexes - Place the little finger inside the mouth with the finger pulp upwards

No suck

Only weak and irregular sucking. Do not withdraw mouth from the stimulus

Weak and regular suck. Withdraw mouth from stimulus a few times Strong suck: (a) irregular; (b) regular, adequately. Remove mouth from stimulus

No suck, but strong "jaw blocking”

Palmar Grasp - Place the index finger into the palm of the hand and gently press the palmar surface. Do not touch the dorsal surface. Test each side separately

No response

Short and weak finger flexion

Strong finger flexion

Strong finger flexion, shoulder lifted up

Very strong grasp; infant can be lifted off the bed/surface

Plantar Grasp - Press thumb on the plantar surface, below the toes. Test each side separately

No response

Partial plantar flexion of toes

Toes curl on the examiner's finger

Leg Placing - Lift infant upright and tap instep by projecting it against the edge of a flat surface. Test each side separately

\section{No response}

Dorsiflexion of ankle only

Complete response of leg placement reflex, with hip and knee flexion; places sole of the foot on the surface

Moro Reflex - One hand supports infant's head at the midline and other hand supports trunk. Raise the infant to $45^{\circ}$ and when infant is relaxed, let head fall $10^{\circ}$. Observe if there are spasms. Repeat 3 times.

No response, or hands open only
Complete abduction of shoulders and arm extension; no adduction

Abduction complete, however delayed or partial adduction

Partial abduction of shoulders and arm extension followed by a smooth adduction

Minimal abduction or adduction. No abduction or adduction; Extension of arms forward. Accentuated adduction only 
Quadro 31 (continuação): Versões finais do processo de adaptação cultural do HNNE expandido

\begin{tabular}{|c|c|c|}
\hline MOVEMENTS & MOVIMENTOS & MOVEMENTS \\
\hline $\begin{array}{l}\text { Spontaneous Movement (quantity) - } \\
\text { Watch infant lying supine. }\end{array}$ & $\begin{array}{l}\text { Movimentos Espontâneos (quantidade). - } \\
\text { Observe o lactente deitado em supino }\end{array}$ & $\begin{array}{l}\text { Spontaneous Movements (quantity) - } \\
\text { Observe infant lying supine }\end{array}$ \\
\hline No movement & Sem movimento & No movement \\
\hline $\begin{array}{l}\text { Sporadic and short isolated } \\
\text { movements }\end{array}$ & Movimentos isolados esporádicos e curtos & Sporadic and short isolated movements \\
\hline Frequent isolated movements & Movimentos isolados frequentes & Frequent isolated movements \\
\hline Frequent generalized movements & Movimentos frequentes generalizados & Frequent generalized movements \\
\hline Continuous exaggerated movements & Movimentos contínuos exagerados & Exaggerated continuous movements \\
\hline $\begin{array}{l}\text { Spontaneous Movement (quality) - } \\
\text { Watch infant lying supine. }\end{array}$ & $\begin{array}{l}\text { Movimentos Espontâneos (qualidade) - } \\
\text { Observe o lactente deitado em supino }\end{array}$ & $\begin{array}{l}\text { Spontaneous Movements (quality) - } \\
\text { Observe infant lying supine }\end{array}$ \\
\hline Only stretches & Alonga-se apenas & Only stretches \\
\hline $\begin{array}{l}\text { Stretches and random abrupt } \\
\text { movements; some smooth movements }\end{array}$ & $\begin{array}{l}\text { Alongamentos e movimentos aleatórios } \\
\text { abruptos; alguns movimentos suaves }\end{array}$ & $\begin{array}{l}\text { Random and abrupt stretches and } \\
\text { movements; some slight movements }\end{array}$ \\
\hline Fluent movements but monotonous & Movimentos fluentes, porém, monótonos & Fluent, but monotonous movements \\
\hline $\begin{array}{l}\text { Fluent alternating movements of arms } \\
+ \text { legs; good variability }\end{array}$ & $\begin{array}{l}\text { Movimentos fluentes alternados de braços e } \\
\text { pernas; boa variabilidade }\end{array}$ & $\begin{array}{l}\text { Alternating fluent movements of arms } \\
\text { and legs; good variability }\end{array}$ \\
\hline $\begin{array}{l}\text { cramped, synchronized; mouthing } \\
\text { jerky or other abnormal movements }\end{array}$ & $\begin{array}{l}\bullet \text { Espasmódico, sincronizado; } \bullet \text { Movimento } \\
\text { de mastigação; } \bullet \text { Espasmos ou outros } \\
\text { movimentos anormais }\end{array}$ & $\begin{array}{l}* \text { Spasmodic, synchronized; } * \text { Chewing } \\
\text { movement; } * \text { Spasms or other abnormal } \\
\text { movements }\end{array}$ \\
\hline $\begin{array}{l}\text { Head Raising Prone - Infant in } \\
\text { prone, head in midline }\end{array}$ & $\begin{array}{l}\text { Elevação da Cabeça em Prono - Lactente } \\
\text { em prono, cabeça na linha média }\end{array}$ & $\begin{array}{l}\text { Head Elevated in Prone - Infant in } \\
\text { prone, head in midline }\end{array}$ \\
\hline No response & Sem resposta & No response \\
\hline Infant rolls head over, chin not raised & $\begin{array}{l}\text { Lactente rola a cabeça para o lado, sem } \\
\text { levantar o queixo }\end{array}$ & $\begin{array}{l}\text { Infant rolls head to side, without raising } \\
\text { the chin }\end{array}$ \\
\hline Infant raises chin, rolls head over & $\begin{array}{l}\text { Lactente levanta o queixo, rola a cabeça para } \\
\text { o lado }\end{array}$ & Infant raises chin, rolls head to the side \\
\hline Infant brings head and chin up & $\begin{array}{l}\text { Lactente levanta a cabeça e o queixo para } \\
\text { cima }\end{array}$ & Infant raises head and chin up \\
\hline Infant brings head up and keeps it up & Lactente leva a cabeça para cima e a mantém & Infant raises head up and maintains it up \\
\hline ABNORMAL SIGNS/PATTERNS & SINAIS/PADRÕES ANORMAIS & SIGNALS/STANDARD PATTERNS \\
\hline Abnormal Hand or Toes Postures & $\begin{array}{l}\text { Postura Anormal das Mãos ou Dedos dos } \\
\text { Pés }\end{array}$ & Abnormal Hand or Toe Posture \\
\hline $\begin{array}{l}\text { Hands open, toes straight most of the } \\
\text { time }\end{array}$ & $\begin{array}{l}\text { Mãos abertas, artelhos esticados na maior } \\
\text { parte do tempo }\end{array}$ & $\begin{array}{l}\text { Open hands, stretched toes most of the } \\
\text { time }\end{array}$ \\
\hline $\begin{array}{l}\text { Intermittent fisting or thumb } \\
\text { adduction }\end{array}$ & Mão fechada intermitente ou polegar aduzido & $\begin{array}{l}\text { Intermittent closed hand or adducted } \\
\text { thumb }\end{array}$ \\
\hline $\begin{array}{l}\text { Continuous fisting or thumb } \\
\text { adduction; index finger flexion, thumb } \\
\text { opposition }\end{array}$ & $\begin{array}{l}\text { Mão fechada continuamente ou polegar } \\
\text { aduzido; flexão do dedo indicador, oposição } \\
\text { do polegar }\end{array}$ & $\begin{array}{l}\text { Hand closed continuously or adducted } \\
\text { thumb; flexion of index finger, } \\
\text { opposition of the thumb }\end{array}$ \\
\hline $\begin{array}{l}\text { Continuous big toe extension or } \\
\text { flexion of all toes }\end{array}$ & $\begin{array}{l}\text { Extensão contínua do hálux ou flexão de } \\
\text { todos os dedos }\end{array}$ & $\begin{array}{l}\text { Continuous extension of the hallux or } \\
\text { flexion of all toes }\end{array}$ \\
\hline Tremor & Tremor & Tremor \\
\hline $\begin{array}{l}\text { No tremor, or tremor only when } \\
\text { crying or only after Moro reflex }\end{array}$ & $\begin{array}{l}\text { Sem tremor ou tremor somente quando chora } \\
\text { ou somente após reflexo de Moro }\end{array}$ & $\begin{array}{l}\text { No tremor, or tremor only when crying } \\
\text { or only after Moro reflex }\end{array}$ \\
\hline Tremor occasionally when awake & Tremor ocasional quando acordado & Occasional tremor when awake \\
\hline Frequent tremors when awake & Tremores frequentes quando acordado & Frequent tremors when awake \\
\hline Continuous tremors & Tremores contínuos & Continuous tremors \\
\hline Startle & Sobressalto/Susto & Startle/ Shock \\
\hline No startle even to sudden noise & Não se assusta mesmo com barulho súbito & $\begin{array}{l}\text { Without startle/shock even with sudden } \\
\text { noise }\end{array}$ \\
\hline $\begin{array}{l}\text { No spontaneous startle but reacts to } \\
\text { sudden noise }\end{array}$ & $\begin{array}{l}\text { Não se assusta espontaneamente, mas reage a } \\
\text { barulhos súbitos }\end{array}$ & $\begin{array}{l}\text { Does not scare spontaneously, but reacts } \\
\text { to sudden noises }\end{array}$ \\
\hline 2-3 spontaneous startles & 2-3 sobressaltos/ sustos espontâneos & 2 or 3 spontaneous startle/shock \\
\hline More than 3 spontaneous startles & Mais que 3 sobressaltos/sustos espontâneos & More than 3 spontaneous startle/shock \\
\hline Continuous startles & Sobressaltos/sustos contínuos & Continuous startle/shock \\
\hline ORIENTATION AND BEHAVIOR & ORIENTAÇÃO E COMPORTAMENTO & ORIENTATION AND BEHAVIOR \\
\hline Eye Appearances & Aparência dos Olhos & Eyes Appearance \\
\hline Does not open eyes & Não abre os olhos & Does not open eyes \\
\hline
\end{tabular}


Quadro 31 (continuação): Versões finais do processo de adaptação cultural do HNNE expandido

Full conjugated eye movements

Transient: nystagmus; strabismus; roving eye movements; sunset sign

Persistent: nystagmus; strabismus; roving eye movements; abnormal pupils

Auditory Orientation - Infant awake. Wrap infant. Hold rattle 10 to $15 \mathrm{~cm}$ from ear.

No reaction

Auditory startle; brightens and stills; no true orientation

Shifting of eyes, head might turn towards source

Prolonged head turn to stimulus; search with eyes, smooth

Turns head (jerkily, abruptly) \& eyes towards noise every time

Visual Orientation - Wrap infant, wake up with rattle if needed or rock gently. Note if baby can see and follow red ball (B) or target (T)

Does not follow or focus on stimuli Stills, focuses, follows briefly to the side but loses stimuli

Follows horizontally and vertically; no head turn

Follows horizontally and vertically, turns head

Follows in a circle

Alertness - Tested as response to visual stimuli (B or T).

Will not respond to stimuli

When awake, looks only briefly

When awake, looks at stimuli but

loses them

Keeps interest in stimuli

Does not tire (hyper-reactive)

Irritability - In response to stimuli Quiet all the time, not irritable to any stimuli

Awakes, cries sometimes when

handled

Cries often when handled

Cries always when handled

Cries even when not handled

Consolability - Ease to quiet infant.

Not crying; consoling not needed Cries briefly; consoling not needed

Cries; becomes quiet when talked to

Cries; need picking up to be consoled

Cries; cannot be consoled

Cry
Movimentos oculares completamente conjugados

Transitório: •nistagmo; •estrabismo; -movimentos oculares lentos; •sinal de pôrdo-sol (olhos caídos)

Persistente: •nistagmo; • estrabismo;

- movimentos oculares lentos; pupilas anormais

Orientação Auditiva - Lactente acordado.

Enrole o lactente. Segure um chocalho entre 10 a $15 \mathrm{~cm}$ da orelha.

Sem reação

Sobressalto auditivo; fica alerta e acalma-se em seguida; sem orientação real

Desvio dos olhos, a cabeça pode se virar em direção à fonte sonora

Vira a cabeça lentamente em direção ao estímulo; busca com olhos; suavemente

Vira a cabeça (abruptamente, com espasmo) e olhos em direção ao barulho o tempo todo

Orientação Visual - Enrole o lactente, acorde-o com o chocalho se necessário, ou sacuda-o gentilmente. Observe se o bebê pode ver e seguir uma bola vermelha (B) ou um objeto $(\mathrm{O})$

Não segue ou foca nos estímulos

Acalma-se, foca, segue rapidamente para o lado, porém perde estímulo

Segue horizontalmente e verticalmente; sem virar a cabeça

Segue horizontalmente e verticalmente; vira a cabeça

Segue o objeto em círculo

Estado de Alerta - Teste as respostas do estímulo visual (B ou O)

Não responde aos estímulos

Quando acordado, apenas olha brevemente

Quando acordado, olha para o estímulo,

porém o perde

Mantém interesse no estímulo

Não se cansa (hiper-reatividade)

Irritabilidade - Em resposta ao estímulo

Quieto o tempo todo, não se irrita com estímulo algum

Desperta, chora algumas vezes quando manuseado

Chora frequentemente quando manuseado Sempre chora quando manuseado Chora mesmo quando não manipulado

Consolabilidade - Facilidade para acalmar o lactente

Não chora; não precisa de consolo

Chora brevemente; não precisa de consolo

Chora; mas fica quieto quando se conversa com ele

Chora; precisa ser carregado para ser consolado

Chora; não pode ser consolado

Choro
Completely conjugated eye movements

Transient: •nystagmus; •strabismus;

- slow eye movements; • sunset sign (droopy eyes)

Persistent: •nystagmus; • strabismus;

-slow eye movements, abnormal pupils

Auditory Orientation - Infant awake.

Wrap the infant. Hold a rattle 10 to 15

$\mathrm{cm}$ from the ear.

No reaction

Auditory startle; stays alert and then calms down; without real orientation

Deviation of eyes, Head may turn towards sound source

Turns head slowly towards the stimulus; search with eyes; slight

Turns head (abruptly, with spasm) and eyes toward the noise all the time

Visual Orientation - Wrap infant, wake with rattle if necessary, or gently shake. Observe if baby can see and follow a red ball (B) or an object (O)

Does not follow or focus on stimuli

Calms down, focuses, follows quickly to side, but loses stimulus

Follows horizontally and vertically; without turning head

Follows horizontally and vertically; turns head Follows object in a circle

Alertness - Test visual stimulus

responses (B or $\mathrm{O}$ )

Does not respond to stimuli

When awake, just looks briefly

When awake, looks at the stimulus, but loses it

Maintains interest in stimulus

Does not get tired (hyperactivity)

Irritability - In response to stimulus

Quiet all the time, not irritated by any stimulus

Awakens, cries sometimes when handled

Cries frequently when handled Always cries when handled

Cries even when not manipulated

Consolability - Easy to calm down the infant

Does not cry; does not need consolation Cries briefly; does not need consolation

Cries; but stays quiet when talked to him

Cries; needs to be carried to be consoled

Cries; cannot be consoled

Cry 
Estudo 1: Tradução e a d a ptação c u 1tura 1|104

Quadro 31 (continuação): Versões finais do processo de adaptação cultural do HNNE expandido

\begin{tabular}{|l|l|l|}
\hline No cry at all & Nenhum choro & No cries \\
\hline Whimpering cry only & Apenas choraminga & Whines only \\
\hline Cries to stimuli but normal pitch & $\begin{array}{l}\text { Chora com estímulos, porém em intensidade } \\
\text { normal }\end{array}$ & $\begin{array}{l}\text { Cries with stimuli, but at normal } \\
\text { intensity }\end{array}$ \\
\hline High-pitched cry; often continuous & Choro agudo; normalmente contínuo & Acute crying; normally continuous \\
\hline SUMMARY OF EXAMINATION & RESUMO DO EXAME: & SUMMARY OF EXAMINATION: \\
\hline HEAD AND TRUNK TONE & TÔNUS DA CABEÇA E TRONCO: & HEAD AND TRUNK TONE: \\
\hline MOTILITY & MOBILIDADE: & MOBILITY: \\
\hline ORIENTATION AND ALETNESS & ORIENTAÇÃO E ALERTA: & ORIENTATION AND ALERTNESS: \\
\hline CONSOLABILITY & CONSOLABILIDADE: & CONSOLABILITY: \\
\hline LIMB TONE & TÔNUS DOS MEMBROS: & LIMB TONE: \\
\hline REFLEXES & REFLEXOS: & REFLEXES: \\
\hline IRRITABILITY & IRRITABILIDADE: & IRRITABILITY: \\
\hline LIST DEVIANT SIGNS & LISTA DE ALTERAÇÕES: & LIST OF CHANGES: \\
\hline
\end{tabular}

Quadro 32: Versões finais do processo de adaptação cultural do HINE INFANT

\begin{tabular}{|c|c|c|}
\hline INGLÊES ORIGINAL & PORTUGUÊS - FINAL & RETROTRADUÇÃO - FINAL \\
\hline $\begin{array}{l}\text { Hammersmith Infant Neurological } \\
\text { Examination }\end{array}$ & $\begin{array}{l}\text { Exame Neurológico Infantil - } \\
\text { Hammersmith }\end{array}$ & $\begin{array}{l}\text { Hammersmith Infant Neurological } \\
\text { Examination }\end{array}$ \\
\hline Name & Nome & Name: \\
\hline Date of birth & Data de Nascimento & Date of birth: \\
\hline Gestational age & Idade gestacional & Gestational age: \\
\hline Date of examination & Data da avaliação & Date of evaluation: \\
\hline SUMMARY OF EXAMINATION & RESUMO DA AVALIAÇÃO & EVALUATION SUMMARY \\
\hline No of asymmetries in section $1:$ & Número de assimetrias da seção 1: & Number of asymmetries in section 1: \\
\hline Neurological items score: & Pontuação dos itens neurológicos: & Neurological items score: \\
\hline Behavioral score: & Pontuação comportamental: & Behavioral score: \\
\hline COMMENTS: & COMENTÁRIOS: & COMMENTS: \\
\hline Cranial nerves functions & Funções dos nervos cranianos & Functions of cranial nerves: \\
\hline Posture & Postura & Posture: \\
\hline Movements & Movimentos & Movements: \\
\hline Tone & Tônus & Tone: \\
\hline Reflexes and reactions & Reflexos e reações & Reflexes and reactions: \\
\hline Behavior & Comportamento & Behavior: \\
\hline $\begin{array}{l}\text { SECTION 1: NEUROLOGICAL } \\
\text { ITEMS }\end{array}$ & SEÇÃO 1: ITENS NEUROLÓGICOS & SECTION 1: NEUROLOGICAL ITEMS \\
\hline Assessment of cranial nerve function & Avaliação da função dos nervos cranianos: & Assessment of cranial nerves function: \\
\hline Column 1 (score 2$)$ & Coluna 1 ( 2 pontos) & Column 1 (score 2) \\
\hline Column2 (score 1,5$)$ & Coluna $2(1,5$ pontos $)$ & Column 2 (score 1.5) \\
\hline Column 3 (score 1) & Coluna 3 ( 1 pontos) & Column 3 (score 1$)$ \\
\hline Column 4 (score 0$)$ & Coluna 4 ( 0 pontos $)$ & Column 4 (score 0$)$ \\
\hline A & $\mathrm{A}$ & A \\
\hline Comment & $\mathrm{C}$ & $\mathrm{C}$ \\
\hline $\begin{array}{l}\text { Facial Appearance (at rest and when } \\
\text { crying or stimulated) }\end{array}$ & $\begin{array}{l}\text { Aparência Facial (em repouso e quando } \\
\text { chorando ou sendo estimulado) }\end{array}$ & $\begin{array}{l}\text { Facial Appearance (At rest and when } \\
\text { crying or being stimulated) }\end{array}$ \\
\hline $\begin{array}{l}\text { Smiles or reacts to stimuli by closing } \\
\text { eyes and grimacing }\end{array}$ & $\begin{array}{l}\text { Sorri ou reage a estímulos fechando os } \\
\text { olhos e fazendo caretas }\end{array}$ & $\begin{array}{l}\text { Smiles or reacts to stimuli by closing eyes } \\
\text { and grimacing }\end{array}$ \\
\hline $\begin{array}{l}\text { Closes eyes but not tightly; poor facial } \\
\text { expression }\end{array}$ & $\begin{array}{l}\text { Fecha os olhos, mas não fortemente; } \\
\text { expressão facial pobre }\end{array}$ & $\begin{array}{l}\text { Close eyes, but not strongly; poor facial } \\
\text { expression }\end{array}$ \\
\hline $\begin{array}{l}\text { Expressionless; does not react to } \\
\text { stimuli }\end{array}$ & Inexpressivo; não reage a estímulos & Inexpressive; does not react to stimuli \\
\hline Eye Appearance & Aparência dos Olhos & Eye Appearance \\
\hline Normal conjugated eye movements & $\begin{array}{l}\text { Movimentos conjugado dos olhos estão } \\
\text { normais }\end{array}$ & Conjugated eye movements are normal \\
\hline $\begin{array}{l}\text { Intermittent. deviation of eyes or } \\
\text { abnormal movements }\end{array}$ & $\begin{array}{l}\text { Intermitente. Desvio dos olhos ou } \\
\text { movimentos anormais }\end{array}$ & $\begin{array}{l}\text { Intermittent. Deviation of eyes or } \\
\text { abnormal movements }\end{array}$ \\
\hline $\begin{array}{l}\text { Continuous. deviation of eyes or } \\
\text { abnormal movements }\end{array}$ & $\begin{array}{l}\text { Contínuo. Desvio dos olhos ou movimentos } \\
\text { anormais }\end{array}$ & $\begin{array}{l}\text { Continuous. Deviation of eyes or } \\
\text { abnormal movements }\end{array}$ \\
\hline
\end{tabular}


Quadro 32 (continuação): Versões finais do processo de adaptação cultural do HINE INFANT

\begin{tabular}{|c|c|c|}
\hline $\begin{array}{l}\text { Auditory Response. Test the } \\
\text { response to rattle or bell }\end{array}$ & $\begin{array}{l}\text { Resposta Auditiva. Teste a resposta } \\
\text { utilizando chocalho ou sino }\end{array}$ & $\begin{array}{l}\text { Auditory Response. Test the response } \\
\text { using a rattle or bell }\end{array}$ \\
\hline Reacts to stimuli on both sides & Reage aos estímulos em ambos os lados & Reacts to stimuli on both sides \\
\hline $\begin{array}{l}\text { Doubtful reaction to stimuli or } \\
\text { asymmetrical }\end{array}$ & Reação duvidosa ou assimétrica a estímulos & $\begin{array}{l}\text { Doubtful or asymmetric reaction to } \\
\text { stimuli }\end{array}$ \\
\hline Does not react to stimuli & Não reage aos estímulos & Does not react to stimuli \\
\hline $\begin{array}{l}\text { Visual Response. Test the ability to } \\
\text { follow a red ball or moving object }\end{array}$ & $\begin{array}{l}\text { Resposta Visual. Teste a habilidade para } \\
\text { seguir uma bola vermelha ou um objeto em } \\
\text { movimento }\end{array}$ & $\begin{array}{l}\text { Visual Response. Test ability to follow a } \\
\text { red ball or moving object }\end{array}$ \\
\hline Follows the object for a complete arc & Segue o objeto durante um arco completo & Follows object during complete arc \\
\hline $\begin{array}{l}\text { Follows the object for an incomplete } \\
\text { arc, or asymmetry }\end{array}$ & $\begin{array}{l}\text { Segue o objeto por um arco incompleto ou } \\
\text { assimetria }\end{array}$ & $\begin{array}{l}\text { Follows the object in an incomplete arc or } \\
\text { asymmetry }\end{array}$ \\
\hline Does not follow the object & Não segue o objeto & Does not follow object \\
\hline $\begin{array}{l}\text { Sucking/Swallowing. Watch the } \\
\text { infant suck on breast or bottle }\end{array}$ & $\begin{array}{l}\text { Sucção/Deglutição. Observe o lactente } \\
\text { sugar o peito ou a mamadeira }\end{array}$ & $\begin{array}{l}\text { Sucking/ Swallowing. Observe sucking } \\
\text { of the breast or bottle }\end{array}$ \\
\hline Good suck and swallowing & Boa sucção e deglutição & Good suck and swallowing \\
\hline Poor suck and/or swallowing & Pobre sucção e/ou deglutição & Poor suck and/or swallowing \\
\hline No suck reflex, no swallowing & Sem reflexo de sucção, sem deglutição & No sucking reflex, no swallowing \\
\hline Head in sitting & Cabeça (sentado) & Head (sitting) \\
\hline Straight, in midline & Alinhada na linha média & Aligned in the midline \\
\hline $\begin{array}{l}\text { Slightly to side or backward or } \\
\text { forward }\end{array}$ & $\begin{array}{l}\text { Levemente inclinada para o lado ou para } \\
\text { trás ou para a frente }\end{array}$ & Slightly tilted to side, back or forward \\
\hline $\begin{array}{l}\text { Markedly to side or backward or } \\
\text { forward }\end{array}$ & $\begin{array}{l}\text { Acentuadamente inclinada para o lado ou } \\
\text { para trás ou para a frente }\end{array}$ & Sharply tilted to side, back or forward \\
\hline Trunk in sitting & Tronco (sentado) & Trunk (sitting) \\
\hline Straight & Alinhado & Aligned \\
\hline Slightly curved or bent to side & $\begin{array}{l}\text { Levemente flexionado ou inclinado para o } \\
\text { lado }\end{array}$ & Slightly curved or bent to side \\
\hline $\begin{array}{l}\text { Very rounded/ rocking back/ bent } \\
\text { sideways }\end{array}$ & $\begin{array}{l}\text { Muito flexionado/oscilando para } \\
\text { trás/inclinado lateralmente }\end{array}$ & $\begin{array}{l}\text { Very curved/swinging backward/bent } \\
\text { sideways }\end{array}$ \\
\hline ARMS at Rest & Braços em Repouso & Arms at Rest \\
\hline $\begin{array}{l}\text { In neutral position: central, straight or } \\
\text { slightly bent }\end{array}$ & $\begin{array}{l}\text { Em posição neutra: centralizados, alinhados } \\
\text { ou levemente flexionados }\end{array}$ & $\begin{array}{l}\text { In neutral position: centralized, aligned or } \\
\text { slightly flexed }\end{array}$ \\
\hline $\begin{array}{l}\text { Slight. internal rotation or external } \\
\text { rotation }\end{array}$ & Leve Rotação interna ou externa & Light Internal or external rotation \\
\hline $\begin{array}{l}\text { Marked. internal rotation or external } \\
\text { rotation or dystonic posture. } \\
\text { hemiplegic posture }\end{array}$ & $\begin{array}{l}\text { Acentuada Rotação interna ou externa ou } \\
\text { postura distônica/postura hemiplégica }\end{array}$ & $\begin{array}{l}\text { Accented Internal or external rotation or } \\
\text { dystonic posture/hemiplegic posture }\end{array}$ \\
\hline Hands & Mãos & \begin{tabular}{|l|} 
Hands \\
\end{tabular} \\
\hline Hands open & Mãos abertas & Hands open \\
\hline Intermittent adducted thumb or fisting & $\begin{array}{l}\text { Intermitente Polegar em adução ou mãos } \\
\text { fechadas }\end{array}$ & $\begin{array}{l}\text { Intermittent Thumb in adduction or closed } \\
\text { fists }\end{array}$ \\
\hline Persistent adducted thumb or fisting & $\begin{array}{l}\text { Persistente Polegar em adução ou mãos } \\
\text { fechadas }\end{array}$ & $\begin{array}{l}\text { Persistent Thumb in adduction or closed } \\
\text { fists }\end{array}$ \\
\hline $\begin{array}{l}\text { Legs in sitting in supine and in } \\
\text { standing }\end{array}$ & Pernas (sentado) (em supino e em pé) & Legs (sitting) (supine and standing) \\
\hline $\begin{array}{l}\text { Able to sit with straight back, and legs } \\
\text { straight or slightly bent (long sitting). } \\
\text { legs in neutral position: straight or } \\
\text { slightly bent }\end{array}$ & $\begin{array}{l}\text { Capaz de sentar com a coluna alinhada e as } \\
\text { pernas estendidas ou ligeiramente } \\
\text { flexionadas (sentado com as pernas } \\
\text { estendidas). Pernas em posição neutra: } \\
\text { alinhadas ou ligeiramente flexionadas }\end{array}$ & $\begin{array}{l}\text { Able to sit with spine aligned and legs } \\
\text { extended or slightly flexed (sitting with } \\
\text { straight legs). Legs in neutral position: } \\
\text { aligned or slightly flexed }\end{array}$ \\
\hline $\begin{array}{l}\text { Slight internal rotation or external } \\
\text { rotation }\end{array}$ & Leve rotação interna ou externa & Slight Internal or external rotation \\
\hline $\begin{array}{l}\text { Sit with straight back but knees bent at } \\
15-20^{\circ} \text {. internal rotation or external } \\
\text { rotation at hips }\end{array}$ & $\begin{array}{l}\text { Senta com a coluna alinhada, mas com os } \\
\text { joelhos flexionados em } 15-20^{\circ} \text {. Rotação } \\
\text { interna ou externa do quadril }\end{array}$ & $\begin{array}{l}\text { Sits with spine aligned but knees flexed at } \\
15-20^{\circ} \text {. Internal or external hip rotation }\end{array}$ \\
\hline
\end{tabular}


Quadro 32 (continuação): Versões finais do processo de adaptação cultural do HINE INFANT

Unable to sit straight unless knees markedly bent (no long sitting). marked. internal rotation or external rotation or fixed extension or flexion or contractures at hips and knees

Feet in supine and in standing Central; in neutral position toes straight midway between flexion and extension

Slight internal rotation or external rotation

Intermittent tendency to stand on tiptoes; or toes up or curling under

Marked internal rotation or external rotation at the ankle. Persistent tendency to stand on tiptoes or toes up or curling under

MOVEMENTS

Quantity - watch infant lying in the supine

Normal

Excessive or sluggish

Minimal or none

Quality

Free, alternating, smooth

Jerky, slight tremor

Cramped \& synchronous; Extensor spasms; Athetoid; Ataxic; Very tremulous; Myoclonic spasm;

Dystonic

\section{TONE}

Scarf Sign - Take the infant's hand and pull the arm across the chest until there is resistance. Note the position of the elbow.

\section{Range}

Passive Shoulder Elevation - Lift arm next to the infant's head. Note resistance at shoulder and elbow.

Resistance, but overcome

No resistance

Resistance, not overcome

Pronation/Supination - Steady upper arm while pronating and supinating forearm. Note resistance.

Full pronation and supination, no resistance

Full pronation and supination but resistance to be overcome

Full pronation and supination not possible, marked resistance

ADDUCTORS - With the infant's legs extended, open them as far as possible. The angle formed by the legs is noted.

Range: $150^{\circ}-80^{\circ}$
Incapaz de sentar com a coluna alinhada, a não ser que os joelhos estejam acentuadamente flexionados (não senta com as pernas estendidas). Acentuada Rotação interna ou externa ou flexão/extensão fixas ou contraturas no quadril e joelhos

Pés - Em supino e em pé

Centralizados; em posição neutra. Dedos dos pés alinhados entre flexão e extensão

Leve Rotação interna ou externa.

Intermitente Tendência de ficar em pé nas pontas dos dedos; ou dedos para cima ou dedos em garra

Acentuada Rotação interna ou externa do tornozelo. Persistente Tendência de ficar em pé nas pontas dos dedos; ou dedos para cima ou dedos em garra

MOVIMENTOS

Quantidade - Observe o lactente deitado em supino

Normal

Excessivo ou lento

Mínimo ou nenhum

Qualidade

Livres, alternados, suaves

Bruscos, tremores leves

*Espasmos sincronizados; *Espasmos extensores; *Atetóide; *Atáxico; *Muito tremor; *Espasmos mioclônicos;

*Distônico

TÔNUS

Sinal de Cachecol - Pegue a mão do lactente e puxe o braço sobre o peito até que haja resistência. Observe a posição do cotovelo.

Amplitude

Elevação Passiva do Ombro - Levante o braço próximo à cabeça do lactente.

Observe a resistência do ombro e do cotovelo.

Resistência, porém, realiza

Sem resistência

Resistência, não realiza

Pronação/Supinação - Estabilize a região superior do braço, enquanto realiza a pronação e supinação do antebraço. Observe a resistência.

Pronação e supinação completas, sem resistência

Pronação e supinação completas, porém a resistência pode ser vencida (movimento pode ser realizado)

Não é possível pronação e supinação completas, resistência acentuada

Adutores - Com as pernas do lactente estendida, abduza na medida do possível. Observe o ângulo formado pelas pernas
Unable to sit with spine aligned, unless knees are markedly flexed (do not sit with legs extended). Accentuated internal or external rotation or fixed

flexion/extension or contractures in the hip and knees

Feet - In supine and standing

Centralized; in neutral position. Toes aligned between flexion and extension

Slight internal or external rotation.

Intermittent Tendency to stand on tiptoes; or toes up or toes in claw

Accented Internal or external rotation in the ankle. Persistent Tendency to stand on tiptoes; or toes up or toes in claw

MOVEMENTS

Quantity - Observe the infant lying in the supine

Normal

Excessive or slow

Minimal or none

Quality

Free, alternating, slight

Abrupt, light tremors

*Synchronized spasms; *Extenders

spasms; *Athetoid; *Ataxic; *A lot of

trembling; *Myoclonic spasms;

$*$ Dystonic

TONE

Scarf Sign - Take infant's hand and pul arm over breast until there is resistance.

Observe elbow position.

Range

Passive Shoulder Lift - Raise the arm up to the infant's head. Observe resistance at shoulder and elbow.

Resistance, but performed

No resistance

Resistance, not performed

Pronation/Supination - Stabilize upper arm while performing pronation and supination the forearm. Observe resistance.

Complete pronation and supination with no resistance

Complete pronation and supination, but resistance can be overcome (movement can be accomplished)

Complete pronation and supination not possible, marked resistance

Adductors - With the infant's legs extended, abduct as far as possible. Observe the angle formed by the legs

Range: $150^{\circ}-80^{\circ}$ 
Quadro 32 (continuação): Versões finais do processo de adaptação cultural do HINE INFANT

\begin{tabular}{|l|}
\hline $150^{\circ}-160^{\circ}$ \\
\hline$>170^{\circ}$ \\
\hline$<80^{\circ}$ \\
\hline $\begin{array}{l}\text { Popliteal Angle - Legs are flexed at } \\
\text { the hip simultaneously on to the side } \\
\text { of the abdomen, then extended at the } \\
\text { knee until there is resistance. Note } \\
\text { angle between lower and upper leg. }\end{array}$ \\
\hline Range: $150^{\circ}-110^{\circ}$ \\
\hline $150^{\circ}-160^{\circ}$ \\
\hline$\sim 90^{\circ}$ or $>170^{\circ}$ \\
\hline$<80^{\circ}$ \\
\hline
\end{tabular}

Ankle Dorsiflexion - With knee extended, dorsiflex ankle. Note the angle between foot and leg.

Range: $30^{\circ}-85^{\circ}$ -

$20^{\circ}-30^{\circ}$

$<20^{\circ}$ or $90^{\circ}$

$>90^{\circ}$

Pulled to Sit - Pull infant to sit by wrists

Ventral Suspension - Hold infant in ventral suspension; note position of back, limbs and head.

REFLEXES AND REACTIONS

Tendon Reflexes

Easily elicitable - biceps, knee, ankle Mildly brisk -biceps, knee, ankle

Brisk - biceps, knee, ankle

Clonus or absent- biceps, knee, ankle

Arm Protection - Pull the infant by

one arm from the supine position and

note the reaction of the opposite side

Arm \& hand extend

Arm semi-flexed

Arm fully flexed

Vertical Suspension - Hold infant under axilla. Make sure legs do not touch any surface.

Kicks symmetrically

Kicks one leg more, or poor kicking

No kicking even if stimulated, or scissoring

Lateral Tilting (describe side up) Infant held vertically, tilt quickly to horizontal. Note spine, limbs, and head

Forward Parachute - Infant held vertically and suddenly tilted forward. Note reaction of the arms.

(after 6 months)

(after 6 months)

SECTION 2: MOTOR

MILESTONES

Head Control

$150^{\circ}-160^{\circ}$
$>170^{\circ}$
$<80^{\circ}$

Ângulo Poplíteo - Flexione

simultaneamente as pernas ao lado do abdome (abdução de quadril), então estenda os joelhos até que haja resistência. Observe o ângulo entre a coxa e a parte inferior da perna

Amplitude: $150^{\circ}-110^{\circ}$

$150^{\circ}-160^{\circ}$

$\sim 90^{\circ}$ ou $>170^{\circ}$

$<80^{\circ}$

Dorsiflexão do Tornozelo - Com o joelho

estendido, realize a dorsiflexão do

tornozelo. Observe o ângulo entre o pé e a perna

Amplitude: $30^{\circ}-85^{\circ}$

$20^{\circ}-30^{\circ}$

$<20^{\circ}$ ou $90^{\circ}$

$>90^{\circ}$

Puxado para Sentar - Segurando nos punhos, puxe o lactente para sentar

Suspensão Ventral - Sustente o lactente em suspensão ventral; observe a posição da coluna, membros e cabeça.

REFLEXOS E REAÇÕES

Reflexos Tendíneos - (bíceps, joelho, tornozelo)

Facilmente desencadeado

Moderadamente rápido

Rápido

Clônus ou ausente

Reação de Proteção - Lactente em posição supina, puxe-o por um braço e observe a reação do lado oposto

Braço e mão estendidos

Braço semi-flexionado

Braço completa-mente flexionado

Suspensão Vertical - Segure o lactente por baixo das axilas. Certifique-se que as pernas não toquem em qualquer superfície. Chuta simetricamente

Chuta mais com uma das pernas, ou chute fraco

Sem chutes mesmo se estimulado, ou posição de tesoura

Inclinação Lateral (descreva o lado voltado para cima) - Lactente mantido na posição vertical, incline rapidamente para a horizontal. Observe a coluna, membros e cabeça.

Reação de Paraquedas - Lactente mantido na posição vertical e subitamente inclinado para frente. Observe a reação dos braços.

(após 6 meses)

(após 6 meses)

SEÇÃO 2: MARCOS MOTORES

Controle da Cabeça $150^{\circ}-160^{\circ}$

$>170^{\circ}$

$<80^{\circ}$

Popliteal Angle - Flex legs

simultaneously on to the side of the abdomen (hip abduction), then extend knees until there is resistance. Observe the angle between the thigh and the lower leg

Range: $150^{\circ}-110^{\circ}$

$150^{\circ}-160^{\circ}$

$\sim 90^{\circ}$ or $>170^{\circ}$

$<80^{\circ}$

\section{Ankle Dorsiflexion - With knee}

extended, perform dorsiflexion the ankle.

Observe the angle between foot and leg

Range: $30^{\circ}-85^{\circ}$

$20^{\circ}-30^{\circ}$

$<20^{\circ}$ or $90^{\circ}$

$>90^{\circ}$

Pulled to Sit - Holding on wrists, pull the infant to sit

Ventral Suspension - Hold the infant in

ventral suspension; observe the position

of spine, limbs, and head.

REFLEXES AND REACTIONS

Tendon Reflections - (biceps, knee, ankle)

Easily triggered

Moderately fast

Fast

Clonus or absent

Protection Reaction - Infant in supine

position, pull by arm and observe reaction from opposite side

Arm and hand extended

Semi- flexed arm

Arm completely flexed

Vertical Suspension - Hold infant under armpits. Make sure legs do not touch any surface.

Kicks symmetrically

Kicks more with one leg or kicks weakly

No kicking even if stimulated, or scissor position

Lateral Tilting (describe the side facing up) - Infant maintained in an upright position, tilt quickly to horizontal.

Observe spine, limbs and head.

Parachute Reaction - Infant maintained in an upright position and suddenly inclined forward. Notice reaction of the arms.

(after 6 months) (after 6 months)

SECTION 2: MOTOR MILESTONES

Head Control


Quadro 32 (continuação): Versões finais do processo de adaptação cultural do HINE INFANT

\begin{tabular}{|c|c|c|}
\hline $\begin{array}{l}\text { Unable to maintain head upright } \\
\text { (normal }<3 \mathrm{mo} \text { ) }\end{array}$ & $\begin{array}{l}\text { Incapaz de manter a cabeça erguida (normal } \\
<3 \text { meses) }\end{array}$ & $\begin{array}{l}\text { Unable to maintain head upright (normal } \\
<3 \text { months) }\end{array}$ \\
\hline Wobbles (normal at $4 \mathrm{mo}$ ) & Oscila (normal aos 4 meses) & Wobbles (normal at 4 months) \\
\hline $\begin{array}{l}\text { All the time maintained upright } \\
\text { (normal at } 5 \mathrm{mo} \text { ) }\end{array}$ & $\begin{array}{l}\text { Mantem erguida o tempo todo (normal aos } \\
5 \text { meses) }\end{array}$ & $\begin{array}{l}\text { Maintains head upright all the time } \\
\text { (normal at } 5 \text { months) }\end{array}$ \\
\hline Sitting & Sentar & Sitting \\
\hline Cannot sit & Não consegue sentar & Cannot sit \\
\hline $\begin{array}{l}\text { Sits with support at hips (normal at } 4 \\
\text { mo) }\end{array}$ & $\begin{array}{l}\text { Senta com apoio no quadril (normal aos } 4 \\
\text { meses) }\end{array}$ & Sits with hip support (normal at 4 months) \\
\hline Props (normal at 6 mo) & Senta com apoio (normal aos 6 meses) & Sits with support (normal at 6 months) \\
\hline Stable sit (normal at $7-8 \mathrm{mo}$ ) & Senta sem apoio (normal aos 7-8 meses) & $\begin{array}{l}\text { Sits without support (normal at 7-8 } \\
\text { months) }\end{array}$ \\
\hline Pivot (rotates) (normal at $9 \mathrm{mo}$ ) & Pivoteia (rotaciona) (normal aos 9 meses) & Pivots (rotates) (normal at 9 months) \\
\hline Voluntary Grasp & Preensão Voluntária & Voluntary Grasp \\
\hline No grasp & Sem preensão & No grasp \\
\hline Uses whole hand & Utiliza a mão inteira & Uses the whole hand \\
\hline $\begin{array}{l}\text { Index finger and thumb but immature } \\
\text { grasp }\end{array}$ & $\begin{array}{l}\text { Com dedo indicador e polegar, porém, } \\
\text { preensão imatura }\end{array}$ & $\begin{array}{l}\text { With index finger and thumb, but } \\
\text { immature grasp }\end{array}$ \\
\hline Pincer grasp & Preensão em pinça & Clamp grasp \\
\hline Ability to Kick (in supine) & Habilidade de Chutar (em supino) & Ability to Kick (in supine) \\
\hline No kicking & Não chuta & No kicking \\
\hline Kicks horizontally legs do not lift & $\begin{array}{l}\text { Chuta horizontalmente, pernas não } \\
\text { levantam }\end{array}$ & Kicks horizontally, legs do not lift \\
\hline Upward (vertically) (normal at $3 \mathrm{mo}$ ) & $\begin{array}{l}\text { Para cima (verticalmente) (normal aos } 3 \\
\text { meses) }\end{array}$ & Upwards (vertically) (normal at 3 months) \\
\hline Touches leg (normal at 4-5 mo) & Toca a perna (normal aos 4-5 meses) & Touches the leg (normal at 4-5 months) \\
\hline Touches toes (normal at 5-6 mo) & $\begin{array}{l}\text { Toca os dedos dos pés (normal aos 5-6 } \\
\text { meses) }\end{array}$ & Touches toes (normal at 5-6 months) \\
\hline Rolling & Rolar & Rolling \\
\hline No rolling & Não rola & No rolling \\
\hline Rolling to side (normal at $4 \mathrm{mo}$ ) & Rola para o lado (normal aos 4 meses) & Rolls to side (normal at 4 months) \\
\hline Prone to supine (normal at $8 \mathrm{mo}$ ) & Prono para supino (normal aos 8 meses) & Prone to supine (Normal at 8 months) \\
\hline Supine to prone (normal at10 mo) & Supino para prono (normal aos 10 meses) & Supine to prone (normal at 10 months) \\
\hline Crowling & Engatinhar & Crawling \\
\hline Does not lift head & Não levanta a cabeça & Does not lift the head \\
\hline On elbow (normal at $3 \mathrm{mo}$ ) & No cotovelo (normal aos 3 meses) & On elbow (normal at 3 months) \\
\hline $\begin{array}{l}\text { On outstretched hand- (normal at } 4 \\
\text { mo) }\end{array}$ & $\begin{array}{l}\text { Em extensão de braços, sobre as mãos } \\
\text { (normal aos } 4 \text { meses) }\end{array}$ & $\begin{array}{l}\text { With arms extended on the hands (normal } \\
\text { at } 4 \text { months) }\end{array}$ \\
\hline $\begin{array}{l}\text { Crawling flat on abdomen (normal at } \\
8 \mathrm{mo} \text { ) }\end{array}$ & $\begin{array}{l}\text { Engatinha com apoio no abdome (normal } \\
\text { aos } 8 \text { meses) }\end{array}$ & $\begin{array}{l}\text { Crawls with abdominal support (normal at } \\
8 \text { months) }\end{array}$ \\
\hline $\begin{array}{l}\text { Crawling on hands and knees (normal } \\
\text { at } 10 \mathrm{mo} \text { ) }\end{array}$ & $\begin{array}{l}\text { Engatinha com } 4 \text { apoios ou com apoio } \\
\text { sobre mãos e joelhos (normal aos } 10 \text { meses) }\end{array}$ & $\begin{array}{l}\text { Crawls with } 4 \text { supports or supported on } \\
\text { hands and knees (normal at } 10 \text { months)) }\end{array}$ \\
\hline Standing & Ficar de Pé & Standing \\
\hline Does not support weight & Não suporta o peso & Does not support weight \\
\hline Supports weight (normal at $4 \mathrm{mo}$ ) & Suporta o peso (normal aos 4 meses) & Supports weight (normal at 4 months) \\
\hline Stands with support (normal at $7 \mathrm{mo}$ ) & Fica em pé com apoio (normal aos 7 meses) & Stands with support (normal at 7 months) \\
\hline Stands unaided (normal at $12 \mathrm{mo}$ ) & $\begin{array}{l}\text { Fica em pé sem ajuda (normal aos } 12 \\
\text { meses) }\end{array}$ & $\begin{array}{l}\text { Stands without help (normal at } 12 \\
\text { months) }\end{array}$ \\
\hline Walking & Marcha & Gait \\
\hline Bouncing (normal at $6 \mathrm{mo}$ ) & $\begin{array}{l}\text { Movimento rítmico de chutes com pernas } \\
\text { alternadas (normal aos } 6 \text { meses) }\end{array}$ & $\begin{array}{l}\text { Rhythmic movement of kicking with } \\
\text { alternating legs (normal at } 6 \text { months) }\end{array}$ \\
\hline $\begin{array}{l}\text { Cruising (walks holding on) (normal } \\
\text { at } 12 \mathrm{mo} \text { ) }\end{array}$ & $\begin{array}{l}\text { Marcha instável (caminha com apoio) } \\
\text { (normal aos } 12 \text { meses) }\end{array}$ & $\begin{array}{l}\text { Unstable gait (walks with support) } \\
\text { (normal at } 12 \text { months) }\end{array}$ \\
\hline $\begin{array}{l}\text { Walking independently (normal at } 15 \\
\text { mo) }\end{array}$ & $\begin{array}{l}\text { Marcha independente (normal aos } 15 \\
\text { meses) }\end{array}$ & Independent gait (normal at 15 months) \\
\hline SECTION 3: BEHAVIOUR & SEÇÃO 3: COMPORTAMENTO & SECTION 3: BEHAVIOR \\
\hline State of Consciousness & Estado de Consciência & State of Consciousness \\
\hline Unrousable & Não desperta & Does not wake up \\
\hline Drowsy & Sonolento & Sleepy \\
\hline
\end{tabular}


Estudo 1: Tradução e a d a ptação cultura 1|109

Quadro 32 (continuação): Versões finais do processo de adaptação cultural do HINE INFANT

\begin{tabular}{|l|l|l|}
\hline Sleep but wakes easily & Sonolento, porém desperta facilmente & Sleepy, but awakens easily \\
\hline Awake but no interest & Desperto, porém, sem interesse & Awake, but no interest \\
\hline Loses interest & Perde interesse & Loses interest \\
\hline Maintains interest & Mantem interesse & Maintains interest \\
\hline Emotional State & Estado Emocional & Emotional State \\
\hline Irritable, not consolable & Irritável, sem consolo & Irritable, not consolable \\
\hline Irritable, mother can console & Irritável, mãe pode consolar & Irritable, mother can console \\
\hline Irritable when approached & Irritável quando manipulado & Irritable when manipulated \\
\hline Neither happy or unhappy & Nem feliz, nem triste & Neither happy or sad \\
\hline Happy smiling & Feliz, sorrindo & Happy, smiling \\
\hline Social Orientation & Orientação Social & Social Orientation \\
\hline Avoiding, withdrawn & Esquiva-se, retraído & Dodges, withdrawing \\
\hline Hesitant & Hesitante & Hesitant \\
\hline Accepts approach & Aceita aproximação & Accepts approach \\
\hline Friendly & Amigável & Friendly \\
\hline Score for Behavior & Pontuação para Comportamento: & Score for Behavior: \\
\hline
\end{tabular}




\subsection{Discussão}

O processo de adaptação cultural foi iniciado pela tradução dos instrumentos para o idioma português do Brasil, por meio de dois tradutores independentes e bilíngues (BEATON et al., 2000; CASSEEP-BORGES et al., 2010), com diferentes formações acadêmicas para aumentar a probabilidade de encontrar termos mais adequados (TANZER, 2005). De acordo com Tanzer (2005), uma tradução adequada deve promover a compreensão linguística, cultural e contextual, para que o construto avaliado possa manter sua integralidade em ambas as culturas. Por outro lado, instrumentos mal traduzidos interferem de forma negativa na validade dos dados (WILD et al., 2005).

Posteriormente, as versões traduzidas foram comparadas por um comitê técnico com o objetivo de elaborar uma versão única e sintetizada (BORSA; DAMÁSIO; BANDEIRA, 2012). Essa versão foi encaminhada ao comitê de especialistas, junto com a versão original para ser avaliado em relação às suas discrepâncias semânticas, idiomáticas, conceituais, culturais e experenciais. O comitê multidisciplinar de especialistas é importante para assegurar a acurácia do conteúdo (EPSTEIN; SANTO; GUILLEMIN, 2015).

A adaptação cultural de um instrumento de medida é um pré-requisito para a investigação de diferenças entre culturas (GUILLEMIN, BOMBARDIER, BEATON, 1993; BADIA, ALONSO, 1995; HERDMAN; FOX-RUSHBY; BADIA, 1997; REICHENHEIM, MORAES, 2007). Guillemin, Bombardier e Beaton (1993) relatam que uma adaptação é considerada eficaz e capaz de mensurar de forma equivalente a um construto somente após adaptado culturalmente.

A adaptação de um instrumento para outra língua é um processo complexo, que leva em consideração o idioma, o contexto cultural e o estilo de vida da população de origem do instrumento. Para isso é necessário cumprir os aspectos: técnicos (ex. uso de instrumentos de autopreenchimento por pessoas analfabetas), linguísticos (os termos podem apresentar significados diferentes na variação de idiomas), semânticos (referente ao mesmo significado), de conteúdo (itens relevantes e apropriados), de critério (mesma interpretação normativa) e conceitual (mesmo construto teórico) (BRISLIN, 1986; FLAHERTY, 1987; SCHEFF, 1987, FLAHERTY et al, 1988; HUNT et al.,1991).

Para Beaton e colaboradores (2000), é imprescindível que sejam obtidas as equivalências conceitual, idiomática, semântica e experimental no processo de adaptação cultural. A equivalência conceitual se refere ao conteúdo explorado pelo instrumento, a equivalência idiomática se refere às expressões idiomáticas e coloquiais, a equivalência 
semântica é relativa à clareza dos itens utilizados e ao significado das palavras enquanto e a equivalência experimental dos itens aborda situações coerentes ao contexto cultural onde o instrumento será utilizado. Para Jorge (2000), muitas das manifestações clínicas, evoluções e prognósticos são dependentes da cultura pela qual o indivíduo está inserido (JORGE, 2000).

Muitos estudiosos relatam métodos e processos diferentes para realizar a tradução e adaptação cultural de um instrumento (FERRER et al., 1996; BEATON et al. 2000; JORGE, 2000; GUILLEMIN; BOMBARDIER; BEATON, 2002; PASQUALI et al. 2010; BORSA; DAMÁSIO; BANDEIRA, 2012; EPSTEIN; SANTO; GUILLEMIN, 2015). Porém, não há um consenso na literatura sobre qual o melhor método a ser seguido.

A adaptação cultural dos instrumentos HNNE (versões expandida e resumida) e HINE para o português do Brasil foi realizada de acordo com procedimentos reconhecidos internacionalmente. Para este estudo, foram seguidas as orientações propostas por Ferrer et al. (1996); Beaton et al. (2000) e Guillemin, Bombardier e Beaton (2002).

Para Mokkink e colaboradores (2012), a relevância e abrangência dos itens devem ser julgados por especialistas ao assunto que se refere, ou seja, se reflete adequadamente ao construto a ser medido. Para isso, deve ser verificado a pertinência e a abrangência dos itens do instrumento. Este item contempla ainda a validade de face.

Participou desta fase, 10 especialistas, a fim de avaliar a validade de face e de conteúdo. Nesta etapa, obteve-se índices satisfatórios de concordância entre os especialistas, para os três instrumentos em questão. A experiência dos especialistas foram cruciais para preservar as características do instrumento que o tornam apropriado para a população-alvo (TANZER, 2005). Todas as sugestões feitas pelo comitê de especialistas foram rigorosamente examinadas e muitas delas foram incluídas nas versões consensuais dos instrumentos, o que foi essencial para a adaptação cultural.

Esse caminho foi sugerido por Ferrer et al. (1996) que destaca que depois de obtidas as traduções, essas deveriam ser avaliadas por um comitê de especialistas e somente depois seguir para a retrotradução. Segundo esses autores, a alteração proposta permite que sejam detectados erros ou problemas de compreensão os quais não poderiam ser notados após a retrotradução ter sido feita, visando a assegurar o objetivo da retrotradução que é o de observar possíveis erros de significado na primeira versão traduzida.

Beaton et al. (2000), sugere que a retrotradução seja realizada por, pelo menos dois tradutores, e que estes não tenham participado da primeira tradução. Este item sugerido também foi acatado pelo estudo em questão. 
A retrotradução é importante, porque é utilizada como meio de interlocução com o autor do instrumento, que geralmente desconhece o idioma cuja adaptação foi realizada. Então, desta forma, possibilita que os autores possam avaliar se os itens mantêm a mesma ideia conceitual que o instrumento original, preservando seu construto (BORSA; DAMÁSIO; BANDEIRA, 2012).

O próximo passo foi encaminhar as versões sínteses (em português e retrotraduzidas) para os autores do instrumento. Os autores do instrumento concordaram com as versões apresentadas, sem nenhuma objeção, fato este que consolidou a versão final sem mais alterações.

De acordo com Beaton et al. (2000), o próximo passo seria conduzir as versões finais para o teste com o público-alvo. Outros estudiosos apoiam essa etapa do pré-teste, sugerindo que a avaliação pelo público-alvo pode ser conduzida uma ou mais vezes, dependendo da necessidade e da complexidade do instrumento a ser adaptado (BORSA; DAMÁSIO; BANDEIRA, 2012). Entretanto, os instrumentos utilizados neste estudo, são aplicados apenas por profissionais da saúde que avaliam as condições neurológicas de seus pacientes. Vale ressaltar que 10 profissionais participaram do comitê de especialistas e nenhum deles apresentaram dúvidas ou desconhecimento sobre qualquer item avaliado. Por se tratar de itens que fazem parte de uma rotina de avaliações por profissionais que atuam nesta área, há um certo domínio e compreensão sobre eles.

As etapas e estágios abordados neste estudo não necessitam de procedimentos estatísticos em sua análise, apenas de uma avaliação de adequação dos itens e estruturação do instrumento. Portanto, é calculado apenas a porcentagem de concordância entre os itens, para se determinar se eles necessitam ou não de uma adequação, seja ela semântica, idiomática, conceitual ou experencial (BORSA; DAMÁSIO; BANDEIRA, 2012).

Após adaptar um instrumento para uma nova cultura, é necessário validá-lo. A validação ocorre através de análises estatísticas sobre a validade de face e confiabilidade do instrumento na população para o qual ele foi adaptado (BORSA; DAMÁSIO; BANDEIRA, 2012). A validação do instrumento se encontra no estudo 2 .

Os instrumentos podem ser utilizados livremente entre os profissionais da saúde que avaliam as condições neurológicas de recém-nascidos e lactentes, e podem ser solicitados por e-mail pelos autores deste manuscrito. 


\subsection{Conclusão}

Este estudo teve por objetivo realizar a tradução e adaptação cultural, através da validação semântica, dos instrumentos HNNE (versão expandida e versão resumida) e HINE para utilização no Brasil; em recém-nascidos e lactentes, para predizer alterações neurológicas como a paralisia cerebral. Estes instrumentos têm potencialidade para ajudar os bebês e suas famílias a identificarem possíveis alterações de caráter neurológico precocemente, e serem encaminhados em tempo hábil para os serviços de reabilitação ou estimulação sensório-motora, a fim de reduzir os danos causados pelo diagnóstico tardio.

Apesar de não existir um consenso na literatura relacionada à adaptação de instrumentos para uso em contextos culturais distintos, estes instrumentos adaptados para o idioma português do Brasil, preencheram os critérios da literatura científica quanto a adaptação cultural.

Desta forma, este estudo contribuiu para que profissionais da saúde como médicos, fisioterapeutas e terapeutas ocupacionais tenham uma ferramenta adequada para avaliar seus pacientes, e assim tomar uma decisão em relação ao seguimento, encaminhamento e/ou orientações que serão passadas. 


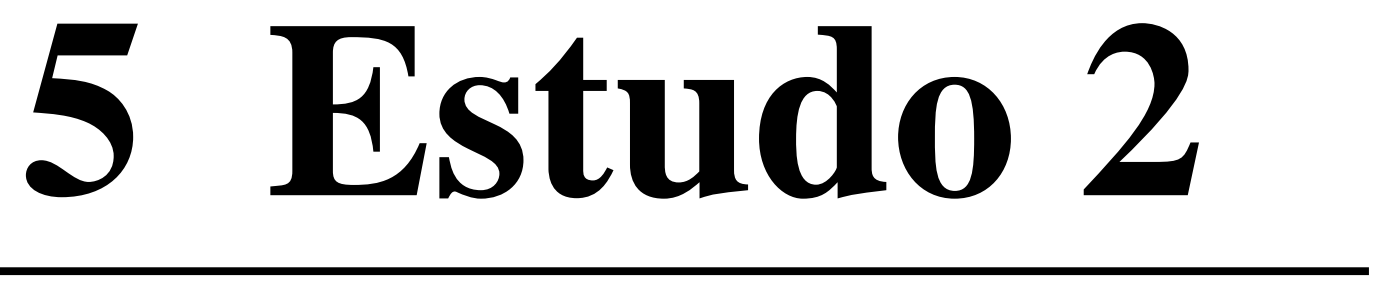

Validação psicométrica da escala Hammersmith Neonatal Neurological Assessment (HNNE) para o Brasil 


\subsection{OBJETIVOS}

Realizar a validação psicométrica do instrumento de avaliação neurológica - HNNE (Hammersmith Neonatal Neurological Assessment) para predição de Paralisia Cerebral (PC) em recém-nascidos brasileiros.

\subsubsection{Objetivos Específicos}

- Analisar as propriedades psicométricas do HNNE no que se refere à validade de construto;

- Avaliar a confiabilidade da versão adaptada, no que se refere à consistência interna dos itens segundo estatística do Coeficiente Alfa de Cronbach;

- Avaliar a confiabilidade da versão adaptada, no que se refere à reprodutibilidade/estabilidade do instrumento, segundo a técnica teste-reteste e de confiabilidades intra e interexaminadores, por meio do Coeficiente de Correlação Intra-Classe;

- Avaliar a validade convergente com a escala AIMS através da correlação de Pearson.

\subsection{Aspectos éticos}

Este estudo respeita as exigências da Resolução 466/12 da Comissão Nacional de Ética em Pesquisa do Conselho Nacional de Saúde do Ministério da Saúde (BRASIL, 2012) e foi aprovado pelo comitê de ética do Hospital das Clínicas da Faculdade de Medicina de Ribeirão Preto da Universidade de São Paulo (HC - FMRP/USP), sob o parecer $n^{\circ} 1.809 .858$. Todos os responsáveis legais pelos participantes assinaram o Termo de Consentimento Livre e Esclarecido - TCLE (anexo D). Este estudo foi desenvolvido entre 2017 e 2018.

\subsection{MATERIAIS E MÉTODO}

\subsubsection{Desenho do estudo}

Estudo transversal e metodológico, não experimental, de validação da escala $H N N E$ Hammersmith Neonatal Neurological Assesment, para detectar riscos de alterações neurológicas em neonatos brasileiros. 


\subsubsection{Participantes}

Participaram do estudo 143 recém-nascidos $(\mathrm{RN})$ que foram recrutados no Hospital das Clínicas da Universidade de São Paulo - Campus Ribeirão Preto e na maternidade municipal de Ribeirão Preto (MATER). Foram admitidos RN prematuros e à termo que apresentassem algum risco para PC.

A amostra para as confiabilidades, foi composta por um subgrupo de $30 \mathrm{RN}$ que foram recrutados no Hospital das Clínicas da Universidade de São Paulo - Campus Ribeirão Preto. Foram admitidos RN prematuros e à termo que apresentassem algum risco para PC.

Foram adotados como sinais de risco para PC, conforme proposto por McIntyre e colaboradores (2011):

- Fatores maternos: história ginecológica anterior de natimortos, vários abortos, morte neonatal, parto prematuro, história familiar de PC e outras predisposições genéticas; incapacidade intelectual, epilepsia; baixo nível socioeconômico e doenças maternais (distúrbios da tireóide, pressão alta não controlada; obesidade).

- Fatores gestacionais: Infecção, anomalias congênitas, gemelaridade, complicações na gravidez (pré-eclâmpsia, hemorragia no segundo e terceiro trimestres, infecção e inflamação, restrição de crescimento intrauterino - CIUR, anormalidades placentárias e outros precursores de parto prematuro).

- Fatores pós-natal: hipoxia durante o parto, acidente vascular cerebral, convulsões, hipoglicemia, icterícia e infecção aguda.

\subsubsection{Local da Pesquisa}

A validação do instrumento em questão foi realizado no Laboratório de Ensino e Pesquisa em Terapia Ocupacional, Infância e Adolescência (LEPTOI), na Universidade de São Paulo - Campus Ribeirão Preto/São Paulo e a coleta de dados, bem como o recrutamento dos participantes, foram realizadas nas unidades de ambulatório de obstetrícia, na maternidade neonatal e na unidade de cuidados intermediários (UCIN), do Hospital das Clínicas de Ribeirão Preto/SP e na MATER de Ribeirão Preto/SP. 


\subsubsection{Instrumento}

O padrão de excelência refere que cada neonato deveria ser avaliado por um exame neurológico de grande abrangência, porém na prática isso costuma não ser realizado pelo alto número de partos e a escassez frequente de colaboradores. Sendo assim, os bebês acabam sendo avaliados de forma global e, em seus aspectos neurológicos, é avaliado tônus, alerta e o reflexo de Moro (MERCURI et al., 2005).

O HNNE é um instrumento de avaliação para recém-nascidos que avalia a condição clínica, considerando as manifestações provenientes de alterações neurológicas. Neste exame é avaliado postura, tônus, reflexos, movimentos espontâneos, sinais anormais, a orientação e comportamento do RN (DUBOWITZ; DUBOWITZ; MERCURI, 1999).

Apesar de ser um teste abrangente, dura em média cerca de 15 minutos, e pode ser aplicado em RN a termo ou prematuro, com condição instável ou estável. O desempenho do RN pode ser avaliado até mesmo se estiver em incubadora; a sequência dos aspectos e itens avaliados, podem ser alterados de acordo com o posicionamento do RN ou do seu estado de alerta (DUBOWITZ; MERCURI; DUBOWITZ, 1998; DUBOWITZ; DUBOWITZ; MERCURI, 1999).

O HNNE possui figuras e descrições em cada item e para pontuar basta marcar a descrição ou a figura que melhor se adapta ao estado do lactente. As pontuações são calculadas pela soma de todos os itens, sendo que cada item pode pontuar 0,$0 ; 0,5 ;$ ou 1,0 , sendo a faixa de normalidade total de 30,5 a 34 (NASCIMENTO et al., 2011). Se o score global estiver na zona limítrofe não significa necessariamente que o RN avaliado apresente anormalidades neurológicas, mas identifica que esta deve manter seguimento neurológico regular (DUBOWITZ; DUBOWITZ; MERCURI, 1999).

A avaliação deve ser realizada quando o lactente estiver alimentado e calmo (DUBOWITZ; RICCI; MERCURI, 2005).

A aplicação do instrumento adaptado seguiu as instruções do HNNE propostas por Dubowitz, Ricci e Mercuri (2005).

\subsubsection{Procedimentos para validação da escala}

Após a finalização do processo de tradução e adaptação cultural do HNNE, que constitui a validação semântica, com aprovação total dos autores (vide Estudo 1), iniciou-se o processo de validação psicométrica com o objetivo de avaliar em que medida tal instrumento pode ser 
considerado válido para o contexto ao qual foi adaptado. Apesar de serem passos distintos, a adaptação e a validação são complementares (BORSA, DAMASIO E BANDEIRA, 2012).

Entende-se por validade do instrumento, a capacidade em mensurar o mais próximo possível, com consistência e estabilidade, o valor real do que é avaliado, ou seja, o grau pelo qual um instrumento é capaz de medir o que se propõe. A validação psicométrica é composta pela avaliação das medidas de consistência interna e reprodutibilidade (REICHENHEIM, MORAES, 2007).

\section{Consistência Interna}

É uma medida que avalia o grau de inter-relação entre os itens, ou seja, verifica se os itens e subitens de um instrumento tem o mesmo conceito e se relacionam. A consistência interna só recebe um significado interpretável, quando a inter-relação entre os itens é determinada por um conjunto de itens que juntos formam um modelo reflexivo (CRONBACH, 1951; CORTINA, 1993). De acordo com Mokkink et al. (2012), um modelo reflexivo é um modelo no qual todos os itens são uma manifestação da mesma construção subjacente, dos quais precisam estar altamente correlacionados e intercambiável. Por isso, é um importante dado para questionários que pretendem medir um único conceito utilizando diversas variáveis (TERWEE et al., 2007).

O teste mais aplicado na estatística para avaliar este fator é o alfa de Cronbach. Seus valores variam de zero a um com correlações positivas entre os itens, sendo considerado aceitáveis os valores entre 0,70 e 0,80 ; bons os valores acima de 0,80; e excelente 0,90(WALTZ; STRICKLAND; LENZ, 2005).

\section{$\underline{\text { Reprodutibilidade }}$}

A reprodutibilidade é uma medida que busca concordância de aplicação e/ou consistência dos resultados, entre diferentes avaliadores ou entre avaliações realizadas em momentos distintos pelo mesmo avaliador. Este dado é obtido através da confiabilidade interavaliador e intra-avaliador, e pelo teste-reteste (PASQUALI, 2010; PORTNEY; WATKINS, 2008; FITZNER, 2007).

Em outras palavras, é considerado quando várias medições são realizadas em condições diferentes, e as pontuações e resultados obtidos sobre o mesmo objeto não se alteram. Esta fase pode ser definida também como validade de face que é uma das etapas necessárias para a validação de conteúdo de um instrumento (MOKKINK et al., 2012). 


\subsubsection{Procedimentos para coleta de dados}

Para a validação da versão brasileira do instrumento Hammersmith Neonatal Neurological Assessment, $143 \mathrm{RN}$ prematuros e nascimento a termo, foram convidados a participarem do estudo, e seus responsáveis assinaram o TCLE.

Foi preenchido uma ficha de caracterização dos participantes que continham 4 seções com as seguintes informações: dados de identificação do paciente, da família, dados da gestação e dados pós-natal.

Na seção de identificação do paciente, consta: número de registro da criança no $\mathrm{HC}$, nome, data de nascimento, idade cronológica, idade gestacional (IG), sexo, peso, comprimento, perímetro cefálico, perímetro torácico, tipo de parto, data prevista para o parto, tempo de trabalho de parto, intercorrência no nascimento, se chorou, se precisou de cuidados na Unidade de Tratamento Intensivo (UTI) neonatal, ou na UCIN, por quanto tempo e o motivo.

$\mathrm{Na}$ seção de identificação da família: Nome do pai e da mãe; idade, profissão e escolaridade de ambos; estado civil dos pais; se possuem outros filhos e idade dos filhos; se tem algum filho com deficiência e se positivo, o tipo de deficiência; renda familiar; telefone e endereço.

$\mathrm{Na}$ seção sobre dados da gestação foi perguntado se a mãe teve dificuldade para engravidar e se precisou fazer algum tratamento; número de gestação; número de aborto; se a gravidez foi desejada, planejada ou se tentou abortar; se o fez o pré-natal e por quantas consultas passou; se realizou os exames de rotina da gestação e seus resultados; se teve alguma doença durante a gestação ou se fez uso de algum medicamento neste período; se fumou, bebeu ou ingeriu drogas; se enfrentou alguma questão emocional; se teve sangramento (por quanto tempo e qual o período), se precisou ficar de repouso (por quanto tempo e qual o período); se sentia o bebê se movimentar na barriga e se houve alguma outra intercorrência não mencionada na ficha.

Os dados pós-natal compreende a história após alta hospitalar e a história do desenvolvimento motor.

Essa ficha serviu, além de caracterizar o participante, garantir se havia algum risco para $\mathrm{PC}$, ainda que fosse um risco isolado e baixo.

Para verificar o desempenho e a condição clínica motora, os lactentes foram avaliados através do HNNE (já descrito anteriormente) e através da escala "Alberta Infant Motor Scale" (AIMS). Trata-se de uma escala observacional que objetiva avaliar o desenvolvimento motor axial e postural do lactente até a aquisição da marcha independente ou até que o lactente complete 18 meses de idade. Esta escala de triagem é composta por 58 itens que ilustram a 
sequência do desenvolvimento do controle postural em quatro posições: prono (21itens), supino (9 itens), sentado (12 itens) e em pé (16 itens). Cada item apresenta uma ilustração do lactente e uma descrição chave sobre o alinhamento postural ou sobre a descarga de peso (PIPER; DARRAH, 1994).

Assim como no HNNE, o lactente deve estar alerta e ativo, e com o mínimo de roupas possíveis. Cada item da AIMS que foi observado gera um ponto que constitui a janela do desenvolvimento. Caso haja alguma postura dentro dessa janela que não foi observada, não se pontua, colocando as iniciais NO (não observado). Ao final da avaliação tem-se um escore bruto para cada posição. O escore das quatro posturas é somado e gera-se um escore total bruto que é lançado no gráfico denominado Curva do Desenvolvimento Motor. Nesta curva de desenvolvimento, os percentis variam de 5\% a 90\%. Quanto maior o percentil, menor a chance de atraso de desenvolvimento motor (PIPER; DARRAH, 1994).

As avaliações ocorreram logo que possível após o nascimento, sendo que alguns RN foram avaliados algumas horas depois e outros foram avaliados poucos dias após o nascimento.

A validade convergente foi avaliada pela correlação do escore da AIMS com o escore do HNNE através do coeficiente de correlação de Pearson. A hipótese aventada era de que maiores escores da escala HNNE correspondessem a maiores escores da AIMS. Os critérios de correlação adotados foram: $\mathrm{p} \leq 0,30$ correlação desprezível; 0.3 a 0.5 indica uma correlação fraca; 0.5 a 0.7 correlação moderada; 0.7 a 0.9 correlação forte; >0,9 correlação muito forte (MUKAKA, 2012).

Para se cumprir a confiabilidade intra-avaliador, foi considerado um subgrupo de 30 participantes, cujas avaliações foram filmadas na Unidade de cuidados intermediários (UCIN) e na maternidade para posterior pontuação. As filmagens não foram captadas através de um tripé fixo, e sim com a ajuda de um colaborador que posicionou a câmera da marca $S O N Y{ }^{\circledR}$, modelo HDR-PJ380 com 8,9 megapixels, de forma que permitiu captar detalhes de cada item da avaliação (figura 5 e 6). Os RN avaliados poderiam estar tanto em incubadora (figura 7) sob cuidados intermediários ou intensivos, quanto no berçário (figura 8). Desta forma, a primeira avaliação ocorreu in loco e a segunda avaliação foi realizada através das imagens que foram assistidas pelo avaliador 1,14 dias após a primeira avaliação para impedir que a memória do mesmo influenciasse os resultados. A análise de concordância foi realizada utilizando o Coeficiente de concordância Kappa de Cohen.

Para se cumprir a confiabilidade inter-avaliador, outro profissional da saúde com experiência neonatal e formação em terapia ocupacional, foi convidado para participar da pesquisa (avaliador 2). Os resultados foram comparados através do Coeficiente de 
concordância Kappa. Para esta análise psicométrica também foi considerado o subgrupo de 30 participantes.

Os avaliadores não receberam nenhum tipo de treinamento prévio, visto que o instrumento é de fácil aplicação e não necessita de experiência anterior ao instrumento, apenas experiência com a área neurológica e/ou neonatal (DUBOWITZ; RICCI; MERCURI, 2005). Entretanto, todas as dúvidas quanto a aplicação do instrumento, foram esclarecidas antes da aplicação do mesmo.

Figura 5: Teste de preensão plantar

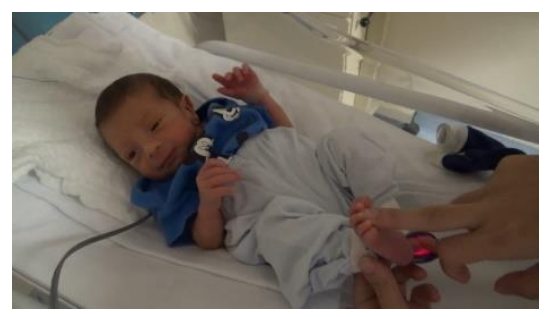

Figura 7: Avaliação na incubadora

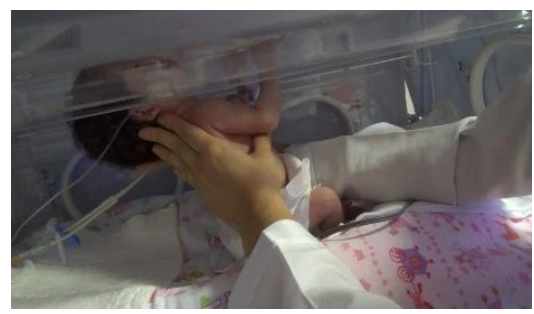

Figura 6: Teste de tônus flexor de cabeça 1

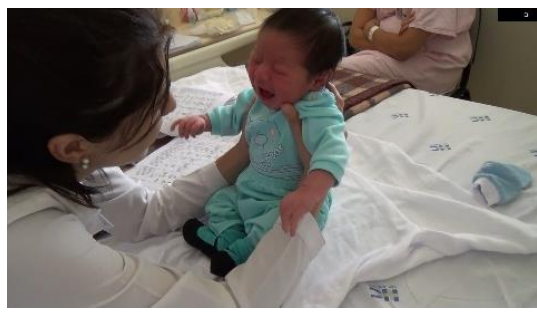

Figura 8: Avaliação no berçário

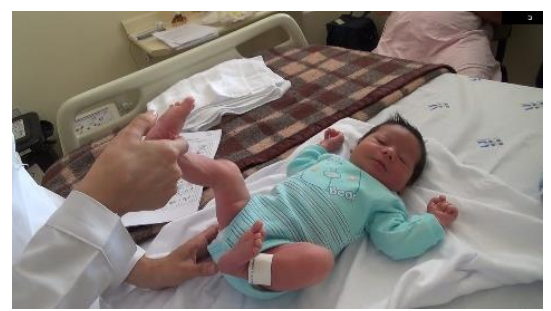

O teste-reteste foi realizado pelo avaliador 1, em outro subgrupo aleatório de 30 participantes, porém, entre estas avaliações não foi respeitado o intervalo de 14 dias, porque os bebês das unidades (maternidade e UCIN) poderiam receber alta a qualquer momento, dificultando o retorno dos mesmos nas unidades de coleta de dados. Além disso, há uma grande variabilidade no comportamento do $\mathrm{RN}$ alterando de forma exponencial os resultados da avaliação. Desta forma, a segunda avaliação ocorreu sempre no mesmo dia que a primeira avaliação, com um intervalo de sono, mamada ou exames de rotina da unidade. $\mathrm{O}$ critério utilizado entre as avaliações, era garantir que o estado comportamental do bebê na segunda avaliação, estivesse igual ou muito parecido com o estado comportamental observado na primeira avaliação.

Após a coleta, os dados foram processados e os testes estatísticos foram aplicados para validação da escala. 


\subsection{Análise dos dados}

Os dados foram processados pelo programa Statistical Package for Social Sciences for Personal Computer (versão 22.0). Foram montados quatro bancos de dados: o primeiro contém informações de todos os participantes; o segundo e o terceiro banco contém informações de um subgrupo de 30 participantes, para as análises intra e inter observador; e o último banco de dados contém as avaliações de teste-reteste formado por outro subgrupo de 30 participantes. Cada participante recebeu um número de identificação que foi utilizado na organização destes - essa medida resguarda a identidade dos participantes e garante que o pesquisador responsável pela análise de dados é cego quanto à identidade dos participantes.

Para a análise descritiva sobre as influências dos riscos para PC em relação aos escores obtidos, foram utilizados teste não paramétrico de Mann-Whitney com significância de 5\% para comparar dois grupos e teste não paramétrico de Kruskal Wallis com a mesma significância para comparar 3 ou mais grupos. Para análise descritiva numérica foi utilizado Coeficiente de Correlação não paramétrica de Spearman.

A análise da confiabilidade foi realizada através da consistência interna e da reprodutibilidade. A consistência interna foi calculada pelo alfa de Cronbach; e as confiabilidades intra e interexaminador, assim como a reprodutibilidade avaliadas através do teste-reteste, foram calculadas utilizando o coeficiente de correlação intraclasse (ICC) e pelo Coeficiente de concordância Kappa de Cohen. A validade convergente foi avaliada pela correlação do escore da HNNE com o escore a AIMS através do coeficiente de correlação de Spearman.

Foi considerado a interpretação dos valores de Kappa e de ICC, conforme Landis e Kock (1977), do qual correlações menores do que 0,41 - são fracas, entre 0,41 e 0,60 - moderada; entre 0,61 e 0,80 - forte ou substancial e entre 0,81 e 1,00 - quase perfeita

\subsection{Resultados}

\subsubsection{Resultados Descritivos/ inferenciais}

Dos 143 neonatos que participaram do estudo, 98 (68,5\%) compuseram o grupo a termo e $45(31,5 \%)$ o grupo pré-termo. Não houve prematuro extremo nesta amostra (IG < 28 semanas), mas participaram 21 prematuros intermediários (IG entre 28 e 34 semanas) e $24 \mathrm{RN}$ 
com prematuridade tardia (IG entre 34 e 36 semanas). Em relação ao sexo 51,7\% (N=74) são meninos e 70,6\% (N=101) dos participantes são brancos. Cento e nove RN $(76,2 \%)$ nasceram com peso adequado para a idade gestacional (AIG) e $17(11,9 \%)$ foram considerados pequenos para a idade gestacional (PIG) e exatamente o mesmo número de participantes - 17 (11,9\%) foram considerados gigantes para a idade gestacional (GIG).

Em relação ao tipo de parto, 55,9\% ( $\mathrm{N}=80)$ dos bebês nasceram via cesárea e 44,1\% $(\mathrm{N}=63)$ nasceram por parto vaginal. Sobre a condição do nascimento, $27(18,9 \%) \mathrm{RN}$ apresentaram APGAR $<7$ no $1^{\circ}$ minuto e destes, 4 receberam esta pontuação no $5^{\circ}$ minuto. Cinquenta e seis RN (39,2\%) precisaram de cuidado intensivo ou intermediário após o nascimento, sendo que $52(36,4 \%)$ enfrentaram alguma intercorrência ao nascer.

Quanto à caracterização da família, 10 (7\%) mães tinham menos de 18 anos, 68 (47,6\%) mães tinham entre 18 e 29 anos, 34 (23,8\%) tinham entre 30 e 34 anos, 31 (21,7\%) acima. Quanto a escolaridade, $23,1 \%(n=33)$ não tinham completado o ensino fundamental; $37,1 \%$ $(\mathrm{n}=53)$ concluíram ensino médio e apenas $3(2,1 \%)$ mães possuem ensino superior. A média da idade do pai foi de 38,2 anos $(15-59)$, sendo que $21,7 \%(n=31)$ não completaram o ensino fundamental, $35,7 \%(n=51)$ possuem ensino médio completo e 3,5\% $(n=5)$ possuem ensino superior.

Nesta amostra, $116(81,1 \%)$ pais moram juntos (sendo 39 casados e 77 em união estável) e a renda familiar variou desde $R \$ 124,00$ até $R \$ 9540,00$, sendo a mediana de $R \$ 2.300,00$.

Em relação aos dados da gestação, 62,2\% das famílias desejaram a gravidez, mas somente $31,5 \%(n=45)$ planejaram. Cento e trinta e duas mães relataram ter feito o pré-natal completo embora a maioria não soubesse quantas sessões tinham frequentado. Menos de $20 \%$ das mães $(n=25)$ fumaram durante a gestação, e menos de $10 \%(n=14)$ beberam socialmente de acordo com a percepção e avaliação delas. Trinta e três mães $(23,1 \%)$ tiveram sangramento e $53(37,1 \%)$ tiveram que ficar de repouso.

Os dados sobre os fatores de risco para PC foram correlacionados com o desempenho obtido pelo HNNE em cada um de seus domínios e no escore total (Tabela 1); observou-se uma tendência de melhor desempenho em reflexos nos $\mathrm{RN}$ que não sofreram intercorrências ao nascer.

O tipo de parto e a permanência na UTI ou na UCIN influenciaram no escore total com diferença significativa (Tabela 1), sendo que os RN nascidos de parto vaginal e os que não necessitaram de cuidados especiais apresentaram maiores escores quando comparados aos RN que nasceram por cesárea ou foram encaminhados para estas unidades. 
O peso ao nascer influenciou no domínio movimento (Tabela 1), sendo que os RN que pertencem ao grupo GIG ( $n=17)$ obtiveram melhor desempenho que os RN que pertencem ao grupo PIG (n=17). A presença de sangramento durante a gestação, influenciou nos domínios de movimento e padrões anormais, sendo que os RN de mães que não apresentaram sangramento obtiveram maiores escores em relação a qualidade e quantidade de movimentos espontâneos; e os RN de mães que tiveram sangramento, apresentaram padrões anormais de postura e movimento.

Não houve diferença significativa entre os escores obtidos no HNNE e o APGAR no $1^{\circ}$ ou $5^{\circ}$ minuto. A idade e a escolaridade da mãe não influenciaram nos escores. Assim como, não houve diferença significativa, caso a mãe tenha bebido ou fumado (Tabela 1). 
Tabela 1: Correlação entre os fatores de risco para PC e o desempenho obtido pelo HNNE

\begin{tabular}{|c|c|c|c|c|c|c|c|}
\hline $\begin{array}{c}\text { Tipo de } \\
\text { Intercorrência }\end{array}$ & Postura (N) & $\begin{array}{c}\text { Padrões de Tônus } \\
(\mathbf{N})\end{array}$ & $\operatorname{Reflexo}(\mathbf{N})$ & Movimentos (N) & $\begin{array}{c}\text { Padrões Anormais } \\
(\mathbf{N})\end{array}$ & Comportamento $(\mathbf{N})$ & Total $(\mathbf{N})$ \\
\hline \multirow{3}{*}{$\begin{array}{c}\text { Intercorrência ao } \\
\text { nascer }\end{array}$} & Não = 91 & Não = 91 & Não = 91 & Não = 91 & Não $=91$ & Não = 91 & Não $=91$ \\
\hline & $\operatorname{Sim}=52$ & $\operatorname{Sim}=52$ & $\operatorname{Sim}=52$ & $\operatorname{Sim}=52$ & $\operatorname{Sim}=52$ & $\operatorname{Sim}=52$ & $\operatorname{Sim}=52$ \\
\hline & $P=0,277$ & $\mathrm{P}=0,133$ & $P=0,064$ & $P=0,986$ & $P=0,688$ & $P=0,964$ & $P=0,997$ \\
\hline \multirow{3}{*}{ Tipo de Parto } & Vaginal $=63$ & Vaginal $=63$ & Vaginal $=63$ & Vaginal $=63$ & Vaginal $=63$ & Vaginal $=63$ & Vaginal $=63$ \\
\hline & Cesárea = 80 & Cesárea $=80$ & Cesárea $=80$ & Cesárea $=80$ & Cesárea $=80$ & Cesárea $=80$ & Cesárea $=80$ \\
\hline & $\mathrm{P}=0,162$ & $\mathrm{P}=0,349$ & $\mathrm{P}=0,345$ & $\mathrm{P}=0,650$ & $P=0,619$ & $\mathrm{P}=0,187$ & $P=0,035$ \\
\hline \multirow{4}{*}{$\begin{array}{l}\text { Classificação do } \\
\text { peso ao nascer }\end{array}$} & $\mathrm{PIG}=17$ & $\mathrm{PIG}=17$ & $\mathrm{PIG}=17$ & $\mathrm{PIG}=17$ & $\mathrm{PIG}=17$ & $\mathrm{PIG}=17$ & $\mathrm{PIG}=17$ \\
\hline & $\mathrm{AIG}=109$ & $\mathrm{AIG}=109$ & $\mathrm{AIG}=109$ & $\mathrm{AIG}=109$ & $\mathrm{AIG}=109$ & $\mathrm{AIG}=109$ & $\mathrm{AIG}=109$ \\
\hline & $\mathrm{GIG}=17$ & $\mathrm{GIG}=17$ & $\mathrm{GIG}=17$ & $\mathrm{GIG}=17$ & $\mathrm{GIG}=17$ & $\mathrm{GIG}=17$ & $\mathrm{GIG}=17$ \\
\hline & $P=0,196$ & $P=0,947$ & $P=0,175$ & $P=0,049$ & $P=0,213$ & $P=0,126$ & $P=0,130$ \\
\hline \multirow{4}{*}{ APGAR } & $1^{\circ}$ minuto & $1^{\circ}$ minuto & $1^{\circ}$ minuto & $1^{\circ}$ minuto & $1^{\circ}$ minuto & $1^{\circ}$ minuto & $1^{\circ}$ minuto \\
\hline & $\mathrm{P}=0,985$ & $P=0,191$ & $\mathrm{P}=0,058$ & $\mathrm{P}=0,914$ & $P=0,244$ & $\mathrm{P}=0,103$ & $P=0,313$ \\
\hline & $5^{\circ}$ minuto & $5^{\circ}$ minuto & $5^{\circ}$ minuto & $5^{\circ}$ minuto & $5^{\circ}$ minuto & $5^{\circ}$ minuto & $5^{\circ}$ minuto \\
\hline & $\mathrm{P}=0,747$ & $P=0,630$ & $\mathrm{P}=0,065$ & $\mathrm{P}=0,511$ & $\mathrm{P}=0,379$ & $\mathrm{P}=0,319$ & $P=0,766$ \\
\hline \multirow{3}{*}{ UTI/UCIM } & Não $=87$ & Não $=87$ & Não $=87$ & Não $=87$ & Não $=87$ & Não $=87$ & Não $=87$ \\
\hline & $\mathrm{Sim}=56$ & $\mathrm{Sim}=56$ & $\mathrm{Sim}=56$ & $\mathrm{Sim}=56$ & $\mathrm{Sim}=56$ & $\operatorname{Sim}=56$ & $\operatorname{Sim}=56$ \\
\hline & $\mathrm{P}=0,141$ & $P=0,086$ & $P=0,417$ & $P=0,776$ & $P=0,645$ & $P=0,046$ & $P=0,022$ \\
\hline \multirow{3}{*}{ Fumou } & Não $=118$ & Não $=118$ & Não $=118$ & Não $=118$ & Não $=118$ & Não $=118$ & Não $=118$ \\
\hline & $\mathrm{Sim}=25$ & $\mathrm{Sim}=25$ & $\mathrm{Sim}=25$ & $\mathrm{Sim}=25$ & $\mathrm{Sim}=25$ & $\mathrm{Sim}=25$ & $\mathrm{Sim}=25$ \\
\hline & $\mathrm{P}=0,442$ & $\mathrm{P}=0,588$ & $\mathrm{P}=0,258$ & $\mathrm{P}=0,441$ & $\mathrm{P}=0,736$ & $\mathrm{P}=0,887$ & $\mathrm{P}=0,598$ \\
\hline \multirow{3}{*}{ Bebida alcoólica } & Não = 129 & Não = 129 & Não = 129 & Não = 129 & Não = 129 & Não = 129 & Não = 129 \\
\hline & $\operatorname{Sim}=14$ & $\operatorname{Sim}=14$ & $\operatorname{Sim}=14$ & $\operatorname{Sim}=14$ & $\operatorname{Sim}=14$ & $\operatorname{Sim}=14$ & $\operatorname{Sim}=14$ \\
\hline & $\mathrm{P}=0,521$ & $\mathrm{P}=0,171$ & $P=0,802$ & $P=0,989$ & $P=0,402$ & $\mathrm{P}=0,354$ & $P=0,651$ \\
\hline
\end{tabular}




\subsubsection{Resultados análise psicométrica}

Para análise psicométrica do HNNE, foi considerada a amostra completa $(n=143)$ e verificada a consistência interna de cada item - tabela 2, e a consistência interna dos domínios (tônus, reflexos, movimentos espontâneos, sinais anormais, a orientação e comportamento) tabela 3; ambos através do alfa de Cronbach.

Tabela 2: Consistência interna por item do HNNE

\begin{tabular}{|c|c|c|}
\hline Item & Sinal & Alfa de Cronbach \\
\hline Postura & + & 0,555 \\
\hline Recolhimento dos Braços & + & 0,543 \\
\hline Tração dos Braços & + & 0,564 \\
\hline Recolhimento das Pernas & + & 0,537 \\
\hline Tração das pernas & + & 0,554 \\
\hline Ângulo poplíteo & + & 0,527 \\
\hline Controle da cabeça 1 & + & 0,538 \\
\hline Controle da cabeça 2 & + & 0,525 \\
\hline Puxar para sentar & + & 0,537 \\
\hline Suspensão ventral & + & 0,549 \\
\hline Tônus flexor 1 & + & 0,564 \\
\hline Tônus flexor 2 & + & 0,542 \\
\hline Tônus Extensor da perna & + & 0,588 \\
\hline Tônus Extensor do pescoço & + & 0,571 \\
\hline Tônus Extensor do tronco & + & 0,557 \\
\hline Reflexo tendíneo & + & 0,542 \\
\hline Reflexo de sucção & + & 0,569 \\
\hline Preensão palmar & + & 0,551 \\
\hline Preensão plantar & + & 0,548 \\
\hline Colocação das pernas & + & 0,539 \\
\hline Reflexo de Moro & + & 0,546 \\
\hline Quantidade de movimentos & + & 0,515 \\
\hline Qualidade de movimentos & + & 0,516 \\
\hline Elevação da cabeça & + & 0,553 \\
\hline Postura anormal & + & 0,545 \\
\hline Tremor & + & 0,549 \\
\hline Sobressalto/susto & + & 0,539 \\
\hline Aparência dos olhos & + & 0,543 \\
\hline Orientação auditiva & + & 0,536 \\
\hline Orientação visual & + & 0,541 \\
\hline Alerta & + & 0,537 \\
\hline Irritabilidade & + & 0,530 \\
\hline Consolabilidade & + & 0,529 \\
\hline Choro & + & 0,527 \\
\hline
\end{tabular}

Ao avaliar a consistência interna, observou-se que a média geral, não apresentou bons resultados (valor Alfa de Cronbach 0,552). O valor mínimo para ser considerado bom é igual ou acima de 0,70. O domínio com pior consistência se refere ao padrão de tônus e a melhor consistência encontrada, se refere aos movimentos espontâneos. 
Tabela 3: Consistência interna por domínio do HNNE

\begin{tabular}{lc}
\hline \hline \multicolumn{1}{c}{ Domínio } & Alfa de Crombah \\
\hline Postura e Tônus & 0,549 \\
Padrão de Tônus & $-0,050$ \\
Reflexos & 0,289 \\
Movimentos espontâneos & 0,584 \\
Sinais anormais & 0,107 \\
Orientação e comportamento & 0,561 \\
Total & 0,552 \\
\hline \hline
\end{tabular}

Para verificar a reprodutibilidade do instrumento, através da confiabilidade intra e inter avaliadores e pelo teste-reteste. E a validade de critério do tipo recorrente foi avaliada cruzando os escores do HNNE com a AIMS.

A confiabilidade inter avaliadores foi realizada por dois avaliadores diferentes, com diferentes formações acadêmicas (fisioterapia e terapia ocupacional); em um subgrupo formado por 30 RN. Foi aplicado os testes de correlação intra-classe (ICC), apresentada na tabela 4, e os testes de Kappa ponderado (Tabela 5). Verificou-se que houve alta concordância entre as avaliações em todos os domínios.

Tabela 4: Confiabilidade inter avaliadores através da correlação Intraclasse

\begin{tabular}{lccc}
\hline \multicolumn{1}{c}{ Domínio } & ICC & IC 95\% & P \\
\hline Postura e Tônus & 0,964 & $0,924-0,983$ & $<0,001$ \\
Padrão de Tônus & 0,969 & $0,934-0,985$ & $<0,001$ \\
Reflexos & 0,951 & $0,897-0,977$ & $<0,001$ \\
Movimentos espontâneos & 0,972 & $0,942-0,987$ & $<0,001$ \\
Sinais anormais & 0,912 & $0,816-0,958$ & $<0,001$ \\
Orientação e comportamento & 0,841 & $0,667-0,924$ & $<0,001$ \\
Total & 0,964 & $0,925-0,983$ & $<0,001$ \\
\hline \hline
\end{tabular}

O teste de kappa ponderado (tabela 5) foi utilizado para avaliar a concordância inter avaliadores em cada item. Os valores estiveram entre 0,400 e 1,0 e foram interpretados de acordo com a sugestão de Landis e Koch (1977): < 0 - Não existe Concordância; 0-0,20 Concordância Mínima; 0,21-0,40 - Concordância Fraca; 0,41-0,60 - Concordância Moderada; 0,61-0,80 - Forte Concordância; 0,81-1,0 - Concordância quase Perfeita. A tabela 5 mostra os valores dos coeficientes de Kappa Ponderado para a concordância inter avaliadores. 
Tabela 5: Valores de Kappa ponderado por item para a confiabilidade inter avaliadores

\begin{tabular}{|c|c|c|c|}
\hline Item & Kappa & IC $95 \%$ & $\mathbf{P}$ \\
\hline Postura & 0,923 & $0,777-1,0$ & $<0,001$ \\
\hline Recolhimento dos Braços & 0,927 & $0,783-1,0$ & $<0,001$ \\
\hline Tração dos Braços & 1,0 & - & $<0,001$ \\
\hline Recolhimento das Pernas & 0,923 & $0,777-1,0$ & $<0,001$ \\
\hline Tração das pernas & 1,0 & - & $<0,001$ \\
\hline Ângulo poplíteo & 0,941 & $0,828-1,0$ & $<0,001$ \\
\hline Controle da cabeça 1 & 0,927 & $0,783-1,0$ & $<0,001$ \\
\hline Controle da cabeça 2 & 0,870 & $0,622-1,0$ & $<0,001$ \\
\hline Puxar para sentar & 1,0 & - & $<0,001$ \\
\hline Suspensão ventral & 1,0 & - & $<0,001$ \\
\hline Tônus flexor 1 & 1,0 & - & $<0,001$ \\
\hline Tônus flexor 2 & 0,889 & $0,676-1,0$ & $<0,001$ \\
\hline Tônus Extensor da perna & 0,861 & $0,676-1,0$ & $<0,001$ \\
\hline Tônus Extensor do pescoço & 1,0 & - & $<0,001$ \\
\hline Tônus Extensor do tronco & 1,0 & - & $<0,001$ \\
\hline Reflexo tendíneo & 0,814 & $0,566-1,0$ & $<0,001$ \\
\hline Reflexo de sucção & 0,889 & $0,676-1,0$ & $<0,001$ \\
\hline Preensão palmar & 0,932 & $0,801-1,0$ & $<0,001$ \\
\hline Preensão plantar & 1,0 & - & $<0,001$ \\
\hline Colocação das pernas & 1,0 & - & $<0,001$ \\
\hline Reflexo de Moro & 0,803 & $0,594-1,0$ & $<0,001$ \\
\hline Quantidade de movimentos & 0,899 & $0,764-1,0$ & $<0,001$ \\
\hline Qualidade de movimentos & 0,817 & $0,629-1,0$ & $<0,001$ \\
\hline Elevação da cabeça & 0,910 & $0,744-1,0$ & $<0,001$ \\
\hline Postura anormal & 1,0 & - & $<0,001$ \\
\hline Tremor & 1,0 & - & $<0,001$ \\
\hline Sobressalto/susto & 0,780 & $0,396-1,0$ & $<0,001$ \\
\hline Aparência dos olhos & 0,850 & $0,654-1,0$ & $<0,001$ \\
\hline Orientação auditiva & 0,894 & $0,691-1,0$ & $<0,001$ \\
\hline Orientação visual & 0,400 & $0,0-0,948$ & $<0,001$ \\
\hline Alerta & 0,471 & $0,0-1,0$ & $<0,001$ \\
\hline Irritabilidade & 0,797 & $0,611-0,983$ & $<0,001$ \\
\hline Consolabilidade & 0,650 & $0,019-1,0$ & $<0,001$ \\
\hline Choro & 0,980 & $0,788-1,0$ & $<0,001$ \\
\hline
\end{tabular}

Dos 34 itens que compõe o instrumento, 28 apresentaram concordância quase perfeita, 4 itens apresentaram forte concordância e apenas dois itens apresentaram concordância moderada. os itens que obtiveram concordância quase perfeita (entre 0,81 e 1,0) foram: postura, recolhimento dos braços, tração dos braços, recolhimento das pernas, tração das pernas, ângulo poplíteo, controle da cabeça 1, controle de cabeça 2, puxar para sentar, suspensão ventral, tônus flexor 1, tônus flexor 2, tônus extensor da perna, tônus extensor do pescoço, tônus extensor do tronco, reflexo tendíneo, reflexo de sucção, preensão palmar, preensão plantar, colocação das pernas, quantidade de movimentos, qualidade de movimentos, elevação de cabeça, postura anormal, tremor, aparência dos olhos, orientação auditiva e choro.

Os itens que apresentaram forte concordância foram: reflexo de moro, sobressalto/susto, irritabilidade, consolabilidade, e os itens que apresentaram concordância moderada: Orientação visual, alerta. 
A confiabilidade intra avaliadores foi realizada em um subgrupo formado por $30 \mathrm{RN}$; sendo que houve um intervalo de 14 dias entre as avaliações realizadas in loco e as avaliações feitas através das filmagens, conforme o intervalo proposto por Terwee e colaboradores (2007). Verificou-se que houve alta concordância entre as avaliações, o que pode ser verificado na tabela 6 que apresenta os valores de correlação intraclasse por domínio, para a concordância intra avaliadores.

Tabela 6: Confiabilidade intra avaliadores por domínio, pela correlação Intraclasse

\begin{tabular}{lccc}
\hline \hline \multicolumn{1}{c}{ Domínio } & ICC & IC 95\% & P \\
\hline Postura e Tônus & 0,944 & $0,887-0,973$ & $<0,001$ \\
Padrão de Tônus & 1,000 & - & $<0,001$ \\
Reflexos & 0,962 & $0,923-0,982$ & $<0,001$ \\
Movimentos espontâneos & 0,993 & $0,986-0,997$ & $<0,001$ \\
Sinais anormais & 0,990 & $0,979-0,995$ & $<0,001$ \\
Orientação e comportamento & 0,964 & $0,925-0,983$ & $<0,001$ \\
Total & 0,955 & $0,908-0,978$ & $<0,001$ \\
\hline \hline
\end{tabular}

A tabela 7 apresenta os resultados obtidos por itens na confiabilidade intra-avaliadores, por meio do Kappa ponderado. Os itens que obtiveram concordância quase perfeita (entre 0,81 e 1,0) foram: Postura, recolhimento dos braços, Tração dos braços, Recolhimento das pernas, tração das pernas, Ângulo poplíteo, controle da cabeça 1, controle de cabeça 2, puxar para sentar, suspensão ventral, tônus flexor 1, tônus flexor 2, tônus extensor da perna, tônus extensor do pescoço, tônus extensor do tronco, reflexo tendíneo, reflexo de sucção, preensão palmar, preensão plantar, colocação das pernas, reflexo de moro, quantidade de movimentos, qualidade de movimentos, elevação de cabeça, tremor, sobressalto/susto, aparência dos olhos, orientação auditiva, Orientação visual e irritabilidade. Os itens que apresentaram forte concordância (entre $0,61$ e 0,8$)$ foram: postura anormal, alerta, consolabilidade e choro. 
Tabela 7: Valores de Kappa ponderado por item para a confiabilidade intra avaliadores

\begin{tabular}{|c|c|c|c|}
\hline Item & Kappa & IC 95\% & $\overline{\mathbf{P}}$ \\
\hline Postura & 0,936 & $0,813-1,0$ & $<0,001$ \\
\hline Recolhimento dos Braços & 0,934 & $0,807-1,0$ & $<0,001$ \\
\hline Tração dos Braços & 0,924 & $0,779-1,0$ & $<0,001$ \\
\hline Recolhimento das Pernas & 1,0 & - & $<0,001$ \\
\hline Tração das pernas & 0,870 & $0,622-1,0$ & $<0,001$ \\
\hline Ângulo poplíteo & 0,939 & $0,822-1,0$ & $<0,001$ \\
\hline Controle da cabeça 1 & 0,928 & $0,789-1,0$ & $<0,001$ \\
\hline Controle da cabeça 2 & 0,870 & $0,622-1,0$ & $<0,001$ \\
\hline Puxar para sentar & 1,0 & - & $<0,001$ \\
\hline Suspensão ventral & 1,0 & - & $<0,001$ \\
\hline Tônus flexor 1 & 1,0 & - & $<0,001$ \\
\hline Tônus flexor 2 & 1,0 & - & $<0,001$ \\
\hline Tônus Extensor da perna & 1,0 & - & $<0,001$ \\
\hline Tônus Extensor do pescoço & 1,0 & - & $<0,001$ \\
\hline Tônus Extensor do tronco & 1,0 & - & $<0,001$ \\
\hline Reflexo tendíneo & 1,0 & - & $<0,001$ \\
\hline Reflexo de sucção & 0,890 & $0,679-1,0$ & $<0,001$ \\
\hline Preensão palmar & 0,935 & $0,810-1,0$ & $<0,001$ \\
\hline Preensão plantar & 0,886 & $0,687-1,0$ & $<0,001$ \\
\hline Colocação das pernas & 0,934 & $0,807-1,0$ & $<0,001$ \\
\hline Reflexo de Moro & 0,931 & $0,798-1,0$ & $<0,001$ \\
\hline Quantidade de movimentos & 0,902 & $0,773-1,0$ & $<0,001$ \\
\hline Qualidade de movimentos & 0,813 & $0,613-1,0$ & $<0,001$ \\
\hline Elevação da cabeça & 1,0 & - & $<0,001$ \\
\hline Postura anormal & 0,795 & $0,597-1,0$ & $<0,001$ \\
\hline Tremor & 0,945 & $0,840-1,0$ & $<0,001$ \\
\hline Sobressalto/susto & 1,0 & - & $<0,001$ \\
\hline Aparência dos olhos & 0,925 & $0,780-1,0$ & $<0,001$ \\
\hline Orientação auditiva & 0,874 & $0,631-1,0$ & $<0,001$ \\
\hline Orientacão visual & 1,0 & - & $<0,001$ \\
\hline Alerta & 0,632 & $0,176-1,0$ & $<0,001$ \\
\hline Irritabilidade & 0,901 & $0,770-1,0$ & $<0,001$ \\
\hline Consolabilidade & 0,652 & $0,023-1,0$ & $<0,001$ \\
\hline Choro & 0,788 & $0,387-1,0$ & $<0,001$ \\
\hline
\end{tabular}

Para avaliar a estabilidade da medida foi aplicado o teste-reteste e calculado a correlação Intraclasse entre os escores obtidos (Tabela 8) e o coeficiente de Kappa ponderado por item (Tabela 9). Nestas avaliações foi encontrada excelente concordância entre os domínios, com ICC de 0,983 no escore total. Quando analisadas as concordâncias por item, encontrou-se concordâncias quase perfeitas, exceto em relação aos itens sobre orientação e comportamento, das quais as taxas de concordância foram altas. 
Tabela 8: Confiabilidade teste-reteste, pela correlação Intraclasse

\begin{tabular}{lccc}
\hline \hline \multicolumn{1}{c}{ Domínio } & ICC & IC 95\% & P \\
\hline Postura e Tônus & 0,996 & $0,991-0,998$ & $<0,001$ \\
Padrão de Tônus & 0,981 & $0,960-0,991$ & $<0,001$ \\
Reflexos & 0,980 & $0,957-0,990$ & $<0,001$ \\
Movimentos espontâneos & 0,961 & $0,918-0,981$ & $<0,001$ \\
Sinais anormais & 0,995 & $0,990-0,998$ & $<0,001$ \\
Orientação e comportamento & 0,854 & $0,693-0,930$ & $<0,001$ \\
Total & 0,983 & $0,964-0,992$ & $<0,001$ \\
\hline \hline
\end{tabular}

Tabela 9: Valores de Kappa ponderado por item para a confiabilidade teste-reteste

\begin{tabular}{lccc}
\hline \hline \multicolumn{1}{c}{ Item } & Kappa & IC 95\% & P \\
\hline Postura & 0,935 & $0,810-1,0$ & $<0,001$ \\
Recolhimento dos Braços & 1,0 & - & $<0,001$ \\
Tração dos Braços & 0,923 & $0,776-1,0$ & $<0,001$ \\
Recolhimento das Pernas & 0,930 & $0,795-1,0$ & $<0,001$ \\
Tração das pernas & 1,0 & - & $<0,001$ \\
Ângulo poplíteo & 0,881 & $0,727-1,0$ & $<0,001$ \\
Controle da cabeça 1 & 1,0 & - & $<0,001$ \\
Controle da cabeça & 0,941 & $0,828-1,0$ & $<0,001$ \\
Puxar para sentar & 1,0 & - & $<0,001$ \\
Suspensão ventral & 1,0 & - & $<0,001$ \\
Tônus flexor 1 & 1,0 & - & $<0,001$ \\
Tônus flexor 2 & 1,0 & - & $<0,001$ \\
Tônus Extensor da perna & 1,0 & - & $<0,001$ \\
Tônus Extensor do pescoço & 0,918 & $0,762-1,0$ & $<0,001$ \\
Tônus Extensor do tronco & 1,0 & - & $<0,001$ \\
Reflexo tendíneo & 1,0 & - & $<0,001$ \\
Reflexo de sucção & 0,886 & $0,687-1,0$ & $<0,001$ \\
Preensão palmar & 0,866 & $0,688-1,0$ & $<0,001$ \\
Preensão plantar & 0,861 & $0,626-1,0$ & $<0,001$ \\
Colocação das pernas & 0,933 & $0,804-1,0$ & $<0,001$ \\
Reflexo de Moro & 0,926 & $0,783-1,0$ & $<0,001$ \\
Quantidade de movimentos & 0,949 & $0,849-1,0$ & $<0,001$ \\
Qualidade de movimentos & 0,813 & $0,619-1,0$ & $<0,001$ \\
Elevação da cabeça & 1,0 & - & $<0,001$ \\
Postura anormal & 0,867 & $0,596-1,0$ & $<0,001$ \\
Tremor & 0,944 & $0,837-1,0$ & $<0,001$ \\
Sobressalto/susto & 1,0 & - & $<0,001$ \\
Aparência dos olhos & 0,924 & $0,777-1,0$ & $<0,001$ \\
Orientação auditiva & 0,873 & $0,630-1,0$ & $<0,001$ \\
Orientação visual & 1,0 & - & \\
Alerta & 0,701 & $0,383-1,0$ & \\
Irritabilidade & 0,893 & $0,754-1,0$ & $0,176-1,0$ \\
Consolabilidade & 0,632 & $0,386-1,0$ & \\
Choro & 0,787 & & \\
\hline \hline & & & \\
\hline
\end{tabular}

Para se cumprir a validação de critério, a validade convergente foi avaliada pela amostra total $(n=143)$ e aplicada a correlação entre AIMS e HNNE através do coeficiente de correlação 
de Pearson e obteve uma correlação moderada no escore total $(r=0,489)$. Estes dados, bem como as correlações por domínio encontram-se na tabela 10.

Tabela 10: Correlação entre escore total e escore por domínio entre AIMS e HNNE.

\begin{tabular}{ccc}
\hline HNNE & AIMS & P \\
\hline Postura & $\mathrm{r}=0,396$ & $<0,001$ \\
Padrões de tônus & $\mathrm{r}=0,106$ & $<0,001$ \\
Reflexos & $\mathrm{r}=0,089$ & $<0,001$ \\
Movimentos & $\mathrm{r}=0,360$ & $<0,001$ \\
Padrões anormais & $\mathrm{r}=0,014$ & $<0,001$ \\
Comportamento & $\mathrm{r}=0,258$ & $<0,001$ \\
Total & $\mathrm{r}=0,489$ & $<0,001$ \\
\hline \hline
\end{tabular}

\subsection{Discussão}

A adaptação cultural do HNNE para o português do Brasil foi realizada de acordo com procedimentos psicométricos reconhecidos na literatura científica, cuja validação, compreende analisar as propriedades de medidas através da consistência interna e reprodutibilidade (REICHENHEIM, MORAES, 2007). A versão resumida do HNNE também pode ser considerada validada pois é uma avaliação mais curta, da qual alguns itens da versão expandida se repetem.

A escolha de adaptar este instrumento para o Brasil se deu devido a abrangência de condições neurológicas avaliadas, o tempo dedicado por profissionais da área da saúde em aplicar o teste - em torno de 15 minutos, e ainda a quantidade de RN que podem ser incluídos nesta avaliação (DUBOWITZ; DUBOWITZ; MERCURI, 1999).

Além disso, a literatura científica aponta o HNNE e o HINE como instrumentos importantes na predição de PC (NOVAK et al., 2017), que pode ser utilizado tanto em RN a termo como prematuro, podendo ser avaliado numa incubadora ou berço comum, estando com uma condição de saúde estável ou instável (DUBOWITZ; MERCURI; DUBOWITZ, 1998; DUBOWITZ; DUBOWITZ; MERCURI, 1999).

Para a validação da versão brasileira do instrumento Hammersmith Neonatal Neurological Assessment, $143 \mathrm{RN}$ - prematuros e nascidos a termo, participaram do estudo.

A literatura aponta a importância do tamanho amostral para que o poder da análise das propriedades psicométricas seja adequado. É recomendado pela psicometria tradicional, dez respondentes por item do questionário. Na versão expandida do HNNE há 34 itens, enquanto na versão resumida são 25 itens; então, seguindo este conceito precisaríamos recrutar entre 250 
a 340 participantes. Entretanto, Sapnas e Zeller (2002) demonstraram que sub-amostras entre 50 e 100 sujeitos são suficientes para se analisarem as propriedades psicométricas especialmente de constructos sociais. Eles acreditam que 10 respondentes por item representam um tamanho amostral acima do necessário e garantem que uma amostra composta por 100 sujeitos é suficiente para verificar as propriedades psicométricas iniciais de um instrumento que está sendo testado em outra população e que este número permite chegar a uma conclusão desejável (SAPNAS; ZELLER, 2002).

Um estudo da Turkia está em processo de validação e adaptação cultural do HINE pelo pesquisador Hatice Adigüzel, cujo título prévio é: Turkish Validity And Reliability Of The Hammersmith Infant Neurological Evaluation (HINE) e contará com 35 participantes. A previsão de término da pesquisa é em Março de 2020, porém ainda não foram publicados resultados preliminares para possível comparação.

\section{Dados Psicométricos}

O HINE e o HNNE são avaliações neurológicas muito utilizadas por profissionais da saúde (HATAAJA et al., 2001; FRISONE et al., 2002; RICCI et al., 2006; ROMEO et al., 2007; ROMEO et al., 2008; AMESS et al., 2009; ROMEO et al., 2009). Entretanto, ao desenvolver estes instrumentos, Hataaja et al. (1999) mencionaram apenas a confiabilidade interexaminadores em bebês típicos, não sendo apresentados valores sobre a confiabilidade intraavaliadores, nem consistência interna e nem validade concorrente ou convergente.

\section{Consistência Interna}

Ao avaliar a consistência interna do HNNE pelo coeficiente Alfa de Cronbrach, observou-se que a média geral foi de 0,55 ; ou seja abaixo do valor considerado aceitável.

O valor de alfa é afetado pelo número de itens que compõem uma escala, assim como, pela população na qual se aplica a escala; isto é, à medida que se aumenta o número de itens, aumenta-se a variância, sistematicamente colocada no numerador, de tal forma que se obtém um valor superestimado da consistência da escala (KRUS e HELMSTADTER, 1993; STREINER, 2003). Além disso, deve-se considerar o tamanho da amostra: quanto maior o número de indivíduos que preenchem uma escala, maior é a variância esperada (BLAND e ALTMAN, 1997).

Os valores considerados aceitáveis para o alfa estão entre 0,70 e 0,90; valores abaixo de 0,70 indicam baixa consistência interna, enquanto valores acima de 0,90 indicam que vários 
itens estão medindo o mesmo elemento de um constructo, ou seja, há redundância ou duplicação de itens (STREINER, 2003).

Como relatado anteriormente, a consistência interna deve ser considerada na elaboração de um instrumento e também em sua aplicação, este estudo refere-se à adaptação do instrumento para a cultura brasileira. E, apesar de termos calculado este valor, ele não foi encontrado em nenhum artigo anteriormente publicado sobre as propriedades psicométricas do HNNE em sua versão original ou em outras versões.

Para Cortina (1993), o alfa de Cronbach não deve ser a única forma de avaliar a adequação de uma escala, afinal o nível de confiabilidade adequado depende da decisão que é realizada com a escala e, também, essa medida não se atenta para o tamanho do teste. Como exemplo, o autor aqui citado propôs uma comparação do alfa de 0,80 para escalas construídas com 3 e dez itens. Para a escala de três itens, a média da correlação entre os itens é 0,57, enquanto, para a escala de dez itens, tal valor vale apenas 0,28.

A escala em questão - HNNE, compreende 34 itens que avaliam, em aspectos muito diferentes, porém amplamente significativos e relevantes para uma predição de PC, as condições neurológicas de um recém-nascido: postura, tônus, reflexos, movimentos espontâneos, sinais anormais, orientação e comportamento do RN (DUBOWITZ; DUBOWITZ; MERCURI, 1999).

Keszei, Novaka e Streiner (2010) relatam que baixos valores de consistência interna podem significar que os itens medem atributos diferentes, que é o que acontece na escala HNNE, onde são avaliados os sistemas motores, visuais, auditivos, o que muitas vezes corrobora com a falta de consistência entre os itens. Além disso, é possível que um recémnascido com PC pode ter somente um comprometimento no seu sistema motor enquanto os outros sistemas podem permaneçam íntegros.

\section{Reprodutibilidade}

Para verificar a reprodutibilidade do instrumento foi realizado o teste-reteste para verificar sensibilidade a mudanças e a confiabilidade inter e intra avaliadores, em um subgrupo formado por $30 \mathrm{RN}$. 


\section{Confiabilidade Inter-avaliadores}

A confiabilidade inter avaliadores foi realizada por dois avaliadores independentes, com diferentes formações acadêmicas e foi encontrado uma alta concordância nos testes de ICC em todos os domínios, sendo que o domínio que obteve menor concordância foi o de orientação e comportamento $(0,841)$ e o de maior concordância foi o domínio de movimentos espontâneos $(0,972)$. Na pontuação total, encontrou-se uma confiabilidade inter avaliador de 0,964 sendo que $82 \%$ dos itens obtiveram concordâncias, avaliadas através do coeficiente de Kappa, quase perfeitas.

Ao desenvolver o instrumento em questão, os autores mencionaram a confiabilidade interexaminadores com coeficientes de correlação próximos a 1 em bebês típicos (HATAAJA et al.,1999); o mesmo foi encontrado por Tedla et al. (2014) que encontrou uma confiabilidade inter avaliadores de 0,98, porém em bebês de alto risco utilizando o HINE. Eeles et al. (2017) apresentaram confiabilidade excelente $(\mathrm{ICC}>0,74)$ para escore total, ao avaliar RN prematuros utilizando o HNNE.

A maior variabilidade em relação às concordâncias ocorreu em relação aos itens de orientação e comportamento que dependia da situação atual do bebê, se ele estava com fome, com sono, excitado, cansado, sob estresse, ou seja, o comportamento do RN varia com o passar do dia.

\section{Confiabilidade Intra-avaliador}

A confiabilidade intra-avaliador foi realizada em um subgrupo formado por $30 \mathrm{RN}$ que tiveram suas avaliações iniciais filmadas; sendo que houve um intervalo de 14 dias entre as avaliações in loco e assistidas, conforme o intervalo proposto por Terwee e colaboradores (2007).

Avaliar através de uma filmagem é um método bastante utilizado na literatura para confiabilidade intra-avaliador, sendo considerada por muitos um método satisfatório (DAUM et al., 2013; HEINEMAN et al., 2013; LOWERY et al., 2014; MATAVA et al., 2015). Alguns pesquisadores expressam suas dificuldades em avaliar os indivíduos a partir de vídeos, pois relatam que a filmagem limita a visualização do avaliado em diferentes ângulos ou que encontram dificuldade para realizar a avaliação por meio dos vídeos (JIA et al., 2011; RATHKE et al., 2011; WONG et al., 2014). Por este motivo, optamos por não deixar o dispositivo fixo em uma base, como um tripé, por exemplo; e convidamos um profissional do setor onde a 
pesquisa foi desenvolvida, para realizar as filmagens captando os detalhes da avaliação e colocando em evidência a resposta do bebê após um estímulo, como o reflexo. Essa forma de avaliação permite que não haja mudanças entre o comportamento ou a resposta do indivíduo, que poderia ser diferente caso a reavaliação ocorresse após 14 dias, comprometendo os dados de confiabilidade.

Verificou-se que houve alta concordância intra-avaliador nos testes de ICC em todos os domínios, sendo que o domínio que obteve menor concordância foi o de postura e tônus $(0,944)$ e o de maior concordância foi o domínio de padrão de tônus $(1,0)$. Na pontuação total, encontrou-se uma confiabilidade inter avaliador de 0,955. Em relação às concordâncias por item, obtidas através do coeficiente de Kappa, $88 \%$ dos itens apresentaram concordâncias quase perfeitas.

Tedla et al. encontraram no HINE um ICC de 0,99 para confiabilidade intra-avaliador na seção 1, e um ICC de 0,97 na seção 3. A sessão 2 não possui pontuação, é uma seção observacional a respeito dos marcos motores, portanto estes autores decidiram não fazer a confiabilidade desta seção.

\section{$\underline{\text { Teste-reteste }}$}

Assim como nas medidas anteriores, o período entre as medições teste-reteste é um fator que deve ser considerado, pois períodos longos são suscetíveis às mudanças, como exemplo, aquisição de novas habilidades ou aprendizagens ou modificações comportamentais, que podem comprometer a interpretação do coeficiente de confiabilidade obtido; já se realizado em um período curto demais, os resultados podem ser contaminados pelo efeito memória da primeira aplicação (KESZEI; NOVAKA; STREINER, 2010).

As avaliações deste estudo ocorreram no mesmo dia, pelo fato das aquisições e comportamentos de um RN serem bastante variáveis. Encontrou-se nesta amostra uma excelente concordância entre todos os domínios com uma variabilidade de ICC entre 0,854 a 0,996; sendo o menor valor atribuído ao domínio de comportamento, que pode variar caso o $\mathrm{RN}$ esteja com fome, sono, cólica ou até mesmo pelo alto grau de manuseio que ocorre no setor para coletas de exames e/ou avaliações; e o maior valor foi para postura e tônus que apesar de ser variável, não altera tanto no mesmo dia.

Ao analisar item por item no teste-reteste, obteve-se uma concordância quase perfeita em 91,17\% ( $\mathrm{n}=31)$ dos itens. Os outros 3 itens (alerta, consolabilidade e choro), tiveram alta 
concordância. Estes itens dependem do estado emocional do bebê, que poderia estar mais cansado, ou com sono em um dos momentos da avaliação.

Segundo Landis e Koch (1977), os valores considerados quase perfeitos são aqueles que estão entre 0.81 a 1.00 ; substancial entre 0.61 a 0.80 ; moderado entre 0.41 a 0.60 ; razoável entre 0.21 a 0.40 e pequeno entre 0 a 0.20 .

$\mathrm{Na}$ literatura, só foi encontrado dados sobre a confiabilidade inter e intra- avaliador.

\section{Validade Convergente}

Para se cumprir a validação de critério, a validade convergente foi avaliada pela amostra total $(n=143)$ e aplicada a correlação entre AIMS e HNNE através do coeficiente de correlação de Pearson e obteve uma correlação moderada com o escore total $(r=0,489)$. Quando avaliadas as correlações por domínio, não houve correlações entre padrões de tônus, reflexos e padrões anormais e uma fraca correlação com o comportamento.

É importante destacar que a AIMS não avalia reflexos, ou tônus e nem padrões anormais, ela só avalia a postura e o desenvolvimento motor grosso. O comportamento de forma geral nem sempre está associado com o comportamento motor. Além disso, a AIMS não é indicada ou sensível para recém nascidos, entretanto, escolhemos utilizar esta escala pois fizemos um acompanhamento preditivo de todos os participantes até os 24 meses (estudo 3) e esta escala é sensível para detectar atrasos no desenvolvimento motor, fazendo com que nosso estudo se torne importante para diferenciar se as pontuações mais baixas são resultados de um simples atraso no desenvolvimento ou se é decorrente de uma afecção neurológica (PIPER; DARRAH, 1994).

Tedla et al. (2014) correlacionaram o HINE com o INFANIB (Infant Neurological International Battery) para analisar a validade concorrente entre elas e encontraram uma correlação adequada (ICC $=0,70)$. O INFANIB possui componentes comuns ao HINE explicando a forte correlação entre os instrumentos.

\subsection{Conclusão}

As propriedades analisadas sugerem que o "Hammersmith Neonatal Neurological $H N N E$ " está validado para a população brasileira e pode ser um instrumento útil para a avaliação neurológica de RN brasileiros, a fim de identificar alterações no desenvolvimento neurológico, e encaminhá-los precocemente para as unidades de estimulação ou reabilitação 
precoce. O HNNE é um instrumento de avaliação de fácil e rápida aplicação, de acesso livre e, portanto, uma opção promissora para ser utilizada no contexto da atenção primária no Brasil.

A disponibilidade de um instrumento de triagem com estas características favorecerá a inclusão da vigilância do desenvolvimento infantil no dia a dia dos profissionais de saúde, possibilitando a intervenção em momento oportuno nos casos suspeitos de alterações. Além disso, o uso de instrumento padronizado e validado para o Brasil permitirá também a geração de informações epidemiológicas para o fomento das políticas públicas e a comparação com estudos realizados em outros países. 


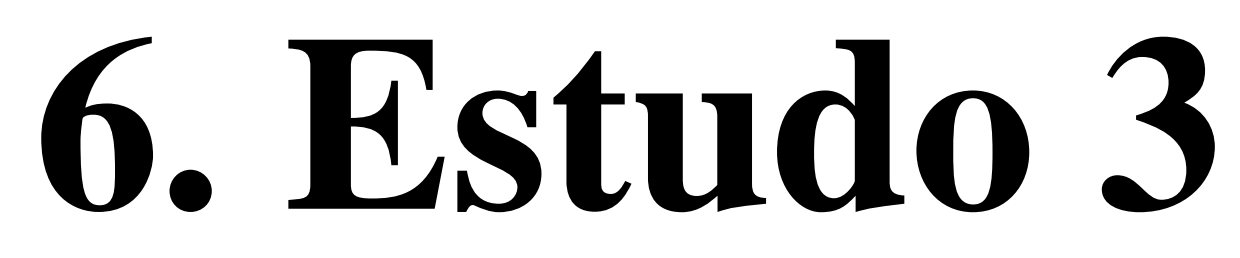

Estudo Preditivo 


\subsection{OBJETIVOS}

Realizar o acompanhamento de recém-nascidos (RN) com risco para PC até os 2 anos de idade, para verificar a sensibilidade do HINE (Hammersmith Infant Neurological Assessment) para predizer alterações neurológicas aos 3, 6, 9 e 12 meses e aos 2 anos.

\subsubsection{Objetivos Específicos}

- Aplicar o HINE em lactentes com nascimento prematuro (<37 semanas de gestação), e em lactentes nascidos a termo que apresente algum risco para PC, para verificar a predição da paralisia cerebral nessa população;

- Correlacionar os escores do HINE com a função motora dos lactentes, no caso de diagnóstico de PC;

- Correlacionar os escores do HINE com os escores da AIMS, que identifica atrasos no desenvolvimento motor, sem que haja necessariamente um comprometimento neurológico.

\subsection{Aspectos éticos}

Este estudo respeita as exigências da Resolução 466/12 da Comissão Nacional de Ética em Pesquisa do Conselho Nacional de Saúde do Ministério da Saúde (BRASIL, 2012) e foi aprovado pelo comitê de ética do Hospital das Clínicas da Faculdade de Medicina de Ribeirão Preto da Universidade de São Paulo (HC - FMRP/USP), sob o parecer n 1.809 .858 . Foi aprovado ainda pelo comitê de ética da MATER, além de ser aprovado pelo Centro de Reabilitação. Todos os responsáveis legais pelos participantes assinaram o Termo de Consentimento Livre e Esclarecido - TCLE (anexo E). Este estudo foi desenvolvido entre 2018 e 2020 .

\subsection{MATERIAIS E MÉTODO}

\subsubsection{Desenho do estudo}

Trata-se de uma investigação metodológica, transversal e longitudinal para verificar se um instrumento de avaliação precoce (HINE) é útil para diagnosticar alterações neurológicas 
que levam à Paralisia Cerebral em lactentes brasileiros. Para isso, foi realizado um acompanhamento preditivo dos participantes até os dois anos de idade e correlacionado os escores do instrumento com a função motora dos lactentes, em casos confirmados de PC; e correlacionado com os escores da AIMS nos outros casos.

\subsubsection{Participantes}

Participaram do estudo 143 recém-nascidos $(\mathrm{RN})$ que foram recrutados no Hospital das Clínicas da Universidade de São Paulo - Campus Ribeirão Preto e na maternidade municipal de Ribeirão Preto (MATER), através de convite aberto aos pais. Foram admitidos RN prematuros ( $<37$ semanas) e à termo ( $>37$ semanas) que apresentassem algum risco para PC.

Foram adotados como sinais de risco para PC, conforme proposto por McIntyre e colaboradores (2011):

- Fatores maternos: idade, história ginecológica anterior de natimortos, vários abortos, morte neonatal, parto prematuro, história familiar de PC e outras predisposições genéticas; incapacidade intelectual, epilepsia; baixo nível socioeconômico e doenças maternais (distúrbios da tireoide, pressão alta não controlada).

- Fatores gestacionais: Infecção, anomalias congênitas, gemelaridade, complicações na gravidez (pré-eclâmpsia, hemorragia no segundo e terceiro trimestres, infecção e inflamação, restrição de crescimento intrauterino - CIUR, anormalidades placentárias e outros precursores de parto prematuro).

- Fatores pós-natal: hipóxia durante o parto, acidente vascular cerebral, convulsões, hipoglicemia, icterícia e infecção aguda.

\subsubsection{Local da Pesquisa}

O desenvolvimento do estudo foi realizado no Laboratório de Ensino e Pesquisa em Terapia Ocupacional, Infância e Adolescência (LEPTOI), na Universidade de São Paulo Campus Ribeirão Preto/São Paulo e a coleta de dados, bem como o recrutamento dos participantes, foram realizadas nas unidades de ambulatório de obstetrícia, na maternidade neonatal e na unidade de cuidados intermediários (UCIN), do Hospital das Clínicas de Ribeirão Preto/SP e na MATER de Ribeirão Preto/SP. O processo de acompanhamento preditivo até os 24 meses, foi realizado no Centro de Reabilitação (CER) de Ribeirão Preto/ SP. 


\subsubsection{Procedimentos para continuidade de validação do instrumento}

O terceiro estudo desta tese, visa continuar o processo complexo de validação dos instrumentos aqui detalhados, além de realizar um estudo preditivo, do qual será avaliado o desenvolvimento neuromotor de crianças com risco para paralisia cerebral através do Hammersmith Infant Neurological Examination (HINE). Então, primeiramente, será abordado as fases de validação que complementam este estudo, seguido do passo-a-passo dos procedimentos adotados.

Em continuidade ao processo de validação do instrumento, esta fase analisou a validade de construto, de critério, responsividade e interpretabilidade do HINE, já que o HNNE é aplicado apenas no RN e o HINE é o instrumento que procede a avaliação inicial (após 30 dias de vida).

\section{Validade de construto}

É definido como o grau em que os escores de um instrumento são consistentes com hipóteses (por exemplo no que diz respeito às relações internas, relações com dezenas de outros instrumentos, ou diferenças entre os grupos pertinentes) com base no pressuposto de que o instrumento mede validamente o construto a ser medido. Para este item devem ser consideradas a validade estrutural e o teste de hipóteses. Em outras palavras, é a habilidade do instrumento para confirmar as hipóteses esperadas e é a mais complexa e difícil de ser determinada. A validade de construto pode ser analisada de acordo com dois aspectos, que são a validade convergente e a validade divergente ou discriminante.

A validade discriminante foi cumprida nesta etapa, quando verificarmos se o instrumento discrimina crianças com PC das crianças que não possuem alterações neurológicas. A validade convergente foi cumprida na última etapa quando se comparou a pontuação do HINE com a classificação motora dos lactentes participantes que tiveram diagnóstico de PC.

\section{Responsividade}

É a capacidade de um instrumento para detectar alterações ao longo do tempo na construção a ser medida. Este item foi cumprido ao acompanharmos trimestralmente os lactentes do nascimento até os 12 meses de vida, e reavaliarmos as condições dos mesmos, frente à algum diagnóstico aos 2 anos de idade. 


\section{Interpretabilidade}

É o grau em que se pode atribuir significado qualitativo a pontuação ou mudança na pontuação quantitativos de um instrumento. A interpretabilidade não é considerada uma propriedade de medida, mas é uma característica importante de um instrumento de medição.

$\mathrm{O}$ instrumento original apresenta a interpretabilidade, uma vez que o escore foi definido comparando-o com uma população normativa.

\subsubsection{Procedimentos para coleta de dados}

Após aprovação dos Comitês de Ética do HC, da MATER e do CER, as mães foram convidadas a participar do estudo, sendo recrutadas na maternidade. Foi explicado às mães os objetivos do estudo, como seria feito a avaliação dos bebês e a importância dos retornos a cada 3 meses para registro evolutivo do comportamento motor e neurológico. Os responsáveis que desejaram participar e se comprometeram com o retorno, assinaram o Termo de Comprometimento Livre e Esclarecido (TCLE) e responderam uma anamnese composta por dados maternos, de gestação, do parto e histórico familiar (detalhado no estudo anterior).

O recém-nascido foi avaliado individualmente pelo HNNE logo que nasceu e reavaliado pelo HINE e pela AIMS aos 3, 6, 9 e 12 meses de idade (a forma de avaliação já foi relatada nos estudos anteriores). $\mathrm{O}$ estado comportamental foi registrado no momento das avaliações, $\mathrm{e}$ para alcançar resultados comparáveis, sempre que possível, todos os bebês foram testados no mesmo estado (estado 4 ou 5). A cada avaliação, todas as famílias eram contatadas via mensagem de texto lembrando-os e confirmando suas respectivas presenças. Caso, não obtivesse resposta, era realizada uma ligação nos números informados na ficha do paciente. Se a mãe não comparecesse na primeira avaliação de acompanhamento, na segunda oportunidade era ligado novamente para o responsável afim de resgatar o participante, e assim por diante.

$\mathrm{Na}$ avaliação era utilizado, chocalho, bolas coloridas e brinquedos. Caso o participante relatasse que não era possível comparecer nas avaliações, era oferecido o atendimento domiciliar. Porém, depois de algumas situações constrangedoras, como por exemplo: mãe de participante que relatou para família ter ido no acompanhamento e o pesquisador presenciou uma briga, já que isso não ocorreu; domicílio localizado em bairros periféricos comandados pelo tráfico, precisando de autorização para entrar na comunidade; avaliação em uma casa em que a mãe informou ser ponto de tráfico; parou-se de oferecer este facilitador. 
O objetivo deste acompanhamento foi verificar em qual idade o instrumento tem maior detecção de preditibilidade e se ele possui a capacidade de alterações ao longo do tempo (responsividade). Aos dois anos, os bebês foram triados e classificados pelo Sistema de Classificação da Função Motora Grossa Expandida e Revisada (GMFCS E \& R) em caso de Paralisia Cerebral. Os escores do HNNE e HINE foram correlacionados com os níveis do (GMFCS E \& R) das crianças com PC e com os escores da AIMS, quando não houve diagnóstico de PC.

O Sistema de classificação de função motora grossa em paralisia cerebral possui cinco níveis de classificação de acordo com as limitações funcionais de crianças e adolescentes de zero a dezoito anos em se locomover e em sentar (controle de tronco). Os níveis variam de acordo com a assistência que a criança necessita, sendo o nível I maior independência e o nível V totalmente dependente. As classificações são divididas ainda por faixa etária, sendo inferior 2 anos, de 2 a 4 anos, de 4 a 6 anos, de 6 a 12 anos e de 12 a 18 anos (PALISANO et al., 2008).

O GMFCS E \& R e sua classificação por faixa etária está disponível no ANEXO C.

Aos 24 meses, foi realizado um novo contato com a família, via telefone ou WhatsApp, para que elas comunicassem o desenvolvimento do bebê, os dados foram registrados para posterior análise. Além disso, ao final da coleta, foi realizada uma investigação através dos prontuários do $\mathrm{HC}$, para saber se havia algum diagnóstico registrado, ou para verificar a condição do desenvolvimento do lactente.

\subsection{RISCOS E BENEFÍCIOS}

Considera-se que toda pesquisa envolvendo seres humanos envolve risco. Entretanto na presente pesquisa, os riscos são mínimos, já que se trata de uma avaliação observacional. Esta pesquisa oferece uma elevada possibilidade de prevenir ou aliviar um problema que afete o bem-estar das pessoas com Paralisia Cerebral, uma vez que a detecção precoce de riscos para PC culmina no encaminhamento precoce para estimulação e/ou reabilitação. Entretanto, caso o participante não deseje participar do estudo, verbalizando, demonstrando por meio de gestos ou mesmo chorando, a avaliação será imediatamente suspensa. O pesquisador que realizará a coleta de dados é fisioterapeuta e possui aprimoramento em Intervenção Precoce.

Os benefícios são de oferecer a população brasileira um instrumento adaptado transculturalmente, o qual será útil para predizer precocemente os riscos para Paralisia Cerebral. Essa pesquisa poderá gerar resultados e publicações científicas que promoverão um embasamento teórico para a prática clínica baseada em evidências científicas, no que tange o 
uso de instrumentos adaptados transculturalmente e validada para um público alvo específico recém-nascidos prematuros ou a termo, com ou sem risco para PC. Em relação aos profissionais da saúde, espera-se oferecer mais uma avaliação terapêutica neurológica não invasiva que seja útil, eficaz e viável para o encaminhamento precoce de crianças com risco de PC que necessitam de intervenção imediata, evitando e /ou diminuindo danos futuros.

\subsection{ANÁLISE DOS DADOS}

Os dados foram processados pelo programa Statistical Package for Social Sciences for Personal Computer (versão 22.0). Foram montados para este estudo dois bancos de dados: o primeiro contém informações sobre a avaliação neonatal; o segundo banco, sobre os dados do acompanhamento preditivo. Cada participante recebeu um número de identificação que foi utilizado na organização destes - essa medida resguarda a identidade dos participantes e garante que o pesquisador responsável pela análise de dados é cego quanto à identidade dos participantes.

Para a análise descritiva e inferencial dos participantes em relação aos escores obtidos, foram utilizados teste não paramétrico de Mann-Whitney com significância de 5\% para comparar dois grupos e teste não paramétrico de Kruskal Wallis com a mesma significância para comparar 3 ou mais grupos. Para análise descritiva numérica foi utilizado Coeficiente de Correlação não paramétrica de Spearman e para análise comparativa entre as avaliações foi utilizado o Coeficiente de Correlação de Pearson.

Para os dados de avaliação do acompanhamento preditivo, foi utilizado a curva de hoc e a validação convergente entre AIMS e HINE e entre GMFCS e HINE.

\subsection{RESULTADOS}

Participaram deste estudo 143 lactentes, sendo quase $70 \%(\mathrm{~N}=98)$ da amostra composta por nascidos a termo. Dentre os participantes prematuros $(\mathrm{N}=45), 46,6 \%(\mathrm{~N}=21)$ ocupam a faixa intermediária (IG entre 28 e 34 semanas) e 24 são prematuros tardios (IG entre 34 e 36 semanas). Não houve RN com prematuridade extrema nesta amostra (Tabela 11).

O intervalo da idade gestacional foi de 29 a 42 semanas, sendo a média da IG: 37,9 no grupo a termo; 35,6 e 31,5 nos subgrupos de prematuros tardios e prematuros intermediários, respectivamente (Tabela 11). Porém, a maioria dos participantes $(49,7 \%)$ nasceram entre 37 e 39 semanas. 
Ao analisar os dados descritivos da amostra total, 51,7\% ( $\mathrm{N}=74)$ são sexo masculino e $70,6 \%(\mathrm{~N}=101)$ dos participantes são da raça branca. Ao analisar individualmente os grupos, a maioria dos pré-termos são do sexo feminino (60\%), enquanto a porcentagem de participantes da raça branca permanece igual $( \pm 70 \%)$ em ambos os grupos (Tabela 11$)$.

Em relação ao peso dos bebês, o grupo a termo obteve uma média de 3,215g $(1,500 \mathrm{~g}-$ $5,405 \mathrm{~g})$; o subgrupo de prematuro tardio apresentou um peso médio de 2,545g $(1,365 \mathrm{~g}-$ $4,180 \mathrm{~g})$ e a média do subgrupo de prematuro intermediário foi de $1,685 \mathrm{~g}(1,125 \mathrm{~g}-1,685 \mathrm{~g})$.

Sobre a classificação do peso dos participantes, $109 \mathrm{RN}(76,2 \%)$ nasceram com peso adequado para a idade gestacional (AIG) e $17(11,9 \%)$ foram considerados pequenos para a idade gestacional (PIG) e exatamente o mesmo número de participantes - 17 (11,9\%) foram considerados gigantes para a idade gestacional (GIG). Quando analisados os grupos individualmente, temos uma porcentagem muito parecida em ambos os grupos; a maioria dos nascidos pré-termo $(77,7 \%)$ e a termo $(75,5 \%)$ apresentaram peso adequado para a idade gestacional. Mas essa porcentagem se distancia nos pontos extremos; apenas 9 bebês $(9,1 \%)$ do grupo a termo são PIG e $15(15,3 \%)$ são GIG, enquanto $8(17,7 \%)$ do grupo pré-termo são classificados como PIG e apenas $2(4,4 \%)$ são GIG (Tabela 11$)$.

A frequência de participantes em cada faixa de IG e a média de peso por semanas encontra-se na tabela 12 .

Tabela 11: Dados descritivos dos participantes do estudo

\begin{tabular}{|c|c|c|c|c|}
\hline & \multirow[b]{2}{*}{$\begin{array}{l}\text { Nascidos à termo } \\
\qquad(\mathbf{N}=98)\end{array}$} & \multicolumn{2}{|c|}{ Prematuros $(\mathrm{N}=45)$} & \multirow[b]{2}{*}{$\begin{array}{c}\text { Total de } \\
\text { Participantes } \\
(\mathrm{N}=\mathbf{1 4 3})\end{array}$} \\
\hline & & $\begin{array}{l}\text { Prematuros } \\
\text { Tardios } \\
(\mathbf{N}=\mathbf{2 4})\end{array}$ & $\begin{array}{c}\text { Prematuros } \\
\text { Intermediários } \\
\qquad(\mathbf{N}=\mathbf{2 1})\end{array}$ & \\
\hline IG & $37,9(37-42)$ & $35,6(34-36,9)$ & $31,5(29-33,9)$ & $37,1(29-42)$ \\
\hline Média do peso ao & 3,215 & 2,545 & 1,685 & 2,878 \\
\hline nascer (mín. e máx.) & $(1,500-5,405)$ & $(1,365-4,180)$ & $(1,125-1,685)$ & $(1,125-5,405)$ \\
\hline PIG & 9 & 5 & 3 & 17 \\
\hline AIG & 74 & 17 & 18 & 109 \\
\hline GIG & 15 & 2 & 0 & 17 \\
\hline Perímetro cefálico $\mathrm{cm}$ & $34,3(27,5-40,5)$ & $32,5(27-36,5)$ & $29,3(24,0-35,0)$ & $(24-40,5)$ \\
\hline Meninos (n) & $56(57,1 \%)$ & $11(45.8 \%)$ & $7(33.3 \%)$ & $74(51,7 \%)$ \\
\hline Meninas (n) & $42(42,8 \%)$ & $13(54,1 \%)$ & $14(66,6 \%)$ & $69(48,3 \%)$ \\
\hline Branco (a) (n) & $69(70,4 \%)$ & $18(75 \%)$ & $14(66,6 \%)$ & $101(70,6 \%)$ \\
\hline Pardo (a) & $25(25,5 \%)$ & $6(25 \%)$ & $4(19 \%)$ & $35(24,4 \%)$ \\
\hline Negro (a) & $4(4,0 \%)$ & $0(0 \%)$ & $3(14,2 \%)$ & $7(4,8 \%)$ \\
\hline
\end{tabular}

Legenda: IG - Idade gestacional; PIG - pequeno para a idade gestacional; AIG - adequado para a idade gestacional; GIG gigante para a idade gestacional; $\mathrm{cm}$ - Medida em centímetros 
Tabela 12: Dados descritivos sobre a frequência de participantes e peso por IG.

\begin{tabular}{lcccc}
\hline \hline & \multicolumn{4}{c}{ Idade Gestacional } \\
& IG & N & \% & PN (g) \\
\hline Prematuros & 29 & 2 & 1,4 & 1,482 \\
Intermediários & 30 & 2 & 1,4 & 1,512 \\
& 31 & 5 & 3,5 & 1,687 \\
Prematuros Tardios & 32 & 7 & 4,9 & 1,719 \\
& 33 & 5 & 3,5 & 1,890 \\
A termo & 34 & 2,1 & 2,346 \\
& 35 & 3 & 2,1 & 2,396 \\
& 36 & 18 & 12,6 & 2,603 \\
& 37 & 24 & 16,8 & 2,760 \\
& 38 & 20 & 14,0 & 3,225 \\
& 39 & 27 & 18,9 & 3,284 \\
& 40 & 16 & 11,2 & 3,551 \\
& 41 & 10 & 7,0 & 3,527 \\
& 42 & 1 & 0,7 & 3,560 \\
\hline
\end{tabular}

Em relação ao tipo de parto e as condições do nascimento, 55,9\% (N=80) dos bebês nasceram via cesárea e 44,1\% (N=63) nasceram por parto vaginal; $27(18,9 \%) \mathrm{RN}$ apresentaram APGAR $<7$ no $1^{\circ}$ minuto e destes, 4 receberam esta pontuação no $5^{\circ}$ minuto. Cinquenta e seis RN $(39,2 \%)$ precisaram de cuidado intensivo ou intermediário após o nascimento, sendo que $52(36,4 \%)$ enfrentaram alguma intercorrência ao nascer (Tabela 13).

Tabela 13: Dados descritivos sobre as condições dos participantes ao nascer

\begin{tabular}{lccc}
\hline \hline & Condições & Frequência (N) & \% \\
\hline \multirow{2}{*}{ Tipo de parto } & Vaginal & 63 & 44,1 \\
& Cesária & 80 & 55,9 \\
\multirow{2}{*}{ APGAR } & $<7\left(1^{\circ}\right.$ minuto $)$ & 27 & 18,9 \\
& $<7\left(5^{\circ}\right.$ minuto $)$ & 4 & 2,8 \\
Unidade de tratamento & UCIN/UTI & 56 & 39,2 \\
\multirow{2}{*}{ Intercorrência ao } & Berçário & 87 & 60,8 \\
nascer & Sim & 52 & 36,4 \\
\hline \hline UCIN - Unidade de cuidados intermediários; UTI - Unidade de tratamento intensivo.
\end{tabular}

Quanto à caracterização da família, 10 (7\%) mães tinham menos de 18 anos, 68 (47,6\%) mães tinham entre 18 e 29 anos, 34 (23,8\%) tinham entre 30 e 34 anos, 31 (21,7\%) acima de 
35 anos. Quanto a escolaridade, $23,1 \%(n=33)$ não tinham completado o ensino fundamental; $37,1 \%(n=53)$ concluíram ensino médio e apenas $3(2,1 \%)$ mães possuem ensino superior. A média da idade do pai foi de 38,2 anos (15 - 59), sendo que 21,7\% (n=31) não completaram o ensino fundamental, 35,7\% $(n=51)$ possuem ensino médio completo e 3,5\% $(n=5)$ possuem ensino superior. Nenhum dos pais tinham pós graduação (Tabela 14).

Nesta amostra, $116(81,1 \%)$ pais moram juntos (sendo 39 casados e 77 em união estável) e a renda familiar variou desde $\mathrm{R} \$ 124,00$ até $\mathrm{R} \$ 9540,00$, sendo a mediana de $\mathrm{R} \$ 2.300,00$ (Tabela 14). O salário mínimo em 2018 (ano da coleta de dados iniciais) era de R\$954,00.

Tabela 14: Dados descritivos sobre a caracterização da família

\begin{tabular}{|c|c|c|c|}
\hline & Descritivos & Frequência $(\mathbf{N})$ & $\%$ \\
\hline \multirow{4}{*}{ Idade das mães } & $<18$ anos & 10 & 7 \\
\hline & Entre 18 e 29 anos & 68 & 47,6 \\
\hline & Entre 30 e 34 anos & 34 & 23,8 \\
\hline & $>35$ anos & 31 & 21,7 \\
\hline \multirow{4}{*}{ Escolaridade das mães } & EF incompleto & 33 & 23,1 \\
\hline & EF completo & 45 & 31,5 \\
\hline & EM completo & 62 & 43,4 \\
\hline & ES completo & 3 & 2,1 \\
\hline \multirow{5}{*}{ Idade dos pais } & $<18$ anos & 6 & 4,2 \\
\hline & Entre 18 e 29 anos & 54 & 37,8 \\
\hline & Entre 30 e 34 anos & 32 & 22,4 \\
\hline & $>35$ anos & 50 & 35 \\
\hline & A mãe não sabe & 1 & 0,7 \\
\hline \multirow{5}{*}{ Escolaridade dos pais } & EF incompleto & 31 & 21,7 \\
\hline & EF completo & 40 & 28 \\
\hline & EM completo & 58 & 40,6 \\
\hline & ES completo & 5 & 3,5 \\
\hline & A mãe não sabia & 9 & 6,3 \\
\hline \multirow{3}{*}{ Estado civil } & Casados & 56 & 39,2 \\
\hline & União Estável & 87 & 60,8 \\
\hline & Solteiros & 52 & 36,4 \\
\hline \multirow{3}{*}{ Renda familiar } & $\leq 2 \mathrm{SM}$ & 47 & 32,9 \\
\hline & Entre 3 e $4 \mathrm{SM}$ & 71 & 49,7 \\
\hline & $\geq 5 \mathrm{SM}$ & 17 & 11,9 \\
\hline
\end{tabular}

Legenda: EF - Ensino Fundamental; EM - Ensino Médio; ES - Ensino Superior; SM - Salário Mínimo. 
As condições clínicas maternas e gestacionais foram obtidas por meio do relato das mães ao responderem ao questionário e os fatores de risco encontrados neste grupo se encontram na tabela 15. A condição de risco mais frequente foi o baixo nível socioeconômico presente em no mínimo 47 (32,8\%) famílias. Este número pode ser ainda maior, pois foi considerado um baixo nível socioeconômico, famílias que possuem até dois salários mínimos vigentes na data da coleta - R \$1908,00 (2018). Porém algumas famílias com número elevados de filhos em fase escolar, vivem com uma renda familiar um pouco acima deste valor, se mantendo num baixo nível socioeconômico.

A segunda condição de risco mais frequente foi de abortos prévios vivenciadas por 44 mães (30,7\%), seguida por hipertensão arterial sistêmica (HAS) presente em 41 mães (28,7\%); infecção de urina - 36 mães $(25,1 \%) ; 35(24,4 \%)$ relataram ser diabéticas e $33(23,1 \%)$ mães apresentaram sangramentos em algum período da gestação, sendo que $53(37,1 \%)$ precisaram ficar em repouso (Tabela 15). Algumas mães apresentavam mais de uma das condições listadas.

Sobre o estilo de vida, 25 (17,4\%) mães tabagistas fumaram durante a gestação e menos de $10 \%(n=14)$ beberam socialmente de acordo com a percepção e avaliação delas. Em relação aos dados da gestação, 62,2\% das famílias desejaram a gravidez, mas somente 31,5\% (n=45) planejaram. Cento e trinta e duas mães relataram ter feito o pré-natal completo embora a maioria não soubesse quantas sessões tinham frequentado. 
Tabela 15: Fatores de riscos maternos e gestacionais

\begin{tabular}{lcc}
\hline \multicolumn{1}{c}{ Fatores de risco maternos e gestacionais } & Frequência & $\begin{array}{c}\text { Porcentagem } \\
(\boldsymbol{\%})\end{array}$ \\
\hline Baixo nível socioeconômico & 47 & 32,8 \\
Abortos prévios & 44 & 30,7 \\
HAS & 41 & 28,7 \\
Infecção de urina & 36 & 25,1 \\
Diabetes & 35 & 24,4 \\
Sangramento & 33 & 23,1 \\
Tabagista & 25 & 17,4 \\
Anemia & 16 & 11,1 \\
Oligoidrâmnio & 15 & 10,5 \\
Idade materna >35 anos/ Pré-eclâmpsia & 13 & 9,1 \\
Idade materna <18 anos & 10 & 6,7 \\
Gestação múltipla & 9 & 6,2 \\
Sífilis & 7 & 4,8 \\
CIUR/ Distúrbios na tireoide & 6 & 4,1 \\
Toxoplasmose & 5 & 3,5 \\
Incompetência istmocervical/ Ovário policístico/ Usuária de drogas & 4 & 2,8 \\
Doenças cardíacas/ Hematomas uterinos/ HIV/ Polidrâmnio & 3 & 2,1 \\
Anormalidades placentárias/ AVE/ Descolamento ovular ou placentário/ & 2 & 1,3 \\
Eritroblastose fetal/ Inseminação artificial/ Lúpus/ Obesidade/ SAF & & \\
Caxumba/ Cisto no ovário/ Citomegalovírus/ Dislipidemia/ Hipotensão/ & & \\
HPV/ Infecção generalizada/ Leiomiomatose uterina/ Miastenia grave/ & 1 & \\
Rubéola/ Síndr. de Help/ Síndr. de Raynaud/ Trombocitopenia/ Tumor no & & \\
cérebro & & \\
\hline \hline & & \\
\hline
\end{tabular}

$\overline{\text { Legenda: AVC - Acidente vascular encefálico; CIUR - Restrição de crescimento intrauterino; HAS - Hipertensão arterial }}$ sistêmica; HIV - vírus da imunodeficiência humana; HPV - Papilomavírus Humano; SAF - Síndrome do Anticorpo Antifosfolipídeo.; Síndr. - Síndrome

Em relação aos lactentes, alguns receberam diagnósticos clínicos intraútero e, outros tiveram algumas condições clínicas de risco, relatadas logo após o nascimento. A condição clínica mais frequente foi a de sofrimento neonatal, presente em quase $26 \%$ dos casos $(\mathrm{N}=37)$. Foi considerado como sofrimento neonatal, quando os $\mathrm{RN}$ apresentaram, logo ao nascer, asfixia, apneia, diminuição da frequência cardíaca e/ou respiratória, utilização de oxigênio ou necessitaram ser intubados. Onze lactentes $(7,6 \%)$ precisaram de tratamento por fototerapia ao apresentar icterícia pela alta produção de bilirrubina (Tabela 16). 
Três $(2,1 \%)$ lactentes apresentam alterações hipoglicêmicas e a mesma quantidade apresentaram infecções por sífilis. Em relação às alterações em níveis neurológicos, teve 1 lactente diagnosticado com hidrocefalia, 1 com macrocefalia, 1 com agenesia parcial do corpo caloso e 1 com Mielomeningoceles associada a Arnold - Chiari II, sem hidrocefalia (Tabela 16).

Tabela 16: Condições clínicas diagnosticadas intraútero ou logo após o nascimento

\begin{tabular}{lcc}
\hline \hline \multicolumn{1}{c}{ Fatores de risco } & Frequência & Porcentagem (\%) \\
\hline Sofrimento fetal (pela frequência cardíaca e/ou respiratória, asfixia, & 37 & 25,9 \\
apneia) & 11 & 7,6 \\
Fototerapia logo após o parto & 6 & 4,1 \\
Hipoglicemia & 3 & 2,1 \\
Aspiração de mecônio & 3 & 2,1 \\
Sífilis ao nascer & 2 & 1,3 \\
Infecção no parto & 2 & 1,3 \\
Hemorragia cerebelar com drenagem espontânea & 1 & 0,7 \\
Óbito durante o parto (gemelaridade) & 1 & 0,7 \\
Hidrocefalia (diagnóstico intraútero) & 1 & 0,7 \\
Síndrome de Hirschrsprung com agangliose total do cólon (diagnóstico & & 0,7 \\
intraútero) & 1 & 0,7 \\
Dismorfias e agenesia parcial do corpo caloso (diagnóstico intraútero) & 1 & 0,7 \\
Macrocefalia & 1 & 0,7 \\
Feto com rim policístico (diagnóstico intraútero) & 1 & 0,7 \\
Síndrome de Down (características observadas ao nascer) & 1 & 0,7 \\
Hematomas cefálicos devido a traumatismo no parto & 1 & 0,7 \\
Onfalecele & 1 & \\
Mielomeningocele + Arnold - Chiari II & & \\
\hline \hline
\end{tabular}

Em relação ao acompanhamento preditivo, 143 lactentes foram avaliados ao nascer, sendo que 79 bebês $(55,2 \%)$ compareceram em pelo menos uma das avaliações preditivas conforme observado na Tabela 17. Após 2 anos do início da coleta, contatou-se novamente as famílias via telefone (para saber se havia algum diagnóstico fechado aos 24 meses de vida do bebê). Neste momento da coleta, localizou-se 73 famílias (51\%).

Quando observado as frequências por acompanhamento, apenas 45,5\% (N=65) das mães compareceram à avaliação de 3 meses; 44,1\% (N=63) dos lactentes foram avaliados no $6^{\circ}$ mês de vida; 37,1\% (N=53) foram avaliados aos 9 meses pelo HINE e 36,4 \% (N=52) foram 
avaliados pela AIMS (o participante tinha tomado vacina, estava cansado e começou a chorar muito, então as avaliações precisaram ser interrompidas, não sendo possível aplicar a AIMS); e 30,1\% (N=43) foram avaliados aos 12 meses (Tabela 17). Este número se torna compreensível quando apenas 49\% (N=70) da amostra são residentes em Ribeirão Preto; os outros 51\% (N=73) moram em cidades vizinhas. O HC é um hospital referência da região, portanto, alguns casos de risco são encaminhados para lá; porém, as mães relatam dificuldade em viajar com um bebê para as consultas de retorno e para participar das avaliações.

É válido ressaltar que as mães que faltaram em determinada avaliação não tiveram seus filhos excluídos do estudo; as ligações e mensagens continuaram na tentativa de fazê-las retornarem ao acompanhamento. Algumas mães faltavam dos encontros por avaliarem que o desenvolvimento do (a) filho (a) estava satisfatória para ela, principalmente se o resultado da última avaliação tivesse sido positivo.

Tabela 17: Frequência dos participantes no decorrer do acompanhamento preditivo

\begin{tabular}{lcc}
\hline \hline \multicolumn{1}{c}{ Tipo de avaliação } & Frequência & Porcentagem (\%) \\
\hline $1^{\mathrm{a}}$ avaliação: HNNE (RN) & 143 & 100 \\
$2^{\mathrm{a}}$ avaliação: acompanhamento HINE/AIMS (3 meses) & 65 & 45,5 \\
$3^{\mathrm{a}}$ avaliação: acompanhamento HINE/AIMS (6 meses) & 63 & 44,1 \\
$4^{\mathrm{a}}$ avaliação: acompanhamento HINE/AIMS (9 meses) & $53 / 52$ & $37,1 / 36,4$ \\
$5^{\mathrm{a}}$ avaliação: acompanhamento HINE/AIMS (12 meses) & 43 & 30,1 \\
Contato com a família para saber os diagnósticos fechados (24 meses) & 76 & 53,1 \\
Mães que compareceram somente em 1 acompanhamento & 13 & 9,1 \\
Mães que comparecem a 2 acompanhamentos & 17 & 11,9 \\
Mães que comparecem a 3 acompanhamentos & 17 & 11,9 \\
Mães que comparecem a 4 acompanhamentos & 32 & 22,4 \\
\hline \hline
\end{tabular}

Além disso, não foi possível o contato com 37 mães (equivalente a 25,9\% da amostra) já na primeira avaliação de retorno pelos seguintes motivos: a mãe trocou de telefone, ou não atendeu o número fornecido ou visualizava as mensagens pelo WhatsApp e não confirmava a presença e nem comparecia à sessão, tornando-se incomunicável (Figura 9).

Ao longo deste acompanhamento preditivo, um lactente faleceu durante uma cirurgia cardíaca, um bebê foi dado à adoção, e um bebê teve internações recorrentes por fraturas múltiplas, aparentemente por maus-tratos e o caso está em investigação. Essas 3 famílias relatadas não compareceram a nenhuma avaliação do acompanhamento preditivo, seja presencial (3 - 12 meses) ou por contato telefônico (24 meses), sendo considerados desistentes. 
O fluxograma a seguir (Figura 9) representa um panorama de participantes e as perdas que houveram durante o seguimento.

Figura 9: Fluxograma de participantes e desistentes

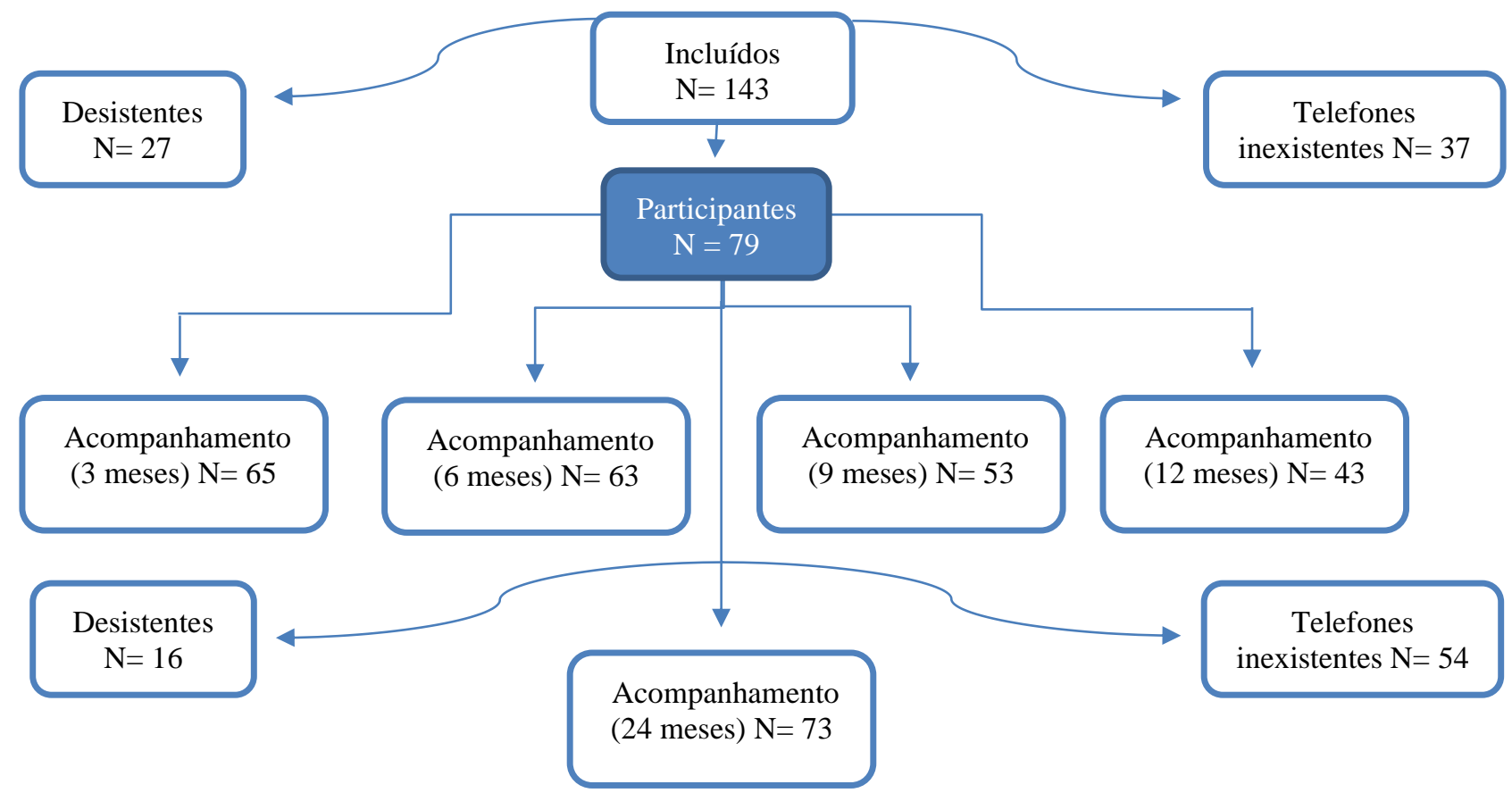

Sobre os escores obtidos através da avaliação neurológica HNNE e HINE, a média dos escores se encontram na Tabela 18 e foram separados pela classificação da IG. Os escores são crescentes de acordo com a maturidade neurológica e motora e aquisição de habilidades mais elaboradas. Os prematuros tardios, tiveram uma média de escore inferior à média obtida pelos prematuros intermediários nas avaliações realizadas aos 3, 6, 9 e 12 meses. Aos 12 meses, os prematuros intermediários tiveram escores médios que superaram os escores dos lactentes nascidos a termo. 
Tabela 18: Média do escore total das avaliações neurológicas, obtido pelos grupos ao nascer e aos 3, 6, 9 e 12 meses de idade.

\begin{tabular}{lcccc}
\hline \hline & Nascidos à termo & $\begin{array}{c}\text { Prematuros } \\
\text { Tardios }\end{array}$ & $\begin{array}{c}\text { Prematuros } \\
\text { Intermediários }\end{array}$ & $\begin{array}{c}\text { Amostra completa } \\
\text { (Escore) }\end{array}$ \\
\hline HNNE - escore total & 19,19 & 18,22 & 17,47 & 18,78 \\
$(\mathrm{~N}=143)$ & $(10,5-26,5)$ & $(9,5-22,5)$ & $(12-23,5)$ & $(9,5-26,5)$ \\
HINE 3 - escore total & 61,29 & 54,86 & 55,61 & 59,45 \\
$(\mathrm{~N}=65)$ & $(46,0-71,0)$ & $(33,5-68,0)$ & $(44,0-64,0)$ & $(33,5-71,0)$ \\
HINE 6- escore total & 68,89 & 65,05 & 66,13 & 67,63 \\
$(\mathrm{~N}=63)$ & $(44,0-76,0)$ & $(48,0-76,0)$ & $(56,0-74,0)$ & $(44,0-76,0)$ \\
HINE 9 - escore total & 74,56 & 71,3 & 73,55 & 73,88 \\
$(\mathrm{~N}=53)$ & $(55,5-78,0)$ & $(56,5-78)$ & $(67,0-78)$ & $(55,5-78,0)$ \\
HINE 12 - escore total & 75,07 & 74,30 & 75,84 & 75,00 \\
$(\mathrm{~N}=43)$ & $(56,0-78)$ & $(59,0-78,0)$ & $(73-78)$ & $(56,0-78,0)$ \\
\hline \hline
\end{tabular}

Os autores do HNNE/HINE apresentam escore de normalidade para ambos os instrumentos divididos em duas categorias: ótimo e sub-ótimo. Para o HNNE o escore ótimo recebe uma pontuação entre 30,5 - 34, enquanto o sub-ótimo está < 30,5. A categoria de escore ótimo representa que a criança possui risco de alteração neurológica, enquanto o escore subótimo pode estar na zona limítrofe, que significa que os sujeitos precisam ser reavaliados ou na zona de risco (representado por escores mais baixos que representam risco para PC) (DUBOWITZ; MERCURI; DUBOWITZ, 1998).

Para o HINE a classificação do escore ótimo e sub-ótimo, realizadas pelos autores do instrumento, dependem da idade do bebê:

- Bebê com 3 meses - $\geq 67$ escore ótimo; $<67$ escore sub-ótimo;

- Bebê com 6 meses - $\geq 70$ escore ótimo; $<70$ escore sub-ótimo;

- Bebê com 9 e 12 meses - $\geq 73$ escore ótimo; $<70$ escore sub-ótimo.

Neste estudo, considerou-se para o HNNE, escore ótimo para lactentes nascidos a termo de 30,5 até 34 e para pré-termo de 25,0 - 30,5, e para o HINE foi considerado escore ótimo >60 e sub-ótimo <60, conforme Mercuri et al. (2003).

Para melhor análise, os lactentes pré-termos foram avaliados de acordo com sua idade cronológica ao invés da idade corrigida, já que eles foram avaliados logo que nasceram assim como os bebês a termo. Como não foi possível corrigir a idade dos prematuros para aplicação do HNNE, mantivemos a avaliação do HINE de acordo com suas idades cronológicas; dessa 
forma pode-se avaliar a condição de maturação e estímulos frente ao escore neurológico e motor (AIMS). A tabela 19 aponta a frequência de lactente por zona ótima e sub-ótima.

Vale lembrar que toda apesar de utilizar os valores da classificação normativa como comparação, toda esta amostra pertence à um grupo de risco.

Tabela 19: Frequência de lactentes pela classificação de escore por normalidade.

\begin{tabular}{cccc}
\hline $\begin{array}{c}\text { Instrumento de } \\
\text { avaliação }\end{array}$ & Classificação por nascimento & Escore Ótimo (N) & Escore Sub-ótimo (N) \\
\hline \multirow{2}{*}{ HNNE (N=143) } & A termo (N=98) & 0 & $98(100 \%)$ \\
& Prematuro tardio (N=24) & 0 & $24(100 \%)$ \\
& Prematuro intermediário (N=21) & 0 & $21(100 \%)$ \\
HINE 3 (N=65) & A termo (N=45) & $12(26,7 \%)$ & $33(73,3 \%)$ \\
& Prematuro tardio (N=10) & $1(10 \%)$ & $9(90 \%)$ \\
& Prematuro intermediário (N=10) & 0 & $10(100 \%)$ \\
HINE 6 (N=63) & A termo (N=39) & $22(56,4 \%)$ & $17(43,6 \%)$ \\
& Prematuro tardio (N=12) & $3(25 \%)$ & $9(75 \%)$ \\
HINE 9 (N=53) & Prematuro intermediário (N=12) & $3(25 \%)$ & $9(75 \%)$ \\
& A termo (N=34) & $27(79,4 \%)$ & $7(20,6 \%)$ \\
& Prematuro tardio (N=9) & $6(66,7 \%)$ & $3(33,3 \%)$ \\
HINE 12 (N=43) & Prematuro intermediário (N=10) & $6(60 \%)$ & $4(40 \%)$ \\
& A termo (N=27) & $22(81,5 \%)$ & $5(18,5 \%)$ \\
& Prematuro tardio (N=10) & $8(80 \%)$ & $2(20 \%)$ \\
\hline \hline
\end{tabular}

Em relação a AIMS, a média dos escores obtidos se encontram na Tabela 20 e também foram separados pela classificação da IG. A AIMS avalia apenas a questão motora dos indivíduos e, portanto, os escores são crescentes de acordo com a aquisição de habilidades motoras mais elaboradas. Os prematuros intermediários tiveram uma média de escore inferior aos prematuros tardios e nascidos à termo, conforme observado na Tabela 16. 
Tabela 20: Média do escore total obtido pelas avaliações motoras aos 3, 6, 9 e 12 meses de idade.

\begin{tabular}{lcccc}
\hline \hline & Nascidos à termo & $\begin{array}{c}\text { Prematuros } \\
\text { Tardios }\end{array}$ & $\begin{array}{c}\text { Prematuros } \\
\text { Intermediários }\end{array}$ & $\begin{array}{c}\text { Amostra completa } \\
\text { (Escore) }\end{array}$ \\
\hline AIMS 3 - escore total & 12,3 & 8,8 & 8 & 11,1 \\
$(\mathrm{~N}=65)$ & $(7,0-9,0)$ & $(6,0-12,0)$ & $(3,0-10,0)$ & $(3,0-19,0)$ \\
AIMS 6- escore total & 28,3 & 20,8 & 18,5 & 25,0 \\
$(\mathrm{~N}=63)$ & $(11,0-46,0)$ & $(12,0-36,0)$ & $(11,0-28,0)$ & $(11,0-46,0)$ \\
AIMS 9 - escore total & 47,1 & 40,5 & 35,7 & 43,8 \\
$(\mathrm{~N}=52)$ & $(32,0-54,0)$ & $(28,0-52,0)$ & $(29,0-50,0)$ & $(18,0-54,0)$ \\
AIMS 12 - escore total & 53,2 & 50,1 & 49,6 & 52,0 \\
$(\mathrm{~N}=43)$ & $(32,0-58,0)$ & $(31,0-58,0)$ & $(41,0-54,0)$ & $(31,0-58,0)$ \\
\hline \hline
\end{tabular}

Ao correlacionar, através do Coeficiente de Correlação de Pearson, as avaliações neurológicas (HINE) com as avaliações observacionais motoras (AIMS) que registram as aquisições motoras evolutivas, encontrou-se uma correlação moderada $(p=0,525-0,664)$ entre as avaliações trimestrais correspondentes dos 3 aos 9 meses e uma correlação forte aos 12 meses $(\mathrm{p}=0,751)-$ Tabela 21 .

Entre as avaliações neurológicas (HINE), foi encontrado uma correlação forte entre as avaliações realizadas aos 6 e 9 meses $(p=0,767)$ e muito forte entre 9 e 12 meses $(p=0,903)$. Entre as avaliações do desenvolvimento motor, as avaliações realizadas entre os 6 e 9 meses e entre os 9 e 12 meses, obtiveram correlações fortes com um $\mathrm{P}=0,754$ e $\mathrm{P}=0,834$, respectivamente (Tabela 21 ).

A tabela 21 apresenta ainda correlações negativas entre os instrumentos HINE e AIMS e o diagnóstico via imagem, ou seja, se o escore de ambas avaliações aumentam, as chances de diagnóstico de PC diminuem. E quanto maior a idade do lactente maior a correlação existente. 
Tabela 21: Correlações entre as avaliações neurológicas e motoras.

\begin{tabular}{|c|c|c|c|c|c|c|c|c|c|}
\hline & HINE $3 \mathrm{~m}$ & HINE $6 \mathrm{~m}$ & HINE 9m & $\begin{array}{c}\text { HINE } \\
12 \mathrm{~m}\end{array}$ & AIMS 3m & AIMS 6m & AIMS 9m & $\begin{array}{c}\text { AIMS } \\
12 \mathrm{~m}\end{array}$ & $\begin{array}{c}\text { Alteração } \\
\text { por } \\
\text { imagem }\end{array}$ \\
\hline \multirow{2}{*}{ HINE $3 \mathrm{~m}$} & 1,000 & $P=0,638$ & $=0638$ & $\mathrm{P}=0,482$ & $\mathrm{P}=0,632$ & $\mathrm{P}=0,475$ & $\mathrm{P}=0,597$ & $\mathrm{P}=0,630$ & $P=-0,286$ \\
\hline & $\mathrm{N}=65$ & $\mathrm{~N}=55$ & $\mathrm{~N}=43$ & $\mathrm{~N}=37$ & $\mathrm{~N}=65$ & $\mathrm{~N}=55$ & $\mathrm{~N}=42$ & $\mathrm{~N}=37$ & $\mathrm{~N}=44$ \\
\hline \multirow{2}{*}{ HINE $6 \mathrm{~m}$} & $\mathrm{P}=0,638$ & $\mathrm{P}=1,000$ & $\mathrm{P}=0,767$ & $\mathrm{P}=0,521$ & $\mathrm{P}=0,472$ & $\mathrm{P}=0,631$ & $\mathrm{P}=0,642$ & $\mathrm{P}=0,670$ & $P=-0,325$ \\
\hline & $\mathrm{N}=55$ & $\mathrm{~N}=63$ & $\mathrm{~N}=46$ & $\mathrm{~N}=38$ & $\mathrm{~N}=55$ & $\mathrm{~N}=63$ & $\mathrm{~N}=45$ & $\mathrm{~N}=38$ & $\mathrm{~N}=43$ \\
\hline \multirow{2}{*}{ HINE 9m } & $\mathrm{P}=0,638$ & $\mathrm{P}=0,767$ & $\mathrm{P}=1,000$ & $\mathrm{P}=0,903$ & $\mathrm{P}=0,325$ & $\mathrm{P}=0,442$ & $\mathrm{P}=0,664$ & $\mathrm{P}=0,819$ & $\mathrm{P}=-0,413$ \\
\hline & $\mathrm{N}=43$ & $\mathrm{~N}=46$ & $\mathrm{~N}=53$ & $\mathrm{~N}=40$ & $\mathrm{~N}=43$ & $\mathrm{~N}=46$ & $\mathrm{~N}=52$ & $\mathrm{~N}=40$ & $\mathrm{~N}=39$ \\
\hline HINE & $\mathrm{P}=0,482$ & $\mathrm{P}=0,521$ & $\mathrm{P}=0,903$ & $\mathrm{P}=1,000$ & $\mathrm{P}=0,215$ & $\mathrm{P}=0,338$ & $\mathrm{P}=0,577$ & $\mathrm{P}=0,751$ & $\mathrm{P}=-0,525$ \\
\hline $12 \mathrm{~m}$ & $\mathrm{~N}=37$ & $\mathrm{~N}=38$ & $\mathrm{~N}=40$ & $\mathrm{~N}=43$ & $\mathrm{~N}=37$ & $\mathrm{~N}=38$ & $\mathrm{~N}=40$ & $\mathrm{~N}=43$ & $\mathrm{~N}=32$ \\
\hline \multirow{2}{*}{ AIMS 3} & $\mathrm{P}=0,631$ & $\mathrm{P}=0,472$ & $\mathrm{P}=0,325$ & $\mathrm{P}=0,215$ & $\mathrm{P}=1,000$ & $\mathrm{P}=0,682$ & $\mathrm{P}=0,563$ & $\mathrm{P}=0,519$ & $\mathrm{P}=-0,248$ \\
\hline & $\mathrm{N}=65$ & $\mathrm{~N}=55$ & $\mathrm{~N}=43$ & $\mathrm{~N}=37$ & $\mathrm{~N}=65$ & $\mathrm{~N}=55$ & $\mathrm{~N}=42$ & $\mathrm{~N}=37$ & $\mathrm{~N}=44$ \\
\hline \multirow{2}{*}{ AIMS 6m } & $\mathrm{P}=0,475$ & $\mathrm{P}=0,631$ & $\mathrm{P}=0,442$ & $\mathrm{P}=0,338$ & $\mathrm{P}=0,682$ & $\mathrm{P}=1,000$ & $\mathrm{P}=0,754$ & $\mathrm{P}=0,578$ & $\mathrm{P}=-0,355$ \\
\hline & $\mathrm{N}=55$ & $\mathrm{~N}=63$ & $\mathrm{~N}=46$ & $\mathrm{~N}=38$ & $\mathrm{~N}=55$ & $\mathrm{~N}=63$ & $\mathrm{~N}=45$ & $\mathrm{~N}=38$ & $\mathrm{~N}=43$ \\
\hline \multirow{2}{*}{ AIMS 9m } & $\mathrm{P}=0,597$ & $\mathrm{P}=0,642$ & $\mathrm{P}=0,670$ & $\mathrm{P}=0,577$ & $\mathrm{P}=0,563$ & $\mathrm{P}=0,754$ & $\mathrm{P}=1,000$ & $\mathrm{P}=0,834$ & $\mathrm{P}=-0,512$ \\
\hline & $\mathrm{N}=42$ & $\mathrm{~N}=45$ & $\mathrm{~N}=52$ & $\mathrm{~N}=40$ & $\mathrm{~N}=42$ & $\mathrm{~N}=45$ & $\mathrm{~N}=52$ & $\mathrm{~N}=40$ & $\mathrm{~N}=38$ \\
\hline AIMS & $\mathrm{P}=0,630$ & $\mathrm{P}=0,670$ & $\mathrm{P}=0,819$ & $\mathrm{P}=0,751$ & $\mathrm{P}=0,519$ & $\mathrm{P}=0,578$ & $\mathrm{P}=0,834$ & $\mathrm{P}=1,000$ & $\mathrm{P}=-0,701$ \\
\hline $12 \mathrm{~m}$ & $\mathrm{~N}=37$ & $\mathrm{~N}=38$ & $\mathrm{~N}=40$ & $\mathrm{~N}=43$ & $\mathrm{~N}=37$ & $\mathrm{~N}=38$ & $\mathrm{~N}=40$ & $\mathrm{~N}=43$ & $\mathrm{~N}=32$ \\
\hline
\end{tabular}

Conforme descrito anteriormente, quando os bebês completaram 24 meses, as mães foram novamente contactadas via telefone ou WhatsApp, para verificar o desenvolvimento dos participantes e se havia alguma manifestação clínica do tipo neurológica. Participaram desta fase $73(51,0 \%)$ mães, sendo que 54 (37,8\%) já não tinham o mesmo contato telefônico (ou o número não existia ou pertencia à uma terceira pessoa que não conhecia a antiga proprietária do número) e apenas 16 mães (11,1\%) não quiseram responder às questões (Figura 9 -pag.154).

Ao final desta coleta de dados, foi consultado o prontuário de registro dos pacientes para confirmar se as informações de diagnósticos eram coerentes com as informações fornecidas pelas responsáveis. Foi verificado o prontuário do total de participantes $(n=143)$ e encontrado $16(11,2 \%)$ casos com alguma alteração neurológica anatômica, comprovada por exame de imagem. Dentre estes 16 casos, 11 se mantiveram presentes no acompanhamento dos 24 meses, ou seja, 11 mães participantes tinham um (a) filho (a) com alguma dessas alterações comprovadas por exame sendo que destes, somente 2 bebês desenvolveram manifestações clínicas de alteração neurológica (tabela 22). Este dado de manifestação clínica é subjetivo, pois 
trata-se de um relato materno e não de uma avaliação neurológica e motora presencial, como realizada nas idades de 3, 6, 9 e 12 meses.

Os participantes 1 e 2 apresentaram manifestações neurológicas graves, tendo diagnóstico de PC precocemente. Apesar disso, as mães não citaram que os filhos tinham PC. $\mathrm{O}$ caso 1 faltou às 2 primeiras sessões pois a mãe não estava conseguindo organizar a rotina e a quantidade de consultas e exames do filho. O caso 2 , compareceu na $3^{\text {a }}$ sessão do acompanhamento (9 meses), mas estava dormindo e a mãe não autorizou acordá-lo; na última sessão, eles se mudaram de cidade, e o paciente realizava 6 sessões de terapia por semana, o que dificultava a ida da mãe para Ribeirão Preto.

O participante 3 não compareceu em nenhuma consulta de acompanhamento (3, 6, 9 e 12 meses), mas participou por telefone do último contato (24 meses). A mãe possui 5 filhos, dentre os quais um deles apresenta hidrocefalia, além da dificuldade de transporte, mas garantiu que o participante em questão não possuía nenhuma manifestação clínica.

Os participantes 4, 5, 6, 7, 8 e 11, obtiveram evoluções clínicas comprovadas pelas avaliações neurológicas, com classificações ótimas ou limítrofes (quando está muito perto da classificação ótima). Nenhum apresentou manifestações clínicas, sendo que os casos 5, 6, 7 e 11 faltaram às consultas de acompanhamento depois de alcançarem excelentes resultados.

Os participantes 9 e 10 participaram somente da avaliação do RN (quando o participante foi recrutado para o estudo) e aos 12 meses por meio do contato telefônico. A mãe e a criança 9 têm espinha bífida (Arnold Chiari do tipo II), sem manifestações neurológicas, somente a dificuldade motora de locomoção. O participante 10 morava em outra cidade e apresentava dificuldades com transporte.

O participante 12 compareceu a todas as consultas de acompanhamento, e aos 12 meses estava fazendo uso de órteses, sendo claramente um caso de PC diparético e apresentando escores sub-ótimos evidentes de alteração neurológica, porém não foi possível o contato aos 24 meses por troca de telefone. Não sendo assim contabilizada a manifestação clínica aos 2 anos de idade, já que o acompanhamento do paciente foi perdido neste momento.

Os participantes 13 a 16, mudaram de telefone logo no início da pesquisa, não sendo possível o contato a partir do $3^{\circ}$ mês.

A tabela 22 detalha cada caso que apresentou alguma alteração neurológica detectada por exame de imagem, logo que o participante nasceu. 
Tabela 22: Descrição dos casos com alteração neurológica comprovada por exames de imagens.

\begin{tabular}{|c|c|c|c|c|c|c|c|c|c|}
\hline Participante & HNNE & $\begin{array}{c}\text { HINE } \\
\mathbf{3 m}\end{array}$ & $\begin{array}{c}\text { HINE } \\
6 \mathrm{~m}\end{array}$ & $\begin{array}{c}\text { HINE } \\
9 \mathrm{~m}\end{array}$ & $\begin{array}{l}\text { HINE } \\
12 \mathrm{~m}\end{array}$ & Classificação & Relato médico & $\begin{array}{c}\text { Alteração em } \\
\text { exame de } \\
\text { imagem }\end{array}$ & $\begin{array}{c}\text { Manifestação } \\
\text { clínica confirmada } \\
\text { pela mãe } \\
\end{array}$ \\
\hline Caso 1 & 11,5 & Faltou & Faltou & 55,5 & 56,0 & Sub-ótimo & PC- GMFCS 3 & SIM & SIM \\
\hline Caso 2 & 10,5 & 46,0 & 44,0 & $\begin{array}{c}\text { Não } \\
\text { avaliado* }\end{array}$ & Faltou & Sub-ótimo & $\begin{array}{l}\text { Microcefalia+ epilepsia+ } \\
\text { encefalopatia hipóxico isquêmico }\end{array}$ & SIM & SIM \\
\hline Caso 3 & 22,5 & Faltou & Faltou & Faltou & Faltou & Sub-ótimo & HPIV grau II bilateral & SIM & NÃO \\
\hline Caso 4 & 16,5 & 61,5 & 74,0 & 78,0 & 76,0 & $\begin{array}{c}\text { Sub-ótimo }(\mathrm{RN}) \\
\text { (limítrofe } 3 \mathrm{~m}) \\
\text { Ótimo }(6,9 \text { e } 12 \mathrm{~m})\end{array}$ & HPIV grau II & SIM & NÃO \\
\hline Caso 5 & 16,0 & 57,0 & 70,0 & Faltou & Faltou & $\begin{array}{c}\text { Sub-ótimo }(\mathrm{RN}+3 \mathrm{~m}) \text {. Ótimo } \\
(6 \mathrm{~m})\end{array}$ & $\begin{array}{l}\text { Céfalo-hematoma devido } \\
\text { traumatismo no parto }\end{array}$ & SIM & NÃO \\
\hline Caso 6 & 16,0 & 49,5 & 68,0 & 72,0 & Faltou & $\begin{array}{l}\text { Sub-ótimo }(\mathrm{RN}+3) \\
\text { (limítrofe } 6 \mathrm{~m} \text { e } 9 \mathrm{~m})\end{array}$ & $\begin{array}{c}\text { Ventriculomegalia à E + } \\
\text { hiperecogenicidade da substância } \\
\text { branca à D sem manifestação } \\
\text { clínica }\end{array}$ & SIM & NÃO \\
\hline Caso 7 & 23,0 & 62,0 & Faltou & Faltou & Faltou & $\begin{array}{l}\text { Sub-ótimo }(\mathrm{RN}) \\
\text { (limítrofe } 3 \mathrm{~m})\end{array}$ & $\begin{array}{l}\text { Anóxia neonatal + cistos } \\
\text { cerebrais congênitos }\end{array}$ & SIM & NÃO \\
\hline Caso 8 & 21,0 & 64,0 & 75,0 & 78,0 & 78,0 & $\begin{array}{l}\text { Sub-ótimo }(\mathrm{RN}) \\
\text { Ótimo }(3,6,9 \text { e } 12 \mathrm{~m})\end{array}$ & Síndrome de Dandy Walker & SIM & NÃO \\
\hline Caso 9 & 16,5 & Faltou & Faltou & Faltou & Faltou & Sub-ótimo & $\begin{array}{c}\text { Espinha bífida lombar sem } \\
\text { hidrocefalia + Arnold Chiari II }\end{array}$ & SIM & NÃO \\
\hline Caso 10 & 20,0 & Faltou & Faltou & Faltou & Faltou & Sub-ótimo & Ventrículomegalia supratentorial & SIM & NÃO \\
\hline Caso 11 & 18,0 & 53,0 & 67,0 & 74,0 & Faltou & $\begin{array}{c}\text { Sub-ótimo } \\
\text { (limítrofe } 6 \text { e 9m) }\end{array}$ & $\begin{array}{l}\text { Hipoplasia de vermis - cerebelar } \\
+ \text { prematuridade }\end{array}$ & SIM & NÃO \\
\hline Caso 12 & 20,5 & 33,5 & 48,0 & 56,5 & 59,0 & Sub-ótimo & $\begin{array}{l}\text { Malformação do SNC por } \\
\text { citalomegalovírus + microcefalia }\end{array}$ & SIM & - \\
\hline Caso 13 & 12,5 & - & - & - & - & Sub-ótimo & $\begin{array}{c}\text { Leucomalácia + cisto } \\
\text { subependimário }\end{array}$ & SIM & - \\
\hline Caso 14 & 23,5 & - & - & - & - & Sub-ótimo & $\begin{array}{c}\text { HPIV grau II+estrabismo } \\
\text { específico }\end{array}$ & SIM & - \\
\hline Caso 15 & 19 & - & - & - & - & Sub-ótimo & Crises de ataxia & SIM & - \\
\hline Caso 16 & 20,5 & - & - & - & - & Sub-ótimo & Neuro-sífilis & SIM & - \\
\hline
\end{tabular}

Legenda: * Participante dormiu na hora do exame; - não foi possível contato com a responsável. 
Os diagnósticos disponíveis nos prontuários $(\mathrm{N}=143)$, se encontram na tabela 23 , enquanto os diagnósticos fornecidos pelas mães $(\mathrm{N}=73)$, estão disponíveis na tabela 24.

Tabela 23: Diagnósticos ou condições relatadas nos prontuários dos participantes.

\begin{tabular}{lcc}
\hline \multicolumn{1}{c}{ Diagnóstico } & Pré-termo & A termo \\
\hline $\begin{array}{l}\text { Anomalias ou malformações diversas } \\
\text { Alterações neurológicas comprovadas por exame com diagnóstico } \\
\text { fechado até os dois anos }\end{array}$ & 2 & 3 \\
Alterações neurológicas comprovadas por exame sem diagnóstico & 4 & 7 \\
fechado até os dois anos & & 3 \\
Alterações visuais & 2 & 1 \\
Problemas metabólicos & 2 & 1 \\
Problemas respiratórios & 1 & 3 \\
Problemas cardíacos & & 1 \\
Deformidades torácicas & 2 & 1 \\
Atraso social & & 2 \\
Fraturas múltiplas - suspeita-se de maus tratos & 1 & 1 \\
Sífilis congênita & & 2 \\
Síndrome de Down & & $\mathrm{N}=71$ \\
Síndrome de Hirschsprung & 2 & $\mathrm{~N}=27$ \\
Telarca precoce & & \\
Nenhum diagnóstico relatado & & \\
\hline \hline
\end{tabular}

Dentre os diagnósticos citados pelas mães $(\mathrm{N}=73), 12$ se referem a doenças de caráter respiratórias como asma, rinite, bronquite e bronquiolite e 5 se refere a algum tipo de anemia; e 5 relataram alguma alteração neurológica, não sendo necessariamente manifestada clinicamente - como ocorre nos dois casos de Síndrome de Dandy Walker (sendo um confirmado e o outro ainda em investigação) e no Arnold Chiari, do tipo II; todavia, dois casos tiveram alterações neurológicas manifestadas, que foram os casos de Hidrocefalia e Microcefalia. Ambos possuem alterações graves, por isso, acredita-se que o diagnóstico tenha sido fechado antes dos 2 anos de idade; porém, nenhuma dessas duas mães citaram a PC como diagnóstico. 
Tabela 24: Diagnósticos relatados pelas mães dos participantes

\begin{tabular}{lc}
\hline \hline \multicolumn{1}{c}{ Diagnóstico } & Frequência \\
\hline Nenhum diagnóstico relatado & 42 \\
Problemas respiratórios & 12 \\
Anemia & 5 \\
Alterações neurológicas comprovadas por exame com diagnóstico fechado até os dois & 3 \\
anos & \\
Alterações neurológicas comprovadas por exame sem diagnóstico fechado até os dois & 2 \\
anos & \\
Problemas cardíacos & 2 \\
Síndrome de Hirschsprung & 2 \\
Alergias alimentares & 1 \\
Anomalias ou malformações diversas & 1 \\
Alterações visuais & 1 \\
Cisto no rim & 1 \\
Suspeita de autismo & 1 \\
Total & 73 \\
\hline \hline
\end{tabular}

Os casos de alteração neurológica estão representados na figura 10 (fluxograma).

Figura 10: Representação dos casos com alguma alteração neurológica

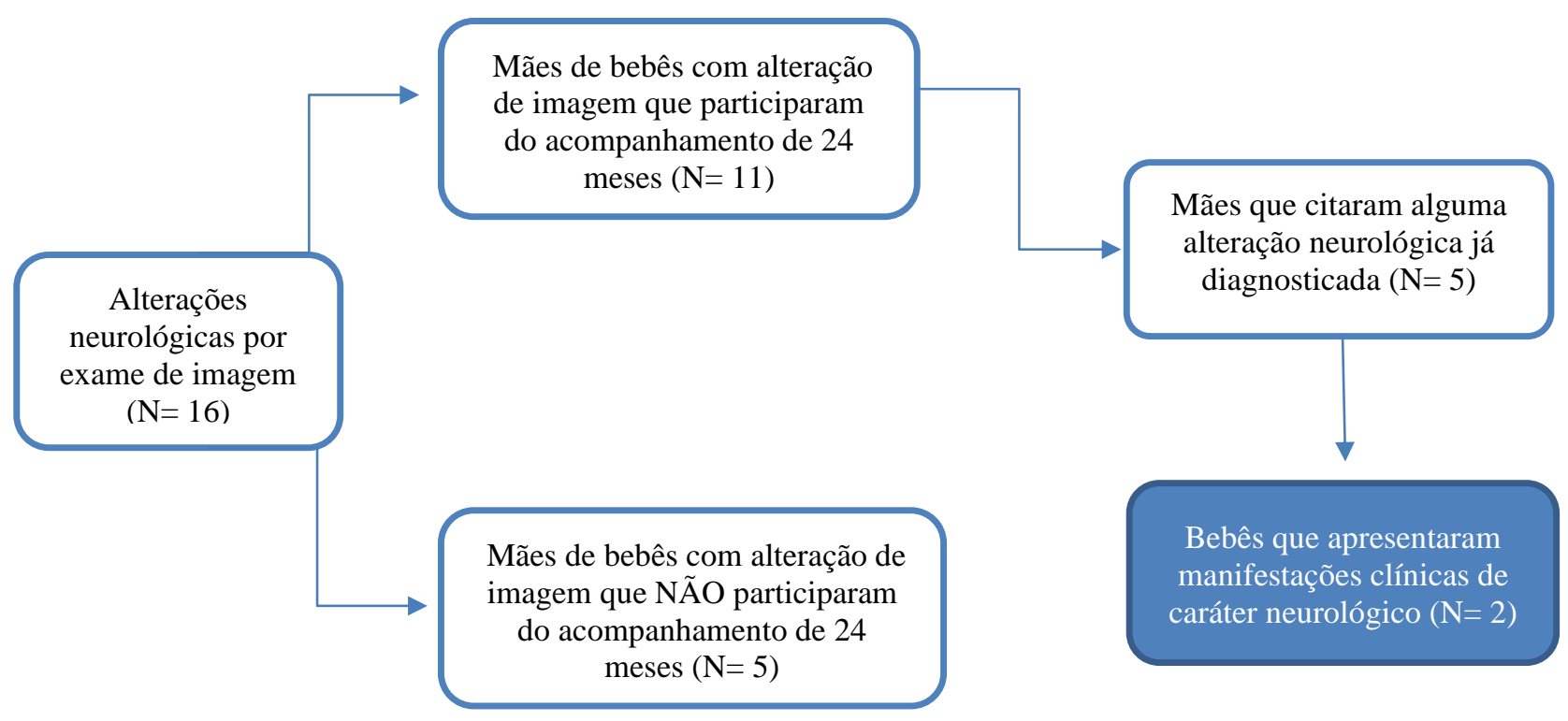

Para avaliar a sensibilidade dos instrumentos HNNE e HINE para predizer uma alteração neurológica, foi utilizado a curva ROC (Figuras 11 e 12). 
A curva ROC, é uma representação gráfica que ilustra o desempenho (ou performance) de um sistema classificador binário à medida que o seu limiar de discriminação varia. $\mathrm{O}$ seu critério de mudança é resultado da operação de duas características (positivos verdadeiros $\mathrm{X}$ positivos falsos). É denominado também como gráfico de sensibilidade x 1-especificidade. Cada resultado de previsão ou instância de uma matriz de confusão representa um ponto no espaço ROC. Quanto maior o espaço de distância do ponto em relação ao centro $(0,5)$ maior a sensibilidade. À medida que o tamanho da amostra aumenta, o ponto ROC de um classificador aleatório tende para a linha diagonal (DELONG; DELONG; CLARKE-PEARSON, 1988).

Na Figura 11 os dados dos escores foram traçados comparando-os com a quantidade de alteração neurológica que correspondem ao exame de imagem. Neste gráfico foi possível notar que as idades mais sensíveis para predição de alterações neurológicas: HINE 6 e 9 meses, seguido de HNNE e HINE 12 meses.

Figura 11: Teste de sensibilidade dos instrumentos HNNE e HINE com o diagnóstico neurológico por exame de imagem.

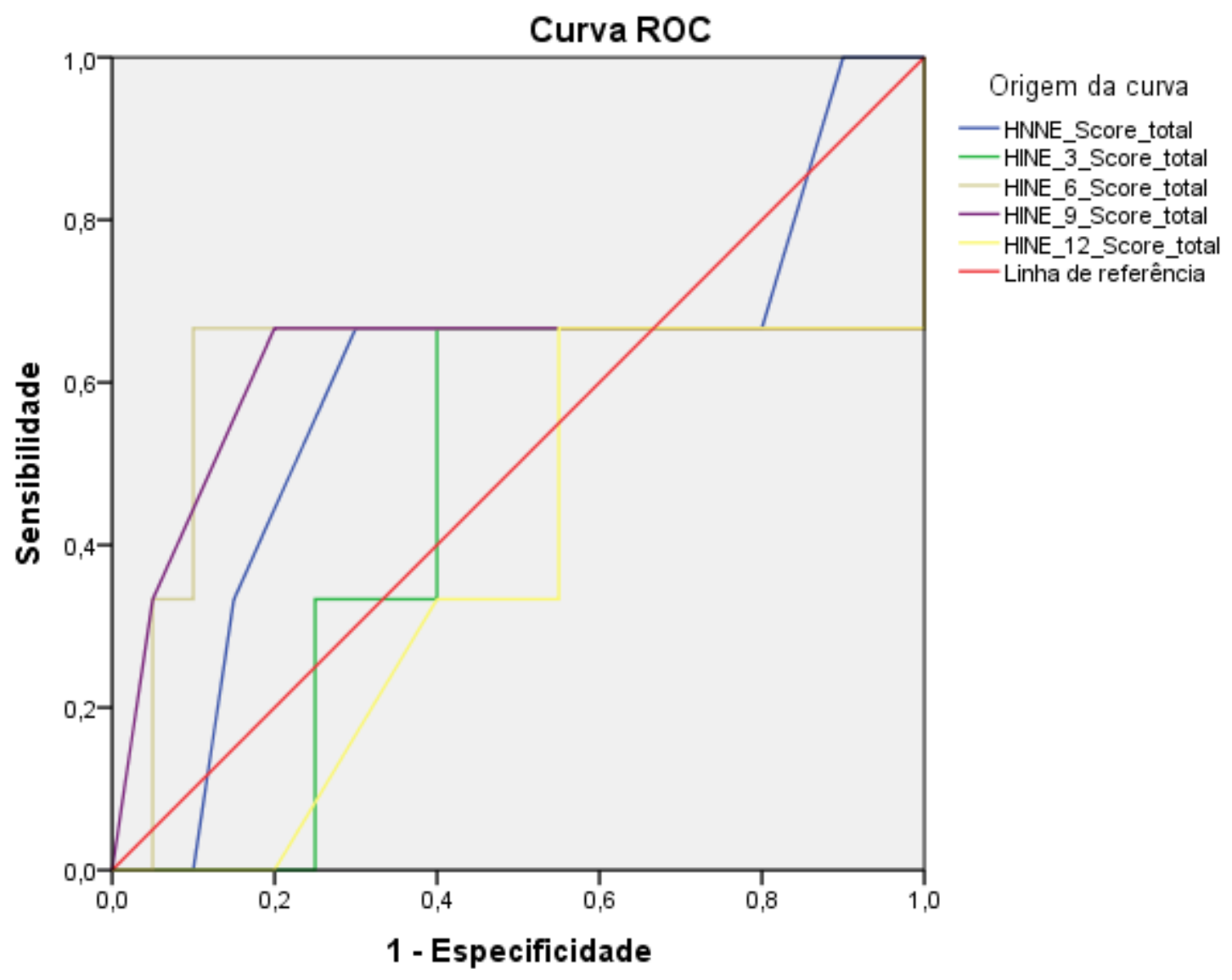

Os segmentos diagonais são produzidos por vínculos. 
Na figura 12, os escores foram comparados aos casos confirmados pelas mães sobre as manifestações clínicas neurológicas, e as idades mais sensíveis foram HINE de 6 meses, seguido por 9 meses e HNNE, concordando com a sensibilidade encontrada ao cruzar os escores com as respostas dos exames neurológicos. Na figura 10, as linhas da curva ROC ficaram mais retas por conta do baixo número de participantes que desenvolveram uma manifestação neurológica.

Figura 12: Teste de sensibilidade dos instrumentos HNNE e HINE com o diagnóstico neurológico, pela sua manifestação clínica.

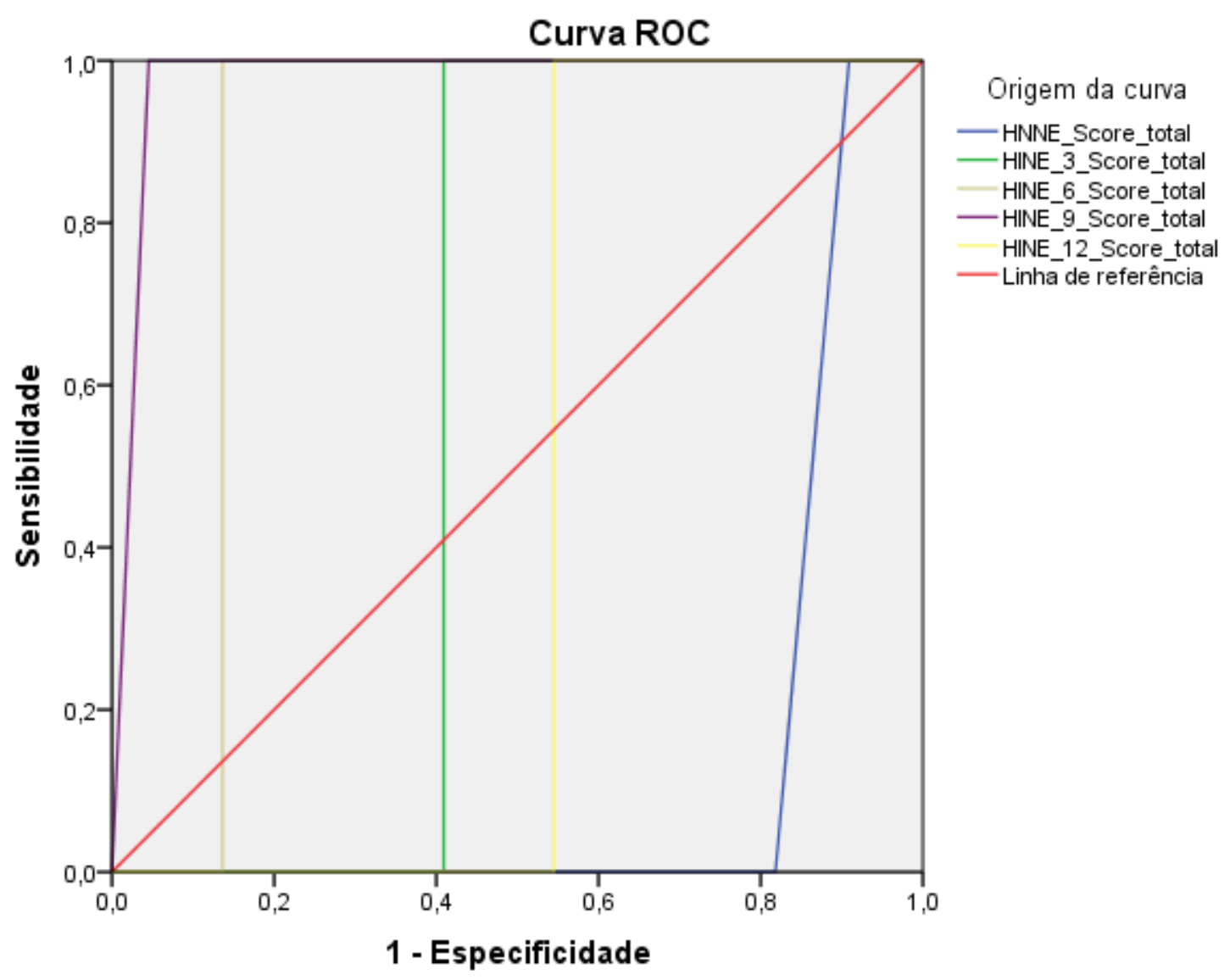

Os segmentos diagonais são produzidos por vínculos. 


\subsection{Discussão}

\section{Dados descritivos}

Participaram deste estudo 143 lactentes, que foram incluídos a partir dos fatores de risco maternos e gestacionais propostos por McIntyre et al. (2011). Estes fatores de risco vão ao encontro com os resultados apontados por Felice, Santos e Pfeifer (2019) em um recente estudo retrospectivo desenvolvido na rede pública de saúde do munícipio de Ribeirão Preto/SP (onde o presente estudo também foi realizado).

Os autores evidenciaram como sendo fatores maternos de risco para PC: aborto espontâneo ou intencional; problemas orgânicos (como asma, bronquite, hipotireoidismo, diabetes, cardiopatias) e alterações neurológicas (como epilepsia, enxaqueca); doenças autoimunes (fibromialgia, tumor, lúpus); problemas psiquiátricos (depressão, síndrome do pânico); problemas ginecológicos e intercorrências pregressas (histerectomia, endometriose, mioma, nódulos, ovário policístico, dificuldade para engravidar, útero infantil), doenças sexualmente transmissíveis (sífilis, e HIV), intercorrências na gestação e em partos anteriores; riscos externos (histórico de uso de drogas, ex-fumante, presidiária); hígida; alterações na pressão arterial, pico hipertensivo, citomegalovírus, pré-eclâmpsia, infecção, sangramento ou hemorragia no trabalho de parto ou parto, situação estressante, ausência de assistência médica, mãe faleceu no parto, mãe alcoolizada no momento do parto (FELICE; SANTOS; PFEIFER, 2019).

Fatores de risco perinatais: trabalho de parto demorado, pouca e nenhuma dilatação, bolsa rota, placenta grau III, placenta presa, descolamento de placenta, parto induzido, pouco líquido amniótico, polihidrâmio, cesárea de urgência, lesão uterina, problemas com a anestesia para cesárea, presença de infecções, apresentação pélvica e posicionamento não adequado, uso de fórceps, problemas com o cordão umbilical. E os fatores de risco pós natais: anóxia, dificuldade ou desconforto respiratório, hipoglicemia, aspiração ou ingestão de mecônio, icterícia, incompatibilidade sanguínea, sofrimento fetal, sopro cardíaco, cianótico, alterações na estatura do bebê, choro abafado, ausência de movimentos ao nascer, crise convulsiva, parada cardíaca, lavagem do estômago, hipotermia, fratura de clavícula ou costela, precisou amadurecer o pulmão, edemas na cabeça, má formação (FELICE; SANTOS; PFEIFER, 2019).

Sobre a condição de riscos maternos encontrados em nossa amostra, os fatores mais frequentes foram: baixo nível socioeconômico em pelo menos 32,8\% das famílias; abortos prévios em 30,7\% das mães; HAS presente em 28,7\% das mães; seguida de infecção de urina 
$(25,1 \%)$; diabetes $(24,4 \%)$; idade materna superior a 35 anos $(21,7 \%)$ e baixa escolaridade (23,1\% não tinham completado o ensino fundamental).

No Brasil, a maioria das crianças prematuras pertencem a famílias de baixo nível socioeconômico, sendo que as características do ambiente físico e a escolaridade dos pais influenciam no desenvolvimento neuromotor dessas crianças (MANCINI et al., 2004).

Outros estudos realizados no Brasil demonstram que a condição socioeconômica da família interfere nas condições do nascimento e no desenvolvimento do bebê no seu primeiro ano de vida (GARCIA et al., 2011) e que crianças de baixa renda apresentam duas vezes mais chance de demonstrarem um teste de triagem suspeito de atraso no seu desenvolvimento neuropsicomotor, comparadas com as de melhor renda, e que o risco para suspeita de atraso aumenta com a diminuição da escolaridade materna (HALPERN et al., 2000).

Em relação a outros fatores de riscos $92,3 \%$ das mães declararam terem feito o pré-natal completo, no entanto, a maioria não soube informar a quantidade de consultas que tinham frequentado; 61 famílias desejaram a gravidez (62,2\%), mas somente 45 planejaram (31,5\%).

É recomendado que as gestantes façam, aproximadamente, 13 consultas de pré-natal para possibilitar diagnósticos precoces e minimizar as intercorrências que podem potencializar os desvios no desenvolvimento do bebê (SPALLICCI et al., 2000). Porém, de acordo com o Ministério da Saúde (BRASIL, 2012a) o total de consultas pré-natais deve ser de, no mínimo, 6 (seis), com acompanhamento intercalado entre médico e enfermeiro, e deve seguir uma lógica de solicitação de exames por período gestacional.

Sobre o estilo de vida, 25 mães eram tabagistas e fumaram durante a gestação $(17,4 \%)$ e menos de 14 beberam socialmente de acordo com a percepção e avaliação delas (10\%).

Com relação aos lactentes, 98 nasceram a termo (70\% da amostra), sendo que o intervalo gestacional foi de 29 a 42 semanas. 74 (quase $52 \%$ da amostra total) foi formada por meninos, porém a maioria dos prematuros $(\mathrm{N}=45)$ são do sexo feminino $(27-60 \%)$. A condição clínica de risco para PC mais frequente, foi sofrimento neonatal presente em 37 lactentes (quase 26\% dos casos).

Sobre a prematuridade, segundo Halpern et al. (2000), bebês com menor tempo de gestação, apresentam $60 \%$ maior risco para apresentar algum problema no desenvolvimento.

De acordo com Cheong e Doyle (2012), prematuros ou lactentes com baixo peso ao nascer apresentam alto risco de desenvolver alterações neurológicas a longo prazo, incluindo deficiências cognitivas, motoras e comportamentais. Relata-se que até $50 \%$ dos prematuros extremos precisam de assistência adicional em idade escolar, e há evidências emergentes das dificuldades de desenvolvimento associadas ao parto prematuro tardio. 
O comportamento também pode sofrer influencias provenientes da prematuridade, de forma que, prematuros equivalentes a termo, possuem um desenvolvimento neurocomportamental variável quando comparado com seus pares nascidos a termo (MERCURI et al., 2003; BROWN et al., 2006).

Sobre os fatores de risco perinatal, a asfixia perinatal, bem como, a prematuridade, a hipoglicemia e as infecções do SNC, estão entre as principais causas de paralisia cerebral (KATHERINE; RATLIFFE, 2002; KOK, 2003; FONSECA, 2004).

Para Mercuri et al. (2005), a asfixia e os insultos hipóxico-isquêmicos são a causa mais frequente de encefalopatia neonatal em bebês a termo. Alguns fatores como presença de convulsões, administração de anticonvulsivantes ou outros fatores não neurológicos associados, tais como, problemas pulmonares, cardíacos ou renais, podem contribuir para anormalidades transitórias do tônus e da capacidade de resposta. Essa variabilidade pode interferir no desempenho avaliado pelo exame neurológico, apresentando como resposta uma condição anormal, mesmo em bebês com lesões menores e desenvolvimento normal.

Os riscos pós-natal para PC, estão fortemente associados com meningite ou encefalite, traumatismo craniano, afogamento, parada cardíaca durante cirurgias, acidentes vasculares cerebrais, tumores, exposição ao chumbo e tromboses pela anemia falciforme (KATHERINE; RATLIFFE, 2002).

Ao verificar o prontuário médico de todos os participantes, verificou-se que somente 16 lactentes tinham realizado algum exame neurológico com resultados positivos para alteração no encéfalo. Cinco casos, não puderam ser verificados porque as responsáveis não foram encontradas nos números telefônicos fornecidos, portanto obteve-se informações de 11 casos apenas.

Dentre os diagnósticos citados pelas mães $(\mathrm{N}=73)$, a maioria $(57,6 \%)$ relatou nunca ter recebido nenhum tipo de diagnóstico. Quase $15 \%$ das mães referiram que seu (a) filho (a) possuía alguma doença de caráter respiratório e somente 5 mães $(6,8 \%)$ relataram algum diagnóstico de alteração neurológica, sendo que somente dois casos manifestaram alterações perceptíveis para as mães. Esta informação chamou atenção, uma vez que os bebês de 11 mães que integraram este grupo tenham exames neurológicos comprovados por alteração em seus prontuários.

Existe uma grande dificuldade em fornecer um diagnóstico precoce baseado em avaliações neurológicas devido à possibilidade de resultados falso-positivos e falso-negativos. Os falsos positivos são possíveis em lactentes com risco de PC, que tiveram situações complicadas em seu período peri e pós natal resultando em anormalidades neurológicas 
transitórias, como acontece em alguns casos de prematuridade e asfixia neonatal, sem evolução de sequelas a longo prazo. Em contrapartida, os resultados falso-negativos são determinados por um período de latência entre a ocorrência de lesões e o início dos sinais clínicos da PC (ROMEO et al, 2015). Para Novak et al. (2017), o HINE é uma ferramenta recomendada para a detecção precoce da PC.

\section{Escore obtido x Escore de normalidade}

Em relação ao desenvolvimento neuromotor, os escores obtidos no presente estudo, através do HNNE, HINE e AIMS, apresentaram resultados crescentes provenientes da maturidade neurológica e dos estímulos vivenciados, sendo que os prematuros intermediários apresentaram escores superiores aos prematuros tardios a partir da avaliação realizada no $3^{\circ}$ mês de vida. O HNNE foi aplicado nos primeiros dias de vida, sendo em alguns casos, aplicados poucas horas após o nascimento. O HINE e a AIMS foram aplicadas no $3^{\circ}, 6^{\circ}, 9^{\circ}$ e $12^{\circ}$ mês de idade cronológica.

De acordo com Mercuri et al. (2005), o HNNE realizado após a segunda semana de vida reflete melhor o estado neurológico do bebê. Entretanto, não foi possível coletar os dados após 2 semanas, por que não havia como controlar a alta do bebê da maternidade; alguns poderiam receber alta no dia seguinte ao nascimento, ou 2 dias depois, enquanto outros podiam ficar mais tempo, por alguma intercorrência. Portanto, decidiu-se aplicar o exame o quanto antes.

Porém, um recém estudo de Romeo et al. (2017) que avaliou uma coorte de $124 \mathrm{RN}$ a termo, de baixo risco, sendo que 62 bebês foram avaliados pelo HNNE nas primeiras 3 horas de vida e os outros 62 foram avaliados entre 3 e 6 h de vida. Todos foram avaliados 48 horas após o nascimento. Para 23/34 dos itens neurológicos, os escores de alcance e mediana foram semelhantes nos três momentos, enquanto que 11 itens restantes, os três grupos apresentaram escores semelhantes, porém com medianas diferentes com diferentes taxas de alteração. Em 6 dos 11 , os escores médios às 3-6h foram semelhantes aos observados às $48 \mathrm{~h}$, mas pareciam ser 'menos maduros' às 0-3h. Somente em um item as pontuações medianas foram consistentemente diferentes nos três momentos. Este estudo sugeriu que o HNNE pode ser realizado de maneira confiável logo após o nascimento, sustentando nossa decisão.

Quando os escores obtidos em nosso estudo foram comparados com o escore de normalidade apresentados pelos autores do instrumento, pode-se notar que as pontuações desta amostra foram expressamente inferiores em ambos os instrumentos, possivelmente pelo fato da amostra completa ter sido formada por um grupo de risco. Outro dado interessante, é que 
prematuros intermediários tiveram melhores escores que os prematuros tardios, a partir dos 3 meses de vida se mantendo até os 12 meses. O avaliador notou que as mães de prematuros intermediários demonstraram maior interesse e dedicação nas estimulações domiciliares.

Em relação aos escores obtidos pelo HNNE em outros estudos brasileiros, há um predomínio de escore abaixo dos escores normativos apresentados pelos autores do instrumento, ainda que a amostra seja formada por participantes de baixo risco para alteração neurológica. É o caso do estudo publicado por Nascimento et al. (2011) que realizaram um estudo prospectivo transversal com $30 \mathrm{RN}$ a termo e com baixo risco para lesões neurológicas. As pontuações obtidas por $20 \%$ da amostra apresentaram um escore total abaixo do esperado, mostrando a necessidade de validação deste instrumento na população brasileira.

Ao utilizar o HINE, outros estudiosos encontraram diferenças entre a projeção do escore normativo apresentado, indicando que alterações neurológicas se relacionam com escores ainda mais baixos.

Haataja e colaboradores (2001) avaliaram 53 crianças nascidas a termo, através do HINE, com idade entre 9 a 14 meses e correlacionaram com encefalopatia hipóxico-isquêmica e com achados de ressonância magnética; o objetivo foi verificar se a pontuação dessa avaliação pode prever a função locomotora nessas crianças nas idades de 2 e 4 anos. Todas as crianças que tiveram uma pontuação global entre 67 e 78 foram capazes de caminhar de forma independente aos 2 anos e sem restrições aos 4 anos. Pontuações entre 40 e 67 foram associados com mobilidade restrita e os escores $<40$ com mobilidade severamente limitada aos 2 e 4 anos. Os menores escores foram associados com lesões dos gânglios basais e de substância branca.

Ricci et al. (2006) realizaram um estudo transversal em 24 crianças com leucomalácia periventricular cística entre 6 a 9 meses de idade para correlacionar precocemente a gravidade da evolução. Pontuações do HINE <40 foram associadas com deficiência motora grave enquanto escores entre 41 - 60 foram associados com comprometimento motor moderado (os lactentes sentavam aos 2 anos, mas não andavam). Escore maior que 60 foram associados com resultado normal. Os autores observaram que os bebês que apresentavam o aumento do tônus extensor do pescoço e tronco, postura flexora dos membros superiores e membros inferiores estendidos, proteção anormal do braço na reação anterior do paraquedas foram associados com a incapacidade de se sentar sem suporte aos 2 anos. Lactentes que apresentaram hipotonia do tronco, membros superiores e inferiores estendidos foram associados como tendo capacidade de se sentar sem suporte, mas incapacidade para andar aos 2 anos de idade.

Frisone et al. 2002 ao estudarem o comportamento neurológico de 74 prematuros com idade entre 9 e 18 meses, avaliado através do HINE, observarem que os sujeitos que 
apresentaram escores $<52$ foram incapazes de andar ou de ficar em pé sem apoio aos 2 anos. Por outro lado, houve lactentes que apresentaram escores subótimos ( $<70$ para esta idade) e evoluíram com um desenvolvimento adequado. Estes casos, como já explicado, são conhecidos como falso-positivo. E outros casos desta amostra, que apresentaram escore ótimos foram associados exames de US sem lesões ou com pequenas lesões que não levaram a uma manifestação clínica (FRISONE et al. 2002).

De acordo com Romeo et. al (2008), o HINE pode ser considerado um instrumento útil ao classificar uma criança com PC. Estes pesquisadores realizaram um estudo retrospectivo com 70 crianças diagnosticadas com PC e observaram uma forte correlação entre a pontuação do HINE nas idades entre 3 e 6 meses e os níveis do GMFCS aos 2 anos de idade. Crianças classificadas nos níveis I e II do GMFCS obtiveram pontuações no HINE entre 40-60 enquanto as crianças classificadas entre os níveis III - V obtiveram pontuações abaixo de 40.

Um estudo desenvolvido em Uganda, com $115 \mathrm{RN}$ a termo de baixo risco, comparou os escores totais deste grupo com os escores normativos do Reino Unido e concluíram que um número significativamente menor de bebês Ugandenses obteve escores ótimos com base nos dados do Reino Unido, e relatam preocupações sobre o uso dessa pontuação de "otimização" do Reino Unido em outros contextos de pesquisa (HAGMANN et al., 2015).

A nossa amostra foi composta por $143 \mathrm{RN}$ de risco, sendo 45 prematuros. Nenhum bebê apresentou escore <40 nas avaliações de 9 e 12 meses e apenas 6 participantes apresentaram pontuações entre 40 e 67 aos 9 meses (sendo 2 entre 40 e 60) e 4 participantes apresentaram pontuações entre 40 e 67 aos 12 meses (sendo 2 entre 40 e 60). Um dos casos que aqui apresentaram manifestações neurológicas, confirmado pela mãe, obteve pontuações abaixo de 60 aos 9 e 12 meses. O segundo caso faltou nas avaliações de 6 e 9 meses, mas apresentou valores bem abaixo na avaliação do RN (HNNE) e no HINE - 3 meses. Esses dados sugerem a necessidade de estudos mais abrangentes que apresentem escores normativos para as crianças brasileiras.

Um recente estudo avaliou o desempenho neurológico de 157 prematuros tardios de alto risco, por meio do HINE aos 6 e 12 meses de idade corrigida e comparou com o sistema de pontuação de otimalidade. Os resultados que eles encontraram foram muito próximos do nosso estudo, com a diferença que utilizamos a idade cronológica como fator de comparação. Eles encontraram uma pontuação global de 59 (47 - 76) de aos 6 meses com pontuações ótimas alcançadas em apenas 25,4\%. Aos 12 meses, eles obtiveram uma pontuação global de 70 (58 78) e alcançaram pontuações ótimas em 63,2\%. Concordando com nossos achados, os subescores de postura, tônus e reflexos aumentaram gradualmente dos 6 aos 12 meses de idade 
corrigida e nascer pequeno para a idade gestacional foi o único fator que influenciou negativamente o escore HINE aos 6 e 12 meses. Eles concluíram que prematuros tardios de alto risco apresentam escores HINE abaixo dos ideais aos 6 e 12 meses de idade (CHATZIIOANNIDIS et al., 2018).

Assim como no presente estudo, ROMEO et al. (2016) investigaram as diferenças no desenvolvimento neurológico, entre prematuros intermediários, prematuros tardios e nascidos a termo, porém em uma amostra considerada de baixo risco. Participaram deste estudo 188 lactentes, sendo 69 prematuros intermediários, 71 prematuros tardios e 48 nascidos a termo que foram avaliados com idade corrigida de 3, 6, 9 e 12 meses. Os prematuros intermediários e tardios apresentam escores globais significativamente menores do que os nascidos a termo concluindo que a idade gestacional influencia no desenvolvimento de bebês avaliados durante os primeiros 2 anos de vida.

\section{Sensibilidade dos instrumentos HNNE/ HINE}

Ao avaliar a sensibilidade dos instrumentos HNNE e HINE (aplicados ao nascer e a cada 3 meses, respectivamente) para predizer uma alteração neurológica, as idades mais sensíveis foram aos 9 e 6 meses, seguido pela avaliação ao nascer (HNNE) e aos 12 meses de vida. É válido lembrar que não houve correção de idade nesta amostra, de forma que os prematuros foram avaliados em sua idade cronológica, o que anula o viés do acompanhamento no sentido de aplicarmos duas escalas distintas no mesmo período de vida, permitindo que tanto prematuros quanto a termo sejam comparados ao receber o mesmo tempo cronológico de estímulos ambientais. Entretanto, a predição por escore pode ter sido influenciado negativamente já que é conhecido na literatura que prematuros levam mais tempo para atingir determinada aquisição em relação aos que nasceram no tempo adequado.

De acordo com alguns pesquisadores, a aplicação de exames neurológicos nos primeiros meses de vida, apresentam pobre valor indicativo de ausência ou presença de lesão neurológica efetiva e, por esse motivo, devem ser associadas aos fatores de risco pré, peri e pós natal, bem como, aos exames de imagem. No entanto, sabe-se que a avaliação da qualidade dos movimentos gerais dos RN é um forte preditor do desenvolvimento neurológico dessas crianças (SERGIO; 2010; HADDERSALGRA 1996; PRECHTL et al.,1991; ALFORD et al., 1990). Vries et al. (1982) e Hopkins e Prechtl (1984) asseguram que esses movimentos se iniciam durante a vida fetal e persistem até 3 ou 4 meses de idade pós termo, quando o exame neurológico habitual passa 
a ter maior valor preditivo. No HNNE há uma parte do exame voltada para a avaliação da quantidade e qualidade do movimento.

Em 2004, Gupta et al. estudaram uma coorte de 66 RN com muito baixo peso e escore do HNNE inferior a 30,5. Todas as crianças realizaram ressonância magnética (RM) de encéfalo e a sensibilidade encontrada foi de $88 \%$ para identificar crianças com alterações neurológicas.

Woodward et al. (2004) concorda com a sensibilidade do HNNE (88\%) para identificar bebês com anormalidades neurológicas indicadas por uma RM, porém relata que a especificidade para detectar bebês sem anormalidade significativas na RM é baixa (46\%).

Concordando com nossos achados, o HINE apresenta maior sensibilidade como apontado pelos estudos a seguir.

Em uma coorte de $74 \mathrm{RN}$ prematuros com IG entre 24 e 30,5 semanas que foram examinados com idades cronológicas entre 9 e 18 meses (assim como no presente estudo, a idade não foi corrigida) para verificar se as pontuações obtidas no HINE podem predizer a função locomotora dessas crianças aos 2 anos de idade; eles relataram que a sensibilidade do instrumento foi de $98 \%$ e a especificidade foi de $85 \%$ (FRISONE et al., 2002)

Pizzardi et al. (2008) estudaram 658 lactentes com encefalopatia neonatal, desde o nascimento até aos 12 meses de idade corrigida e evidenciaram um alto poder preditivo de PC utilizando a HINE em todas as idades (3, 6, 9 e 12 meses).

Romeo et al. (2013) avaliaram longitudinalmente, através do HINE, 1541 lactentes prematuros e a termo (de alto risco) aos 3, 6, 9 e 12 meses e compararam com resultados motores aos 24 meses. Aos 3 meses, escores <56 apresentaram alta sensibilidade ( 90\%) e especificidade para o desenvolvimento de PC, sendo que escores $<40$ foram encontrados somente em crianças que desenvolveram uma forma grave de PC. Lactentes com uma leve incapacidade podem se associar com escores na faixa normal ou anormal. Neste estudo, os escore do HINE não foram associados aos achados ultrassonográficos, portanto, não foi fornecida uma correlação de valor prognóstico.

Um recente estudo sugere a combinação de escores totais do HINE com um escore de assimetria para ajudar os profissionais a diferenciar bebês com hemiplegia daqueles com desenvolvimento típico. Para isso, foi avaliado 74 lactentes com PC, sendo 28 quadriplégicos, 11 diplégicos e 35 hemiplégicos. Os escores totais médios do HINE e escore de assimetria foram respectivamente: para hemiplegia - 57,5 x 10; e para aqueles sem PC - 76 e 0 . A sensibilidade e a especificidade para distinguir a hemiplegia do desenvolvimento típico, combinando um escore HINE total < 63 e um escore de assimetria > 5 foram 91,8 e 100\%, respectivamente (HAY et al., 2018). 
De acordo com Romeo et al. 2008, os bebês com PC hemiplégica, costumam ter escores HINE acima dos limiares de normalização para o distúrbio, dificultando a diferenciação de bebês com desenvolvimento típico ou atrasos leves em idades precoces. Por isso, acredita-se que o uso de um escore de assimetria associado com o escore do HINE seria útil para diferenciar formas mais leves de PC daqueles sem PC, em um acompanhamento clínico. Além disso, o escore de assimetria também pode fornecer uma categorização útil das características topográficas da PC na infância (HAY et al., 2018).

Mais um estudo sobre a confiabilidade do HINE para a predição de alterações neurológicas em prematuros está em andamento no Abha Private Hospital - Arábia Saldita, pelos estudiosos Ameen, Fleifel e Abdelghani (2020). Este estudo pretende comparar o HINE, em termos de sensibilidade para predição precoce para a síndrome neurológica tardia, com a ressonância magnética, que ainda hoje é considerado padrão ouro para diagnóstico de alterações neurológicas. Este projeto tem como título "Reliability of Hammersmith Examination in Prediction of Neurological Outcomes In Preterm Infants - Observational Study (REHAPENO)", porém, os resultados preliminares ainda não foram publicados.

\section{Correlação HNNE/HINE com outros instrumentos}

Ao correlacionar os escores alcançados pelos instrumentos AIMS e HINE, encontrouse uma correlação moderada $(\mathrm{p}=0,525$ - 0,664) entre as avaliações trimestrais correspondentes dos 3 aos 9 meses e uma correlação forte aos 12 meses $(\mathrm{p}=0,751)$. Vale ressaltar que estes instrumentos não avaliam os mesmos componentes diretos, sendo um específico para as condições motoras (AIMS) e o outro para as condições neurológicas (HINE). Entretanto, as manifestações motoras são resultantes do funcionamento e desenvolvimento adequado do SNC.

O presente estudo demonstrou correlações negativas entre os instrumentos HINE e AIMS e o diagnóstico via imagem, expressando que se o escore de ambas avaliações aumentam, a chance de diagnóstico de PC diminui. As correlações aumentam em detrimento do aumento da idade.

Em pacientes com encefalopatia hipóxica-isquêmica, a combinação do HINE com a RM ajuda a fornecer informações prognósticas mais precisas do que ferramentas individuais (FRISONE et al., 2002; RICCI et al., 2006).

Crianças com alterações precoces e graves de PC, evidenciada pelo HINE associado ao exame de imagem, foram relacionados com lesões posteriores ao trígono e raramente a lesões 
anteriores ao trígono. A imagem colaborou com a verificação de que a variabilidade dos escores do HINE se relacionam com o local das lesões (RICCI et al. 2006).

Exames de RM neonatal normal ou lesões moderadas da substância branca com desempenho motor normal foram associadas a escore HINE ótimos (>73) que não evoluíram para PC. Enquanto, lesões graves nos gânglios da base foram associadas a escores sub-ótimos do HINE (<40) com desenvolvimento de PC grave. Nas crianças com lesões mínimas e moderadas nos gânglios da base, o HINE ajudou a distinguir entre aqueles com escores ótimos e resultado normal, e outros com escores abaixo do ideal que geralmente apresentavam comprometimento motor (75\%) - sentam-se independentemente, mas não andam. Em bebês com lesões graves na substância branca, sem envolvimento dos gânglios da base, o HINE realizado a partir de 6 meses ajudou a identificar aqueles com comprometimento motor moderado. Foi encontrado resultados falso-negativos no HINE por volta dos 3 meses de idade. No período neonatal foi encontrado sinais óbvios de comprometimento neurológico com hipotonia axial e de membros, sendo que o tônus se normalizou após 5 a 6 semanas e ao longo dos primeiros meses, mas que aumentaram a partir dos 6 meses. Todos esses bebês desenvolveram PC, apesar de todos terem conseguido sentar-se sem apoio aos 2 anos e, em alguns casos, também andar com apoio (FRISONE, et al., 2002; RICCI et al., 2006).

Em outro estudo retrospectivo, os pesquisadores associaram o HINE a dois exames (Método de Prechtl de avaliação qualitativa de movimentos generalizados - GMs e US) para avaliar a precisão do prognóstico de 903 RN prematuros. Aos 2 anos de idade, os bebês foram reavaliados e os autores concluíram que a integração dos dois métodos mostrou ser mais eficaz do que as avaliações individuais para prever o prognóstico neurológico. A combinação dos dois instrumentos permitiu ainda descriminar a topografia da PC entre unilateral, bilateral e diplégica. Neste estudo, o US teve a menor correlação com a PC em comparação com os outros dois instrumentos (ROMEO et al., 2008).

Concordando com o estudo citado anteriormente, Romeo et al. (2016) relatam que a combinação do HINE com o GMs é mais útil na predição precoce da PC ao avaliar o desenvolvimento neurológico de prematuros do que em qualquer uma das duas avaliações isoladamente.

\subsection{Conclusão}

O diagnóstico de PC baseia-se na observação de muitos sinais clínicos e neurológicos e ocorre geralmente entre 12 e 24 meses. Antes dessa idade a PC ainda é vista no Brasil como 
um período oculto ou silencioso que não pode ser totalmente definido. Porém, esta tese apresenta dados científicos sobre diagnóstico de PC precisamente antes dos 6 meses corrigidos. O diagnóstico precoce, favorece o encaminhamento do paciente para a estimulação precoce, minimizando os efeitos das alterações neurológicas.

Em relação ao HNNE, a literatura aponta como um instrumento de excelente utilidade clínica sendo recomendado como avaliação de escolha quando os médicos necessitam de uma avaliação discriminativa e preditiva mais curta, que não necessita de treinamento formal (WUSTHOFF, 2013; NOBLE, BOYD, 2012; EL-DIB, 2011). Também é consenso entre os pesquisadores, que o HINE é preditivo para bebês entre 3 e 14 meses de idade com paralisia cerebral (FRISONE et al., 2002; ROMEO et al., 2008; HAATAJA et al., 2001). O HINE apresenta sensibilidade de $90 \%$ e sua confiabilidade é válida.

Nossos resultados mostraram que tanto o HNNE quanto o HINE são preditivos para alteração motora comprovadas por exame de imagem e por manifestações neurológicas clínicas, apesar do N ser pequeno nesta última análise. Sugere-se um estudo para normatizar os escores para população brasileira de alto e baixo risco.

Espera-se com este estudo, incentivar avaliações precoces de bebês de alto risco, sugerindo que estes instrumentos sejam incorporados às clínicas de acompanhamento neonatal do Brasil. Ambos os instrumentos são acessíveis, de fácil aplicabilidade e possuem um tempo de aplicação entre 5 a 15 minutos, e são, a partir de agora, validados e adaptados para a população brasileira propondo linguagem comum no processo de acompanhamento. 


\section{REFERÊNCIAS BIBLIOGRÁFICAS ${ }^{1}$}

ACPR Group. Australian Cerebral Palsy Register Report. Sydney: Cerebral Palsy Alliance, 2013.

ACPR Group. Report of the Australian Cerebral Palsy Register, Birth Years 1993-2009, September 2016. https: //www.cpregister.com/pubs/pdf/ACPR-Report_Web_2016.pdf. Accessed 2019.

ALEXANDRE, N. M. C.; COLUCI, M. Z. O Validade de conteúdo nos processos de construção e adaptação de instrumentos de medidas. Ciência \& Saúde Coletiva, Rio de Janeiro, v. 16, n. 7, p. 3061-3068, 2011

AMANO, D.; MAZZITELLI, C.; DURIGON, O. F. S. Eficiência dos procedimentos de movimentação passiva na estimulação precoce de crianças prematuras normais. Rev. fisioter. Univ. São Paulo, v., 8, p. 108-108, 2001.

AMESS et al. Early prediction of neurological outcome by term neurological examination and cranial ultrasound in very preterm infants. Acta Pædiatrica. v. 98, p. 448-53, 2009.

ARMSTRONG, B.K.; WHITE, E.; SARACCI, R. Principles of exposure measurement in epidemiology. New York, Tojio, Oxford University Press, Oxford, 1994.

ARNAUD, C. et al. Parent-reported quality of life of children with cerebral palsy in Europe. Pediatrics, v. 121, p. 54-64, 2008

BADAWI, N. et al. Cerebral palsy following term newborn encephalopathy: a population-based study. Dev Med Child Neurol. V. 47, p. 293-298, 2005.

BADIA, X.; ALONSO, J. Re-scaling the Spanish version of the Sickness Impact Profi le: an opportunity for the assessment of cross-cultural equivalence. J Clin Epidemiol. V. 48, n. 7, p. 949-57, 1995.

BAIRD, G.; MCCONACHIE, H.; SCRUTTON, D. Parents' perceptions of disclosure of the diagnosis of cerebral palsy. Arch Dis Child. V. 83, p. 475-480, 2000.

BAX, M. et al. Proposed definition and classification of cerebral palsy, Developmental Medicine and Child Neurology, v. 47, p. 571-576, 2005.

BEATON, D. E.; et al. Guidelines for the process of cross-cultural adaptation of self-report measures. SPINE, V. 25, n.24, p. 3186-3191, 2000.

BEATON, D. et al. Recommendations for the cross-cultural adaptation of the DASH \& QuickDASH outcome measures. Institute for Work \& Health, v. 1, n. 1, p. 1-45, 2007.

BLAND, J. M.; ALTMAN, D. G. Cronbach’s alpha. British Medical Journal. p. 314-572. 1997. BODEAU-LIVINEC, F. et al. Do very preterm twins and singletons differ in their neurodevelopment at 5 years of age? Archives of Disease in Childhood - Fetal and Neonatal Edition v. 98, p. 480-487, 2013. 
BORSA, J.C.; DAMASIO, B.F.; BANDEIRA, D.R. Adaptação e validação de instrumentos psicológicos entre culturas: algumas considerações. Paidéia, v.22, n.53, p.423-432, 2012.

BOSANQUET, M. et al. A systematic review of tests to predict cerebral palsy in young children. Dev Med Child Neurol. V. 55, p. 418-426, 2013.

BRANDÃO, J. S. Tratamento precoce na paralisia cerebral. In: Lianza S. Medicina de reabilitação. Rio de Janeiro: Guanabara Koogan; 1985. p.241-65.

BRASIL. Conselho Nacional de Saúde. Resolução n 466, de 12 de dezembro de 2012. Aprova normas regulamentadoras de pesquisas envolvendo seres humanos. Brasília: Diário Oficial da União, 2012.

BRASIL. Ministério da Saúde. Secretaria de Atenção à Saúde. Departamento de Ações Programáticas Estratégicas. Diretrizes de atenção à pessoa com paralisia cerebral - Brasília: Ministério da Saúde, 2013. 80 p.

BRISLIN, R. The Wording and Translation of Research Instruments. In: Lonner, J.W.; Berry, J.W. (eds.) Field Methods in Cross-Cultural Research, Beverly Hill, Sage, 1986.

BROGREN, E.; FORSSBERG, H.; HADDERS-ALGRA. Postural control in sitting children with cerebral palsy. Neuroscience and Biobehavioral Reviews. V.22, p. 591-596, 1998.

BROWN, N. C.; DOYLE, L. W.; BEAR, M. J.; INDER, T. E. Alterations in neurobehavior at term reflect differing perinatal exposures in very preterm infants. Pediatrics, v. 118, p. 24612471, 2006.

CAPUTE A. J. et al. Motor functions associated primitive refflex profiles. Dev Med Child Neurol. v. 24, p. 662-9, 1982.

CAPUTE A. J. et al. Primitive reflex profile. Phys Ther, v. 58, p. 1061-5, 1978.

CHATZIIOANNIDIS, I.; et al. Neurological outcome at 6- and 12-months corrected age in hospitalised late preterm infants -a prospective study. Eur J Paediatr Neurol. V. 22; n. 4; p. 602$609,2018$.

CHEONG, J. L. Y.; DOYLE, L. W. Increasing rates of prematurity and epidemiology of late preterm birth. Journal of Paediatrics and Child Health, v. 48, p. 784-788, 2012.

CIONI G. et al. Comparison between observation of spontaneous movements and neurologic examination in preterm infants. J Pediatr v. 130, p. 704- 11, 1997.

CORTINA, J. M. What is coefficient alpha? An examination of theory and applications. Journal of Applied Psychology V. 78, p. 98-104, 1993.

COSTER, W. J.; MANCINI, M. C. Recomendações para a tradução e adaptação. Revista de Terapia Ocupacional da Universidade de São Paulo, São Paulo, v. 26, n. 1, p. 50-7, 2015.

CRONBACH, L. J. Coefficient Alpha and the Internal Structure of Tests. Psychometrika V.16, p. 297-334, 1951. 
CRONBACH, L. J.; GLESER, G. C.; NANDA, H.; RAJARATNAM, N. The dependability of behavioral measurements: Theory for generalizability of scores and profiles. New York: John Wiley. 1972.

CRONBACH, L. J.; MEEHL, P. E. Construct validity in psychological tests. Psychological Bulletin, v. 52 n. 4, p. 281-302, 1955. Disponível em: 〈http://dx.doi.org/10.1037/h0040957〉.

CUNHA, A. B.; POLIDO, G. J.; BELlA, G. P.; GARBELlinI, D.; FORNASARI, A.C., Relação entre o alinhamento postural e desempenho motor em crianças com paralisia cerebral. Revista Fisioterapia e Pesquisa, v. 16, n. 1, p. 22- 27, 2009.

DAUM, C. et al. Interobserver agrément and validity of bedside "positive signs "e for functional weakness, sensory and gait disorders in conversion disorder; a pilot study. J Neurol Neurosurg Psychiatry, n. 56, p. 425-430, 2015.

DelONG, E. R.; DeLONG, D. M.; CLARKE-PEARSON, D. L. Comparing the areas under two or more correlated receiver operating characteristic curves: a nonparametric approach. Biometrics v. 44, p. 837-845, 1988.

DIAMENT, A. J.; CYPEL, S.; REED, U. C. Neurologia Infantil. 5a edição. São Paulo, SP: Atheneu, 2010.

DUBOWITZ L, DUBOWITZ V, MERCURI E. The neurological assessment of the preterm and full-term infant. Clinics in Developmental Medicine, Vol. 148. London: McKeith Press. 1999.

DUBOWITZ L, MERCURI E, DUBOWITZ V. An optimality score for the neurological examination of the term newborn. Disabil Rehabil v. 133, p. 406-416, 1998.

DUBOWITZ, L. M. S.; A. et al. Neurologic signs in neonatal intraventricular hemorrhage: a correlation with real-time ultrasound. J Pediatr. V. 99, n. 1, p. 127-33, 1981.

DUBOWITZ, L. M. S.; DUBOWITZ, V. The Neurological assessment of preterm and full-term newborn infant. Clin Dev Med, v. 79, n. 1, p. 103-8, 1981

DUBOWITZ, L. M. S.; et al. Correlation of neurologic assessment in the preterm newborn infant with outcome at 1 year. J Pediatr. V. 105, p. 452-6, 1984.

DUBOWITZ, L.; RICCI, D.; MERCURI, E. The Dubowitz Neurological Examination of the Full-Term Newborn. Mental Retardation and Developmental Disabilities Research Reviews, V.11, p. 52-60, 2005.

EELES A. et al. Reliability of neurobehavioral assessments from birth to term equivalent age in preterm and term born infants. Phys Occup Ther Pedi. V. 37; p. 108-19, 2017.

EINSPIELER, C. et al. Prechtl's method on the qualitative assessment of general movements in preterm, term and young infants. Clinics in developmental medicine. London: Mac Keith Press, 2004. 
EINSPIELER, C. et al. The early markers for later dyskinetic cerebral palsy are different from those for spastic cerebral palsy. Neuropediatrics, v. 33, p. 73- 8, 2002.

EL-DIB, M. Neurodevelopmental assessment of the newborn: An opportunity for prediction of outcome. Brain Dev, v. 33, p. 95-105, 2011.

ELIASSON A, et al. Mini-MACS: development of the Manual Ability Classification System for children younger than 4 years of age with signs of cerebral palsy. Dev Med Child Neurol. V. 59, n. 1, p. 72-8, 2016.

ELLENBERG, J. H.; NELSON, K. B. Cluster of perinatal events identifying infants at high risk for death or disability. J Pediatr V. 113, p. 546-552, 1988.

EPSTEIN; J., SANTO, M. R.; GUILLEMIN, F. A review of guidelines for cross-cultural adaptation of questionnaires could not bring out a consensus. J Clin Epidemiol. V. 68, n. 4, p. 435-42, 2015.

EREMENCO S. L., CELLA D., ARNOLD B. J., A comprehensive method for the translation and cross-cultural validation of health status questionnaires. Eval Health Prof, v. 28, n. 2, p. 212-32, 2005.

FELICE, T. M. N.; SANTOS, J. L. F.; PFEIFER, L. I. Estudo retrospectivo de fatores de risco materno, pré e perinatal para paralisia cerebral na rede pública de saúde / Retrospective study of maternal, gestational and labor risk factors for cerebral palsy in the public health system. Medicina (Ribeiräo Preto) v. 52, n. 3, jul.-set. 2019.

FERRARI, F. et al. Cramped synchronized general movements in preterm infants as an early marker for cerebral palsy. Arch Pediatr Adolesc Med, v.156, p. 460-7, 2002.

FERRER, M. et al. Validity and reability of the St George's respiratory Questionnaire after adaptation to a different language and culture: the Spanish example. European Respiratory Journal. v. 9, n. 6, p. 1160-6, 1996.

FIGUEIREDO, H. B. Diagnóstico precoce da paralisia cerebral. In: Fontes JAS. Assistência materno-infantil. Rio de Janeiro: Cultura Médica; 1984

FITZNER, K. Reliability and validity. Diabetes Education Journal, v. 33, n. 5, p. 775-780, 2007.

FLAHERTY, J. A. Appropriate and Inappropriate Research Methodologies for Hispanic Mental Health. In: Gaviria, M. (ed.) Health and Behavior: Research Agenda for Hispanics. Chicago, University of Illinois Press, 1987.

FLAHERTY, J. A. et al. Developing Instruments for Cross-cultural Psychiatry Research. Jounal of Nervous and Mental Diseases. V. 176, p. 257-263, 1988.

FLAHERTY, J.A. Appropriate and Inappropriate Research Methodologies for Hispanic Mental Health. In: Gaviria, M. (ed.) Health and Behavior: Research Agenda for Hispanics. Chicago, University of Illinois Press, 1987. 
FLAHERTY, J.A. et al. Developing Instruments for Cross-cultural Psychiatry Research. Jounal of Nervous and Mental Diseases. V. 176, p. 257-263, 1988.

FLEHMIG, I. Atlas do Desenvolvimento Normal e seus Desvios no Lactente: Diagnóstico e Tratamento Precoce do Nascimento até o $18^{\circ}$ mês. $1^{\text {a }}$ edição. São Paulo, SP: Atheneu, 2005.

FONSECA, L. F. Abordagem Neurológica da Criança com Paralisia Cerebral: causas e exames complementares. In: LIMA, C. L. A; FONSECA, L F. Paralisia Cerebral: neurologia, ortopedia e reabilitação. Rio de Janeiro: Guanabara Koogan, 2 004. p. 45-66

FORMIGA, C. K. M. R., PEDRAZZANI, E. S., TUDELLA, E. Intervenção precoce com bebês de risco. São Paulo: Ed. Atheneu. 2010

FRISONE, M. F. et al. Prognostic value of the neurologic optimality score at 9 and 18 months in preterm infants born before 31 weeks' gestation. J Pediatr V. 140, n. 1, p. 57-60, 2002.

FUNAYAMA, A. R. C. Exame Neurológico em crianças. Medicina, Ribeirão Preto, v. 29, p. 32-43, 1996.

GARCIA P. A. et al. Influência de fatores de risco no desenvolvimento neuromotor de lactentes pré-termo no primeiro ano de vida. Revista Movimenta. V. 4, n. 2, 2011.

GOMES, C. et. al. Paralisia Cerebral. In: LIANZA, S. Medicina de reabilitação. $3^{\text {a }}$ ed., Rio de Janeiro: Guanabara/Koogan, 2001, p.281-282.

GORTER, J. W. et al. Use of the GMFCS in infants with CP: the need for reclassification at age 2 years or older. Dev Med Child Neurol. V.51, p. 46-52, 2008.

GRANILD-JENSEN, J. B.; RACKAUSKAITE, G.; FLACHS, E. M.; ULDALL, P. Predictors for early diagnosis of cerebral palsy from national registry data. Dev Med Child Neurol. V. 57, n 10, p. 931-935, 2015.

GRANTHAM-MCGREGOR, S.; et al. International Child Development Steering Group. Child development in developing countries 1: Developmental potential in the first 5 years for children in developing countries. Lancet. V. 369, p. 60-70, 2007.

GUDMUNDSSON, E. Guidelines for translating and adapting psychological instruments. Nordic Psychology, v.61, n.2, p. 29-45, 2009.

GUILLEMIN, F.; BOMBARDIER, C.; BEATON, D. Cross-cultural adaptation of healthrelated quality of life measures: literature review and proposed guidelines. J Clin Epidemiol, v. 46, n. 12, p. $1417-32,1993$.

HAATAJA, L. et al. Application of a scorable neurologic examination in healthy term infants aged 3 to 8 months. J Pediatr v. 143, p. 546, 2003.

HAATAJA, L. et al. Neurologic examination in infants with hypoxic-ischemic encephalopathy at age 9 to 14 months: use of optimality scores and correlation with magnetic resonance imaging findings. J Pediatr v.138, p. 332-7, 2001. 
HAATAJA, L. et al. Optimality score for the neurologic examination of the infant at 12 and 18 months of age. J Pediatr v. 135, p.153-61, 1999.

HAGGLUND, G. et al. Prevention of dislocation of the hip in children with cerebral palsy. The first ten years of a population-based prevention programme. J Bone Joint Surg Br v. 87, p. 95-101, 2005.

HAGMANN, C. F. et al. Neonatal neurological examination in well newborn term Ugandan infants. Early Hum Dev. V. 91, n. 12, p. 739-49.

HALPERN, R. et al. Fatores de Risco para Suspeita de Atraso no Desenvolvimento Neuropsicomotor aos 12 meses de Vida. Jornal de Pediatria, v. 76, n. 6, p. 421-428. 2000.

HALPERN, R.; FIGUEIRAS, A.C.M. Influências ambientais na saúde mental da criança. Jornal de Pediatria, v. 80, n. 2, Porto Alegre, 2004.

HAMBLETON, R.K. Issues, designs, and technical guidelines for adapting tests into multiple languages and cultures. In R. K. Hambleton, P. F. Merenda, \& C. D. Spielberger (Eds.), Adapting educational and psychological tests for cross-cultural assessment. Mahwah, NJ: Lawrence Erlbaum, p.3-38, 2005.

HAY, K. et al. Hammersmith Infant Neurological Examination asymmetry score detects hemiplegic Cerebral Palsy from typical development. Pediatric Neurology; v. 87, p. 70-74, 2018.

HAYES, B. E. Measuring Customer Satisfaction: Survey design, use, and statistical analysis methods. Milwaukee, Wisconsin: ASQC Quality Press, 1998.

HEINEMAN, K. R. et al. Reliability and concurrent validity of the Infant Motor Profile. Developmental Medicine \& Child Neurology, v. 55, p. 539-545, 2013.

HERDMAN, M.; FOX-RUSHBY, J.; BADIA X. "Equivalence" and the translation and adaptation of health-related quality of life questionnaires. Qual Life Res. Vol. 6, n. 3, p. 23747, 1997.

HIEU, N. T. et al. Neurological status of low-risk vietnamese newborns: a comparison with a british newborn cohort. J Health Popul Nutr. V. 24, n. 1, p. 57-63, 2006.

HIMMELMANN, K. et al. Gross and fine motor function and accompanying impairments in cerebral palsy. Dev Med Child Neurol v. 48, p. 417-423, 2006.

HIMMELMANN, K.; HAGBERG, G.; UVEBRANT, P. The changing panorama of cerebral palsy in Sweden. X. Prevalence and origin in the birth-year period 1999-2002. Acta Paediatr v. 99, p.1337-1343, 2010.

HIMMELMANN, K.; UVEBRANT, P. Function and neuroimaging in cerebral palsy: a population-based study. Dev Med Child Neurol v. 53, p. 516-521, 2011. 
HIRATUKA, E.; MATSUKURA, T. S.; PFEIFER, L. I. Adaptação transcultural para o Brasil do Sistema de Classificação da Função Motora Grossa (GMFCS). Revista Brasileira de Fisioterapia, São Paulo, v. 14, p. 537-544, 2010.

HUBERMANN, L.; BOYCHUCK, Z.; SHEVELL, M.; MAJNEMER, A. Age at referral of children for initial diagnosis of cerebral palsy and rehabilitation: current practices. $J$ Child Neurol. V. 31, n. 3, p. 364-369, 2016.

HUNT, S. M., et al. Cross-cultural adaptation of health measures. European Group for health management and quality of life assessment. Health Policy, vol. 19, n. 1, p. 33-44, 1991.

INTERNATIONAL TEST COMMISSION. International Test Commission guidelines for translating and adapting tests. 2010 Recuperado em 2 de junho 2013, de http://www.intestcom.org/upload/sitefi les/40.pdf

JAHNSEN, R. et al. Musculoskeletal pain in adults with cerebral palsy compared with the general population. J Rehabil Med v. 36, p. 78-84, 2004.

JIA, X. et al. G. Reproducibility and reliability of the snyder classification of superior labral anterior posterior lesions among shoulder surgeons. Am J. Sports Med, v. 39, p. 986-991, 2011.

JOHANSSON, S. et al. Risk of high blood pressure among young men increases with the degree of immaturity at birth. Journal of American Heart Association. V. 112, p. 3430-6, 2005.

JORGE, M.R. Adaptação Cultural de Instrumentos de Pesquisa em Saúde Mental. In: C.Gorenstein, L.H.S.G.Andrade. A.W.Zuardi (Ed.) Escalas de Avaliação Clínica em Psiquiatria e Psicofarmacologia. São Paulo, Lemos Editorial, p. 53-58, 2000.

KAARESEN, P. I. et al. A randomized controlled trial of an early intervention program in low birth weight children: outcome at 2 years. Early Human Development, v. 84, p. 201-209, 2008.

KATHERINE, T; RATLIFFE, M. A. Paralisia Cerebral. In: Fisioterapia na Clínica Pediátrica: guia para equipe de fisioterapeutas. São Paulo: Editora Santos, 2002. p. 163217.

KESZEI, A. P.; NOVAKA, M.; STREINER, D.L. Introduction to health measurement scales. Journal of Psychosomatic Research. v. 68, n. 4, p. 319-23, 2010.

KHANDAKER, G. et al. Bangladesh Cerebral Palsy Register (BCPR): a pilot study to develop a national cerebral palsy $(\mathrm{CP})$ register with surveillance of children for CP. BMC Neurol. v.15, p. 173, 2015.

KOK, F. As Principais Afecções em Neurologia Infantil - Encefalopatias Não Progressivas: deficiência mental e paralisia cerebral. In: NITRIN I, R; BACHESCHI, L. A. A Neurologia que todo Médico Deve Saber. 2.ed. São Paulo: Atheneu, 2003. 
KOLLER et al. The process of reconciliation: evaluation of guidelines for translating qualityof-life questionnaires. Expert Rev. Pharmacoecon. Outcomes Res. V. 12, n. 2, p. 189-197, 2012.

KRAGELOH-MANN, I.; HORBER, V. The role of magnetic resonance imaging in elucidating the pathogenesis of cerebral palsy: a systematic review. Dev Med Child Neurol v. 49, p. 144$151,2007$.

KRUS, D. J.; HELMSTADTER, G. C. The problem of negative reliabilities. Educational and Psychological Measurement. v. 53, p. 643-650. 1993.

LANDIS, J. R.; KOCH, G. G. The measurement of observer agreement for categorical data. Biometrics. V. 33, n. 1, p. 159-174, 1977.

LENT, R. Cem Bilhões de Neurônios: Conceitos Fundamentais de Neurociências. 2a edição. São Paulo, SP: Atheneu, 2010.

LEVITT S. Tratamiento de la paralisis cerebral y del retraso motor. Buenos Aires: Panamericana; 1982. p.14-27

LOPES, V.; MAIA, J. A. Períodos críticos ou sensíveis: revisitar um tema polêmico à luz da investigação empírica. Revista Paulista De Educação Física, v. 14, n. 2, p. 128-140, 2000.

LOWERY, J. P. et al. Pacific acuity test: testability, validity, and interobserver reliability. Optometry and Vision Science, v. 91, n. 1, p. 76-85, 2014.

MAITRE, N. L.; SLAUGHTER, J. C.; ASCHNER, J. L. Early prediction of cerebral palsy after neonatal intensive care using motor development trajectories in infancy. Early Hum Dev. V. 89, p. 781-786, 2013.

MANCINI, M. C. et al. Efeito moderador do risco social na relação entre risco biológico e desempenho funcional infantil. Rev Bras de Saúde Matern infant. v. 4, p. 2534, 2004.

MATAVA, M. J. et al. Multirater agreement of the causes of anterior cruciate ligament reconstruction failure: a radiographic and video analysis of the MARS cohort. Am J Sports Med, v. 43, n. 2, p. 310-319, 2015.

MCCONNELL, K.; JOHNSTON, L.; KERR, C. Upper limb function and deformity in cerebral palsy: a review of classification systems. Developmental Medicine \& Child Neurology, v. 53, p.799-805, 2011.

MCGREADY R, et al. Neonatal neurological testing in resource- poor settings. Ann Trop Paediatr v. 20, p. 323-336, 2000.

MCINTYRE, S. et al. Cerebral palsy-don't delay. Developmental Disabilities Research Reviews, v. 17, n. 2, p. 114-129, 2011.

MENEZES, P.R.; NASCIMENTO, A.F. Validade e confiabilidade das escalas de avaliação em psiquiatria. Escalas de Avaliação Clínica em Psiquiatria e Psicofarmacologia. Revista Brasileira de Psiquiatria, v. 26, n.1, p. 23-28, 2000. 
MERCURI E. et al. Neurological examination of preterm infants at term age: comparison with term infants. J Pediatr. V. 142, p. 647-55, 2003.

MERCURI, E. et al. Neonatal neurological examination in infants with hypoxic Ischaemic encephalopathy: correlation with MRI findings. Neuropediatrics. V. 30, P. 83-9, 1999.

MERCURI, E. et al. The neurological examination of the newborn baby. Early Human Development, v. 81, n. 12, p. 947-756, 2005.

MOKKINK, L. B. et al. The COSMIN checklist for assessing the methodological quality of studies on measurement properties of health status measurement instruments: an international Delphi study. Quality of Life Research v. 19, p. 539-549, 2010.

MOKKINK, L. B. et al. The COSMIN Manual. 2012. <Disponível em: http://www.cosmin.nl/images/upload/files/COSMIN\%20checklist\%20manual\%20v9.pdf>

Acessado em Outubro de 2015.

MOLNAR, G. E. Cerebral Palsy: prognosis and how to judge it. Pediatr Ann. V. 8, p. 596$605,1979$.

MORALES, N. M. O. et al. Psychometric properties of child health assessment questionnaire (CHAQ) applied to children and adolescents with cerebral palsy. Health and Quality of Life Outcomes. V. 6, n. 109, p. 1-10, 2008.

MORRIS, C. Definition and classification of cerebral palsy: a historical perspective. Dev Med Child Neurol Suppl. V. 109, P. 3-7, 2007.

NASCIMENTO, K. K. et al. Avaliação neurológica de recém-nascidos a termo de baixo risco pelo Método Dubowitz. Arquivos Brasileiros de Ciências da Saúde, v. 36, n. 3, p. 135-139, 2011.

NELSON, K. B. Causative factors in cerebral palsy. Clin Obstet Gynecol, v. 51, n. 4, p. 749$762,2008$.

NELSON, K. B.; ELLENBERG, J. H. Antecedents of cerebral palsy. Multivariate analysis of risk. N Engl J Med v. 315, p. 81-86, 1986.

NEWMAN, C. J, O'REGAN, M.; HENSEY, O. Sleep disorders in children with cerebral palsy. Dev Med Child Neurol v. 48, p. 564-568, 2006.

NOBLE, Y.; BOYD, R. Neonatal assessments for the preterm infant up to 4 months corrected age: a systematic review. Developmental Medicine \& Child Neurology, v. 54, p. 129-139, 2012.

NOVAK, I. et al. Early, Accurate Diagnosis and Early Intervention in Cerebral Palsy: Advances in Diagnosis and Treatment. JAMA Pediatr. v. 171, p.897-907, 2017.

NOVAK, I. Evidence-based diagnosis, health care, and rehabilitation for children with cerebral palsy. Journal of Child Neurology, V. 29, n. 8, p1141-1156, 2014. 
NOVAK, I.; HINES M.; GOLDSMITH, S.; BARCLAY, R. Clinical prognostic messages from a systematic review on cerebral palsy. Pediatrics, v. 130, n. 5, p. 1285-1312, 2012.

ODDING, E.; ROEBROECK, M. E.; STAM, H. J. The epidemiology of cerebral palsy: Incidence, impairments and risk factors. Disability and Rehabilitation. V. 28, n. 4, p. 183$191,2006$.

OHL, A. et al. T. Test-Retest Reliability of the Sensory Profile Caregiver Questionnaire. The American Journal of Occupational Therapy, Bethesda, v. 66, n. 4, 2012.

OLHWEILER, L.; SILVA, A. R.; ROTTA, N. T. Estudo dos reflexos primitivos em pacientes recém-nascidos pré-termo normais no primeiro ano de vida. Arquivo Neuropsiquiatria, v. 63, n. 2-A, p. 294-297, 2005.

OSKOUI, M.; COUTINHO, F.; DYKEMAN, J.; JETTE, N.; PRINGSHEIM, T. An update on the prevalence of cerebral palsy: a systematic review and meta-analysis. Dev Med Child Neurol. V. 55, n. 6, p. 509-519, 2013.

OSLER W. The Cerebral Palsies of Childhood. London: HK. Lewis, 1889.

PAKULA et al. Cerebral Palsy: Classification and Epidemiology. Physical Medicine and Rehabilitation Clinics of North America. N. 20, p. 425-452, 2009.

PALISANO R. et al. Gross Motor Function Classification System for cerebral palsy. Development Medicine and Child Neurology. V. 39, p. 214-223, 1997.

PALMER, P. G. et al. Neurological and neurobehavioral differences between preterm infants at term and full-term newborn infants. Neuropediatrics. v. 13, p. 183-9, 1982.

PAPALIA, D. E.; OLDS, S. W.; FELDMAN, R. D. Desenvolvimento Humano. $7^{\text {a }}$ edição. Porto Alegre, RS: Artmed, 2000.

PARKES, J. et al. Oromotor dysfunction and communication impairments in children with cerebral palsy: a register study. Dev Med Child Neurol v. 52, p. 1113-1119, 2010.

PARKES, J. et al. Psychological problems in children with cerebral palsy: a cross-sectional European study. J Child Psychol Psychiatry v. 49, p. 405-413, 2008.

PARMELEE, A. F. H.; MICHAELIS, M. D. Neurological examination of the newborn. In: Hellmuth J, editor. The exceptional infant. New York7 Brunner Mazel; p. 3- 23, 1971.

PASQUALI, L. Princípios de elaboração de escalas psicológicas. Revista de Psiquiatria Clínica, São Paulo, v. 25, n. 5, p. 206-213, 1998.

PASQUALI, L. Psicometria. Rev. esc. enferm. USP, São Paulo, v. 43, p. 992-999, Dec. 2009.

PASQUALI, L. Psicometria: teoria dos testes na psicologia e na educação. Petrópolis. Editora Vozes, 2003. 
PASQUALI, L. Técnicas de exame psicológico. TEP: Manual. São Paulo, Casa do Psicólogo, 2001.

PASQUALI, L. Testes referentes a construto: teoria e modelo de construção. In: PASQUALI, L., et. al. Instrumentação psicológica: fundamentos e práticas. Porto Alegre: Artmed, 2010. p. 165-198.

PATO, T. R. et. al. Epidemiologia da paralisia cerebral. Acta Fisiátrica, vol. 2, n. 9, p. 71-76, 2002.

PEDROSO, F. S.; ROTTA, N. T. Neurological examination in the healthy term newborn. Arq Neuropsiquiatr. V. 61, n. 2-A, p. 165-9, 2003.

PHAROAH, P. O. Risk of cerebral palsy in multiple pregnancies. Clin Perinatol v. 33, p. 301313, 2006.

PIPER, M. C.; DARRAH, J. Motor assesment of the developing infant. Philadelphia: W.B. Sounders Company, 1994.

PIZZARDI, A. et al. Infant neurological examination from 3 to 12 months: predictive value of the single items. Neuropediatrics. V. 39, p. 344-346, 2008.

PORTNEY, L. G.; WATKINS, M. P. Foundations of clinical research: applications to practice 3.ed. Upper Saddle River, NJ: Prentice Hall Health, 2008.

PRECHTL, H. F. R. et al. An early marker for neurological deficits after perinatal brain lesions. Lancet v. 349, p. 1361-3, 1997.

PRECHTL, H. F. R; DIJKSTRA, J. Neurological diagnosis of cerebral injury in the newborn. In: ten Berge BS, editor. Prenatal care. Groningen7 Noordhof; 1960.

RANGEL, V. O. et al. Validade de Confiabilidade do Childhood Health Assessment Questionaire (CHAQ) adaptado para crianças e adolescentes com Paralisia Cerebral. IN: VI Encontro Interno de Iniciação Científica/ $X$ Seminário de Iniciação CientíficaUniversidade Federal de Uberlândia, Uberlândia, 2006.

RATHKE, K. M.; SCHAUBLE, B.; FESSLER, A. J.; SO, E. L. Reliability of seizure semiology in patients with 2 seizure Foci. Arch Neurol, v. 68, n. 6, p. 778-775, 2011.

REICHENHEIM, M. E; MORAES, C. L. Operacionalização de adaptação cultural de instrumentos de aferição usados em epidemiologia. Rev Saúde Pública. Vol. 41, n. 4, p. 66573, 2007.

RICCI, D. et al. Neurological examination at 6 to 9 months in infants with cystic periventricular leukomalacia. Neuropediatrics v. 37, p. 247-52, 2006.

RICCI, D. et al. Neurological examination of preterm infants at term equivalent age. Early Human Development, v. 84, p. 751-761, 2008. 
RICCI, D. et al. Sequential neurological examinations in infants with neonatal encephalopathy and low apgar scores: relationship with brain MRI. Neuropediatrics v. 37, p. 148-53, 2006.

RICHARDSON, R. J. Pesquisa Social, Métodos e Técnicas. Ed. Atlas, $2^{\circ}$ Ed., São Paulo. 1989. ROIJEN, L. E. et al. Development of bladder control in children and adolescents with cerebral palsy. Dev Med Child Neurol v. 43, p. 103-107, 2001.

ROMEO, D. M. et al. Application of a scorable neurological examination to near-term infants: Longitudinal data. Neuropediatrics, v. 38, p. 233-238, 2007.

ROMEO, D. M. et al. Early psychomotor development of low-risk preterm infants: Influence of gestational age and gender. EJPN. V. 20, p. 518-523, 2016.

ROMEO, D. M. et al. Neonatal neurological examination during the first $6 \mathrm{~h}$ after birth. Early Hum Dev. V. 108, p. 41-44, 2017.

ROMEO, D. M. et al. Neurological assessment in infants discharged from a neonatal intensive care unit. Eur. J. Paediatr. Neurol. V. 17, p. 192-198, 2013.

ROMEO, D. M. M. et al. Early neurologic assessment in preterm-infants: integration of traditional neurologic examination and observation of general movements. Eur J Paediatr Neurol v. 12, p. 183-189, 2008.

ROMEO, D. M. M. et al. Neuromotor development in infants with cerebral palsy investigated by the Hammersmith infant neurological examination during the first year of age. Eur $\mathbf{J}$ Paediatr Neurol v. 12, p. 24-31, 2008.

ROMEO, D. M. M. et al. Prognostic value of a scorable neurological examination from 3 to 12 months post-term age in very preterm infants: A longitudinal study. Early Hum Dev. V. 85, p. 405-8, 2009.

ROMEO, D. M.; RICCI, D.; BROGNA, C.; MERCURI, E. Use of the Hammersmith Infant Neurological Examination in infants with cerebral palsy: A critical review of the literature. Dev. Med. Child Neurol. V. 58, p. 240-245, 2016.

ROSENBAUM, P. et al. A report: the definition and classification of cerebral palsy. Developmental Medicine \& Child Neurology, London, v.49, n.6, p.8-14, 2007.

ROTTA, N.T. Paralisia Cerebral, novas perspectivas terapêuticas. Jornal de Pediatria, v. 78 (Supl.1): S48-S54, 2002.

SCHEFF, T.S. Is Accurate Cross-cultural Translation Possible? Current Anthropology, v.28 p.365. 1987.

SEME-CIGLENECKI, P. Predictive Value of Assessment of General Movements for Neurological Development of High-Risk Preterm Infants: Comparative Study. Croat Med J v. 44, p. 721-727, 2003.

SHEPHERD, R. B. Fisioterapia em Pediatria. $3^{\text {a }}$ edição. São Paulo, SP: Santos, 1996. 
SHEVELL, M. I.; DAGENAIS, L.; HALL, N. Comorbidities in cerebral palsy and their relationship to neurologic subtype and GMFCS level. Neurology v. 72, p. 2090-2096, 2009.

SHUMWAY-COOK, A.; WOOLLACOTT, M. H. Motor Control: Theory and Practical Applications. $2^{a}$ edição. Philadelphia, USA: Lippincott Williams \& Wilkins, 2001.

SIGURDARDOTTIR, S.; VIK, T. Speech, expressive language, and verbal cognition of preschool children with cerebral palsy in Iceland. Dev Med Child Neurol v. 53, p. 74-80, 2011.

SOO B. et al. Hip displacement in cerebral palsy. J Bone Joint Surg Am v. 88, p. 121-129, 2006.

SPALLICCI, M. D. B. et al. Estudo de algumas variáveis maternas relacionadas com a prematuridade no hospital universitário da Universidade de São Paulo. Rev. Med. HU-USP v. 10, p. 19-23, 2000.

SPITTLE, A. J. et al. Early developmental intervention programs post hospital discharge to prevent motor and cognitive impairments in preterm infants. Cochrane Database Syst Rev, v. 24 , n. 11, 2015

SPITTLE, A. J.; DOYLE, L. W.; BOYD, R. N. A systematic review of the clinimetric properties of neuromotor assessments for preterm infants during the first year of life. Developmental Medicine and Child Neurology, V. 50, P. 254-266, 2008.

STREINER, D. L. Being inconsistent about consistency: when coefficient alpha does and doesn’t matter. Journal of Personality Assessment. v. 80, p. 217-222. 2003.

STREINER, D. L.; NORMAN, G. R. Health measurement scales. A practical guide to their development and use. 4 ed. New York: Oxford University Press; 2008.

TANZER, N. K. Developing tests for use in multiple languages and cultures: A plea for simultaneous development. In: Hambleton RK, Merenda PF, Spielberger CD, editors. Adapting educational and psychological tests for cross-cultural assessment. Mahwah: Lawrence. Erlbaum; 2005. p. 235-64.

TERWEE, C. B. et al. Quality criteria were proposed for measurement properties of health status questionnaires. Journal of Clinical Epidemiology. v. 60, n. 1, p. 34-42, 2007.

URBINA, S. Fundamentos da testagem psicológica. Porto Alegre: Artmed, 2007. Scientific Advisory Committee of the Medical Outcomes Trust - SAC Instrument Review Criteria, p. 3:4, 1995.

VASTA, I.; KINALI, M.; MESSINA, S. et al. Can clinical signs identify newborns with neuromuscular disorders? J Pediatr, v. 146, p. 73-9, 2005.

VIEIRA, M. E. B.; RIBEIRO, F. V.; FORMIGA, C. K. M. R. Principais instrumentos de avaliação do desenvolvimento da criança de zero a dois anos de idade. Rev Movimenta. V. 2, n. 1, p. 23-31, 2009. 
WALTZ, C. F.; STRICKLAND, O. L.; LENZ, E. R. Measurement in nursing research. 2.ed. Philadelphia: Davis Company, 2005. p. 161-94.

WATSON, L.; BLAIR, E.; STANLEY F. Report of the Western Australian Cerebral Palsy Register to birth year 1999. West Perth, Australia: Telethon Institute for Child Health Research. 2006.

WILD, D. et al. Principles of good practice for the translation and cultural adaptation process for patient-reported outcomes (PRO) measures: report of the ISPOR task force for translation and cultural adaptation. Value Health, v.8, n.2, p. 94-104, 2005.

WONG, C. K. Interrrater reliability of the Berg Balance Scale when used by clinicians of various exprience levels to assess people with lower limb amputations. Phys Ther, v. 94, p. 371-378, 2014.

WOODWARD, L. J. et al. Can neurobehavioral examination predict the presence of cerebral injury in the very low birthweight infant? Journal of Developmental \& Behavioral Pediatrics, v.25, p. 326-334, 2004.

WOOLLACOTT, M. H.; SHUMWAY-COOK, A. Postural dysfunction during standing and walking in children with cerebral palsy: what are the underlying problems and what new therapies might improve balance? Neural Plast. V. 12, n. 2-3, p. 211-272, 2005.

WU YW, et al. Cerebral palsy in a term population: risk factors and neuroimaging findings. Pediatrics v. 118, p. 690-697, 2006.

WUSTHOFF, C. How to use: the neonatal neurological examination. Archives of Disease in Childhood, Education and Practice Edition, v. 98, p. 148-153, 2013. 


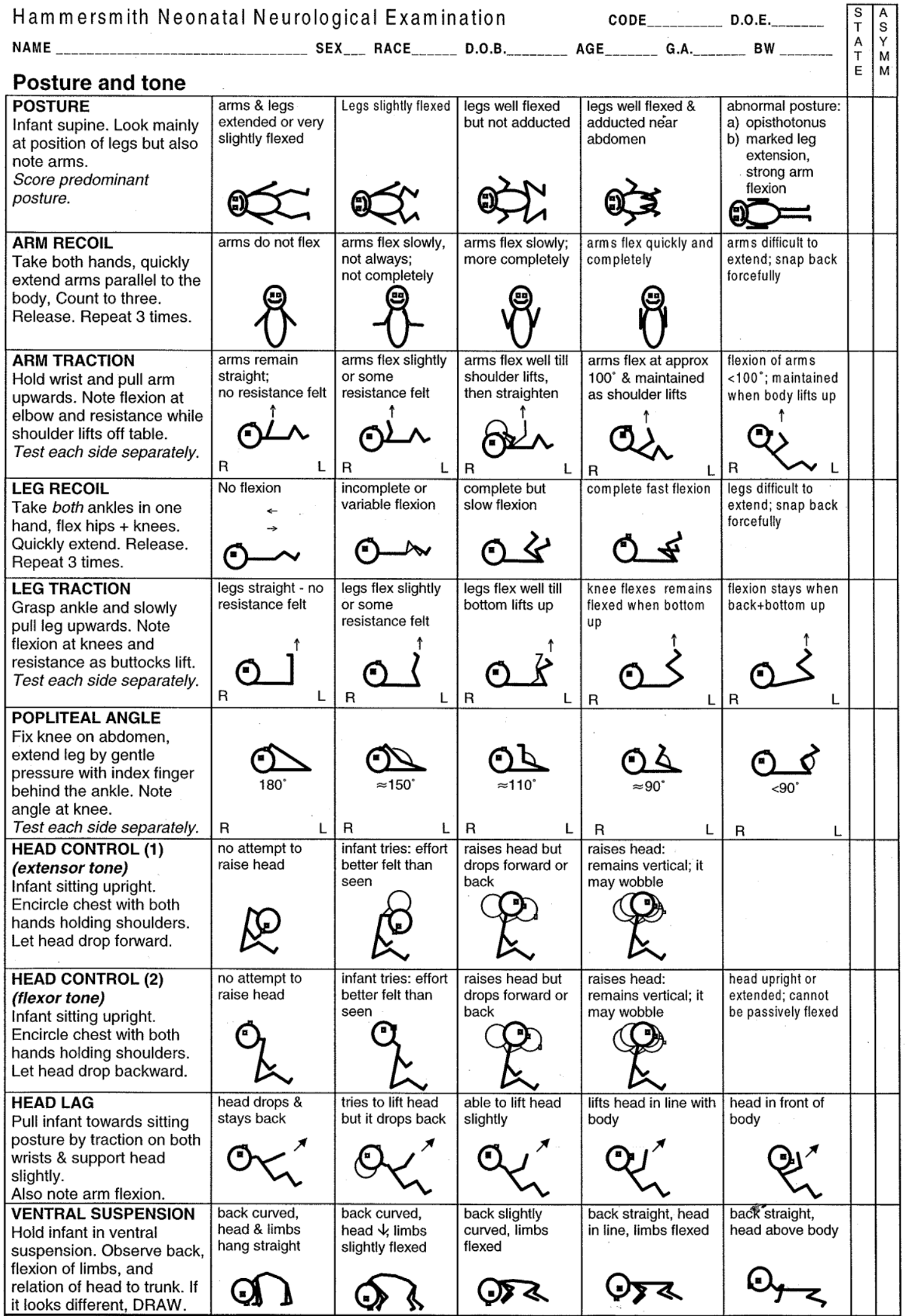


Tone patterns

\begin{tabular}{|c|c|c|c|c|}
\hline $\begin{array}{l}\text { FLEXOR TONE (1) } \\
\text { (on traction: arm versus leg) } \\
\text { Compare scores of arm } \\
\text { traction with leg traction. }\end{array}$ & $\begin{array}{l}\text { score for arm } \\
\text { flexion less than } \\
\text { leg flexion }\end{array}$ & $\begin{array}{l}\text { score for arm } \\
\text { flexion equal to } \\
\text { leg flexion }\end{array}$ & $\begin{array}{l}\text { score for arm flexion } \\
\text { more than leg flexion } \\
\text { but difference } 1 \\
\text { column or less } \\
\end{array}$ & $\begin{array}{l}\text { score for arm flexion } \\
\text { more than leg flexion } \\
\text { but difference more } \\
\text { than } 1 \text { column } \\
\end{array}$ \\
\hline $\begin{array}{l}\text { FLEXOR TONE (2) } \\
\text { (arm versus leg) } \\
\text { Posture in supine. }\end{array}$ & & $\begin{array}{l}\text { arms and legs } \\
\text { flexed }\end{array}$ & $\begin{array}{l}\text { strong arm flexion } \\
\text { with strong leg } \\
\text { extension } \\
\text { intermittent } \\
\end{array}$ & $\begin{array}{l}\text { strong arm flexion } \\
\text { with strong leg } \\
\text { extension } \\
\text { continuous } \\
\end{array}$ \\
\hline $\begin{array}{l}\text { LEG EXTENSOR TONE } \\
\text { Compare scores of leg } \\
\text { traction and popliteal angle. }\end{array}$ & $\begin{array}{l}\text { score for leg traction } \\
\text { more than score for } \\
\text { popliteal angle }\end{array}$ & $\begin{array}{l}\text { score for leg traction } \\
\text { equal to score for } \\
\text { popliteal angle }\end{array}$ & $\begin{array}{l}\text { score for leg traction } \\
\text { less than score for } \\
\text { popliteal angle, by } \\
1 \text { column only } \\
\end{array}$ & $\begin{array}{l}\text { score for leg traction } \\
\text { less than score for } \\
\text { popliteal angle, by } \\
\text { more than } 1 \text { column } \\
\end{array}$ \\
\hline $\begin{array}{l}\text { NECK EXTENSOR TONE } \\
\text { (SITTING) } \\
\text { Compare scores of head } \\
\text { control } 1 \text { and } 2 \text {. }\end{array}$ & $\begin{array}{l}\text { score for head } \\
\text { extension less } \\
\text { than head flexion }\end{array}$ & $\begin{array}{l}\text { score for head } \\
\text { extension equal } \\
\text { to head flexion }\end{array}$ & $\begin{array}{l}\text { score for head } \\
\text { extension more than } \\
\text { head flexion. but } \\
\text { difference } 1 \text { column } \\
\text { or less } \\
\end{array}$ & $\begin{array}{l}\text { score for head } \\
\text { extension more than } \\
\text { head flexion but } \\
\text { difference more than } \\
1 \text { column } \\
\end{array}$ \\
\hline $\begin{array}{l}\text { INCREASED EXTENSOR } \\
\text { TONE (HORIZONTAL) } \\
\text { Compare scores of head lag } \\
\text { and ventral suspension. }\end{array}$ & $\begin{array}{l}\text { score for ventral } \\
\text { suspension less } \\
\text { than head lag }\end{array}$ & $\begin{array}{l}\text { score for ventral } \\
\text { suspension } \\
\text { equal to head lag }\end{array}$ & $\begin{array}{l}\text { score for ventral } \\
\text { suspension more } \\
\text { than head lag but } \\
\text { difference } 1 \text { column } \\
\text { or less }\end{array}$ & $\begin{array}{l}\text { score for ventral } \\
\text { suspension more } \\
\text { than head lag but } \\
\text { difference more than } \\
1 \text { column } \\
\end{array}$ \\
\hline
\end{tabular}

\section{Reflexes}

\begin{tabular}{|c|c|c|c|c|c|}
\hline $\begin{array}{l}\text { TENDON REFLEX } \\
\text { Test biceps, knee, and ankle } \\
\text { jerks. }\end{array}$ & absent & felt, not seen & seen & $\begin{array}{l}\text { "exaggerated" } \\
\text { (very brisk) }\end{array}$ & clonus \\
\hline $\begin{array}{l}\text { SUCK / GAG } \\
\text { Little finger into mouth with } \\
\text { pulp of finger upwards. }\end{array}$ & $\begin{array}{l}\text { no gag / no } \\
\text { suck }\end{array}$ & $\begin{array}{l}\text { weak irregular } \\
\text { suck only } \\
\text { No stripping }\end{array}$ & $\begin{array}{l}\text { weak regular suck } \\
\text { Some stripping }\end{array}$ & $\begin{array}{l}\text { strong suck: } \\
\text { (a) irregular } \\
\text { (b) regular } \\
\text { Good stripping } \\
\end{array}$ & $\begin{array}{l}\text { no suck } \\
\text { but strong clenching }\end{array}$ \\
\hline $\begin{array}{l}\text { PALMAR GRASP } \\
\text { Put index finger into the } \\
\text { hand and gently press } \\
\text { palmar surface. Do not touch } \\
\text { dorsal surface. } \\
\text { Test each side separately. }\end{array}$ & R L & $\begin{array}{l}\text { short, weak } \\
\text { flexion of } \\
\text { fingers }\end{array}$ & $\begin{array}{l}\text { strong flexion of } \\
\text { fingers } \\
\mathrm{R} \quad \mathrm{L} \\
\end{array}$ & $\begin{array}{l}\text { strong finger flexion, } \\
\text { shoulder } \uparrow\end{array}$ & $\begin{array}{l}\text { very strong grasp; } \\
\text { infant can be lifted off } \\
\text { couch } \\
\text { R }\end{array}$ \\
\hline $\begin{array}{l}\text { PLANTAR GRASP } \\
\text { Press thumb on the sole } \\
\text { below the toes. } \\
\text { Test each side separately. }\end{array}$ & $\begin{array}{l}\text { no } \\
\text { response } \\
\mathrm{R} \quad \mathrm{L} \\
\end{array}$ & $\begin{array}{l}\text { partial plantar } \\
\text { flexion of toes } \\
\mathrm{R} \quad \mathrm{L}\end{array}$ & $\begin{array}{l}\text { toes curve around } \\
\text { the examiner's } \\
\text { finger } \\
\mathrm{R}\end{array}$ & & \\
\hline $\begin{array}{l}\text { PLACING } \\
\text { Lift infant in an upright } \\
\text { position and stroke the } \\
\text { dorsum of the foot against a } \\
\text { protruding edge of a flat } \\
\text { surface. } \\
\text { Test each side separately. }\end{array}$ & R L & $\begin{array}{l}\text { dorsiflexion of } \\
\text { ankle only }\end{array}$ & $\begin{array}{l}\text { full placing } \\
\text { response with } \\
\text { flexion of hip and } \\
\text { knee \& placing } \\
\text { sole on surface } \\
\text { R }\end{array}$ & & \\
\hline $\begin{array}{l}\text { MORO REFLEX } \\
\text { One hand supports infant's } \\
\text { head in midline, the other the } \\
\text { back. Raise infant to } 45^{\circ} \text { and } \\
\text { when infant is relaxed let } \\
\text { head fall through } 10^{\circ} \text {. Note if } \\
\text { jerky. } \\
\text { Repeat } 3 \text { times. }\end{array}$ & $\begin{array}{l}\text { no } \\
\text { response, } \\
\text { or opening } \\
\text { of hands } \\
\text { only }\end{array}$ & $\begin{array}{l}\text { full abduction } \\
\text { at shoulder } \\
\text { and extension } \\
\text { of the arms; } \\
\text { no adduction }\end{array}$ & $\begin{array}{l}\text { full abduction, } \\
\text { but only delayed } \\
\text { or partial } \\
\text { adduction }\end{array}$ & $\begin{array}{l}\text { partial abduction at } \\
\text { shoulder, and } \\
\text { extension of arms } \\
\text { followed by smooth } \\
\text { adduction }\end{array}$ & $\begin{array}{l}\text { - minimal abduction or } \\
\text { adduction } \\
\text { - no abduction or } \\
\text { adduction; only } \\
\text { forward extension of } \\
\text { arms } \\
\text { - marked adduction } \\
\text { only }\end{array}$ \\
\hline & & & & & Q \\
\hline
\end{tabular}


Movements

Hammersmith Neonatal Neurological Examination p 3

\begin{tabular}{|l|l|l|l|l|l|}
\hline $\begin{array}{l}\text { SPONTANEOUS } \\
\text { MOVEMENT (quantity) } \\
\text { Watch infant lying supine. }\end{array}$ & no movement & $\begin{array}{l}\text { sporadic and } \\
\text { short isolated } \\
\text { movements }\end{array}$ & $\begin{array}{l}\text { frequent isolated } \\
\text { movements }\end{array}$ & $\begin{array}{l}\text { frequent generalized } \\
\text { movements }\end{array}$ & $\begin{array}{l}\text { continuous } \\
\text { exaggerated } \\
\text { movements }\end{array}$ \\
\hline $\begin{array}{l}\text { SPONTANEOUS } \\
\text { MOVEMENT (quality) } \\
\text { Watch infant lying supine. }\end{array}$ & only stretches & $\begin{array}{l}\text { stretches and } \\
\text { random abrupt } \\
\text { movements; } \\
\text { some smooth } \\
\text { movements }\end{array}$ & $\begin{array}{l}\text { fluent movements } \\
\text { but monotonous }\end{array}$ & $\begin{array}{l}\text { fluent alternating } \\
\text { movements of arms } \\
\text { +legs; } \\
\text { good variability }\end{array}$ & $\begin{array}{l}\text { cramped, } \\
\text { synchronized; } \\
\text { mouthing } \\
\text { jerky or other } \\
\text { abnormal } \\
\text { movements }\end{array}$ \\
\hline $\begin{array}{l}\text { HEAD RAISING PRONE } \\
\text { Infant in prone, head in } \\
\text { midline. }\end{array}$ & no response & $\begin{array}{l}\text { infant rolls head } \\
\text { over, chin not } \\
\text { raised }\end{array}$ & $\begin{array}{l}\text { infant raises chin, } \\
\text { rolls head over }\end{array}$ & $\begin{array}{l}\text { infant brings head } \\
\text { and chin up }\end{array}$ & $\begin{array}{l}\text { infant brings head } \\
\text { up and keeps it up }\end{array}$ \\
\hline
\end{tabular}

Abnormal signs/patterns

\begin{tabular}{|c|c|c|c|c|c|}
\hline $\begin{array}{l}\text { ABNORMAL HAND OR } \\
\text { TOE POSTURES }\end{array}$ & & $\begin{array}{l}\text { hands open, toes } \\
\text { straight most of } \\
\text { the time }\end{array}$ & $\begin{array}{l}\text { intermittent fisting } \\
\text { or thumb } \\
\text { adduction }\end{array}$ & $\begin{array}{l}\text { continuous fisting or } \\
\text { thumb adduction; } \\
\text { index finger flexion, } \\
\text { thumb opposition }\end{array}$ & $\begin{array}{l}\text { continuous big } \\
\text { toe extension or } \\
\text { flexion of all toes }\end{array}$ \\
\hline TREMOR & & $\begin{array}{l}\text { no tremor, or } \\
\text { tremor only when } \\
\text { crying or only } \\
\text { after Moro reflex }\end{array}$ & $\begin{array}{l}\text { tremor } \\
\text { occasionally } \\
\text { when awake }\end{array}$ & $\begin{array}{l}\text { frequent tremors } \\
\text { when awake }\end{array}$ & $\begin{array}{l}\text { continuous } \\
\text { tremors }\end{array}$ \\
\hline STARTLE & $\begin{array}{l}\text { no startle } \\
\text { even to } \\
\text { sudden noise }\end{array}$ & $\begin{array}{l}\text { no spontaneous } \\
\text { startle but reacts } \\
\text { to sudden noise }\end{array}$ & $\begin{array}{l}2-3 \text { spontaneous } \\
\text { startles }\end{array}$ & $\begin{array}{l}\text { more than } 3 \\
\text { spontaneous startles }\end{array}$ & $\begin{array}{l}\text { continuous } \\
\text { startles }\end{array}$ \\
\hline
\end{tabular}

Orientation and behaviour

\begin{tabular}{|c|c|c|c|c|c|}
\hline EYE APPEARANCES & $\begin{array}{l}\text { does not } \\
\text { open eyes }\end{array}$ & & $\begin{array}{l}\text { full conjugated eye } \\
\text { movements }\end{array}$ & $\begin{array}{l}\text { transient } \\
\text { - nystagmus } \\
\text { - strabismus } \\
\text { - roving eye } \\
\text { movements } \\
\text { - sunset sign }\end{array}$ & $\begin{array}{l}\text { persistent } \\
\text { - nystagmus } \\
\text { - strabismus } \\
\text { - roving eye } \\
\text { movements } \\
\text { abnormal pupils }\end{array}$ \\
\hline $\begin{array}{l}\text { AUDITORY } \\
\text { ORIENTATION } \\
\text { Infant awake. Wrap infant. } \\
\text { Hold rattle } 10 \text { to } 15 \mathrm{~cm} \\
\text { from ear. }\end{array}$ & no reaction & $\begin{array}{l}\text { auditory startle; } \\
\text { brightens and } \\
\text { stills; no true } \\
\text { orientation }\end{array}$ & $\begin{array}{l}\text { shifting of eyes, } \\
\text { head might turn } \\
\text { towards source }\end{array}$ & $\begin{array}{l}\text { prolonged head turn } \\
\text { to stimulus; search } \\
\text { with eyes; smooth }\end{array}$ & $\begin{array}{l}\text { turns head (jerkily, } \\
\text { abruptly) \& eyes } \\
\text { towards noise } \\
\text { every time }\end{array}$ \\
\hline $\begin{array}{l}\text { VISUAL ORIENTATION } \\
\text { Wrap infant, wake up with } \\
\text { rattle if needed or rock } \\
\text { gently. Note if baby can } \\
\text { see and follow red ball (B) } \\
\text { or target }(\mathrm{T}) \text {. }\end{array}$ & \begin{tabular}{|l|}
$\begin{array}{l}\text { does not } \\
\text { follow or } \\
\text { focus on } \\
\text { stimuli } \\
\text { B }\end{array}$ \\
\end{tabular} & $\begin{array}{l}\text { stills, focuses, } \\
\text { follows briefly to } \\
\text { the side but } \\
\text { loses stimuli } \\
\text { B }\end{array}$ & $\begin{array}{l}\text { follows horizontally } \\
\text { and vertically; } \\
\text { no head turn } \\
\text { B } \quad T \\
\end{array}$ & $\begin{array}{l}\text { follows horizontally } \\
\text { and vertically; turns } \\
\text { head }\end{array}$ & $\begin{array}{l}\text { follows in a } \\
\text { circle }\end{array}$ \\
\hline $\begin{array}{l}\text { ALERTNESS } \\
\text { Tested as response to } \\
\text { visual stimuli ( } \mathrm{B} \text { or } \mathrm{T}) \text {. }\end{array}$ & \begin{tabular}{|l} 
will not \\
respond to \\
stimuli
\end{tabular} & $\begin{array}{l}\text { when awake, } \\
\text { looks only briefly }\end{array}$ & $\begin{array}{l}\text { when awake, looks } \\
\text { at stimuli but loses } \\
\text { them }\end{array}$ & $\begin{array}{l}\text { keeps interest in } \\
\text { stimuli }\end{array}$ & $\begin{array}{l}\text { does not tire } \\
\text { (hyper-reactive) }\end{array}$ \\
\hline $\begin{array}{l}\text { IRRITABILITY } \\
\text { In response to stimuli. }\end{array}$ & $\begin{array}{l}\text { quiet all the } \\
\text { time, not } \\
\text { irritable to } \\
\text { any stimuli } \\
\end{array}$ & $\begin{array}{l}\text { awakes, cries } \\
\text { sometimes when } \\
\text { handled }\end{array}$ & $\begin{array}{l}\text { cries often } \\
\text { when handled }\end{array}$ & $\begin{array}{l}\text { cries always } \\
\text { when handled }\end{array}$ & $\begin{array}{l}\text { cries even when } \\
\text { not handled }\end{array}$ \\
\hline $\begin{array}{l}\text { CONSOLABILITY } \\
\text { Ease to quiet infant. }\end{array}$ & $\begin{array}{l}\text { not crying; } \\
\text { consoling not } \\
\text { needed } \\
\end{array}$ & $\begin{array}{l}\text { cries briefly; } \\
\text { consoling not } \\
\text { needed }\end{array}$ & $\begin{array}{l}\text { cries; becomes } \\
\text { quiet when talked } \\
\text { to } \\
\end{array}$ & $\begin{array}{l}\text { cries; needs picking } \\
\text { up to be consoled }\end{array}$ & $\begin{array}{l}\text { cries; } \\
\text { cannot be } \\
\text { consoled } \\
\end{array}$ \\
\hline CRY & no cry at all & $\begin{array}{l}\text { whimpering cry } \\
\text { only }\end{array}$ & $\begin{array}{l}\text { cries to stimuli but } \\
\text { normal pitch }\end{array}$ & & $\begin{array}{l}\text { High-pitched cry; } \\
\text { often continuous }\end{array}$ \\
\hline
\end{tabular}

SUMMARY OF EXAMINATION:

HEAD AND TRUNK TONE:

MOTILITY:

ORIENTATION AND ALERTNESS:

CONSOLABILITY:
LIMB TONE

REFLEXES:

IRRITABILITY:

LIST DEVIANT SIGNS: 
HAMMERSMITH SHORT NEONATAL NEUROLOGICAL EXAMINATION

NAME: CODE: No. OF EXAM:

D.O.B. D.O.E.: AGE:

\section{POSTURE}

Baby lying on back. Look mainly at position of the legs, but also note arms. You may change drawing.

\section{ARM RECOIL}

Quickly extend

(straighten) both arms; put

next to body. Count to

two. Let go.

Repeat 3 times.

Hold wrist and pull

upward. Note flexion at

arm, and resistance while

shoulder lifts off table.

\section{LEG RECOIL}

Take both ankles, bend

hips+knee. Quickly extend

when infant not pushing.

Let go. Repeat X 3

LEG TRACTION

Hold ankle, pull leg

upwards. Look at flexion \&

resistance as bottom

pulled up.

\section{POPLITEAL ANGLE}

Fix knee on abdomen

(belly), try to extend knee

with first finger. Note

distance (angle) between

upper and lower limb.

\section{HEAD CONTROL (1)}

Baby sitting upright.

Encircle chest with both

hands holding shoulders.

Let head drop forward.

HEAD CONTROL (2)

Baby sitting upright.

Encircle chest with both

hands holding shoulders.

Let head drop backward.

\section{HEAD LAG}

Pull baby to sit by the wrists \& support head slightly.

\section{VENTRAL SUSPENSION}

Hold baby horizontal

under the belly. Look at

posture of back, arms,

legs, and head. If it looks different, DRAW!

G.A.: SEX

BW:

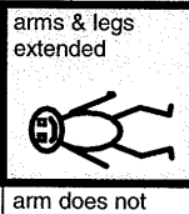

arm does not arm flexes

$\begin{array}{ll}\text { flex } & \text { slowly, not }\end{array}$

always, not

completely

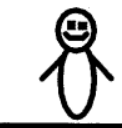

arm remains straight - no resistance
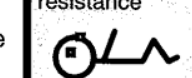

No flexion

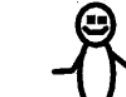

arm flexes

\begin{tabular}{l|l} 
slightly or some \\
resistance felt
\end{tabular}$\quad \begin{aligned} & \text { till shoulder lifts, } \\
& \text { then straightens }\end{aligned}$

legs well flexed $\quad$ legs well flexed \& but not adducted adducted near

belly

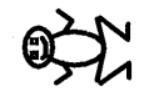

arm flexes

slowly, more

completely

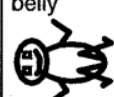

arm flexes and

remains flexed
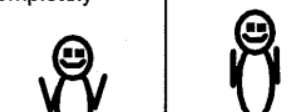

arm difficult to

extend; snap back

forcefully
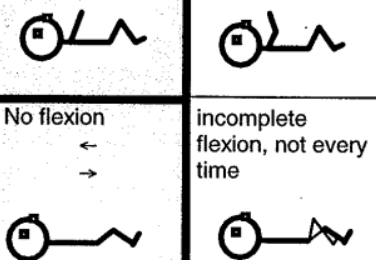

time

leg straight - no
resistance
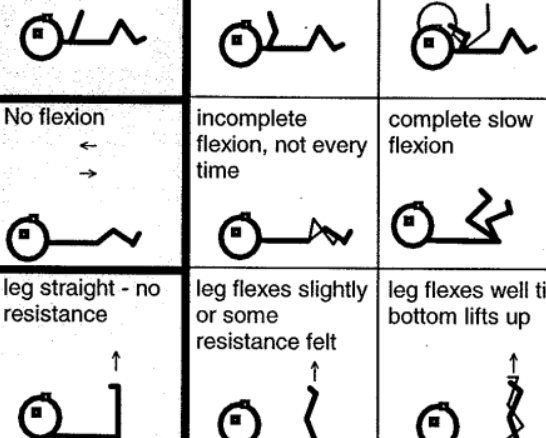

complete fast

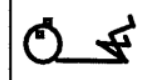

legs difficult to

extend; snap back

forcefully

\begin{tabular}{l|c|l}
$\begin{array}{l}\text { leg flexes slightly } \\
\text { or some } \\
\text { resistance felt }\end{array}$ & $\begin{array}{l}\text { leg flexes well till } \\
\text { bottom lifts up }\end{array}$ & $\begin{array}{l}\text { knee flexes - } \\
\text { remains flexed } \\
\text { when bottom up }\end{array}$
\end{tabular}

exion stays when back+bottom up

$00^{1} 03^{1} 03^{i}$

better felt than
drops forward or
back


MOVEMENTS

\begin{tabular}{|c|c|c|c|c|c|c|c|}
\hline & & & & & & STATE & ASYMM \\
\hline $\begin{array}{l}\text { SPONTANEOUS } \\
\text { MOVEMENT } \\
\text { Watch baby while (s)he is } \\
\text { lying on back. }\end{array}$ & no movement & $\begin{array}{l}\text { few stretches, } \\
\text { no other } \\
\text { movement }\end{array}$ & $\begin{array}{l}\text { jerky movement, } \\
\text { stretches, but } \\
\text { also some } \\
\text { smooth } \\
\text { movement }\end{array}$ & $\begin{array}{l}\text { smooth } \\
\text { movements of } \\
\text { arms + legs }\end{array}$ & $\begin{array}{l}\text { fits, cramped } \\
\text { or other } \\
\text { abnormal } \\
\text { movements: } \\
\text { DESCRIBE!! }\end{array}$ & & \\
\hline $\begin{array}{l}\text { ABNORMAL HAND OR } \\
\text { TOE POSTURES }\end{array}$ & hands open & $\begin{array}{l}\text { hands fisted or } \\
\text { thumbs adduct } \\
\text { intermittently but } \\
\text { open }\end{array}$ & $\begin{array}{l}\text { hands fist or } \\
\text { thumb adducts, } \\
\text { or finger \& thumb } \\
\text { oppose } \\
\end{array}$ & $\begin{array}{l}\text { big toe up } \\
\text { (extended) } \\
\text { or all toes flex }\end{array}$ & & & \\
\hline TREMOR. & no tremor & \begin{tabular}{|l|} 
tremor only \\
when crying or \\
after Moro reflex
\end{tabular} & $\begin{array}{l}\text { some tremor } \\
\text { when awake }\end{array}$ & $\begin{array}{l}\text { frequent } \\
\text { tremors }\end{array}$ & $\begin{array}{l}\text { continuous } \\
\text { tremors }\end{array}$ & & \\
\hline $\begin{array}{l}\text { STARTLE } \\
\text { Similar movements to } \\
\text { Moro reflex but not doing } \\
\text { Moro test }\end{array}$ & no startle & $\begin{array}{l}\text { startle to sudden } \\
\text { noise or bang on } \\
\text { table }\end{array}$ & $\begin{array}{l}2 \text { or } 3 \\
\text { spontaneous } \\
\text { startles }\end{array}$ & $\begin{array}{l}3-5 \\
\text { spontaneous } \\
\text { startles }\end{array}$ & $\begin{array}{l}\text { more than } 6 \\
\text { spontaneous } \\
\text { startles }\end{array}$ & & \\
\hline REFLEXES = test both & sides & & & & & & \\
\hline $\begin{array}{l}\text { SUCK \& GAG } \\
\text { Watch on breast; if no } \\
\text { suck is seen, put little } \\
\text { finger into mouth with pulp } \\
\text { of finger upwards. }\end{array}$ & $\begin{array}{l}\text { no gag / no } \\
\text { suck }\end{array}$ & $\begin{array}{l}\text { weak suck only: } \\
\text { (a) irregular } \\
\text { (b) regular } \\
\text { No stripping. }\end{array}$ & $\begin{array}{l}\text { infant sucks well } \\
\text { on the breast }\end{array}$ & $\begin{array}{l}\text { strong suck: } \\
\text { (a) irregular } \\
\text { (b) regular } \\
\text { Good stripping }\end{array}$ & $\begin{array}{l}\text { no suck } \\
\text { but strong } \\
\text { clenching }\end{array}$ & & \\
\hline $\begin{array}{l}\text { PALMAR GRASP } \\
\text { Stroke inside of hand. } \\
\text { DO NOT TOUCH BACK } \\
\text { OF HAND!! } \\
\end{array}$ & no reaction & $\begin{array}{l}\text { short, weak } \\
\text { flexion of fingers }\end{array}$ & $\begin{array}{l}\text { strong flexion of } \\
\text { fingers }\end{array}$ & $\begin{array}{l}\text { strong finger } \\
\text { flexion, } \\
\text { shoulder } \uparrow\end{array}$ & $\begin{array}{l}\text { strong finger } \\
\text { flexion, whole } \\
\text { body } \uparrow\end{array}$ & & \\
\hline $\begin{array}{l}\text { PLANTAR GRASP } \\
\text { Press on sole below toes. }\end{array}$ & no response & $\begin{array}{l}\text { toes flex (bend) } \\
\text { slightly }\end{array}$ & \begin{tabular}{|l|} 
toes curve \\
around finger
\end{tabular} & & & & \\
\hline $\begin{array}{l}\text { MORO REFLEX } \\
\text { Put baby in position shown } \\
\text { in drawing } 1 \text { below. Bring } \\
\text { head forward and } \\
\text { suddenly let it fall back } \\
\text { slightly. }\end{array}$ & no response & $\begin{array}{l}\text { full abduction of } \\
\text { the arms, } \\
\text { extension at the } \\
\text { elbow, no } \\
\text { adduction }\end{array}$ & $\begin{array}{l}\text { full abduction, } \\
\text { little or delayed } \\
\text { adduction }\end{array}$ & $\begin{array}{l}\text { arms do not } \\
\text { fully abduct but } \\
\text { good adduction }\end{array}$ & $\begin{array}{l}\cdot \text { adduction } \\
\text { only } \\
\text { - extension at } \\
\text { the elbow only }\end{array}$ & & \\
\hline $\begin{array}{l}\text { PLACING } \\
\text { Hold infant upright. Stroke } \\
\text { front of the baby's lower } \\
\text { leg on edge of table. }\end{array}$ & $\begin{array}{l}\text { nothing } \\
\text { happens }\end{array}$ & $\begin{array}{l}\text { baby flexes } \\
\text { ankle }\end{array}$ & $\begin{array}{l}\text { baby flexes hip, } \\
\text { knee, and ankle } \\
\& \text { steps on table }\end{array}$ & & & & \\
\hline
\end{tabular}

\section{ORIENTATION AND BEHAVIOUR}

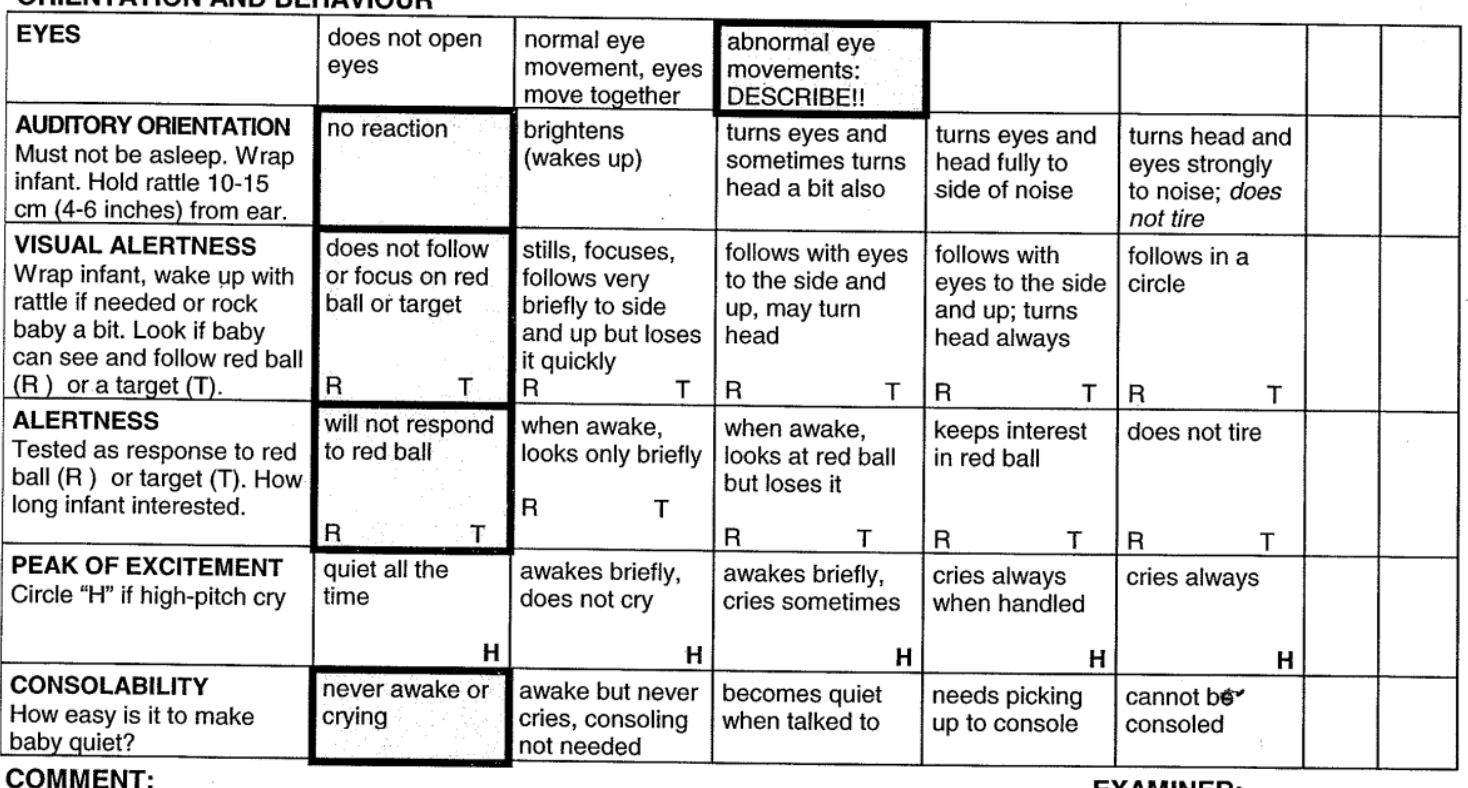

COMMENT: 


\section{HAMMERSMITH INFANT NEUROLOGICAL EXAMINATION}

Name:

Gestational age:
Date of birth:

Date of examination:

\begin{tabular}{|l|}
\hline \multicolumn{1}{|c|}{ SUMMARY OF EXAMINATION } \\
\hline No of asymmetries in section 1: \\
\hline \\
\hline Neurological items score: \\
\hline \\
\hline Behavioural score: \\
\hline
\end{tabular}

\section{COMMENTS:}

Cranial nerves functions

Posture

Movements

Tone

Reflexes and reactions

Behaviour

\section{SECTION 1 : NEUROLOGICAL ITEMS}

Assessment of cranial nerve function

\begin{tabular}{|c|c|c|c|c|c|c|}
\hline & column 1 (score 2) & c. 2 (sc. 1.5$)$ & column 3 (score 1) & column 4 (score 0 ) & $\mathbf{A}$ & comment \\
\hline $\begin{array}{l}\text { Facial appearance } \\
\text { (at rest and when } \\
\text { crying or stimulated) }\end{array}$ & $\begin{array}{l}\text { smiles or reacts } \\
\text { to stimuli by closing } \\
\text { eyes and grimacing }\end{array}$ & & $\begin{array}{l}\text { closes eyes but not tightly; } \\
\text { poor facial expression }\end{array}$ & $\begin{array}{l}\text { expressionless; } \\
\text { does not react } \\
\text { to stimuli }\end{array}$ & & \\
\hline Eye appearance & $\begin{array}{l}\text { normal conjugated } \\
\text { eye movements }\end{array}$ & & $\begin{array}{c}\text { intermittent } \\
\text { deviation of eyes or } \\
\text { abnormal movements }\end{array}$ & $\begin{array}{c}\text { continuous } \\
\text { deviation of eyes or } \\
\text { abnormal movements }\end{array}$ & & \\
\hline $\begin{array}{l}\text { Auditory response } \\
\text { test the response to } \\
\text { rattle or bell }\end{array}$ & $\begin{array}{l}\text { reacts to stimuli on } \\
\text { both sides }\end{array}$ & & $\begin{array}{c}\text { doubtful reaction to stimuli } \\
\text { or asymmetrical }\end{array}$ & $\begin{array}{l}\text { does not react } \\
\text { to stimuli }\end{array}$ & & \\
\hline $\begin{array}{l}\text { Visual response } \\
\text { test the ability to follow a } \\
\text { red ball or moving object }\end{array}$ & $\begin{array}{c}\text { follows the object for a } \\
\text { complete arc }\end{array}$ & & $\begin{array}{l}\text { follows the object for an } \\
\text { incomplete arc, } \\
\text { or asymmetry }\end{array}$ & $\begin{array}{l}\text { does not follow } \\
\text { the object }\end{array}$ & & \\
\hline $\begin{array}{l}\text { Sucking/swallowing } \\
\text { watch the infant suck on } \\
\text { breast or bottle }\end{array}$ & $\begin{array}{l}\text { good suck and } \\
\text { swallowing }\end{array}$ & & $\begin{array}{l}\text { poor suck and/or } \\
\text { swallowing }\end{array}$ & $\begin{array}{l}\text { no sucking reflex, } \\
\text { no swallowing }\end{array}$ & & \\
\hline
\end{tabular}




\begin{tabular}{|c|c|c|c|c|c|}
\hline & column 1 (score 2) & c 2 (sc.1.5) & column 3 (score 1) & column 4 (score 0 ) & A \\
\hline $\begin{array}{l}\text { Head } \\
\text { in sitting }\end{array}$ & $\underbrace{\text { tats }}_{\text {straight; in midline }}$ & & $\underbrace{}_{\substack{\text { slightly to side or backward } \\
\text { or forward }}}$ & 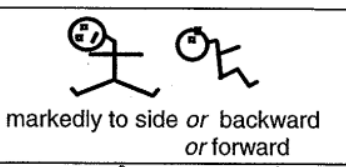 & \\
\hline $\begin{array}{l}\text { Trunk } \\
\text { in sitting }\end{array}$ & $\underset{\text { straight }}{\mathscr{W}}$ & & 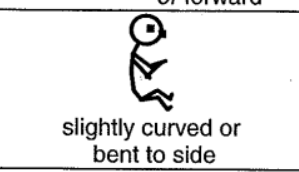 & $\underset{\substack{\text { very } \\
\text { rounded }}}{\substack{\text { rocking } \\
\text { back }}} \underbrace{(2)}_{\substack{\text { bent } \\
\text { sideways }}}$ & \\
\hline $\begin{array}{l}\text { Arms } \\
\text { at rest }\end{array}$ & $\begin{array}{l}\text { in neutral position: } \\
\text { central, } \\
\text { straight or slightly bent }\end{array}$ & & $\begin{array}{l}\text { slight } \\
\text { internal rotation or } \\
\text { external rotation }\end{array}$ & $\begin{array}{c}\text { marked } \\
\text { internal rotation or } \\
\text { external rotation or } \\
\text { dystonic posture } \\
\text { hemiplegic posture } \\
\end{array}$ & \\
\hline Hands & hands open & & $\begin{array}{c}\text { intermittent } \\
\text { adducted thumb } \\
\text { or fisting }\end{array}$ & $\begin{array}{l}\text { persistent } \\
\text { adducted thumb } \\
\text { or fisting }\end{array}$ & \\
\hline $\begin{array}{l}\text { Legs } \\
\text { in sitting } \\
\\
\text { in supine and } \\
\text { in standing }\end{array}$ & $\begin{array}{l}\text { able to sit with straight } \\
\text { back, and legs } \\
\text { straight or slightly bent } \\
\text { (long sitting) } \\
\text { legs in neutral } \\
\text { position: } \\
\text { straight or } \\
\text { slightly bent }\end{array}$ & $\begin{array}{l}\text { slight } \\
\text { internal } \\
\text { rotation or } \\
\text { external } \\
\text { rotation }\end{array}$ & $\begin{array}{l}\text { sit with straight back but } \\
\text { knees bent at } 15-20^{\circ} \\
\text { internal rotation or } \\
\text { external rotation } \\
\text { at hips }\end{array}$ & $\begin{array}{l}\text { unable to sit straight unless } \\
\text { knees markedly bent } \\
\text { (no long sitting) } \\
\text { marked } \\
\text { internal rotation or } \\
\text { external rotation } \\
\text { or } \\
\text { fixed extension or flexion or } \\
\text { contractures at hips and knees }\end{array}$ & \\
\hline $\begin{array}{l}\text { Feet } \\
\text { in supine and } \\
\text { in standing }\end{array}$ & $\begin{array}{l}\text { central; in neutral } \\
\text { position } \\
\\
\text { toes straight midway } \\
\text { between flexion and } \\
\text { extension }\end{array}$ & & $\begin{array}{c}\text { slight } \\
\text { internal rotation or } \\
\text { external rotation } \\
\text { intermittent } \\
\text { tendency to stand on } \\
\text { tiptoes; or } \\
\text { toes up or } \\
\text { curling under }\end{array}$ & $\begin{array}{c}\text { marked } \\
\text { internal rotation or } \\
\text { external rotation at the ankle } \\
\text { persistent } \\
\text { tendency to stand on tiptoes } \\
\text { or } \\
\text { toes up or } \\
\text { curling under }\end{array}$ & \\
\hline
\end{tabular}

\section{Movements}

\begin{tabular}{|l|c|l|l|l|}
\hline $\begin{array}{l}\text { Quantity } \\
\text { watch infant } \\
\text { lying in the } \\
\text { supine }\end{array}$ & normal & $\begin{array}{c}\text { excessive or } \\
\text { sluggish }\end{array}$ & $\begin{array}{c}\text { minimal or } \\
\text { none }\end{array}$ \\
\hline Quality & $\begin{array}{c}\text { free, } \\
\text { alternating, } \\
\text { smooth }\end{array}$ & $\begin{array}{l}\text { jerky, } \\
\text { slight tremor }\end{array}$ & $\begin{array}{l}\text { cramped \& synchronous } \\
\text { extensor spasms } \\
\text { athetoid } \\
\text { ataxic } \\
\text { very tremulous } \\
\text { myoclonic spasm } \\
\text { dystonic }\end{array}$ \\
\hline
\end{tabular}


Tone

\begin{tabular}{|l|c|c|c|c|c|c|}
\hline $\begin{array}{l}\text { Scarf sign } \\
\text { Take the infant's hand and pull } \\
\text { the arm across the chest until } \\
\text { there is resistance. Note the } \\
\text { position of the elbow. }\end{array}$ & column 1 (score 2) & c. 2 (sc.1.5) & column 3 (score 1) & column 4 (score 0) & Range: \\
\hline $\begin{array}{l}\text { Passive shoulder } \\
\text { elevation } \\
\text { Lift arm next to the infant's } \\
\text { head. Note resistance at } \\
\text { shoulder and elbow. }\end{array}$
\end{tabular}

Reflexes and reactions

\begin{tabular}{|c|c|c|c|c|}
\hline Tendon Reflexes & $\begin{array}{l}\text { easily elicitable } \\
\text { biceps knee ankle }\end{array}$ & $\begin{array}{l}\text { mildly brisk } \\
\text { bic knee ank }\end{array}$ & $\begin{array}{lll} & \text { brisk } \\
\text { biceps } & \text { knee ankle }\end{array}$ & $\begin{array}{l}\text { clonus or absent } \\
\text { biceps knee ankle }\end{array}$ \\
\hline $\begin{array}{l}\text { Arm protection } \\
\text { Pull the infant by one arm from } \\
\text { the supine position and note } \\
\text { the reaction of the opposite } \\
\text { side. }\end{array}$ & arm \& hand extend & & arm semi-flexed & arm fully flexed \\
\hline $\begin{array}{l}\text { Vertical suspension } \\
\text { Hold infant under axilla. Make } \\
\text { sure legs do not touch any } \\
\text { surface. }\end{array}$ & kicks symmetrically & & $\bigcap_{\substack{\text { kicks one leg more, or } \\
\text { poor kicking }}}$ & $\overbrace{\substack{\text { no kicking even if } \\
\text { stimulated, } \\
\text { or scissoring }}}$ \\
\hline $\begin{array}{l}\text { Lateral tilting (describe } \\
\text { side up). Infant held vertically, } \\
\text { tilt quickly to horizontal. Note } \\
\text { spine, limbs, and head. }\end{array}$ & $\mathbf{R}$ & ?L & $\mathbf{R}$ & ${ }_{\mathrm{R}}$ \\
\hline $\begin{array}{l}\text { Forward parachute } \\
\text { Infant held vertically and } \\
\text { suddenly tilted forward. Note } \\
\text { reaction of the arms. }\end{array}$ & (after 6 months) & & (after 6 months) & \\
\hline
\end{tabular}


SECTION 2: MOTOR MILESTONES

\begin{tabular}{|c|c|c|c|c|c|c|}
\hline $\begin{array}{l}\text { Head } \\
\text { control }\end{array}$ & $\begin{array}{c}\text { unable to } \\
\text { maintain } \\
\text { head upright } \\
\text { (normal }<3 \\
\text { mo) }\end{array}$ & $\begin{array}{c}\text { wobbles } \\
\text { (normal at } 4 \mathrm{mo} \text { ) }\end{array}$ & $\begin{array}{c}\text { all the time } \\
\text { maintained } \\
\text { upright } \\
\text { (normal at } 5 \mathrm{mo} \text { ) }\end{array}$ & & & \\
\hline Sitting & cannot sit & sits with support & $\underbrace{\text { props }}_{\text {(normal at } 6 \mathrm{mo})}$ & stable sit & pivots (rotates) & $\begin{array}{l}\text { Observed: } \\
\text { Reported (age): }\end{array}$ \\
\hline $\begin{array}{l}\text { Voluntary } \\
\text { grasp }\end{array}$ & no grasp & uses whole hand & $\begin{array}{l}\text { index finger and } \\
\text { thumb but } \\
\text { immature grasp }\end{array}$ & pincer grasp & & $\begin{array}{l}\text { Observed: } \\
\text { Reported (age): }\end{array}$ \\
\hline $\begin{array}{l}\text { Ability to } \\
\text { kick } \\
\text { (in supine) }\end{array}$ & no kicking & $\begin{array}{l}\text { kicks horizontally } \\
\text { legs do not lift }\end{array}$ & $\begin{array}{c}\text { upward } \\
\text { (vertically) }\end{array}$ & touches leg & touches toes & $\begin{array}{l}\text { Observed: } \\
\text { Reported (age): }\end{array}$ \\
\hline Rolling & no rolling & $\begin{array}{l}\text { rolling to side } \\
\text { (normal at } 4 \mathrm{mo} \text { ) }\end{array}$ & $\begin{array}{l}\text { prone to supine } \\
\text { (normal at mo) }\end{array}$ & $\begin{array}{l}\text { supine to prone } \\
\text { (normal at mo) }\end{array}$ & & $\begin{array}{l}\text { Observed: } \\
\text { Reported (age): }\end{array}$ \\
\hline Crawling & $\begin{array}{l}\text { does not lift } \\
\text { head }\end{array}$ & (normal at $3 \mathrm{mo}$ ) & on outstretched & crawling flat on & crawling on hands & $\begin{array}{l}\text { Observed: } \\
\text { Reported (age): }\end{array}$ \\
\hline Standing & $\begin{array}{l}\text { does not } \\
\text { support } \\
\text { weight }\end{array}$ & $\begin{array}{l}\text { supports weight } \\
\text { (normal at } 4 \mathrm{mo} \text { ) }\end{array}$ & $\begin{array}{l}\text { stands with } \\
\text { support } \\
\text { (normal at } 7 \mathrm{mo} \text { ) }\end{array}$ & $\begin{array}{l}\text { stands unaided } \\
\text { (normal at } 12 \mathrm{mo} \text { ) }\end{array}$ & & $\begin{array}{l}\text { Observed: } \\
\text { Reported (age): }\end{array}$ \\
\hline Walking & & $\begin{array}{l}\text { bouncing } \\
\text { (normal at } 6 \mathrm{mo} \text { ) }\end{array}$ & $\begin{array}{l}\text { cruising (walks } \\
\text { holding on) }\end{array}$ & $\begin{array}{c}\text { walking } \\
\text { independently } \\
\text { (normal at } 15 \mathrm{mo} \text { ) }\end{array}$ & & $\begin{array}{l}\text { Observed: } \\
\text { Reported (age): }\end{array}$ \\
\hline
\end{tabular}

SECTION 3: BEHAVIOUR

\begin{tabular}{|c|c|c|c|c|c|c|c|}
\hline & 1 & 2 & 3 & 4 & 5 & 6 & Comment \\
\hline $\begin{array}{l}\text { State of } \\
\text { consciousness }\end{array}$ & unrousable & drowsy & $\begin{array}{c}\text { sleepy but } \\
\text { wakes easily }\end{array}$ & $\begin{array}{l}\text { awake but } \\
\text { no interest }\end{array}$ & $\begin{array}{l}\text { loses } \\
\text { interest }\end{array}$ & $\begin{array}{l}\text { maintains } \\
\text { interest }\end{array}$ & \\
\hline Emotional state & $\begin{array}{l}\text { irritable, not } \\
\text { consolable }\end{array}$ & $\begin{array}{l}\text { irritable, } \\
\text { mother can } \\
\text { console }\end{array}$ & $\begin{array}{c}\text { irritable } \\
\text { when } \\
\text { approached }\end{array}$ & $\begin{array}{l}\text { neither } \\
\text { happy or } \\
\text { unhappy }\end{array}$ & $\begin{array}{l}\text { happy, } \\
\text { smiling }\end{array}$ & & \\
\hline Social orientation & $\begin{array}{l}\text { avoiding, } \\
\text { withdrawn }\end{array}$ & hesitant & $\begin{array}{l}\text { accepts } \\
\text { approach }\end{array}$ & friendly & & & \\
\hline
\end{tabular}

Score for behaviour: 


\section{EXAME NEUROLÓGICO NEONATAL - HAMMERSMITH}

Nome:

Data da avaliação: _______Data de Nascimento:
Sexo: Raça: Idade gestacional:
Registro do paciente:

Peso ao nascimento:

\section{POSTURA E TÔNUS}

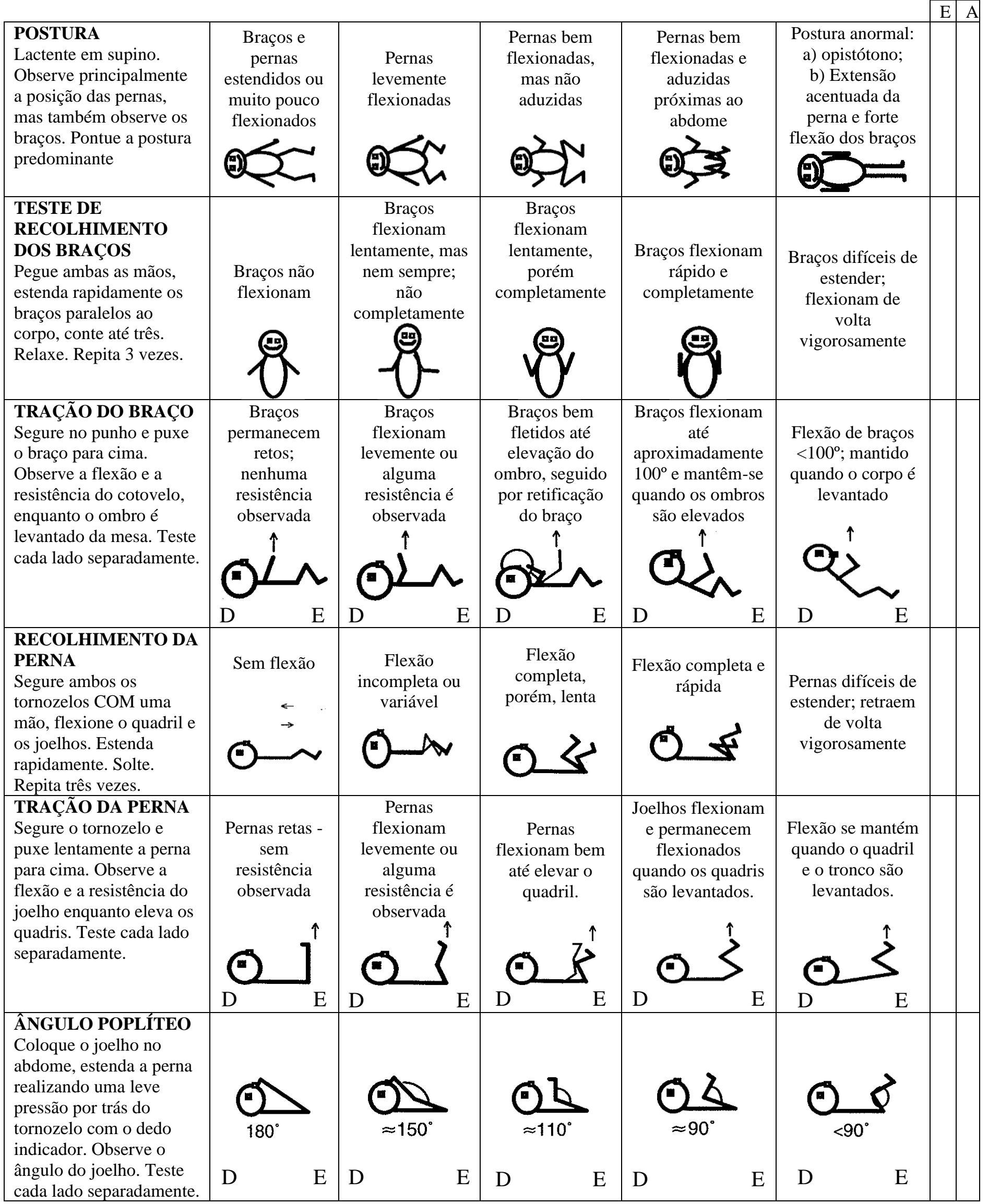




\begin{tabular}{|c|c|c|c|c|c|}
\hline $\begin{array}{l}\text { CONTROLE DA } \\
\text { CABEÇA (1) } \\
\text { (tônus extensor). } \\
\text { Lactente sentado. Abrace } \\
\text { o peito com ambas as } \\
\text { mãos, segurando os } \\
\text { ombros. Deixe a cabeça } \\
\text { cair para frente. }\end{array}$ & $\begin{array}{l}\text { Nenhuma } \\
\text { tentativa de } \\
\text { levantar a } \\
\text { cabeça }\end{array}$ & $\begin{array}{c}\text { Lactente tenta } \\
\text { levantar; esforço } \\
\text { é mais sentido } \\
\text { do que } \\
\text { observado }\end{array}$ & $\begin{array}{c}\text { Levanta a } \\
\text { cabeça, mas cai } \\
\text { para a frente ou } \\
\text { para trás }\end{array}$ & $\begin{array}{l}\text { Levanta a cabeça: } \\
\text { permanece na } \\
\text { vertical; podendo }\end{array}$ & \\
\hline $\begin{array}{l}\text { CONTROLE DA } \\
\text { CABEÇA (2) } \\
\text { (tônus flexor). } \\
\text { Lactente sentado. Abrace } \\
\text { o peito com ambas as } \\
\text { mãos, segurando os } \\
\text { ombros. Deixe a cabeça }\end{array}$ & $\begin{array}{l}\text { Nenhuma } \\
\text { tentativa de } \\
\text { levantar a } \\
\text { cabeça }\end{array}$ & $\begin{array}{l}\text { Lactente tenta } \\
\text { levantar; esforço } \\
\text { é mais sentido } \\
\text { do que } \\
\text { observado }\end{array}$ & $\begin{array}{l}\text { Levanta a } \\
\text { cabeça, mas cai } \\
\text { para a frente ou } \\
\text { para trás }\end{array}$ & $\begin{array}{l}\text { Levanta a cabeça: } \\
\text { permanece na } \\
\text { vertical; podendo } \\
\text { oscilar }\end{array}$ & $\begin{array}{c}\text { Cabeça ereta ou } \\
\text { estendida, não } \\
\text { pode ser } \\
\text { flexionada } \\
\text { passivamente }\end{array}$ \\
\hline $\begin{array}{l}\text { PUXAR PARA } \\
\text { SENTAR } \\
\text { Puxe o lactente para a } \\
\text { postura sentada com } \\
\text { tração em ambos os } \\
\text { punhos e apoiando } \\
\text { levemente a cabeça. } \\
\text { Observe também a flexão } \\
\text { do braço. }\end{array}$ & $\begin{array}{c}\text { Cabeça cai e } \\
\text { permanece } \\
\text { para trás }\end{array}$ & $\begin{array}{c}\text { Tenta levantar a } \\
\text { cabeça, mas esta } \\
\text { cai para trás }\end{array}$ & $\begin{array}{c}\text { Capaz de } \\
\text { levantar } \\
\text { levemente a } \\
\text { cabeça }\end{array}$ & $\begin{array}{c}\text { Levanta a cabeça } \\
\text { alinhada com o } \\
\text { tronco }\end{array}$ & $\begin{array}{c}\text { Cabeça à frente } \\
\text { do corpo }\end{array}$ \\
\hline $\begin{array}{l}\text { SUSPENSÃO } \\
\text { VENTRAL } \\
\text { Segure o lactente em } \\
\text { suspensão ventral. } \\
\text { Observe a coluna, flexão } \\
\text { dos membros e relação } \\
\text { da cabeça com o tronco. } \\
\text { Se ele parecer diferente, } \\
\text { DESENHE }\end{array}$ & $\begin{array}{l}\text { Tronco } \\
\text { flexionado. } \\
\text { Cabeça e } \\
\text { membros } \\
\text { suspensos e } \\
\text { alinhados }\end{array}$ & $\begin{array}{c}\text { Tronco } \\
\text { flexionado. } \\
\text { Cabeça para } \\
\text { baixo (seta) e } \\
\text { membros } \\
\text { levemente } \\
\text { flexionados }\end{array}$ & $\begin{array}{c}\text { Tronco } \\
\text { levemente } \\
\text { flexionado. } \\
\text { Membros } \\
\text { flexionados }\end{array}$ & $\begin{array}{c}\text { Tronco alinhado, } \\
\text { cabeça alinhada } \\
\text { com o corpo, } \\
\text { membros } \\
\text { flexionados }\end{array}$ & $\begin{array}{c}\text { Tronco alinhado, } \\
\text { cabeça acima do } \\
\text { corpo }\end{array}$ \\
\hline
\end{tabular}

E - Estado de alerta; A - Assimetria

\section{PADRÕES DE TÔNUS}

\begin{tabular}{|c|c|c|c|c|c|c|}
\hline & & & & & & $\mathrm{A}$ \\
\hline $\begin{array}{l}\text { TÔNUS FLEXOR (1) } \\
\text { (tração: braço vS. } \\
\text { perna). } \\
\text { Compare pontuação da } \\
\text { tração dos braços com a } \\
\text { tração das pernas }\end{array}$ & $\begin{array}{l}\text { Pontuação para } \\
\text { flexão dos braços } \\
\text { é menor que a } \\
\text { flexão das pernas }\end{array}$ & $\begin{array}{l}\text { Pontuação para } \\
\text { flexão dos braços } \\
\text { é igual a flexão } \\
\text { das pernas }\end{array}$ & $\begin{array}{l}\text { Pontuação da flexão } \\
\text { dos braços é maior } \\
\text { que a flexão das } \\
\text { pernas, porém com } \\
\text { diferença de } 1 \\
\text { coluna ou menos }\end{array}$ & $\begin{array}{l}\text { Pontuação da flexão } \\
\text { dos braços é maior } \\
\text { que a flexão das } \\
\text { pernas, porém com } \\
\text { diferença de } 1 \\
\text { coluna ou mais }\end{array}$ & & \\
\hline $\begin{array}{l}\text { TÔNUS FLEXOR (2) } \\
\text { (braço vs. perna) } \\
\text { Postura em supino. }\end{array}$ & & $\begin{array}{l}\text { Braços e pernas } \\
\text { flexionados }\end{array}$ & $\begin{array}{l}\text { Forte flexão do } \\
\text { braço com forte } \\
\text { extensão } \\
\text { intermitente da } \\
\text { perna }\end{array}$ & $\begin{array}{l}\text { Forte flexão do } \\
\text { braço com forte } \\
\text { extensão contínua } \\
\text { da perna }\end{array}$ & & \\
\hline $\begin{array}{l}\text { TÔNUS EXTENSOR } \\
\text { DA PERNA } \\
\text { Compare a pontuação da } \\
\text { tração da perna e do } \\
\text { ângulo poplíteo }\end{array}$ & $\begin{array}{c}\text { Pontuação da } \\
\text { tração da perna é } \\
\text { maior que a } \\
\text { pontuação do } \\
\text { ângulo poplíteo }\end{array}$ & $\begin{array}{c}\text { Pontuação da } \\
\text { tração da perna é } \\
\text { igual a pontuação } \\
\text { do ângulo } \\
\text { poplíteo }\end{array}$ & $\begin{array}{l}\text { Pontuação da tração } \\
\text { da perna é menor } \\
\text { que a pontuação do } \\
\text { ângulo poplíteo, } \\
\text { com diferença de } \\
\text { somente } 1 \text { coluna }\end{array}$ & $\begin{array}{l}\text { Pontuação da tração } \\
\text { da perna é menor } \\
\text { que a pontuação do } \\
\text { ângulo poplíteo, } \\
\text { porém com } \\
\text { diferença maior que } \\
1 \text { coluna } \\
\end{array}$ & & \\
\hline $\begin{array}{l}\text { TÔNUS EXTENSOR } \\
\text { DO PESCOÇO } \\
\text { (sentado). }\end{array}$ & $\begin{array}{l}\text { Pontuação da } \\
\text { extensão de } \\
\text { cabeça é menor }\end{array}$ & $\begin{array}{c}\text { Pontuação da } \\
\text { extensão de } \\
\text { cabeça é igual à }\end{array}$ & $\begin{array}{c}\text { Pontuação da } \\
\text { extensão da cabeça } \\
\text { é maior que a }\end{array}$ & $\begin{array}{c}\text { Pontuação da } \\
\text { extensão de cabeça } \\
\text { é maior que da }\end{array}$ & & \\
\hline
\end{tabular}


A n ex o s 200

\begin{tabular}{|c|c|c|c|c|}
\hline $\begin{array}{l}\text { Compare a pontuação do } \\
\text { controle de cabeça } 1 \text { e } 2 \text {. }\end{array}$ & $\begin{array}{c}\text { que a da flexão de } \\
\text { cabeça }\end{array}$ & $\begin{array}{l}\text { da flexão de } \\
\text { cabeça }\end{array}$ & $\begin{array}{l}\text { flexão da cabeça, } \\
\text { porém com } \\
\text { diferença de } 1 \text { uma } \\
\text { coluna ou menos }\end{array}$ & $\begin{array}{c}\text { flexão de cabeça, } \\
\text { porém com } \\
\text { diferença maior que } \\
1 \text { coluna }\end{array}$ \\
\hline $\begin{array}{l}\text { AUMENTO DE } \\
\text { TÔNUS EXTENSOR } \\
\text { (horizontal) } \\
\text { Compare a pontuação do } \\
\text { controle da cabeça no } \\
\text { puxar para sentar e na } \\
\text { suspensão ventral. }\end{array}$ & $\begin{array}{l}\text { Pontuação do } \\
\text { controle de } \\
\text { cabeça na } \\
\text { suspensão ventral } \\
\text { é menor que a no } \\
\text { puxar para sentar }\end{array}$ & $\begin{array}{l}\text { Pontuação do } \\
\text { controle da } \\
\text { cabeça na } \\
\text { suspensão ventral } \\
\text { é igual a } \\
\text { pontuação do } \\
\text { puxar para sentar }\end{array}$ & $\begin{array}{c}\text { Pontuação do } \\
\text { controle da cabeça } \\
\text { na suspensão } \\
\text { ventral é maior que } \\
\text { a do puxar para } \\
\text { sentar, porém com } \\
\text { diferença de } 1 \\
\text { coluna ou menos }\end{array}$ & $\begin{array}{c}\text { Pontuação do } \\
\text { controle da cabeça } \\
\text { na suspensão } \\
\text { ventral é maior que } \\
\text { a do puxar para } \\
\text { sentar, porém com } \\
\text { diferença maior que } \\
1 \text { coluna } \\
\end{array}$ \\
\hline
\end{tabular}

E - Estado de alerta; A - Assimetria

\section{REFLEXOS}

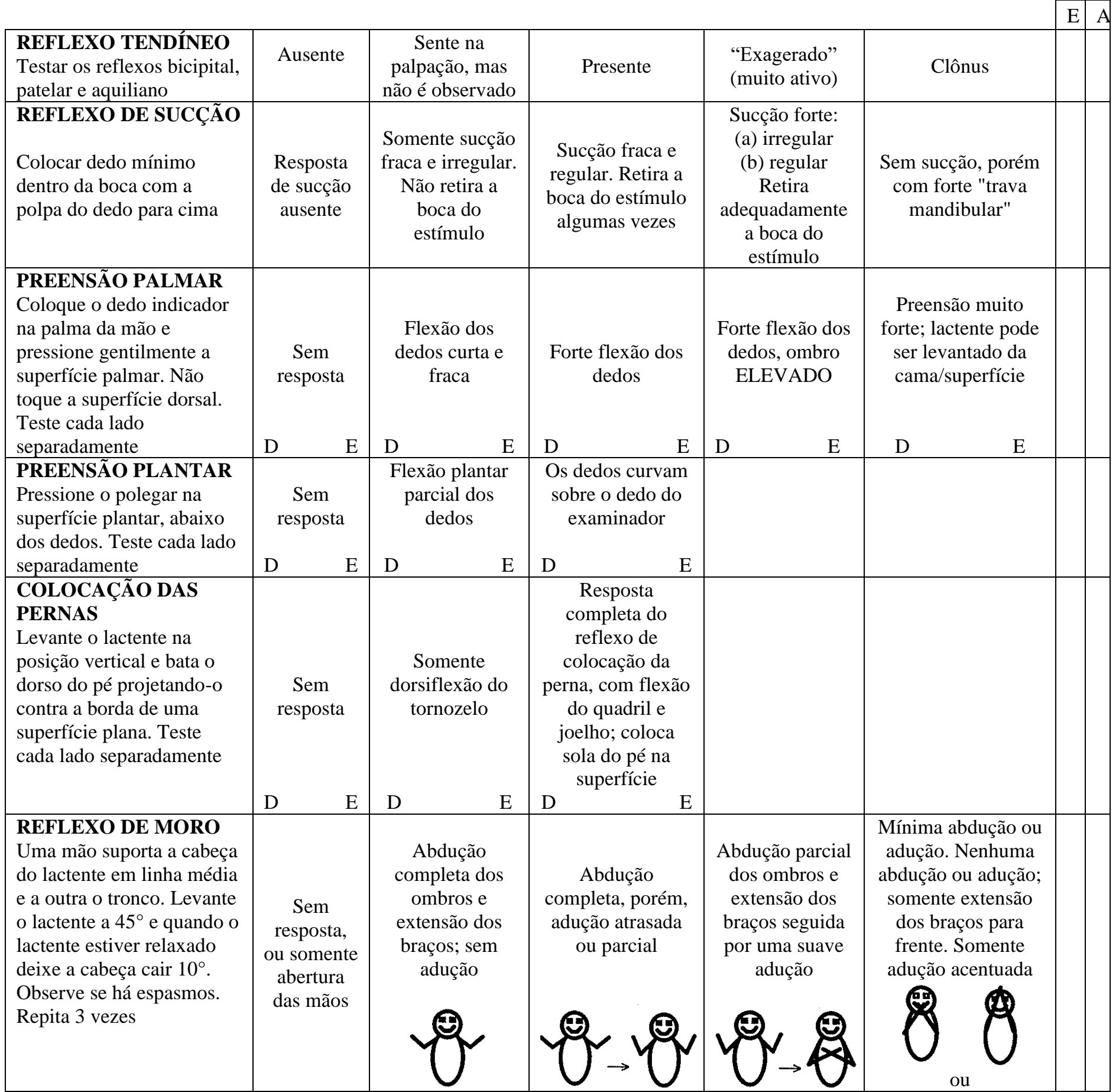




\begin{tabular}{|c|c|c|c|c|c|}
\hline $\begin{array}{l}\text { MOVIMENTOS } \\
\text { ESPONTÂNEOS } \\
\text { (quantidade). } \\
\text { Observe o lactente deitado } \\
\text { em supino }\end{array}$ & $\begin{array}{c}\text { Sem } \\
\text { movimento }\end{array}$ & $\begin{array}{l}\text { Movimentos } \\
\text { isolados } \\
\text { esporádicos e } \\
\text { curtos }\end{array}$ & $\begin{array}{l}\text { Movimentos } \\
\text { isolados } \\
\text { frequentes }\end{array}$ & $\begin{array}{l}\text { Movimentos } \\
\text { frequentes } \\
\text { generalizados }\end{array}$ & $\begin{array}{l}\text { Movimentos } \\
\text { contínuos } \\
\text { exagerados }\end{array}$ \\
\hline $\begin{array}{l}\text { MOVIMENTOS } \\
\text { ESPONTÂNEOS } \\
\text { (qualidade) } \\
\text { Observe o lactente deitado } \\
\text { em supino }\end{array}$ & $\begin{array}{c}\text { Alonga-se } \\
\text { apenas }\end{array}$ & $\begin{array}{l}\text { Alongamentos e } \\
\text { movimentos } \\
\text { aleatórios } \\
\text { abruptos; alguns } \\
\text { movimentos } \\
\text { suaves }\end{array}$ & $\begin{array}{l}\text { Movimentos } \\
\text { fluentes, porém, } \\
\text { monótonos }\end{array}$ & $\begin{array}{c}\text { Movimentos } \\
\text { fluentes } \\
\text { alternados de } \\
\text { braços e pernas; } \\
\text { boa } \\
\text { variabilidade }\end{array}$ & $\begin{array}{l}\text {-Espasmódico, } \\
\text { sincronizado; } \\
\text {-Movimento de } \\
\text { mastigação; } \\
\text { •Espasmos ou } \\
\text { outros movimentos } \\
\text { anormais }\end{array}$ \\
\hline $\begin{array}{l}\text { ELEVAÇÃO DA } \\
\text { CABEÇA EM PRONO } \\
\text { Lactente em prono, cabeça } \\
\text { na linha média }\end{array}$ & $\begin{array}{l}\text { Sem } \\
\text { resposta }\end{array}$ & $\begin{array}{l}\text { Lactente rola a } \\
\text { cabeça para o } \\
\text { lado, sem } \\
\text { levantar o } \\
\text { queixo } \\
\end{array}$ & $\begin{array}{l}\text { Lactente levanta o } \\
\text { queixo, rola a } \\
\text { cabeça para o lado }\end{array}$ & $\begin{array}{l}\text { Lactente levanta } \\
\text { a cabeça e o } \\
\text { queixo para } \\
\text { cima }\end{array}$ & $\begin{array}{c}\text { Lactente leva a } \\
\text { cabeça para cima e } \\
\text { a mantém }\end{array}$ \\
\hline
\end{tabular}

E - Estado de alerta; A - Assimetria

\section{SINAIS/PADRÕES ANORMAIS}

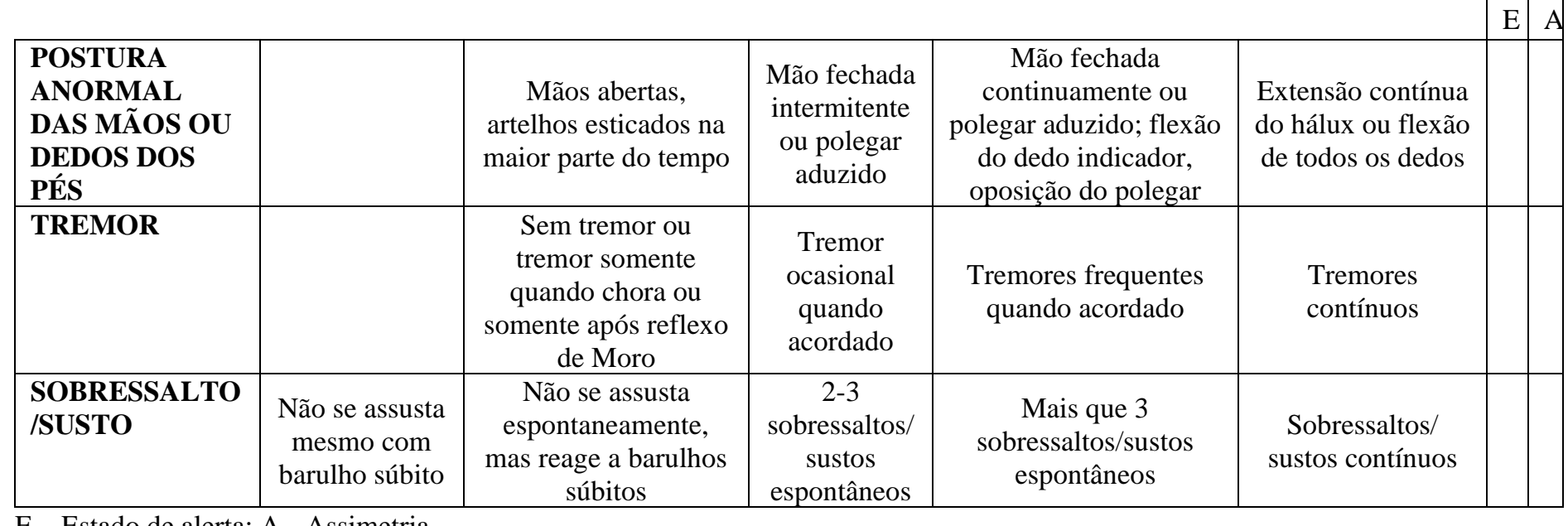

E - Estado de alerta; A - Assimetria

\section{ORIENTAÇÃO E COMPORTAMENTO}

\begin{tabular}{|c|c|c|c|c|c|}
\hline APARENCIA DOS OLHOS & $\begin{array}{c}\text { Não abre os } \\
\text { olhos }\end{array}$ & & $\begin{array}{l}\text { Movimentos } \\
\text { oculares } \\
\text { completament } \\
\text { e conjugados }\end{array}$ & $\begin{array}{l}\text { Transitório: } \\
\text { •nistagmo; } \\
\text { •estrabismo; } \\
\text { •movimentos } \\
\text { oculares lentos; } \\
\text { • sinal de pôr-do-sol } \\
\text { (olhos caídos) }\end{array}$ & $\begin{array}{l}\text { Persistente: } \\
\text { •nistagmo; } \\
\text { - estrabismo; } \\
\text { •movimentos } \\
\text { oculares } \\
\text { lentos; pupilas } \\
\text { anormais }\end{array}$ \\
\hline $\begin{array}{l}\text { ORIENTAÇÃO AUDITIVA } \\
\text { Lactente acordado. Enrole o } \\
\text { lactente. Segure um chocalho } \\
\text { entre } 10 \text { a } 15 \mathrm{~cm} \text { da orelha. }\end{array}$ & Sem reação & $\begin{array}{c}\text { Sobressalto } \\
\text { auditivo; fica } \\
\text { alerta e } \\
\text { acalma-se em } \\
\text { seguida; sem } \\
\text { orientação real }\end{array}$ & $\begin{array}{l}\text { Desvio dos } \\
\text { olhos, a } \\
\text { cabeça pode se } \\
\text { virar em } \\
\text { direção à fonte } \\
\quad \text { sonora }\end{array}$ & $\begin{array}{l}\text { Vira a cabeça } \\
\text { lentamente em } \\
\text { direção ao estímulo; } \\
\text { busca com olhos; } \\
\text { suavemente }\end{array}$ & $\begin{array}{c}\text { Vira a cabeça } \\
\text { (abruptamente, } \\
\text { com espasmo) } \\
\text { e olhos em } \\
\text { direção ao } \\
\text { barulho o } \\
\text { tempo todo }\end{array}$ \\
\hline \multirow[t]{2}{*}{$\begin{array}{l}\text { ORIENTAÇÃO VISUAL } \\
\text { Enrole o lactente, acorde-o } \\
\text { com o chocalho se necessário, } \\
\text { ou sacuda-o gentilmente. } \\
\text { Observe se o bebê pode ver e } \\
\text { seguir uma bola vermelha (B) } \\
\text { ou um objeto }(\mathrm{O})\end{array}$} & $\begin{array}{l}\text { Não segue ou } \\
\text { foca nos } \\
\text { estímulos }\end{array}$ & \multirow[t]{2}{*}{$\begin{array}{l}\text { Acalma-se, } \\
\text { foca, segue } \\
\text { rapidamente } \\
\text { para o lado, } \\
\text { porém perde } \\
\text { estímulo }\end{array}$} & \multirow[t]{2}{*}{$\begin{array}{c}\text { Segue } \\
\text { horizontalmen } \\
\text { te e } \\
\text { verticalmente; } \\
\text { sem virar a } \\
\text { cabeça } \\
\text { B O }\end{array}$} & $\begin{array}{c}\text { Segue } \\
\text { horizontalmente e } \\
\text { verticalmente; vira } \\
\text { a cabeça }\end{array}$ & $\begin{array}{l}\text { Segue o objeto } \\
\text { em círculo }\end{array}$ \\
\hline & $\mathrm{B} \quad \mathrm{O}$ & & & $\mathrm{O}$ & $\mathrm{O}$ \\
\hline
\end{tabular}


A n e x o s $\mid 202$

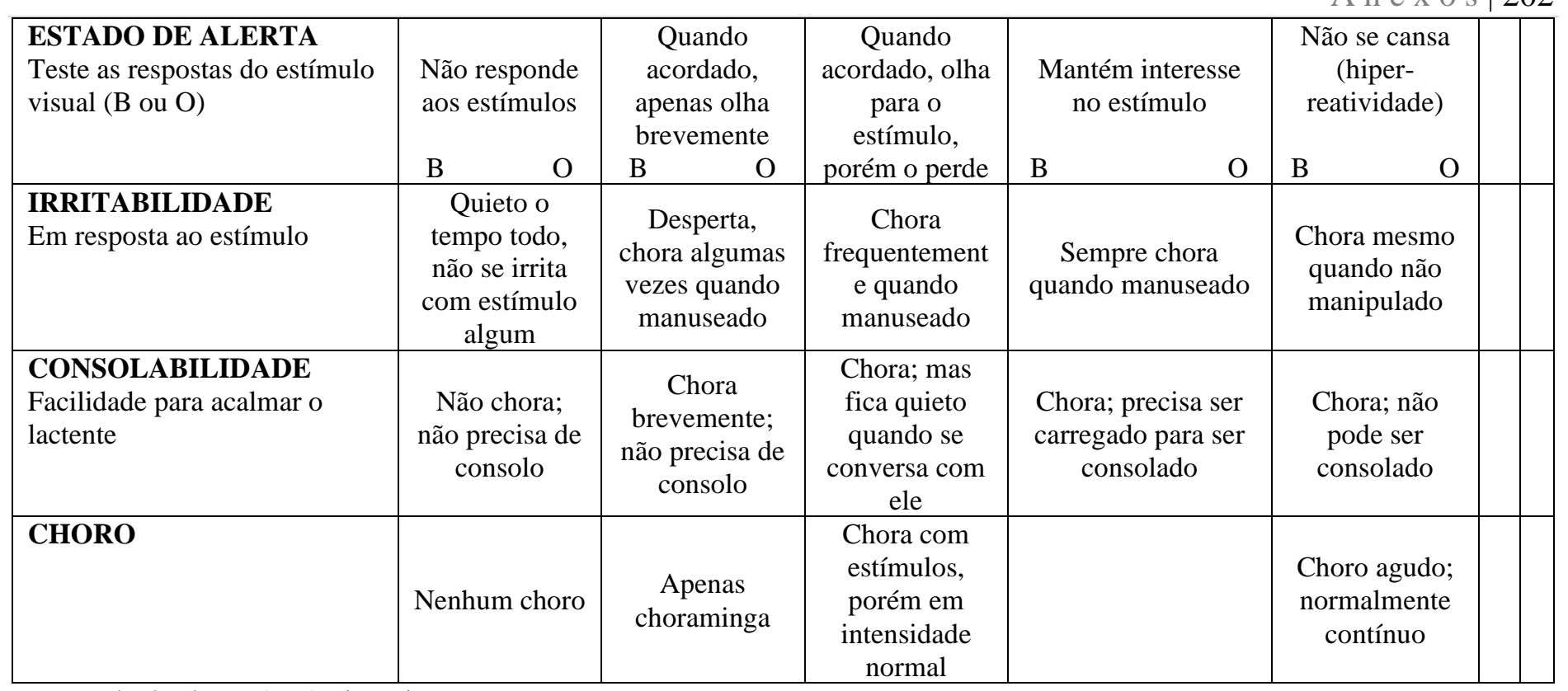

E - Estado de alerta; A - Assimetria

\section{RESUMO DO EXAME:}

TÔNUS DA CABEÇA E TRONCO:

TÔNUS DOS MEMBROS:

MOBILIDADE:

REFLEXOS:

ORIENTAÇÃO E ALERTA:

IRRITABILIDADE:

CONSOLABILIDADE:

LISTA DE ALTERAÇÕES: 


\section{EXAME NEUROLÓGICO NEONATAL RESUMIDO - HAMMERSMITH}

Nome:

Data de Nascimento:

Data da Avaliação:

Registro do paciente: Idade:
IG:
Número da avaliação: Sexo:

Peso ao nascimento:

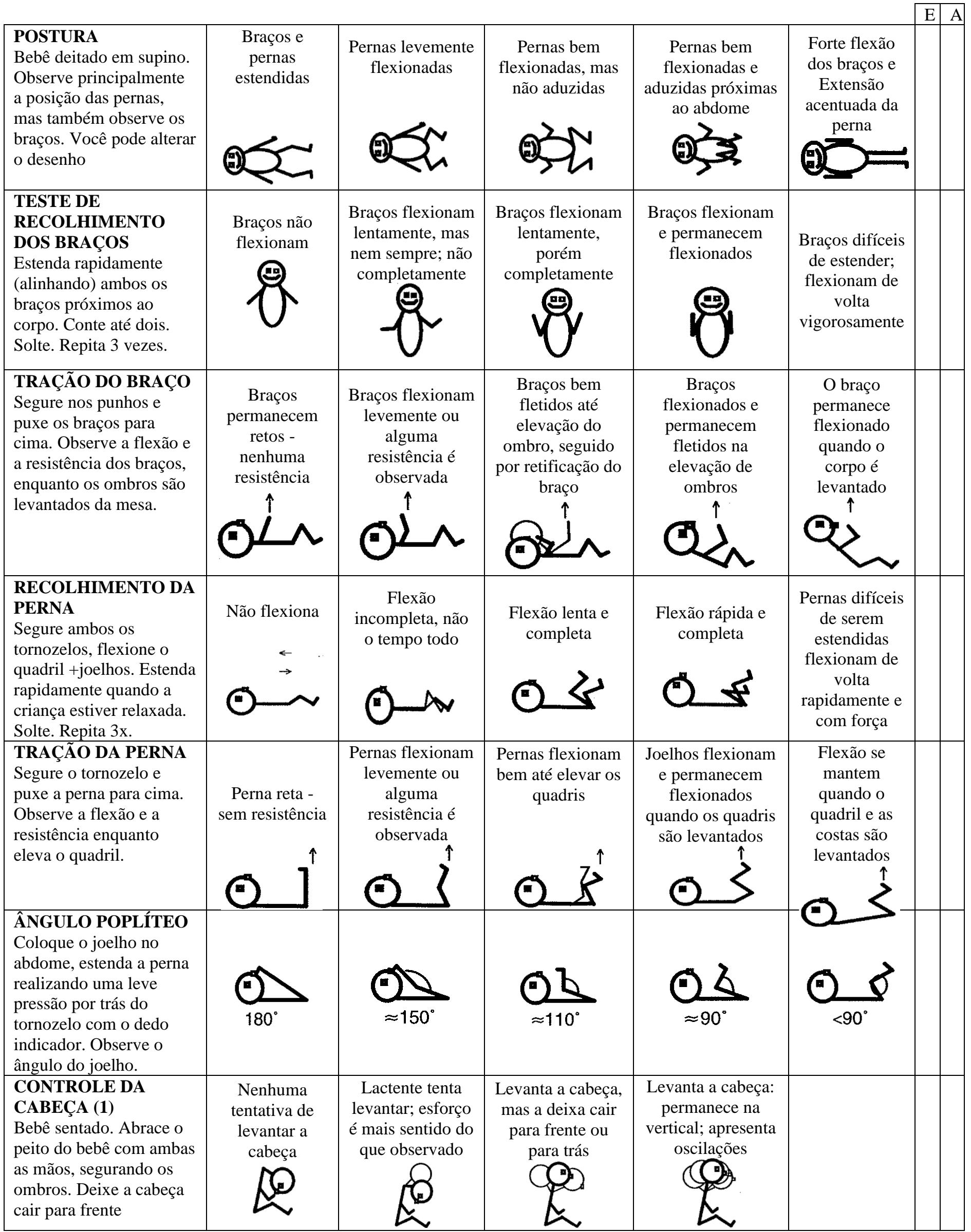




\begin{tabular}{|c|c|c|c|c|c|}
\hline $\begin{array}{l}\text { CONTROLE DA } \\
\text { CABEÇA (2) } \\
\text { Bebê sentado. Abrace o } \\
\text { peito com ambas mãos, } \\
\text { segurando os ombros. } \\
\text { Deixe a cabeça cair para } \\
\text { trás. }\end{array}$ & $\begin{array}{l}\text { Nenhuma } \\
\text { tentativa de } \\
\text { levantar a } \\
\text { cabeça }\end{array}$ & $\begin{array}{l}\text { Lactente tenta } \\
\text { levantar; esforço } \\
\text { é mais sentido do } \\
\text { que observado }\end{array}$ & $\begin{array}{c}\text { Levanta a cabeça, } \\
\text { mas a deixa cair } \\
\text { para frente ou }\end{array}$ & $\begin{array}{l}\text { Levanta a cabeça: } \\
\text { permanece na } \\
\text { vertical; apresenta } \\
\text { oscilações }\end{array}$ & $\begin{array}{c}\text { Cabeça ereta } \\
\text { ou estendida, } \\
\text { não pode ser } \\
\text { flexionada } \\
\text { passivamente } \\
\text { (empurrada } \\
\text { para a frente) }\end{array}$ \\
\hline $\begin{array}{l}\text { PUXAR PARA } \\
\text { SENTAR } \\
\text { Puxe o bebê pelos } \\
\text { punhos para sentar e } \\
\text { apoie levemente a } \\
\text { cabeça. }\end{array}$ & $\begin{array}{c}\text { Cabeça cai e } \\
\text { permanece para } \\
\text { trás }\end{array}$ & $\begin{array}{l}\text { Tenta levantar a } \\
\text { cabeça, mas esta } \\
\text { cai para trás }\end{array}$ & $\begin{array}{c}\text { Capaz de levantar } \\
\text { levemente a } \\
\text { cabeça }\end{array}$ & $\begin{array}{c}\text { Levanta a cabeça } \\
\text { alinhada com o } \\
\text { tronco }\end{array}$ & $\begin{array}{l}\text { Cabeça à } \\
\text { frente do } \\
\text { corpo }\end{array}$ \\
\hline $\begin{array}{l}\text { SUSPENSÃO } \\
\text { VENTRAL } \\
\text { Segure o bebê pelo } \\
\text { abdome em suspensão } \\
\text { ventral. Observe a } \\
\text { postura das costas, } \\
\text { braços, pernas e cabeça. } \\
\text { Se ele parecer diferente, } \\
\text { DESENHE }\end{array}$ & $\begin{array}{l}\text { Tronco } \\
\text { flexionado. } \\
\text { Cabeça e } \\
\text { membros } \\
\text { suspensos e } \\
\text { alinhados }\end{array}$ & $\begin{array}{c}\text { Tronco } \\
\text { flexionado, } \\
\text { cabeça e } \\
\text { membros } \\
\text { levemente } \\
\text { flexionados }\end{array}$ & $\begin{array}{c}\text { Tronco } \\
\text { levemente } \\
\text { flexionado. } \\
\text { Membros } \\
\text { flexionados }\end{array}$ & $\begin{array}{l}\text { Tronco reto, } \\
\text { cabeça alinhada } \\
\text { com o tronco, } \\
\text { membros } \\
\text { flexionados }\end{array}$ & $\begin{array}{c}\text { Tronco } \\
\text { alinhado, } \\
\text { cabeça acima } \\
\text { do corpo } \\
\text { a }\end{array}$ \\
\hline
\end{tabular}

E - Estado de alerta; A - Assimetria

\section{MOVIMENTOS}

\begin{tabular}{|c|c|c|c|c|c|c|}
\hline & & & & & & $\mathrm{E}$ \\
\hline $\begin{array}{l}\text { MOVIMENTOS } \\
\text { ESPONTÂNEOS } \\
\text { Observe o lactente } \\
\text { enquanto ele (a) está } \\
\text { deitado em supino }\end{array}$ & $\begin{array}{c}\text { Sem } \\
\text { movimento }\end{array}$ & $\begin{array}{l}\text { Poucos } \\
\text { alongamentos, } \\
\text { nenhum outro } \\
\text { movimento }\end{array}$ & $\begin{array}{c}\text { Espasmos, } \\
\text { alongamentos, mas } \\
\text { também alguns } \\
\text { movimentos mais } \\
\text { suaves. }\end{array}$ & $\begin{array}{c}\text { Movimentos } \\
\text { suaves de braços e } \\
\text { pernas }\end{array}$ & $\begin{array}{l}\text { Convulsões, } \\
\text { espasmos ou } \\
\text { outros } \\
\text { movimentos } \\
\text { anormais: } \\
\text { DESCREVA!! }\end{array}$ & \\
\hline $\begin{array}{l}\text { POSTURA } \\
\text { ANORMAL DAS } \\
\text { MÃOS OU DEDOS } \\
\text { DOS PÉS }\end{array}$ & $\begin{array}{c}\text { Mãos } \\
\text { abertas }\end{array}$ & $\begin{array}{l}\text { Mãos fechadas ou } \\
\text { polegares } \\
\text { aduzidos de forma } \\
\text { intermitente, } \\
\text { porém abertos } \\
\end{array}$ & $\begin{array}{l}\text { Mãos fechadas ou } \\
\text { polegar aduzido, ou } \\
\text { dedo (indicador) e } \\
\text { polegar em } \\
\text { oposição. }\end{array}$ & $\begin{array}{l}\text { Hálux para cima } \\
\text { (estendido) ou } \\
\text { todos os dedos } \\
\text { flexionados }\end{array}$ & & \\
\hline TREMOR & $\begin{array}{l}\text { Sem } \\
\text { tremor }\end{array}$ & $\begin{array}{l}\text { Tremor somente } \\
\text { quando chora ou } \\
\text { após reflexo de } \\
\text { Moro }\end{array}$ & $\begin{array}{l}\text { Alguns tremores } \\
\text { quando acordado }\end{array}$ & $\begin{array}{l}\text { Tremores } \\
\text { frequentes }\end{array}$ & $\begin{array}{l}\text { Tremores } \\
\text { contínuos }\end{array}$ & \\
\hline $\begin{array}{l}\text { SOBRESSALTO/ } \\
\text { SUSTO } \\
\text { Movimentos semelhantes } \\
\text { aos do Reflexo de Moro, } \\
\text { porém não executado no } \\
\text { teste de Moro }\end{array}$ & $\begin{array}{l}\text { Sem susto/ } \\
\text { sobressalto }\end{array}$ & $\begin{array}{l}\text { Susto/sobressaltos } \\
\text { com barulhos } \\
\text { súbitos ou ao } \\
\text { bater na mesa }\end{array}$ & $\begin{array}{c}2 \text { ou } 3 \\
\text { sustos/sobressaltos } \\
\text { espontâneos }\end{array}$ & $\begin{array}{l}3-5 \text { sustos/ } \\
\text { sobressaltos } \\
\text { espontâneos }\end{array}$ & $\begin{array}{c}\text { Mais que } 6 \\
\text { sustos/sobressalt } \\
\text { os espontâneos }\end{array}$ & \\
\hline
\end{tabular}

E - Estado de alerta; A - Assimetria

\section{REFLEXOS = teste ambos os lados}

\begin{tabular}{|c|c|c|c|c|c|c|c|}
\hline & & & & & & $\mathrm{E}$ & $\mathrm{A}$ \\
\hline $\begin{array}{l}\text { REFLEXO DE } \\
\text { SUCÇÃO - Observe no } \\
\text { peito, se não for } \\
\text { percebida a sucção, } \\
\text { coloque o dedo mínimo } \\
\text { dentro da boca com a } \\
\text { polpa do dedo para cima }\end{array}$ & $\begin{array}{l}\text { Sucção } \\
\text { ausente }\end{array}$ & $\begin{array}{l}\text { Somente sucção } \\
\text { fraca: } \\
\text { a) irregular; } \\
\text { b) regular. } \\
\text { Não remove a } \\
\text { boca do estímulo }\end{array}$ & $\begin{array}{l}\text { Lactente suga bem } \\
\text { no peito }\end{array}$ & $\begin{array}{l}\text { Sucção forte: } \\
\text { (a) irregular; } \\
\text { (b) regular. } \\
\text { Retira } \\
\text { adequadamente a } \\
\text { boca do estímulo }\end{array}$ & $\begin{array}{l}\text { Não suga, } \\
\text { porém, } \\
\text { apresenta forte } \\
\text { "pega" }\end{array}$ & & \\
\hline $\begin{array}{l}\text { PREENSÃO PALMAR } \\
\text { Pressione a palma da } \\
\text { mão. NÃO TOQUE O } \\
\text { DORSO DA MÃO!! }\end{array}$ & $\begin{array}{c}\text { Sem } \\
\text { reação }\end{array}$ & $\begin{array}{l}\text { Flexão dos dedos } \\
\text { fraca e curta }\end{array}$ & $\begin{array}{l}\text { Forte flexão dos } \\
\text { dedos }\end{array}$ & $\begin{array}{c}\text { Forte flexão dos } \\
\text { dedos, ombro } \uparrow\end{array}$ & $\begin{array}{c}\text { Forte flexão dos } \\
\text { dedos, corpo } \\
\text { inteiro } \uparrow\end{array}$ & & \\
\hline
\end{tabular}




\begin{tabular}{|c|c|c|c|c|c|}
\hline $\begin{array}{l}\text { PREENSÃO } \\
\text { PLANTAR } \\
\text { Pressione na superfície } \\
\text { plantar abaixo dos dedos } \\
\text { dos pés. }\end{array}$ & $\begin{array}{l}\text { Sem } \\
\text { resposta }\end{array}$ & $\begin{array}{c}\text { Dedos flexionam } \\
\text { (dobram) } \\
\text { ligeiramente }\end{array}$ & $\begin{array}{l}\text { Dedos flexionam } \\
\text { em torno do dedo } \\
\text { do examinador }\end{array}$ & & \\
\hline $\begin{array}{l}\text { REFLEXO DE MORO } \\
\text { Coloque o bebê na } \\
\text { posição ilustrada no } \\
\text { desenho } 1 \text { abaixo. Traga } \\
\text { a cabeça para a frente e } \\
\text { de forma repentina } \\
\text { deixe-a cair levemente } \\
\text { para trás }\end{array}$ & $\begin{array}{l}\text { Sem } \\
\text { resposta }\end{array}$ & $\begin{array}{c}\text { Abdução } \\
\text { completa dos } \\
\text { braços, extensão } \\
\text { dos cotovelos; } \\
\text { nenhuma adução }\end{array}$ & $\begin{array}{c}\text { Abdução completa, } \\
\text { aducão breve ou } \\
\text { atrasada }\end{array}$ & $\begin{array}{c}\text { Braços não } \\
\text { abduzem } \\
\text { totalmente, porém } \\
\text { boa adução }\end{array}$ & $\begin{array}{l}\text { - Somente } \\
\text { adução; } \\
\text { - Somente } \\
\text { extensão do } \\
\text { cotovelo }\end{array}$ \\
\hline \begin{tabular}{l}
\multicolumn{1}{c}{$\frac{1}{\text { COLOCAÇÃO DAS }}$} \\
PERNAS \\
Segure o lactente na \\
posição vertical. Toque o \\
dorso do pé do bebê na \\
borda da mesa.
\end{tabular} & $\begin{array}{l}\text { Nada } \\
\text { acontece }\end{array}$ & $\begin{array}{c}\text { Bebê flexiona o } \\
\text { tornozelo }\end{array}$ & $\begin{array}{c}\text { Bebê flexiona } \\
\text { quadril, joelho e } \\
\text { tornozelo e pisa na } \\
\text { mesa }\end{array}$ & & \\
\hline
\end{tabular}

E - Estado de alerta; A - Assimetria

\section{ORIENTAÇÃO E COMPORTAMENTO}

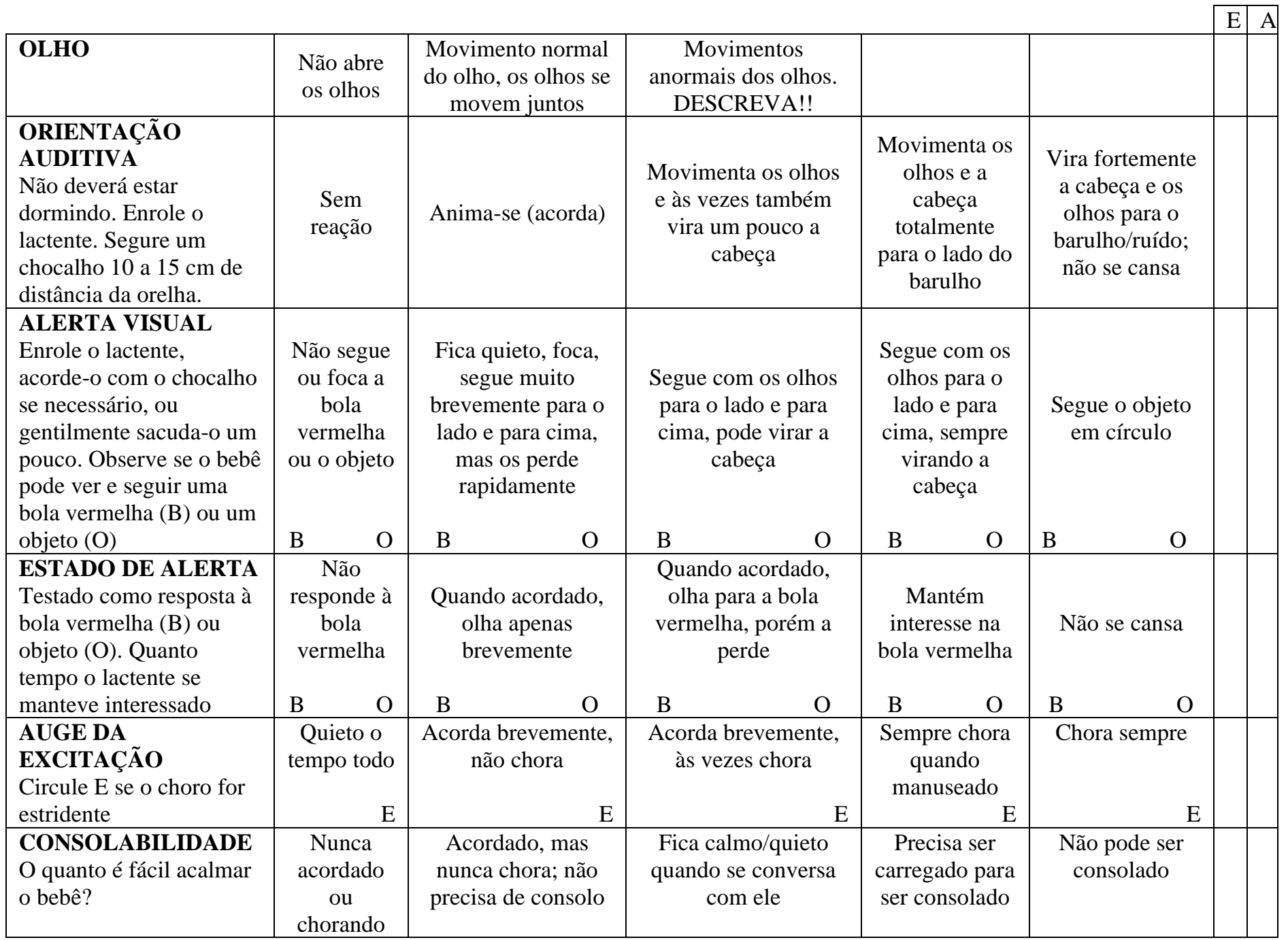

E - Estado de alerta; A - Assimetria 


\section{EXAME NEUROLÓGICO INFANTIL - HAMMERSMITH}

Nome:

Idade gestacional:
Data de Nascimento:

Data da avaliação:

\begin{tabular}{|l|}
\hline \multicolumn{1}{|c|}{ RESUMO DA AVALIAÇÃO } \\
\hline Número de assimetrias da seção 1: \\
\hline Pontuação dos itens neurológicos: \\
\hline Pontuação comportamental: \\
\hline
\end{tabular}

\section{COMENTÁRIOS:}

\section{Funções dos nervos cranianos}

Postura

Movimentos

Tônus

Reflexos e reacões

Comportamento

\section{SEÇÃO 1: ITENS NEUROLÓGICOS}

Avaliação da função dos nervos cranianos:

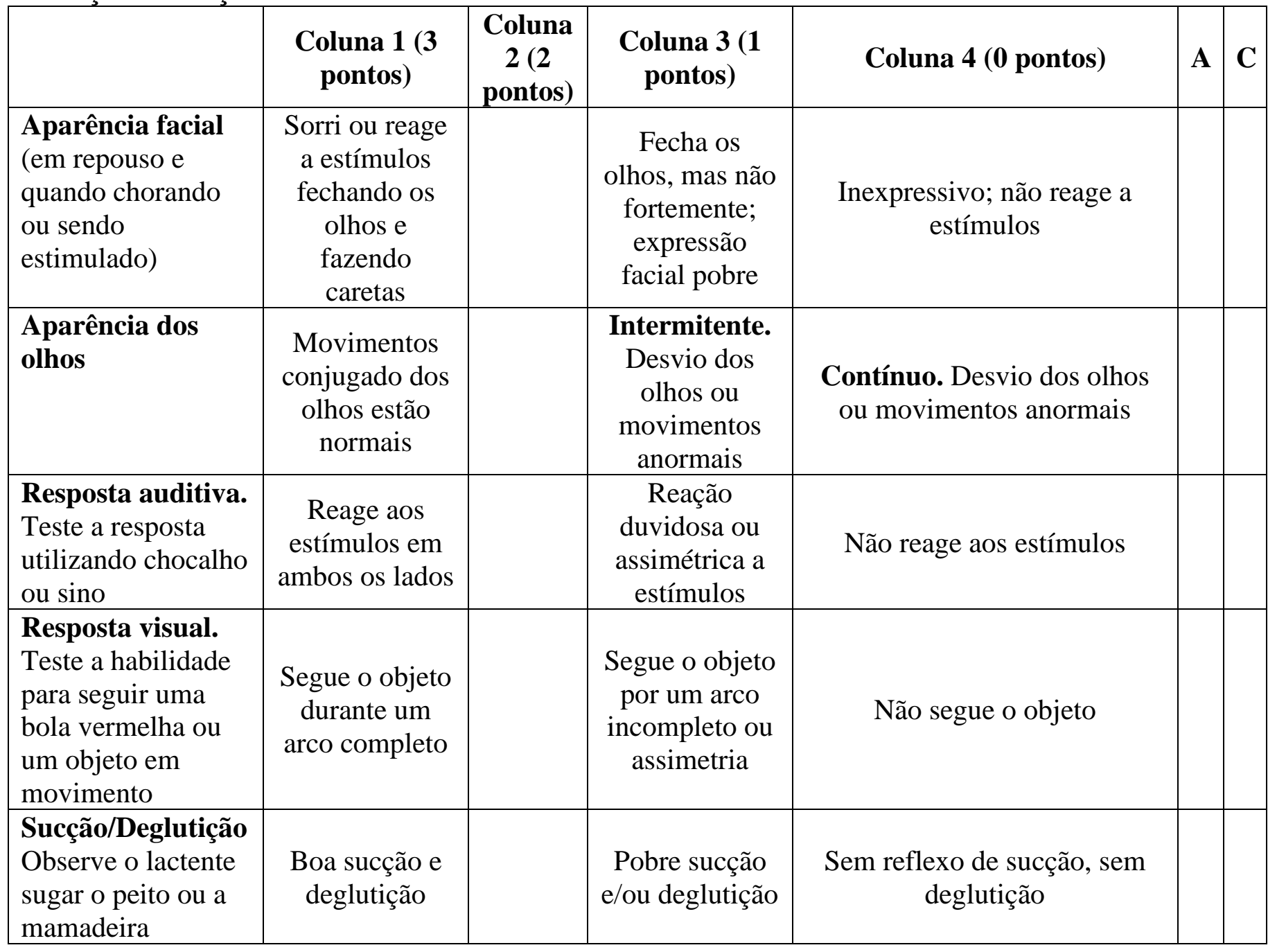




\begin{tabular}{|c|c|c|c|c|}
\hline Cabeça (sentado) & $\underbrace{(98}_{\substack{\text { Alinhada na } \\
\text { linha média }}}$ & & $\underbrace{}_{\substack{\text { Levemente } \\
\text { inclinada para } \\
\text { o lado ou para } \\
\text { trás ou para a } \\
\text { frente }}}$ & 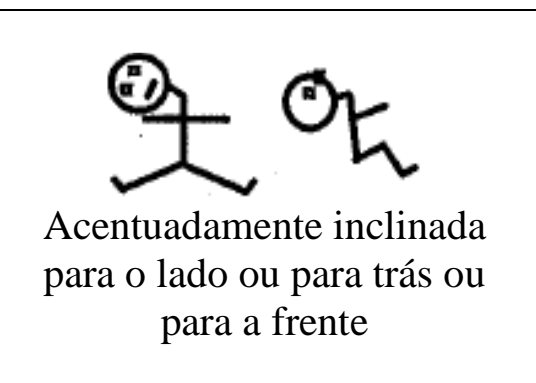 \\
\hline Tronco (sentado) & E & & $\begin{array}{c}\text { Levemente } \\
\text { flexionado ou } \\
\text { inclinado para } \\
\text { o lado }\end{array}$ & 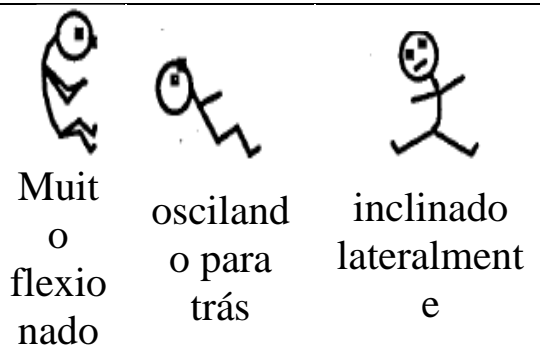 \\
\hline $\begin{array}{l}\text { Braços } \\
\text { em repouso }\end{array}$ & $\begin{array}{l}\text { Em posição } \\
\text { neutra: } \\
\text { centralizados, } \\
\text { alinhados ou } \\
\text { levemente } \\
\text { flexionados }\end{array}$ & & $\begin{array}{c}\text { Leve } \\
\text { Rotação } \\
\text { interna ou } \\
\text { externa }\end{array}$ & $\begin{array}{c}\text { Acentuada } \\
\text { Rotação interna ou externa ou } \\
\text { postura distônica } \\
\text { postura hemiplégica }\end{array}$ \\
\hline Mãos & Mãos abertas & & $\begin{array}{l}\text { Intermitente } \\
\text { Polegar em } \\
\text { adução ou } \\
\text { mãos fechadas }\end{array}$ & $\begin{array}{c}\text { Persistente } \\
\text { Polegar em adução ou mãos } \\
\text { fechadas }\end{array}$ \\
\hline (sentado) & $\begin{array}{c}\text { Capaz de } \\
\text { sentar com a } \\
\text { coluna } \\
\text { alinhada e as } \\
\text { pernas } \\
\text { estendidas ou } \\
\text { ligeiramente } \\
\text { flexionadas } \\
\text { (sentado com } \\
\text { as pernas } \\
\text { estendidas). } \\
\text { P } \\
\text { Pernas em } \\
\text { posição neutra: } \\
\text { alinhadas ou } \\
\text { ligeiramente } \\
\text { flexionadas }\end{array}$ & $\begin{array}{l}\text { Leve } \\
\text { rotação } \\
\text { interna } \\
\text { ou } \\
\text { externa }\end{array}$ & $\begin{array}{l}\text { Senta com a } \\
\text { coluna } \\
\text { alinhada, mas } \\
\text { com os joelhos } \\
\text { flexionados em } \\
15-20^{\circ} \text {. } \\
\text { Rotação } \\
\text { interna ou } \\
\text { externa do } \\
\text { quadril }\end{array}$ & $\begin{array}{l}\text { Incapaz de sentar com a } \\
\text { coluna alinhada, a não ser que } \\
\text { os joelhos estejam } \\
\text { acentuadamente flexionados } \\
\text { (não senta com as pernas } \\
\text { estendidas). } \\
\text { Acentuada Rotação interna ou } \\
\text { externa ou flexão/extensão } \\
\text { fixas ou contraturas no quadril } \\
\text { e joelhos }\end{array}$ \\
\hline $\begin{array}{l}\text { Pés } \\
\text { Em supino e em pé }\end{array}$ & $\begin{array}{l}\text { Centralizados; } \\
\text { em posição } \\
\text { neutra. } \\
\text { Dedos dos pés } \\
\text { alinhados entre }\end{array}$ & & $\begin{array}{l}\text { Leve Rotação } \\
\text { interna ou } \\
\quad \text { externa } \\
\text { Intermitente } \\
\text { Tendência de } \\
\text { ficar em pé nas }\end{array}$ & $\begin{array}{l}\text { Acentuada Rotação interna ou } \\
\text { externa do tornozelo. } \\
\text { Persistente Tendência de ficar } \\
\text { em pé nas pontas dos dedos; } \\
\text { ou dedos para cima ou dedos } \\
\text { em garra }\end{array}$ \\
\hline
\end{tabular}




\begin{tabular}{|l|c|l|c|l|l|}
\hline & $\begin{array}{c}\text { flexão e } \\
\text { extensão }\end{array}$ & & $\begin{array}{c}\text { pontas dos } \\
\text { dedos; ou } \\
\text { dedos para } \\
\text { cima ou dedos } \\
\text { em garra }\end{array}$ & & \\
\hline
\end{tabular}

$\mathrm{A}=$ Assimetria. $\mathrm{C}=$ Comentários

\section{Movimentos}

\begin{tabular}{|l|c|c|c|c|c|}
\hline $\begin{array}{l}\text { Quantidade } \\
\text { Observe o } \\
\text { lactente deitado } \\
\text { em supino }\end{array}$ & Normal & $\begin{array}{c}\text { Excessivo ou } \\
\text { lento }\end{array}$ & Mínimo ou nenhum & C \\
\hline Qualidade & $\begin{array}{l}\text { Livres, } \\
\text { alternados, } \\
\text { suaves }\end{array}$ & $\begin{array}{l}\text { Bruscos, } \\
\text { tremores leves }\end{array}$ & $\begin{array}{l}\text { *Espasmos sincronizados; } \\
* \text { Atetóide; } \\
* \text { Atáxico; } \\
\text { *Muito tremor; } \\
\text { *Espasmos mioclônicos; } \\
\text { *Distônico }\end{array}$ & \\
\hline
\end{tabular}

\section{Tônus}

\begin{tabular}{|c|c|c|c|c|c|c|}
\hline & $\begin{array}{c}\text { Coluna } 1(2 \\
\text { pontos) }\end{array}$ & $\begin{array}{c}\text { Coluna } 2 \\
(1,5 \\
\text { pontos })\end{array}$ & $\begin{array}{c}\text { Coluna } 3 \text { (1 } \\
\text { pontos) }\end{array}$ & $\begin{array}{c}\text { Coluna } 4(0 \\
\text { pontos })\end{array}$ & $\mathbf{A}$ & C \\
\hline $\begin{array}{l}\text { Sinal de cachecol: Pegue a } \\
\text { mão do lactente e puxe o } \\
\text { braço sobre o peito até que } \\
\text { haja resistência. Observe a } \\
\text { posição do cotovelo. }\end{array}$ & Af & & & $\bigoplus_{\mathrm{D}} \underbrace{\mathrm{E}}_{\mathrm{D}}$ & & \\
\hline $\begin{array}{l}\text { Elevação passiva do } \\
\text { ombro - Levante o braço } \\
\text { próximo à cabeça do } \\
\text { lactente. Observe a } \\
\text { resistência do ombro e do } \\
\text { cotovelo. }\end{array}$ & $\begin{array}{c}\text { Resistência, porém, } \\
\text { realiza }\end{array}$ & & Sem resistência & $\begin{array}{c}\text { Resistência, não } \\
\text { realiza } \\
\mathrm{D}\end{array}$ & & \\
\hline $\begin{array}{l}\text { Pronação/Supinação - } \\
\text { Estabilize a região superior } \\
\text { do braço, enquanto realiza } \\
\text { a pronação e supinação do } \\
\text { antebraço. Observe a } \\
\text { resistência. }\end{array}$ & $\begin{array}{c}\text { Pronação e } \\
\text { supinação } \\
\text { completas, sem } \\
\text { resistência }\end{array}$ & & $\begin{array}{c}\text { Pronação e } \\
\text { supinação } \\
\text { completas, porém } \\
\text { a resistência pode } \\
\text { ser vencida } \\
\text { (movimento pode } \\
\text { ser realizado) }\end{array}$ & $\begin{array}{l}\text { Não é possível } \\
\text { pronação e } \\
\text { supinação } \\
\text { completas, } \\
\text { resistência } \\
\text { acentuada }\end{array}$ & & \\
\hline $\begin{array}{l}\text { Adutores - Com as pernas } \\
\text { do lactente estendida, } \\
\text { abduza na medida do } \\
\text { possível. Observe o ângulo } \\
\text { formado pelas pernas }\end{array}$ & $\underbrace{\text { Amplitude: }}_{\mathrm{E}}$ & $150^{\circ}-$ & $\underbrace{>170^{\circ}}_{\mathrm{D}}$ & \}$_{\mathrm{D}}^{<80^{\circ}}$ & & \\
\hline
\end{tabular}




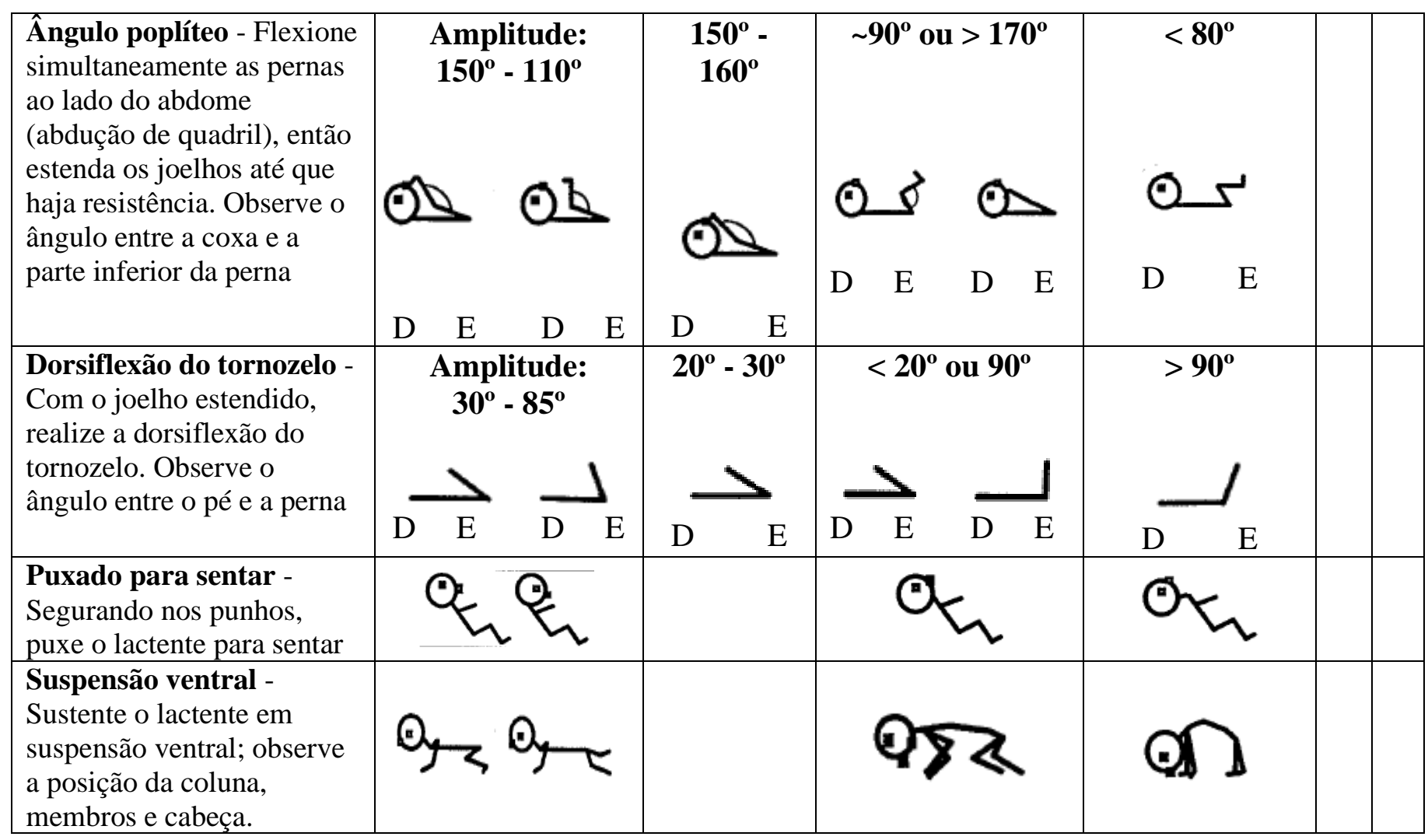

$\mathrm{A}=$ Assimetria. $\mathrm{C}=$ Comentários

\section{Reflexos e Reações}

\begin{tabular}{|c|c|c|c|c|c|c|}
\hline $\begin{array}{l}\text { Reflexos tendíneos } \\
\text { (bíceps, joelho, tornozelo) }\end{array}$ & $\begin{array}{c}\text { Facilmente } \\
\text { desencadeado }\end{array}$ & $\begin{array}{l}\text { Moderadame } \\
\text { nte rápido }\end{array}$ & Rápido & Clônus ou ausente & $\mathbf{A}$ & $\mathbf{C}$ \\
\hline $\begin{array}{l}\text { Reação de proteção - } \\
\text { Lactente em posição supina, } \\
\text { puxe-o por um braço e } \\
\text { observe a reação do lado }\end{array}$ & $\begin{array}{l}\text { Braço e mão } \\
\text { estendidos }\end{array}$ & & $\begin{array}{l}\text { Braço semi- } \\
\text { flexionado }\end{array}$ & 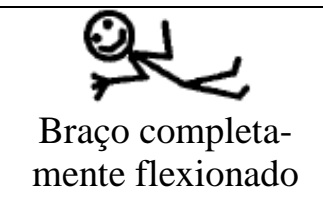 & & \\
\hline oposto & D $\quad E$ & & $\mathrm{D} \quad \mathrm{E}$ & $\mathrm{D} \quad \mathrm{E}$ & & \\
\hline $\begin{array}{l}\text { Suspensão vertical - Segure } \\
\text { o lactente por baixo das } \\
\text { axilas. Certifique-se que as } \\
\text { pernas não toquem em } \\
\text { qualquer superfície. }\end{array}$ & $\Omega_{\substack{\text { Chuta } \\
\text { simetricamente }}}$ & & $\begin{array}{l}\text { Chuta mais com } \\
\text { uma das pernas, } \\
\text { ou chute fraco }\end{array}$ & $\begin{array}{c}\text { Sem chutes mesmo } \\
\text { se estimulado, ou } \\
\text { posição de tesoura }\end{array}$ & & \\
\hline $\begin{array}{l}\text { Inclinação lateral (descreva } \\
\text { o lado voltado para cima). } \\
\text { Lactente mantido na posição } \\
\text { vertical, incline rapidamente } \\
\text { para a horizontal. Observe a } \\
\text { coluna, membros e cabeça. }\end{array}$ & $\mathrm{D}$ & $\mathrm{D}$ & 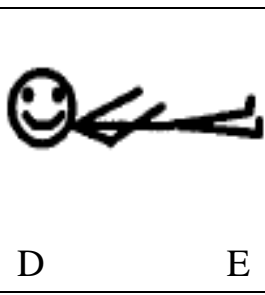 & 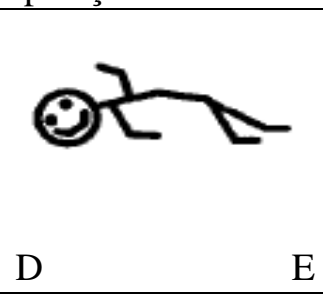 & & \\
\hline $\begin{array}{l}\text { Reação de paraquedas- } \\
\text { Lactente mantido na posição } \\
\text { vertical e subitamente } \\
\text { inclinado para frente. } \\
\text { Observe a reação dos braços. }\end{array}$ & (após 6 meses) & & (após 6 meses) & & & \\
\hline
\end{tabular}


SEÇÃO 2: MARCOS MOTORES

\begin{tabular}{|c|c|c|c|c|c|c|}
\hline $\begin{array}{l}\text { Controle da } \\
\text { cabeça }\end{array}$ & $\begin{array}{c}\text { Incapaz de } \\
\text { manter a } \\
\text { cabeça erguida } \\
\text { (normal }<3 \\
\text { meses) }\end{array}$ & $\begin{array}{l}\text { Oscila (normal } \\
\text { aos } 4 \text { meses) }\end{array}$ & $\begin{array}{c}\text { Mantem } \\
\text { erguida o } \\
\text { tempo todo } \\
\text { (normal aos } 5 \\
\text { meses) }\end{array}$ & & & $\begin{array}{l}\text { Observad } \\
\text { o: } \\
\text { Reportado } \\
\text { (idade): }\end{array}$ \\
\hline Sentar & $\begin{array}{l}\text { Não consegue } \\
\text { sentar }\end{array}$ & $\begin{array}{c}\text { Senta com } \\
\text { apoio no } \\
\text { quadril } \\
\begin{array}{c}\text { (normal aos } 4 \\
\text { meses) }\end{array}\end{array}$ & $\begin{array}{c}\text { Senta com } \\
\text { apoio } \\
\begin{array}{c}\text { (normal aos } 6 \\
\text { meses) }\end{array}\end{array}$ & $\begin{array}{l}\text { Senta sem } \\
\text { apoio } \\
\text { (normal } \\
\text { aos 7-8 } \\
\text { meses) }\end{array}$ & $\begin{array}{c}\text { Pivoteia } \\
\text { (rotaciona) } \\
\text { (normal } \\
\text { aos } 9 \\
\text { meses) }\end{array}$ & $\begin{array}{l}\text { Observad } \\
\text { o: } \\
\text { Reportado } \\
\text { (idade): }\end{array}$ \\
\hline $\begin{array}{l}\text { Preensão } \\
\text { voluntária }\end{array}$ & Sem preensão & $\begin{array}{l}\text { Utiliza a mão } \\
\text { inteira }\end{array}$ & $\begin{array}{l}\text { Com dedo } \\
\text { indicador e } \\
\text { polegar, } \\
\text { porém, } \\
\text { preensão } \\
\text { imatura } \\
\end{array}$ & $\begin{array}{l}\text { Preensão } \\
\text { em pinça }\end{array}$ & & $\begin{array}{l}\text { Observad } \\
\text { o: } \\
\text { Reportado } \\
\text { (idade): }\end{array}$ \\
\hline $\begin{array}{l}\text { Habilidade } \\
\text { de chutar } \\
\text { (em supino) }\end{array}$ & Não chuta & $\begin{array}{c}\text { Chuta } \\
\text { horizontalment } \\
\text { e, pernas não } \\
\text { levantam }\end{array}$ & $\begin{array}{c}\text { Para cima } \\
\text { (verticalmente) } \\
\text { (normal aos } 3 \\
\text { meses) }\end{array}$ & $\begin{array}{c}\text { Toca a } \\
\text { perna }\end{array}$ & $\begin{array}{c}\text { Toca os } \\
\text { dedos dos } \\
\text { pés } \\
\text { (normal } \\
\text { aos 5-6 } \\
\text { meses) }\end{array}$ & $\begin{array}{l}\text { Observad } \\
\text { o: } \\
\text { Reportado } \\
\text { (idade): }\end{array}$ \\
\hline Rolar & Não rola & $\begin{array}{l}\text { Rola para o } \\
\text { lado (normal } \\
\text { aos } 4 \text { meses) }\end{array}$ & $\begin{array}{c}\text { Prono para } \\
\text { supino (normal } \\
\text { aos? meses) }\end{array}$ & $\begin{array}{c}\text { Supino } \\
\text { para prono } \\
\text { (normal } \\
\text { aos ? } \\
\text { meses) }\end{array}$ & & $\begin{array}{l}\text { Observad } \\
\text { o: } \\
\text { Reportado } \\
\text { (idade): }\end{array}$ \\
\hline Engatinhar & $\begin{array}{c}\text { Não levanta a } \\
\text { cabeça }\end{array}$ & 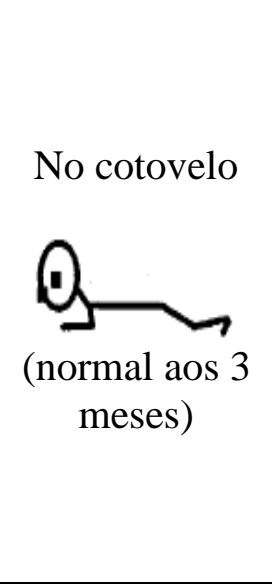 & $\begin{array}{l}\text { Em extensão } \\
\text { de braços, } \\
\text { sobre as mãos }\end{array}$ & $\begin{array}{c}\text { Engatinha } \\
\text { com apoio } \\
\text { no } \\
\text { abdome } \\
\text { (normal } \\
\text { aos } 8 \\
\text { meses) }\end{array}$ & $\begin{array}{c}\text { Engatinha } \\
\text { com } 4 \\
\text { apoios ou } \\
\text { com apoio } \\
\text { sobre } \\
\text { mãos e } \\
\text { joelhos } \\
\text { (normal } \\
\text { aos } 10 \\
\text { meses) }\end{array}$ & $\begin{array}{l}\text { Observad } \\
\text { o: }\end{array}$ \\
\hline Ficar de pé & $\begin{array}{c}\text { Não suporta o } \\
\text { peso }\end{array}$ & $\begin{array}{c}\text { Suporta o peso } \\
\text { (normal aos } 4 \\
\text { meses) }\end{array}$ & $\begin{array}{c}\text { Fica em pé } \\
\text { com apoio } \\
\text { (normal aos } 7 \\
\text { meses) }\end{array}$ & $\begin{array}{c}\text { Fica em pé } \\
\text { sem ajuda } \\
\text { (normal } \\
\text { aos } 12 \\
\text { meses) } \\
\end{array}$ & & $\begin{array}{l}\text { Observad } \\
\text { o: } \\
\text { Reportado } \\
\text { (idade): }\end{array}$ \\
\hline
\end{tabular}




\begin{tabular}{|c|c|c|c|c|}
\hline Marcha & $\begin{array}{l}\text { Movimento } \\
\text { rítmico de } \\
\text { chutes com } \\
\text { pernas } \\
\text { alternadas } \\
\text { (normal aos } 6 \\
\text { meses) }\end{array}$ & $\begin{array}{c}\text { Marcha } \\
\text { instável } \\
\text { (caminha com } \\
\text { apoio) (normal } \\
\text { aos } 12 \text { meses) }\end{array}$ & $\begin{array}{c}\text { Marcha } \\
\text { independe } \\
\text { nte } \\
\text { (normal } \\
\text { aos 15 } \\
\text { meses) }\end{array}$ & $\begin{array}{l}\text { Observad } \\
\text { o: } \\
\text { Reportado } \\
\text { (idade): }\end{array}$ \\
\hline
\end{tabular}

SEÇÃO 3: COMPORTAMENTO

\begin{tabular}{|l|c|c|c|c|c|c|c|}
\hline & $\mathbf{1}$ & $\mathbf{2}$ & $\mathbf{3}$ & $\mathbf{4}$ & $\mathbf{5}$ & $\mathbf{6}$ & Comentários \\
\hline $\begin{array}{l}\text { Estado de } \\
\text { consciência }\end{array}$ & $\begin{array}{c}\text { Não } \\
\text { desperta }\end{array}$ & Sonolento & $\begin{array}{c}\text { Sonolento, } \\
\text { porém } \\
\text { desperta } \\
\text { facilmente }\end{array}$ & $\begin{array}{c}\text { Desperto, } \\
\text { porém, } \\
\text { sem } \\
\text { interesse }\end{array}$ & $\begin{array}{c}\text { Perde } \\
\text { interesse }\end{array}$ & $\begin{array}{c}\text { Mantem } \\
\text { interesse }\end{array}$ & \\
\hline $\begin{array}{l}\text { Estado } \\
\text { emocional }\end{array}$ & $\begin{array}{c}\text { Irritável, } \\
\text { sem } \\
\text { consolo }\end{array}$ & $\begin{array}{c}\text { Irritável, } \\
\text { mãe pode } \\
\text { consolar }\end{array}$ & $\begin{array}{c}\text { Irritável } \\
\text { quando } \\
\text { manipulado }\end{array}$ & $\begin{array}{c}\text { Nem feliz, } \\
\text { nem triste }\end{array}$ & $\begin{array}{c}\text { Feliz, } \\
\text { sorrindo }\end{array}$ & & \\
\hline $\begin{array}{l}\text { Orientação } \\
\text { social }\end{array}$ & $\begin{array}{c}\text { Esquiva- } \\
\text { se, } \\
\text { retraído }\end{array}$ & Hesitante & $\begin{array}{c}\text { Aceita } \\
\text { aproximação }\end{array}$ & Amigável & & & \\
\hline
\end{tabular}


ANEXO C

\section{Hammersmith Infant Neurological Assessment}

Mayara Correr <mayara.correr@gmail.com>

26 de outubro de 2015 16:48

Para: mercuri@rm.unicatt.it

Dear Dr.Mercuri,

My name is Mayara Thais Correr, I am physiotherapist and master's student at the University of São Paulo (USP), Brazil, supervised by PhD. Luzia Iara Pfeifer. We are conducting a survey about newborn neurological examinations and would like to use the instrument Hammersmith Neonatal Neurological Assessment. We would like to know if there are any researcher or research group in Brazil authorized to perform the cross-cultural adaptation process of this instrument for the Portuguese spoken in this country. If not, we would like to request permission to carry out this process.

Sincerely.

Mayara Correr

Fisioterapeuta

Pós graduanda em Neurociências

Faculdade de Medicina de Ribeirão Preto - USP

\section{Hammersmith Infant Neurological Assessment}

Eugenio Mercuri <eumercuri@gmail.com>

7 de novembro de 2015 04:20

Para: Mayara Correr <mayara.correr@gmail.com>, Lil Dubowitz <lil.dubowitz@gmail.com>, Victor Dubowitz

$<$ v.dubowitz@imperial.ac.uk>, Alessy Beaver <alessy@mackeith.co.uk>

Cc: mercuri <mercuri@rm.unicatt.it>

\section{Dear Dr Corre}

I am very happy ogf your interest in the neurological assessment. Formally, for a cross cultural adaptation, you should write to the publishers plus all 3 authors (all in $\mathrm{cc}$ ) for getting permission to translate snd use the forms together with an outline of the project that you are planning

As far as I am concerned I would be happy to grant permission but it would be nice to see a proposal

best wishes

Eugenio 


\section{Hammersmith Infant Neurological Assessment}

Mayara Correr <mayara.correr@gmail.com>

1 de dezembro de 2015 17:44

Para: Eugenio Mercuri <eumercuri@gmail.com>, Lil Dubowitz<lil.dubowitz@gmail.com>, Victor Dubowitz <v.dubowitz@imperial.ac.uk>, Alessy Beaver <alessy@mackeith.co.uk>, mercuri <mercuri@rm.unicatt.it> Cc: Luzia lara Pfeifer <luziara@fmrp.usp.br>

Dear authors

As solicited, we are sending attached our proposal (objectives and methods) to all authors see how we are planning to carrying out the cross adaptation of the HINE. We are requesting authorization to conduct this process here in Brazil. The contact my supervisor of doctorate degree is in cc

best wishes

Mayara Correr

[Texto das mensagens anteriores oculto]

\section{Hammersmith Infant Neurological Assessment}

Eugenio Mercuri <eumercuri@gmail.com>

Para: Mayara Correr <mayara.correr@gmail.com>

Cc: Luzia lara Pfeifer <luziara@fmrp.usp.br>

Dear Dr Correr

the scientific plan seems to be appropriate and very interesting and we are happy to have the assessment translated and validated in Brazil as long as this is part of a research/clinical project and not a commercial one.

On a sad note, Lilly Dubowitz passed away last week in London and translating the assessment in another language is a nice way to honor her memory.

Best wishes

Eugenio Mercuri 
ANEXO D

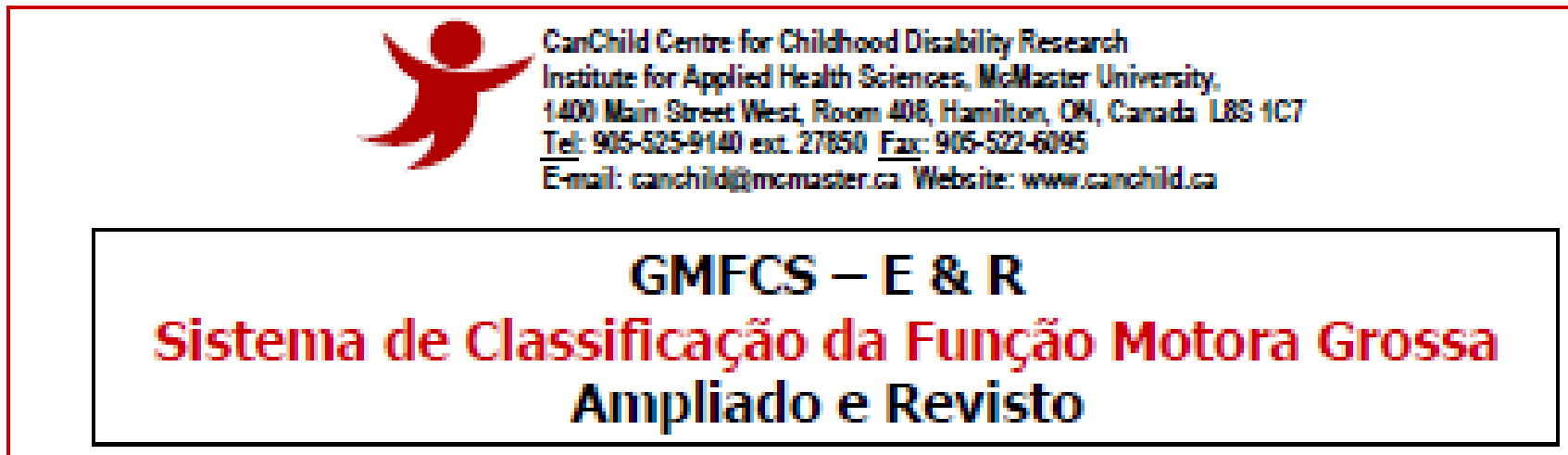

GUFCS - E a R 62007 CanChild Centre for C- dhood Disabily Research, MeMaster University Robert Palisano, Peter Rosenboum, Doreen Bartett, Michael Livingsion

GHFCS 91997 CanChild Centre for Child nood Disbi 'y Restarch, NeWaster Univers'ty Fobert Palsano, Pefer Fosenbaum, stephen Walter, Dianne Fussell, Elen Wood, Barbara Gal.ppi

[Reference: Dev Med child Neurol 1997,39:214-223]

GMFCS - E \& R O Versio Bras eira

Traduzido por Daniela Baleroni Rodrigues Siwa, Luzia lara Pfeifer e Carolina Arájo Rodrigues Fungyama (Programa de PósGraduaço en Neurociencias e Céncias do Compoitamento - Faculdade de Medicina de Fibeirâo Preib, Universidade de săo Pouls]

\section{INTRODUCÄO E INSTRUCÓES AO USUÁROO}

O Sistema de Classificaģo da Função Motora Grossa (GMFCS) para paralisia cerebral é baceado no movimento iriciado volurtariamente, com énfase no sentar, transferéncias e mobilidade. Ao defirirmos um sistema de classificaça em cinco níveis, nosso principal crtério é que as distinços ertre os ríveis devam ser significalivas nal vida diaria. As distingoes sabo baseadas nas limitagoes funcionais, na necessidade de dispositwos manuais para mobilidade (tais como andadores, mulebs ou bengalas) ou mokilidade sokre rodas, e em menor grau, na qualidade do movimerto. As distinģes entre os Niveis I| e II rŏo sto tăo nífidas como a dos outros niveis, particularmente para criangas com menos de dois anos de idade.

O GMFCS amplado (2007) inclui jovens entre $12 \mathrm{e} 18$ anos de idade e enfatiza os conceitos inerentes da Classificaça Intemacional de Funcionaldade, hoapacidade e Saude da Orgarizaço Mundal da Saúde (CIF). Nós sugerimos que os usuários estejam atentos ao impacto que os fatores ambientais e pagsoais possam ter sobre of que se obsena sobre as crianças e jovers ou no que eles relatam fazer. 0 enfoque do GMFCS esth em determirar qual nivel melhor representa as habilidades e limitaçoses na funçäo motora grosas que a criança ou o jovem apresentam. A énfase deve estar no desemperho habitual em casa, na escola e nos ambientes comunitários (lou seja, no que eles fazem), ao imés de ser no que se sake que eles sáo capaces de fizer melhor [capacidade]. Portanto, é importarte dassificar o desempenho atual da funçáo motora grossa e näo indür julgamertos sobre a qualidade do movimento ou prognóstico de melhora.

O erfoque de coda nivel é o método de mobilidade que é mais caracteristico no desemperho após os 6 anos de idade. As descriobes das hakilidodes e limitapoes funcionais para cada faixa etária sâo amplas e nảo se pretende descrever todos os aspectos da funçăo da criançajovem indvidualmente. Por exemplo, um bebe com hemiplega que é incapaz de engatirhar sobre suss mäos e joe hos, mas que por outro babo se encaion na descrigáo do Nivel lou seja, é capaz de puxar-se para for em pé e andarh, sería dassifoada no rível L. A escala é ordinal, sem intençáo de que as distäncias entre os nweis sejam consideradas iguais entre os niveis ou que as crianças e jovens com paralisia cerebral sejam igualmente distrikuidas nos cinco niveis. Um resumo das distinçes entre codo par de hiveis é fomecido para ajudar na determinação do nivel que mais se assemelha ả funçăo motora 
grossa atual da criança ou do jowem.

Nós recorhecemos que as manifeshacóes da função motbra grossa sejam dependentes da idade, especialmente durante a lactäncia e primeira irfäncia. Para cada nivel sóo formecidas descricoes separadas en diferentes faixas etarias. Deve-se considerar a idade corrigida de crianças com menos de 2 anos de idade se elas forem prennaturas. As descriģes para faixa etária de 6 a 12 anos e de 12 a 18 anos de idade refletem o possivel impacto dos fatores ambienta's (por exemplo, distáncias ra escola e na comuridade) e fatores pessojis (por exemplo, recessidades Energébicas e preferéncias socia's) nos métodos de mobilidade.

Um esforgo foi feito para enfatizar as habilidades ao inves das Imitap̧es. Assin, como principio geral, a funça motora grossa das criangas e jovens que sajo capazes de realizar funçóes describs em certo rivivel será provavelmente classfooda reste nivel de funģo ou em un nivel acina; ao contrário, a funģo motora grossa de crianças e jovens que năo conseguem realizar as funçoes de certo nivel devem ser classifoadas abaco doquele nivel de função.

\section{DEFINICÖES OPERACIONAIS}

Andador de apoio corporal - um dispositivo de mobildade que apoija a pelve e o tronco. A criançajovem é fisica mente posicionada (o) ro andador por outra pessoa.

Diapositivo de mobilidade manual - bengalas, mulebs e andadores anteriones e fosteriores que não apóiam o tronco durante a marcha.

Asaistëncia física - Outra pessoa ajuda manualmente a criançalo jovem a se mover.

Mobilidade motorizada - A criangalo jovem controla atwamente o joystck ou o interuptor elétrico que permite uma mobilidade independerte. A base de mokilibde pode ser uma codeira de rodas, um scooter ou ouro tpo de dispositwo de mobilidade motorizado.

Cadeira de rodas manual de auto-propulaão-a criançalo jovem utiliza os braços e as móos ou os pés afvamente para impulsionar as rodas e se mover.

Transportado - Uma pessoa manualmente empurta o dispositivo de moklidade fer exemplo, cadeira de rodas, carrirho de bebe ou de passeio) para mover a criangal jovem de um lugar ao outro.

Andar - A menos que especificado de cutra maneira, indica rerhuma ajuda fícica de cubra pessoa, ou uso de qualquer dispositivo de mobilidade manual. Uma órtese [ou seja, uma braçadeira ou tala] pode ser usado.

Mobilidade aobre rodas - Refere-se a qualquer tipo de dispositvo com rodas que permite movimento (jor exemplo, carrirho, cadeira de rodas manual ou motorizada).

\section{CARACTERISTICAS GERAIS PARA CADA NIVEL}

NívEL I - Anda sem limibg̣es

NÍVEL II - Arda com limitaposes

NíVEL III - Anda ue izando un dispositivo marual de mobiidade

NIVEL N - Auro-mobilidade com limibgobe; pode utizar mobilidade motorizada.

NíVEL V - Transportado em uma cadeira de rodas manual. 


\section{DISTINCÓES ENTRE OS NIVEIS}

Distinços entre ce niveis I a lI - crangas e jovers do rível II, quando comparados às criangas e jovens do rivel I,

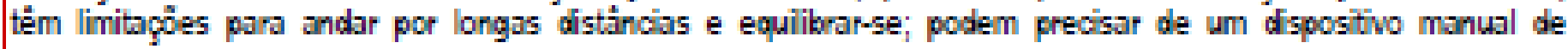
mobilidade ao aprender a andar; podem utilizar um dispositivo com rodas quando caminham por longas distăncias em espocos extemos e na comridade; requerem o uso de corimão para subir e degcer escadas; e rão săo capazes de correr e pular.

Diatinçose entre os niveis II e III - As crianças e os jovens no nivel II sóo capazes de andar sem um dispositivo manual de moblidode depois dos quatro anos de idade (embora possam optar por utilizá-b às vezes). As crianças e os jovers do nível III precisam de um dispositivo marual de mobilidade para andar em espagos intemos e o uso de mobilidade sokre rodas fora de casa e ra comur idade.

Distinçoses entre os niveia III a IV - as crianças e jovers que estăo no nível III sertam-se sozirhos ou requerem no maximo um apoio extemo limibdo para sentar-se; eles sio mais independertes nas trarsferéncias para a postura em Fé e andam com um dispositvo manual de mobildade. As crianças e jowers no niwel IV sentam-se (geralmente apoiadosh mas a autolocomoç̃o é limitada. É ma's provável que as crianças e jovens no Nivel $\mathrm{V}$ sejam transportadas em uma cadeira de rodas manual ou que utilizem a mobiidade motbrizada.

Diatinçós entre os Niveis $\mathrm{N}$ e V - As crianças e jovens no N'vel V tëm graves limitaģóes no controle do cabega e tronco e requerem tecnologia assistiva ampla e ajuda fisica. A autolocomoçáo é conseguida apenas se a criançal jovem pode aprender como operar wna codeira de rolas motorizada.

\section{Sistema de Classificação da Funçäo Motora Grossa - Ampliado e Revisto (GMFCS - E \& R)}

\section{ANTES DO ANIVERSÁRIO DE 2 ANOS}

WIVLL In Bebes sentam-se no chōo, mantén-se sentados e dexam esta posigo con ambas as móos lives para manipular objelos os bebes engatinham ịobre as móso e jolhosh puxam-se para far em pé e dóo passos segurando-se nos móveis. Os bebes andam ente 16 meses e 2 anos de idade sem a necessidade de aparehos para auxiliar a locomopón.

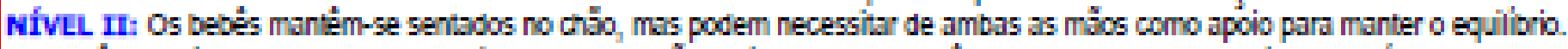
os bebes rastejam em prono ou engänham (sobre móos e johos). Os bebes poden puxar-se para ficar em pé e dar passos segurando-se nos móveis.

MivLL III Os bebes mantem-se sentados no chōo quando há apoio na parte inferior do tronco. Os bebes robm e rastejam para frente em prono.

MivLi IV: Os bebês apresentam controle de cabeç, mas necessitam de apoio de fronco para sentarem-se no chấ. Os bebes conseguem rolar para a posicho supino podem rolar para a posiço prono.

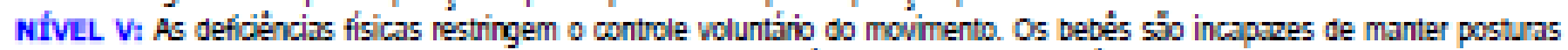

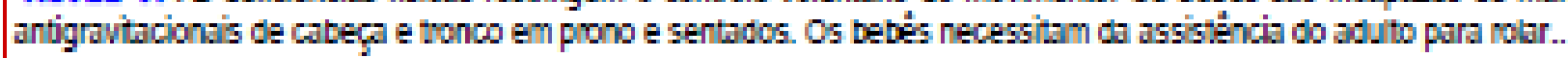

\section{ENTRE O SEGUNDOE O QUARTO ANIVERSARIO}

WIVLL II As crianças sentam-se no chóo com ambas as móos lives para manipular objetos, os movimentos de sentar e levantar-

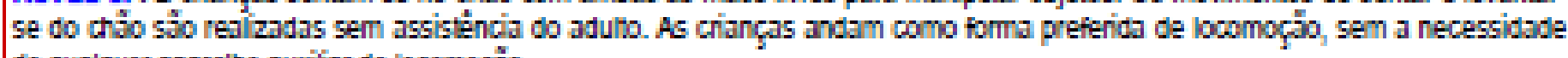
de qualquer apareho auxilar de locomogio.

WIVLL II As criancas sentam-se no chô, mas podem ter dficuldades de equilibrio quando ambas as móos estbo lives para

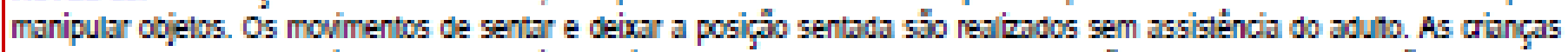

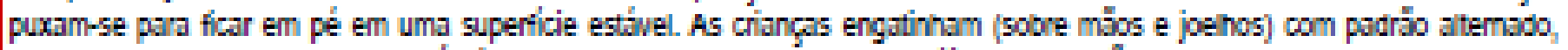
andam de lado segurano-se nos móveis e andam usando aparelhos para auxiliar a locomoço como 
forma preferida de boconocó.

MívLL III As criançs mantemre sentadas no chōo freqüentemente na posibjo de W (sentar entre os quadris e os joenos en

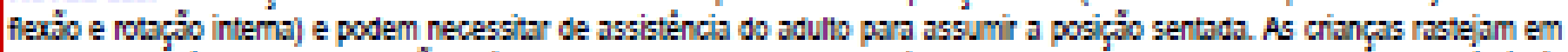
prono ou engatinam (score as mosos e jelhos), frequenterente sem movimentos altemados de pena, como meboos principais de auto-boomogóo. As crianças podem puxar-se para levantar em uma superficie estävel e andar de lodo segurando-se nos móveis por distánciss curtas. As cianças podem andar distänciss curtas nos espapos internos utlizando um dispositivo manual de mobilidode (andador) eajuda de um adulo para diecionála e giräla.

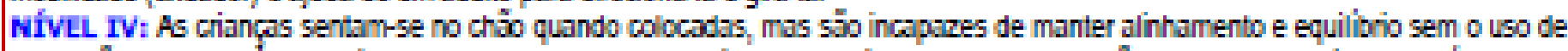
suas máos para apoio. As criancas frequentemente necessilam de equpamento de adaptapio para sentar e ficar em pé. A autobocomóo para carbs distäncis (dentro de uma sala) é alcancada por méo do rolar, rastejar em prono ou engatinhar sobre as moss e jehos sem movimento atemodo de pernas.

MIVLL Vi As deficiencias fisicas restingen o cortole voluntátio do moimento e a capacidade de manter posturas antigravibonais de cabeg e trono. Todas as aress de funço motora estab limitadas. As limitapes funconais do sentar e ficar em pe nóo sto complatanente compensoda por meio do uso de equipamentos adapativo e de tecnobga assistiva. No n'vel $V_{2}$ as crangas no tam meios para se mover inependentemente e sob transporbdas. Somente agumas criancs conseguem a autolocomog fo utilzando uma cadeira de rodas motorizada com extensas adaptaģes.

\section{ENTRE O QUARTO E O SEXTO ANIVERSARIO}

WIVLL. In As crianças sentam-se na cadeira, mantërn-se sentbus e levantam-se dela sem a necessidade de apoio das mbs. As criances soem do chbo e da cadeira para a posigho em pe sem a necessidade de objebs de apoio. As criangas andam nos espaços intenos e externos e sobem escadas. Inicham habildades de correr e pular.

WfVLL II: As criancas sertam-se na codera com ambas as mb̂os lives para manipular objetos. As crianças saem do chấ e da cadeira para a posiço em pé, mas geralmente requerem uma superficie estovel para empurrarse ou impusionar-se para cima com $0 s$ membos superiones. As criangas andam sem a necessidade de um dispositivo manual de mobilidode en espapos internos e en curbs distincias en espogos extemos planos. As crianças sobem escadas segurandose no corrimbo, mas s5o incapares de corer e pular.

MIVLL III As changas sentam-se en codeira comum, mas poden necescitar de apoio pévico e de trono para maximizar a funço manual. As crianças sentam-se e levantam-se da codera usando uma superíice estóvel para empurrar-se ou impulsionarse para cina com seus brops. As criangs andam dom un dispoitivo manul de mobilode en superficis planas e sobm egcadas com a assistencia de um adulio. As criangas trequentemente só transporbos quanco percomen longas distinciss e quando em espagos etenos em terrenos irnegulares.

AivLL IV: As criangas sentam em uma cadeira, mas precisam de um assento adaptado para controle de tronco e para muimizar a funço manual. As crianças sentam-se e levantam-se da cadeira com a ajua de um aduto ou de uma superficie estível para empurrar-se ou impulsionar-se com seus bragos. As criançs podem, na melhor das hipóteses, andar por ourtas distäcias com o andacor e com supeviso do aduto, mas tem dificuldades en virar e manter o equilibrio em superfices

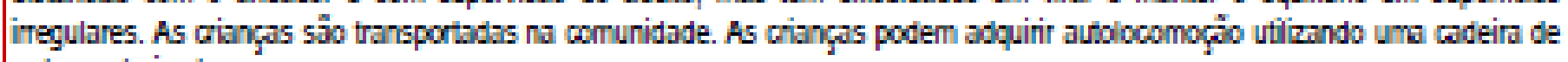
rodas motorizoda.

MívLL V: As defičencias físicas restringem o controle voluntário do movimento e a habilidade para manter posturas antigravitaconais de cabega e tronco. Todas as aress da funço motora estío limitadas. As limitgoes funcionais no sentar e ficar em pé nóo sáo completamente compensadas por meio do uso de equipamento adaptativo e tecrologia assistiva. No nivel $V_{n}$ as

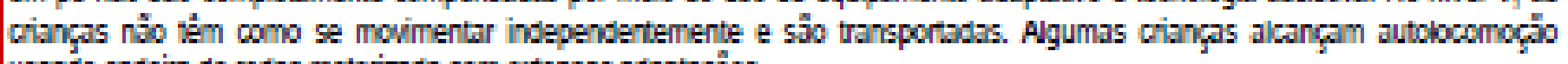
usano cadeira de rodas mobrizda com extensas adapbobes.

\section{ENTRE O SEXTO E O DÉCIMO SEGUNDO ANIVERSÁRIO}

Wirel Is As dianças caminham em casa, na escola, em espap̧os externos e na comuridade. As criancas sóo capazes de subir e descer meio-fos e escadas sem assisténcia física ou sem o uso de corimbo. As criangas apregentam habilidades motonas grossas

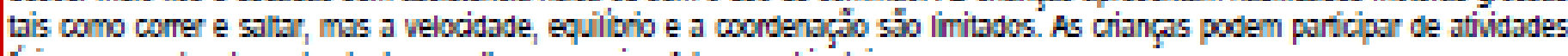
fiscas e esportes depewano das excolnas persois e fabres ambientais. 
Aivel II: As criancas caminham na maioria dos ambientes. As crianças podem apresentar difeuldode em caminhar longas distäncias e de equilibrio en terrenos irregulares, inchingofes, áreas com muibs pessoas, espocos fechados ou quano carregam objebs. As criancas sobem e descem escadas seguranob em cominso ou com assisténcia física se nö hour este tipo de apoio Em espaps extemos e na comunidade, as criançs podem andar con assisténcia física, um dispositivo manual de moblidade, ou utilizr a mobilidade sobre rodas quando perconem longas distáncias. As criangas tëm, na melhor das hipóteces, apenas habilidade mínima para realzar as habilidades motoras gossas tais como comer e pular. As limitapos no desempenho das habilidades

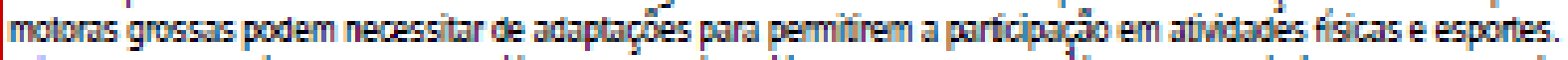

Mivel III: As crancas andm utilzano un disositio manual de moilidade na maioria dos espogs intemos. quans Sentadas, as criançs podem erigir um dino de seguranca para alinhamento pévico e equilibro. As transtekéncias de sentado para en pé e do chōo para posicjo em pé requerem assistencia física de uma pessoa ou uma superfice de apoio. Quando mowem-se por longas distancias, as ciancas utilam aquma foma de mobilidade sobre was. As crancas poulan subir ou degcer egcadas segurando em um comin3o com superviso ou assistencia fisica. As limitapes na marcha podem necessitar de

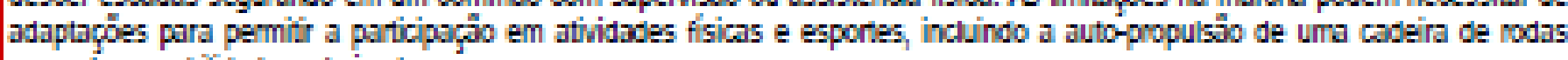
manual ou mobldade mobizada.

Mivel IVi As criancas uflizam métodos de mobildade que requerem assistencia física ou mobilidade motorizoda na maioria dos ambientes. As criangas requeren assento adaptado para o controle pébios e do tono e assistancis fisia para a maioria das transferencias. Em casa, as criancas movem-se no chbo (rolar, amastar ou engatinnarh andam curtas distäncas com assibencia fisica ou utilizm mobildade motorizada. Qundo posicionodas, as cianças podem uti izar um andador de apoio corporal em casa ou na escola. Na escola, em espaps exenos e na comuridade, as criancas sób transporadas em uma cadeira de podas manual

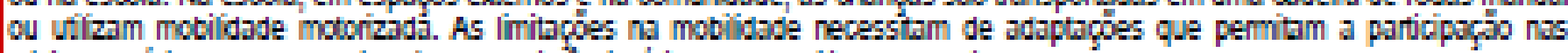
ativades fisicas e esportes, induindo a assistencia física ebu moilidade motorizada.

Nivel Vi As crianças So transportadas em uma cadeira de rodas manual em todos os ambientes. As criancas sâo limitadas em sua habilidade de munter as posturas anti-gravitacionais da cabega tronos e de controlar os movimentos dos brapos e pemos.

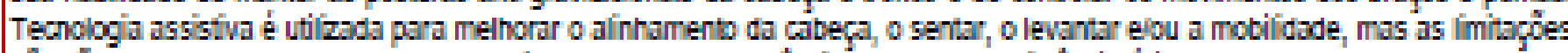

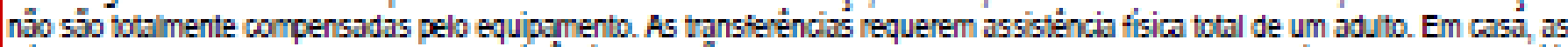
criangas podem se bonover por curtas distancias no chî́o ou poden ser camegadas por um adulo. As criancas poden adquirir

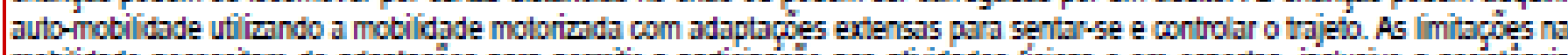

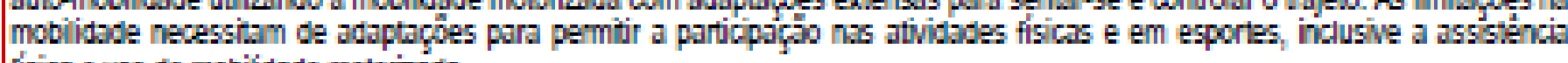
física e uso de nobilidade motrizida.

\section{ENTRE O DECIMO SEGUNDO E DECCMO OITAVO ANNERSÁRIO}

Wived It os jovens andam en casa, na escola, em espops extemos e na comunidode os jovens sto capazes de subir e descer

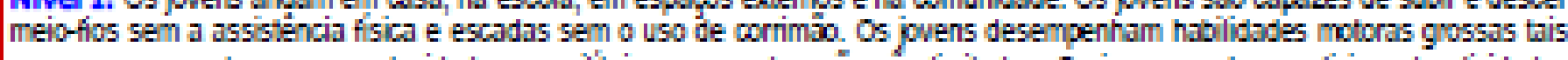
como comer e pular, mas a velocidade, o equilibrio a coondenapo sto limitados. os jovens podem participar de atividades fisicas e esportes dependendo de escolhas pessois e fatores ambientais.

Wivel II: Os jovens andam na maiona dos ambientes. os fatores ambientais (tais como terrens irregulares, inclinacos, longas

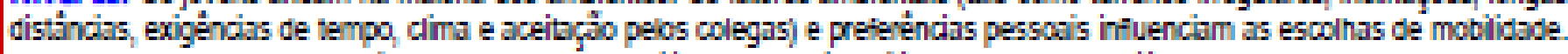
Na escola ou wo trabalho, of jovers podem andar util lando um dispositio manual de mobilidade por seguranga. Em espapos externos e na comunidade, os jovens podem utílizar a mobildade sobre rodas quando percorrem longas distáncias. Os jovens

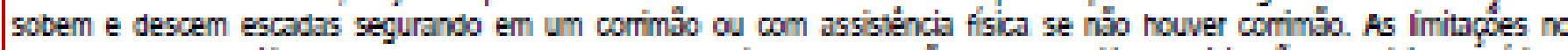
desempeno de habiliodes motoras grossas poden necessitar de adaptapes para permitir a participacio nas ativades físicas e esportes.

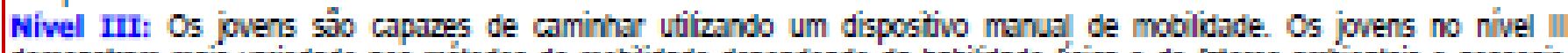
demonstram mais varibude nos métodos de mobilibole dependendo da habilidade fisica e de fatores ambientis e pessois, quando comparaos a jovens de outros niveis. Quano estio sentados, os jovens podem predisar de um cinto de seguranga para

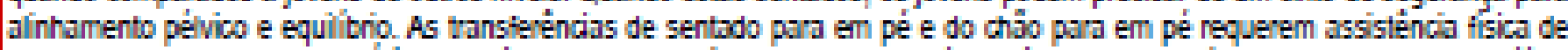
uma pessoa ou de uma superficie de apoio. Na escola, os jovens podem autb-impulsionar uma cadeira de rodas manual ou utilizar

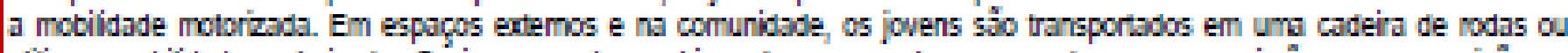
utilizam mobilidade motorizada. os jovens podem subir e descer escadas segurano em um corrimbo com supervisob ou assisténcia física. As limitap̧es na marcha poden necessitar de adaptap̧es para pentitir a particpopio en afivibdes físicas e esportes induino a aub-propulsb de uma cadeira de rodas manual ou mobilisde mobrada.

Mivel IV: Os jovens usam a mobilidade sobre rodas na maiona dos ambientes os jovens necessitam de assento adaptado para of controle pévico e do trono. Assisténcia física de 1 ou 2 pessoas é necessári para as transferencias. 
Os jovens podem apoiar o peso con as pernas para ajuar nas transferéncas para fcar em pé. Em espacos internos, 06 jouens podem andar por curtas distäncias com zseistencia fisica, uti lam a mobilidade sobre wodas, ou, quando posicionados, utilizam um andador de apoio corporal. Os jovens ș̌́ fsicamente capazes de operar uma codera de rodas motorizada. Quano o uso de uma Cadeira de rodas motorizda nóo tor possivel ou nóo disponivel, os jovens sob transportados em uma cadeira de rodas manual. As

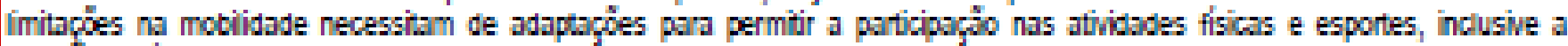
assistencia física elou mobilibade motorizada.

Nivel V: os jovens so transportados em uma codeira de rodas manual en twos os ambientes os jovens șo limitados em sua habilidade para manter as posturas antigravitacionais da cabeca e trono e o controle dos movimentos dos bracos e pernas. Tecologia assiktua é utilizada para melhorar o alinhamento da cabeca, o gentar, o ficar de pé, e a moilidade, mas as limitaçes

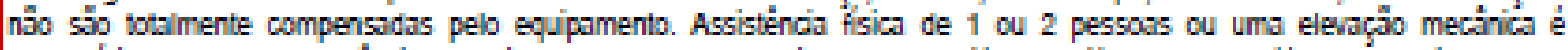
necessária para as transferéncias. Os jovers podem conseguir a auto-mobilidade utilzando a mobilidade motorizada com adaptapos extensas para sentar e para o controle do trajeto As limitacoes na mobilidade necessitam de adaptapoes pora permitir a particpapo nas atividades fisicas e espones induindo a assistancia flica e o uso de mobilade notorizada. 


\title{
ANEXO E - TCLE (especialistas)
}

\author{
TERMO DE CONSENTIMENTO LIVRE E ESCLARECIDO - TCLE \\ (Obrigatório para as pesquisas Científicas em Seres Humanos - Resolução nº 466/2012- CNS) \\ AOS ESPECIALISTAS
}

Título da Pesquisa: “Adaptação transcultural e validação do instrumento Hammersmith Infant Neurological Assessment (HINE) para lactentes brasileiros com risco de Paralisia Cerebral”.

Pesquisadoras responsáveis: Mayara Thais Correr / mayara.correr@gmail.com / (19) 99267-2557 e Luzia Iara Pfeifer / luziara@fmrp.usp.br / (16) 3602-4976 ou 3797-3154 - Departamento de Neurociências e Ciências do Comportamento - Hospital das Clínicas de Ribeirão Preto. Em caso de dúvidas éticas, entrar em contato com o Comitê de Ética em Pesquisa: (16) 3602-2228. Av. Bandeirantes, 3900 - Monte Alegre - CEP 14.049-900 Ribeirão Preto - S.P.

Te convidamos a participar desta pesquisa. No caso de concordar em participar da pesquisa, favor assinar este documento ao final. Objetivos da pesquisa: 1 - Realizar a tradução e adaptação transcultural do instrumento Hammersmith Infant Neurological Assessment (HINE) para a língua portuguesa; 2- avaliar a validade transcultural deste instrumento; 3 - Realizar o acompanhamento preditivo dos lactentes aos 2 anos de idade e correlacionar a pontuação do instrumento com o Gross Motor Function Classification System for Cerebral Palsy - GMFCS, caso o lactente tenha Paralisia Cerebral (PC). Procedimentos do estudo: O estudo será dividido em 3 etapas. Na primeira etapa, será realizada a tradução inicial do instrumento por 2 tradutores independentes e um juiz que resolverá as discrepâncias linguísticas, gramaticais e semânticas. Após, será realizada uma síntese das traduções (versão comum) que passará por um processo de retrotradução para a língua original do instrumento, com 2 retrotradutores independentes. As versões retrotraduzidas serão sintetizadas após um consenso determinando a versão comum da retrotradução. As versões consensuais serão avaliadas por um Comitê de Especialistas quanto às questões semânticas, idiomática, conceitual e experiencial, a fim de consolidar as versões e desenvolver a versão pré-final do instrumento que será utilizada na fase de pré-teste. Caso você decida participar do estudo, você fará parte deste Comitê de Especialistas. Você responderá a um protocolo, que será enviado por e-mail, composto por itens de análise semântica e de conteúdo com respostas em formato dicotômicas simples com as opções: "de acordo" e "não está de acordo" e "claro" e "não claro", sendo que em caso negativo, há opção de apresentar as sugestões de mudança. Esta etapa é importante para a equivalência transcultural, pois assegura a validade de conteúdo do instrumento que será avaliada pela porcentagem de concordância. Para análise dos dados, serão calculados o Índice de Validade de Conteúdo (IVC) e o grau de concordância entre os especialistas através da "Porcentagem de Concordância". As $2^{\mathrm{a}}$ e $3^{\mathrm{a}}$ etapas se dedicam a validade de face, confiabilidade inter e intra-avaliadores e estudo preditivo. Riscos e Desconfortos: Esta etapa pode apresentar riscos como potenciais constrangimentos para aplicação e análise do instrumento, desta forma você está livre para participar ou não deste processo e se retirar em qualquer fase da análise do instrumento. Custo/Reembolso para o participante: Não há nenhum valor econômico, a receber ou a pagar, por sua participação no estudo. Qualquer esclarecimento sobre o estudo poderá ser dado sempre que necessário. Esse documento é composto por duas vias, que deverão ser assinadas e rubricadas por todos os envolvidos, sendo uma via para o pai e/ou responsável e outra para a pesquisadora.

Nome do participante:

Assinatura: Data: 1

Nome do pesquisador:

Assinatura:

Data: I 


\title{
ANEXO F - TCLE CUIDADORES
}

\author{
TERMO DE CONSENTIMENTO LIVRE E ESCARECIDO - TCLE \\ (Obrigatório para as pesquisas Científicas em Seres Humanos - Resolução nº 466/2012- CNS) \\ AOS CUIDADORES
}

Título da Pesquisa: “Adaptação transcultural e validação do instrumento Hammersmith Infant Neurological Assessment (HINE) para lactentes brasileiros com risco de Paralisia Cerebral”.

Pesquisadoras responsáveis: Mayara Thais Correr / mayara.correr@gmail.com / (19) 99267-2557 e Luzia Iara Pfeifer / luziara@fmrp.usp.br / (16) 3602-4976 ou 3797-3154 - Departamento de Neurociências e Ciências do Comportamento - Hospital das Clínicas de Ribeirão Preto. Em caso de dúvidas éticas, entrar em contato com o Comitê de Ética em Pesquisa: (16) 3602-2228. Av. Bandeirantes, 3900 - Monte Alegre - CEP 14.049-900 Ribeirão Preto - S.P.

Convidamos seu (a) filho (a) a participar desta pesquisa. No caso de concordar em participar da pesquisa, favor assinar este documento ao final. Objetivos da pesquisa: Traduzir e adaptar para a cultura brasileira, um instrumento de avaliação neurológica (Hammersmith Infant Neurological Assessment - HINE) e verificar através deste instrumento, possíveis atrasos motores que futuramente o bebê possa apresentar. Procedimentos do estudo: $\mathrm{O}$ estudo foi dividido em 3 etapas. $\mathrm{Na} 1^{\mathrm{a}}$ e $2^{\mathrm{a}}$ etapa, foram realizadas as traduções e adaptação cultural do instrumento, gerando a Versão Brasileira do Hammersmith Infant Neurological Assessment. O seu (a) filho (a) participará da $3^{\text {a }}$ etapa do estudo, que engloba a avaliação do desenvolvimento motor em 6 momentos diferentes: 1) logo após o nascimento, 2) quando ele (a) completar 3 meses, 3) quando ele (a) completar 6 meses, 4) quando ele (a) completar 9 meses, 5) quando ele (a) completar 12 meses e 6) quando ele (a) completar 24 meses. As avaliações terão duração média de 20 minutos e seu filho (a) deverá estar confortável (com o mínimo de roupas possíveis) no momento da avaliação, a qual poderá ser filmada. Ele (a) poderá ser estimulado (a) com brinquedos e por orientação verbal do terapeuta. Garantimos que seu (a) filho (a) não será identificado (a) e as filmagens serão utilizadas apenas para posterior avaliação e comparação evolutiva. Todas as informações coletadas possuem finalidade terapêutica e serão utilizadas para pesquisas auxiliando os profissionais a encaminharem os bebês que apresentem uma baixa pontuação no instrumento, para a estimulação precoce beneficiando o seu desenvolvimento. Riscos e Desconfortos: As avaliações motoras requerem estimulações e manuseios, entretanto, caso o bebê chore ou demonstre irritabilidade durante este processo, a avaliação será imediatamente interrompida. Você estará livre para autorizar ou não a participação de seu (a) filho (a) no estudo, ou para retirá-lo (a) deste em qualquer momento do seu processo, de modo que nenhum ônus ou prejuízo (em qualquer natureza) será cobrado. Custo/Reembolso para o participante: Não há nenhum valor econômico, a receber ou a pagar, por sua participação no estudo. Confidencialidade da pesquisa: Garantimos o anonimato de seu (a) filho (a) e realizaremos as filmagens somente após sua autorização. Após a análise dos dados as filmagens serão destruídas. Qualquer esclarecimento sobre o estudo poderá ser dado sempre que necessário. Ao final da pesquisa, será dada uma explicação para você sobre o que foi identificado na avaliação de seu (a) filho. Esse documento é composto por duas vias, que deverão ser assinadas e rubricadas por todos os envolvidos, sendo uma via para o pai e/ou responsável e outra para a pesquisadora.

Nome do participante: assinatura: data:

Nome do pesquisador: assinatura: data: 